\title{
FCRD Advanced Reactor (Transmutation) Fuels Handbook
}

Dawn E. Janney, Cynthia A. Papesch, Scott C. Middlemas

With contributions from D. Burkes, R. Fielding, T. Hartmann, T. Hyde, D.D. Keiser Jr., J.R. Kennedy, A. Maddison, R. Mariani, T.P. O'Holleran, B.H. Sencer, and L. Squires

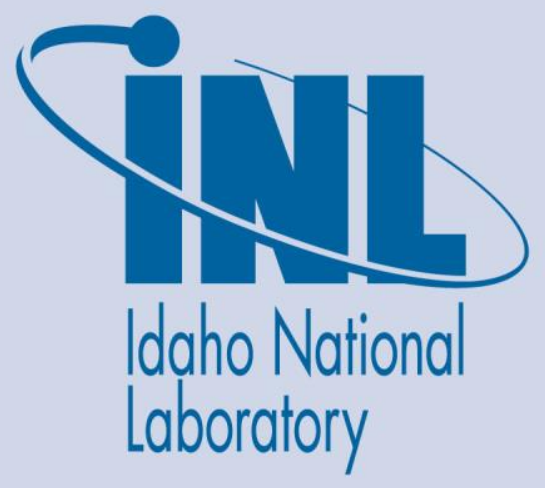

September 2016

The INL is a U.S. Department of Energy National Laboratory operated by Battelle Energy Alliance 


\section{DISCLAIMER}

This information was prepared as an account of work sponsored by an agency of the U.S. Government. Neither the U.S. Government nor any agency thereof, nor any of their employees, makes any warranty, expressed or implied, or assumes any legal liability or responsibility for the accuracy, completeness, or usefulness, of any information, apparatus, product, or process disclosed, or represents that its use would not infringe privately owned rights. References herein to any specific commercial product, process, or service by trade name, trade mark, manufacturer, or otherwise, does not necessarily constitute or imply its endorsement, recommendation, or favoring by the U.S. Government or any agency thereof. The views and opinions of authors expressed herein do not necessarily state or reflect those of the U.S. Government or any agency thereof. 
INL/EXT-15-36520

Revision 1

\title{
FCRD Advanced Reactor (FCRD Advanced Reactor (Transmutation) Fuels Handbook
}

\author{
Dawn E. Janney, Cynthia A. Papesch, Scott C. Middlemas \\ With contributions from D. Burkes, R. Fielding, T. Hartmann, T. Hyde, D.D. \\ Keiser Jr., J.R. Kennedy, A. Maddison, \\ R. Mariani, T.P. O'Holleran, B.H. Sencer, and L. Squires
}

September 2016

\begin{abstract}
Idaho National Laboratory
Idaho Falls, Idaho 83415
\end{abstract}

http://www.inl.gov

Prepared for the

U.S. Department of Energy

Office of Nuclear Energy

Under DOE Idaho Operations Office

Contract DE-AC07-05ID14517 
INTENTIONALLY BLANK 


\section{SUMMARY}

Transmutation of minor actinides such as $\mathrm{Np}, \mathrm{Am}$, and $\mathrm{Cm}$ in spent nuclear fuel is of international interest because of its potential for reducing the long-term health and safety hazards caused by the radioactivity of the spent fuel. One important approach to transmutation (currently being pursued by the DOE Fuel Cycle Research \& Development Advanced Fuels Campaign) involves incorporating the minor actinides into U-Pu-Zr alloys, which can be used as fuel in fast reactors. U-Pu-Zr alloys are well suited for electrolytic refining, which leads to incorporation rare-earth fission products such as $\mathrm{La}, \mathrm{Ce}, \mathrm{Pr}$, and $\mathrm{Nd}$. It is, therefore, important to understand not only the properties of U-Pu-Zr alloys but also those of U-Pu-Zr alloys with concentrations of minor actinides (Np, Am) and rare-earth elements ( $\mathrm{La}, \mathrm{Ce}, \mathrm{Pr}$, and $\mathrm{Nd}$ ) similar to those in reprocessed fuel.

In addition to requiring extensive safety precautions, alloys containing $\mathrm{U}, \mathrm{Pu}$, and minor actinides ( $\mathrm{Np}$ and $\mathrm{Am}$ ) are difficult to study for numerous reasons, including their complex phase transformations, characteristically sluggish phasetransformation kinetics, tendency to produce experimental results that vary depending on the histories of individual samples, rapid oxidation, and sensitivity to contaminants such as oxygen in concentrations below a hundred parts per million. Although less toxic, rare-earth elements such as $\mathrm{La}, \mathrm{Ce}, \mathrm{Pr}$, and $\mathrm{Nd}$ are also difficult to study for similar reasons. Many of the experimental measurements were made before 1980, and the level of documentation for experimental methods and results varies widely. It is, therefore, not surprising that little is known with certainty about $\mathrm{U}-\mathrm{Pu}-\mathrm{Zr}$ alloys, particularly those that also contain minor actinides and rare-earth elements. General acceptance of results commonly indicates that there is only a single measurement for a particular property.

This handbook summarizes currently available information about $\mathrm{U}, \mathrm{Pu}, \mathrm{Zr}$, $\mathrm{Np}, \mathrm{Am}, \mathrm{La}, \mathrm{Ce}, \mathrm{Pr}$, and Nd and alloys of two or three of these elements. It contains information about phase diagrams and related information (including phases and phase transformations); heat capacity, entropy, and enthalpy; thermal expansion; and thermal conductivity and diffusivity. In addition to presenting information about materials properties, the handbook attempts to provide information about how well the property is known and how much variation exists between measurements. Although it includes some results from models, its primary focus is experimental data.

The Handbook is organized in two sections: one with information about the $\mathrm{U}-\mathrm{Pu}-\mathrm{Zr}$ ternary and one with information about other elements and binary and 
ternary alloys in the U-Np-Pu-Am-La-Ce-Pr-Nd-Zr system. Within each section, information about elements is presented first, followed by information about binary alloys, then information about ternary alloys. The order in which the elements in each alloy are mentioned follows the order in the first sentence of this paragraph.

Much of the information on the U-Pu-Zr system repeats information from the FCRD Transmutation Fuels Handbook 2015. Most of the other data has been published elsewhere (although scattered throughout numerous references, some quite obscure); however, some data from Idaho National Laboratory is presented here for the first time.

As the FCRD programmatic mission evolves, future editions of this handbook will begin to include other advanced reactor fuel designs and compositions. Hence, the title of the handbook will transition to the Advanced Reactor Fuels Handbook. 


\section{ACKNOWLEDGEMENTS}

We would like to thank the staff of the INL Research Library. Their ability to find even the most obscure documents is truly outstanding. This work would not have been possible without their enthusiastic help and expertise.

We would also like to thank Dr. Steven L. Hayes for his support and insightful comments, and Dr. Pavel Medvedev for Russian translation.

Funding for researching and writing the handbook was provided by the U.S. Department of Energy, Office of Nuclear Energy, under DOE Idaho Operations Office Contract DE-AC07-05ID14517. 
INTENTIONALLY BLANK 


\section{CONTENTS}

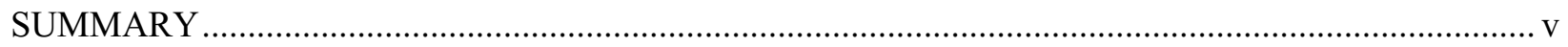

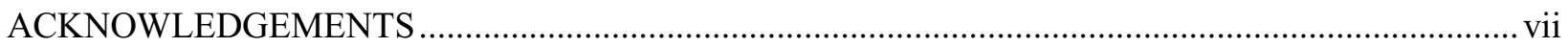

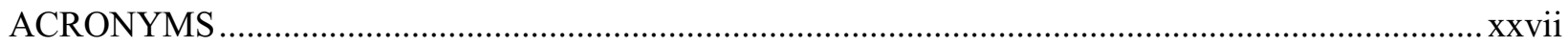

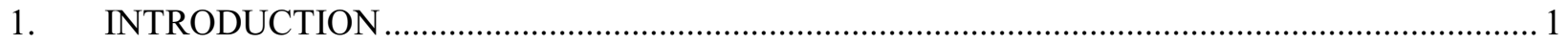

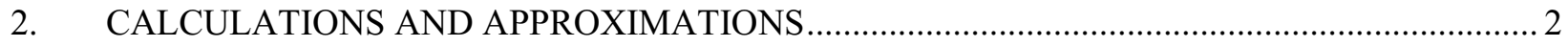

2.1 BASIC CONSTANTS, UNITS, AND CONVERSION FACTORS .................................. 2

2.2 RELATIONSHIPS BETWEEN MASSES, VOLUMES AND DENSITIES ....................... 4

2.3 CALCULATING VOLUMES AND DENSITIES FROM HIGH-PRESSURE DATA: THE CLAUSIUS-CLAPEYRON RELATION ....................................................... 4

2.4 CALCULATING THERMAL CONDUCTIVITY FROM THERMAL DIFFUSIVITY, DENSITY, AND HEAT CAPACITY ….................................................. 5

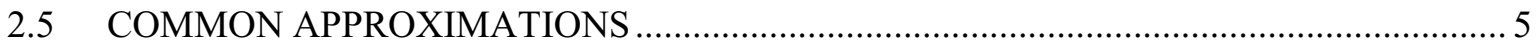

2.5.1 APPROXIMATE HEAT CAPACITIES: THE KOPP-NEUMANN LAW ................ 5

2.5.2 APPROXIMATE THERMAL CONDUCTIVITIES: THE WIEDEMANNFRANZ LAW 5

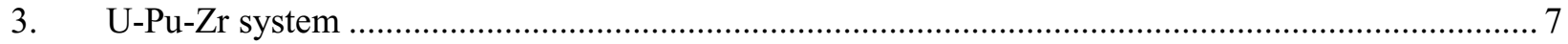

3.1 PHASES, PHASE DIAGRAMS, PHASE TRANSFORMATIONS, PHASE-TRANSFORMATION ENTHALPIES

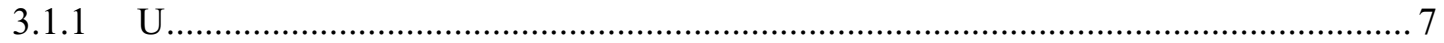

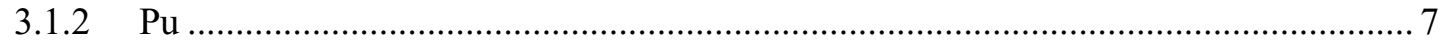

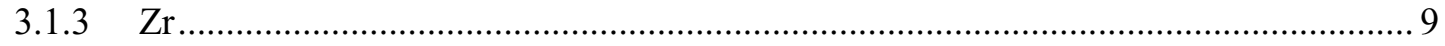

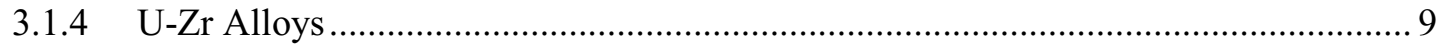

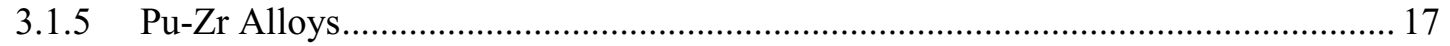

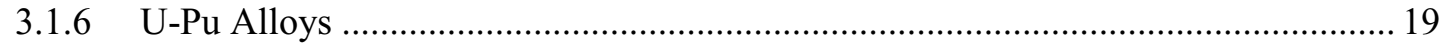

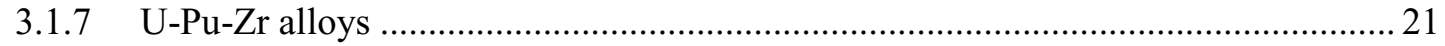

3.2 HEAT CAPACITY AND RELATED PROPERTIES (ENTROPY, ENTHALPY,

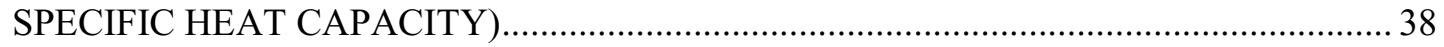

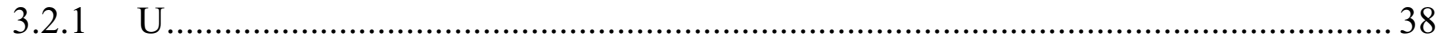

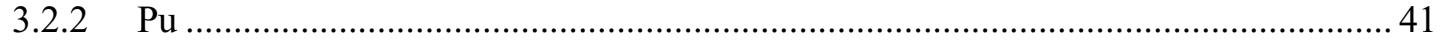

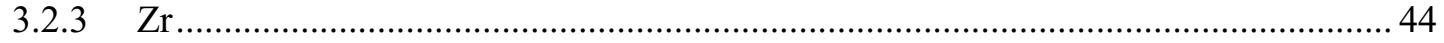

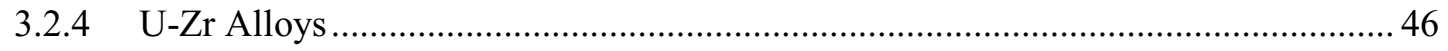

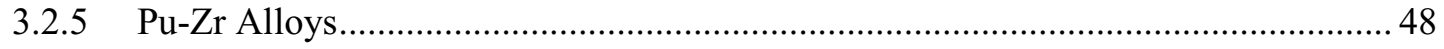

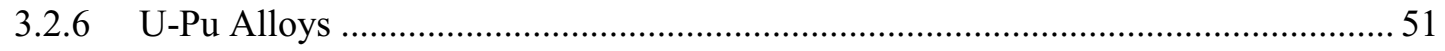




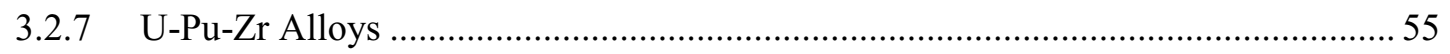

3.3 THERMAL EXPANSION, THERMAL EXPANSION COEFFICIENTS, AND

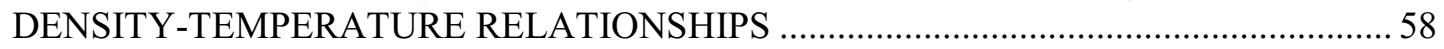

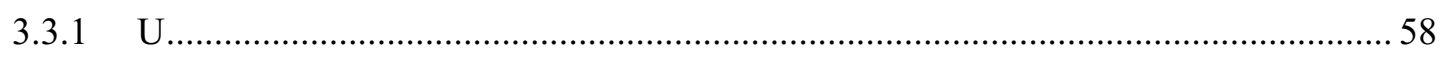

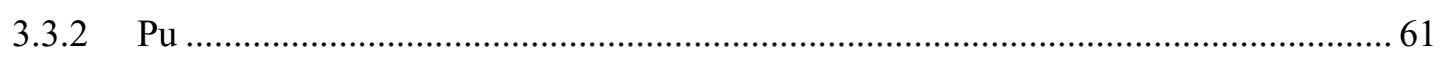

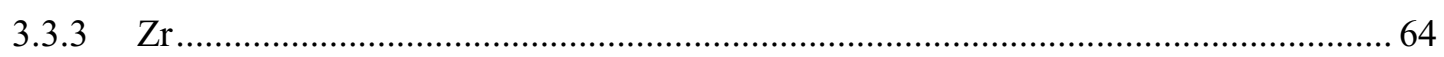

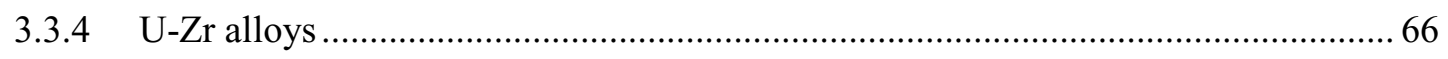

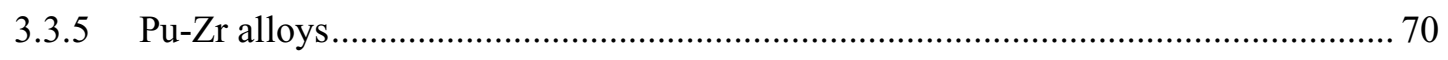

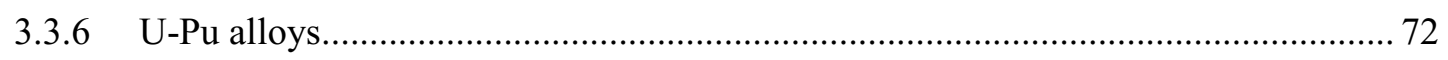

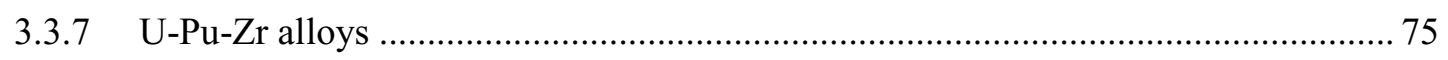

3.4 THERMAL CONDUCTIVITY AND THERMAL DIFFUSIVITY ................................... 78

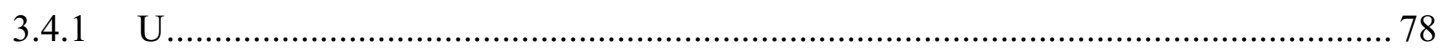

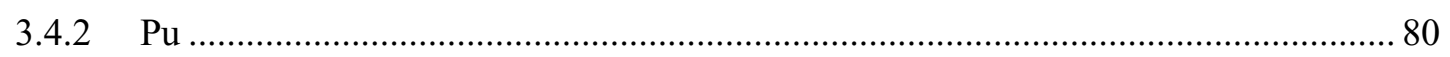

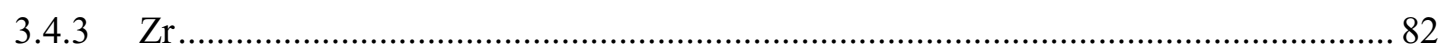

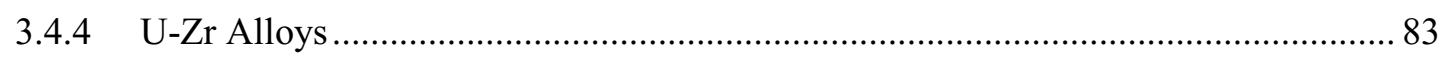

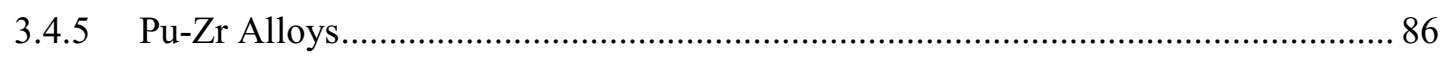

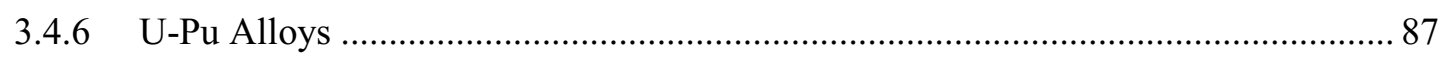

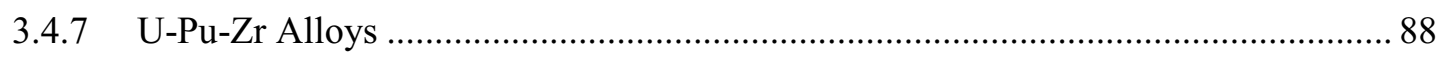

4. Minor actinides, rare-earth elements, and their alloys.............................................................. 91

4.1 PHASES, PHASE DIAGRAMS, PHASE TRANSFORMATIONS, PHASE-TRANSFORMATION ENTHALPIES ................................................................. 91

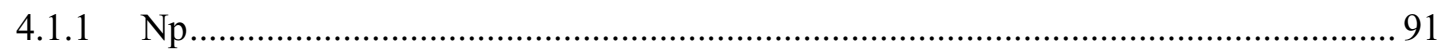

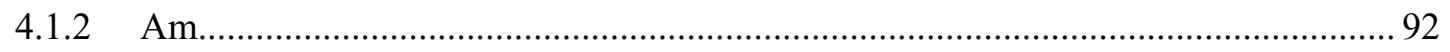

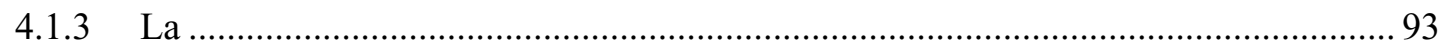

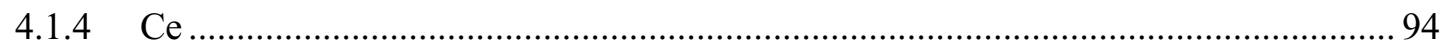

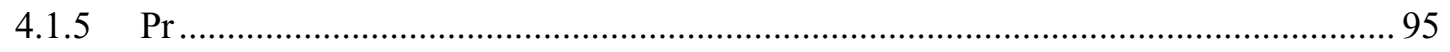

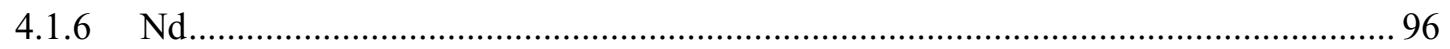

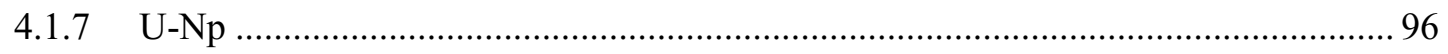

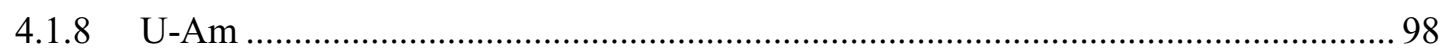

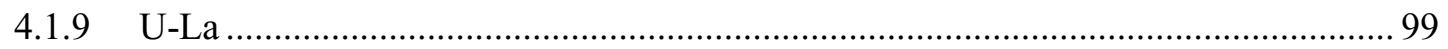

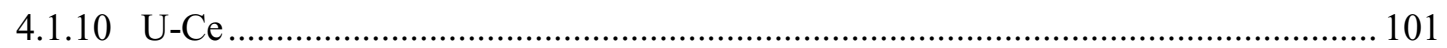

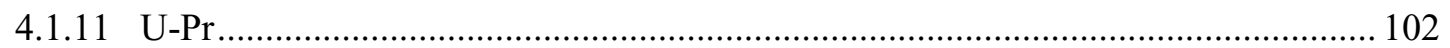

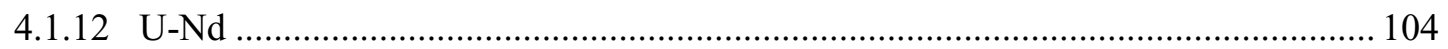

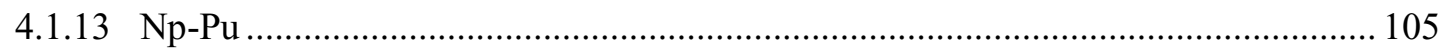

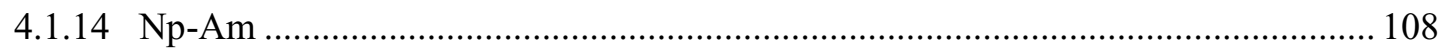




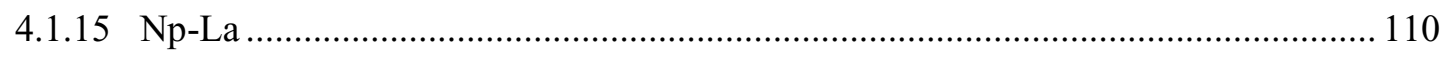

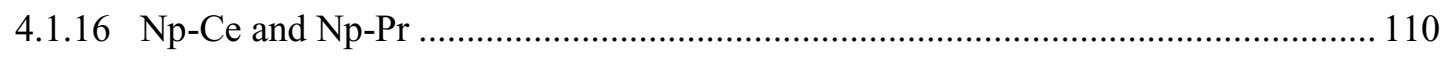

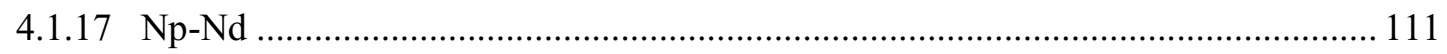

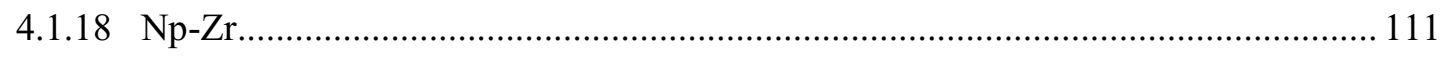

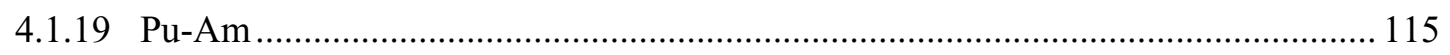

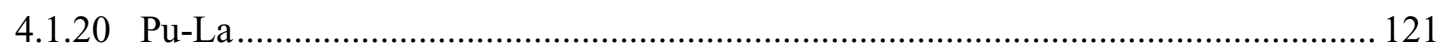

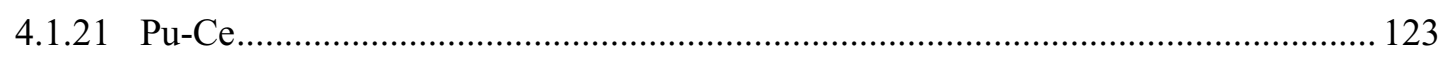

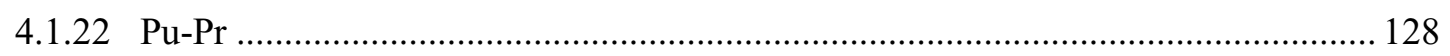

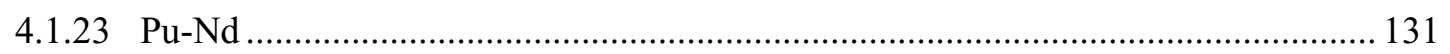

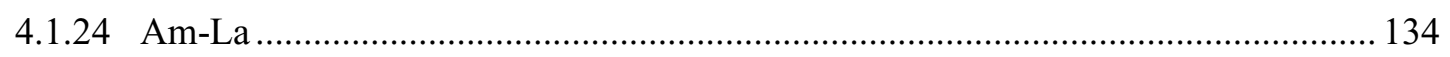

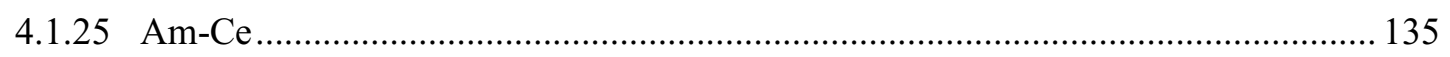

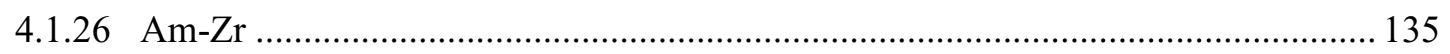

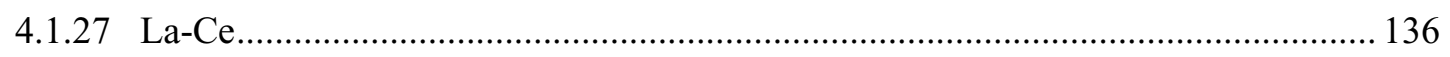

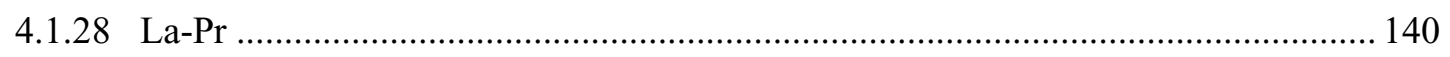

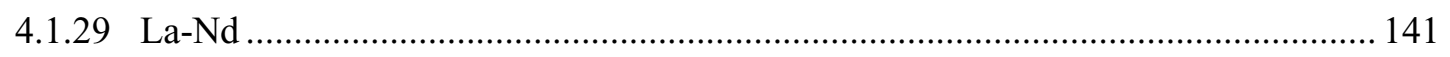

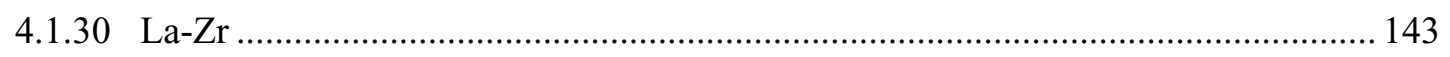

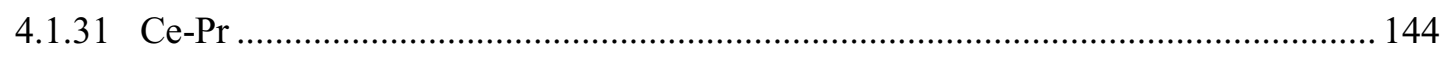

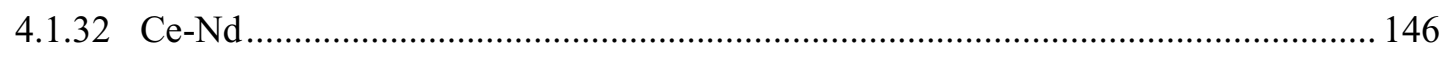

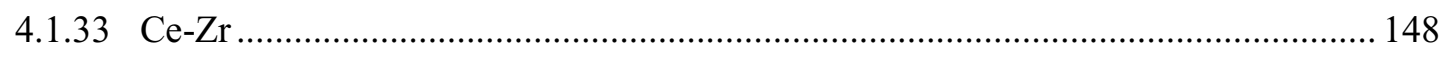

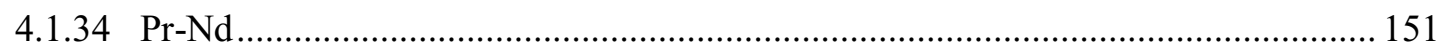

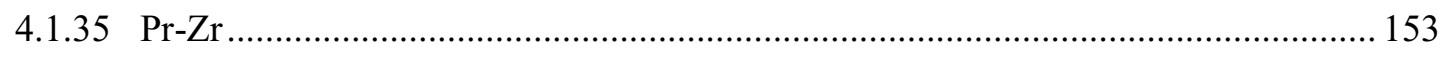

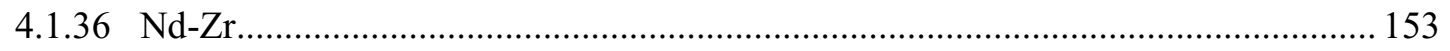

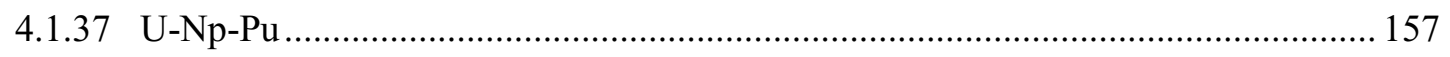

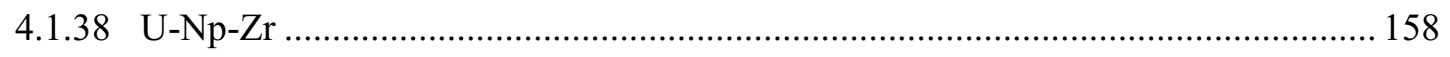

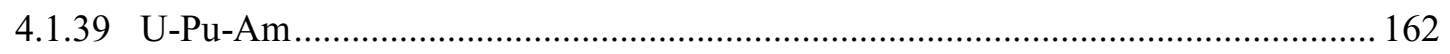

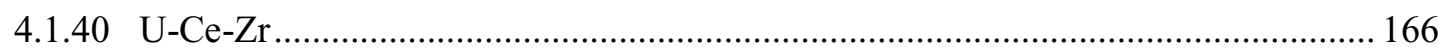

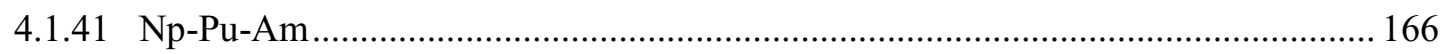

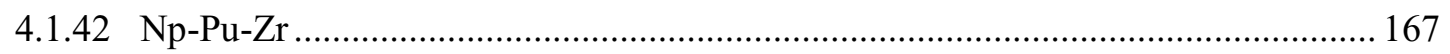

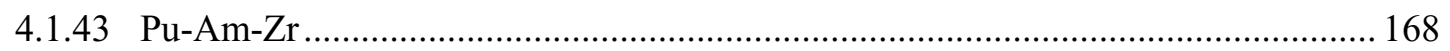

4.2 HEAT CAPACITY AND RELATED PROPERTIES (ENTROPY, ENTHALPY,

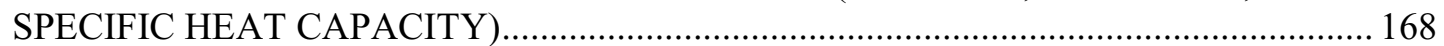

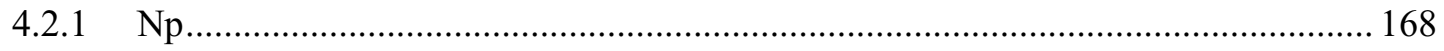

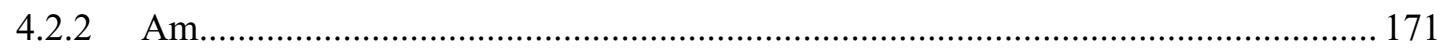

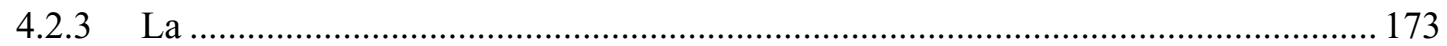

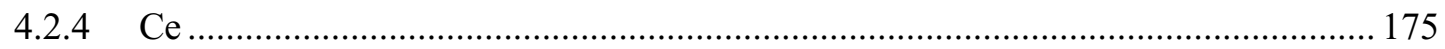




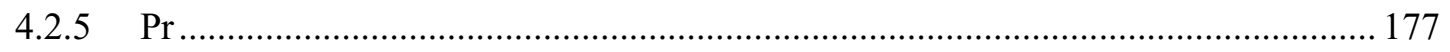

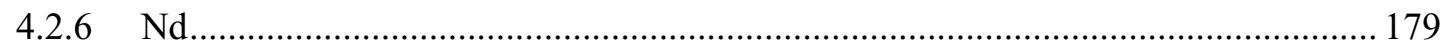

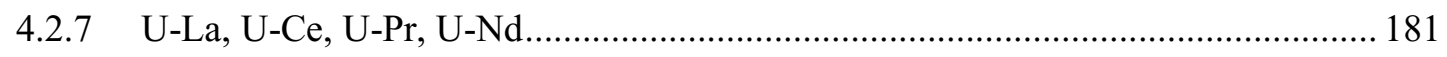

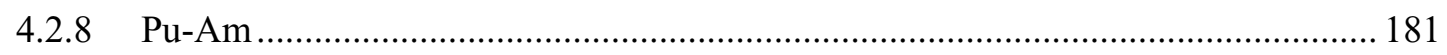

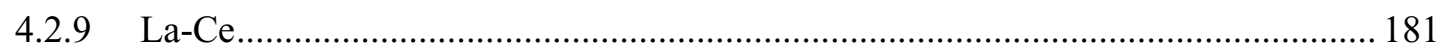

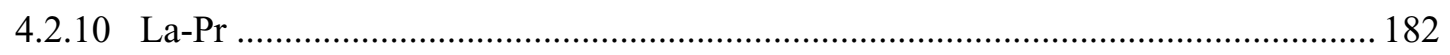

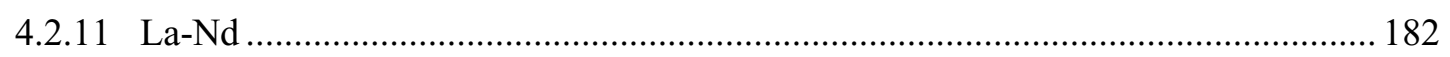

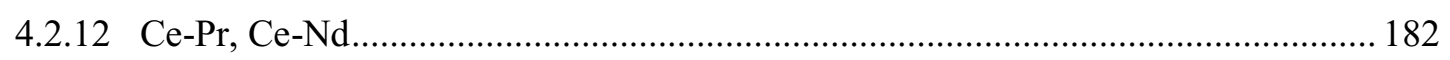

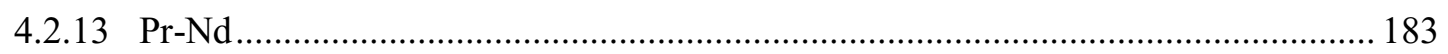

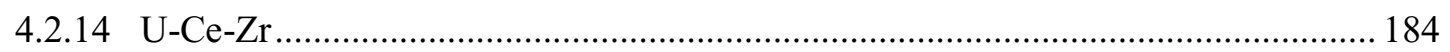

4.3 THERMAL EXPANSION, THERMAL EXPANSION COEFFICIENTS, AND

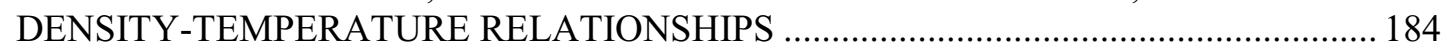

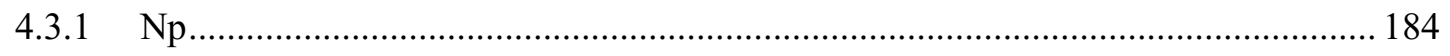

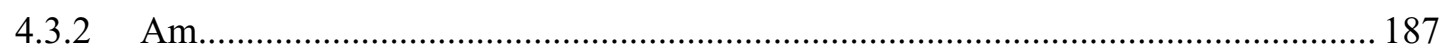

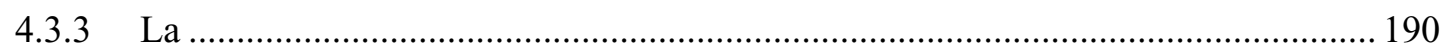

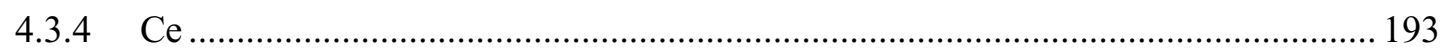

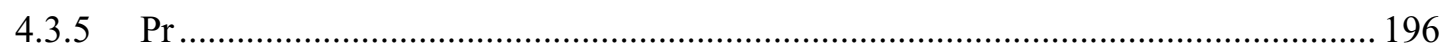

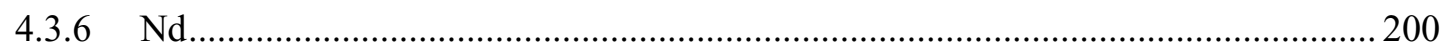

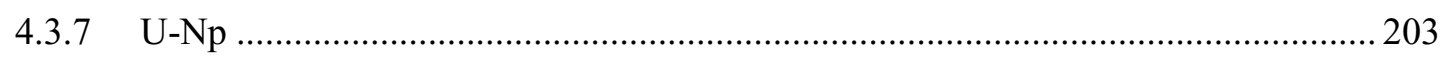

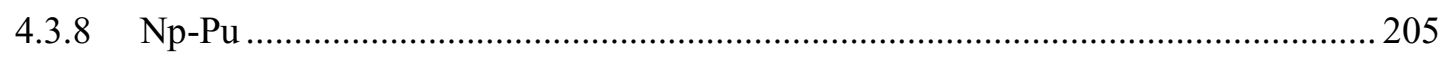

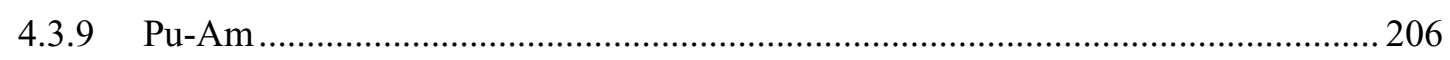

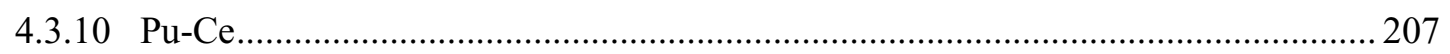

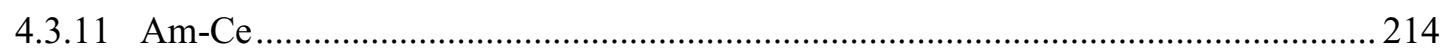

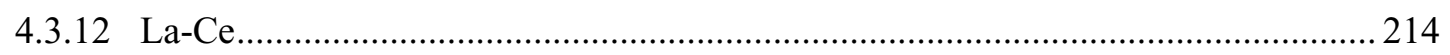

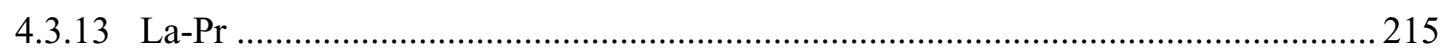

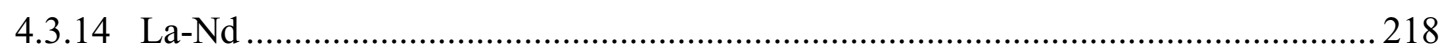

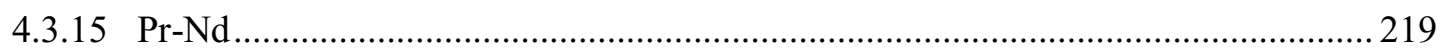

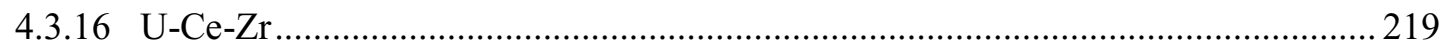

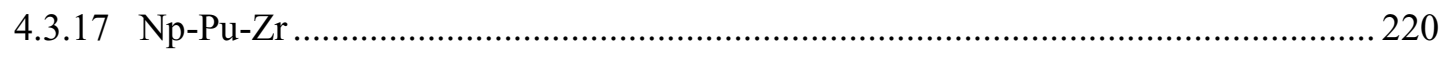

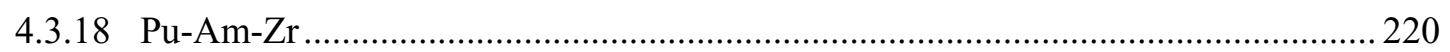

4.4 THERMAL CONDUCTIVITY AND THERMAL DIFFUSIVITY .................................. 220

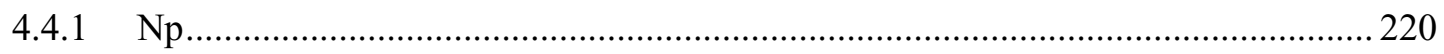

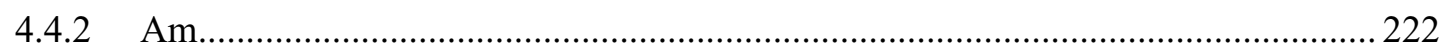

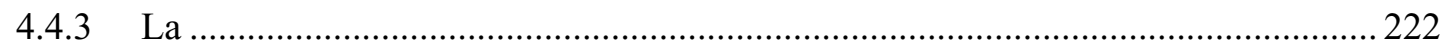

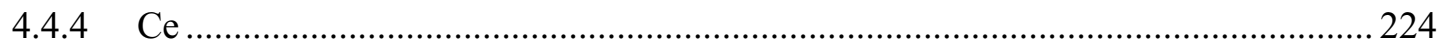




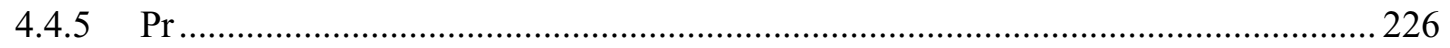

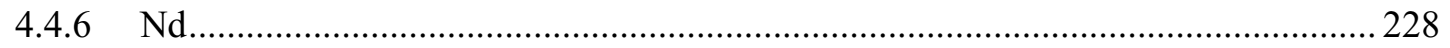

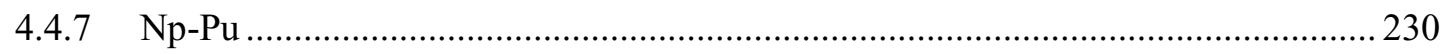

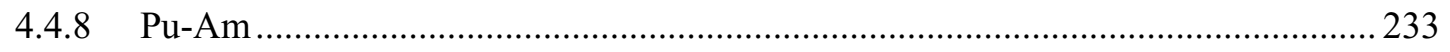

4.4 .9 Pu-Ce

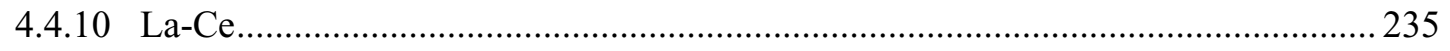

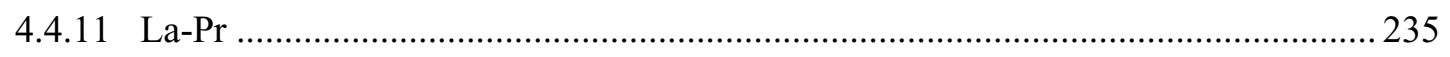

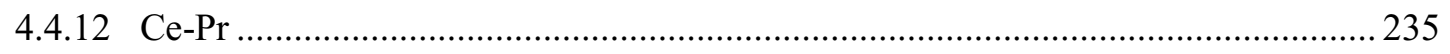

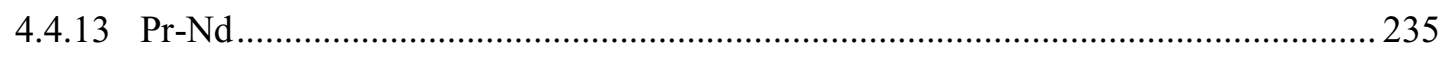

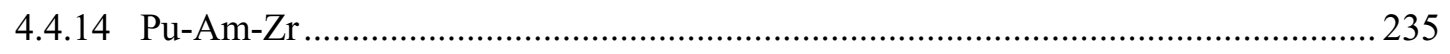

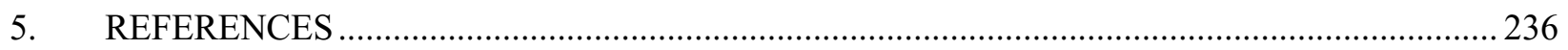

\section{FIGURES}

Figure 1. Temperature dependence of the Lorenz number for $\mathrm{Nd}$ (red curve) with theoretical value (dashed black line) for comparison (re-drawn with selected data from reference [16])

Figure 2. U-Zr phase diagram according to Sheldon and Peterson [41], with changes suggested by Akabori et al. 1992 [48] near large arrow. The liquidus and solidus measured by Balakrishnan et al. [50] are shown in red.

Figure 3. Partial U-Zr phase diagram based on Rough and Bauer [46] 16

Figure 4. $\mathrm{Pu}-\mathrm{Zr}$ phase diagram simplified from Okamoto [92]. High-Pu phases (allotropes of $\alpha-\mathrm{Pu}, \boldsymbol{\beta}-\mathrm{Pu}, \boldsymbol{\gamma}-\mathrm{Pu}$, and $\boldsymbol{\delta}^{\prime}-\mathrm{Pu}$ ) are not shown.

Figure 5. U-Pu phase diagram simplified from Peterson and Foltyn [106]. High-Pu phases (allotropes of $\boldsymbol{\alpha}-\mathrm{Pu}, \boldsymbol{\beta}-\mathrm{Pu}, \boldsymbol{\gamma}-\mathrm{Pu}, \boldsymbol{\delta}-\mathrm{Pu}$, and $\boldsymbol{\delta}^{\prime}-\mathrm{Pu}$ ) are not shown for simplicity and have at most a few at $\% \mathrm{U}$.

Figure 6. Compositions (in at \%) of alloys whose phase-transition temperatures and enthalpies were measured at INL

Figure 7. Compositions (in wt $\%$ ) of alloys whose phase-transition temperatures and enthalpies were measured at INL

Figure 8. Experimentally determined liquidus temperatures in ${ }^{\circ} \mathrm{C}$, with melting temperatures of $\mathrm{U}, \mathrm{Pu}$, and $\mathrm{Zr}$ for comparison [66, 90, 119, 125, 135]

Figure 9. Experimentally determined solidus temperatures in ${ }^{\circ} \mathrm{C}$, with melting temperatures of $\mathrm{U}$, $\mathrm{Pu}$, and $\mathrm{Zr}$ for comparison $[66,119,125,135]$

Figure 10. Liquidus temperatures $\left({ }^{\circ} \mathrm{C}\right)$ from models of Leibowitz et al. [66] (solid lines), Kurata [62] (dotted lines), and Ogata [5] (colored symbols showing examples of calculated points, with each color indicating a different temperature). Melting temperatures of $U$, $\mathrm{Pu}$, and $\mathrm{Zr}$ are shown for comparison. 
Figure 11. Solidus temperatures $\left({ }^{\circ} \mathrm{C}\right)$ from models of Leibowitz et al. [66] (solid lines), Kurata [62] (dotted lines), and Ogata [5] (colored symbols showing examples of calculated points)

Figure 12. Ternary projection of low-temperature limit of $(\gamma-U)$ solid solution from Mound Laboratory [98, 131] (solid lines) with corresponding temperature contours from O'Boyle and Dwight [121] (dotted lines). 32

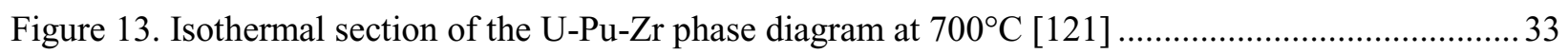

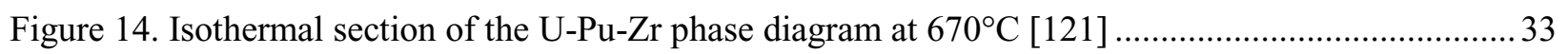

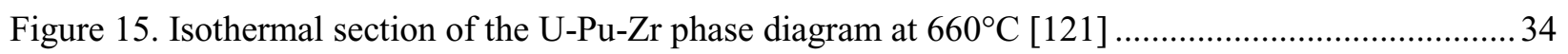

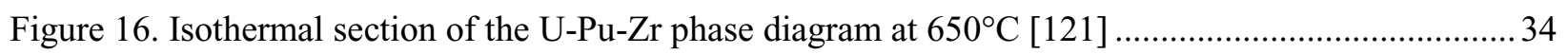

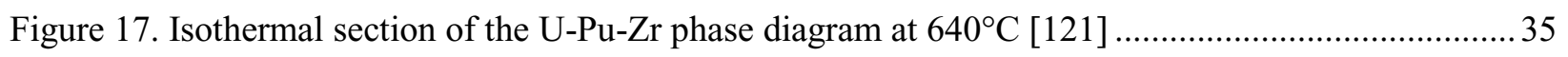

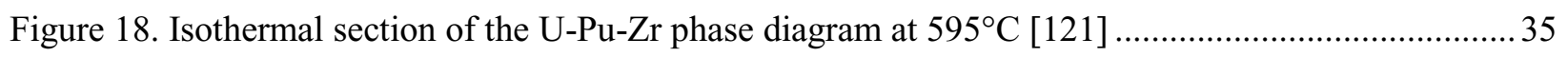

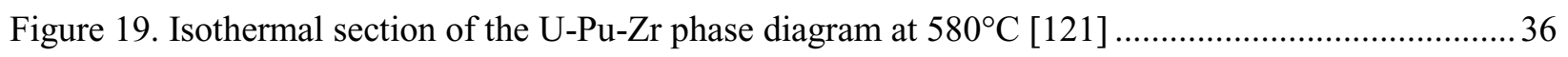

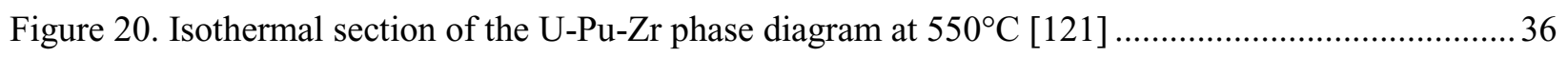

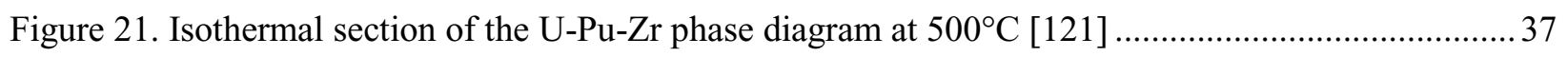

Figure 22. Heat capacities of solid and liquid U. Values from Konings and Beneš [2]

(Equation 10, Equation 11, Equation 12, and Equation 13) are preferred.

Figure 23. Heat capacity of $U$ as an ideal gas. Values from Konings and Beneš were calculated from Equation 14and Equation 15

Figure 24. Heat capacities of solid and liquid Pu. Values from Konings and Beneš [2] (solid black

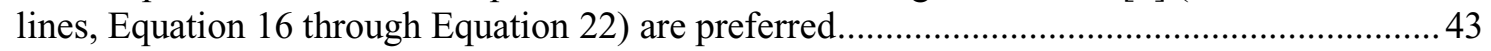

Figure 25. Heat capacity of 239Pu as an ideal gas, calculated using Equation 23 and Equation 24 ..........44

Figure 26. Heat capacities of solid Zr phases (IAEA data calculated using Equation 25 and Equation 26)

Figure 27. Measured heat capacities for U-Zr alloys with $13-41$ at $\% \mathrm{Zr}(\sim 5.5-21 \mathrm{wt} \% \mathrm{Zr})$ at temperatures from 300-850 K [84-86, 142, 143]. Different line types indicate different references.

Figure 28. Specific heat (J/g K) of Pu-30 wt\% Zr and Pu-40 wt\% $\mathrm{Zr}$ from 300-980 K upon heating at $10 \mathrm{~K} / \mathrm{min}$

Figure 29. Specific heat (J/g K) of Pu-30 wt $\% \mathrm{Zr}$ and $\mathrm{Pu}-40 \mathrm{wt} \% \mathrm{Zr}$ from $356-962 \mathrm{~K}$ upon cooling at $10 \mathrm{~K} / \mathrm{min}$.

Figure 30. DSC curve vs. temperature (K) for the $\mathrm{Pu}-\mathrm{Zr}$ alloys.

Figure 31. Incremental enthalpy $(\mathrm{H}(\mathrm{T})-\mathrm{H}(298))$ of $\mathrm{U}-10 \mathrm{Pu}$, calculated from Equation 28 , Equation 29, Equation 30, and Equation 31

Figure 32. Heat capacity of U-10Pu (calculated from Equation 32, Equation 33, Equation 34, and Equation 35), with the heat capacity of $U$ [2] for comparison.

Figure 33. Incremental enthalpy $(\mathrm{H}(\mathrm{T})-\mathrm{H}(25))$ of $\mathrm{U}-15 \mathrm{Pu}-10 \mathrm{Zr}$ [117]. Note that temperature is in ${ }^{\circ} \mathrm{C}$. Triangles are measured data points, and the polynomial fit is calculated from Equation 36 and Equation 37. 
Figure 34. Heat capacity of U-15Pu-10Zr, calculated from Equation 38 and Equation 39 [117].

The heat capacity of pure $U$ [2] is provided for comparison.

Figure 35. Thermal expansion of polycrystalline $U$ [6, 148], calculated using Equation 40 through Equation 44.

Figure 36. Density of U. Data labeled "Klepfer and Chiotti" and "Lawson et al." are from references [147] and [18]. Data labeled "Touloukian" were calculated using Equation 45 and Touloukian's equations for thermal expansion (Equation 40, Equation 42, and Equation 43). Data labeled "Konings et al." were calculated using Equation 46.

Figure 37. Linear thermal expansion of polycrystalline $\mathrm{Pu}$ [158].

Figure 38. Thermal expansion of polycrystalline Zr, calculated from Equation 48 and Equation 49

Figure 39. Thermal expansion of U-Zr alloys according to Saller et al. and Touloukian et al. [6, $165]$, with thermal expansion of $U$ and $\operatorname{Zr}[6,160]$ for comparison. Values for $10 \mathrm{wt} \%$ and $20 \mathrm{wt} \% \mathrm{Zr}$ are polynomial fits to tabulated data from Touloukian et al. [6]

Figure 40. Thermal expansion of $U$ and $U-Z r$ alloys according to Basak et al. [148]

Figure 41. Thermal expansion of Pu-Zr alloys, calculated from data in Table 11 [166] using a reference temperature of $400^{\circ} \mathrm{C}$

Figure 42. Thermal expansion of U-15 wt\% (15 at\%) Pu, calculated using Equation 63, Equation 64, and Equation 65

Figure 43. Thermal conductivity of $U$ (Equation 66, Equation 67, and Equation 68).

Figure 44. Thermal conductivity of $\mathrm{Pu}$. Data from Alexander and Wood were calculated from Equation 69 through Equation 73.

Figure 45. Thermal conductivity of $\mathrm{Zr}$ [175], plotted using Equation 75

Figure 46. Thermal conductivity of $\mathrm{U}-\mathrm{Zr}$ alloys, with conductivity of $\mathrm{U}$ and $\mathrm{Zr}$ for comparison [8, $84,170,172,176]$

Figure 47. Measured and predicted thermal conductivity for $\mathrm{U}-\mathrm{Zr}$ alloys with 6-17 wt\% Zr. Ogata's predicted value is from Equation 76.

Figure 48. Thermal diffusivity of $\mathrm{Pu}-10 \mathrm{wt} \% \mathrm{Zr}$ and $\mathrm{Pu}-30 \mathrm{wt} \% \mathrm{Zr}$ alloys (INL preliminary data). Data for $\mathrm{Pu}-10 \mathrm{wt} \%$ alloy are the average of two measurements.

Figure 49. Thermal conductivity of U-Pu-Zr alloys. [125, 129, 168, 178]....

Figure 50. Comparison of measured and predicted thermal conductivity of $\mathrm{U}-\mathrm{Pu}-\mathrm{Zr}$ alloys 90

Figure 51. U-Np phase diagram proposed by Mardon and Pearce (re-drawn from [248]) .98

Figure 52. U-Am phase diagram proposed by Perron et al. (re-drawn from [112])

Figure 53. Tentative U-La phase diagram drawn for this Handbook based on the work of Okamoto [261], with experimental data from Haefling and Daane [258] (red "+" symbols), Rough and Bauer [47] (red squares), and Shoji et al. [259] (green circles)

Figure 54. U-Ce phase diagram after Gschneidner [9 Figure 120]. Colored symbols indicate phase boundaries from Haefling and Daane [258] (red "+" symbols), Rough and Bauer [47] (red squares), and Shoji et al. [259] (green circles). 
Figure 55. Tentative partial U-Pr phase diagram drawn for this handbook, with experimental data from Haefling and Daane ([258], red “+” symbols) and Rough and Bauer ([47], red squares). Phase boundaries were based on those in the U-Ce system.

Figure 56. Tentative partial U-Nd phase diagram based onthat of Parnell et al. [265], displaying only the temperature range for which there is experimental data. Red "+" symbols indicate data from Haefling and Daane [258]. Red squares indicate data from Rough and Bauer [47] 104

Figure 57. Np-Pu phase diagram of Sheldon and Peterson (re-drawn from [272]) ..... 108

Figure 58. Np-Am phase diagram calculated by Ogawa [110, 275]. Red arrows show compositions corresponding to experimental data.

Figure 59. Tentative Np-Zr phase diagram proposed by Gibson and Haire [289]. Colored symbols show data from Table 18. Red symbols are data from Gibson and Haire [288, 289]; blue symbols are data from Rodríguez et al. [285].

Figure 60. Tentative Np-Zr phase diagram proposed by Rodríguez et al. [285], showing only temperatures from 100 to $1000{ }^{\circ} \mathrm{C}$. Colored symbols are as in Figure 59.

Figure 61. Lattice parameters of $(\beta-\mathrm{Am}, \delta$-Pu) solid solutions [295, 299] 116

Figure 62. Experimentally determined Pu-Am phase diagram according to Ellinger et al. [294, 295]. $\alpha, \beta, \gamma, \delta, \delta$ ' and $\varepsilon$ indicate Pu solid solution phases. Although this phase diagram is based on the most thoroughly documented experimental study of the Pu-Am system to date, it is no longer generally accepted.

Figure 63. Experimentally determined Pu-Am phase diagram according to Shushakov et al. [296]. $\alpha, \beta, \gamma, \delta, \delta$ ' and $\varepsilon$ indicate $\mathrm{Pu}$ phases.

Figure 64. Pu-Am phase diagram of Okamoto [305], which combines the experimental data of Ellinger et al. [295] with modeling by Ogawa [110]. $\alpha, \beta, \gamma, \delta, \delta$ ' and $\varepsilon$ indicate $\mathrm{Pu}$ phases.

Figure 65. Calculated Pu-Am phase diagram of Gotcu-Freis et al. [297], which shows immiscibility of $\varepsilon$-Pu and $\gamma$-Am solid solutions. $\alpha, \beta, \gamma, \delta, \delta$ ' and $\varepsilon$ indicate Pu solid solution phases.

Figure 66. Calculated Pu-Am phase diagram of Turchi et al. [298], which shows a continuous solid solution between $\varepsilon$-Pu and $\gamma$-Am. This phase diagram has two " $\beta+\delta$ " fields because of a small miscibility gap in the $(\delta, \beta$-Am) solid solution. $\alpha, \beta, \gamma, \delta, \delta$ ' and $\varepsilon$ indicate $\mathrm{Pu}$ solid solution phases.

Figure 67. Pu-La phase diagram of Ellinger et al. (re-drawn from [306]) .............................................. 123

Figure 68. Pu-Ce phase diagram of Ellinger et al. (re-drawn from [308]) .......................................... 126

Figure 69. Pu-Ce phase diagram of Selle et al. (re-drawn from [309])................................................ 127

Figure 70. Composite Pu-Ce phase diagram (re-drawn from Okamoto [315]) ..................................... 128

Figure 71. Pu-Pr phase diagram of Kutaitsev et al. (re-drawn from [317]) .......................................... 130

Figure 72. Pu-Pr phase diagram of Ellinger et al. (re-drawn from [318])............................................ 131

Figure 73. Pu-Nd phase diagram of Kutaitsev et al. [317].................................................................. 133

Figure 74. Pu-Nd phase diagram after Ellinger et al. [312, 318] ...................................................... 134

Figure 75. Calculated Am-Zr phase diagram (after [250]) ............................................................. 136 
Figure 76: Lattice spacings for ( $\beta$-La, $\gamma$-Ce) solid solutions. Blue symbols indicate values summarized by Gschneidner and Calderwood [10], red symbols indicate values from Scott et al. [325].

Figure 77: La-Ce phase diagram after Gschneidner and Calderwood [10] with data from Bulanova et al. [326] (blue crosses) and equilibrium temperature from Gschneidner and Pecharsky [228] (green circle)...

Figure 78. Hypothetical La-Pr phase diagram (reference [337] with phase-transformation temperatures adjusted to match the recommendations in Sections 4.1.3 and 4.1.5)

Figure 79. La-Nd phase diagram after Gschneidner and Calderwood [10]. Red symbols represent data from $\mathrm{Wu}$ et al. [339]: plus symbols are $(\beta-\mathrm{La})$, x symbols are $(\alpha-\mathrm{Nd})$, and superimposed symbols indicate that both phases were identified.

Figure 80. Ce-Pr phase diagram after Gschneidner and Calderwood [10], with phasetransformation temperatures for $\mathrm{Ce}$ and $\mathrm{Pr}$ from Sections 4.1.4 and 4.1.5 of this handbook

Figure 81. Tentative Ce-Nd phase diagram after Okamoto [337] with experimental data from Speight et al. [348] (red; + indicates an alloy with reported fcc lattice parameters, * indicates an alloy with reported dhcp lattice parameters), Keiser [349] (green; x symbols indicate boundaries of the two-phase region), and Hachimi et al. [350] (blue; open circle indicates an alloy with predominantly fcc structure, filled circle indicates an alloy with dhcp structure).

Figure 82. Commonly reproduced Ce-Zr phase diagram suggested by Moffatt [357], based on the assumption that the $\mathrm{Ce}-\mathrm{Zr}$ and Ce-Ti phase diagrams are similar (redrawn from [360])

Figure 83. Recent Ce-Zr phase diagram based on new experimental data and thermodynamic modeling (after Mattern et al. [355]). Solid lines indicate areas with new data.

Figure 84: Pr-Nd phase diagram after [363], with phase-transformation temperatures adjusted slightly for consistency with recommendations in Sections 4.1.5 and 4.1.6 of this handbook.

Figure 85: Nd-Zr phase diagram after Mattern et al. [372]. Solid lines indicate areas with new data.

Figure 86. Calculated U-Np-Pu phase diagram [62], with phase identifications suggested by comparison to binary phase diagrams. $\beta$ refers to $\beta$-U solid solutions, $\delta$ refers to $\delta$ (U,Np) solid solutions, and $\gamma$ refers to $\gamma-(\mathrm{U}, \mathrm{Np})$ or $\gamma$-(U,Pu) depending on composition.

Figure 87: Tentative partial isothermal section of the $\mathrm{U}-\mathrm{Np}-\mathrm{Zr}$ system at $700{ }^{\circ} \mathrm{C}$ suggested by Rodríguez et al. [285] .

Figure 88: Tentative partial isothermal section of the $\mathrm{U}-\mathrm{Np}-\mathrm{Zr}$ system at $595{ }^{\circ} \mathrm{C}$ suggested by Rodríguez et al. [285].

Figure 89: Tentative partial isothermal section of the $\mathrm{U}-\mathrm{Np}-\mathrm{Zr}$ system at $520{ }^{\circ} \mathrm{C}$ suggested by Rodríguez et al. [285].

Figure 90. Calculated isothermal sections at $1200 \mathrm{~K}$ based on the models of Ogawa [110], Kurata [250] (as calculated by Perron et al. [112 Figure 7]), and the preferred model of Perron et al. [112 Figure 8].

Figure 91. Calculated isothermal sections at $900 \mathrm{~K}$ based on the model of Kurata [250] (as calculated by Perron et al. [112 Figure 7]) and the preferred model of Perron et al. [112 Figure 8]. 
Figure 92. Calculated isothermal sections at $600 \mathrm{~K}$ based on the model of Kurata [250] (as calculated by Perron et al. [112 Figure 7]) and the preferred model of Perron et al. [112 Figure 8].

Figure 93. Calculated isothermal sections at $300 \mathrm{~K}$ based on the model of Kurata [250] (as calculated by Perron et al. [112 Figure 7]) and the preferred model of Perron et al. [112 Figure 8].

Figure 94. Isothermal sections calculated by Ogawa [110]

Figure 95. Isothermal section calculated by Kurata $[62,250]$.

Figure 96. Heat capacity of $\alpha-\mathrm{Np}[2,387,388]$.

Figure 97. Estimated heat capacities of $\beta$-, $\gamma$-, and liquid $\mathrm{Np}$, with the heat capacities of $\mathrm{U}$ and $\mathrm{Pu}$ phases on which the estimates are based. Heat-capacity values for $\mathrm{Np}$ are from Konings $\&$ Beneš [2]. Solid lines indicate tetragonal phases (space groups $P 42_{1} 2$ for $\beta$-Np, $P 42 m n m$ for $\beta-\mathrm{U}$, and $I 4 / \mathrm{mmm}$ for $\delta$ '-Pu), dotted lines indicate bcc phases (space group $\operatorname{Im} 3 \mathrm{~m})$, and dashed lines indicate liquids.

Figure 98. Estimated heat capacity of Am, showing values from Oetting et al. [4], Konings [392], and Ward et al. [19 Table A.6]

Figure 99. Heat capacity of La (references [396, 398, 399, 401, 402] and Equation 78, Equation 79, Equation 80, and Equation 81))....

Figure 100. Heat capacity of Ce (references [400, 403] and Equation 82 through Equation 85).

Data of Spedding et al. for $\gamma$-Ce is dashed to make it possible to see values from

Konings and Beneš.

Figure 101. Heat capacity of $\operatorname{Pr}$ (references [396, 401, 402, 405, 406] and Equation 88 through Equation 90)

Figure 102. Heat capacity of $\mathrm{Nd}$ (references [399, 403] and Equation 90 through Equation 93). 180

Figure 103. Heat capacity of a La-Ce alloy with 50 at $\%$ La, estimated using the Kopp-Neumann Law and elemental heat capacities from the equations in Sections 4.2.3 and 4.2.4 of this handbook. Heat capacities of $\mathrm{La}$ and $\mathrm{Ce}$ are included for comparison. Colors indicate compositions, and line types (dots, etc.) indicate phases. The fcc alloy is a solid solution between $\beta$-La and $\gamma$-Ce.

Figure 104. Heat capacity of a Pr-Nd alloy with 50 at\% Pr, estimated using the Kopp-Neumann Law with heat capacities of Pr and Nd from the equations in Sections 4.2.5 and 4.2.6 of this handbook. Heat capacities of pure Pr and Nd are included for comparison. Colors indicate compositions, and line types (dots, etc.) indicate phases. The dhcp alloy is a solid solution of $\alpha-\operatorname{Pr}$ and $\alpha-\mathrm{Nd}$, and the bec alloy is a solid solution of $\beta-\operatorname{Pr}$ and $\beta-\mathrm{Nd}$..

Figure 105. Instantaneous coefficients of thermal expansion for polycrystalline $\alpha$ - and $\beta$-Np at selected temperatures [191 Table 4]

Figure 106. Density and molar volume of Np from Zachariasen's X-ray data [184]

Figure 107. Thermal expansion of $\alpha$-Am. The $a$ and $c$ lattice parameters are from McWhan et al. (Equation 94 and Equation 95); "Konings" value is from Equation 96.

Figure 108: Thermal expansion of single crystals of $\alpha$ - and $\beta$-La, based on values calculated from Equation 97 through Equation 99 using a reference temperature of $300 \mathrm{~K}$. Dotted line for $\beta$-La indicates that it is likely to be present (particularly during coolig) but is not thermodynamically stable. 
Figure 109: Densities and molar volumes of La phases ([221], Equation 100, Equation 101).

Dashed lines show properties of $\beta$-La at temperatures where it is thermodynamically unstable but likely to occur; dotted lines show extrapolation beyond the upper temperatures of the equations following [221 Figure 1].

Figure 110: Thermal expansion of $\gamma$-Ce, based on values calculated from Equation 102 using a reference temperature of $300 \mathrm{~K}$.

Figure 111: Densities and molar volumes of $\gamma$-Ce (lines calculated from Equation 103) and $\rho-\mathrm{Ce}$ (symbols showing values from reference [221]. 196

Figure 112: Thermal expansion of a and c lattice parameters of $\alpha$-Pr, calculated from Equation 104 and Equation 105 with a reference temperature of $300 \mathrm{~K}$ 198

Figure 113: Molar volumes of Pr phases (Equation 106 and references [221 Table 2] and [245 Figure 4])

Figure 114: Thermal expansion of $\alpha-N d$. "a" and "c" are single-direction expansions in the $a$ and $c$ directions, based on values calculated from Equation 107 and Equation 108 using a reference temperature of $300 \mathrm{~K}$. The "polycrystalline" value is a weighted average of the single-direction values. 202

Figure 115: Molar volumes and densities of $\alpha-\mathrm{Nd}$ (curves) and $\beta-\mathrm{Nd}$ (squares) (Equation 109 and reference [221]).

Figure 116. Thermal expansion of individual lattice parameters of Np-14.9 wt\% U (solid lines), with $\beta$-Np lattice parameters for comparison (dotted lines) (after [254 Fig. 4])

Figure 117. Room-temperature densities of U-Np alloys from pycnometry (re-drawn from [254 Figure 2]). Although Mardon and Pearce did not identify the phases involved, their phase diagram shows that the three room-temperature phases are $(\beta-\mathrm{Np}), \delta$-(U,Np), and $(\alpha-U)$

Figure 118. Thermal expansion of Am-stabilized $\delta$-Pu alloys (re-drawn from [296 Figure 2]), based on changes in the a lattice parameter from high-temperature X-ray diffraction. Numbers next to the curves indicate alloy compositions in (\% Am) 206

Figure 119. Lattice parameters of $\delta$-Pu alloys from X-ray diffraction data (Equation 110 and Table 27) 208

Figure 120. Linear thermal expansion from Equation 110, Equation 111, and Table 27. 209

Figure 121. Coefficients of thermal expansion, Ce-stabilized $\delta$-Pu alloys [166, 429]. The dashed line represents the "best fit" estimate of Goldberg et al.

Figure 122: Coefficient of thermal expansion of $\boldsymbol{\varepsilon}$-Pu solid solutions in $\mathrm{Pu}-\mathrm{Ce}$ alloys as a function of composition (re-drawn from [429 Figure 7]) .

Figure 123: Change in length of Pu-Ce alloys associated with the transition from $\delta$-Pu to $\varepsilon$-Pu structures as a function of composition [429 Figure 6] .

Figure 124. Densities of La-Ce liquids calculated using Equation 112 and Table 29

Figure 125. Densities of La-Pr liquids calculated using Equation 113 and Table 30. Solid lines show data from reference [433]; dotted lines show data from reference [432].

Figure 126. Densities of La-Nd liquids calculated using Equation 114 and Table 31

Figure 127. Thermal conductivity of Np calculated using the theoretical value of the Lorenz number $\left(2.44 \times 10^{-8} \mathrm{~W} \Omega / \mathrm{K}^{2}\right)$ and electrical resistivity data from Lee [435]..... 


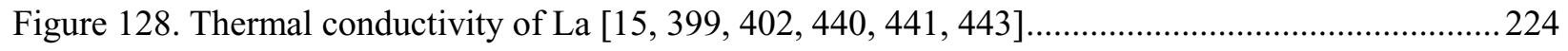

Figure 129. Thermal conductivity of Ce based on references $[8,15,399,402,443-446] \ldots \ldots \ldots \ldots \ldots \ldots \ldots . . . . .226$

Figure 130. Thermal conductivity of $\alpha$-Pr from references [399, 402, 443-445] ….............................228

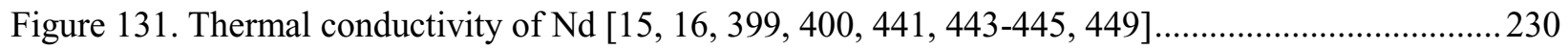

Figure 132. Electrical resistivity of $\mathrm{Pu}$ and Np-Pu alloys (after [456 Figure 2.9], with lowertemperature data not shown). Data for each material is expressed relative to R0, the resistivity of the material at $273 \mathrm{~K}$. Numbers next to curves indicate compositions (in at $\% \mathrm{~Np}$ ).

Figure 133. Thermal conductivities (blue squares) and electrical resistivities (red diamonds) from Olsen and Elliott [455] 233

Figure 134. Thermal diffusivity of Pu-12Am-40Zr (Equation 115 and Equation 116) 236

\section{TABLES}

Table 1. Transformation temperatures and enthalpies of solid U-Zr alloys [49 Table 2, 77 Table $\mathrm{V}, 84,85$ Table 4,86 Table 2]. $\delta$ refers to $\delta$ - $\left(\mathrm{UZr}_{2}\right)$.

Table 2. Solidus and liquidus measurements of $\mathrm{U}-\mathrm{Zr}$ alloys, with melting $\mathrm{T}$ of $\mathrm{Zr}$ for comparison

(Balakrishnan et al. [50 Table 6, 77 Table V, 84]

Table 3. Onset temperatures for peaks at temperatures above $400^{\circ} \mathrm{C}$ in recent INL data, measured during heating.....

Table 4. Combined enthalpies for all transformations at temperatures between 400 and $800^{\circ} \mathrm{C}$ corresponding to data summarized in Table 2 . .25

Table 5. Experimental and calculated liquidus temperatures $\left({ }^{\circ} \mathrm{C}\right)$ for $\mathrm{U}-\mathrm{Zr}$ and $\mathrm{U}-\mathrm{Pu}-\mathrm{Zr}$ alloys .29

Table 6. Experimental and calculated solidus temperatures $\left({ }^{\circ} \mathrm{C}\right)$ for $\mathrm{U}-\mathrm{Zr}$ and $\mathrm{U}-\mathrm{Pu}-\mathrm{Zr}$ alloys 30

Table 7. Heat capacities of $\boldsymbol{\gamma}$-(U,Zr) solid solutions at $1000 \mathrm{~K}$ .48

Table 9. Thermal expansion coefficients $(10-6 / \mathrm{K})$ of solid and liquid $\mathrm{Pu}[6,22,158]$.

Table 10. Mean linear coefficients of thermal expansion along single directions for anisotropic $\mathrm{Pu}$ phases [22].

Table 11. Coefficients for equations expressing lengths of U-Pu alloys, $L=a+b \times T+c \times T 2$, where $\mathrm{L}$ is a length (for dilatometer data) or lattice parameter (for X-ray data) and $\mathrm{T}$ is a temperature in ${ }^{\circ} \mathrm{C}$ [166]. The authors emphasize that these coefficients should only be used within the stated temperature ranges.

Table 12. Coefficients of thermal expansion for $\boldsymbol{\delta}-(\mathrm{Pu}, \mathrm{Zr})$. Data for Pu are from reference [22]; other data are from reference [166]. Coefficients should not be used outside the listed temperature ranges.

Table 13. Lattice parameters and unit-cell volume for $\zeta-(\mathrm{U}, \mathrm{Pu})$ as a function of temperature, based on data read from [116 Figure 8]. 
Table 14. Thermal expansion coefficients for U-Pu-Zr alloys between room temperature and $600^{\circ} \mathrm{C}$.

Table 15. Thermal expansion coefficients for U-Pu-Zr alloys between room temperature and $600^{\circ} \mathrm{C}$. 76

Table 16. Length changes (in \%) from phase transformations in U-Pu-Zr alloys. ................................. 77

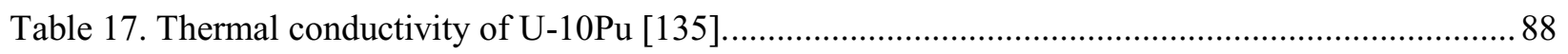

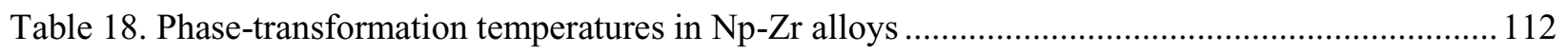

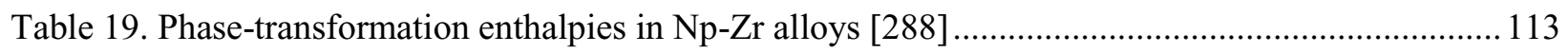

Table 20. Lattice parameters of arc-melted La and Am-La alloys [319] ............................................. 135

Table 21: Phase transformations in the Nd-Zr system [371 Table III, 372 Table 3, 373 Figure 4]. Subscripts in the data from Mattern et al. indicate the calculated composition (at $\% \mathrm{Zr}$ )

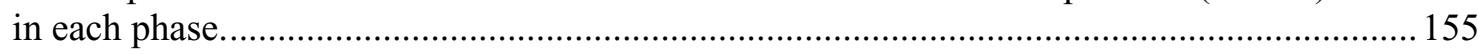

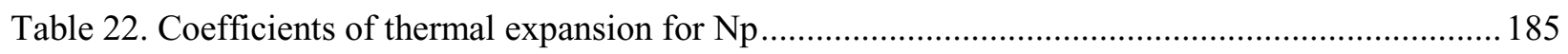

Table 23. Coefficients of thermal expansion for La. Coefficients with ranges of temperatures are

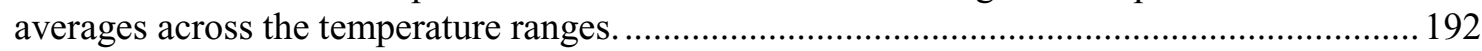

Table 24. Coefficients of thermal expansion for $\gamma$-Ce (single crystals and polycrystals)....................... 195

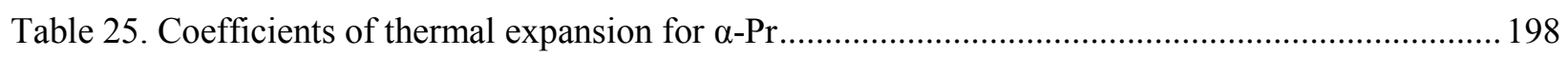

Table 26. Coefficients of thermal expansion for $\alpha-\mathrm{Nd}$..................................................................... 201

Table 27. Coefficients for calculating thermal expansion of Pu-Ce alloys using Equation 110 [166] 207

Table 28. Average coefficients of linear thermal expansion for Ce-stablized $\delta$-Pu alloys [166] 209

Table 29. Coefficients for calculating densities of La-Ce liquids (after [432]) .....................................215

Table 30. Coefficients for calculating densities of La-Pr liquids..........................................................216

Table 31. Coefficients for calculating densities of La-Nd liquids (after [432])....................................218

Table 32. Electrical resistivity and thermal conductivity of Np-Pu alloys with the ( $\alpha-\mathrm{Pu})$ structure at $300 \mathrm{~K}$. Resistivity data are from [455]; conductivity values were calculated assuming a Lorenz number of $3.15 \times 10^{-8} \mathrm{~W} \Omega \mathrm{K}^{-2}$.

Table 33. Electrical resistivity and thermal conductivity of Pu-Am alloys at $300 \mathrm{~K}$. Thermal conductivities were calculated using the Wiedemann-Franz Law with the Lorenz number for $\mathrm{Pu}$ 


\section{EQUATIONS}

Equation 1. Conversion of weight fractions to mole fractions .................................................................. 3

Equation 2. Conversion of mole fractions to weight fractions ….......................................................... 3

Equation 3. Basic relationship between density ( $\rho)$, mass (M), and volume (V) ................................... 4

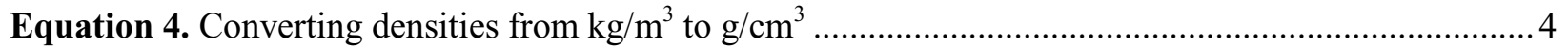

Equation 5. Calculating the density in $\mathrm{g} / \mathrm{cm}^{3}$ from information about a unit cell................................... 4

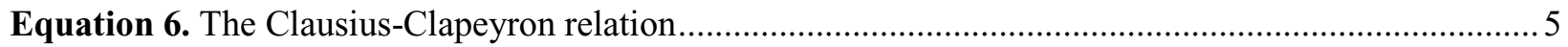

Equation 7. Calculating thermal conductivity from thermal diffusivity, density, and heat capacity........... 5

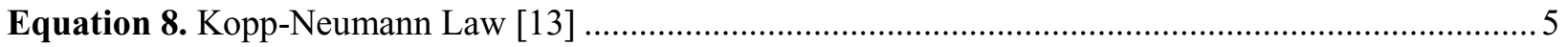

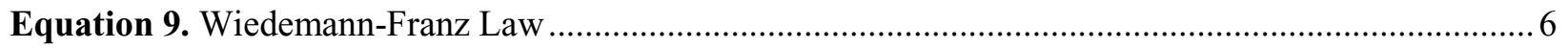

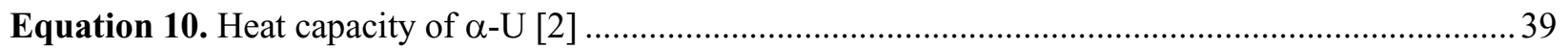

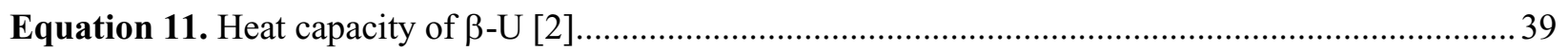

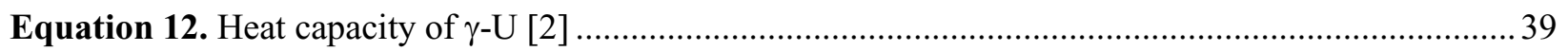

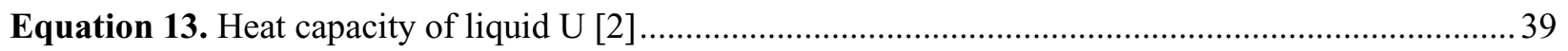

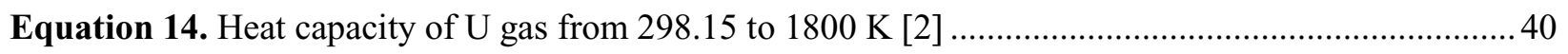

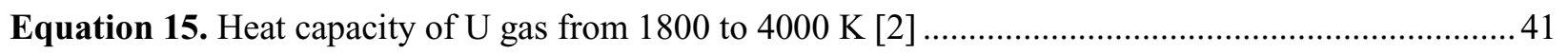

Equation 16. Heat capacity of $\alpha-\mathrm{Pu}([2]$ with temperature range from [137]) ........................................ 41

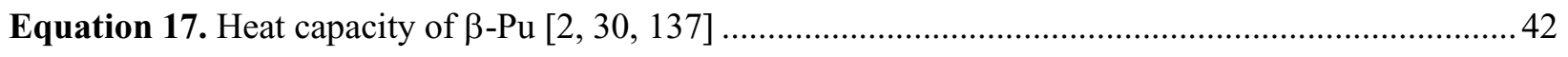

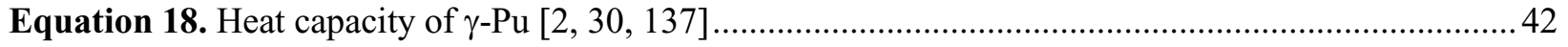

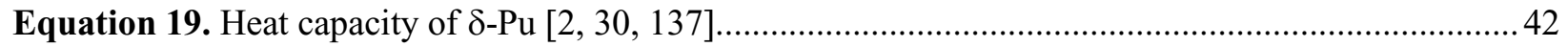

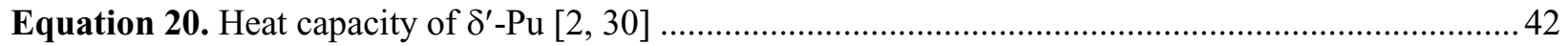

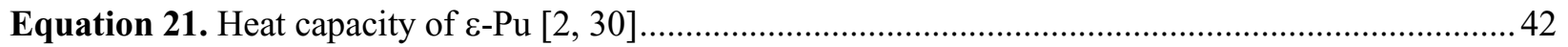

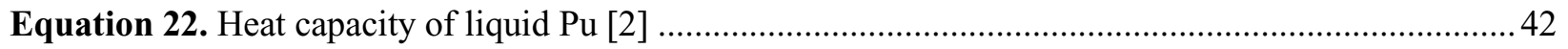

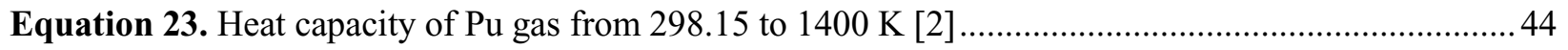

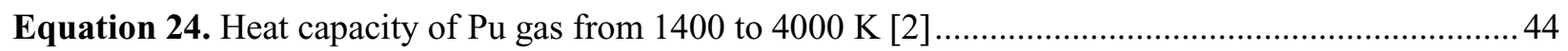

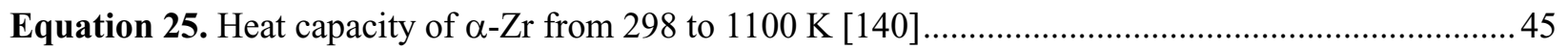

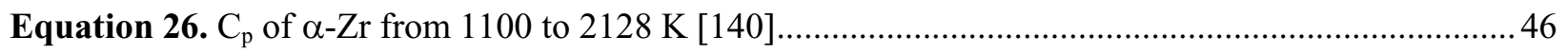

Equation 27. Heat capacity of U-20 at\% Zr (U-9 wt\% Zr) alloy from 289 to $852 \mathrm{~K}$ (Polynomial from reference [84], fitting data from reference [86]) ......................................................... 47

Equation 28. Specific heat of Pu-30Zr alloy from 355-879 K .............................................................. 48

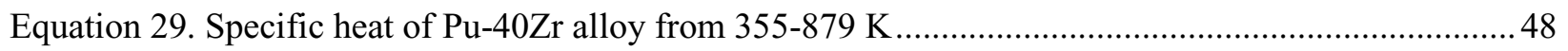

Equation 30. Incremental enthalpy of $(\alpha-U)$ phase in $\mathrm{U}-10 \mathrm{Pu}$ between 298 and $865 \mathrm{~K}$ [106] ................52

Equation 31. Incremental enthalpy of $(\beta-\mathrm{U})$ phase in $\mathrm{U}-10 \mathrm{Pu}$ between 875 and $1000 \mathrm{~K}$ [106]..............52 
Equation 32. Incremental enthalpy of $(\gamma-\mathrm{U})$ phase in $\mathrm{U}-10 \mathrm{Pu}$ between 1020 and $1310 \mathrm{~K}$ [106] .............52

Equation 33. Incremental enthalpy of U-10Pu liquid between 1365 and $1500 \mathrm{~K}$ [106] ........................53

Equation 34. Heat capacity of $(\alpha-\mathrm{U})$ phase in $\mathrm{U}-10 \mathrm{Pu}$ between 298 and $865 \mathrm{~K}$ [106] ..........................54

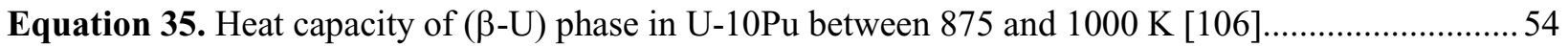

Equation 36. Heat capacity of $(\gamma-\mathrm{U})$ phase in $\mathrm{U}-10 \mathrm{Pu}$ between 1020 and $1310 \mathrm{~K}[106]$.......................54

Equation 37. Heat capacity of U-10Pu liquid between 1365 and $1500 \mathrm{~K}$ [106] ...................................54

Equation 38. Incremental enthalpy of $\mathrm{U}-15 \mathrm{Pu}-10 \mathrm{Zr}$ between 25 and $600{ }^{\circ} \mathrm{C}[117]$.............................56

Equation 39. Incremental enthalpy of $\mathrm{U}-15 \mathrm{Pu}-10 \mathrm{Zr}$ between 650 and $1150{ }^{\circ} \mathrm{C}$ [117] .........................56

Equation 40. Heat capacity of U-15Pu-10Zr between 25 and $600{ }^{\circ} \mathrm{C}$ [117] ........................................57

Equation 41. Heat capacity of U-15Pu-10Zr between 650 and $1150^{\circ} \mathrm{C}$ [117] ...................................57

Equation 42. Mean thermal expansion of polycrystalline $\alpha-U$ according to Touloukian et al. [6] ...........59

Equation 43. Measured thermal expansion of polycrystalline $\alpha-U$ according to Basak et al. [148] .........59

Equation 44. Mean thermal expansion of polycrystalline $\beta-U$ [ 3 Table 8] ............................................59

Equation 45. Provisional values for mean thermal expansion of polycrystalline $\gamma$-U according to Touloukian et al. [6] 60

Equation 46. Mean thermal expansion of polycrystalline $\gamma$-U according to Basak et al. [148]...............60

Equation 47. Density of solid U as a function of thermal expansion [3] .................................................60

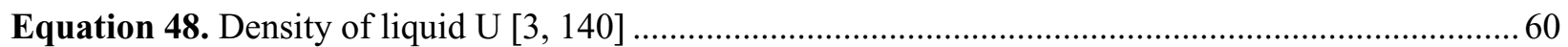

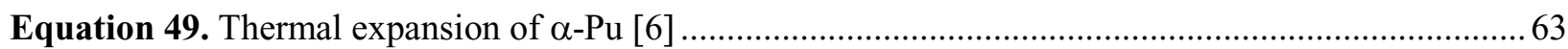

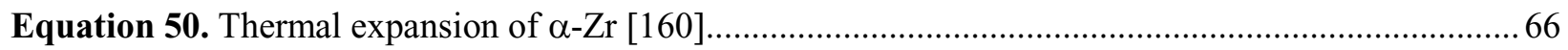

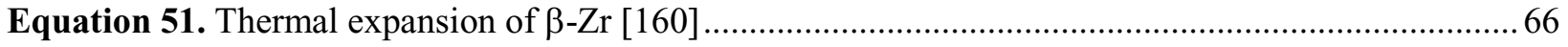

Equation 52. Mean linear thermal expansion coefficient for polycrystalline $\alpha-\mathrm{Zr}$ from 293 to $1130 \mathrm{~K}[160]$... 66

Equation 53. Mean linear thermal expansion coefficient for polycrystalline $\beta-\mathrm{Zr}$ ( $\alpha$ in units of $10^{-6} / \mathrm{K}$, T in K, T from 1200 to $1830 \mathrm{~K}$ ) [160] 66

Equation 54. Density of solid Zr from 298 to $2128 \mathrm{~K}$ [140] 66

Equation 55. Thermal expansion of U-10 wt\%-Zr from 293 to $900 \mathrm{~K}$ according to Touloukian et al. [6].....

Equation 56. Thermal expansion of U-20 wt\%-Zr from 293 to $900 \mathrm{~K}$ according to Touloukian et al. [6].

Equation 57. Thermal expansion of $(\alpha-U)$ in $U-2$ wt\%-Zr from 323 to $923 \mathrm{~K}$ according to Basak et al. [148].

Equation 58. Thermal expansion of $(\gamma-\mathrm{U})$ in $\mathrm{U}-2 \mathrm{wt} \%-\mathrm{Zr}$ from 998 to $1173 \mathrm{~K}$ according to Basak et al [148]

Equation 59. Thermal expansion of $(\alpha-U)$ in $U-5$ wt $\%-Z r$ from 323 to $923 \mathrm{~K}$ according to Basak et al. [148]. 
Equation 60. Thermal expansion of $(\gamma-\mathrm{U})$ in $\mathrm{U}-5 \mathrm{wt} \% \mathrm{Z}-\mathrm{Zr}$ from 998 to $1173 \mathrm{~K}$ according to Basak et al. [148].

Equation 61. Thermal expansion of $(\alpha-U)$ in $\mathrm{U}-7 \mathrm{wt} \%-\mathrm{Zr}$ from 323 to $923 \mathrm{~K}$ according to Basak et al. [148].

Equation 62. Thermal expansion of $(\gamma-\mathrm{U})$ in $\mathrm{U}-7 \mathrm{wt} \%$-Zr from 998 to $1173 \mathrm{~K}$ according to Basak et al. [148].

Equation 63. Thermal expansion of $(\alpha-\mathrm{U})$ in $\mathrm{U}-10 \mathrm{wt} \%-\mathrm{Zr}$ from 323 to $923 \mathrm{~K}$ according to Basak et al. [148].

Equation 64. Thermal expansion of $(\gamma-\mathrm{U})$ in $\mathrm{U}-10 \mathrm{wt} \%-\mathrm{Zr}$ from 998 to $1173 \mathrm{~K}$ according to Basak et al. [148].

Equation 65. Thermal expansion of $(\alpha-\mathrm{U})$ in $\mathrm{U}-15 \mathrm{wt} \%-\mathrm{Pu}$ from 393 to $823 \mathrm{~K}$ according to Kaity et al. [118].

Equation 66. Thermal expansion of $(\beta-\mathrm{U})$ in $\mathrm{U}-15 \mathrm{wt} \%$-Pu from 863 to $973 \mathrm{~K}$ according to Kaity et al. [118]....

Equation 67. Thermal expansion of $(\gamma-\mathrm{U})$ in $\mathrm{U}-15 \mathrm{wt} \%$-Pu from 1023 to $1163 \mathrm{~K}$ according to

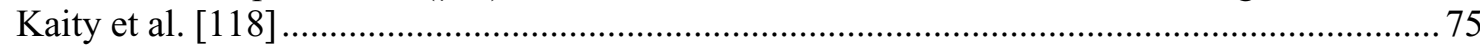

Equation 68. Thermal conductivity of $\mathrm{U}$ from 255 to $1173 \mathrm{~K}$ according to Kim et al. [170] .................. 79

Equation 69. Thermal conductivity of $U$ from 298 to $823 \mathrm{~K}$ according to Kaity et al. [84] .................... 79

Equation 70. Thermal conductivity of $U$ from 293 to $1405 \mathrm{~K}$ according to the IAEA [140].................. 79

Equation 71. Thermal conductivity of $\alpha$-Pu from 294 to $394 \mathrm{~K}$ according to Alexander and Wood [173].

Equation 72. Thermal conductivity of $\beta$-Pu from 415 to $490 \mathrm{~K}$ according to Alexander and Wood [173]

Equation 73. Thermal conductivity of $\gamma$-Pu from 491 to $595 \mathrm{~K}$ according to Alexander and Wood [173]

Equation 74. Thermal conductivity of $\delta$-Pu from 602 to $696 \mathrm{~K}$ according to Alexander and Wood [173]

Equation 75. Thermal conductivity of $\varepsilon$-Pu from 750 to $822 \mathrm{~K}$ according to Alexander and Wood [173]

Equation 76. Approximate thermal conductivity of $\mathrm{Pu}$ from 400 to $820 \mathrm{~K}$ according to Alexander and Wood [173]. 82

Equation 77. Approximate thermal conductivity of Pu according to Fink and Leibowitz [175] ..............83

Equation 78. Estimated thermal conductivity of $\mathrm{U}-\mathrm{Zr}$ alloys according to Ogata [72] ..........................85

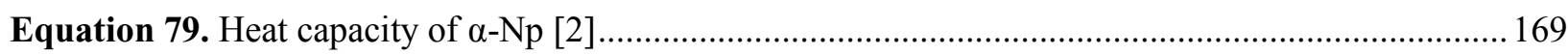

Equation 80. Heat capacity of $\alpha$-La [2] 174

Equation 81. Heat capacity of $\beta$-La (after [2], but with the last coefficient multiplied by T rather than $\mathrm{T}^{2}$ for consistency with data from Berg et al. [396]) 174

Equation 82. Heat capacity of $\gamma$-La [2]. 174

Equation 83. Heat capacity of La liquid $\left(C_{p}\right.$ in $\left.J / m o l-K\right)[2]$. 174 


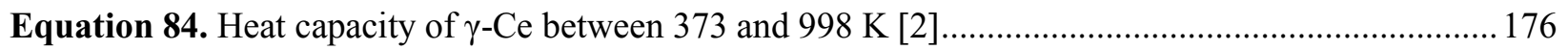

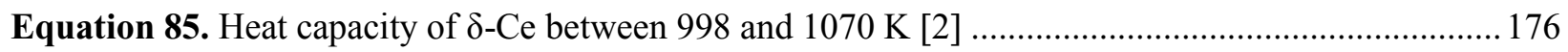

Equation 86. Heat capacity of Ce liquid between 1070 and $2500 \mathrm{~K}$ [2] ............................................ 176

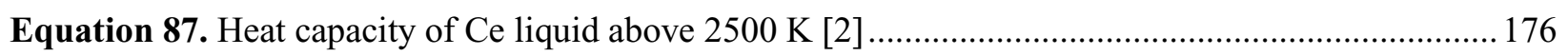

Equation 88. Heat capacity of Ce liquid between 1400 and $1700 \mathrm{~K}$ [404] .......................................... 176

Equation 89. Heat capacity of Ce liquid between 1700 and $2500 \mathrm{~K}$ [404] .......................................... 176

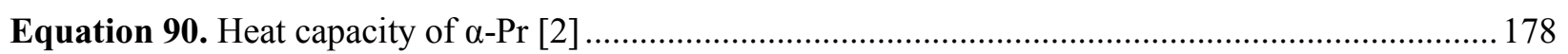

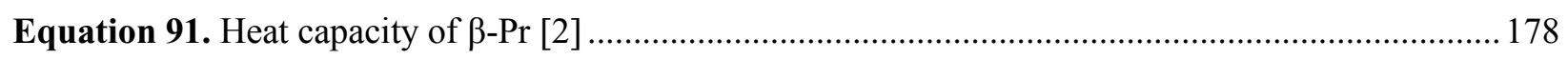

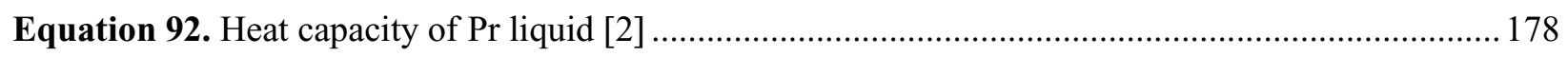

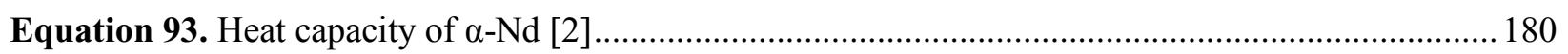

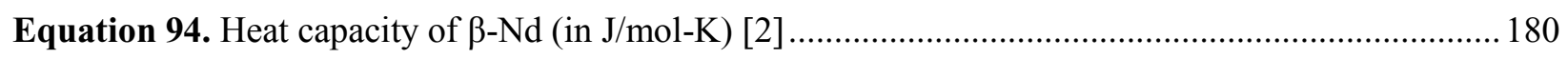

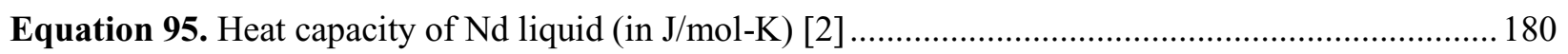

Equation 96. Lattice parameter of $\alpha$-Am parallel to the $a$ crystallographic direction [201] ................... 188

Equation 97. Lattice parameter of $\alpha$-Am parallel to the $c$ crystallographic direction [201] .................. 188

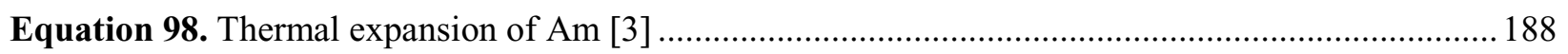

Equation 99. $a$ lattice parameter of $\alpha$-La between 20 and $293{ }^{\circ} \mathrm{C}[221$ Table IV] ............................... 190

Equation 100. $c$ lattice parameter of $\alpha$-La between 20 and $293{ }^{\circ} \mathrm{C}[221$ Table IV] .............................. 190

Equation 101. Lattice parameter of $\beta$-La between 20 and $598^{\circ} \mathrm{C}$ [221 Table IV] ................................ 190

Equation 102. Molar volume of $\alpha$-La between 20 and $293^{\circ} \mathrm{C}$ [221 Table IV] ...................................... 192

Equation 103. Molar volume of $\beta$-La between 20 and $598^{\circ} \mathrm{C}$ [221 Table IV] ..................................... 193

Equation 104. $a$ lattice parameter of $\gamma$-Ce between 20 and $619^{\circ} \mathrm{C}$ [221 Table IV] .............................. 194

Equation 105. Density of $\gamma$-Ce between 20 and $619^{\circ} \mathrm{C}$ [221 Table IV] ............................................. 195

Equation 106. $a$ lattice parameter of $\alpha$-Pr between 20 and $449^{\circ} \mathrm{C}$ [221 Table IV] .............................. 197

Equation 107. $c$ lattice parameter of $\alpha$-Pr between 20 and $449^{\circ} \mathrm{C}$ [221 Table IV] ............................... 197

Equation 108. Molar volume of $\alpha$-Pr between 20 and $293{ }^{\circ} \mathrm{C}$ [221 Table IV] ...................................... 199

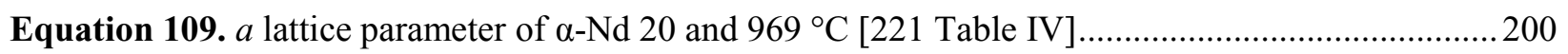

Equation 110. $c$ lattice parameter of $\alpha$-Nd between 20 and $969^{\circ} \mathrm{C}$ [221 Table IV]..............................200

Equation 111. Molar volume of $\alpha$-Nd between 20 and $696^{\circ} \mathrm{C}$ [221 Table IV] ....................................202

Equation 112. Lattice parameter (for X-ray diffraction data) or sample length (for dilatometer data) for Pu-Ce alloys, to be used with coefficients from Table 26 [166] .............................. 207

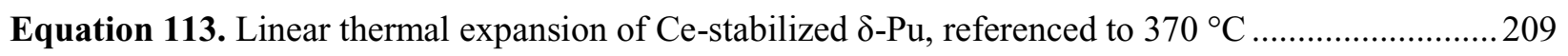

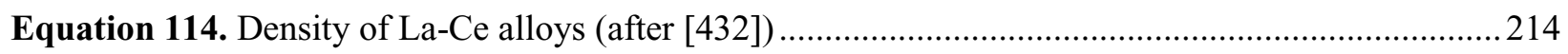

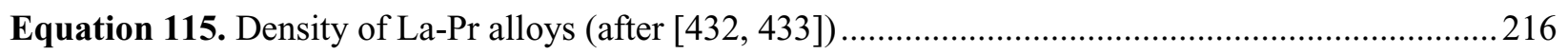

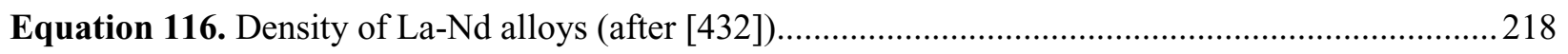

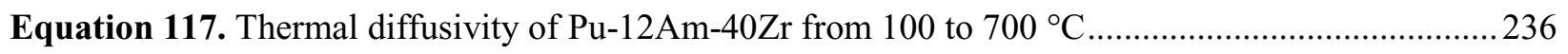


Equation 118. Thermal diffusivity of $\mathrm{Pu}-12 \mathrm{Am}-40 \mathrm{Zr}$ from 700 to $1000{ }^{\circ} \mathrm{C}$ 


\section{ACRONYMS}

AFC

ANL

bcc

CALPHAD

CEA

dhcp

DOE

DSC

DTA

fcc

FCRD

hcp

IAEA

INL

NIST-JANAF

OECD/NEA

SI

TMA
Advanced Fuels Campaign

Argonne National Laboratory

Body-centered cubic (a crystal structure)

CALculation of PHAse Diagrams

Commissariat a l'Energie Atomique (French Atomic Energy Commission)

Double hexagonally close packed (a crystal structure)

U. S. Department of Energy

Differential scanning calorimetry

Differential thermal analysis

Face-centered cubic (a crystal structure)

Fuel Cycle Research and Development

Hexagonally close packed (a crystal structure)

International Atomic Energy Agency

Idaho National Laboratory

National Institute of Standards and Technology - Joint Army, Navy, Air Force

Organisation for Economic Co-Operation and Development/Nuclear Energy Agency

Systeme International d'Unites (French) (International System of Units)

Thermomechanical analysis 
INTENTIONALLY BLANK 


\section{FCRD Advanced Reactor (Transmutation) Fuels Handbook}

\section{INTRODUCTION}

Transmutation of minor actinides such as $\mathrm{Np}, \mathrm{Am}$, and $\mathrm{Cm}$ in spent nuclear fuel is of international interest because of its potential for reducing the long-term health and safety hazards caused by the radioactivity of the spent fuel. For this reason, the DOE Fuel Cycle Research \& Development (FCRD) Advanced Fuels Campaign (AFC) has been performing research on nuclear fuel technologies that could be used in conjunction with a future actinide transmutation mission. One important approach to transmutation involves incorporating the minor actinides into U-Pu-Zr alloys, which can be used as fuel in fast reactors. U-Pu-Zr alloys are well suited for electrolytic refining, which leads to retention of rareearth fission products such as $\mathrm{La}, \mathrm{Ce}, \mathrm{Pr}$, and $\mathrm{Nd}$. It is, therefore, important to understand not only the properties of $\mathrm{U}-\mathrm{Pu}-\mathrm{Zr}$ alloys but also those of $\mathrm{U}-\mathrm{Pu}-\mathrm{Zr}$ alloys with concentrations of minor actinides $(\mathrm{Np}$, $\mathrm{Am})$ and rare-earth elements ( $\mathrm{La}, \mathrm{Ce}, \mathrm{Pr}$, and $\mathrm{Nd}$ ) similar to those in reprocessed fuel.

This handbook focuses on phases and key thermophysical properties of elements and alloys of interest for FCRD transmutation fuels. It has three parts: introductory material, a survey of properties of elements and alloys in the U-Pu-Zr system, and a survey of elements and binary and ternary alloys in the broader U-Np-Pu-Am-La-Ce-Pr-Nd-Zr system. More complex alloys will be covered in later years. The section on U-Pu-Zr alloys repeats much of the information in the FCRD Transmutation Fuels Handbook 2015 [1] for convenience in finding this information. As the FCRD programmatic mission evolves, future editions of this handbook will begin to include other advanced reactor fuel designs and compositions. Hence, the title of the handbook will transition to the Advanced Reactor Fuels Handbook.

The handbook is intended to serve two audiences. One audience is researchers, who may find it useful to know what has been measured, where it has been published, and what kinds of information are needed. A second audience is modelers, who need a concise summary of information about specific properties and the accuracy with which they are known. The two audiences have different needs, and the handbook is a compromise intended to be useful to both. Therefore, it includes summaries of research results and needs, but generally does not present the original data. It also includes numerous graphs and, where available, equations that provide convenient approximations to materials properties for modelers. It is important to understand that many of the equations provided in this handbook were developed by fitting polynomials to data and have no physical basis; while they can be used with caution for design studies, fuel modelers will probably want to use the original experimental data to develop or validate their own equations and/or models. Although the handbook includes some citations to research involving development of models, its primary focus is experimental data.

Information about many of the binary and ternary alloys of rare-earth elements and minor actinides has apparently never been published, as indicated by gaps in the table of contents. Many of the measurements presented in this Handbook were made before 1980. Some are incomplete or of poor quality. Where possible, the handbook relies on previous thorough reviews of experimental data (e.g., references [2-10]) rather than presenting new interpretations of the old information. It is expected that researchers will refer to the original references for details that are not presented here.

The material in the handbook includes information about the phases, heat capacities, thermal expansions, and thermal conductivities of some elements and alloys of interest for FCRD transmutation fuels. It is not intended to be a comprehensive guide to FCRD fuels and fuel materials. Topics that are specifically excluded include: fuel types not specifically intended for transmutation in a fast neutron spectrum (e.g., fuels for light-water and high-conversion water reactors); properties not relevant to fuels 
(e.g., measurements at high pressures or below room temperature); spatially varying properties (e.g., microstructures); changes due to irradiation; issues involved in materials supplies and fuel fabrication; and (to the extent that they can be avoided) properties whose values depend on characteristics or histories of specific samples.

The metals and alloys in this edition of the Handbook are uniquely difficult to study for a number of reasons. Experimental designs may be constrained by the hazards (including radioactivity) of some of the materials. Kinetics of phase transformations are commonly sluggish, and it is highly unlikely that all of the samples in previous research had equilibrium phases and microstructures. Thermal cycling effects (changes in sample characteristics that are not fully reversed during cooling) are commonly reported and may be significant. Careful control of impurities (particularly oxygen) during sample fabrication and data collection is both crucial and difficult, and concentrations below $100 \mathrm{ppm}$ in samples may significantly affect thermophysical properties. Fabrication techniques, such as arc-casting, can alter the nominal weight composition of desired alloys leaving them with a different composition than originally formulated. For all of these reasons, differences between measured values for similar alloys are commonly far larger than the estimated errors for individual measurements. Further research on well-characterized materials with careful control of impurities is needed for almost all of the alloys discussed here.

\section{CALCULATIONS AND APPROXIMATIONS}

\subsection{BASIC CONSTANTS, UNITS, AND CONVERSION FACTORS}

Much of the experimental data on the U-Pu-Zr system was reported in the 1940s through 1970s, before SI units and the Kelvin temperature scale were generally adopted. Therefore, it is sometimes necessary to convert between units.

Useful unit conversions include [11]:

- $\quad$ Temperature in Kelvin $(\mathrm{K})=$ Temperature in Celsius $\left({ }^{\circ} \mathrm{C}\right)+273.15$

- 1 calorie $(\mathrm{cal})=4.1868$ Joules $(\mathrm{J})$

- 1 calorie/second $(\mathrm{cal} / \mathrm{sec})=4.184$ Watts $(\mathrm{W})$

- 1 Ångstrom $(\AA)=1 \times 10^{-8} \mathrm{~cm}$

Numerical values of properties that vary with temperature (e.g., heat capacities and thermal expansion coefficients) generally do not change when temperatures are converted between ${ }^{\circ} \mathrm{C}$ and $\mathrm{K}$. The Lorenz constant (Section 2.5.2) is an exception, and requires units of absolute temperature such as $\mathrm{K}$.

Most of the references in the bibliography count "moles" in a material based on the number of atoms it contains, even if those atoms are of different elements. However, a few references count formula units rather than atoms in defining moles, and therefore consider that a mole of $\mathrm{UZr}_{2}$ has three times as many atoms as a mole of $U$. This handbook assumes that all moles have the same number of atoms, so that quantities expressed in moles and gram-atoms are equivalent.

Allotropic solid solutions may be indicated by parentheses. For example, $(\alpha-\mathrm{Zr})$ has the same structure as pure $\alpha-\mathrm{Zr}$, but may contain other elements such as $\mathrm{U}$ and $\mathrm{Pu}$.

Compositions of alloys are commonly expressed in one of four units: Weight fractions, weight percentages, atomic fractions, and atomic percentages. Weight fractions can be converted to atomic fractions and vice versa using Equation 1 and Equation 2.

Weight fractions can be converted to weight percent, and atomic fractions to atomic percent, by multiplying by 100 . 
Equation 1. Conversion of weight fractions to mole fractions

$$
x_{i}=\frac{\frac{w_{i}}{M_{i}}}{\sum_{i}\left(\frac{w_{i}}{M_{i}}\right)}
$$

where $w_{i}$ and $x_{i}$ are the weight and atomic fractions of element $i$ and $M_{i}$ is the atomic weight of the element

Equation 2. Conversion of mole fractions to weight fractions

$$
w_{i}=\frac{x_{i} \times M_{i}}{\sum_{i}\left(x_{i} \times M_{i}\right)}
$$

where $w_{i}$ and $x_{i}$ are the weight and atomic fractions of element $i$ and $M_{i}$ is the atomic weight of the element 


\subsection{RELATIONSHIPS BETWEEN MASSES, VOLUMES AND DENSITIES}

Equation 3 defines the basic relationship between density, mass, and volume. Although each of these quantities can be expressed in a variety of units, it is convenient to convert densities to a single unit (e.g., $\mathrm{g} / \mathrm{cm}^{3}$ ) to make comparisons easier. Equation 4 is particularly useful in understanding many of the publications by Soviet researchers, and Equation 5 is useful for calculating densities from crystal structures determined by X-ray or neutron diffraction.

Equation 3. Basic relationship between density $(\rho)$, mass $(\mathrm{M})$, and volume (V)

$\rho=\mathrm{m} / \mathrm{V}$

where $\rho$ is density, $\mathrm{m}$ is mass, and $\mathrm{V}$ is volume

Two variants of this equation are particularly useful:

Equation 4. Converting densities from $\mathrm{kg} / \mathrm{m}^{3}$ to $\mathrm{g} / \mathrm{cm}^{3}$

$\rho_{1}=\rho_{2} \times 10^{-3}$

where $\rho_{1}$ is the density in $\mathrm{g} / \mathrm{cm}^{3}$ and $\rho_{2}$ is the same density in $\mathrm{kg} / \mathrm{m}^{3}$

Equation 5. Calculating the density in $\mathrm{g} / \mathrm{cm}^{3}$ from information about a unit cell

$\rho=\frac{M_{u c}}{V_{u c}}=\frac{M_{M o l} \times Z}{N \times V}=\frac{1.66 \times M_{M o l} \times Z}{V}$

where $\rho$ is the density of a unit cell in $\mathrm{g} / \mathrm{cm}^{3}, \mathrm{M}_{\mathrm{uc}}$ and $\mathrm{V}_{\mathrm{uc}}$ are the mass and volume of the unit cell, $\mathrm{M}_{\mathrm{mol}}$ is the molar weight of the material in grams, $\mathrm{Z}$ is the number of atoms per unit cell ( 6 for hcp materials, 4 for fcc materials, and 2 for bcc materials), $N$ is Avogadro's number $\left(6.022 \times 10^{23}\right)$, and $\mathrm{V}$ is the unit cell volume in $\AA^{3}$

The unit cell volume can be calculated from the lattice parameters:

- For cubic unit cells (including fcc and bcc), $\mathrm{V}=a^{3}$, where $a$ is the lattice parameter

- For tetragonal unit cells, $\mathrm{V}=a^{2} \times c$, where $a$ and $c$ are the lattice parameters

- For hexagonal unit cells (including hcp and dhcp), $\mathrm{V}=\frac{\sqrt{3}}{2} \times a^{2} \times c \approx 0.866 \times a^{2} \times c$, where $a$ and $c$ are the lattice parameters

- For orthorhombic unit cells, $\mathrm{V}=a \times b \times c$, where $a, b$, and $c$ are lattice parameters

- For monoclinic unit cells, $\mathrm{V}=a \times b \times c \times \sin \beta$, where $a, b$, and $c$, and $\beta$ are lattice parameters

Formulas for calculating volumes of other unit cells can be found in standard crystallographic references, e.g. [12 Appendix 9]

\subsection{CALCULATING VOLUMES AND DENSITIES FROM HIGH- PRESSURE DATA: THE CLAUSIUS-CLAPEYRON RELATION}

Although high-pressure experiments are outside the scope of this Handbook, some researchers have combined results of these experiments with measured phase-transition enthalpies using the ClausiusClapeyron relation from classical thermodynamics (Equation 6) to determine volume changes associated with atmospheric-pressure phase transitions. If the volume of one of the phases is known, the volume of the other can be calculated from the volume change. 
Equation 6. The Clausius-Clapeyron relation

$$
\frac{d P}{d T}=\frac{\Delta S}{\Delta V}
$$

where $\mathrm{P}$ is pressure, $\mathrm{T}$ is temperature, $\mathrm{dP} / \mathrm{dT}$ is the slope of the tangent to a phase boundary on a pressure-temperature diagram, $\Delta \mathrm{S}$ is the change in enthalpy due to the phase transition, and $\Delta \mathrm{V}$ is the change in volume due to the phase transition

\subsection{CALCULATING THERMAL CONDUCTIVITY FROM THERMAL DIFFUSIVITY, DENSITY, AND HEAT CAPACITY}

Thermal conductivity can be calculated from thermal diffusivity, heat capacity, and density using Equation 7. It is important to note that all of the terms in this equation are functions of temperature, and that room-temperature values may not be appropriate for calculating thermal conductivity at other temperatures.

Equation 7. Calculating thermal conductivity from thermal diffusivity, density, and heat capacity

$$
\mathrm{k}(\mathrm{T})=\alpha(\mathrm{T}) \times \rho(\mathrm{T}) \times \mathrm{C}_{\mathrm{p}}(\mathrm{T})
$$

where $\mathrm{k}$ is thermal conductivity, $\alpha$ is thermal diffusivity, $\rho$ is density, and $\mathrm{C}_{\mathrm{p}}$ is constant-pressure heat capacity

It may be useful to re-calculate thermal conductivity as a result of improved knowledge of thermal diffusivity, heat capacity, or density.

\subsection{COMMON APPROXIMATIONS}

Heat capacities and thermal conductivities or diffusivities for a number of alloys in this Handbook are not available. In some cases, it is possible to estimate the values of these properties in terms of available measurements by use of well-established relationships such as the Kopp-Neumann Law and the Wiedemann-Franz (sometimes called Wiedemann-Franz-Lorenz) Law. Although the estimates provided by these laws are likely to be more useful than a complete absence of information, neither should be considered a substitute for experimental measurements. The use of either of these laws in this Handbook always indicates a need for further research.

\subsubsection{APPROXIMATE HEAT CAPACITIES: THE KOPP-NEUMANN LAW}

The Kopp-Neumann Law approximates the heat capacity of an alloy from its composition and the heat capacities of its constituent elements (Equation 8). As noted by Tsuji [13], this law "should be applied with caution for alloys especially near magnetic and phase transitions."

Equation 8. Kopp-Neumann Law [13]

$$
C_{p}=\sum_{i=1}^{n} X_{i} C_{p_{i}}
$$

where $C_{p}$ is the heat capacity of the alloy and $X_{i}$ and $C_{p_{i}}$ refer to the atomic fractions and atomic heat capacities of each of the $n$ elements in the alloy.

\subsubsection{APPROXIMATE THERMAL CONDUCTIVITIES: THE WIEDEMANN-FRANZ LAW}

The Wiedemann-Franz (also called Wiedemann-Franz-Lorenz) Law states that the ratio of thermal conductivity to electrical conductivity in metals is proportional to absolute temperature. The proportionality constant is commonly called the "Lorenz number," and is designated by L. In practice, the 
Wiedemann-Franz law is commonly applied using electrical resistivity rather than conductivity (Equation 9).

Equation 9. Wiedemann-Franz Law

$$
\mathrm{kx} \rho_{\mathrm{R}}=\mathrm{L} \times \mathrm{T}
$$

where $\mathrm{k}$ is thermal conductivity, $\rho_{\mathrm{R}}$ is electrical resistivity, $\mathrm{L}$ is the Lorenz number, and $\mathrm{T}$ is the temperature in $\mathrm{K}$

The theoretical (also called "Sommerfeld") value of L calculated from quantum statistics is $2.44 \times 10^{-8}$ $\mathrm{W} \Omega \mathrm{K}^{-2}\left(=2.44 \times 10^{-8} \mathrm{~V}^{2} \mathrm{~K}^{-2}\right)$. In practice, however, experimentally determined values of $\mathrm{L}$ vary between different materials and temperatures. Reasons why the actual and theoretical values differ are beyond the scope of this handbook, but are summarized in references [14] and [15].

Binkele measured the temperature dependence of the Lorenz number for a number of rare-earth elements and found that it decreased with temperature, only reaching the Lorenz number at $~ 1000 \mathrm{~K}$ [16] (Figure 1). Although he did not measure the temperature dependence of $\mathrm{La}, \mathrm{Ce}$, or $\mathrm{Pr}$, a decrease in Lorenz number with increasing temperature is consistent with the difference in Lorenz numbers calculated from thermal conductivity and electrical resistivity data at room temperature and melting temperature for $\mathrm{La}, \mathrm{Ce}, \mathrm{Pr}$, and $\mathrm{Nd}$ in the CRC Handbook of Chemistry and Physics [17 Tables 9 and 12].

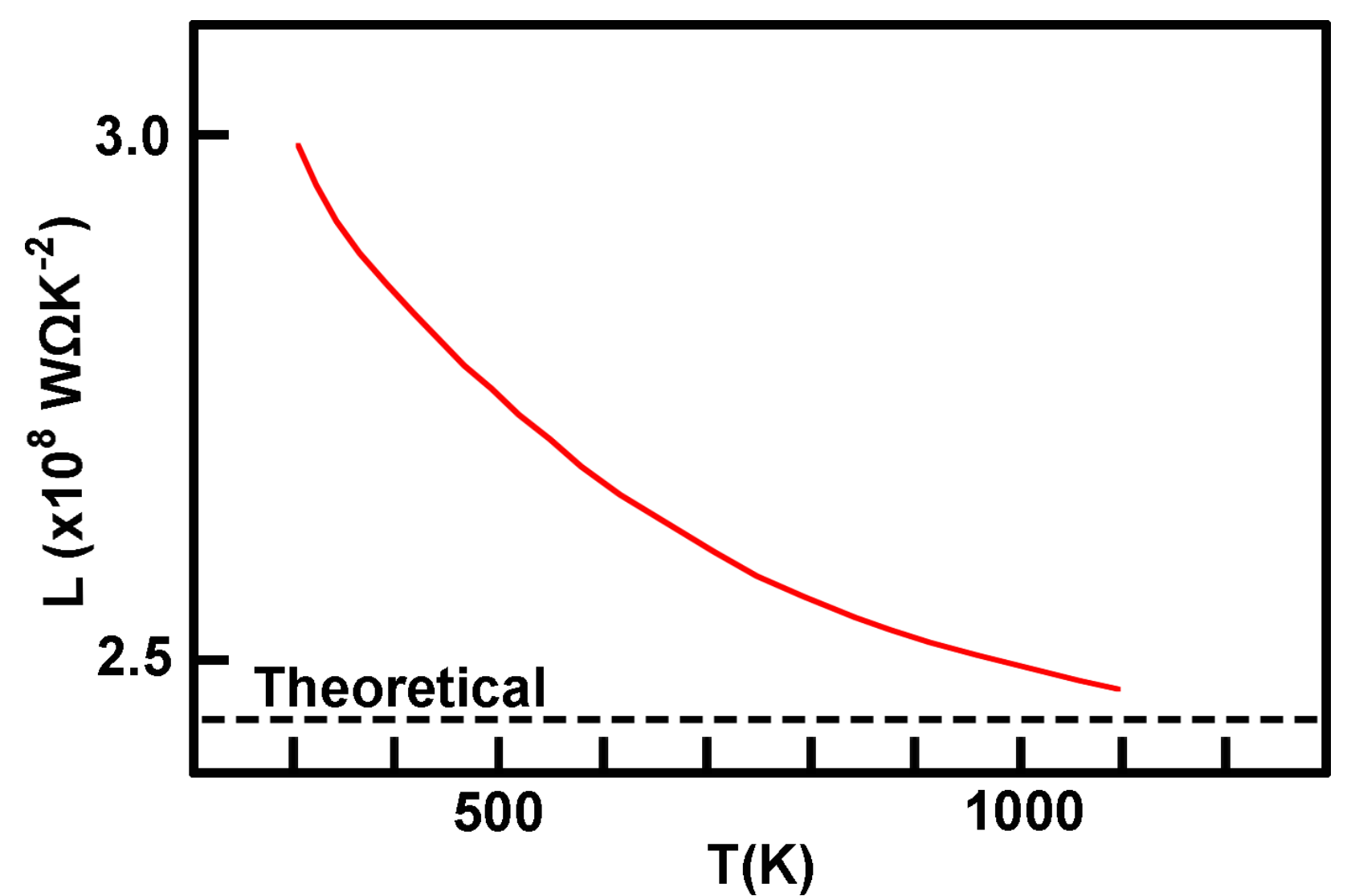

Figure 1. Temperature dependence of the Lorenz number for $\mathrm{Nd}$ (red curve) with theoretical value (dashed black line) for comparison (re-drawn with selected data from reference [16]) 


\section{U-Pu-Zr system \\ 3.1 PHASES, PHASE DIAGRAMS, PHASE TRANSFORMATIONS, PHASE-TRANSFORMATION ENTHALPIES}

\subsubsection{U}

U has three phases that are stable atmospheric pressure. With the exception of the space group for $\beta-U$, crystal structures and lattice parameters have been known for decades, and there is little variation between references. The values presented here are based on one of the few new studies since the 1970s, and were obtained using high-resolution neutron-diffraction data [18].

- $\alpha$-U, orthorhombic (space group Cmcm), $a=2.8359 \AA, b=5.8678 \AA, c=4.9554 \AA$ at $298 \mathrm{~K}$

- $\beta$-U, tetragonal (space group $P 4_{2} / m n m$ ), $a=10.7589 \AA, c=5.6531 \AA$ at $955 \mathrm{~K}$

- $\gamma$-U, bcc (space group $\operatorname{Im} \overline{3} m$ ), $a=3.5355 \AA$ at $1060 \mathrm{~K}$.

Most of the experimental measurements of phase-transformation and melting temperatures were made before 1970, and later references are based on interpretation of the earlier data. Major reviews include those by Oetting et al. [4] for the IAEA, Ward et al. [19], Grenthe et al. [20] for the OECD/NEA, and Konings and Beneš [2] (with key results repeated in [3]). Recommended transformation temperatures and enthalpies from all of the reviews are similar.

Recommended phase-transformation temperatures and range of measured values are [2]:

- $\quad \alpha-\beta, 941 \pm 2 \mathrm{~K}$ (based on 10 publications with original measurements, which range from 933 to $943 \mathrm{~K}$ )

- $\quad \beta-\gamma, 1049 \pm 2 \mathrm{~K}$ (based on 9 publications with original measurements, which range from 1037 to $1050 \mathrm{~K})$

- $\gamma$-liquid, $1407 \pm 2$ (based on 7 publications with original measurements, which range from 1401 to $1406 \mathrm{~K})$.

The recommended phase-transformation enthalpies $\left(\Delta \mathrm{H}_{\mathrm{t}}\right)$ and range of measured values are [2]:

- $\quad \alpha-\beta, 2.85 \pm 0.15 \mathrm{~kJ} / \mathrm{mol}$ (based on 6 publications with original measurements, which range from 2.63 to $3.26 \mathrm{~kJ} / \mathrm{mol}$ )

- $\quad \beta-\gamma, 4.62 \pm 0.5 \mathrm{~kJ} / \mathrm{mol}$ (based on 6 publications with original measurements, which range from 4.18 to $4.87 \mathrm{~kJ} / \mathrm{mol})$

- $\gamma$-liquid, $8.47 \pm 1.00 \mathrm{~kJ} / \mathrm{mol}$ (based on 6 publications with original measurements, which range from 7.03 to $12.1 \mathrm{~kJ} / \mathrm{mol})$.

\subsection{2 $\mathrm{Pu}$}

Pure $\mathrm{Pu}$ has six phases that are stable at atmospheric pressure. Crystal structures and lattice parameters are well known, and there is little variation between references. Recommended phase-transformation temperatures and enthalpies from major reviews agree to within a few degrees.

$\mathrm{Pu}$ phase transformations are sensitive to small amounts of alloying elements. Some elements (Al, Ga, $\mathrm{Ce}, \mathrm{Am}, \mathrm{In}, \mathrm{Tl}$, and $\mathrm{Sc}$ ) stabilize the $\delta$-Pu structure so that it is retained at room temperature, and others ( $\mathrm{Si}, \mathrm{Zn}, \mathrm{Zr}, \mathrm{Hf}$, and perhaps Th and trivalent lanthanides such as Dy, Er, Tm, Lu, and Tb) allow the $\delta$-Pu structure to be retained as a metastable phase during rapid cooling [21]. Np extends the stability of the $\alpha-\mathrm{Pu}$ structure [21]. The stability of Pu phases is significantly affected by high pressures, with $\gamma, \delta$, and $\delta^{\prime}$ becoming unstable at pressures of a few hundred MPa [22]. 
Recent modeling research includes calculations of Landau free energies associated with phase transformations [23], development and evaluation of atomic-scale models for a number of alloys (e.g., [24-27]), and models of the electronic behavior and volume-temperature phase diagram of Pu [28].

Space groups and lattice parameters of the pure Pu phases stable at atmospheric pressure are [22].

- $\quad \alpha-P u$, monoclinic (space group $P 2_{1} / m$ ), $a=6.183 \AA, b=4.822 \AA, c=10.963 \AA, \beta=101.79^{\circ}$

- $\quad \beta-\mathrm{Pu}$, monoclinic (space group $I 2 / m$ ), $a=9.284 \AA, b=10.463 \AA, c=7.859 \AA, \beta=93.13^{\circ}$ (The unconventional space group $I 2 / m$ is equivalent to space group $C 2 / m$ with origin choice 3 [29])

- $\quad \gamma$-Pu, orthorhombic, space group Fddd, $a=3.159 \AA, b=5.768 \AA, c=10.162 \AA$

- $\delta$-Pu, fcc (space group $F m \overline{3} m$ ), $a=4.637 \AA$

- $\quad \delta^{\prime}-\mathrm{Pu}$, body-centered tetragonal (space group $\mathrm{I} 4 / \mathrm{mmm}$ ), $a=3.34 \AA, c=4.44 \AA$

- $\varepsilon-\mathrm{Pu}$, bcc (space group $\operatorname{Im} \overline{3} m), a=3.636 \AA$.

Most of the experimental measurements of phase-transformation and melting temperatures were made before 1970, and later references are based on new interpretations of the earlier data. Major reviews include those by Oetting et al. [4] for the IAEA, Ward et al. [19], Lemire et al. [30] for the OECD/NEA, and Konings and Beneš [2] (with key results repeated in [3]). Recommended transformation temperatures from all of the reviews are in general agreement.

The recommended phase-transformation temperatures and range of measured values are [2]:

- $\alpha-\beta, 399 \pm 1 \mathrm{~K}$ (based on 23 publications with original measurements, which range from 383 to $406 \mathrm{~K}$ )

- $\quad \beta-\gamma, 488 \pm 1 \mathrm{~K}$ (based on 21 publications with original measurements, which range from 457 to $490 \mathrm{~K}$ )

- $\gamma-\delta, 596 \pm 2 \mathrm{~K}$ (based on 20 publications with original measurements, which range from 579 to $599 \mathrm{~K}$ )

- $\delta-\delta^{\prime}, 741 \pm 2 \mathrm{~K}$ (based on 19 publications with original measurements, which range from 713 to $745 \mathrm{~K}$ )

- $\delta^{\prime}-\varepsilon, 759 \pm 4 \mathrm{~K}$ (based on 19 publications with original measurements, which range from 733 to $759 \mathrm{~K}$ )

- $\varepsilon$-liquid, $913 \pm 2 \mathrm{~K}$ (based on 10 publications with original measurements, which range from 907 to $914 \mathrm{~K})$.

However, more recent work by Ennaceur [31-34] showed that phase-transformation temperatures differ by several degrees in samples with different thermal histories. Ennaceur also demonstrated that phase-transition kinetics are strongly influenced by thermal history, presumably because of internal strain accumulated during earlier phase transitions.

Recommended phase-transformation enthalpies $\left(\Delta \mathrm{H}_{\mathrm{t}}\right)$ from the reviews of Ward et al. [19], Lemire et al. [30], and Konings and Beneš [2] are similar, and are somewhat higher than those of Oetting et al. [4] and the values used by Boiveneau [35]. Values from Konings and Beneš are repeated here because they are recent and are based on a thorough analysis of all of the available data. The recommended phase-transformation enthalpies and range of measured values are [2]:

- $\quad \alpha-\beta, 3.706 \pm 0.03 \mathrm{~kJ} / \mathrm{mol}$ (based on 13 publications with original measurements, which range from $3.16-5.02 \mathrm{~kJ} / \mathrm{mol})$

- $\beta-\gamma, 0.478 \pm 0.02 \mathrm{~kJ} / \mathrm{mol}$ (based on 11 publications with original measurements, which range from $0.51-0.70 \mathrm{~kJ} / \mathrm{mol}$ )

- $\gamma-\delta, 0.713 \pm 0.05 \mathrm{~kJ} / \mathrm{mol}$ (based on 11 publications with original measurements, which range from $0.52-0.80 \mathrm{~kJ} / \mathrm{mol}$ ) 
- $\delta-\delta^{\prime}, 0.065 \pm 0.02 \mathrm{~kJ} / \mathrm{mol}$ (based on 10 publications with original measurements, which range from $0-0.10 \mathrm{~kJ} / \mathrm{mol}$ )

- $\quad \delta^{\prime}-\varepsilon, 1.711 \pm 0.05 \mathrm{~kJ} / \mathrm{mol}$ (based on 11 publications with original measurements, which range from $1.59-2.12 \mathrm{~kJ} / \mathrm{mol})$

- $\varepsilon$-liquid, $2.766 \pm 0.1 \mathrm{~kJ} / \mathrm{mol}$ (based on 6 publications with original measurements, which range from $2.22-3.30 \mathrm{~kJ} / \mathrm{mol})$.

\subsubsection{Zr}

$\mathrm{Zr}$ has two equilibrium solid phases at atmospheric pressure. A third phase, $\omega-\mathrm{Zr}$, is not stable in pure $\mathrm{Zr}$ at atmospheric pressure but is commonly mentioned in discussions of actinide- $\mathrm{Zr}$ phases because of its structural similarity U-Zr phases. Crystal structures and lattice parameters of both of the equilibrium phases of $\mathrm{Zr}$ are well known, and there is little variation between references.

The crystal structures and lattice parameters of $\mathrm{Zr}$ phases stable at atmospheric pressure are [36]:

- $\quad \alpha-Z r$, hcp (space group $P 6_{3} / m m c$ ), $a=3.2316 \AA, c=5.1475 \AA$

- $\quad \beta-Z r$, bcc (space group $\operatorname{Im} \overline{3} m), a=3.6090 \AA$.

The generally accepted temperatures and enthalpies for $\mathrm{Zr}$ phase transformations are:

- $\quad \alpha-\beta, 863{ }^{\circ} \mathrm{C}(1136 \mathrm{~K})$ [36], enthalpy $3.98 \mathrm{~kJ} / \mathrm{mol}[37]$.

- $\beta$-liquid, $1855^{\circ} \mathrm{C}(2127 \mathrm{~K})[38,39]$, enthalpy $21.00 \mathrm{~kJ} / \mathrm{mol}[40]$.

\subsubsection{U-Zr Alloys}

\subsubsection{Introduction}

Many features of the U-Zr phase diagram have been known since the 1950s, and a widely accepted phase diagram was developed by Sheldon and Peterson in the late 1980s [41, 42]. Key features of U-Zr phase diagrams include a high-temperature body-centered cubic solid solution between $\gamma-U$ and $\beta-Z r$ that separates into two body-centered cubic phases $\left(\gamma_{1}\right.$ and $\left.\gamma_{2}\right)$ at lower temperatures, the existence of a single intermediate phase $\left(\delta-\mathrm{UZr}_{2}\right)$ that is stable at room temperature, and limited solubility of $\mathrm{U}$ in $\alpha-\mathrm{Zr}$ and of $\mathrm{Zr}$ in $\alpha-U$ and $\beta-U$. However, recent work by Ahn and colleagues $[43,44]$ suggests that the Sheldon and Peterson phase diagrams may not be a correct representation of the transformation from ( $\alpha-U)$ to $(\beta-U)$ solid solutions, and that an early phase diagram by Rough and Bauer [45-47] may represent this transformation more accurately. The $(\alpha-U)$ to $(\beta-U)$ transformation occurs in alloys with at most $\sim 1$ at $\%$ $\mathrm{Zr}$, but has implications for phase transformations in alloys with $\mathrm{Zr}$ concentrations up to $\sim 60$ at $\%$. Further work is needed to resolve this issue. Regardless of the outcome of this work, the boundaries for $\delta-\mathrm{UZr}_{2}$ established by Akabori et al. $[48,49]$ should be considered more accurate than those in either the Rough and Bauer or the Sheldon and Peterson phase diagram.

Recent measurements of liquidus temperatures for the entire U-Zr binary system [50] are consistent with the phase diagram of Sheldon and Peterson. The measured solidus temperatures are consistent with the Sheldon and Peterson phase diagram for alloys with less than $\sim 30$ at $\% \mathrm{Zr}$, and are higher than the temperatures in the phase diagram by up to $\sim 50{ }^{\circ} \mathrm{C}$ for compositions with higher concentrations of $\mathrm{Zr}$.

Experimental work on $\mathrm{U}-\mathrm{Zr}$ alloys is complicated by sluggish kinetics at a spatial scale large enough for measurement by optical or microprobe techniques (but perhaps not on a scale of nanometers [51, 52]), a high degree of sensitivity to impurities such as $\mathrm{O}$ and $\mathrm{N}$ in concentrations of a few hundred ppm (e.g., $[41,53])$, and a tendency to form significant quantities of a high-Zr phase not expected from phase diagrams. Phases, microstructures, and reaction enthalpies may differ between samples with the same nominal composition and different thermal histories $[43,54-56]$. Recent research into phase-transition 
mechanisms has emphasized the importance of metastable phases, and may explain many of the variations in experimental data.

Models of U-Zr phases, phase segregation mechanisms and microstructure development, and the UZr phase diagram have been developed using a variety of approaches (e.g., [5, 55, 57-75]).

\subsubsection{Phases and Phase Transformations}

\subsection{Phases}

Stable phases in the $\mathrm{U}-\mathrm{Zr}$ system are:

- $\quad \gamma-(\mathrm{U}, \mathrm{Zr}$ ): bcc (space group $\operatorname{Im} \overline{3} m)$ solid solution between $\gamma-\mathrm{U}$ and $\beta-\mathrm{Zr}$, which separates into $\gamma_{1}$ (U-rich) and $\gamma_{2}$ (Zr-rich) phases as a result of a miscibility gap whose maximum is at $\sim 722^{\circ} \mathrm{C}$ and 30 at $\% \mathrm{Zr}$ [41]. Lattice parameters of $\gamma-(\mathrm{U}, \mathrm{Zr})$ vary linearly between those of $\gamma-\mathrm{U}$ and $\beta-\mathrm{Zr}$ as a function of the concentration of $\mathrm{Zr}[41,76]$.

- $\quad(\alpha-Z r)$ : Allotropic modification of $\alpha-Z r$ that can dissolve up to 1 at $\% U$ [41].

- $(\alpha-U)$ : Allotropic modification of $\alpha-U$ that can dissolve up to 0.5 at $\% \mathrm{Zr}$ [41]. Rai et al. reported that the $a$ lattice parameter of this phase increased from $2.85 \AA$ in pure $\mathrm{U}$ to $2.87 \AA$ in an alloy with 10 $\mathrm{wt} \% \mathrm{Zr}$, the $b$ lattice parameter decreased from $6.86 \AA$ in pure $\mathrm{U}$ to $5.85 \AA$ in an alloy with $10 \mathrm{wt} \%$ $\mathrm{Zr}$, and the $c$ lattice parameter increased slightly from $4.96 \AA$ in pure $\mathrm{U}$ to $4.97 \AA$ in an alloy with 10 $\mathrm{wt} \% \mathrm{Zr}$. The lattice parameters for pure $\mathrm{U}$ in this study are within $\sim 0.015 \AA$ of the values recommended in Section 3.1.1 [77].

- $\quad(\beta-\mathrm{U})$ : Allotropic modification of $\beta-\mathrm{U}$ that can dissolve up to $1.1 \mathrm{at} \% \operatorname{Zr}$ [41].

- $\delta$-(U,Zr) $)_{2}$ (commonly referred to as $\delta-\mathrm{UZr}_{2}$ ): Hexagonal intermediate phase (space group P6/mmm, $a$ $=5.03 \AA, c=3.09$ for a sample with $\sim 70.7$ at $\% \operatorname{Zr~[49]).~Lattice~parameters~increase~with~increasing~}$ temperature or concentration of $\mathrm{Zr}[48,49]$. The stability range for this phase is commonly considered to be $\sim 64-80$ at $\% \mathrm{Zr}$ [48]; however, phase boundaries are strongly dependent on concentrations of impurities such as $\mathrm{O}$ and $\mathrm{N}$ [41]. The presence of this phase in a specific sample may also be strongly dependent on thermal history (e.g., $[55,56])$. $\delta$-UZr 2 has commonly been difficult to detect in X-ray diffraction patterns, possibly because the transformation from $(\gamma-\mathrm{U}, \mathrm{Zr})$ to $\delta-\mathrm{UZr}_{2}$ involves the metastable $\omega$ phase as an intermediate [78].

$\mathrm{U}-\mathrm{Zr}$ alloys commonly have U-bearing high-Zr inclusions in alloys that phase diagrams indicate have too little $\mathrm{Zr}$ to form $\alpha-\mathrm{Zr}$ or $\beta-\mathrm{Zr}$ (e.g., [79]). These inclusions are commonly referred to as "oxygen-stabilized $\alpha$-Zr." Little is known about them, and further research is needed to determine what they are, why they form, and whether they are stable.

A variety of metastable phases have been identified in U alloys. Nomenclature for identifying these phases is complex and may vary between references. In general, prime or double prime symbols indicate crystallographic variations, and subscripts indicate variations in appearance in optical metallographs (e.g., acicular habit or banded structure) [80]. Metastable U-Zr phases mentioned in this handbook include $\alpha^{\prime}$ (crystallographically similar to $\alpha-U), \gamma^{\prime \prime}$ (crystallographically similar to $\gamma-U$ ), and $\omega$ (crystallographically similar to $\omega-\mathrm{Zr}$ ).

\subsection{Solid-state phase transitions}

Several metastable phases have been observed during transitions from $\gamma-(\mathrm{U}, \mathrm{Zr})$ to $(\alpha-\mathrm{U})$ and $\delta$-(UZr2) solid solutions. Although these phases do not appear in phase diagrams, their presence can complicate experimental studies of equilibrium phenomena. Whether these phases form in a given sample depends on its cooling rate as well as its composition [77, 78, 81-83]. 
According to the phase diagram of Sheldon and Peterson, $\delta-\mathrm{UZr}_{2}$ forms by the peritectoid reaction $(\alpha-U)+\gamma_{2} \leftrightarrow \delta$ at $\sim 615^{\circ} \mathrm{C}$ and the eutectoid reaction $\gamma_{2} \leftrightarrow(\alpha-\mathrm{Zr})+\delta$ at $\sim 606^{\circ} \mathrm{C}[41,48]$. Transformation mechanisms are poorly understood, although it is generally agreed that the transformation from $\gamma_{2}$ to $\delta$ $\mathrm{UZr}_{2}$ is an $\omega$-transformation analogous to that in $\mathrm{Ti}, \mathrm{Zr}$, and $\mathrm{Hf}$, and involves ordering of $\mathrm{Zr}$ atoms in the $\gamma_{2}$ crystal structure to form the metastable $\omega$ structure followed by collapse of the $\gamma_{2}$ lattice planes to form $\delta$-UZr $2[55,56,78]$. Unless the sample is cooled very slowly $(\sim 0.1 \mathrm{~K} / \mathrm{min})$, the room-temperature assemblage is likely to be a combination of $(\alpha-\mathrm{U}), \alpha^{\prime}$, and $\delta-\mathrm{UZr}_{2}[77]$.

A recent study by Rai et al. indicates that details of the transformations involved in the disappearance of $\delta-\mathrm{UZr}_{2}$ during heating may depend on the starting phases in the sample [77]. If the sample starts with an equilibrium assemblage of $\alpha-U$ and $\delta$-( $\left(\mathrm{UZr}_{2}\right)$, the $\delta-\mathrm{UZr}_{2}$ will form $\gamma-(\mathrm{U}, \mathrm{Zr})$ directly. But, if the sample starts with a disequilibrium assemblage of $\alpha-\mathrm{U}, \alpha$, and $\delta-\mathrm{UZr}_{2}$, it will undergo two reactions: a first reaction leading to the disappearance of $\alpha$ ' by "relaxation" to form $\alpha-U$ and a second reaction leading to the disappearance of $\delta-\mathrm{UZr}_{2}$. Temperatures of these reactions are similar, and they may occur concurrently.

Table 1 lists measured phase-transformation temperatures and enthalpies from $\mathrm{U}-\mathrm{Zr}$ alloys. It also lists the reactions associated with each phase transformation, as identified by the researchers who measured the temperatures and enthalpies. Data from references [43] and [44] demonstrates variations in phase-transformation temperatures as a result of differences in thermal history, but was not included in Table 1 because it required correction for changes in sample masses caused by oxidation during DSC/TGA measurements. Enthalpies of reactions involving $(\alpha-U)$ or $(\alpha-\mathrm{Zr})$ are related to the proportions of the phases in the alloys [49].

Table 1. Transformation temperatures and enthalpies of solid U-Zr alloys [49 Table 2, 77 Table V, 84, 85 Table 4, 86 Table 2]. $\delta$ refers to $\delta$-( $\left(\mathrm{UZr}_{2}\right)$.

$\begin{array}{cccccc}\begin{array}{c}\mathrm{T} \\ \left({ }^{\circ} \mathrm{C}\right)\end{array} & \begin{array}{c}\mathrm{at} \% \\ \mathrm{Zr}\end{array} & \Delta \mathrm{H}(\mathrm{J} / \mathrm{g}) & \Delta \mathrm{H}(\mathrm{KJ} / \mathrm{mol}) & \text { Reaction } & \text { Reference } \\ 580 & 5 & 1.21 & & \alpha+\delta \leftrightarrow \alpha+\gamma_{2} & {[77]} \\ 584 & 5 & & \left(\alpha+\gamma_{2} \leftrightarrow \beta+\gamma_{2}\right) & {[77]} \\ 670 & 5 & 11.2 & & \left(\beta+\gamma_{2} \leftrightarrow \beta+\gamma_{1}\right) & {[77]} \\ 696 & 5 & 14.9 & \beta+\gamma_{1} \leftrightarrow \gamma & {[77]} \\ 715 & 5 & 11.1 & \alpha+\delta \leftrightarrow \alpha+\gamma_{2} & {[77]} \\ 582 & 12 & 1.85 & & & {[49]} \\ 602 & 12 & & & \left(\alpha+\gamma_{2} \leftrightarrow \beta+\gamma_{2}\right) & {[77]} \\ 680 & 12 & 10.7 & & \left(\beta+\gamma_{2} \leftrightarrow \beta+\gamma_{1}\right) & \text { [77] } \\ 695 & 12 & 12.3 & & \gamma_{1}+\gamma_{2} \leftrightarrow \gamma & {[77]}\end{array}$




\begin{tabular}{|c|c|c|c|c|c|}
\hline $\begin{array}{c}\mathrm{T} \\
\left({ }^{\circ} \mathrm{C}\right)\end{array}$ & $\begin{array}{l}\text { at } \% \\
\mathrm{Zr}\end{array}$ & $\Delta \mathrm{H}(\mathrm{J} / \mathrm{g})$ & $\Delta \mathrm{H}(\mathrm{KJ} / \mathrm{mol})$ & Reaction & Reference \\
\hline 570 & 14 & & & & {$[84]$} \\
\hline 614 & 14 & & & $\delta \rightarrow \gamma(\mathrm{U}, \mathrm{Zr})$ & {$[85]$} \\
\hline 667 & 14 & & & $(\alpha-U) \rightarrow(\beta-U)$ & {$[85]$} \\
\hline 670 & 14 & & & $\beta \leftrightarrow \alpha+\gamma^{\prime \prime}$ & [84] \\
\hline 691 & 14 & & & $(\beta-\mathrm{U}) \rightarrow \gamma(\mathrm{U}, \mathrm{Zr})$ & {$[85]$} \\
\hline 695 & 14 & & & $\gamma \leftrightarrow \beta+\gamma^{\prime \prime}$ & {$[84]$} \\
\hline 606 & 20 & & 1.57 & $\alpha+\delta \leftrightarrow \alpha+\gamma$ & {$[86]$} \\
\hline 684 & 20 & & 1.43 & $\alpha+\gamma \leftrightarrow \beta+\gamma$ & {$[86]$} \\
\hline 698 & 20 & & 0.19 & $\beta+\gamma \leftrightarrow \gamma_{1}+\gamma_{2}$ & {$[86]$} \\
\hline 738 & 20 & & 0.10 & $\gamma_{1}+\gamma_{2} \leftrightarrow \gamma$ & {$[86]$} \\
\hline 585 & 22.5 & 3.71 & & $\alpha^{\prime}+\delta \leftrightarrow \alpha+\gamma_{2}$ & {$[77]$} \\
\hline 683 & 22.5 & 10.26 & & $\left(\alpha+\gamma_{2} \leftrightarrow \beta+\gamma_{2}\right)$ & {$[77]$} \\
\hline 696 & 22.5 & 8.01 & & $\left(\beta+\gamma_{2} \leftrightarrow \beta+\gamma_{1}\right)$ & {$[77]$} \\
\hline 722 & 22.5 & 1.51 & & $\gamma_{1}+\gamma_{2} \leftrightarrow \gamma$ & {$[77]$} \\
\hline 601 & 30 & & 2.63 & & [49] \\
\hline 619 & 35 & & & $\delta \rightarrow \gamma(\mathrm{U}, \mathrm{Zr})$ & {$[85]$} \\
\hline 665 & 35 & & & $(\alpha-U) \rightarrow(\beta-U)$ & [85] \\
\hline 686 & 35 & & & $(\beta-\mathrm{U}) \rightarrow \delta(\mathrm{U}, \mathrm{Zr})$ & {$[85]$} \\
\hline 606 & 51 & & 3.95 & & [49] \\
\hline 612 & 62 & & 5.35 & & [49] \\
\hline 609 & 67 & & 5.56 & & [49] \\
\hline 606 & 71 & & 5.17 & & [49] \\
\hline 619 & 72 & & & $\delta \rightarrow \gamma(\mathrm{U}, \mathrm{Zr})$ & [85] \\
\hline 584 & 81 & & 4.41 & & [49] \\
\hline 594 & 85 & & 3.98 & & [49] \\
\hline
\end{tabular}




\begin{tabular}{cccccc}
$\begin{array}{c}\mathrm{T} \\
\left({ }^{\circ} \mathrm{C}\right)\end{array}$ & $\begin{array}{c}\mathrm{at} \% \\
\mathrm{Zr}\end{array}$ & $\Delta \mathrm{H}(\mathrm{J} / \mathrm{g})$ & $\Delta \mathrm{H}(\mathrm{KJ} / \mathrm{mol})$ & Reaction & Reference \\
\hline 598 & 90 & 2.51 & & {$[49]$} \\
\hline 601 & 91 & & $\delta \rightarrow \gamma(\mathrm{U}, \mathrm{Zr})$ & {$[85]$} \\
\hline 597 & 95 & 1.04 & & {$[49]$}
\end{tabular}

\subsection{Liquidus and Solidus}

Balakrishnan et al. recently published the first measurements of the entire liquidus and solidus of the $\mathrm{U}-\mathrm{Zr}$ system, based on measurements from $\mathrm{Zr}$ and 18 alloys with different compositions [50]. Their technique involved melting a small spot of each alloy using RF induction in a Knudsen cell and measuring the liquidus and solidus temperatures by changes in optical reflectivity.

Table 2 shows the available measurements of the liquidus and solidus. The solidus temperatures measured by Rai et al. are consistent with the results of Balakrishnan et al. for alloys with 5 and 12 at $\% \mathrm{Zr}$.

However, the solidus temperature measured by Rai et al. for the alloy with $22.5 \mathrm{at} \% \mathrm{Zr}$ seems anomalously high, possibly because of reported difficulties in obtaining an accurate baseline [77]. The solidus temperatures measured by Kaity et al. [84] are consistent with the solidus measurements of Balakrishnan et al.; however, the single liquidus measurement by Kaity et al. is significantly below the measurements of Balakrishnan et al. Balakrishnan et al. suggested that this difference was due to a hightemperature reaction between liquid $U$ and the alumina crucibles used by Kaity et al. [50].

The entire liquidus of the Sheldon and Peterson phase diagram is consistent with the new data, as is the solidus for compositions with less than $\sim 30$ at $\% \mathrm{Zr}$ (Figure 2). The solidus in the Sheldon and Peterson phase diagram is below the new measurements of Balakrishnan et al. by up $\sim 50{ }^{\circ} \mathrm{C}$ for compositions with higher concentrations of $\mathrm{Zr}$.

Table 2. Solidus and liquidus measurements of $\mathrm{U}-\mathrm{Zr}$ alloys, with melting $\mathrm{T}$ of $\mathrm{Zr}$ for comparison (Balakrishnan et al. [50 Table 6, 77 Table V, 84]

$\begin{array}{ccccc}\begin{array}{c}\text { At\% } \\ \mathrm{Zr}\end{array} & \begin{array}{c}\text { Solidus } \\ \mathrm{T}(\mathrm{K})\end{array} & \begin{array}{c}\text { Enthalpy of melting } \\ (\mathrm{kJ} / \mathrm{mol})\end{array} & \begin{array}{l}\text { Liquidus } \\ \mathrm{T}(\mathrm{K})\end{array} & \text { Reference } \\ 1.9 & 1411 & 1429 & {[50]} \\ 2.1 & 1413 & & 1465 & {[50]} \\ 4.9 & 1418 & 23.18 & & {[50]} \\ 5 & 1426 & & 1525 & {[57]} \\ 10.1 & 1452 & & & {[50]} \\ 11.8 & 1441 & & & {[50]} \\ 12 & 1446 & 26.87 & 1488 & {[84]} \\ 14 & 1448 & & 1550 & {[50]}\end{array}$




$\begin{array}{ccccc}22.5 & 1521 & 1628 & {[50]} \\ 22.5 & 1644 & 30.65 & 1690 & {[77]} \\ 29.9 & 1576 & 1776 & {[50]} \\ 39.9 & 1659 & 1843 & {[50]} \\ 50 & 1744 & 1914 & {[50]} \\ 59.9 & 1832 & 1975 & {[50]} \\ 69 & 1900 & & {[50]} \\ 74.5 & 1937 & & {[50]} \\ 75 & 1956 & 2003 & {[50]} \\ 82.9 & 2002 & & {[50]} \\ 84.9 & 2031 & 2060 & {[50]} \\ 89.9 & 2067 & 2088 & {[50]} \\ 94.9 & 2084 & 2109 & {[50]} \\ 100 & 2128 & 2128 & \end{array}$

\subsubsection{Phase Diagrams}

Important features of the U-Zr phase diagram have been known since the 1950s (e.g., [45, 53]). Chiotti [87] and Sheldon and Peterson [41] suggested phase diagrams based on a review of the available data. Okamoto modified the 1989 Sheldon and Peterson phase diagram (Figure 2) by substituting the calculated liquidus and solidus from Leibowitz et al. [67] for the original experimentally determined curves to produce the 1990 "Sheldon and Peterson" phase diagram [42]. The Sheldon and Peterson phase diagrams (both versions) were widely accepted for many years, although Akabori et al. [48] suggested small changes for alloys with $\sim 80-85 \mathrm{at} \% \mathrm{Zr}$. 


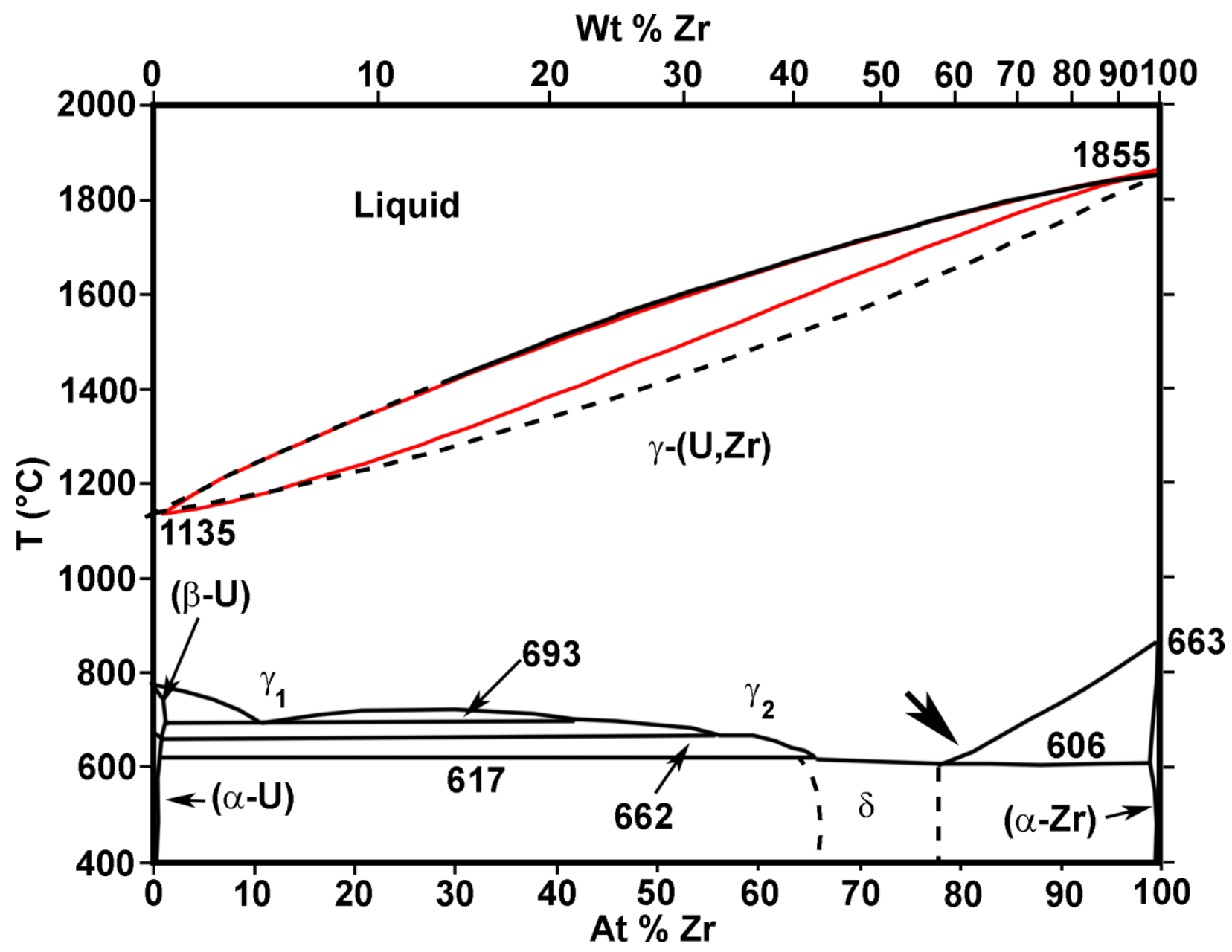

Figure 2. U-Zr phase diagram according to Sheldon and Peterson [41], with changes suggested by Akabori et al. 1992 [48] near large arrow. The liquidus and solidus measured by Balakrishnan et al. [50] are shown in red.

Recently, however, Ahn and colleagues [43, 44] have suggested that the Sheldon and Peterson phase diagrams do not represent transitions in high-U compositions correctly, and that an earlier phase diagram proposed by Rough and Bauer $[45,47]$ may be more accurate. The primary difference between the two phase diagrams involves the nature of the phase transformation involving $\alpha-\mathrm{U}, \beta-\mathrm{U}$ and $\gamma-(\mathrm{U}, \mathrm{Zr})$ : in the Sheldon and Peterson phase diagrams (e.g., Figure 2), this reaction is $(\beta-U) \leftrightarrow(\alpha-U)+\gamma_{2}$ (eutectoid); in the Rough and Bauer phase diagrams (e.g., Figure 3), it is $(\beta-U)+\gamma_{1} \leftrightarrow(\alpha-U)$ (peritectoid). Although the transformation occurs only in alloys with less than $\sim 1$ at $\% \mathrm{Zr}$, it has implications for phase relationships in all alloys with more than $\sim 40$ at $\%$ U. If the Sheldon and Peterson phase diagram is correct, there is a broad $(\beta-U)+\gamma_{2}$ field, and the transformation at $684^{\circ} \mathrm{C}$ corresponds to the $\left(\alpha+\gamma_{2} \leftrightarrow \beta+\gamma_{2}\right)$ reaction; if the Rough and Bauer phase diagram is correct, there is no $(\beta-\mathrm{U})+\gamma_{2}$ field and the transformation at $684^{\circ} \mathrm{C}$ corresponds to the $\left(\alpha+\gamma_{2} \leftrightarrow \alpha+\gamma_{1}\right)$ reaction. 


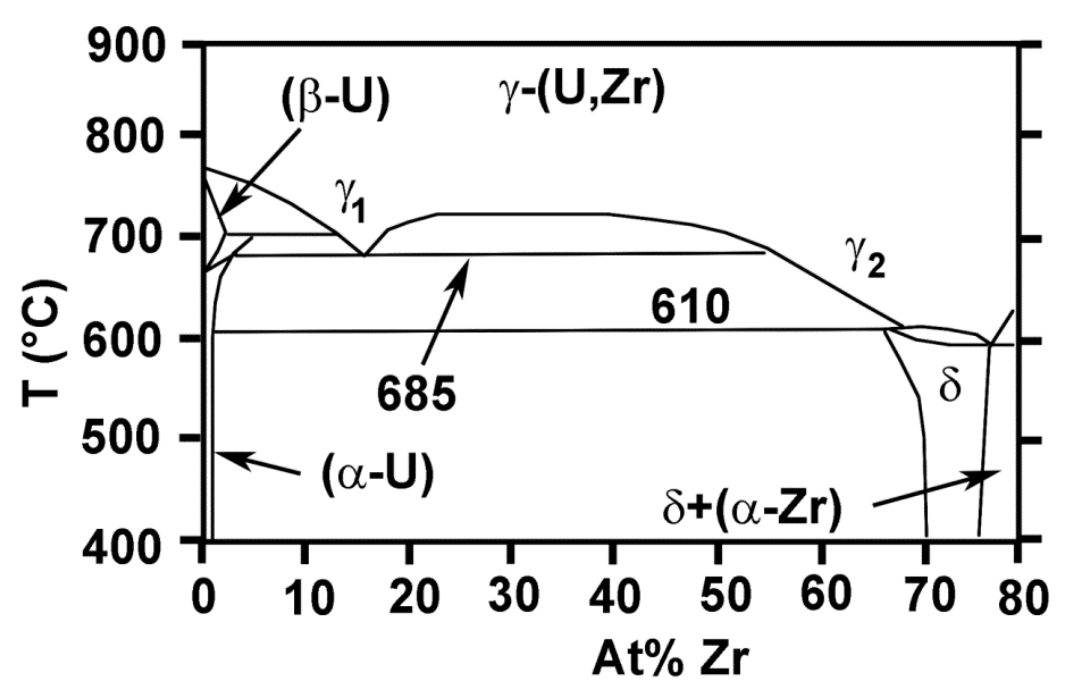

Figure 3. Partial U-Zr phase diagram based on Rough and Bauer [46]

Another consequence of the difference between phase diagrams is that alloys with $10-20 \mathrm{wt} \%(\sim 22-$ 40 at $\%) \mathrm{Zr}$ will undergo three phase transformations at temperatures below $\sim 700^{\circ} \mathrm{C}$ if the Sheldon and Peterson phase diagrams are correct, but only two if the Bauer and Rough phase diagram is correct [43, 44]. The experimental data are inconclusive. TGA traces from two of the three samples whose nominal compositions have $10 \mathrm{wt} \% \mathrm{Zr}$ measured by Ahn et al. [43] show two peaks, and one shows three. Measurements by Ahn et al. of an alloy with $20 \mathrm{wt} \% \mathrm{Zr}$ show only two peaks, but a measurement of an alloy with the same nominal composition by Matsui et al. [86] shows three. Takahashi et al. [85] found only two peaks at temperatures below $700^{\circ} \mathrm{C}$ in their work on an alloy with 35 at $\%(\sim 17 \mathrm{wt} \%) \mathrm{Zr}$. Kaity et al. [84] found three peaks below $700^{\circ} \mathrm{C}$ in a sample with $6 \mathrm{wt} \% \mathrm{Zr}$, but attributed one of them (at $\left.570^{\circ} \mathrm{C}\right)$ to a martensitic transformation in $(\alpha-\mathrm{U})$.

Further work is clearly needed to understand the phase transformations in samples with less than $\sim 75$ at $\% \mathrm{Zr}$. Recent work emphasizing the importance of thermal history and metastable phases (Section 3.1.4.2) suggests that simply counting phase transitions will not be enough to determine which phase diagram best represents the U-Zr system.

Solidus and liquidus temperatures in the original Sheldon and Peterson phase diagram [41] and the Rough and Bauer phase diagram [45, 47] are both based on experimental data from Summers-Smith [88]. More recent measurements $[66,84,89,90]$ suggest that these solidus and liquidus temperatures may be too high by a few tens of ${ }^{\circ} \mathrm{C}$ for intermediate compositions. Measurements by Kaity et al. [84] from an alloy with $6 \mathrm{wt} \% \mathrm{Zr}$ are consistent with the solidus temperature in the Sheldon and Peterson phase diagram but suggest that the liquidus temperature is too high by several tens of degrees. 


\subsubsection{Pu-Zr Alloys}

\subsubsection{Introduction}

$\mathrm{Pu}-\mathrm{Zr}$ alloys have been investigated for almost 60 years, with much of the experimental data collected during the 1950s and 1960s. Key features of the $\mathrm{Pu}-\mathrm{Zr}$ phase diagram include continuous solubility between the body-centered cubic phases $\beta-\mathrm{Zr}$ and $\varepsilon-\mathrm{Pu}$, extensive solubility of $\mathrm{Zr}$ in $\delta$-Pu and limited solubility in $\alpha-\mathrm{Pu}, \beta-\mathrm{Pu}, \gamma-\mathrm{Pu}$, and $\delta^{\prime}-\mathrm{Pu}$, and the existence of $\theta-(\mathrm{Pu}-\mathrm{Zr})$ as an intermediate phase that is stable at room-temperature. The available experimental data were synthesized by Okamoto [91, 92] to produce a single phase diagram. However, many details of the phase diagram remain poorly known, particularly those involving temperatures below $\sim 400^{\circ} \mathrm{C}$ or concentrations of $\mathrm{Zr}$ below $\sim 30$ at $\%$ or above $\sim 65$ at $\%$.

A calculated $\mathrm{Pu}-\mathrm{Zr}$ phase diagram by Kurata $[57,62]$ is in reasonable agreement with experimentally determined boundaries for the $\delta$-(Pu-Zr) and $\alpha-\mathrm{Zr}$ phases at temperatures above $\sim 500^{\circ} \mathrm{C}$. This phase diagram does not include lower-temperature phases such as $\theta-(\mathrm{Pu}-\mathrm{Zr})$ because of a lack of thermodynamic data.

Work on $\mathrm{Pu}-\mathrm{Zr}$ alloys is complicated by sluggish kinetics, high sensitivity to low concentrations of oxygen and other impurities leading to the possible formation of oxygen-stabilized low-temperature phases, and the metallurgical complexity and unique characteristics of $\mathrm{Pu}$. As a result of these difficulties, the identities of some possible $\mathrm{Pu}-\mathrm{Zr}$ phases are controversial, and there is little published data on phase transformations.

\subsubsection{Phases and Phase Transformations}

The generally accepted $\mathrm{Pu}-\mathrm{Zr}$ phases are:

- $\quad(\alpha-\mathrm{Pu})$ :Allotropic modification of $\alpha-\mathrm{Pu}$ with a low solubility for $\mathrm{Zr}$ [92]

- $\quad(\beta-\mathrm{Pu})$ :Allotropic modification of $\beta$-Pu with a low solubility for $\mathrm{Zr}$ [92]

- $\quad(\delta-\mathrm{Pu}, \mathrm{Zr}$ ): Allotropic modification of $\delta$-Pu with an extensive solubility for $\mathrm{Zr}$. The crystal structure is bcc (space group $F m \overline{3} m$ ), $a=4.640 \AA$ for an alloy with 10 at\% Zr [93] and $4.572 \AA$ for an alloy with 55 at $\% \operatorname{Zr}[93])$

- $\quad\left(\delta^{\prime}-\mathrm{Pu}\right)$ :Allotropic modification of $\delta^{\prime}-\mathrm{Pu}$ with a low solubility for $\mathrm{Zr}$ [92]

- $\quad(\alpha-\mathrm{Zr})$ :Allotropic modification of $\alpha-\mathrm{Zr}$ with a low solubility for $\mathrm{Pu}$ [92]

- $\quad \varepsilon$-(Pu,Zr): Body-centered cubic (space group $\operatorname{Im} \overline{3} m$ ) solid solution between $\varepsilon$-Pu and $\beta$-Zr. Lattice parameters increase with increasing concentration of $\mathrm{Zr}$ for alloys with less than $\sim 14 \mathrm{at} \% \mathrm{Zr}$, contrary to predictions from Vegard's law [94].

- $\quad \theta$-(Pu-Zr), sometimes called $\mathrm{Pu}_{4} \mathrm{Zr}$ or $\mathrm{Pu}_{6} \mathrm{Zr}$ : Tetragonal (space group $P_{4} / n c c, a=10.89 \AA, c=14.89$ $\AA$ [95]) phase with $\sim 10-30 \mathrm{at} \% \mathrm{Zr}$.

Other Pu phases that have been suggested but do not appear in the phase diagram of Okamoto [92] include:

- $\quad \kappa-\mathrm{PuZr}_{2}$ : Hexagonal (space group $P_{6} / \mathrm{mmm}, a=5.055 \AA, c=3.123 \AA$ [93]) intermediate phase with $\sim 75$ at $\% \mathrm{Zr}$. This phase is isostructural with $\delta-\mathrm{UZr}_{2}$. Marples synthesized it from filings and reported that it was slow to form and decomposed peritectoidally to $\alpha-\mathrm{Zr}$ and $\delta-(\mathrm{Pu}, \mathrm{Zr})$ at $380^{\circ} \mathrm{C}$ [93].

Although this phase appears in early phase diagrams [93, 96], later researchers have been unable to synthesize it and have suggested that it is oxygen-stabilized [97-101]. 
- $\quad$-(Pu, $\mathrm{Zr}$ ) (structure unknown, contains $~ 19-24 \mathrm{at} \% \mathrm{Zr}$ ). The phase diagram of Ellinger and Land [101] shows that this phase decomposes congruently into $\delta$ - $(\mathrm{Pu}, \mathrm{Zr})$ at $\sim 335^{\circ} \mathrm{C}$. There are apparently no other published reports of this phase.

- $\zeta-\mathrm{Pu}_{28} \mathrm{Zr}$ (tetragonal, space group $I_{1} / a, a=18.1899 \AA, c=7.8576 \AA$ [102]) intermediate phase with contains $\sim 2.5-3$ at $\%$ Zr. This phase was first reported by Ellinger and Land [101]. Taylor [103] observed it in samples that had been heat treated at $200^{\circ} \mathrm{C}$ for 6 weeks and determined that it decomposes peritectoidally to $\gamma-\mathrm{Pu}$ and $\delta-\mathrm{Pu}$ at $275^{\circ} \mathrm{C}$.

$\mathrm{Pu}-\mathrm{Zr}$ alloys commonly have $\mathrm{Pu}$-bearing high-Zr inclusions in alloys that phase diagrams indicate have too little $\mathrm{Zr}$ to form $\alpha-\mathrm{Zr}$ or $\beta-\mathrm{Zr}$ (e.g., [104]). These inclusions are commonly referred to as "oxygen-stabilized $\alpha$-Zr." Little is known about them, and further research is needed to determine why they form and whether they are stable.

\subsubsection{Phase Diagrams}

Early experimental Pu-Zr phase diagrams were proposed by Bochvar et al. [96] and Marples [93]. Later research led to the removal of $\kappa-\mathrm{PuZr}_{2}$ as a result of data suggesting that it was oxygen-stabilized. Maeda et al. [105] resolved discrepancies in solidus and liquidus temperatures. Suzuki et al. [99] explored compositions with 50-100 at\% Zr, and Taylor [103] explored high-Pu compositions. All of the experimental data were synthesized by Okamoto [91, 92] to produce a single phase diagram, which has been simplified in Figure 4. Despite numerous areas of uncertainty, this remains the best available phase diagram for the Pu-Zr binary.

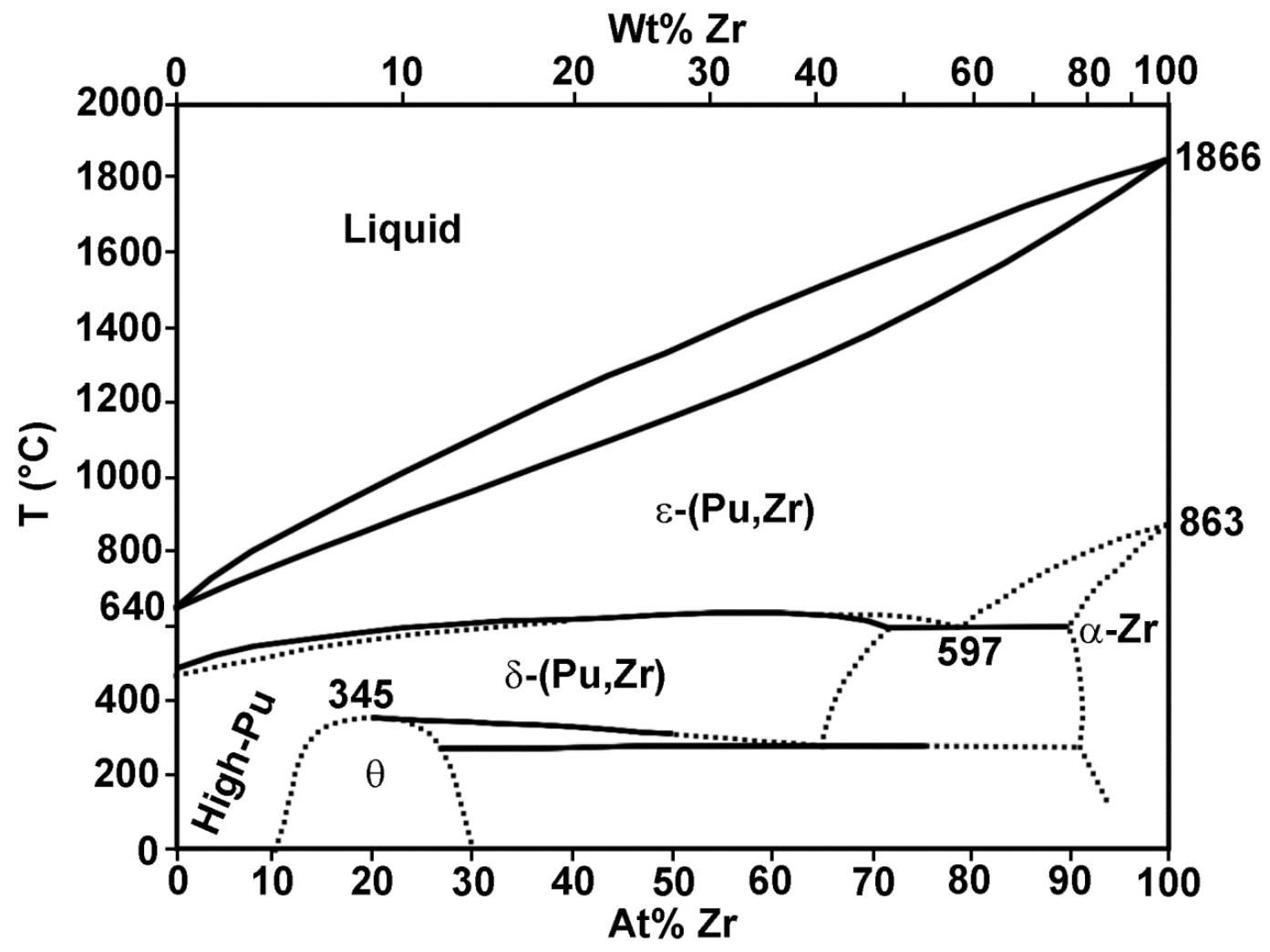

Figure 4. $\mathrm{Pu}-\mathrm{Zr}$ phase diagram simplified from Okamoto [92]. High-Pu phases (allotropes of $\alpha-\mathrm{Pu}, \beta-\mathrm{Pu}$, $\gamma-\mathrm{Pu}$, and $\left.\delta^{\prime}-\mathrm{Pu}\right)$ are not shown. 


\subsubsection{U-Pu Alloys}

\subsubsection{Introduction}

The U-Pu system has the unusual feature that solidus and liquidus both have minima at the same intermediate composition and temperature $\left(\sim 12 \mathrm{at} \% \mathrm{U}\right.$ and $\left.610^{\circ} \mathrm{C}\right)$ [106]. There are two intermediate U-Pu phases: $\zeta_{-}(\mathrm{U}, \mathrm{Pu})$, which can have $\sim 25-72$ at $\% \mathrm{U}$ and is stable at room temperature, and $\eta-(\mathrm{Pu}-\mathrm{Zr})$, which can have between $\sim 3$ and 70 at $\% \mathrm{U}$ and is stable at temperatures between 278 and $705^{\circ} \mathrm{C}$. With the exception of a continuous solid solution between $\gamma-\mathrm{U}$ and $\varepsilon-\mathrm{Pu}$, no $\mathrm{Pu}$ phase can dissolve more than $\sim 2$ at $\%$ U, and no U phase can dissolve more than $\sim 20$ at $\% \mathrm{Pu}$.

The 1989 U-Pu phase diagram proposed by Peterson and Foltyn [106] (Figure 5) is generally accepted, although more recent measurements suggest that the solidus may be slightly higher than shown by this phase diagram and the liquidus may be lower by at least $30^{\circ} \mathrm{C}$ for some compositions [107].

Kinetics of phase transformations are sluggish, and experimental results are likely to vary between samples with different thermal histories (e.g., [97, 108]).

Models of the U-Pu phase diagram based on thermodynamic properties include those of Leibowitz et al.[109], Ogawa [110], and Y. Okamoto et al. [107]. Kurata [57, 60, 62] developed an internally consistent database of thermodynamic properties and used the CALPHAD approach to calculate a phase diagram that agrees well with the experimental data. Landa and colleagues modeled U-Pu alloys using $a b$ initio and density functional theory approaches [111-113].

\subsubsection{Phases and Phase Transformations}

The U-Pu phases include a continuous solid solution between $\gamma$-U and $\varepsilon-\mathrm{Pu}$, allotropic modifications of other $\mathrm{U}$ and $\mathrm{Pu}$ phases, and the intermediate phases $\zeta-(\mathrm{U}, \mathrm{Pu})$ and $\eta-(\mathrm{U}, \mathrm{Pu})$. With the exception of a continuous solid solution between $\gamma-\mathrm{U}$ and $\varepsilon-\mathrm{Pu}$, no Pu phase can dissolve more than $\sim 2$ at $\% \mathrm{U}$, and no $\mathrm{U}$ phase can dissolve more than $\sim 20 \mathrm{at} \% \mathrm{Pu}$. Therefore, it seems reasonable to use crystallographic data for $\mathrm{U}$ and $\mathrm{Pu}$ (Sections 3.1.1 and 3.1.2) for allotropic modifications of $\mathrm{U}$ and $\mathrm{Pu}$ phases unless other information is given below.

The U-Pu phases are:

- $\quad(\alpha-\mathrm{Pu})$ : Allotropic modification of $\alpha-\mathrm{Pu}$. Peterson and Foltyn report a maximum solubility of $\sim 0.2$ at $\% \mathrm{U}$ [106]; however, a report by Kittel et al. [114] that incorporation of 2 at $\%$ U shrinks the lattice parameters by $\sim 0.1$ to $0.3 \%$ without significantly changing the lattice angle $\beta$ suggests that the maximum solubility of $U$ may be at least $2 \%$.

- $\quad(\beta-\mathrm{Pu})$ : Allotropic modification of $\beta-\mathrm{Pu}$ with a maximum solubility of 2 at $\% \mathrm{U}$ [106]

- $\quad(\gamma-\mathrm{Pu})$ : Allotropic modification of $\gamma-\mathrm{Pu}$ with a maximum solubility of $0.7 \mathrm{at} \% \mathrm{U}$ [106]

- $\quad(\delta-\mathrm{Pu})$ : Allotropic modification of $\delta$-Pu with a maximum solubility of 0.3 at\% $\mathrm{U}[106]$

- $\quad\left(\delta^{\prime}-\mathrm{Pu}\right)$ : Allotropic modification of $\delta^{\prime}-\mathrm{Pu}$ with a maximum solubility of 1.5 at $\% \mathrm{U}$ [106]

- $\quad(\alpha-U)$ : Allotropic modification of $\alpha-U$ with a maximum solubility of 15 at $\% \mathrm{Pu}[97,106,115]$. Incorporation of $\mathrm{Pu}$ increases $a$ and $c$ lattice parameters and decreases $b$. Room-temperature lattice parameters of an alloy with $15 \mathrm{wt} \% \mathrm{Pu}$ are $a=2.8625 \AA, b=5.8562 \AA$, and $c=4.9631 \AA$ [115].

- $\quad(\beta-\mathrm{U})$ : Allotropic modification of $\beta-\mathrm{U}$ with a maximum solubility of 20 at $\% \mathrm{Pu}[106]$

- $\quad \gamma-(\mathrm{U}, \mathrm{Pu}): \mathrm{A}$ continuous bcc solid solution between $\gamma-\mathrm{U}$ and $\varepsilon-\mathrm{Pu}[106]$

- $\quad \zeta(\mathrm{U}, \mathrm{Pu})$ : This phase has $25-74$ at\% $\mathrm{U}$ and is stable at room temperature [106]. Although some early structure determinations indicated that it might be cubic, neutron diffraction data indicate that it has a 
large rhombohedral unit cell with a lattice angle close to 90 degrees (space group $R \overline{3} m, a=10.6583$ $\AA, \alpha=89.736^{\circ}$ at $29^{\circ} \mathrm{C}$ for a sample with $60 \mathrm{at} \% \mathrm{Pu}$ ) [116].

- $\quad \eta-(\mathrm{U}, \mathrm{Pu})$, a high-temperature phase with 4 to 70 at $\% \mathrm{U}$ [106]. The crystal structure of this phase has not been determined, although Ellinger et al. [108] suggested that it might be tetragonal with $a=$ 10.57 and $c=10.76 \AA$ for a sample with 25 at $\% \mathrm{U}$ that had been quenched from $500^{\circ} \mathrm{C}$.

The only published measurements of phase-transition temperatures are based on isothermal drop-calorimetry data from an alloy with $10 \mathrm{wt} \%(10 \mathrm{at} \%) \mathrm{Pu}$ [117]. The original reference does not explicitly tabulate phase-transformation temperatures; however, they can be inferred from polynomial representations of the data by other authors $[87,106]$. These temperatures are:

- $\quad(\alpha-U)$ to $(\beta-U): 865-875 \mathrm{~K}$

- $\quad(\beta-\mathrm{U})$ to $(\gamma-\mathrm{U}): 1000-1020 \mathrm{~K}$

- $\quad(\gamma-\mathrm{U})$ to liquid: $1310-1365 \mathrm{~K}$.

Direct measurements of phase-transition enthalpies are lacking. However, differences between incremental enthalpies for a sample with $10 \mathrm{wt} \%(\sim 10 \mathrm{at} \%) \mathrm{Pu}$ and those for pure $\mathrm{U}$ are negligible [87], suggesting that phase-transition enthalpies for this alloy are similar to those for pure $U$.

Savage [117] reported that the heat of fusion of a U-10Pu alloy is $2.4 \mathrm{kcal} / \mathrm{g}$-atom $(\sim 10 \mathrm{~kJ} / \mathrm{mol})$, as compared to his measurement of $2.9 \mathrm{kcal} / \mathrm{g}$-atom $(\sim 12.1 \mathrm{~kJ} / \mathrm{mol})$ for pure $\mathrm{U}$. This value for the heat of fusion of pure $U$ is at the maximum of the range of experimental values (Section 3.1.1), and it seems likely that the heat of fusion of $\mathrm{U}-10 \mathrm{Pu}$ in the same publication is also high. In the absence of new experimental data, it seems reasonable to assume that the difference between the heats of fusion of $U$ and $\mathrm{U}-10 \mathrm{Pu}$ (a decrease of $\sim 2 \mathrm{~kJ} / \mathrm{mol}$ ) is accurate.

\subsubsection{Phase Diagrams}

Numerous researchers have investigated the U-Pu phase diagram, beginning in the 1950s (e.g., [107, 108, 117-119]. In 1989, Peterson and Foltyn [106] combined an experimental phase diagram proposed by Ellinger et al. [108] with other data to produce a phase diagram that is still widely accepted (Figure 5). More recent measurements by Y. Okamoto et al. [107] are consistent with sub-solidus phase-transition temperatures in the Peterson and Foltyn phase diagram, but suggest that the solidus may be slightly higher and the liquidus may be lower by $\sim 30^{\circ} \mathrm{C}$ or more. It has been suggested that Peterson and Foltyn phase diagram should be modified as a result of these measurements [107, 120]; however, recent reviews and experimental publications (e.g., $[21,62,118]$ ) continue to use the phase diagram of Peterson and Foltyn. 


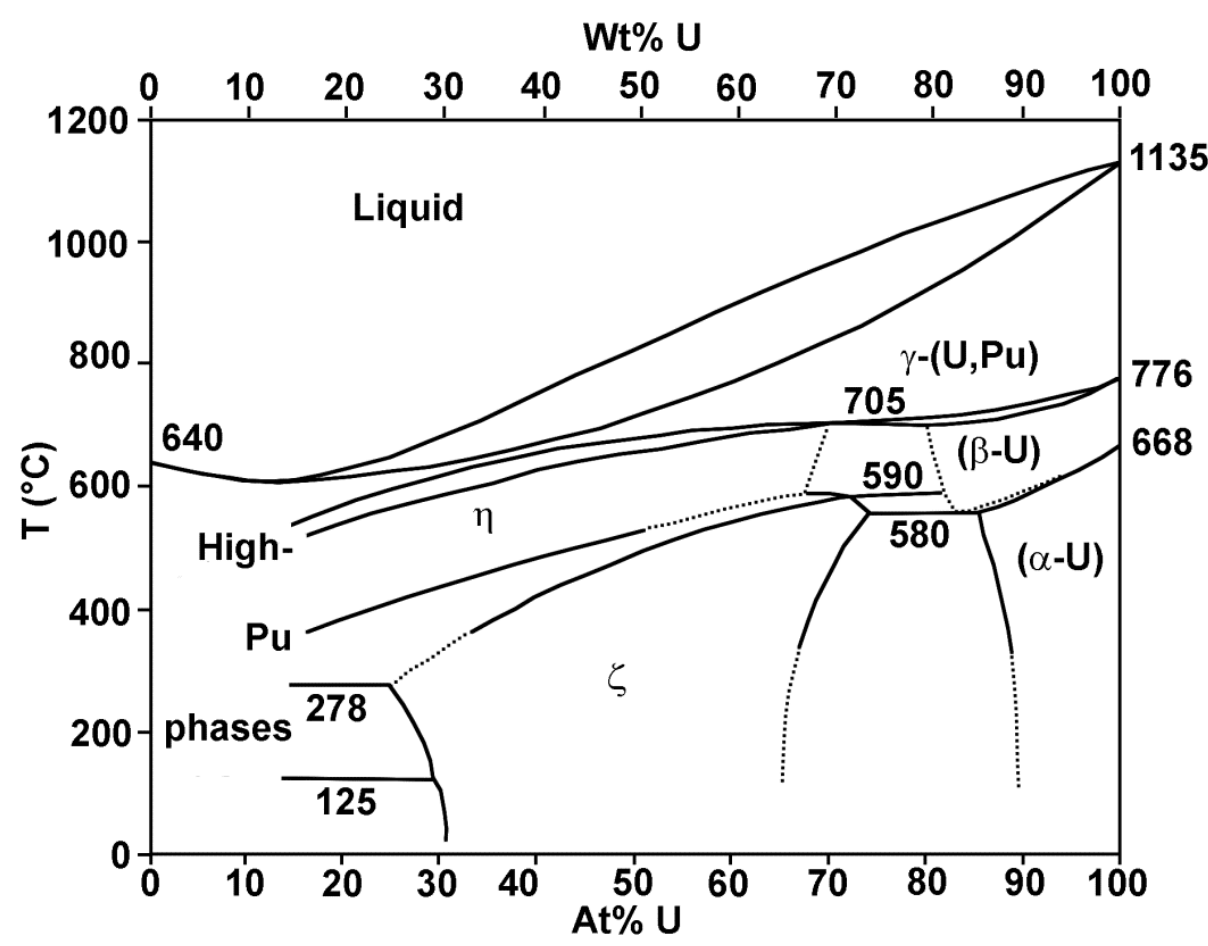

Figure 5. U-Pu phase diagram simplified from Peterson and Foltyn [106]. High-Pu phases (allotropes of $\alpha-\mathrm{Pu}, \beta-\mathrm{Pu}, \gamma-\mathrm{Pu}, \delta-\mathrm{Pu}$, and $\left.\delta^{\prime}-\mathrm{Pu}\right)$ are not shown for simplicity and have at most a few at $\% \mathrm{U}$.

\subsubsection{U-Pu-Zr alloys}

\subsubsection{Introduction}

Although U-Pu-Zr alloys have been investigated for more than 50 years, the only experimentally determined ternary phase diagram was published by O'Boyle and Dwight in 1970 [121]. This phase diagram is represented by a series of isothermal sections at temperatures between 500 and $700^{\circ} \mathrm{C}$ and a table of possible phase-transformation reactions.

There is general agreement that all of the phases in the U-Pu-Zr system at temperatures above $\sim 500$ ${ }^{\circ} \mathrm{C}$ are allotropic modifications of phases in the U-Pu, U-Zr, and Pu-Zr systems. The first phase to crystallize for all U-Pu-Zr ternary compositions is a bcc solid solution between $\gamma-\mathrm{U}, \varepsilon-\mathrm{Pu}$, and $\beta-\mathrm{Zr}$, which transforms to a number of lower-temperature phases by solid-state reactions. These reactions are characteristically slow, and annealing times of 25 days at $700^{\circ} \mathrm{C}$ and five months at $590^{\circ} \mathrm{C}$ were required to obtain grains large enough for microprobe analyses [121]. Thus, it is likely that characterization results are influenced by thermal histories of the specific samples analyzed.

All of the experimental measurements of liquidus and solidus temperatures are from samples with high concentrations of $\mathrm{U}$ or $\mathrm{Pu}$. Three approaches to estimating solidus and liquidus temperatures for other compositions have been suggested $[5,57,62,66,72]$. Although the three approaches produce results that differ by $\sim 100^{\circ} \mathrm{C}$ for some compositions, currently available data are not adequate to determine which model is best.

Data on phase-transformation enthalpies are generally lacking. However, researchers at Idaho National Laboratory (INL) recently obtained this data for six U-Pu-Zr alloys.

Other recent research has emphasized modeling. Landa and colleagues developed density functional theory models for the U-Pu-Zr system [122], Wenzhong and Unal [123] and Galloway et al. 
[124]addressed ways to incorporate U-Pu-Zr phase diagrams into the Moose-Bison fuel performance code, and Kurata $[57,60]$ compiled a thermodynamic database and used it to calculate isothermal diagrams that are in reasonably good agreement with the isothermal sections of O'Boyle and Dwight.

\subsubsection{Phases and Phase Transformations}

U-Pu-Zr alloys have been investigated extensively. At least 50 measurements of sub-solidus phase transformation temperatures [98, 119, 125-127] and 75 determinations of phases in annealed samples [121, 128-130] have been previously reported, although much of the data are described as "preliminary."

All of the known phases in the U-Pu-Zr ternary system are allotropic modifications of phases in the $\mathrm{U}-\mathrm{Pu}, \mathrm{U}-\mathrm{Zr}$, or Pu-Zr system. These phases include:

- $\quad(\alpha-U)$ : Allotropic modification of $\alpha$-U that can incorporate up to $\sim 15$ at $\% \mathrm{Pu}$ and 0.5 at $\% \mathrm{Zr}([121]$ and Sections 3.1.4 and 3.1.6 of this handbook).

- $\quad(\beta-\mathrm{U})$ : Allotropic modification of $\beta-\mathrm{U}$ that can incorporate up to $\sim 20 \mathrm{at} \% \mathrm{Pu}$ and $1.1 \mathrm{at} \% \mathrm{Zr}$ (reference [121] and Sections 3.1.4 and 3.1.6 of this handbook).

- $\quad(\alpha-Z r)$ : Allotropic modification of $\alpha-Z r$ that can incorporate up to 1 at $\% \mathrm{U}$ and also has a low solubility for $\mathrm{Pu}$ (Sections 3.1.4 and 3.1.5 of this handbook).

- $\quad(\eta)$ : Modification of $\eta-(\mathrm{U}, \mathrm{Pu})$, with a limited solubility for $\mathrm{Zr}$ [121].

- $\quad(\zeta)$ : Allotropic modification of $\zeta-(\mathrm{U}, \mathrm{Pu})$. O’Boyle and Dwight indicate that this phase can contain up to $\sim 5$ at $\% \mathrm{Zr}$, and that the solubility of $\mathrm{Zr}$ decreases at lower temperatures. In contrast, researchers from Mound Laboratory $\left[98,131\right.$ ] found that this phase can contain up to 9 at $\% \mathrm{Zr}$ at $675^{\circ} \mathrm{C}$, and that the solubility of $\mathrm{Zr}$ increases at lower temperatures to a maximum of $\sim 20$ at $\%$ at $640^{\circ} \mathrm{C}$. The unit cell size increases by $\sim 0.02 \%$ as a result of the incorporation of $\operatorname{Zr}[121]$.

- $\left(\delta-\mathrm{UZr}_{2}\right)$ : Allotropic modification of $\delta-\mathrm{UZr}_{2}$ with extensive solubility for Pu. O'Boyle and Dwight [121] suggest a possible continuous solid solution with $\kappa-\mathrm{PuZr}_{2}$; however, $\kappa-\mathrm{PuZr}_{2}$ does not appear in recent $\mathrm{Pu}-\mathrm{Zr}$ phase diagrams because of research suggesting that it is oxygen-stabilized. O'Boyle and Dwight [121] report that the lattice parameter of $\delta-\mathrm{UZr}_{2}$ increases with $\mathrm{Pu}$ concentrations in alloys with 0,10 , or 20 at $\% \mathrm{Pu}$.

- $(\delta-\mathrm{Pu})$ : Allotropic modification of $\delta$-Pu, which has extensive solubility with $\mathrm{Zr}$ but can dissolve at most $\sim 0.3$ at $\% \mathrm{U}$ (Sections 3.1.5 and 3.1.6 of this handbook).

- $\quad(\alpha-\mathrm{Pu}),(\beta-\mathrm{Pu}),(\gamma-\mathrm{Pu})$, and $\left(\delta^{\prime}-\mathrm{Pu}\right)$ : Allotropic modifications of Pu phases with low solubilities for both $\mathrm{U}$ and $\mathrm{Zr}$.

- $\quad\left(\zeta-\mathrm{Pu}_{28} \mathrm{Zr}\right)$ and $(\theta)$ : Allotropic modifications of $\zeta-\mathrm{Pu}_{28} \mathrm{Zr}$ and $\theta-(\mathrm{Pu}, \mathrm{Zr})$. These phases are poorly known even in binary alloys, and occur only at temperatures below the isothermal sections of O’Boyle and Dwight [121].

- $\quad(\gamma)$ : A body-centered cubic solid solution between $\gamma-\mathrm{U}, \beta-\mathrm{Zr}$, and $\varepsilon-\mathrm{Pu}$, commonly referred to as $(\gamma-U)$.

$\mathrm{U}-\mathrm{Pu}-\mathrm{Zr}$ alloys commonly have high-Zr inclusions that contain up to $4.0 \mathrm{wt} \% \mathrm{U}$ and $2.5 \mathrm{wt} \% \mathrm{Pu}$ in alloys that phase diagrams indicate have too little $\mathrm{Zr}$ to form $\alpha-\operatorname{Zr}$ or $\beta-\operatorname{Zr}$ (e.g.,[66, 121, 132-134]). These inclusions are commonly referred to as "oxygen-stabilized $\alpha-Z r$ " because O'Boyle and Dwight [121] noted that the quantity of inclusions increased with increases in the partial pressure of oxygen in the atmosphere in which the samples were cast. Little is known about these inclusions, and further research is needed to determine why they form and whether they are stable.

Researchers at INL measured phase-transition temperatures and enthalpies for six U-Pu-Zr alloys by DSC (Table 3, Figure 6, Figure 7). Many of the peaks were broad or asymmetrical, suggesting that 
individual peaks in the DSC data probably represent multiple phase transformations occurring at similar temperatures. Peak shapes and phase-transformation temperatures in the INL data are comparable to previously published data from samples with similar compositions [98, 119, 125-127].

The INL data were collected in an air-atmosphere glovebox. Despite a flowing cover gas with oxygen concentration below the parts per billion range, the samples developed visible oxide layers during data collection.

Because of peak overlaps in the DSC curves, it was not possible to separate peaks from individual transformations. However, total enthalpies were calculated from the areas under all of the peaks corresponding to temperatures between 400 and $800^{\circ} \mathrm{C}$ (Table 4). No other enthalpy values for comparison with the INL data are available.

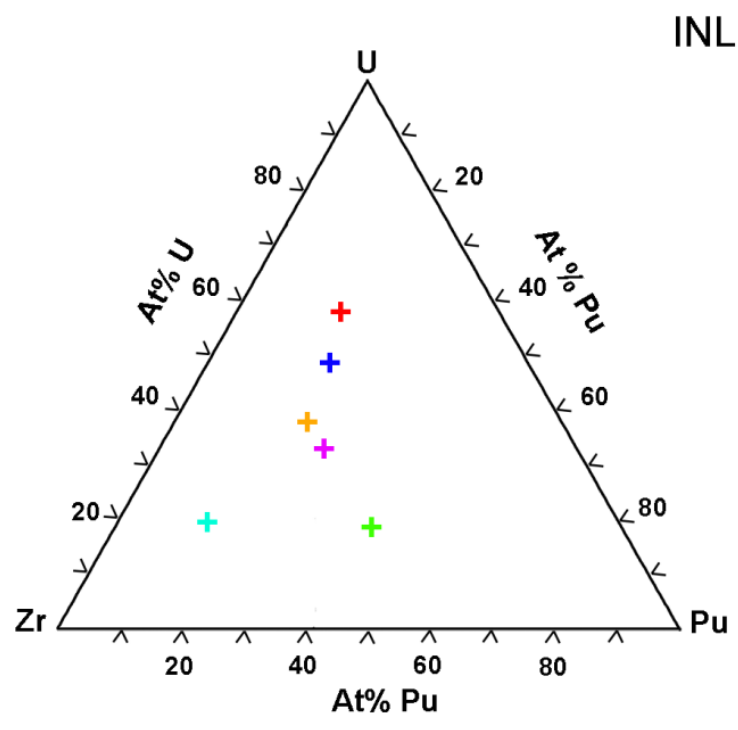

INL sample compositions, at\%

$+\mathrm{U}-17 \mathrm{Pu}-23 \mathrm{Zr}$

$+\mathrm{U}-27 \mathrm{Pu}-40 \mathrm{Zr}$

$+\mathrm{U}-19 \mathrm{Pu}-32 \mathrm{Zr}$

$+\mathrm{U}-12 \mathrm{Pu}-68 \mathrm{Zr}$

$+\mathrm{U}-41 \mathrm{Pu}-40 \mathrm{Zr}$

$+\mathrm{U}-22 \mathrm{Pu}-40 \mathrm{Zr}$

Figure 6. Compositions (in at $\%$ ) of alloys whose phase-transition temperatures and enthalpies were measured at INL 


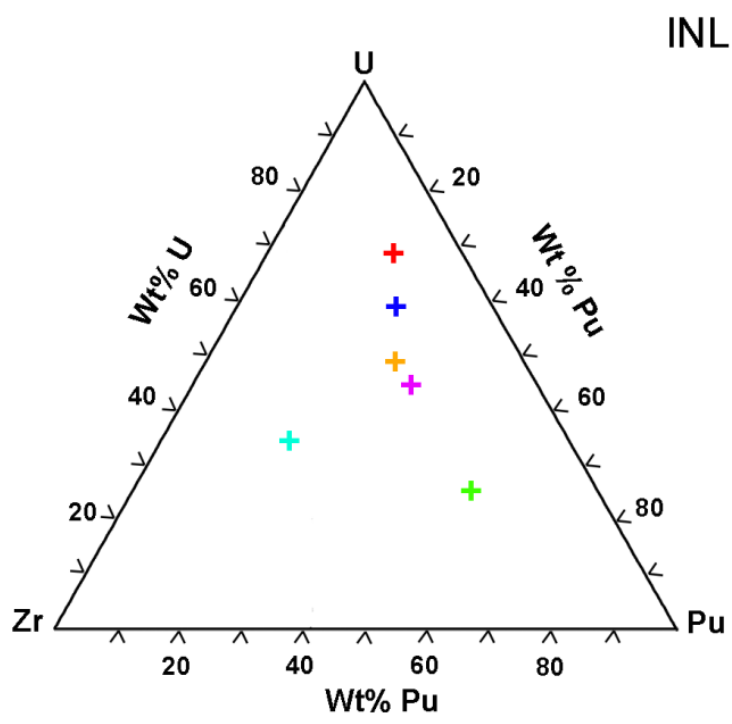

NL sample compositions, wt $\%$

$+\mathrm{U}-20 \mathrm{Pu}-10 \mathrm{Zr}$

$+\mathrm{U}-36.5 \mathrm{Pu}-20 \mathrm{Zr}$

$+\mathrm{U}-24 \mathrm{Pu}-15 \mathrm{Zr}$

$+\mathrm{U}-20 \mathrm{Pu}-45 \mathrm{Zr}$

$+\mathrm{U}-55 \mathrm{Pu}-20 \mathrm{Zr}$

+ U-30Pu-20Zr

Figure 7. Compositions (in wt $\%$ ) of alloys whose phase-transition temperatures and enthalpies were measured at INL

Table 3. Onset temperatures for peaks at temperatures above $400^{\circ} \mathrm{C}$ in recent INL data, measured during heating

\begin{tabular}{cccc}
\hline $\begin{array}{c}\text { Composition } \\
(\text { wt } \%)\end{array}$ & $\begin{array}{c}\text { Composition } \\
(\text { at } \%)\end{array}$ & $\begin{array}{c}\text { First } \\
\text { transition }\left({ }^{\circ} \mathrm{C}\right)\end{array}$ & $\begin{array}{c}\text { Second } \\
\text { transition }\left({ }^{\circ} \mathrm{C}\right)\end{array}$ \\
\hline U-55Pu-20Zr & U-41Pu-40Zr & 502 & 518 \\
U-20Pu-45Zr & U-12Pu-68Zr & 591 & 570 \\
U-36.5Pu-20Zr & U-27Pu-40Zr & 551 & 598 \\
U-30Pu-20Zr & U-22Pu-40Zr & 570 & 637 \\
U-24Pu-15Zr & U-19Pu-32Zr & 574 & 654 \\
\hline U-20Pu-10Zr & U-17Pu-23Zr & 580 & \\
\hline
\end{tabular}


Table 4. Combined enthalpies for all transformations at temperatures between 400 and $800^{\circ} \mathrm{C}$ corresponding to data summarized in Table 2

\begin{tabular}{ccc}
\hline $\begin{array}{c}\text { Composition } \\
(\text { wt\%) }\end{array}$ & $\begin{array}{c}\text { Composition } \\
(\text { at\% })\end{array}$ & $\Delta \mathrm{H}_{\mathrm{Tr}}(\mathrm{J} / \mathrm{g})$ \\
\hline $\mathrm{U}-55 \mathrm{Pu}-20 \mathrm{Zr}$ & $\mathrm{U}-41 \mathrm{Pu}-40 \mathrm{Zr}$ & $35.75 \pm 0.57$ \\
$\mathrm{U}-20 \mathrm{Pu}-45 \mathrm{Zr}$ & $\mathrm{U}-12 \mathrm{Pu}-68 \mathrm{Zr}$ & $32.37 \pm 0.07$ \\
$\mathrm{U}-36.5 \mathrm{Pu}-20$ & $\mathrm{U}-27 \mathrm{Pu}-40 \mathrm{Zr}$ & $27.76 \pm 0.1$ \\
$\mathrm{Zr}$ & & \\
$\mathrm{U}-30 \mathrm{Pu}-20 \mathrm{Zr}$ & $\mathrm{U}-22 \mathrm{Pu}-40 \mathrm{Zr}$ & $32.28 \pm 0.71$ \\
$\mathrm{U}-24 \mathrm{Pu}-15 \mathrm{Zr}$ & $\mathrm{U}-19 \mathrm{Pu}-32 \mathrm{Zr}$ & $29.07 \pm 0.36$ \\
$\mathrm{U}-20 \mathrm{Pu}-10 \mathrm{Zr}$ & $\mathrm{U}-17 \mathrm{Pu}-23 \mathrm{Zr}$ & $30.54 \pm 0.3$ \\
\hline
\end{tabular}

\subsubsection{Phase Diagrams}

\subsection{Liquidus and Solidus}

Several research groups have measured the solidus and liquidus temperatures of U-Pu-Zr alloys [66, 90, 119, 125, 135] (Figure 8 and Figure 9). A cursory examination of the figures shows that drawing smooth temperature contours requires either assuming very large error bars for individual measurements or discounting some of the data. Leibowitz et al. [66] suggested that data from reference [119], which includes all of the high-Pu data, should be discounted because its liquidus temperature for a Pu- $15 \mathrm{at} \% \mathrm{Zr}$ alloy is $\sim 200^{\circ} \mathrm{C}$ higher than the values accepted by other researchers (e.g., [92, 103]). However, determining the liquidus temperature for this alloy from reference [119] requires extrapolating temperatures beyond the isothermal contours suggested by the authors. Solidus temperatures for $\mathrm{Pu}-\mathrm{Zr}$ alloys and both solidus and liquidus temperatures for U-Pu alloys in reference [119] are within $\sim 30^{\circ} \mathrm{C}$ of those accepted by other researchers [92, 103]. Given the relatively poor knowledge of all of the systems involved, it seems reasonable to accept the data from ternary U-Pu-Zr alloys in reference [119] pending further investigation. However, it must be remembered that measured liquidus temperatures from reference [119] may be anomalously high. 


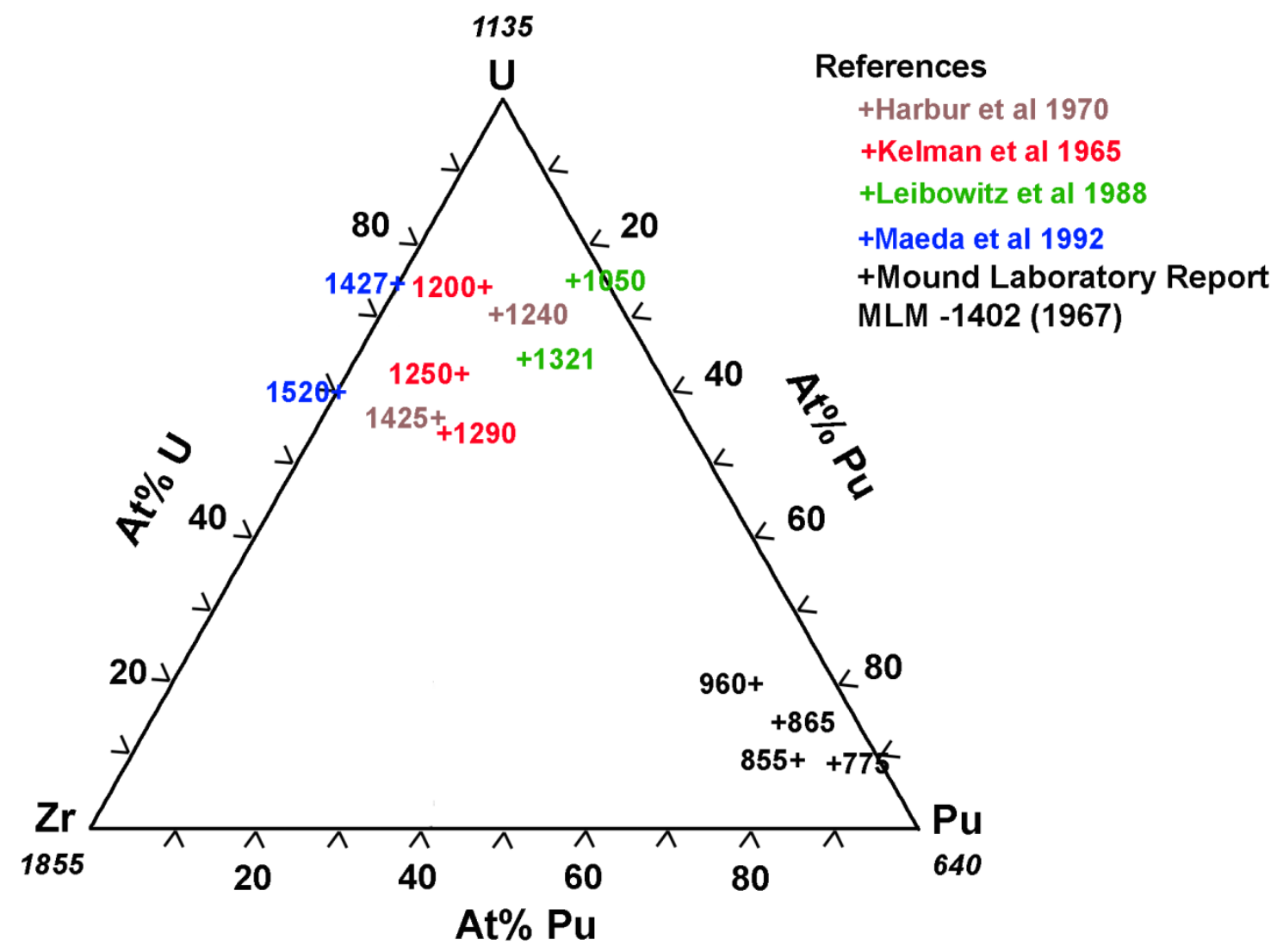

Figure 8. Experimentally determined liquidus temperatures in ${ }^{\circ} \mathrm{C}$, with melting temperatures of $\mathrm{U}, \mathrm{Pu}$, and $\mathrm{Zr}$ for comparison $[66,90,119,125,135]$ 


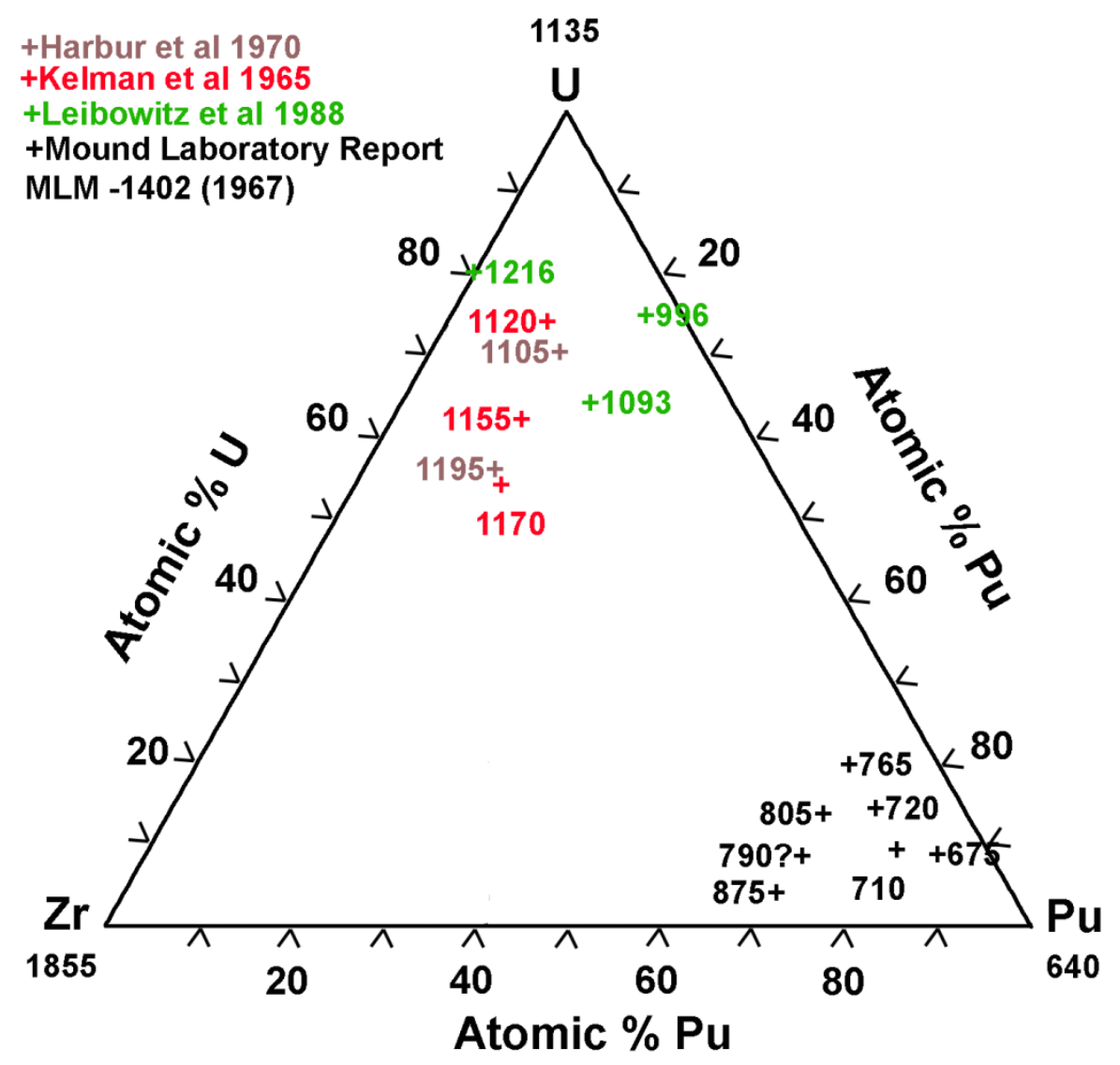

Figure 9. Experimentally determined solidus temperatures in ${ }^{\circ} \mathrm{C}$, with melting temperatures of $\mathrm{U}, \mathrm{Pu}$, and $\mathrm{Zr}$ for comparison $[66,119,125,135]$

Based on these measurements, Leibowitz et al. [66] developed thermodynamic models for the liquidus and solidus. Later analyses by Kurata [60] made it possible to for Ogata $[5,72]$ to derive analytical expressions for liquidus and solidus temperatures for compositions with less than $80 \mathrm{at} \% \mathrm{Zr}$ and more $\mathrm{U}$ than $\mathrm{Pu}$. These expressions match experimental data on the $\mathrm{U}-\mathrm{Zr}$ and $\mathrm{U}-\mathrm{Pu}-\mathrm{Zr}$ systems [66, $90,125,135]$ to within $60^{\circ} \mathrm{C}$ for the solidus and $130^{\circ} \mathrm{C}$ for the liquidus. Somewhat later, Kurata [57, 62] calculated liquid and solidus temperatures using CALPHAD, and obtained agreement with the data in references [125] and [66] to within $\pm 20^{\circ} \mathrm{C}$.

Figure 10, Figure 11, Table 5, and Table 6 compare liquidus and solidus temperatures calculated using the three models. Data from the Ogata model are selected points calculated after algebraic manipulation to obtain a quadratic equation for the concentration of $\mathrm{Pu}$ corresponding to a given temperature and concentration of Zr. Solidus and liquidus temperatures from the three models generally agree with each other better than they do with the data for compositions with more than $\sim 50$ at $\% \mathrm{U}$, but commonly differ by several tens of degrees. 


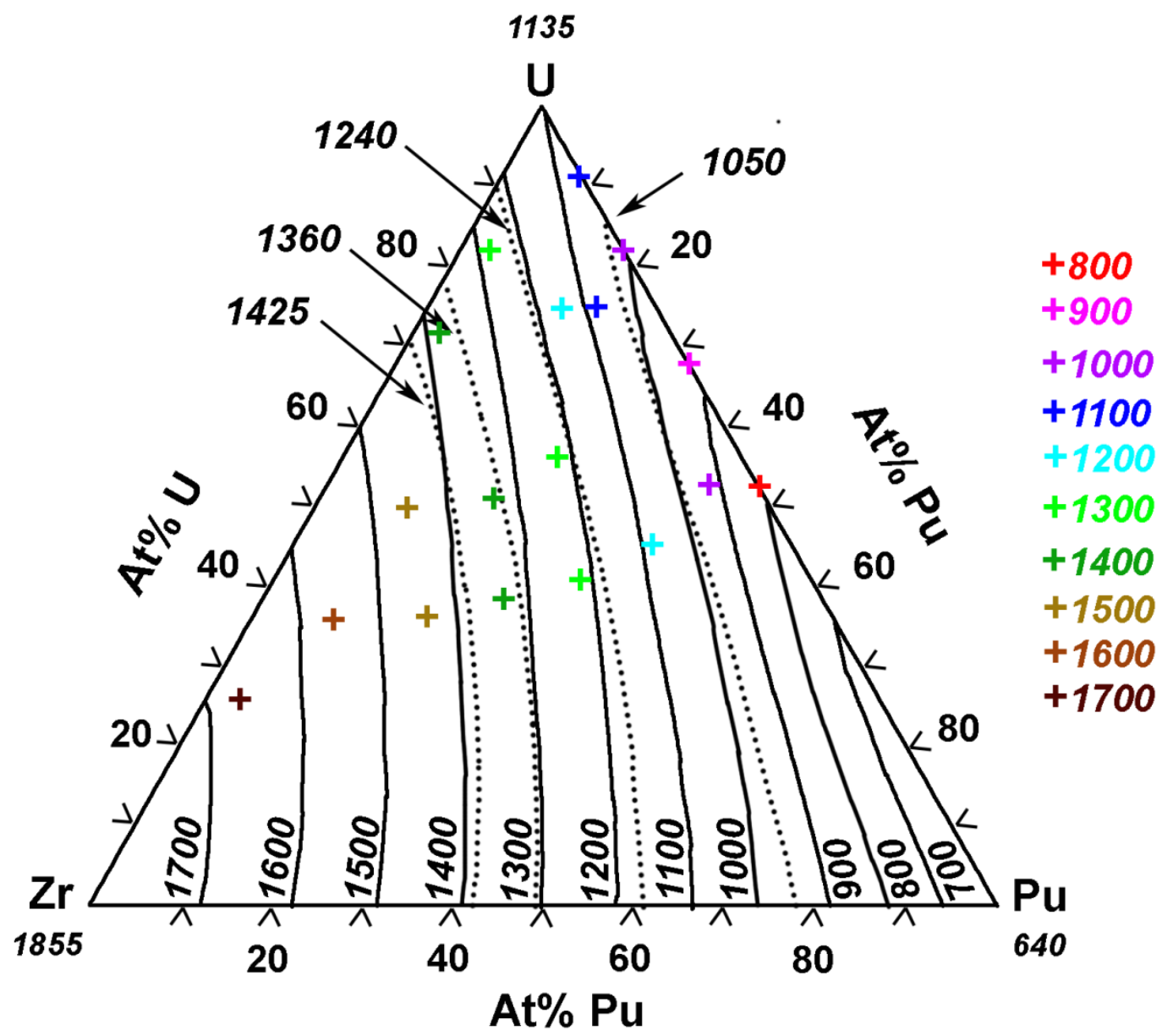

Figure 10. Liquidus temperatures $\left({ }^{\circ} \mathrm{C}\right)$ from models of Leibowitz et al. [66] (solid lines), Kurata [62] (dotted lines), and Ogata [5] (colored symbols showing examples of calculated points, with each color indicating a different temperature). Melting temperatures of $\mathrm{U}, \mathrm{Pu}$, and $\mathrm{Zr}$ are shown for comparison. 


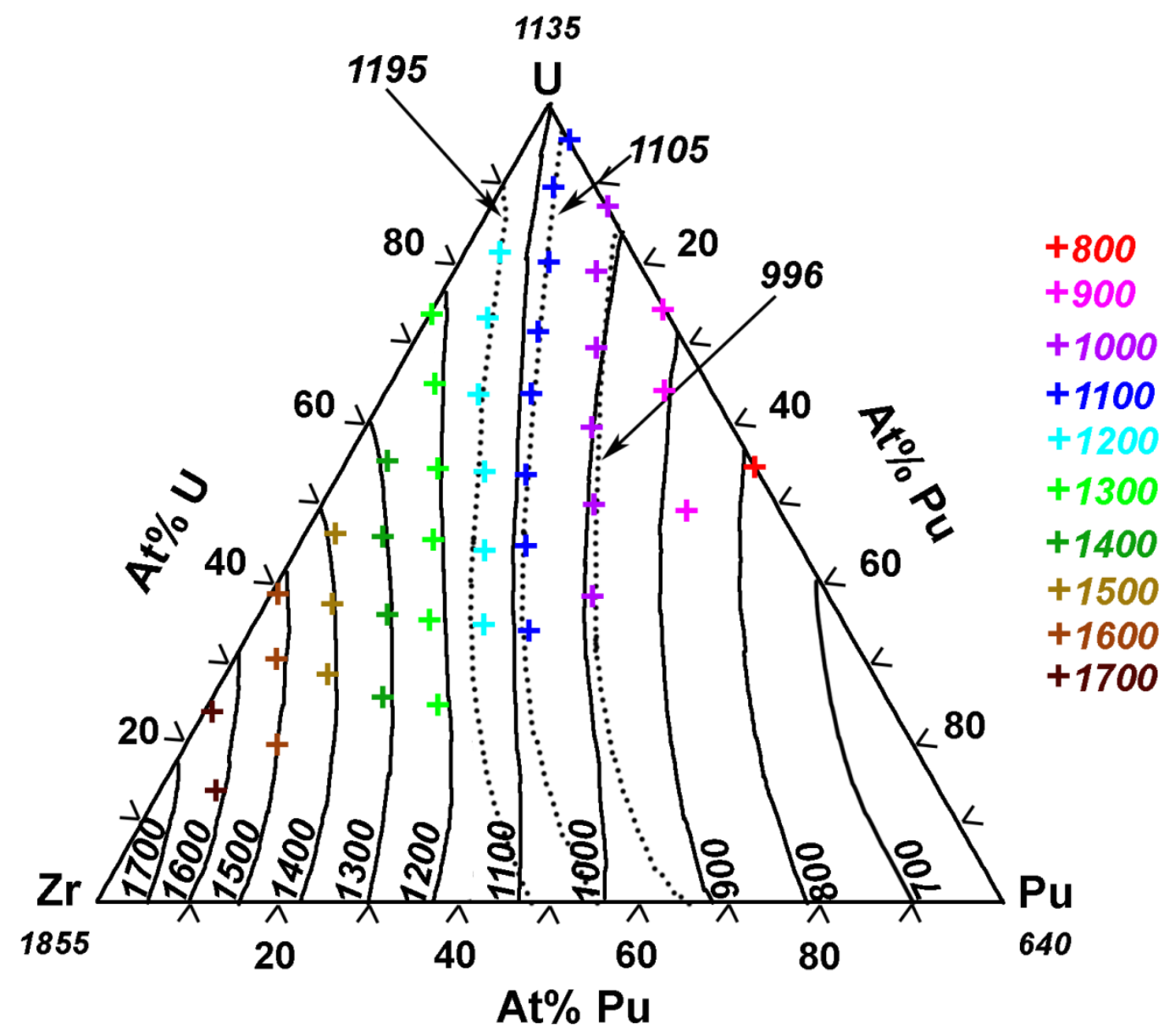

Figure 11. Solidus temperatures $\left({ }^{\circ} \mathrm{C}\right)$ from models of Leibowitz et al. [66] (solid lines), Kurata [62] (dotted lines), and Ogata [5] (colored symbols showing examples of calculated points)

Table 5. Experimental and calculated liquidus temperatures $\left({ }^{\circ} \mathrm{C}\right)$ for $\mathrm{U}-\mathrm{Zr}$ and $\mathrm{U}-\mathrm{Pu}-\mathrm{Zr}$ alloys

\begin{tabular}{|c|c|c|c|c|c|}
\hline \multirow{2}{*}{$\begin{array}{l}\text { Composition } \\
\text { (wt\%) }\end{array}$} & \multirow{2}{*}{$\begin{array}{l}\text { Composition } \\
\text { (at } \%)\end{array}$} & \multicolumn{4}{|c|}{ Liquidus temperature $\left({ }^{\circ} \mathrm{C}\right)$} \\
\hline & & $\begin{array}{l}\text { Experimental } \\
\text { [reference] }\end{array}$ & $\begin{array}{l}\text { Oga } \\
\text { ta [5] }\end{array}$ & $\begin{array}{l}\text { Kurata } \\
{[62]}\end{array}$ & $\begin{array}{l}\text { Leibowitz } \\
\text { et al. [66] }\end{array}$ \\
\hline $\mathrm{U}-15 \mathrm{Pu}-7 \mathrm{Zr}$ & $\mathrm{U}-13 \mathrm{Pu}-16 \mathrm{Zr}$ & $1240[125]$ & $1^{128}$ & $\sim 1250$ & 1268 \\
\hline $\mathrm{U}-15 \mathrm{Pu}-13.5 \mathrm{Zr}$ & $\mathrm{U}-12 \mathrm{Pu}-29 \mathrm{Zr}$ & $1425[125]$ & $3^{141}$ & $\sim 1390$ & 1394 \\
\hline $\mathrm{U}-8.4 \mathrm{Zr}$ & $\mathrm{U}-19.3 \mathrm{Zr}$ & $1358[66]$ & $3^{135}$ & $\sim 1350$ & 1371 \\
\hline $\mathrm{U}-20 \mathrm{Pu}-1 \mathrm{Zr}$ & $\begin{array}{l}\mathrm{U}-19.5 \mathrm{Pu}- \\
3.3 \mathrm{Zr}\end{array}$ & $1050[66]$ & $3^{106}$ & $\sim 1060$ & 1060 \\
\hline
\end{tabular}




\begin{tabular}{|c|c|c|c|c|c|}
\hline $\mathrm{U}-22 \mathrm{Pu}-6 \mathrm{Zr}$ & $\begin{array}{l}\mathrm{U}-19.3 \mathrm{Pu}- \\
14.5 \mathrm{Zr}\end{array}$ & $1321[66]$ & $6^{124}$ & $\sim 1230$ & 1216 \\
\hline $\mathrm{U}-11.1 \mathrm{Pu}-6.3 \mathrm{Zr}$ & $\mathrm{U}-10 \mathrm{Pu}-15 \mathrm{Zr}$ & 1200 [135] & $\begin{array}{ll} & 128 \\
0 & \end{array}$ & $\sim 1250$ & $\sim 1225$ \\
\hline $\mathrm{U}-15 \mathrm{Pu}-10 \mathrm{Zr}$ & $\begin{array}{l}\mathrm{U}-12.9 \mathrm{Pu}- \\
22.5 \mathrm{Zr}\end{array}$ & 1250 [135] & $3 \quad 135$ & $\sim 1330$ & $\sim 1310$ \\
\hline $\begin{array}{l}\mathrm{U}-18.5 \mathrm{Pu}- \\
14.1 \mathrm{Zr}\end{array}$ & $\mathrm{U}-15 \mathrm{Pu}-30 \mathrm{Zr}$ & 1290 [135] & $3 \quad 141$ & $\sim 1380$ & $\sim 1350$ \\
\hline $\mathrm{U}-11 \mathrm{Zr}$ & $\mathrm{U}-24.4 \mathrm{Zr}$ & 1427 [90] & $0^{140}$ & $\sim 1400$ & $\sim 1390$ \\
\hline $\mathrm{U}-20 \mathrm{Zr}$ & U-39.3Zr & 1520 [90] & $0^{152}$ & $>1425$ & $\sim 1500$ \\
\hline
\end{tabular}

Table 6. Experimental and calculated solidus temperatures $\left({ }^{\circ} \mathrm{C}\right)$ for $\mathrm{U}-\mathrm{Zr}$ and $\mathrm{U}-\mathrm{Pu}-\mathrm{Zr}$ alloys

\begin{tabular}{|c|c|c|c|c|c|}
\hline $\begin{array}{c}\text { Composition } \\
(\mathrm{wt} \%)\end{array}$ & $\begin{array}{c}\text { Composition } \\
(\mathrm{at} \%)\end{array}$ & \multicolumn{3}{|c|}{ Solidus Temperature $\left({ }^{\circ} \mathrm{C}\right)$} \\
\hline & & $\begin{array}{c}\text { Experimental } \\
\text { [reference] }\end{array}$ & $\begin{array}{c}\text { Ogata } \\
{[5]}\end{array}$ & $\begin{array}{c}\text { Kurata } \\
{[62]}\end{array}$ & $\begin{array}{c}\text { Leibowitz } \\
\text { et al. [66] }\end{array}$ \\
\hline $\mathrm{U}-15 \mathrm{Pu}-7 \mathrm{Zr}$ & $\mathrm{U}-13 \mathrm{Pu}-16 \mathrm{Zr}$ & $1105[125]$ & 1098 & $\sim 1105$ & 1121 \\
\hline $\begin{array}{c}\mathrm{U}-15 \mathrm{Pu}- \\
13.5 \mathrm{Zr}\end{array}$ & $\mathrm{U}-12 \mathrm{Pu}-29 \mathrm{Zr}$ & $1195[125]$ & 1213 & $\sim 1195$ & 1187 \\
\hline $\mathrm{U}-8.4 \mathrm{Zr}$ & $\mathrm{U}-19.3 \mathrm{Zr}$ & $1216[66]$ & 1268 & $>1195$ & 1221 \\
\hline $\mathrm{U}-20 \mathrm{Pu}-1 \mathrm{Zr}$ & $\mathrm{U}-19.5 \mathrm{Pu}-3.3 \mathrm{Zr}$ & $996[66]$ & 961 & $<996$ & 1012 \\
\hline $\mathrm{U}-22 \mathrm{Pu}-6 \mathrm{Zr}$ & $\mathrm{U}-19.3 \mathrm{Pu}-$ & $1093[66]$ & 1038 & $\sim 1040$ & 1071 \\
\hline $\begin{array}{l}\mathrm{U}-11.1 \mathrm{Pu}- \\
6.3 \mathrm{Zr}\end{array}$ & $\mathrm{U}-10 \mathrm{Pu}-15 \mathrm{Zr}$ & $1120[135]$ & 1124 & $\sim 1110$ & $\sim 1095$ \\
\hline $\mathrm{U}-15 \mathrm{Pu}-10 \mathrm{Zr}$ & $\mathrm{U}-12.9 \mathrm{Pu}-$ & $1155[135]$ & 1154 & $\sim 1150$ & $\sim 1115$ \\
\hline $\begin{array}{c}\mathrm{U}-18.5 \mathrm{Pu}- \\
14.1 \mathrm{Zr}\end{array}$ & $\mathrm{U}-15 \mathrm{Pu}-30 \mathrm{Zr}$ & $1170[135]$ & 1195 & $\sim 1190$ & $\sim 1140$ \\
\hline
\end{tabular}

\subsection{Sub-solidus Reactions}

In the 1960s, several groups of researchers attempted to determine the U-Pu-Zr phase diagram by combining data on phase-transition temperatures with phases in annealed samples. Researchers at Mound Laboratory identified possible sub-solidus reactions and constructed a diagram showing the temperatures at which the $(\gamma-\mathrm{U})$ solid solution transforms to lower-temperature phases $[98,131]$. The Mound 
Laboratory researchers also compiled a tentative table of reactions [98] but did not use their results to suggest phase diagrams or isothermal sections.

In 1970, O'Boyle and Dwight considered all of the available data (including the data used by Mound Laboratory and their own new measurements of the lower temperature boundary of the $(\gamma-U)$ solid solution) and published a series of isothermal sections at temperatures between 500 and $700^{\circ} \mathrm{C}$ [121]. These diagrams remain the only experimentally determined phase diagrams for the U-Pu-Zr system.

Figure 12 compares the temperatures of the highest sub-solidus reactions according to O'Boyle and Dwight and researchers from Mound Laboratory. The two sources used much of the same data and, therefore, should not be considered independent. However, both suggest that compositions of interest for fuels are likely to transform between the $(\gamma-\mathrm{U})$ solid solution and some combination of $(\beta-\mathrm{U}), \eta-(\mathrm{U}, \mathrm{Pu})$, and $\zeta-(\mathrm{U}, \mathrm{Pu})$ at temperatures between 650 and $700^{\circ} \mathrm{C}$. 


\section{Temperature $\left({ }^{\circ} \mathrm{C}\right)$}

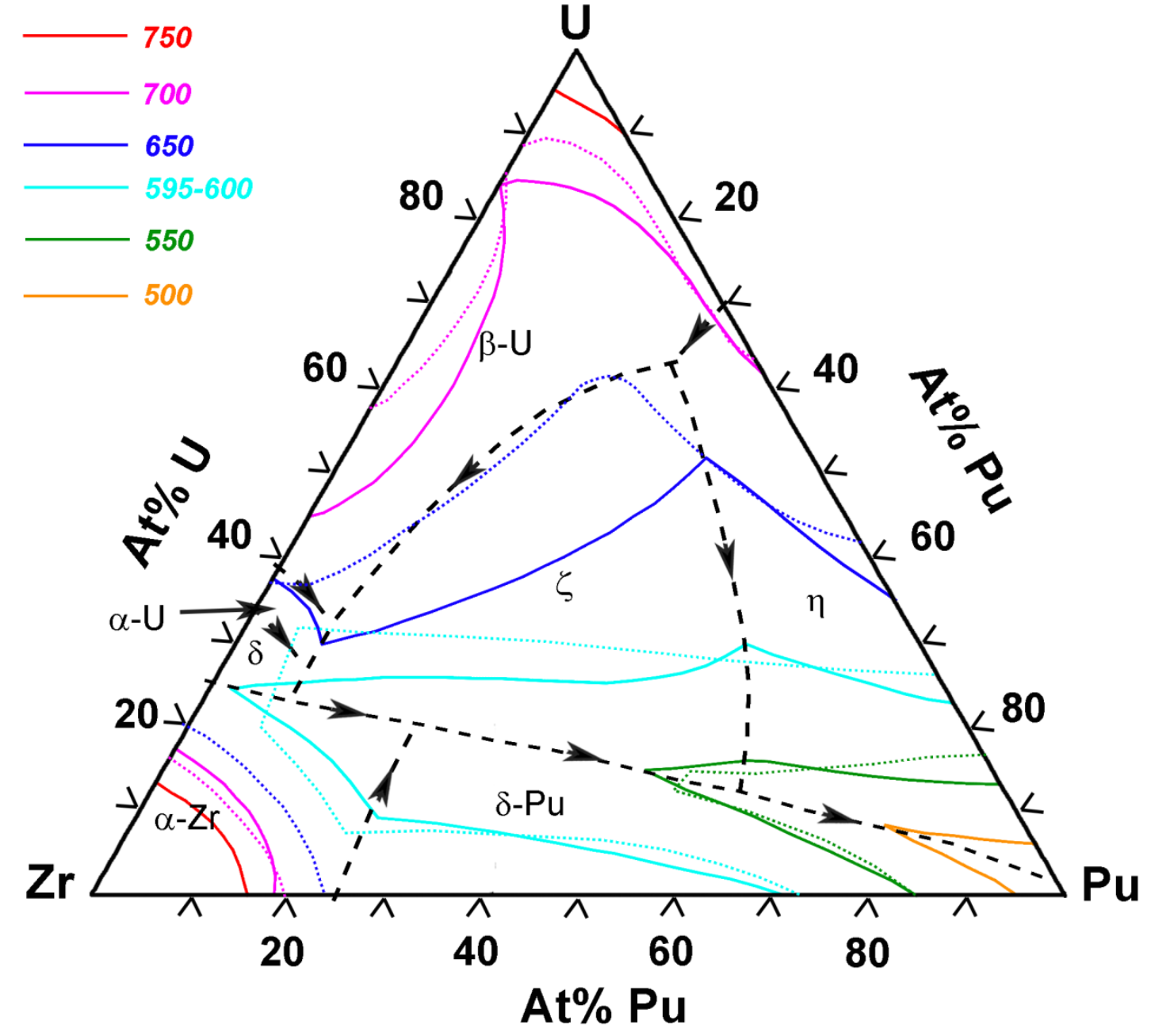

Figure 12. Ternary projection of low-temperature limit of $(\gamma-\mathrm{U})$ solid solution from Mound Laboratory $[98,131]$ (solid lines) with corresponding temperature contours from O'Boyle and Dwight [121] (dotted lines)

Figure 13 through Figure 21 show the isothermal sections of O'Boyle and Dwight [121] with compositions of the INL samples shown in colors corresponding to those in Figure 6. The diagrams show numerous phases with narrow composition ranges, which are probably not known to the accuracy implied by the diagrams. There are also several areas where four-phase reactions are indicated. Further research on the U-Pu-Zr phase diagram is clearly needed, particularly at relatively low temperatures. 


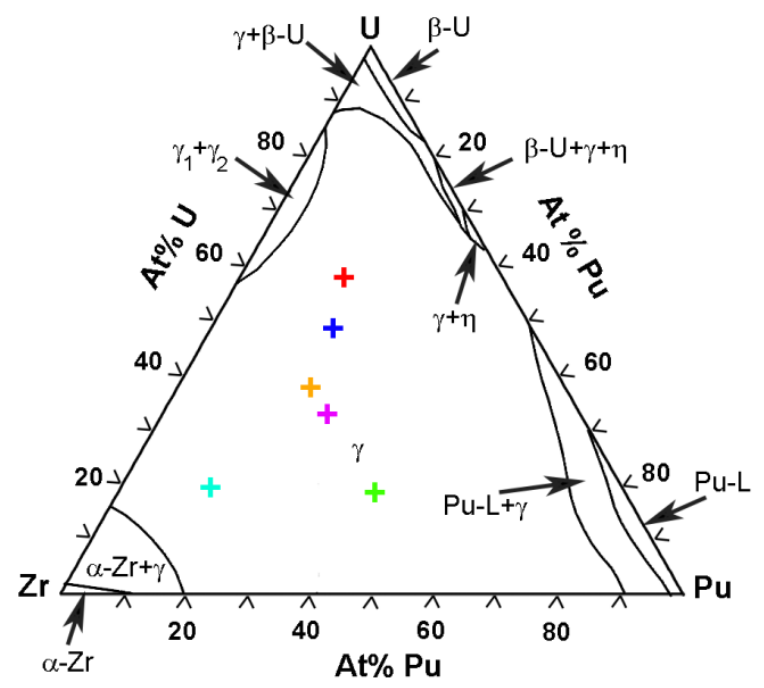

Figure 13. Isothermal section of the U-Pu-Zr phase diagram at $700^{\circ} \mathrm{C}[121]$

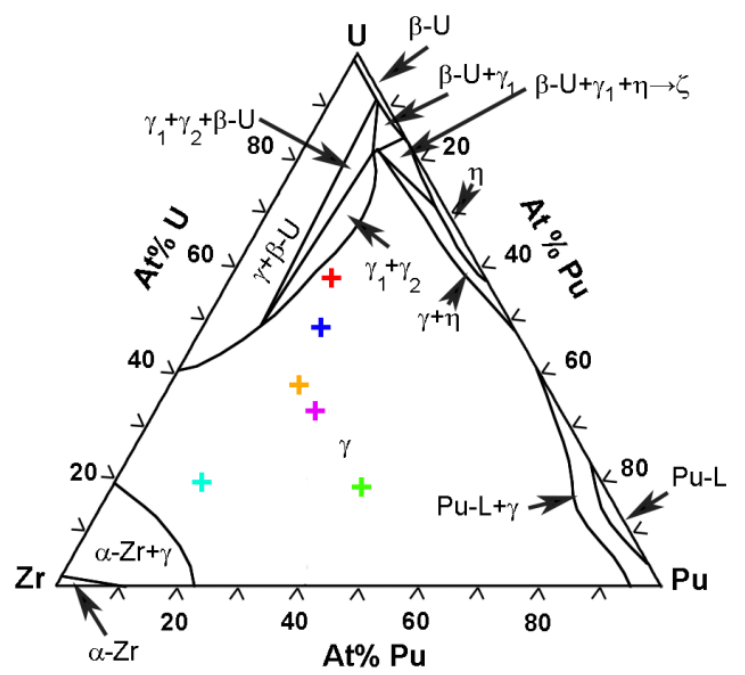

Figure 14. Isothermal section of the U-Pu-Zr phase diagram at $670^{\circ} \mathrm{C}[121]$ 


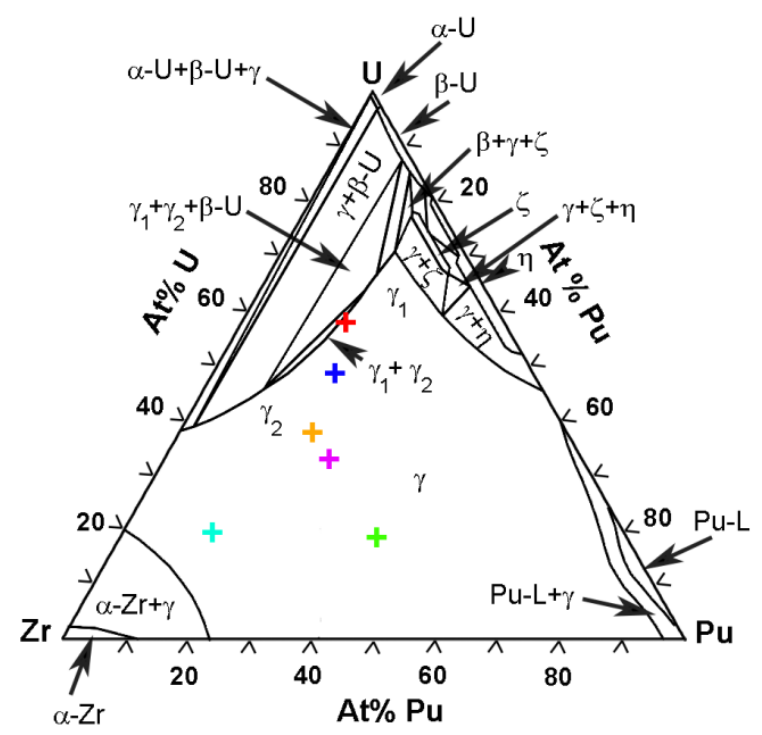

Figure 15. Isothermal section of the U-Pu-Zr phase diagram at $660^{\circ} \mathrm{C}[121]$

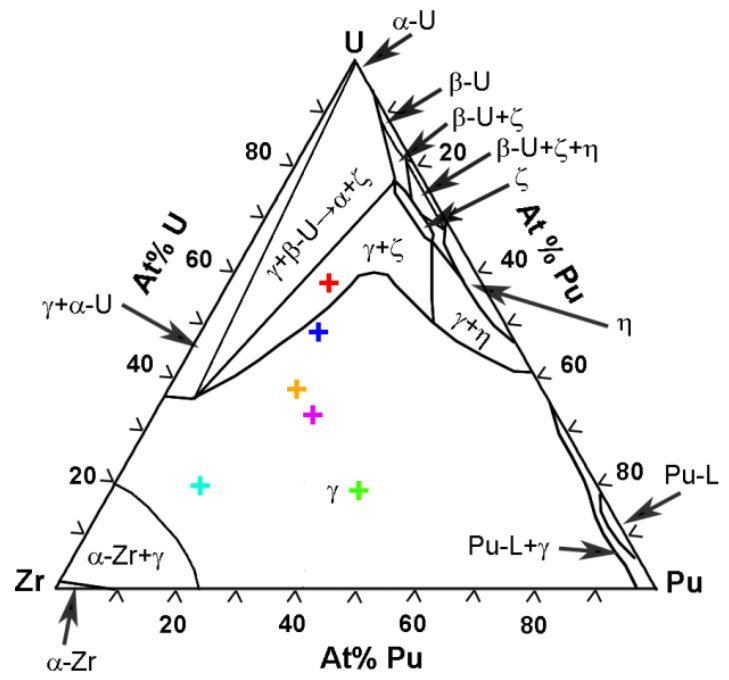

Figure 16. Isothermal section of the U-Pu-Zr phase diagram at $650^{\circ} \mathrm{C}[121]$ 


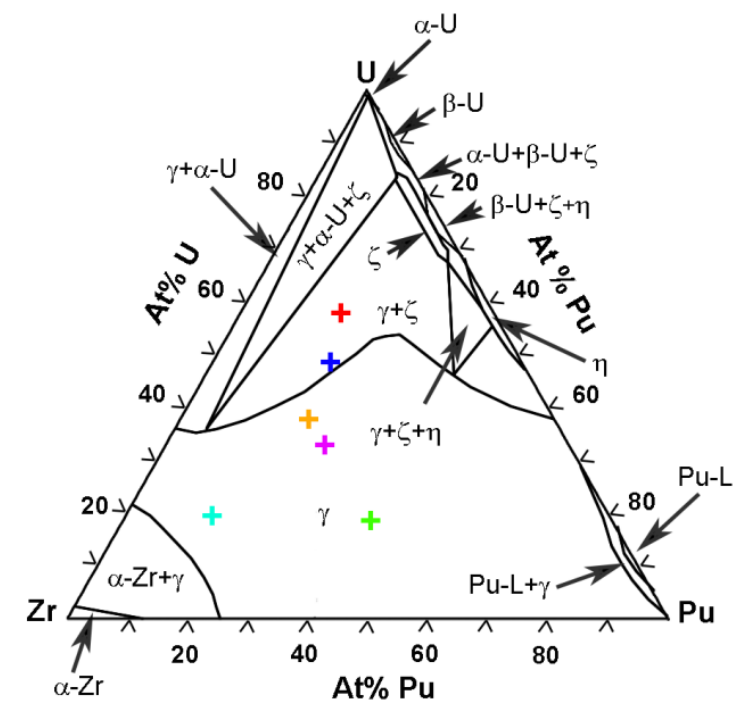

Figure 17. Isothermal section of the U-Pu-Zr phase diagram at $640^{\circ} \mathrm{C}$ [121]

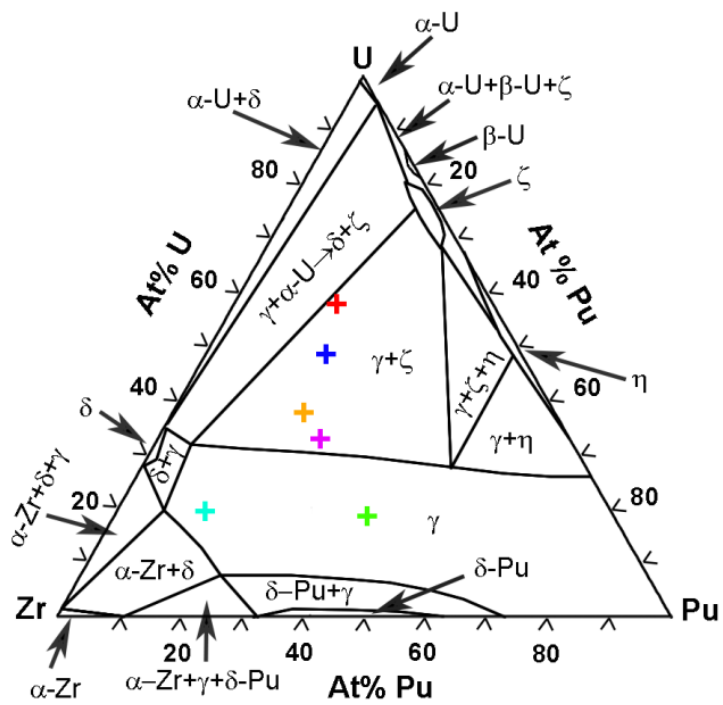

Figure 18. Isothermal section of the U-Pu-Zr phase diagram at $595^{\circ} \mathrm{C}$ [121] 


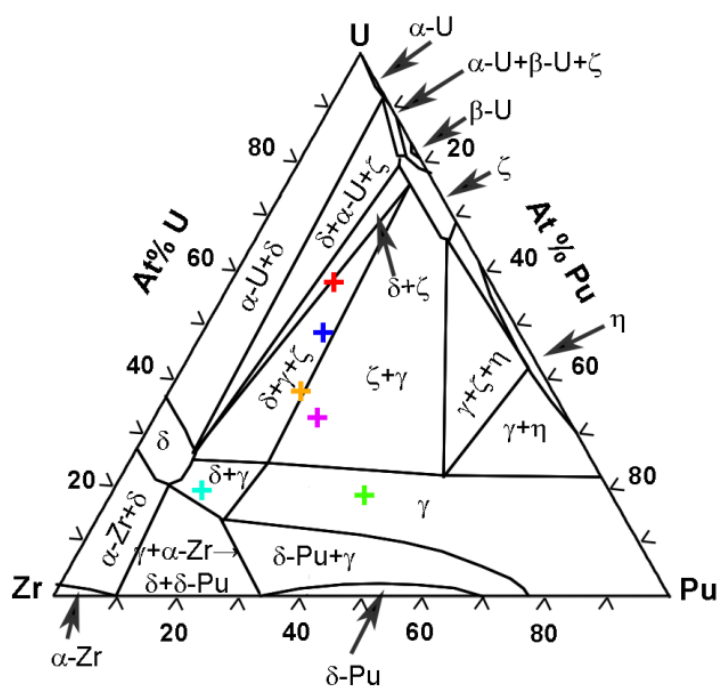

Figure 19. Isothermal section of the U-Pu-Zr phase diagram at $580^{\circ} \mathrm{C}[121]$

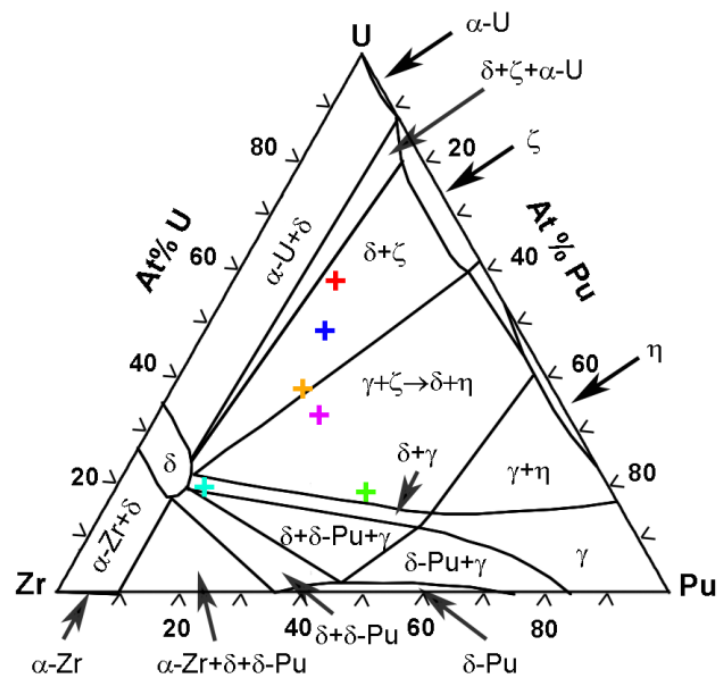

Figure 20. Isothermal section of the U-Pu-Zr phase diagram at $550^{\circ} \mathrm{C}$ [121] 


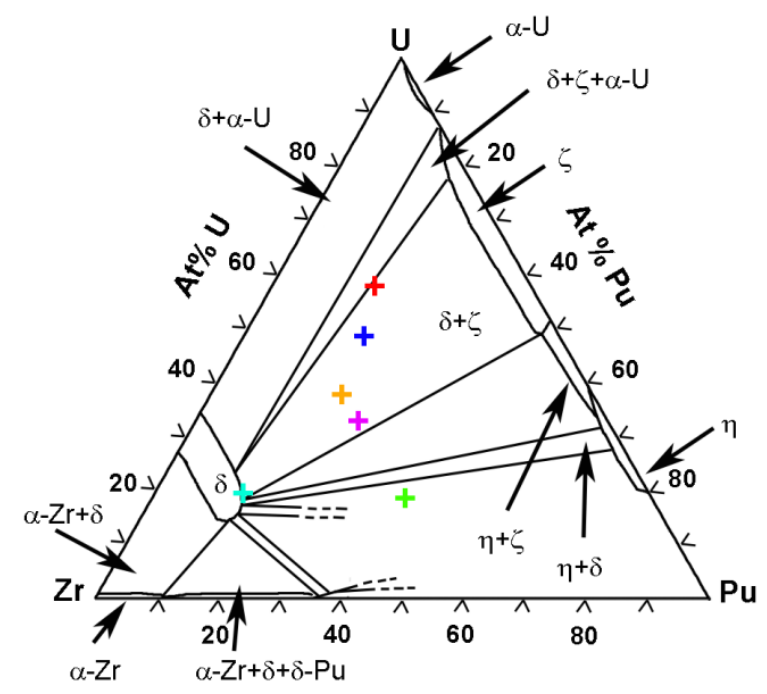

Figure 21. Isothermal section of the U-Pu-Zr phase diagram at $500^{\circ} \mathrm{C}$ [121] 


\subsection{HEAT CAPACITY AND RELATED PROPERTIES (ENTROPY, ENTHALPY, SPECIFIC HEAT CAPACITY)}

\subsubsection{U}

\subsubsection{Introduction}

The heat capacity of $U$ has been extensively studied, with most measurements originally published between 1947 and 1980 and independent critical reviews of the available data in 1976 and 2010 [2, 4]. Recommended values for the heat capacity of $\alpha-U$ are similar in both reviews. Although both agree that the heat capacities of $\beta-U$ and liquid $U$ are independent of temperature, their recommended values differ by $5-10 \%$. The reviews also disagree about the possible temperature dependence of the heat capacity of $\gamma$-U. The major reason for the differences between the reviews is that the 1976 review [4] used primarily measurements of heat capacity, while the 2010 review [2] also considered measurements of incremental enthalpy. The recommendations of the 2010 review are presented here and were reprinted in reference [3]; recommendations from the 1976 review can be found in a number of sources (e.g., [4, 20, 136]).

The standard enthalpy of solid U, standard entropy of uranium gas, and enthalpy of formation of uranium gas are generally accepted values (e.g., [2]). They are:

- $\mathrm{S}^{0}(298.15 \mathrm{~K})=50.20 \pm 0.20 \mathrm{~J} / \mathrm{mol} \cdot \mathrm{K}$ for $\alpha-\mathrm{U}$

- $\mathrm{S}^{0}(298.15 \mathrm{~K})=199.79 \pm 0.10 \mathrm{~J} / \mathrm{mol} \cdot \mathrm{K}$ for $\mathrm{U}$ gas

- $\Delta_{\mathrm{f}} H^{0}(298.15 \mathrm{~K})=533 \pm 8 \mathrm{~kJ} / \mathrm{mol}$ for $\mathrm{U}$ gas

\subsubsection{Heat Capacities of Solid and Liquid Phases}

Major reviews and assessments of data on the heat capacity of $U$ include those by Oetting et al. [4] as part of an IAEA series on the chemical thermodynamics of actinide elements and compounds and by Konings and Beneš [2] as part of a recent critical review of thermodynamic properties of lanthanide and actinide metals. Grenthe et al. [20] fitted a new polynomial to the $\alpha-U$ data of Oetting et al. in their review of chemical thermodynamics for NEA/OECD, and Konings et al. [3] followed Konings and Beneš in a recent review of nuclear materials.

Figure 22 shows the heat capacities for solid and liquid $U$ recommended by Oetting et al. [4] and by Konings and Beneš [2]. As shown in the figure, both reviews recommend similar values for the heat capacity of $\alpha$-U at temperatures above $\sim 300 \mathrm{~K}$. The heat capacity of $\beta-\mathrm{U}$ in reference [2] is almost $10 \%$ larger than that in reference [4] (47.12 vs $42.3 \mathrm{~J} / \mathrm{mol} \cdot \mathrm{K})$, and the heat capacity of liquid $\mathrm{U}$ is almost $5 \%$ smaller $(46.45 \mathrm{vs} 48.69 \mathrm{~J} / \mathrm{mol} \cdot \mathrm{K})$. The average values for the heat capacity of $\gamma$-U are similar in both reviews (38.31 J/mol $\cdot \mathrm{K}$ in reference [4] and 39.05 J/mol $\cdot \mathrm{K}$ in reference [2]), although reference [4] suggests that the heat capacity of this phase is independent of temperature and reference [2] indicates that it is not.

Almost all of the original data on heat capacities and incremental enthalpies of solid and liquid $U$ were originally published between about 1947 and 1980. However, Oetting et al. [4] considered primarily measurements of heat capacity, while Konings and Beneš [2] also considered measurements of incremental enthalpy. In the absence of further experimental data, it seems reasonable to consider the recommendations of Konings and Beneš (Equation 10 through Equation 13) to be a more accurate representation of the heat capacities of solid and liquid $U$ phases than the recommendations of Oetting et al. because Konings and Beneš considered a larger amount of data collected using a wider variety of measurement techniques, including some techniques that are well-suited to collecting high-temperature data. 


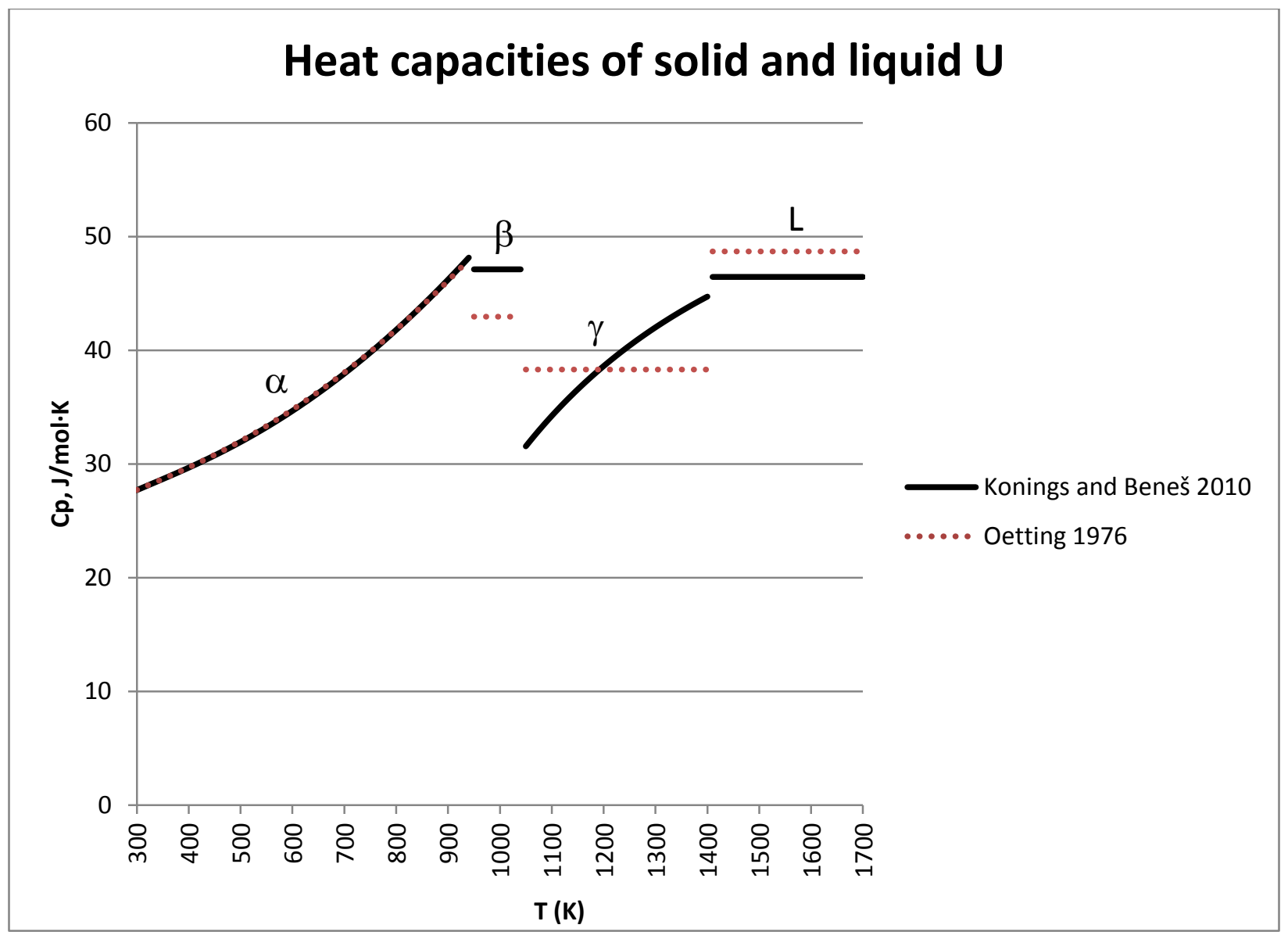

Figure 22. Heat capacities of solid and liquid U. Values from Konings and Beneš [2] (Equation 10, Equation 11, Equation 12, and Equation 13) are preferred.

Equation 10. Heat capacity of $\alpha-U[2]$

$\mathrm{C}_{\mathrm{p}}=28.4264-6.9587 \times 10^{-3} \times \mathrm{T}+29.8744 \times 10^{-6} \times \mathrm{T}^{2}-0.11888 \times 10^{6} \times \mathrm{T}^{-2}$

where $\mathrm{C}_{\mathrm{p}}$ is constant-pressure heat capacity in $\mathrm{J} / \mathrm{mol} \cdot \mathrm{K}$ and $\mathrm{T}$ is temperature in $\mathrm{K}$

Equation 11. Heat capacity of $\beta-U$ [2]

$\mathrm{C}_{\mathrm{p}}=47.12$

where $\mathrm{C}_{\mathrm{p}}$ is constant-pressure heat capacity in $\mathrm{J} / \mathrm{mol} \cdot \mathrm{K}$

Equation 12. Heat capacity of $\gamma-\mathrm{U}[2]$

$\mathrm{C}_{\mathrm{p}}=61.6420-33.1644 \times 10^{6} \times \mathrm{T}^{-2}$

where $C_{p}$ is constant-pressure heat capacity in $\mathrm{J} / \mathrm{mol} \cdot \mathrm{K}$ and $\mathrm{T}$ is temperature in $\mathrm{K}$

Equation 13. Heat capacity of liquid U [2]

$\mathrm{C}_{\mathrm{p}}($ liquid $\mathrm{U})=46.45$ 
where $\mathrm{C}_{\mathrm{p}}$ is constant-pressure heat capacity in $\mathrm{J} / \mathrm{mol} \cdot \mathrm{K}$

\subsubsection{Heat Capacity of the Ideal Gas}

Oetting et al. [4] calculated the heat capacity of uranium as an ideal gas from information on electronic levels available before 1975. They tabulated values at temperatures from 0 to $6000 \mathrm{~K}$, although they described their values above $2000 \mathrm{~K}$ as "interim." Grenthe et al. [20] fitted a polynomial to Oetting's values for temperatures from 298.15 to $2500 \mathrm{~K}$. More recently, Konings and Beneš [2] re-calculated the heat capacity of uranium gas, using newer data and a larger number of electronic energy levels, and fitted it with two polynomials (Equation 14 and Equation 15).

As shown in Figure 23, the two sets of data agree to within $\sim 1 \%$ for temperatures between $\sim 300$ and $2000 \mathrm{~K}$. If heat capacities above $4000 \mathrm{~K}$ are required, the "interim" values of Oetting et al. [4 Table A1.6] are the only available values.

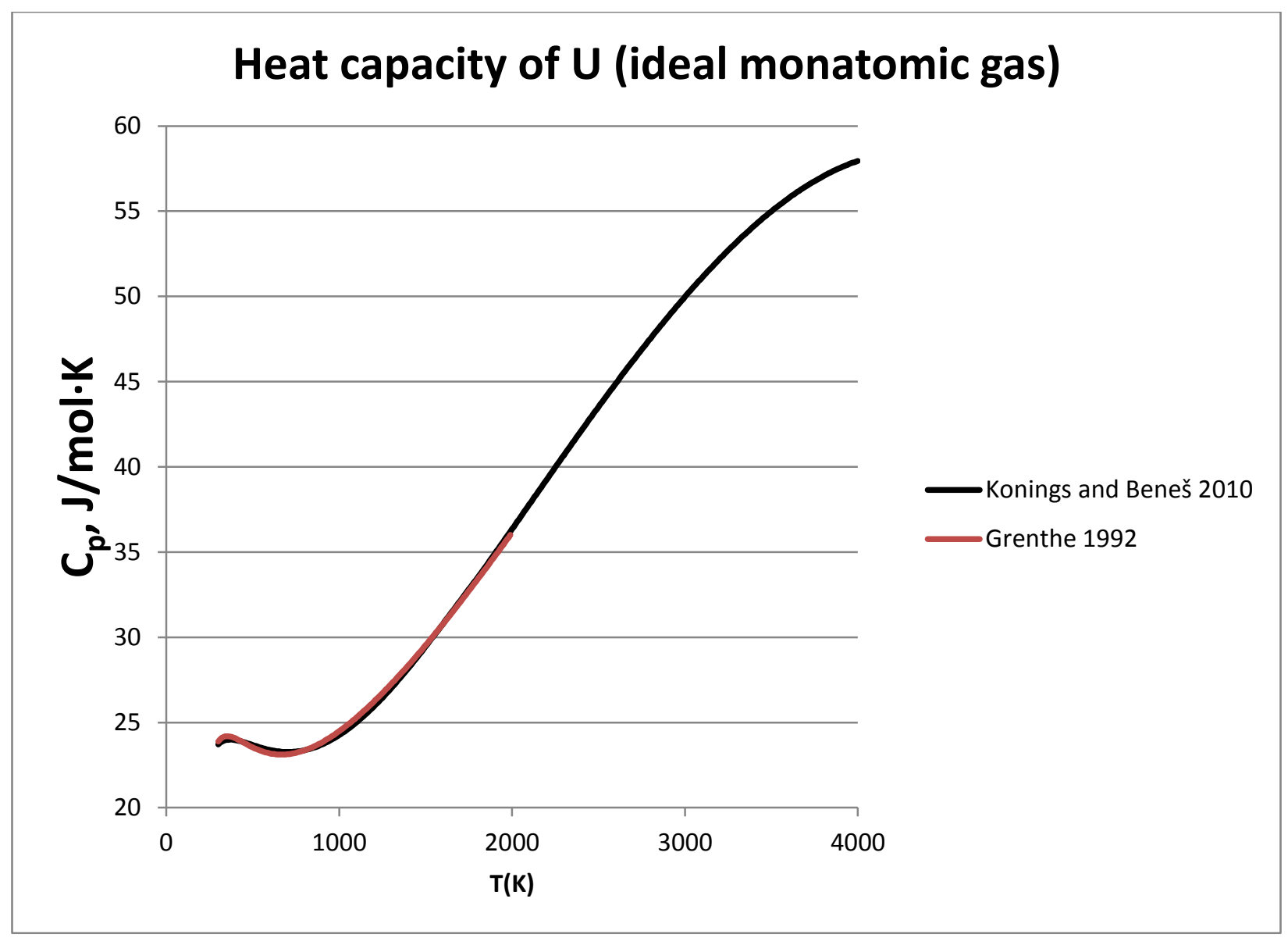

Figure 23. Heat capacity of $U$ as an ideal gas. Values from Konings and Beneš were calculated from Equation 14and Equation 15.

Equation 14. Heat capacity of $\mathrm{U}$ gas from 298.15 to $1800 \mathrm{~K}$ [2]

$$
\mathrm{C}_{\mathrm{p}}=35.1688-32.2466 \times 10^{-3} \times \mathrm{T}+27.0474 \times 10^{-6} \times \mathrm{T}^{2}-5.3433 \times 10^{-9} \times \mathrm{T}^{3}-3.6652 \times 10^{5} \times \mathrm{T}^{-2}
$$


where $\mathrm{C}_{\mathrm{p}}$ is constant-pressure heat capacity in $\mathrm{J} / \mathrm{mol} \cdot \mathrm{K}$, $\mathrm{T}$ is temperature in $\mathrm{K}$, and $\mathrm{T}$ is between 298.15 and $1800 \mathrm{~K}$

Equation 15. Heat capacity of U gas from 1800 to $4000 \mathrm{~K}$ [2]

$$
\mathrm{C}_{\mathrm{p}}=4.9298+10.4892 \times 10^{-3} \times \mathrm{T}+3.7043 \times 10^{-6} \times \mathrm{T}^{2}-0.7598 \times 10^{-9} \times \mathrm{T}^{3}+6.8108 \times 10^{6} \times \mathrm{T}^{-2}
$$

where $C_{p}$ is constant-pressure heat capacity in $\mathrm{J} / \mathrm{mol} \cdot \mathrm{K}$, $\mathrm{T}$ is temperature in $\mathrm{K}$, and $\mathrm{T}$ is between 1800 and $4000 \mathrm{~K}$

\subsubsection{Pu}

\subsubsection{Introduction}

Numerous researchers have studied the heat capacity of $\mathrm{Pu}$, with most results originally published before 1984. Major reviews were published by Oetting et al. [4] as part of an IAEA series on the chemical thermodynamics of actinide elements and compounds and Konings and Beneš [2] as part of a recent critical review of thermodynamic properties of lanthanide and actinide metals. The data of Oetting et al. [4] are no longer commonly used because of later experimental results obtained by Oetting and Adams [137], which are quoted by later reviews including those of Lemire et al. [30] for NEA/OECD and Konings and Beneš [2]. Key results from Konings and Beneš [2] were repeated in a recent review of nuclear materials by Konings et al. [3].

The standard enthalpy of solid $\mathrm{Pu}$ at $298.15 \mathrm{~K}$, standard entropy of Pu gas, and enthalpy of formation of $\mathrm{Pu}$ gas are:

- $\mathrm{S}^{0}(298.15 \mathrm{~K})=54.46 \pm 0.80 \mathrm{~J} / \mathrm{mol} \cdot \mathrm{K}$ for $\alpha-\mathrm{Pu}[2,30]$

- $\mathrm{S}^{0}(298.15 \mathrm{~K})=177.19 \pm 0.10 \mathrm{~J} / \mathrm{mol} \cdot \mathrm{K}$ for $\mathrm{Pu}$ gas [2]

- $\Delta_{\mathrm{f}} H^{0}(298.15 \mathrm{~K})=348.9 \pm 3.0 \mathrm{~kJ} / \mathrm{mol}$ for Pu gas [2].

\subsubsection{Heat Capacities of Solid and Liquid Phases}

Figure 24 shows the heat capacities for solid and liquid $\mathrm{Pu}$ recommended by Lemire et al. [30] and by Konings and Beneš [2]. These reviews have identical heat capacities for $\beta$-, $\gamma$-, and $\delta$-Pu because both are quoting equations from Oetting and Adams [137]. The heat capacity for $\alpha-\mathrm{Pu}$ is also based on the work of Oetting and Adams, except that Konings and Beneš adjusted it slightly upward to match their preferred values for lower-temperature measurements. Heat capacities for $\delta^{\prime}$ and $\varepsilon$-Pu are identical in both reviews because they are originally from a Mound Laboratory report by Wittenberg et al. (reference [138]). The heat capacity for liquid Pu recommended by Konings and Beneš is also from the report by Wittenberg et al., and the source of the heat capacity for liquid Pu recommended by Lemire et al. is not specified. The preferred values (from reference [2]) are expressed by Equation 16 through Equation 22.

Measurement of low-temperature heat capacities in $\alpha-\mathrm{Pu}$ is complicated by radioactive self-heating. This effect does not affect the data presented here because defects are sufficiently mobile at room temperature and above to heal the damage rapidly enough that it does not affect measurements [22].

Equation 16. Heat capacity of $\alpha-\mathrm{Pu}([2]$ with temperature range from [137])

$$
\mathrm{C}_{\mathrm{p}}=17.6186+45.5523 \times 10^{-3} \times \mathrm{T}
$$

where $C_{p}$ is constant-pressure heat capacity in $\mathrm{J} / \mathrm{mol} \cdot \mathrm{K}, \mathrm{T}$ is temperature in $\mathrm{K}$, and $\mathrm{T}$ is between 330 and $390 \mathrm{~K}$ 
Equation 17. Heat capacity of $\beta-\mathrm{Pu}[2,30,137]$

$\mathrm{C}_{\mathrm{p}}=27.4160+13.060 \times 10^{-3} \times \mathrm{T}$

where $C_{p}$ is constant-pressure heat capacity in $\mathrm{J} / \mathrm{mol} \cdot \mathrm{K}, \mathrm{T}$ is temperature in $\mathrm{K}$, and $\mathrm{T}$ is between 408 and $476 \mathrm{~K}$

Equation 18. Heat capacity of $\gamma-\mathrm{Pu}[2,30,137]$

$\mathrm{C}_{\mathrm{p}}=22.0233+22.959 \times 10^{-3} \times \mathrm{T}$

where $\mathrm{C}_{\mathrm{p}}$ is constant-pressure heat capacity in $\mathrm{J} / \mathrm{mol} \cdot \mathrm{K}, \mathrm{T}$ is temperature in $\mathrm{K}$, and $\mathrm{T}$ is between 493 and $586 \mathrm{~K}$

Equation 19. Heat capacity of $\delta$-Pu $[2,30,137]$

$\mathrm{C}_{\mathrm{p}}=28.4781+10.807 \times 10^{-3} \times \mathrm{T}$

where $\mathrm{C}_{\mathrm{p}}$ is constant-pressure heat capacity in $\mathrm{J} / \mathrm{mol} \cdot \mathrm{K}, \mathrm{T}$ is temperature in $\mathrm{K}$, and $\mathrm{T}$ is between 602 and $680 \mathrm{~K}$

Equation 20. Heat capacity of $\delta^{\prime}-\mathrm{Pu}[2,30]$

$\mathrm{C}_{\mathrm{p}}=35.56$

where $\mathrm{C}_{\mathrm{p}}$ is constant-pressure heat capacity in $\mathrm{J} / \mathrm{mol} \cdot \mathrm{K}$ and $\mathrm{T}$ is temperature in $\mathrm{K}$

Equation 21. Heat capacity of $\varepsilon-\mathrm{Pu}[2,30]$

$\mathrm{C}_{\mathrm{p}}(\varepsilon-\mathrm{Pu})=33.72$

where $\mathrm{C}_{\mathrm{p}}$ is constant-pressure heat capacity in $\mathrm{J} / \mathrm{mol} \cdot \mathrm{K}$ and $\mathrm{T}$ is temperature in $\mathrm{K}$

Equation 22. Heat capacity of liquid $\mathrm{Pu}$ [2]

$\mathrm{C}_{\mathrm{p}}($ liquid $\mathrm{Pu})=42.80$

where $C_{p}$ is constant-pressure heat capacity in $\mathrm{J} / \mathrm{mol} \cdot \mathrm{K}$ and $\mathrm{T}$ is temperature in $\mathrm{K}$ 


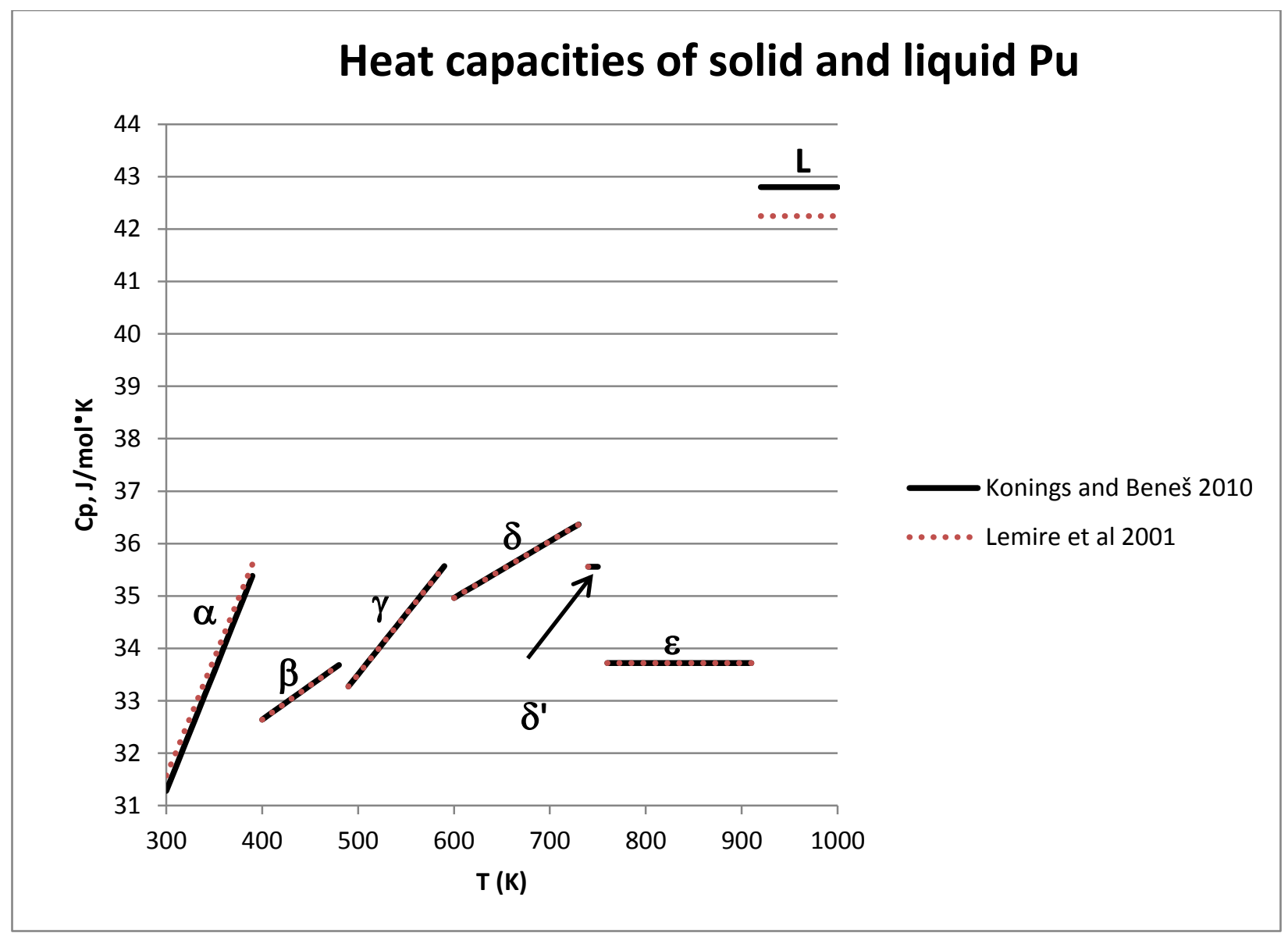

Figure 24. Heat capacities of solid and liquid Pu. Values from Konings and Beneš [2] (solid black lines, Equation 16 through Equation 22) are preferred

\subsubsection{Heat Capacity of the Ideal Gas}

Konings and Beneš [2] calculated the heat capacity of ${ }^{239} \mathrm{Pu}$ as an ideal gas and fitted the heat capacity by two polynomials (Figure 25, Equation 23, and Equation 24). These polynomials match those calculated from a similar database at temperatures up to $2000 \mathrm{~K}$ by Lemire et al. [30] to within a few hundredths of a $\mathrm{J} / \mathrm{mol} \cdot \mathrm{K}$. 


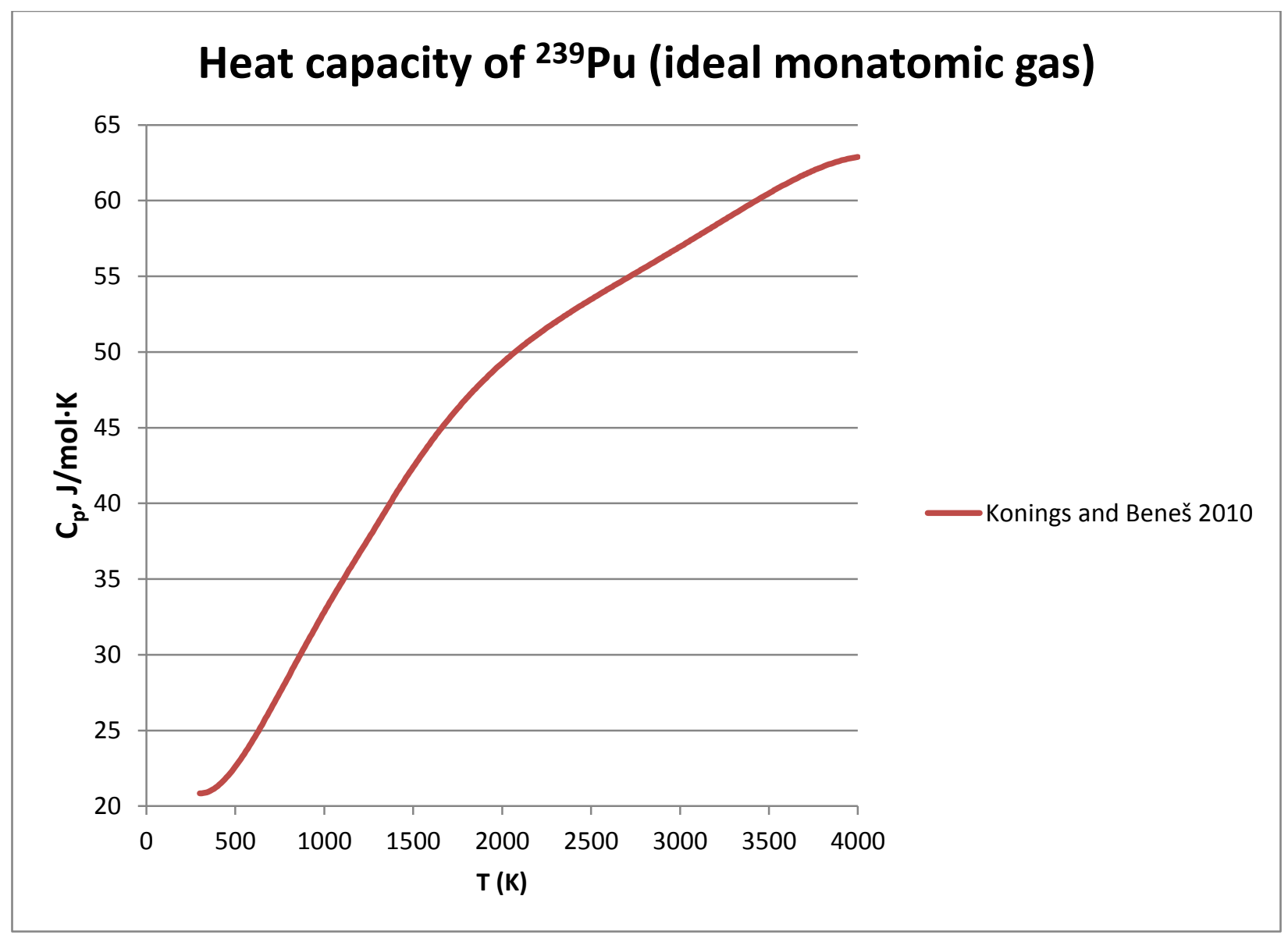

Figure 25. Heat capacity of 239Pu as an ideal gas, calculated using Equation 23 and Equation 24

Equation 23. Heat capacity of Pu gas from 298.15 to $1400 \mathrm{~K}$ [2]

$\mathrm{C}_{\mathrm{p}}=24.2954-37.0413 \times 10^{-3} \times \mathrm{T}+95.1224 \times 10^{-6} \times \mathrm{T} 2-65.8404 \times 10^{-9} \times \mathrm{T}^{3}+$ $16.2344 \times 10^{-12} \times \mathrm{T}^{4}+6.7865 \times 10^{4} \times \mathrm{T}^{-2}$

where $\mathrm{C}_{\mathrm{p}}$ is constant-pressure heat capacity in $\mathrm{J} / \mathrm{mol} \cdot \mathrm{K}$, $\mathrm{T}$ is temperature in $\mathrm{K}$, and $\mathrm{T}$ is between 298.15 and $1400 \mathrm{~K}$

Equation 24. Heat capacity of Pu gas from 1400 to $4000 \mathrm{~K}$ [2]

$\mathrm{C}_{\mathrm{p}}=-112.0172+187.5714 \times 10^{-3} \times \mathrm{T}-86.6780 \times 10^{-6} \times \mathrm{T}^{2}+18.8245 \times 10^{-9} \times \mathrm{T}^{3}-$ $1.5431 \times 10^{-12} \times \mathrm{T}^{4}+2.7817 \times 10^{7} \mathrm{~T}^{-2}$

where $\mathrm{C}_{\mathrm{p}}$ is constant-pressure heat capacity in $\mathrm{J} / \mathrm{mol} \cdot \mathrm{K}, \mathrm{T}$ is temperature in $\mathrm{K}$, and $\mathrm{T}$ is between 1400 and $4000 \mathrm{~K}$

\subsubsection{Zr}

\subsubsection{Introduction}

Many measurements of the heat capacities of $\alpha$ - and $\beta$ - $\mathrm{Zr}$ have been made. Recommended values in the NIST-JANAF tables and recent IAEA publications $[139,140]$ differ by a few $\mathrm{J} / \mathrm{mol} \cdot \mathrm{K}$ for $\alpha-\mathrm{Zr}$, with much smaller differences for $\beta-Z r$. 
The heat capacity of liquid $\mathrm{Zr}$ has been measured at temperatures as high as $2200 \mathrm{~K}$, and the heat capacity of the ideal monatomic gas has been calculated $[39,139]$. These values are not presented here because of their limited relevance for FCRD fuels.

\subsubsection{Heat Capacities of Solid Phases}

Measurements of the heat capacity of solid Zr were reviewed by Milošević \& Maglić [141] and show generally good agreement. Values recommended by the IAEA [140] for $\alpha-\mathrm{Zr}$ are slightly higher than those in the NIST-JANAF tables [139] (Figure 26), for reasons that are not clear.

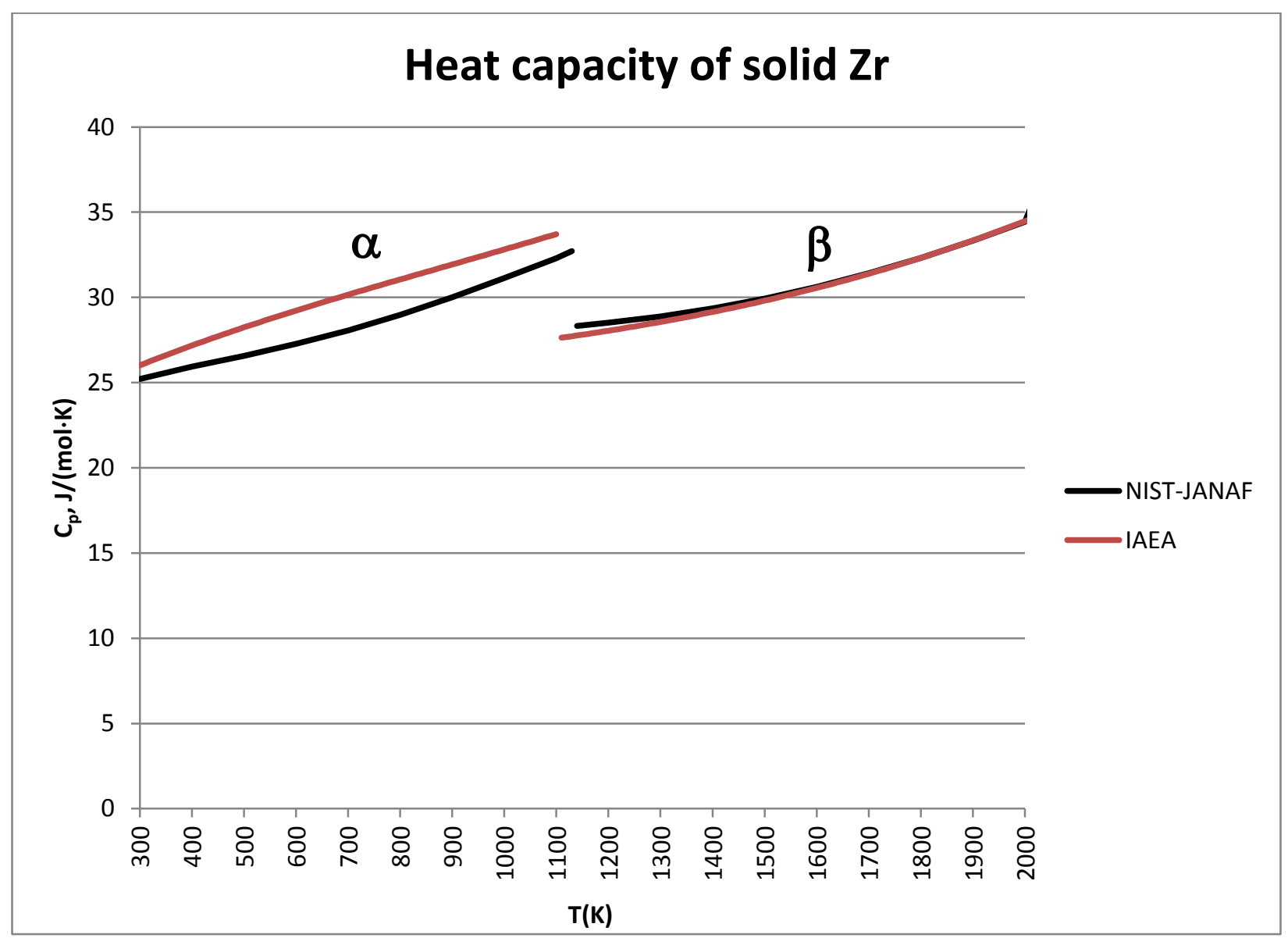

Figure 26. Heat capacities of solid Zr phases (IAEA data calculated using Equation 25 and Equation 26)

The IAEA heat-capacity values can be calculated using Equation 25 and Equation 26. These equations express heat capacity in $\mathrm{J} /(\mathrm{kg} \cdot \mathrm{K})$, which can be converted to $\mathrm{J} /(\mathrm{mol} \cdot \mathrm{K})$ by multiplying by 0.09122 (the molar weight of $\mathrm{Zr}$, expressed in $\mathrm{kg}$ ). Corresponding equations for the NIST-JANAF heat-capacity values have not been published.

Equation 25. Heat capacity of $\alpha-Z r$ from 298 to $1100 \mathrm{~K}$ [140]

$$
\mathrm{C}_{\mathrm{p}}=238.596+0.181 \times \mathrm{T}-96.1 \times 10^{-6} \times \mathrm{T}^{2}+36.2 \times 10^{-9} \times \mathrm{T}^{3}
$$


where $\mathrm{C}_{\mathrm{p}}$ is constant-pressure heat capacity in $\mathrm{J} / \mathrm{kg} \cdot \mathrm{K}, \mathrm{T}$ is temperature in $\mathrm{K}$, and $\mathrm{T}$ is between 298 and $1100 \mathrm{~K}$

Equation 26. $\mathrm{C}_{\mathrm{p}}$ of $\alpha-\mathrm{Zr}$ from 1100 to $2128 \mathrm{~K}$ [140]

$\mathrm{C}_{\mathrm{p}}=276.462+0.0141 \times \mathrm{T}-3.08 \times 10^{-6} \times \mathrm{T}^{2}+10.7 \times 10^{-9} \times \mathrm{T}^{3}$

where $\mathrm{C}_{\mathrm{p}}$ is constant-pressure heat capacity in $\mathrm{J} / \mathrm{kg} \cdot \mathrm{K}, \mathrm{T}$ is temperature in $\mathrm{K}$, and $\mathrm{T}$ is between 1100 and $2128 \mathrm{~K}$

\subsubsection{U-Zr Alloys}

\subsubsection{Introduction}

Although a number of researchers have measured heat capacities of $\mathrm{U}-\mathrm{Zr}$ alloys at temperatures between $\sim 300$ and $850 \mathrm{~K}$, measured heat capacities of alloys with similar compositions made by different research groups may differ by $20-30 \%$. When measurements of different compositions made by a single research group are compared, heat capacities decrease with increasing concentration of $\mathrm{Zr}$.

Heat capacities between $\sim 850$ and $1000 \mathrm{~K}$ ( $~ 850$ and $900 \mathrm{~K}$ for high-Zr compositions) are highly dependent on composition because of phase transformations, and cannot be represented by smoothed values.

Heat capacities of $(\gamma-\mathrm{U}, \beta-\mathrm{Zr})$ solid solutions are only slightly dependent on temperature.

\subsubsection{Heat Capacities Below $850 \mathrm{~K}$}

Heat capacities of U-Zr alloys reported by Fedorov and Smirnov [142] were generally accepted until the late 1980s (e.g., [41, 87]). Later experimental work by Matsui et al. [86] and Takahashi et al. [85] suggested that these heat capacities were too high. More recent heat-capacity measurements of alloys with 6 and $7 \mathrm{wt} \% \mathrm{Zr}(\sim 14$ and 16.4 at\% Zr) [84, 143] are higher than those from Matsui et al. and Takahashi et al. [85, 86], and are higher than those of Federov and Smirnov [142] for alloys with similar compositions at some temperatures. Comparisons of heat capacity values from different compositions measured by the same research groups $[85,142]$ both indicate that heat capacities of U-Zr alloys decrease with increases in the concentration of $\mathrm{Zr}$.

Figure 27 shows measured heat capacities for U-Zr alloys with 13-41 at $\% \mathrm{Zr}$ at temperatures between 300 and $850 \mathrm{~K}$. Values for alloys with similar compositions measured by different research groups (e.g., 14 at\% Zr [85], 14.28 at\% Zr [84], and 16.4 at\% Zr [143]) differ by 20 - 30\%. Further data are clearly needed to obtain reliable heat-capacity values.

A recent review by Ogata [5] reported that the data of Matsui et al. [86] are in good agreement with a thermodynamic analysis by Kurata et al. [61] for temperatures below $850 \mathrm{~K}$. In the absence of further high-quality measurements, it seems appropriate to use the data of Matsui et al. for U-Zr alloys with less than $\sim 40$ at $\%(\sim 20 \mathrm{wt} \%) \mathrm{Zr}$.

Tabulated data values for the data from Matsui et al. can be found in reference [86]. However, a more convenient approach may be to use a polynomial that Kaity et al. fitted to these data [84] (Equation 27), noting that heat capacity is expressed in $\mathrm{J} / \mathrm{gram} \cdot \mathrm{K}$. 


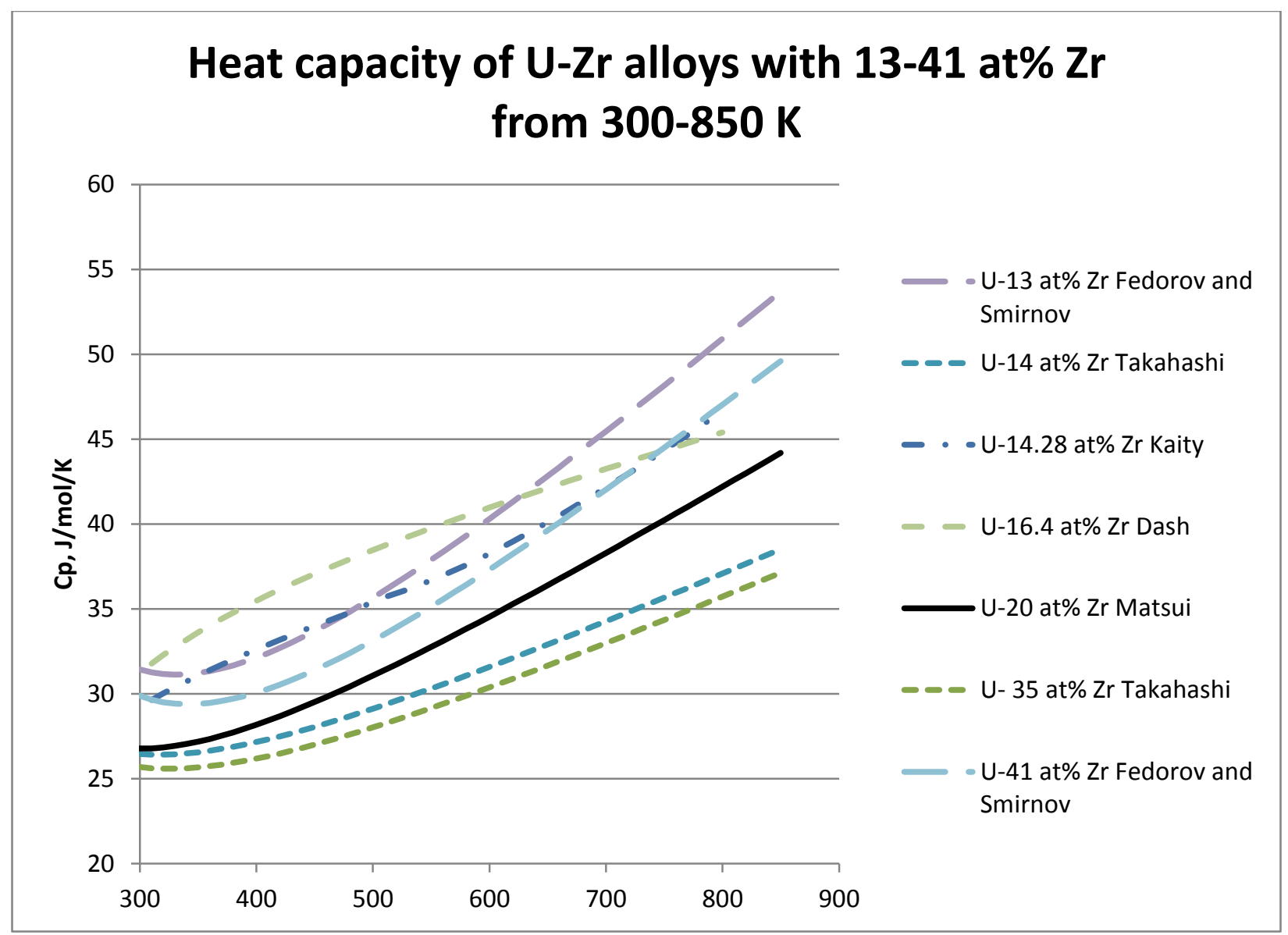

Figure 27. Measured heat capacities for U-Zr alloys with $13-41$ at $\% \mathrm{Zr}(\sim 5.5-21 \mathrm{wt} \% \mathrm{Zr})$ at temperatures from 300-850 K [84-86, 142, 143]. Different line types indicate different references.

Equation 27. Heat capacity of U-20 at $\%$ Zr (U-9 wt \% Zr) alloy from 289 to $852 \mathrm{~K}$ (Polynomial from reference [84], fitting data from reference [86]).

$\mathrm{C}_{\mathrm{p}}=37.99+0.2 \times \mathrm{T}+2.73 \times 10^{6} / \mathrm{T}^{2}$

where $\mathrm{C}_{\mathrm{p}}$ is constant-pressure heat capacity in $\mathrm{J} / \mathrm{gram} \cdot \mathrm{K}$, $\mathrm{T}$ is temperature in $\mathrm{K}$, and $\mathrm{T}$ is between 289 and $852 \mathrm{~K}$

\subsubsection{Heat Capacities between 850 and $1000 \mathrm{~K}$}

Heat capacities are highly dependent on composition and temperature between $\sim 850$ and $1000 \mathrm{~K}$ for samples with high concentrations of $\mathrm{U}$ ( $\sim 850$ and $900 \mathrm{~K}$ for samples with high concentrations of $\mathrm{Zr}$ ) because of phase transformations involved in the formation of $\gamma-(\mathrm{U}, \mathrm{Zr})$. Heat-capacity measurements for specific samples and temperatures can be found in the original references [84-86]. 


\subsubsection{Heat Capacities of $\gamma-(U, Z r)$ Solid Solutions}

Heat capacities of $\gamma-(\mathrm{U}, \mathrm{Zr})$ solid solutions at $1000 \mathrm{~K}$ are summarized in Table 7. Experimental measurements [85, 86, 142] and thermodynamic models [5] show only a limited dependence on temperature. Data from reference [86] appear anomalously high relative to data from reference [85]. Ogata [5] notes that the data of Takahashi et al. [85] are in good agreement with the thermodynamic analysis of Kurata et al. [61] for temperatures above 900K. Although further investigation is required, it seems reasonable to use the data of [85] at this point. It also seems likely that heat capacities in $\gamma-(\mathrm{U}, \mathrm{Zr})$ decrease slightly with increasing concentrations of $\mathrm{Zr}$.

Table 7. Heat capacities of $\gamma-(\mathrm{U}, \mathrm{Zr})$ solid solutions at $1000 \mathrm{~K}$.

\begin{tabular}{cccc}
\hline $\mathrm{At} \% \mathrm{Zr}$ & $\mathrm{Wt} \% \mathrm{Zr}$ & $\begin{array}{c}\mathrm{C}_{\mathrm{p}} \\
(\mathrm{J} / \mathrm{mol} \cdot \mathrm{K})\end{array}$ & Reference \\
\hline 14 & 6 & 35.8 & {$[85]$} \\
20 & 9 & 44.45 & {$[86]$} \\
35 & 17 & 34.3 & {$[85]$} \\
72 & 50 & 31.1 & {$[85]$} \\
91 & 80 & 31.0 & {$[85]$} \\
\hline
\end{tabular}

\subsubsection{Pu-Zr Alloys}

\subsubsection{Introduction}

There are apparently no published measurements of the heat capacity of any Pu-Zr alloy. New INL data was collected using differential scanning calorimetry (DSC) techniques and the resulting data curves were examined to determine specific heat, enthalpy, and phase transition temperatures. Preliminary INL measurements of alloys with 30 and $40 \mathrm{wt} \% \mathrm{Zr}$ indicate that the specific heat of both alloys are similar and that the specific heat of the alloy with $30 \% \mathrm{Zr}$ is lower than that of the alloy with $40 \% \mathrm{Zr}$. Data was collected on a sample of $\mathrm{Pu}-10 \mathrm{wt} \% \mathrm{Zr}$ however only phase transition temperatures could be determined from this sample.

\subsubsection{Heat Capacity}

The measured specific heat data as a function of temperature upon heating and cooling for $\mathrm{Pu}$ with 30 and $40 \mathrm{wt} \% \mathrm{Zr}$ (55 and 65 at\%) are given in Figure 28 (heating) and Figure 29 (cooling). Equation 28 and Equation 29 give second-order polynomial fits to approximate the temperature-dependent specific heat upon heating.

Equation 28. Specific heat of Pu-30Zr alloy from 355-879 K

$$
\mathrm{C}_{\mathrm{p}}=-9 \times 10^{-8} \mathrm{xT}^{2}+2 \times 10^{-6} \mathrm{xT}+0.1821
$$

Where $\mathrm{C}_{\mathrm{p}}$ is the specific heat in $\mathrm{J} / \mathrm{g}-\mathrm{K}$, $\mathrm{T}$ is temperature in $\mathrm{K}$, and $\mathrm{T}$ is between 355 and $879 \mathrm{~K}$. The correlation coefficient $\left(\mathrm{R}^{2}\right)$ for this equation is 0.964 .

Equation 29. Specific heat of $\mathrm{Pu}-40 \mathrm{Zr}$ alloy from $355-879 \mathrm{~K}$

$$
\mathrm{C}_{\mathrm{p}}=-5 \times 10^{-8} \mathrm{xT}^{2}-9 \times 10^{-5} \times \mathrm{T}+0.2468
$$

Where $C_{p}$ is the specific heat in $\mathrm{J} / \mathrm{g}-\mathrm{K}$, $\mathrm{T}$ is temperature in $\mathrm{K}$, and $\mathrm{T}$ is between 355 and $879 \mathrm{~K}$. The correlation coefficient $\left(\mathrm{R}^{2}\right)$ for this equation is 0.960 . 
These equations cover specific heat from approximately room temperature to $880 \mathrm{~K}$ where the heat capacity of these $\mathrm{Pu}-\mathrm{Zr}$ alloys appears to be without phase transitions. Above $880 \mathrm{~K}$ the heat capacity is dependent upon the composition of the alloy due to the $\delta$ - $(\mathrm{Pu}, \mathrm{Zr}) \rightarrow \varepsilon-(\mathrm{Pu}, \mathrm{Zr})$ phase transformation. Therefore, no equation for specific heat in this temperature range was determined.

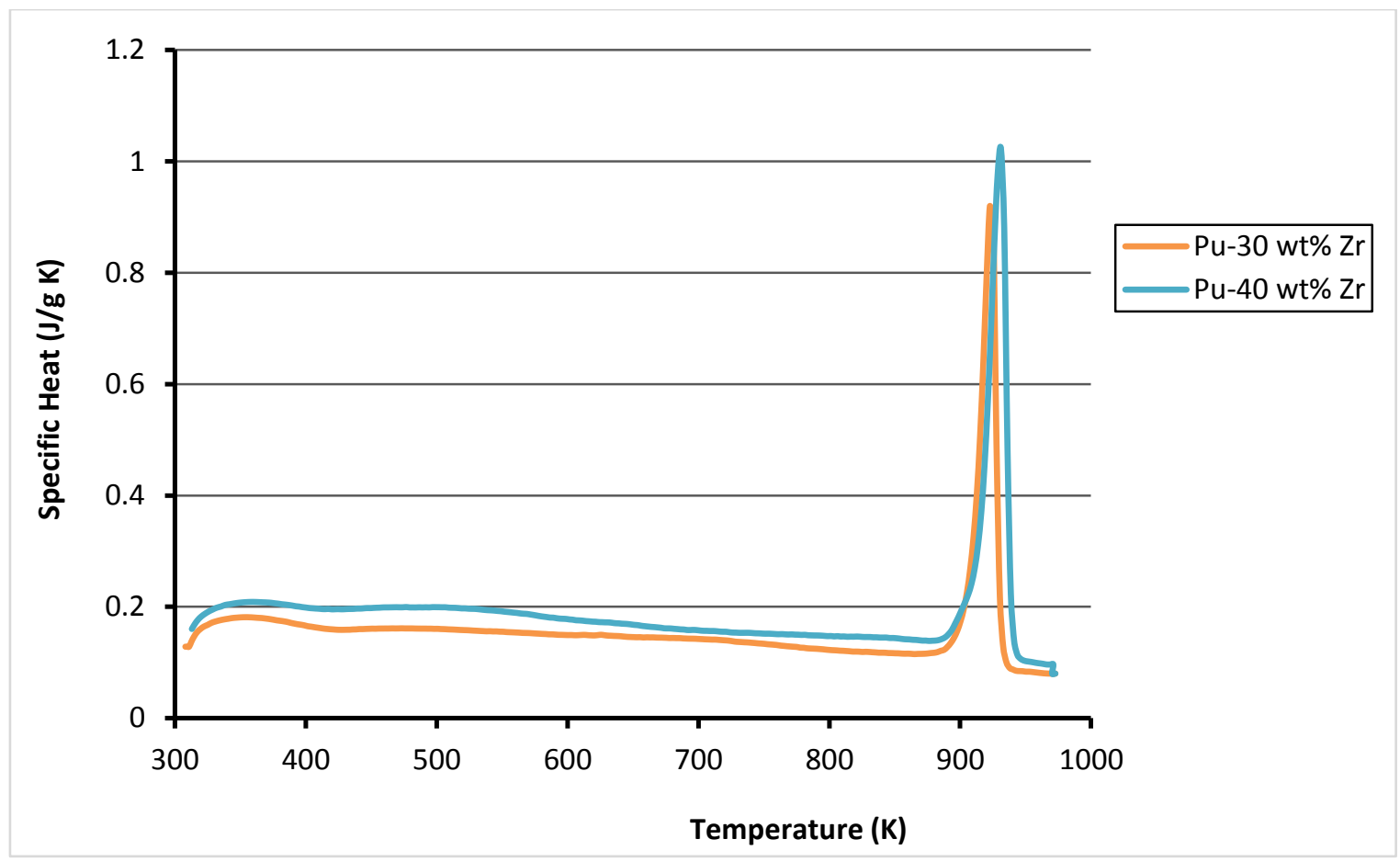

Figure 28. Specific heat (J/g K) of $\mathrm{Pu}-30 \mathrm{wt} \% \mathrm{Zr}$ and $\mathrm{Pu}-40 \mathrm{wt} \% \mathrm{Zr}$ from 300-980 K upon heating at $10 \mathrm{~K} / \mathrm{min}$ 


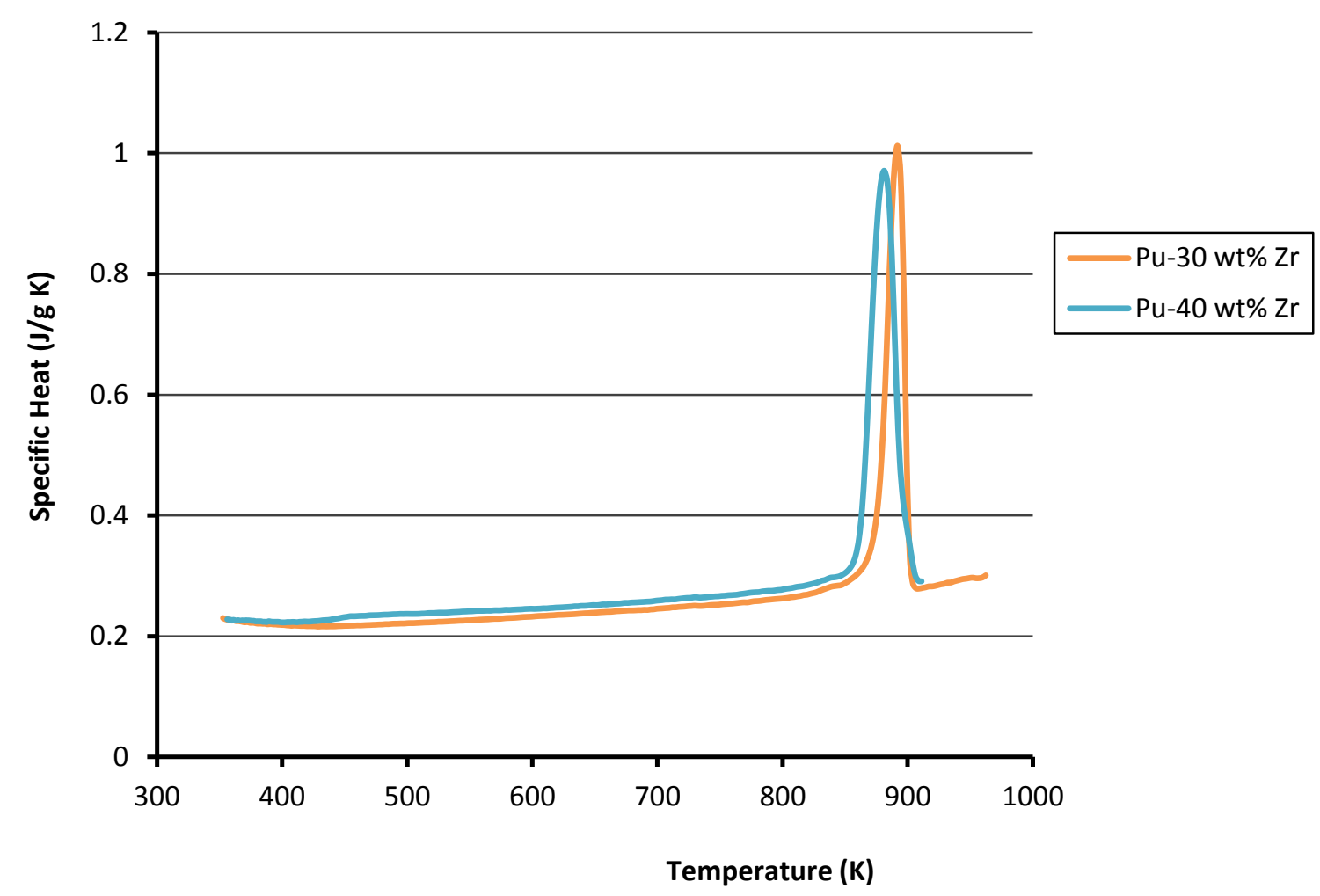

Figure 29. Specific heat (J/g K) of Pu-30 wt $\% \mathrm{Zr}$ and $\mathrm{Pu}-40 \mathrm{wt} \% \mathrm{Zr}$ from 356-962 K upon cooling at $10 \mathrm{~K} / \mathrm{min}$.

The onset and end temperatures of the phase transition peaks agree well with the $\mathrm{Pu}-\mathrm{Zr}$ phase diagram (Section 3.1.5.3). The DSC curve showing these peaks for all alloys is given in Figure 30. For both the $\mathrm{Pu}-30 \mathrm{wt} \% \mathrm{Zr}$ and $\mathrm{Pu}-40 \mathrm{wt} \% \mathrm{Zr}$ alloys, the endothermic peak corresponds to the $\delta$ - $(\mathrm{Pu}, \mathrm{Zr}) \rightarrow \varepsilon-(\mathrm{Pu}, \mathrm{Zr})$ phase transformation, with predicted onset transformation temperatures of around $900 \mathrm{~K}$ and $910 \mathrm{~K}$, respectively. The enthalpies of these transformations $\left(\Delta \mathrm{H}_{\mathrm{tr}}\right)$ are $8.19 \mathrm{~J} / \mathrm{g}$ for Pu-30 wt $\% \mathrm{Zr}$ and $10.37 \mathrm{~J} / \mathrm{g}$ for $\mathrm{Pu}-40 \mathrm{wt} \% \mathrm{Zr}$, respectively.

The $\mathrm{Pu}-10 \mathrm{wt} \% \mathrm{Zr}$ alloy is located at a different region of the phase diagram and is predicted to undergo two phase transformations upon heating from ambient temperature to $980 \mathrm{~K}$, namely $\theta-\mathrm{Pu} \rightarrow$ $\delta$-(Pu,Zr) and $\delta-(\mathrm{Pu}, \mathrm{Zr}) \rightarrow \varepsilon-(\mathrm{Pu}, \mathrm{Zr})$. These are predicted to occur at around $618 \mathrm{~K}$ and $823 \mathrm{~K}$, respectively and the DSC curve confirms this. While the onset and peak temperatures for this alloy generally appear to match well with the predicted phase diagrams, the specific heat values for the Pu-10 $\mathrm{wt} \% \mathrm{Zr}$ alloy were too uncertain to report. Further testing will be performed on this sample to obtain more statistically reliable data. 


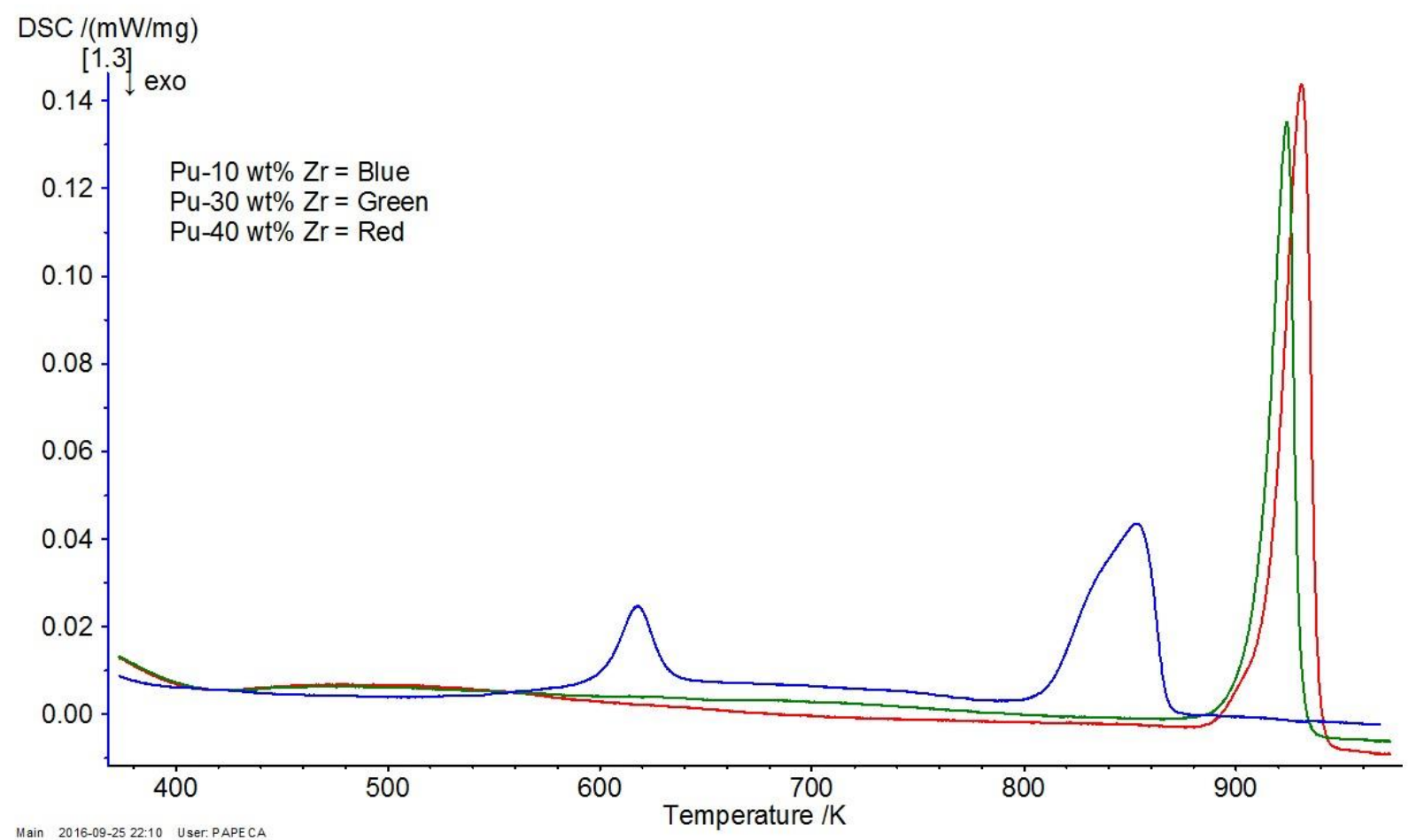

Figure 30. DSC curve vs. temperature $(\mathrm{K})$ for the $\mathrm{Pu}-\mathrm{Zr}$ alloys.

\subsubsection{U-Pu Alloys}

\subsubsection{Introduction}

Almost all of the published experimental data about the heat capacity of any of U-Pu alloy are from a single paper by Savage [117], who calculated specific heats from incremental enthalpies measured with drop calorimetry. Savage concluded that the heat capacity of a U-10Pu alloy was similar to that of pure U. He presented quadratic equations representing heat capacities of individual phases as functions of temperature. Chiotti et al. [87] proposed Equation 30 through Equation 33 as alternative equations matching the same data. These equations were accepted (with modifications to express heat capacity in $\mathrm{J} / \mathrm{mol} \cdot \mathrm{K}$ rather than $\mathrm{cal} / \mathrm{mol} \cdot \mathrm{K}$ ) by Peterson and Foltyn in their presentation of the currently accepted phase diagram [106].

It is important to note that Savage's conclusion that the heat capacities of $\mathrm{U}$ and $\mathrm{U}-10 \mathrm{Pu}$ are similar was based on measurements of $U$ that were available at the time of his research. Savage's measurements for $\alpha-U$ and the average heat capacity of $\gamma-U$ are similar to the recommended values for pure $U$ in Section 3.2.1, but his values for $\beta-U$ and liquid $U$ are not. In the absence of new experimental data, it seems reasonable to qualitatively accept Savage's conclusion that heat capacities of U and U-10 Pu are similar, even when this leads to disagreement with his quantitative values. Further research is needed to test this suggestion, and to investigate thermophysical properties of other U-Pu alloys.

\subsubsection{Incremental Enthalpy of U-10Pu}

Figure 31 shows the incremental enthalpy of $\mathrm{U}-10 \mathrm{Pu}$, as represented by Peterson and Foltyn's polynomial fit to Savage's experimental results $[106,117]$. The incremental enthalpies of $(\beta-U),(\gamma-U)$, and liquid are linear functions of temperature. 


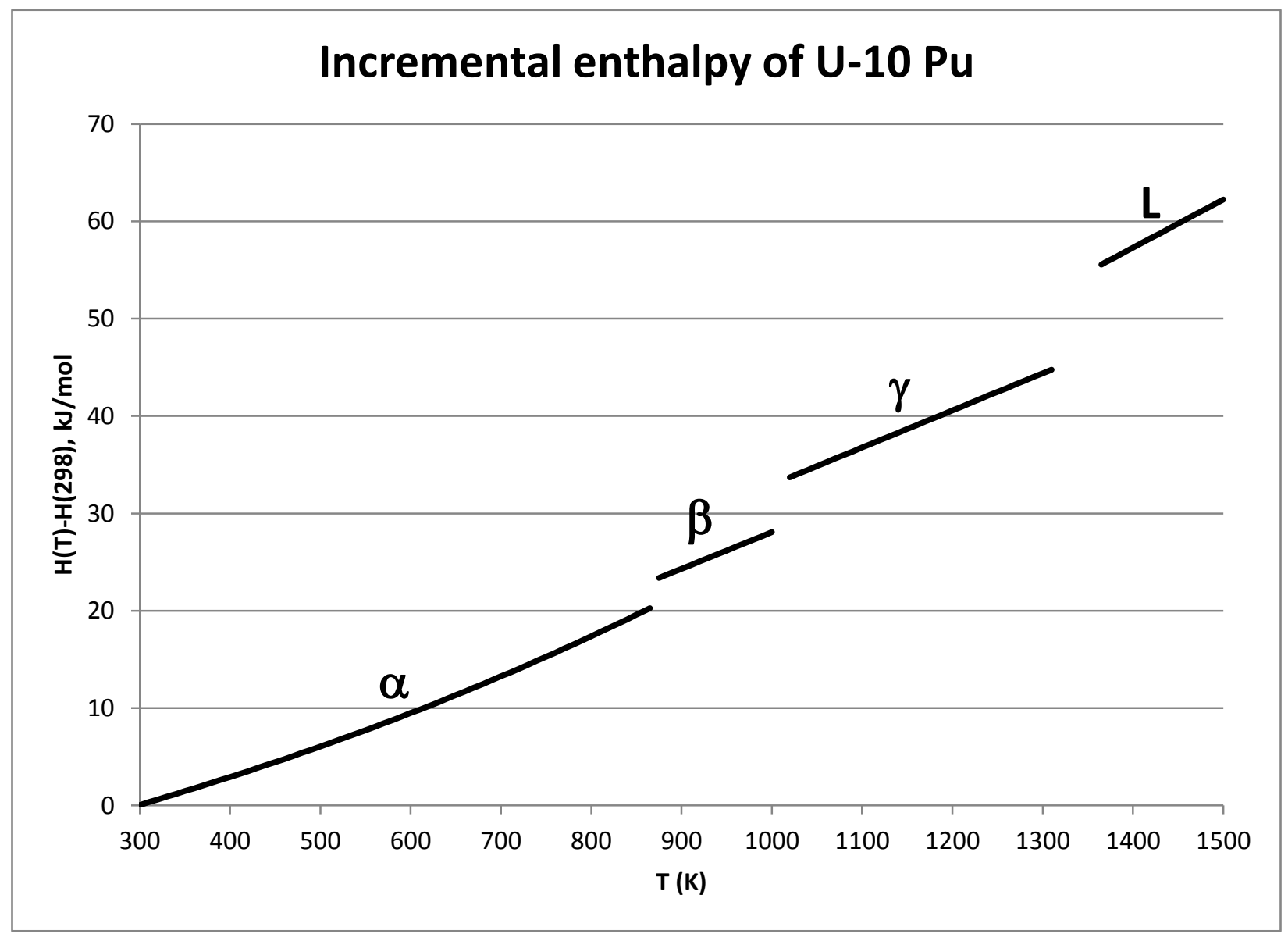

Figure 31. Incremental enthalpy $(\mathrm{H}(\mathrm{T})-\mathrm{H}(298))$ of $\mathrm{U}-10 \mathrm{Pu}$, calculated from Equation 30, Equation 31, Equation 32, and Equation 33

Equation 30. Incremental enthalpy of $(\alpha-\mathrm{U})$ phase in U-10Pu between 298 and $865 \mathrm{~K}$ [106]

$\mathrm{H}(\mathrm{T})-\mathrm{H}(298)=-3948+12.196 \times \mathrm{T}+3.774 \times 10^{-2} \times \mathrm{T}^{2 / 2}-4.074 \times 10^{5} \times \mathrm{T}^{-1}$

where $\mathrm{H}$ is enthalpy at temperature $\mathrm{T}$ in $\mathrm{J} / \mathrm{mol}, \mathrm{H}(298)$ is enthalpy at $298 \mathrm{~K} \mathrm{in} \mathrm{J/mol,} \mathrm{T}$ is temperature in $\mathrm{K}$, and $\mathrm{T}$ is between 298 and $865 \mathrm{~K}$

Equation 31. Incremental enthalpy of ( $\beta-\mathrm{U})$ phase in U-10Pu between 875 and $1000 \mathrm{~K}$ [106] $\mathrm{H}(\mathrm{T})-\mathrm{H}(298)=-9517.3+37.572 \times \mathrm{T}$

where $\mathrm{H}$ is enthalpy at temperature $\mathrm{T}$ in $\mathrm{J} / \mathrm{mol}, \mathrm{H}(298)$ is enthalpy at $298 \mathrm{~K} \mathrm{in} \mathrm{J/mol,} \mathrm{T}$ is temperature in $\mathrm{K}$, and $\mathrm{T}$ is between 875 and $1000 \mathrm{~K}$

Equation 32. Incremental enthalpy of $(\gamma-\mathrm{U})$ phase in $\mathrm{U}-10 \mathrm{Pu}$ between 1020 and $1310 \mathrm{~K}$ [106] $\mathrm{H}(\mathrm{T})-\mathrm{H}(298)=-5189.4+38.116 \times \mathrm{T}$ 
where $\mathrm{H}$ is enthalpy at temperature $\mathrm{T}$ in $\mathrm{J} / \mathrm{mol}, \mathrm{H}(298)$ is enthalpy at $298 \mathrm{~K} \mathrm{in} \mathrm{J/mol,} \mathrm{T}$ is temperature in $\mathrm{K}$, and $\mathrm{T}$ is between 1020 and $1310 \mathrm{~K}$

Equation 33. Incremental enthalpy of U-10Pu liquid between 1365 and $1500 \mathrm{~K}$ [106]

$\mathrm{H}(\mathrm{T})-\mathrm{H}(298)=-11867+49.371 \times \mathrm{T}$

where $\mathrm{H}$ is enthalpy at temperature $\mathrm{T}$ in $\mathrm{J} / \mathrm{mol}, \mathrm{H}(298)$ is enthalpy at $298 \mathrm{~K} \mathrm{in} \mathrm{J/mol,} \mathrm{T}$ is temperature in $\mathrm{K}$, and $\mathrm{T}$ is between 1365 and $1500 \mathrm{~K}$

A slightly earlier paper by Kelman et al. [135 Table VII] reported the enthalpy difference between $25^{\circ} \mathrm{C}$ and melting for a U-10Pu alloys as $46 \mathrm{cal} / \mathrm{g}(\sim 45.8 \mathrm{~kJ} / \mathrm{mol}$, consistent with the results published by Savage [117]). These data were repeated by Kittel [114]. Since Savage was an author of the Kelman et al. paper, the enthalpies in all three publications $[114,117,135]$ may represent the same experimental results.

\subsubsection{Heat Capacity of U-10Pu}

Figure 32 shows the heat capacity of $\mathrm{U}-10 \mathrm{Pu}$, as represented by Peterson and Foltyn's polynomial fit to Savage's experimental results [106, 117] (Equation 34 through Equation 37). Recommended values for the heat capacity of pure $U$ from Konings and Beneš [2] are shown for comparison. The heat capacities of $(\alpha-\mathrm{U})$ in $\mathrm{U}-10 \mathrm{Pu}$ and pure $\alpha-\mathrm{U}$ are similar, and the average heat capacity for $(\gamma-\mathrm{U})$ in $\mathrm{U}-10 \mathrm{Pu}$ is slightly smaller than that for pure $\gamma-\mathrm{U}$. Heat capacities of $(\beta-\mathrm{U})$ in $\mathrm{U}-10 \mathrm{Pu}$ and of liquid $\mathrm{U}-10 \mathrm{Pu}$ are independent of temperature, as they are for U. However, the reported values of the heat capacities of $(\beta-U)$ and liquid U-10 Pu differ significantly from those for pure U. Further research is needed to understand why these differences occur, and to measure the heat capacities of other U-Pu alloys. 


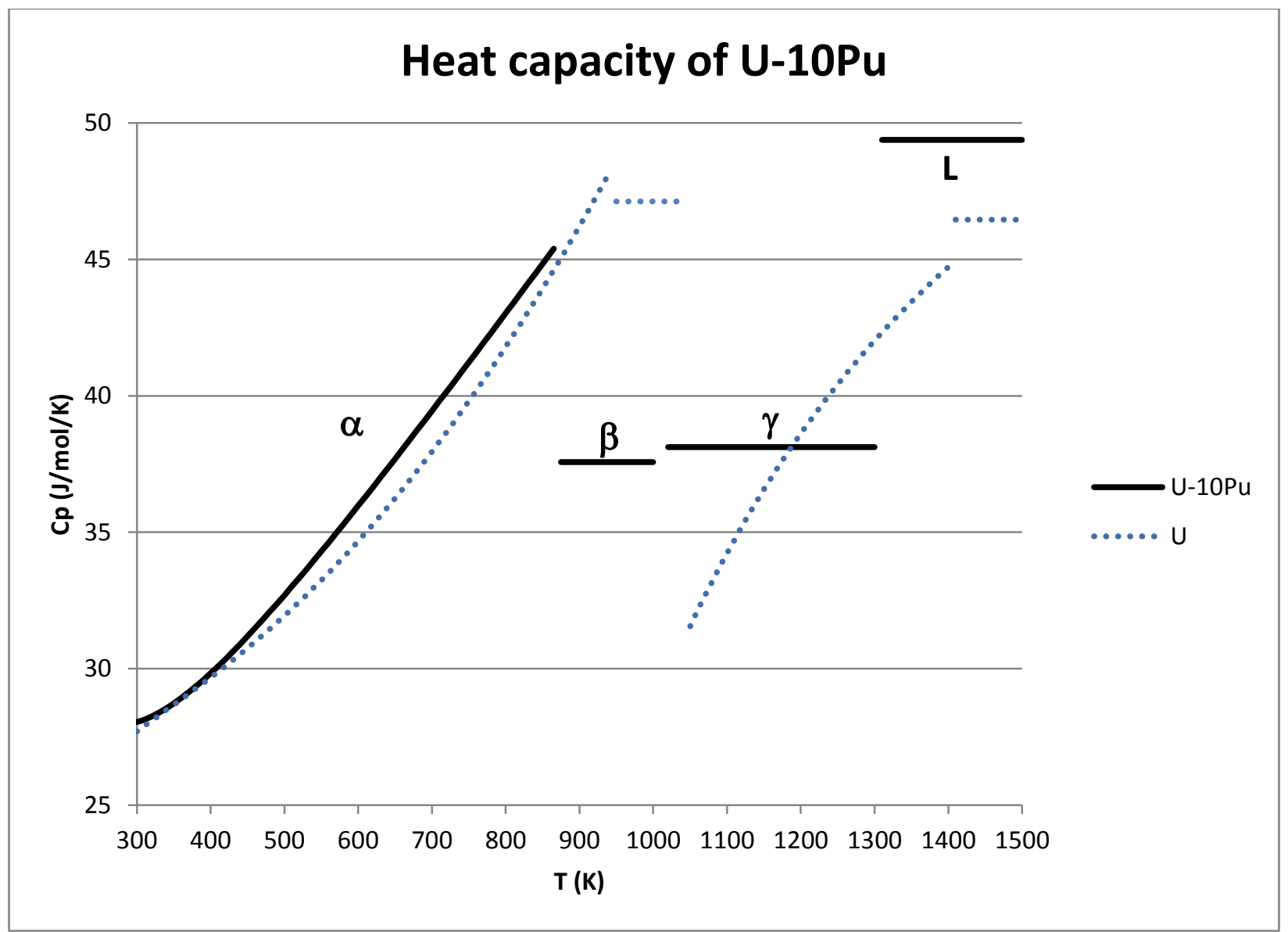

Figure 32. Heat capacity of U-10Pu (calculated from Equation 34, Equation 35, Equation 36, and Equation 37), with the heat capacity of $U$ [2] for comparison

Equation 34. Heat capacity of ( $\alpha-U)$ phase in U-10Pu between 298 and $865 \mathrm{~K}$ [106]

$\mathrm{C}_{\mathrm{p}}=12.196+3.774 \times 10^{-2} \times \mathrm{T}+4.074 \times 10^{5} \times \mathrm{T}^{-2}$

where $C_{p}$ is constant-pressure heat capacity in $\mathrm{J} / \mathrm{mol} \cdot \mathrm{K}$, $\mathrm{T}$ is temperature in $\mathrm{K}$, and $\mathrm{T}$ is between 298 and $865 \mathrm{~K}$

Equation 35. Heat capacity of ( $\beta-\mathrm{U})$ phase in U-10Pu between 875 and $1000 \mathrm{~K}$ [106]

$\mathrm{C}_{\mathrm{p}}=37.572$

where $\mathrm{C}_{\mathrm{p}}$ is constant-pressure heat capacity in $\mathrm{J} / \mathrm{mol} \cdot \mathrm{K}$

Equation 36. Heat capacity of $(\gamma-\mathrm{U})$ phase in $\mathrm{U}-10 \mathrm{Pu}$ between 1020 and $1310 \mathrm{~K}$ [106]

$\mathrm{C}_{\mathrm{p}}=38.116$

where $\mathrm{C}_{\mathrm{p}}$ is constant-pressure heat capacity in $\mathrm{J} / \mathrm{mol} \cdot \mathrm{K}$

Equation 37. Heat capacity of U-10Pu liquid between 1365 and $1500 \mathrm{~K}$ [106]

$\mathrm{C}_{\mathrm{p}}=49.371$ 
where $\mathrm{C}_{\mathrm{p}}$ is constant-pressure heat capacity in $\mathrm{J} / \mathrm{mol} \cdot \mathrm{K}$

\subsubsection{U-Pu-Zr Alloys}

\subsubsection{Introduction}

The only published experimental data about the heat capacity of any of U-Pu-Zr alloy are from a single paper by Savage [117], which includes the specific heat of U-15 wt $\% \mathrm{Pu}-10 \mathrm{wt} \% \mathrm{Zr}$ calculated from incremental enthalpies measured using drop calorimetry. Savage concluded that the heat capacity of $\mathrm{U}-15 \mathrm{Pu}-10 \mathrm{Zr}$ is similar to that of pure $\mathrm{U}$ at temperatures up to about $500^{\circ} \mathrm{C}$ and about $10 \%$ lower than that of $\mathrm{U}$ at temperatures of $800^{\circ} \mathrm{C}$ and above. However, comparison of Savage's U-Pu-Zr data with heat-capacity data from pure $U$ [2] suggests that the heat capacities of the two materials are sufficiently similar that the recommended heat-capacity values for $U$ from reference [2] can be used to represent the heat capacity of $\mathrm{U}-15 \mathrm{Pu}-10 \mathrm{Zr}$ even at temperatures above $800^{\circ} \mathrm{C}$. Recommended heat capacities from other references such as Oetting et al. and Grenthe et al. $[4,20]$ are less similar to the heat capacity of $\mathrm{U}-15 \mathrm{Pu}-10 \mathrm{Zr}$ because they treat the heat capacity of $\gamma-\mathrm{U}$ as independent of temperature.

Further work on other $\mathrm{U}-\mathrm{Pu}-\mathrm{Zr}$ alloys is clearly required, including research at higher temperatures.

\subsubsection{Incremental Enthalpy of U-15 wt\% Pu-10 wt\% Zr}

Figure 33 shows Savage's measurements of the incremental enthalpy of U-15Pu-10Zr. Symbols indicate measured data, and curves represent Savage's fit to the measured data (Equation 38 and Equation 39). Savage attributes the abrupt rise in the incremental enthalpy between 600 and $650^{\circ} \mathrm{C}$ to the transformation from $(\alpha-U)$ to $(\gamma-U)$ and disappearance of $\left(\delta-U_{2}\right)$. Although Savage does not give a minimum temperature, the non-zero incremental enthalpy at $0^{\circ} \mathrm{C}$ suggests that in practice this equation should not be extrapolated to temperatures below the measured range. 


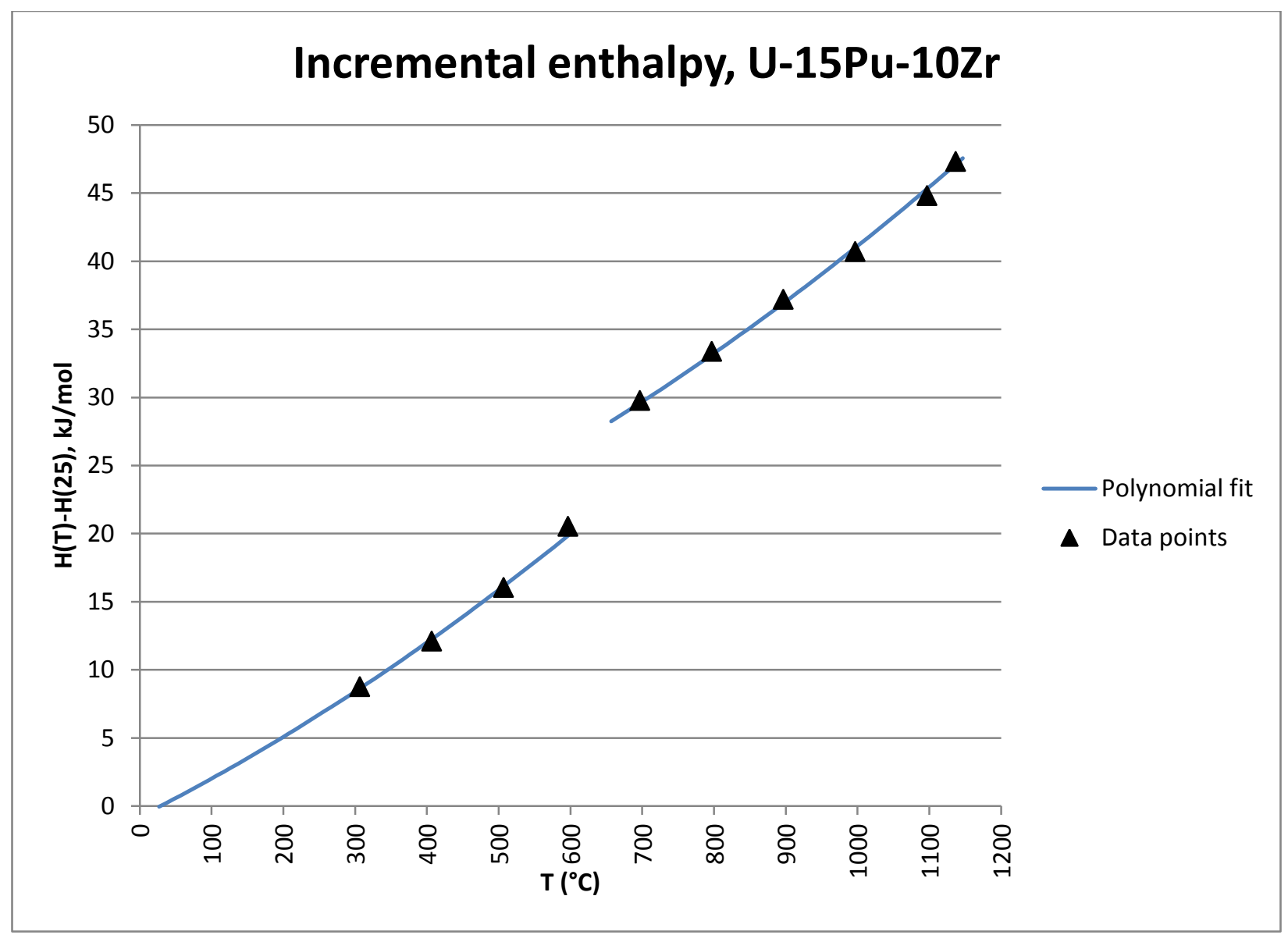

Figure 33. Incremental enthalpy $(\mathrm{H}(\mathrm{T})-\mathrm{H}(25))$ of $\mathrm{U}-15 \mathrm{Pu}-10 \mathrm{Zr}$ [117]. Note that temperature is in ${ }^{\circ} \mathrm{C}$. Triangles are measured data points, and the polynomial fit is calculated from Equation 38 and Equation 39.

Equation 38. Incremental enthalpy of U-15Pu-10Zr between 25 and $600{ }^{\circ} \mathrm{C}$ [117]

$\mathrm{H}(\mathrm{T})-\mathrm{H}(25)=-0.185+0.00636 \times \mathrm{T}+0.00000318 \times \mathrm{T}^{2}$

where $\mathrm{H}$ is enthalpy at temperature $\mathrm{T}$ in $\mathrm{kcal} / \mathrm{mol}, \mathrm{H}(25)$ is enthalpy at $25^{\circ} \mathrm{C}$ in $\mathrm{kcal} / \mathrm{mol}$, $\mathrm{T}$ is temperature in ${ }^{\circ} \mathrm{C}$, and $\mathrm{T}$ is between 25 and $600{ }^{\circ} \mathrm{C}$

Equation 39. Incremental enthalpy of U-15Pu-10Zr between 650 and $1150{ }^{\circ} \mathrm{C}$ [117]

$\mathrm{H}(\mathrm{T})-\mathrm{H}(25)=2.91+0.00379 \times \mathrm{T}+0.00000312 \times \mathrm{T}^{2}$

where $\mathrm{H}$ is enthalpy at temperature $\mathrm{T}$ in $\mathrm{kcal} / \mathrm{mol}, \mathrm{H}(25)$ is enthalpy at $25^{\circ} \mathrm{C}$ in $\mathrm{kcal} / \mathrm{mol}$, $\mathrm{T}$ is temperature in ${ }^{\circ} \mathrm{C}$, and $\mathrm{T}$ is between 650 and $1150{ }^{\circ} \mathrm{C}$

\subsubsection{Heat capacity of U-15 wt\% Pu-10 wt\% Zr}

Figure 34 shows the heat capacity of U-15Pu-10Zr calculated from the incremental enthalpy data in Section 3.2.7.2, with recommended values for the heat capacity of pure U from Konings and Beneš [2] (Section 3.2.1) for comparison. Savage et al. represented the heat capacity of U-15Pu-10Zr by two equations. Equation 40 corresponds to temperatures below the transformation of $(\alpha-U)$ to $(\gamma-U)$ and the disappearance of $\left(\delta-\mathrm{UZr}_{2}\right)$ at $\sim 600^{\circ} \mathrm{C}$, and Equation 41 corresponds to $(\gamma-\mathrm{U})\left(\sim 650-1150^{\circ} \mathrm{C}\right)$. Both equations are linear functions of temperature. 


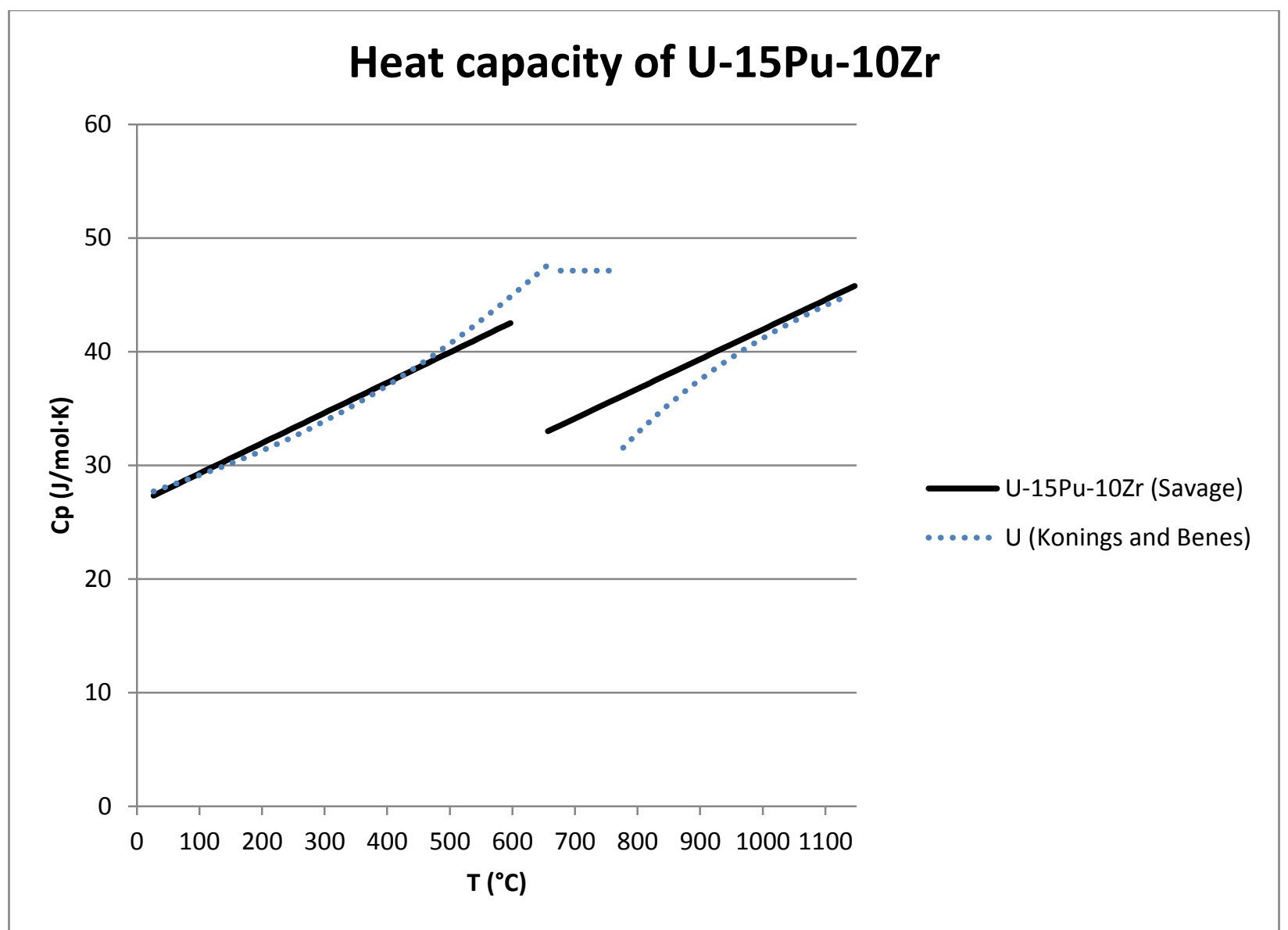

Figure 34. Heat capacity of U-15Pu-10Zr, calculated from Equation 40 and Equation 41 [117]. The heat capacity of pure $U[2]$ is provided for comparison.

Equation 40. Heat capacity of U-15Pu-10Zr between 25 and $600{ }^{\circ} \mathrm{C}$ [117]

$\mathrm{C}_{\mathrm{p}}=6.36+0.00636 \times \mathrm{T}$

where $\mathrm{C}_{\mathrm{p}}$ is constant-pressure heat capacity in cal/ $\mathrm{mol} \cdot{ }^{\circ} \mathrm{C}$, $\mathrm{T}$ is temperature in ${ }^{\circ} \mathrm{C}$, and $\mathrm{T}$ is between 25 and $600{ }^{\circ} \mathrm{C}$

Equation 41. Heat capacity of U-15Pu-10Zr between 650 and $1150^{\circ} \mathrm{C}$ [117]

$\mathrm{C}_{\mathrm{p}}=3.79+0.00623 \times \mathrm{T}$

where $\mathrm{C}_{\mathrm{p}}$ is constant-pressure heat capacity in cal/ mol ${ }^{\circ} \mathrm{C}$, $\mathrm{T}$ is temperature in ${ }^{\circ} \mathrm{C}$, and $\mathrm{T}$ is between 650 and $1150^{\circ} \mathrm{C}$ 


\subsection{THERMAL EXPANSION, THERMAL EXPANSION COEFFICIENTS, AND DENSITY-TEMPERATURE RELATIONSHIPS}

\subsubsection{U}

\subsubsection{Introduction}

Numerous measurements of the thermal expansion of $\alpha-U$ have been published, and results are generally in good agreement. Although only a few measurements of thermal expansion of $\beta$ - $U$ have been published, they are in good agreement. Data on thermal expansion of $\gamma-U$ are rare.

Thermal expansion of single crystals of $\alpha-U$ is highly anisotropic, with increases in length along two of three mutually orthogonal directions and a decrease in length along the third during heating. It is commonly assumed that the thermal expansion of a polycrystalline $U$ sample can be predicted from single-crystal data. In practice, however, polycrystalline U samples develop surface roughness, change shape, and increase in volume (and therefore decrease in density) as a result of thermal cycling, presumably because of internal strains from differential expansion of adjacent crystals with different orientations (e.g., [144-147]). This effect can be large, as shown by a $100 \%$ increase in the length of one sample [147]. Consequences of thermal cycling are highly sample-dependent and may be influenced by factors such as grain size, preferred orientation, sample fabrication and processing, and thermal history.

\subsubsection{Thermal Expansion}

Touloukian et al. [6] published recommended thermal expansion values for single crystals and polycrystalline samples of $\alpha-U$ and provisional thermal expansion values for $\beta-U$ and $\gamma-U$ based on a review of 48 previously published measurements (Figure 35). These measurements were obtained using a variety of techniques and samples. More recent thermal expansion measurements of $\alpha-U$ and $\gamma-U$ from dilatometry of an as-cast sample of polycrystalline U by Basak et al. [148] are significantly below the values of Touloukian et al., although the thermal expansion of $\alpha$-U reported by Basak et al. is comparable to the lowest values reported by Touloukian et al.

Further investigation is needed to determine which results are most representative of the actual behavior of polycrystalline $U$, with possible consideration of preferred orientations expected in materials of interest to the FCRD program. 


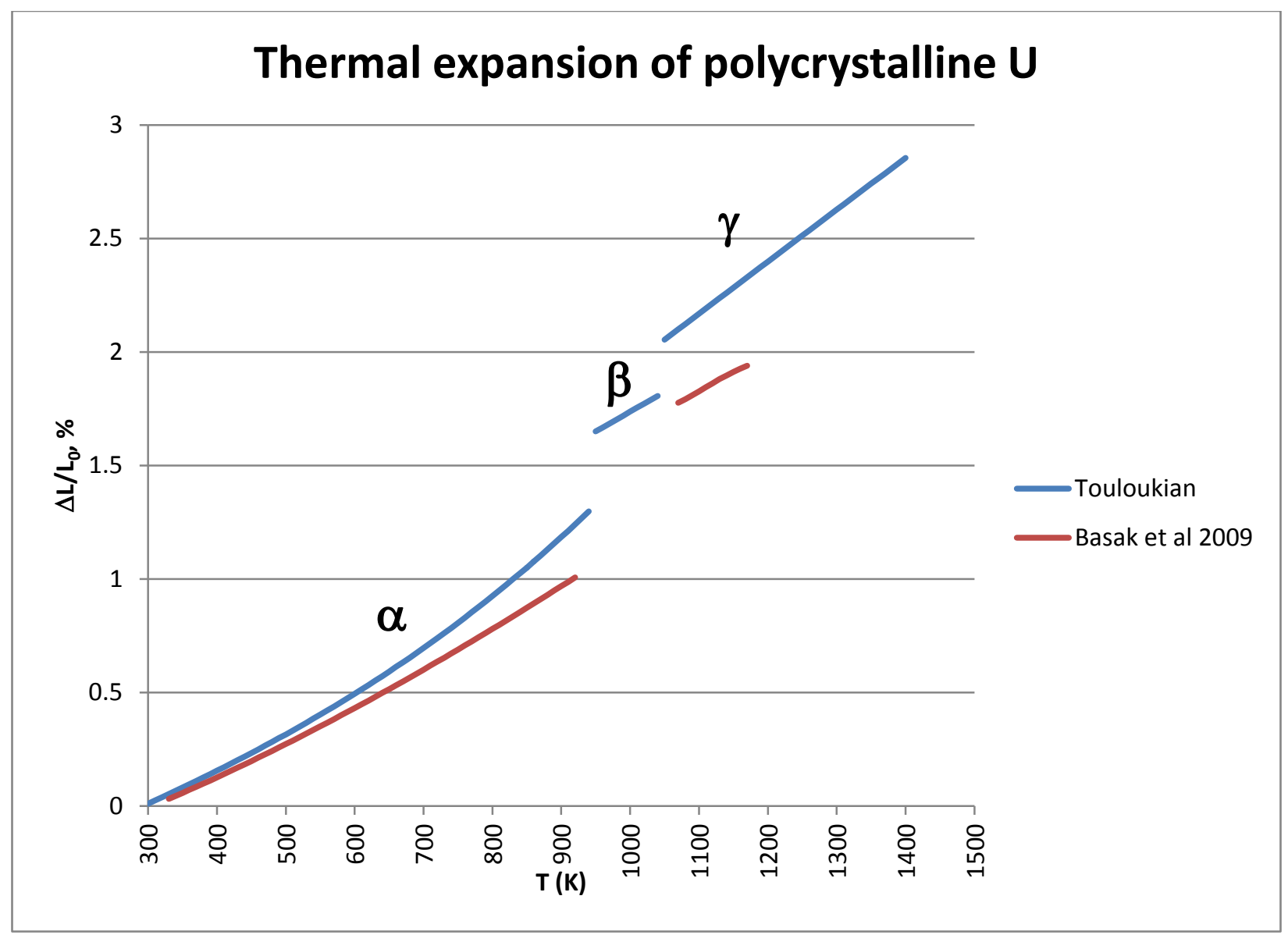

Figure 35. Thermal expansion of polycrystalline $U$ [6, 148], calculated using Equation 42 through Equation 46

Two equations were developed to represent the mean thermal expansion of polycrystalline $\alpha-\mathrm{U}$ :

Equation 42. Mean thermal expansion of polycrystalline $\alpha-U$ according to Touloukian et al. [6]

$\left(\mathrm{L}-\mathrm{L}_{0}\right) / \mathrm{L}_{0}=-0.379+1.264 \times 10^{-3} \times \mathrm{T}-8.982 \times 10^{-8} \times \mathrm{T}^{2}+6.844 \times 10^{-10} \times \mathrm{T}^{3}$

where $\left(\mathrm{L}-\mathrm{L}_{0}\right) / \mathrm{L}_{0}$ is thermal expansion in \%, T is temperature in $\mathrm{K}, \mathrm{T}$ is between 293 and $941 \mathrm{~K}, \mathrm{~L}$ is the length at temperature $\mathrm{T}$, and $\mathrm{L}_{0}$ is length at $293 \mathrm{~K}$

Equation 43. Measured thermal expansion of polycrystalline $\alpha$-U according to Basak et al. [148]

$\left(\mathrm{L}-\mathrm{L}_{0}\right) / \mathrm{L}_{0}=-0.326+8.338 \times 10^{-4} \times \mathrm{T}+8.038 \times 10^{-7} \times \mathrm{T}^{2}-1.465 \times 10^{-10} \times \mathrm{T}^{3}$

where $\left(\mathrm{L}-\mathrm{L}_{0}\right) / \mathrm{L}_{0}$ is thermal expansion in \%, T is temperature in $\mathrm{K}$, $\mathrm{T}$ is between 323 and $923 \mathrm{~K}$, $\mathrm{L}$ is the length at temperature $\mathrm{T}$, and $\mathrm{L}_{0}$ is length at $323 \mathrm{~K}$

Although Touloukian et al. [6] and Basak et al. [148] did not publish equations expressing the thermal conductivity of $\beta-U$, Konings et al. [3] developed Equation 44 to represent the data used to determine the provisional values of Touloukian et al. [6].

Equation 44. Mean thermal expansion of polycrystalline $\beta-\mathrm{U}$ [3 Table 8]

$\left(\mathrm{L}-\mathrm{L}_{0}\right) / \mathrm{L}_{0}=8.04 \times 10^{-5}+1.729 \times 10^{-5} \times \mathrm{T}$ 
Where $\left(\mathrm{L}-\mathrm{L}_{0}\right) / \mathrm{L}_{0}$ is thermal expansion in \%, T is temperature in $\mathrm{K}, \mathrm{T}$ is between 945 and $1045 \mathrm{~K}$, $\mathrm{L}$ is the length at temperature $\mathrm{T}$, and $\mathrm{L}_{0}$ is length at $293 \mathrm{~K}$

Polynomials representing the thermal expansion of $\gamma-U$ are:

Equation 45. Provisional values for mean thermal expansion of polycrystalline $\gamma-\mathrm{U}$ according to Touloukian et al. [6]

$$
\left(\mathrm{L}-\mathrm{L}_{0}\right) / \mathrm{L}_{0}=-0.149+1.775 \times 10^{-3} \times \mathrm{T}+4.382 \times 10^{-7} \times \mathrm{T}^{2}-1.239 \times 10^{-10} \times \mathrm{T}^{3}
$$

Where $\left(\mathrm{L}-\mathrm{L}_{0}\right) / \mathrm{L}_{0}$ is thermal expansion in \%, T is temperature in $\mathrm{K}, \mathrm{T}$ is between 1048 and 1400 $\mathrm{K}, \mathrm{L}$ is the length at temperature $\mathrm{T}$, and $\mathrm{L}_{0}$ is length at $293 \mathrm{~K}$

Equation 46. Mean thermal expansion of polycrystalline $\gamma$-U according to Basak et al. [148]

$$
\left(\mathrm{L}-\mathrm{L}_{0}\right) / \mathrm{L}_{0}=81.794-21.986 \times 10^{-2} \times \mathrm{T}+19.985 \times 10^{-5} \times \mathrm{T}^{2}-6.006 \times 10^{-8} \times \mathrm{T}^{3}
$$

Where $\left(\mathrm{L}-\mathrm{L}_{0}\right) / \mathrm{L}_{0}$ is thermal expansion in \%, T is temperature in $\mathrm{K}, \mathrm{T}$ is between 1063 and 1173

$\mathrm{K}, \mathrm{L}$ is the length at temperature $\mathrm{T}$, and $\mathrm{L}_{0}$ is length at $323 \mathrm{~K}$

\subsubsection{Thermal Expansion Coefficients}

Average values for linear thermal expansion coefficients of $\alpha-\mathrm{U}$ parallel to the $a, b$, and $c$ crystallographic directions are $26.5 \times 10^{-6} \mathrm{~K}^{-1},-2.4 \times 10^{-6} \mathrm{~K}^{-1}$, and $23.9 \times 10^{-6} \mathrm{~K}^{-1}$ over temperature ranges from $25-325^{\circ} \mathrm{C}$ [136]. Touloukian et al. [6] provide an extensive tabulation of older data from individual samples, and Lawson et al. [18] published high-resolution neutron-diffraction data.

The linear thermal expansion coefficients for $\beta$-U are $\sim 23 \times 10^{-6} \mathrm{~K}^{-1}$ parallel to $a$ and $\sim 5 \times 10^{-6} \mathrm{~K}^{-1}$ parallel to $c[18,147,149]$, corresponding to an average thermal expansion coefficient of $\sim 17 \times 10^{-6} \mathrm{~K}^{-1}$.

The linear thermal expansion coefficient for $\gamma$ - $\mathrm{U}$ is $(22.5 \pm 1.3) \times 10^{-6} \mathrm{~K}^{-1}$ [147].

\subsubsection{Density}

Room-temperature densities of $U$ phases are [150]:

- $\alpha-U, 19.04 \mathrm{~g} / \mathrm{cm}^{3}$

- $\beta-\mathrm{U}, 18.11 \mathrm{~g} / \mathrm{cm}^{3}$

- $\gamma-\mathrm{U}, 18.06 \mathrm{~g} / \mathrm{cm}^{3}$.

The high-temperature density of solid $U$ can calculated from the room-temperature volume and thermal expansion (Equation 47) or from high-temperature diffraction data. The high-temperature density of liquid U can be calculated using Equation 48.

Equation 47. Density of solid $U$ as a function of thermal expansion [3]

$$
\rho(T)=\frac{238}{12.50\left(1+3 \frac{\Delta L}{L_{0}(T)}\right)}
$$

Where $\rho(T)$ is the density at temperature T, M is the atomic mass (238 for $\mathrm{U}-238$ ), $\mathrm{V}_{0}$ is the molar volume at the reference temperature $\left(12.50 \mathrm{~cm}^{3} /\right.$ mol near room temperature for $\left.\alpha-\mathrm{U}\right)$, and $\Delta \mathrm{L} / \mathrm{L}_{0}$ is the thermal expansion expressed as a fraction

The density of liquid $U$ can be calculated using an equation developed by the IAEA and repeated by Konings et al. (Equation 48).

Equation 48. Density of liquid U [3, 140]

$$
\rho=20.332-2.146 \times \mathrm{T}
$$


where $\rho$ is the density in $\mathrm{g} / \mathrm{cm}^{3}, \mathrm{~T}$ is temperature in $\mathrm{K}$, and $\mathrm{T}$ is between 1405 and $2100 \mathrm{~K}$

Figure 36 shows the density of U. If densities from more than one kind of information are available, they are in good agreement.

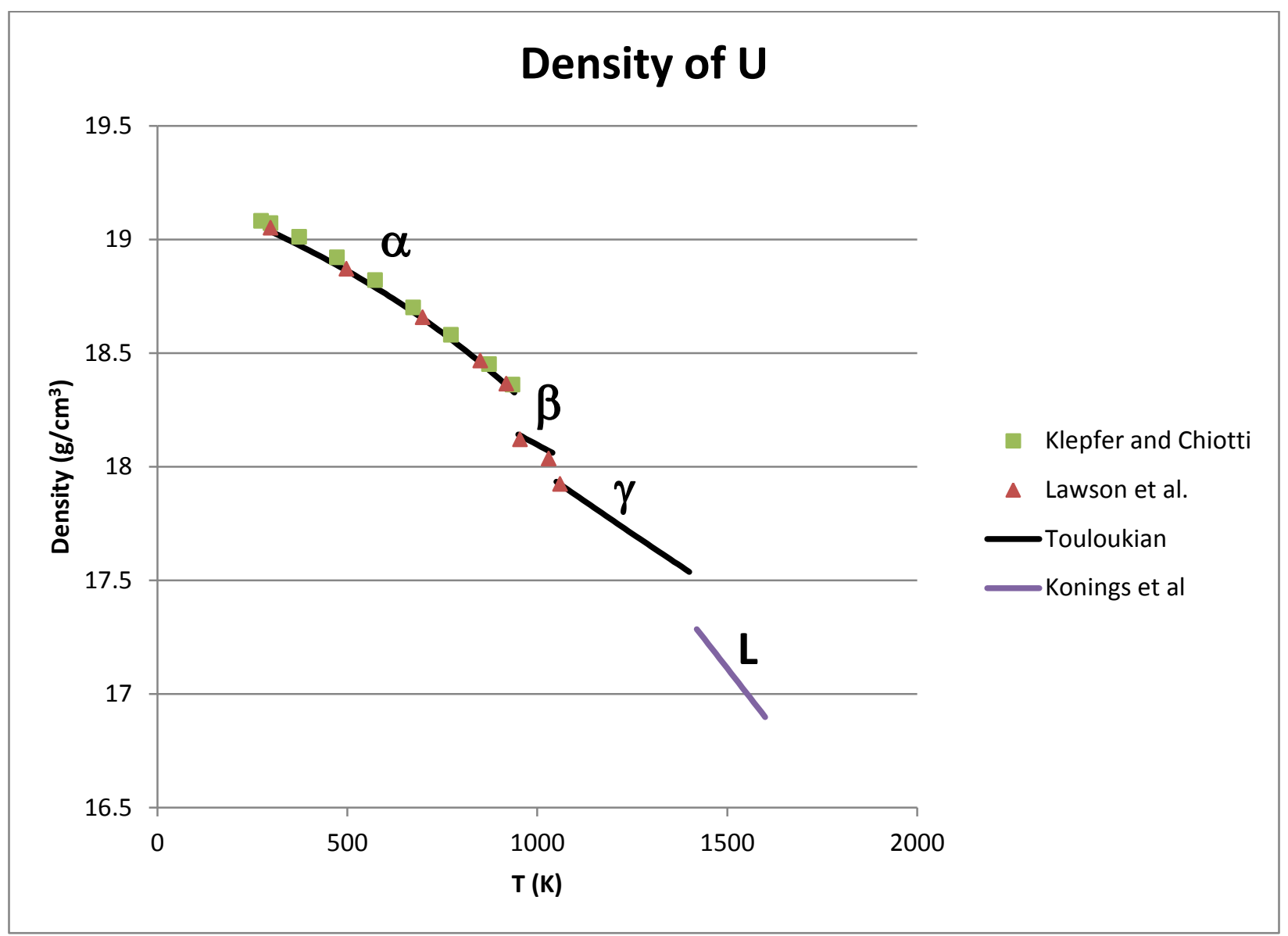

Figure 36. Density of U. Data labeled "Klepfer and Chiotti" and "Lawson et al." are from references [147] and [18]. Data labeled "Touloukian" were calculated using Equation 47 and Touloukian's equations for thermal expansion (Equation 42, Equation 44, and Equation 45). Data labeled "Konings et al." were calculated using Equation 48.

\subsection{2 $\mathrm{Pu}$}

\subsubsection{Introduction}

Measuring the thermal expansion of $\mathrm{Pu}$ is difficult, and there are wide variations between individual measurements reported in the literature. Detailed studies of phase-transformation mechanisms by Ennaceur [31-34, 151] show that transformations in individual samples are affected by factors such as previous thermal and phase-transformation history, and that the order in which transformations occur may be different during heating and cooling. Understanding thermal expansion is further complicated by the anisotropic thermal expansion of $\alpha-\mathrm{Pu}, \beta-\mathrm{Pu}, \gamma-\mathrm{Pu}$, and $\delta^{\prime}-\mathrm{Pu}$, and by the negative thermal expansion of $\delta$-Pu and $\delta^{\prime}-\mathrm{Pu}$. Even when phase transformations are not involved, thermal expansion of polycrystalline aggregates may vary between individual samples. Addition of a few at $\%$ of alloying elements such as $\mathrm{Ga}$ and $\mathrm{Al}$ produces large changes in thermal expansion behavior [21]. 
Recent research on the thermal expansion of $\mathrm{Pu}$ has emphasized understanding the negative expansion of $\delta-\mathrm{Pu}$ and its consequences for other properties [152-157].

\subsubsection{Thermal Expansion}

Reviews of experimental measurements of thermal expansion of $\mathrm{Pu}[6,21,22,158]$ generally agree about the thermal expansion of individual Pu phases (Figure 37), although expansions associated with phase transformations are less consistent.

Equations representing the thermal dependence of $\alpha$-Pu have been developed by Schonfeld and Tate [158] and by Touloukian et al. [6] (Equation 49). Values produced by the two equations agree to within $\sim 0.1 \%$.

The thermal expansions of $\beta-, \gamma-, \delta-, \delta^{\prime}$, and $\varepsilon-\mathrm{Pu}$ are linear functions temperature and can be represented using the thermal expansion coefficients in Table 8.

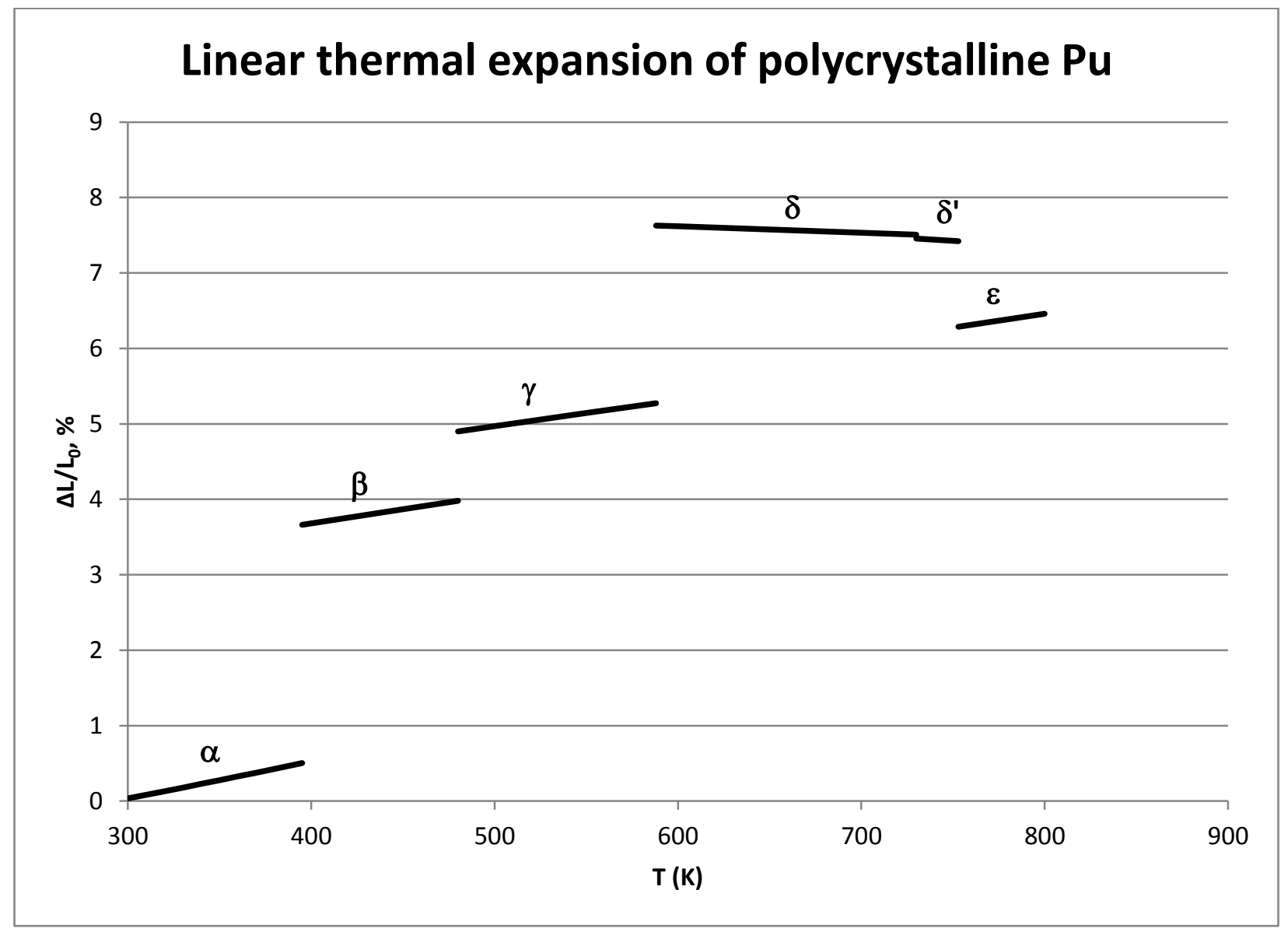

Figure 37. Linear thermal expansion of polycrystalline $\mathrm{Pu}$ [158]. 
Equation 49. Thermal expansion of $\alpha-\mathrm{Pu}[6]$

$\left(\mathrm{L}-\mathrm{L}_{0}\right) / \mathrm{L}_{0}=-0.407+4.099 \times 10^{-3} \times(\mathrm{T}-200)+3.552 \times 10^{-6} \times(\mathrm{T}-200)^{2}-3.360 \times 10^{-9} \times(\mathrm{T}-200)^{3}$

Where $\left(\mathrm{L}-\mathrm{L}_{0}\right) / \mathrm{L}_{0}$ is thermal expansion in $\%$, T is temperature in $\mathrm{K}, \mathrm{T}$ is between 200 and $395 \mathrm{~K}, \mathrm{~L}$ is the length at temperature $\mathrm{T}$, and $\mathrm{L}_{0}$ is length at $293 \mathrm{~K}$

\subsubsection{Thermal Expansion Coefficients}

Table 8 summarizes mean coefficients of thermal expansion for $\beta-, \gamma-, \delta-, \delta$ '-, $\varepsilon$ - and liquid $\mathrm{Pu}$ from several reviews. There is generally good agreement between the reviews for all of the phases in the table. Values for solid phases are for ideal polycrystalline materials with no preferred orientation. The thermal expansion coefficients in the table are largely independent of temperature, and the mean coefficients can be used throughout the stability fields of the individual phases [159]. The thermal expansion coefficient of $\alpha-\mathrm{Pu}$ is not included in the table because the thermal expansion of $\alpha-\mathrm{Pu}$ is a non-linear function of temperature, so its thermal expansion is not a constant. Values for liquid $\mathrm{Pu}$ are volumetric thermal expansion coefficients, each of which is approximately three times the corresponding linear coefficient, and are independent of temperature.

Table 8. Thermal expansion coefficients $(10-6 / \mathrm{K})$ of solid and liquid $\mathrm{Pu}[6,22,158]$.

\begin{tabular}{cccc}
\hline Phase & $\begin{array}{c}\text { Reference } \\
{[22]}\end{array}$ & Reference [6] & $\begin{array}{c}\text { Reference } \\
{[158]}\end{array}$ \\
\hline$\beta$ & 42 & 37.3 & 42.3 \\
$\gamma$ & $34.6 \pm 0.7$ & 34.6 & 34.7 \\
$\delta$ & $-8.6 \pm 0.3$ & -8.6 & -9.0 \\
$\delta^{\prime}$ & $-65.6 \pm 10.1$ & -16.1 & -66 \\
$\varepsilon$ & 36.5 & 36.6 & \\
Liquid & 93 (volumetric) & 90.4 (volumetric) & \\
\hline
\end{tabular}

Table 9 shows values of mean coefficients of thermal expansion along single directions for anisotropic $\mathrm{Pu}$ phases. $\delta$-Pu, $\varepsilon-\mathrm{Pu}$, and liquid are not included in the table because their thermal expansion is isotropic. 
Table 9. Mean linear coefficients of thermal expansion along single directions for anisotropic $\mathrm{Pu}$ phases [22].

\begin{tabular}{ccccc}
\hline Phase & Coefficient ${ }^{\mathrm{a}}$ & Crystallographic orientation & $\begin{array}{c}\text { Temperature range } \\
\left({ }^{\circ} \mathrm{C}\right)\end{array}$ & $\begin{array}{c}\text { Value } \\
\left(\mathrm{x} 10^{-6} / \mathrm{C}\right)\end{array}$ \\
\hline$\alpha$ & $\bar{\alpha}_{1}$ & $\perp$ c-axis & $21-104$ & 60 \\
& $\bar{\alpha}_{2}$ & $\|$ b-axis & & 75 \\
$\beta$ & $\bar{\alpha}_{3}$ & $\|$ c-axis & & 29 \\
& $\bar{\alpha}_{1}$ & & $93-190$ & 94 \\
& $\bar{\alpha}_{2}$ & $\|$ b-axis & & 14 \\
$\gamma$ & $\bar{\alpha}_{3}$ & $\perp(10 \overline{1})$ & & 19 \\
& $\bar{\alpha}_{\mathrm{a}}$ & $\|$ a-axis & $210-310$ & $-19.7 \pm 1.0$ \\
& $\bar{\alpha}_{\mathrm{b}}$ & $\|$ b-axis & & $39.5 \pm 0.6$ \\
$\delta^{\prime}$ & $\bar{\alpha}_{\mathrm{c}}$ & $\|$ c-axis & & $84.3 \pm 1.6$ \\
& $\bar{\alpha}_{\mathrm{a}}$ & $\|$ a-axis & $452-480$ & $444.8 \pm 12.1$ \\
& $\bar{\alpha}_{\mathrm{c}}$ & $\|$ c-axis & & $-1063.5 \pm 18.2$ \\
\hline
\end{tabular}

a. Overbar indicates that these are mean coefficients; subscripts identify individual coefficients. All coefficients for each phase are mutually orthogonal.

b. In space group $I 2 / m$

\subsubsection{Density}

The density of $\mathrm{Pu}$ varies by at most a few tenths of a gram per cubic centimeter within each phase. These differences can be neglected for most purposes because they are relatively small compared to differences between phases and to the likely uncertainties in the density data.

Densities of $\mathrm{Pu}$ phases (in $\mathrm{g} / \mathrm{cm}^{3}$ at listed temperatures) are [140]:

- $\quad \alpha-\mathrm{Pu}, 19.816(298 \mathrm{~K})$

- $\quad \beta-\mathrm{Pu}, 17.770(463 \mathrm{~K})$

- $\gamma-\mathrm{Pu}, 17.140(508 \mathrm{~K})$

- $\delta-\mathrm{Pu}, 15.920(593 \mathrm{~K})$

- $\quad \delta^{\prime}-\mathrm{Pu}, 16.01(723 \mathrm{~K})$

- $\quad \varepsilon-\mathrm{Pu}, 16.48(783 \mathrm{~K})$.

\subsubsection{Zr}

\subsubsection{Introduction}

The thermal expansion of $\alpha-\mathrm{Zr}$ is anisotropic. There is generally good agreement about its thermal expansion for single-crystal and polycrystalline materials $[6,160]$. Variations in expansion as a result of thermal cycling have been reported [160]. The thermal expansion of $\beta-\mathrm{Zr}$ is less commonly studied, but there is generally good agreement about linear expansion of polycrystalline materials at temperatures up to $\sim 1800 \mathrm{~K}$. Higher-temperature measurements (to $2100 \mathrm{~K}$ for $\beta-\mathrm{Zr}$ and $2300 \mathrm{~K}$ for liquid) have been reported by Paradis and Rhim [39].

Other research has emphasized detailed investigation of changes in thermal expansion during the $\alpha-\beta$ phase transformation [161], extending measurements to higher temperatures [39, 141, 160], and modeling $[162,163]$. 


\subsubsection{Thermal Expansion}

Figure 38 shows recently recommended values for the thermal expansion of polycrystalline $\mathrm{Zr}$ [160], which are expressed by Equation 50 and Equation 51. Values for thermal expansion (in \%) differ by less than 0.05 from the earlier recommendations of Touloukian et al. [6], with the largest difference occurring immediately above the phase transformation.

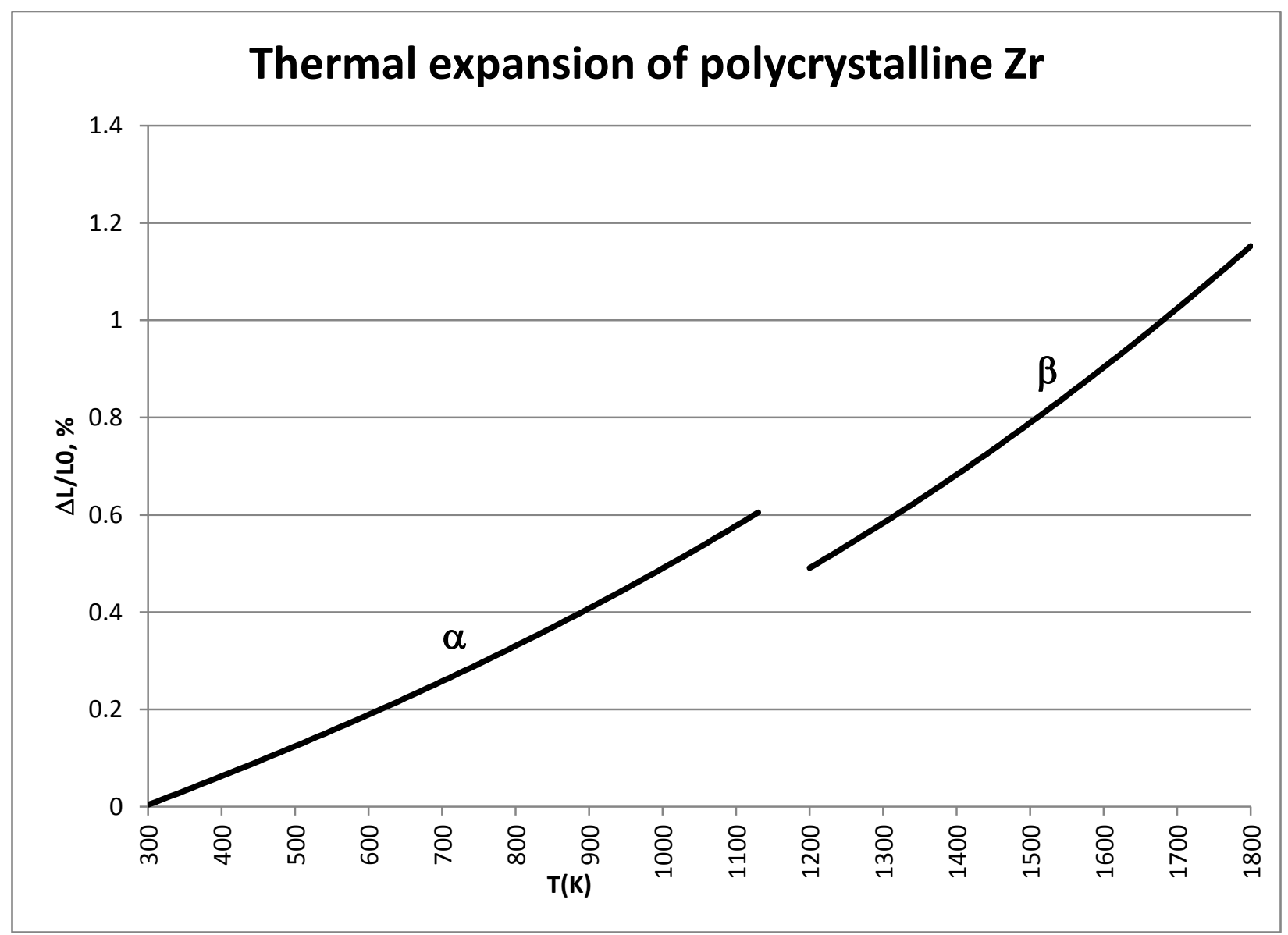

Figure 38. Thermal expansion of polycrystalline Zr, calculated from Equation 50 and Equation 51 
Equation 50. Thermal expansion of $\alpha-\operatorname{Zr}[160]$

$\left(\mathrm{L}-\mathrm{L}_{0}\right) / \mathrm{L}_{0}=5.7406 \times 10^{-4} \times(\mathrm{T}-293)+1.1888 \times 10^{-7} \times(\mathrm{T}-293)^{2}+7.0155 \times 10^{-11} \times(\mathrm{T}-293)^{3}$

where $\left(\mathrm{L}-\mathrm{L}_{0}\right) / \mathrm{L}_{0}$ is thermal expansion in \%, T is temperature in $\mathrm{K}, \mathrm{T}$ is between 293 and $1130 \mathrm{~K}$, $\mathrm{L}$ is the length at temperature $\mathrm{T}$, and $\mathrm{L}_{0}$ is the length at $293 \mathrm{~K}$

Equation 51. Thermal expansion of $\beta-\operatorname{Zr}[160]$

$\left(\mathrm{L}-\mathrm{L}_{0}\right) / \mathrm{L}_{0}=1.894 \times 10^{-4} \times(\mathrm{T}-293)+3.9735 \times 10^{-7} \times(\mathrm{T}-293)^{2}-1.0345 \times 10^{-11} \times(\mathrm{T}-293)^{3}$

where $\left(\mathrm{L}-\mathrm{L}_{0}\right) / \mathrm{L}_{0}$ is thermal expansion in $\%$, T is temperature in $\mathrm{K}, \mathrm{T}$ is between 1200 and $1830 \mathrm{~K}$, $\mathrm{L}$ is the length at temperature $\mathrm{T}$, and $\mathrm{L}_{0}$ is the length at $293 \mathrm{~K}$

\subsubsection{Thermal Expansion Coefficients}

Equation 52 and Equation 53 express the mean linear thermal expansion coefficients corresponding to the curves in Figure 38. $[160]$

Equation 52. Mean linear thermal expansion coefficient for polycrystalline $\alpha-Z r$ from 293 to $1130 \mathrm{~K}$

$\bar{\alpha} \times 10^{6}=5.7406+1.1888 \times 10^{-3} \times(\mathrm{T}-293)+7.0155 \times 10^{-7} \times(\mathrm{T}-293)^{2}$

where $\bar{\alpha}$ is thermal expansion in units of $10^{-6} / \mathrm{K}$, $\mathrm{T}$ is temperature in $\mathrm{K}$, and $\mathrm{T}$ is between 293 and $1130 \mathrm{~K}$

Equation 53. Mean linear thermal expansion coefficient for polycrystalline $\beta-\operatorname{Zr}\left(\bar{\alpha}\right.$ in units of $10^{-6} / \mathrm{K}$, $\mathrm{T}$ in $\mathrm{K}$, $\mathrm{T}$ from 1200 to $1830 \mathrm{~K})$ [160]

$\bar{\alpha} \times 10^{6}(\beta-\mathrm{Zr})=1.894+3.9735 \times 10^{-3} \times(\mathrm{T}-293)-1.0345 \times 10^{-7} \times(\mathrm{T}-293)^{2}$ for $1200<\mathrm{T}<1830$

where $\bar{\alpha}$ is thermal expansion in units of $10^{-6} / \mathrm{K}$, T is temperature in $\mathrm{K}$, and T is between 1200 and $1830 \mathrm{~K}$

Paradis and Rhim [39] determined that the volume expansion coefficients for $\beta$ - $\mathrm{Zr}$ and liquid $\mathrm{Zr}$ at $2128 \mathrm{~K}$ (the melting temperature) are $2.35 \times 10^{-5} \mathrm{~K}^{-1}$ and $4.6 \times 10^{-5} \mathrm{~K}^{-1}$, respectively.

\subsubsection{Density}

Densities of $\mathrm{Zr}$ phases (in $\mathrm{g} / \mathrm{cm}^{3}$ at listed temperatures) are:

- $\quad \alpha-Z r, 6.52(298 \mathrm{~K})[164]$

- $\quad \beta-Z r, 6.47(1250 \mathrm{~K})[39]$

- $\quad$ Liquid Zr 6.24 (2128 K) [39].

According to a recent review by the IAEA [140], the density of solid $\mathrm{Zr}$ can be approximated by Equation 54, which neglects the relatively small density difference due to the $\alpha-\beta$ phase transformation.

Equation 54. Density of solid Zr from 298 to 2128 K [140]

$\rho=6550-0.1685 \times \mathrm{T}$

Where $\rho$ is a density in $\mathrm{kg} / \mathrm{m}^{3}$, $\mathrm{T}$ is temperature in $\mathrm{K}$, and $\mathrm{T}$ is between 298 and $2128 \mathrm{~K}$

\subsubsection{U-Zr alloys}

\subsubsection{Introduction}

Data on the thermal expansion of polycrystalline U-Zr alloys with up to $\sim 20 \mathrm{wt} \% \mathrm{Zr}$ are originally from one of two publications (Saller et al. [165], which was the source of all of the data from this 
composition range in the review of Touloukian et al. [6], and Basak et al. [148]). Both publications show similar thermal expansion behavior for all alloys in this composition range at temperatures up to $\sim 800 \mathrm{~K}$. However, there is an important qualitative difference: data reported by Saller et al. indicate that the thermal expansion of $\mathrm{U}-\mathrm{Zr}$ alloys decreases with increasing concentration of $\mathrm{Zr}$. In contrast, data reported by Basak et al. indicate that, at least for alloys with up to $10 \mathrm{wt} \% \mathrm{Zr}$, the thermal expansion increases with increasing concentration of Zr. This qualitative difference becomes quantitatively important at higher temperatures, leading to differences in thermal expansion of up to $\sim 0.5 \%$ for similar alloys. Further work is required to resolve this disagreement.

\subsubsection{Thermal Expansion}

Figure 39 shows linear thermal expansion measurements from polycrystalline $\mathrm{U}-\mathrm{Zr}$ alloys with up to $\sim 15.5 \mathrm{wt} \% \mathrm{Zr}$ [6]. The figure also shows polynomial fits for alloys with 10 and $20 \% \mathrm{Zr}$ (Equation 55 and Equation 56), which Touloukian et al. considered accurate to within $\pm 7 \%$ for the entire temperature range. Thermal expansion curves for $U$ and $\operatorname{Zr}$ (Equation 42, Equation 44, Equation 45, Equation 50, and Equation 51) are shown for comparison. Although individual measurements vary slightly, these data shows a strong tendency for thermal expansion to decrease with increasing concentration of Zr. This tendency is consistent with the relative thermal expansion of $\mathrm{U}$ and $\mathrm{Zr}$ and the existence of a continuous solid solution between $\gamma$-U and $\beta$-Zr (Section 3.1.4).

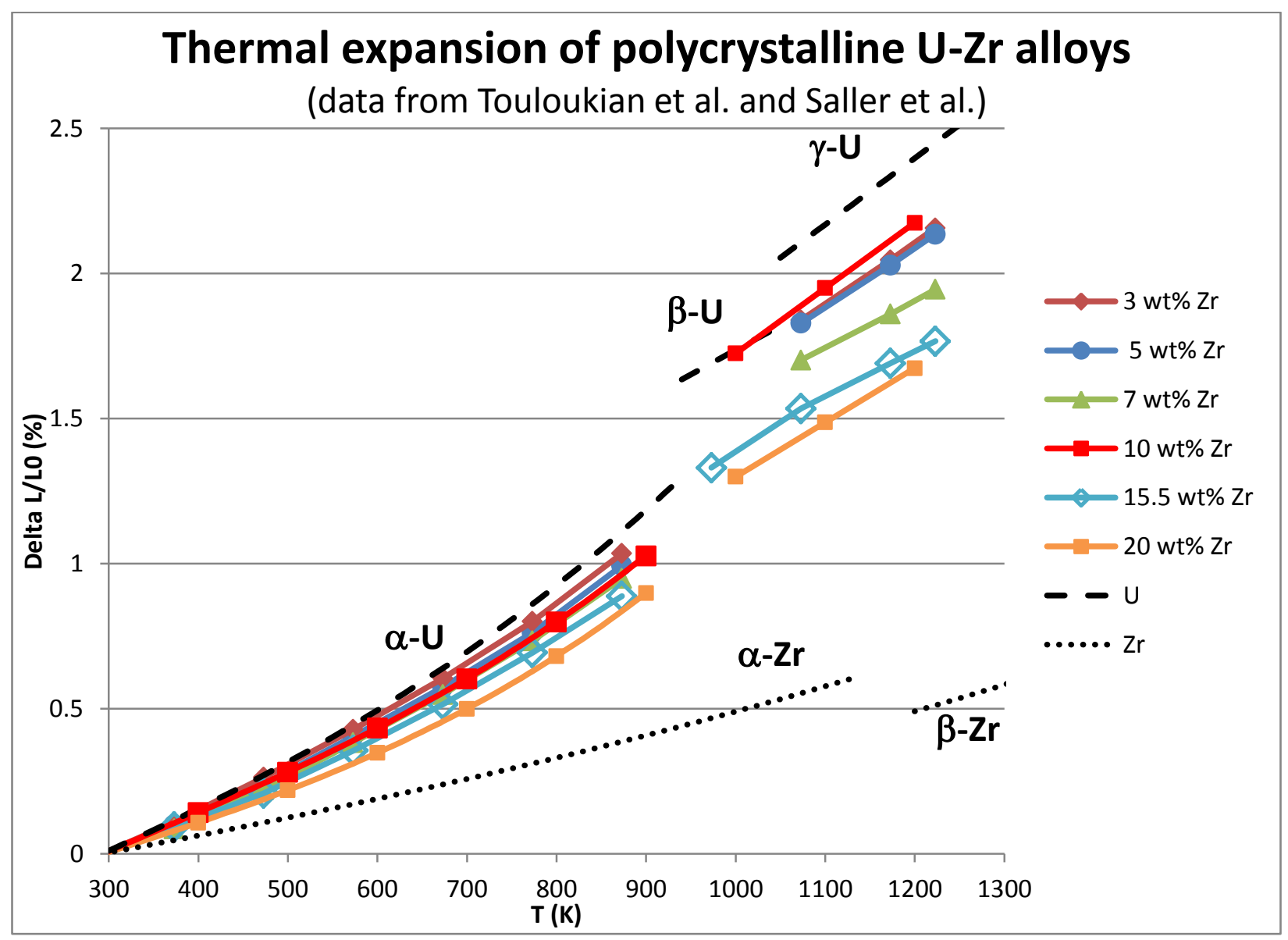

Figure 39. Thermal expansion of U-Zr alloys according to Saller et al. and Touloukian et al. [6, 165], with thermal expansion of $\mathrm{U}$ and $\mathrm{Zr}$ [6, 160] for comparison. Values for $10 \mathrm{wt} \%$ and $20 \mathrm{wt} \% \mathrm{Zr}$ are polynomial fits to tabulated data from Touloukian et al. [6] 
Figure 40 shows results of recent dilatometry experiments by Basak et al. [148] (Equation 57 through Equation 64), which show that thermal expansion increases in alloys with up to $10 \mathrm{wt} \% \mathrm{Zr}$. The thermal conductivity of $U$ from the same publication (Equation 43 and Equation 46) is shown for comparison. As noted by Basak et al., there is a significant difference between pure $\mathrm{U}$ and an alloy with $2 \mathrm{wt} \% \mathrm{Zr}$.

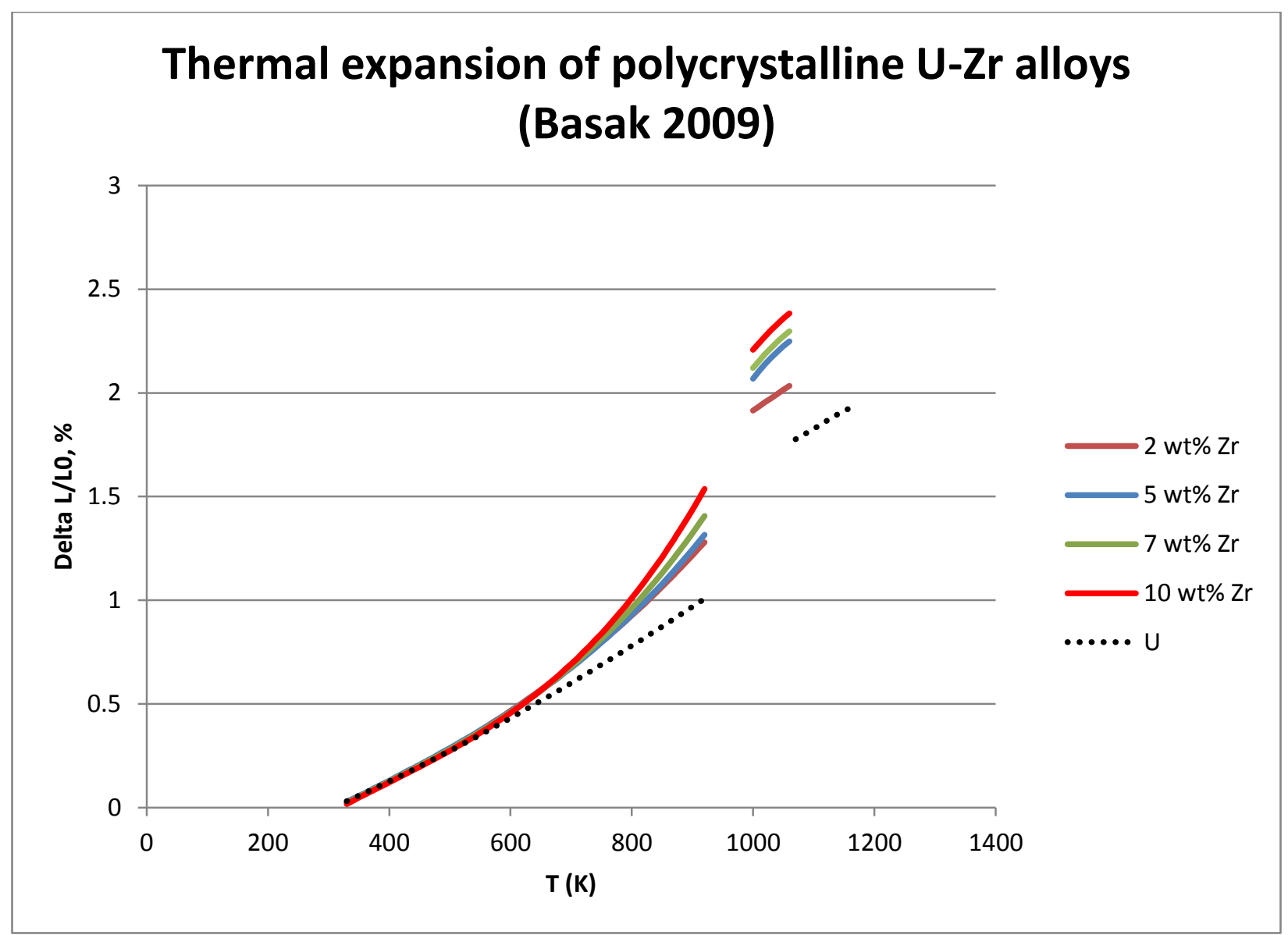

Figure 40. Thermal expansion of $U$ and $U-Z r$ alloys according to Basak et al. [148]

Equation 55 and Equation 56 express the recommended thermal expansion values for $(\alpha-U)$ in well-annealed alloys with 10 and $20 \mathrm{wt} \% \mathrm{Zr}$ from reference [6]. Both equations are reported as accurate to within $\pm 7 \%$ over the entire temperature range. 

[6]

Equation 55. Thermal expansion of U-10 wt\%-Zr from 293 to $900 \mathrm{~K}$ according to Touloukian et al.

$$
\left(\mathrm{L}-\mathrm{L}_{0}\right) / \mathrm{L}_{0}=-0.424+1.658 \times 10^{-3} \times \mathrm{T}-1.052 \times 10^{-6} \times \mathrm{T}^{2}+1.115 \times 10^{-9} \times \mathrm{T}^{3}
$$

where $\left(\mathrm{L}-\mathrm{L}_{0}\right) / \mathrm{L}_{0}$ is thermal expansion in \%, T is temperature in $\mathrm{K}$, T is between 293 and $900 \mathrm{~K}, \mathrm{~L}$ is the length at temperature $\mathrm{T}$, and $\mathrm{L}_{0}$ is length at $293 \mathrm{~K}$ [6]

Equation 56. Thermal expansion of U-20 wt\%-Zr from 293 to $900 \mathrm{~K}$ according to Touloukian et al.

$$
\left(\mathrm{L}-\mathrm{L}_{0}\right) / \mathrm{L}_{0}=-0.301+1.160 \times 10^{-3} \times \mathrm{T}-7.790 \times 10^{-7} \times \mathrm{T}^{2}+1.080 \times 10^{-9} \times \mathrm{T}^{3}
$$

where $\left(\mathrm{L}-\mathrm{L}_{0}\right) / \mathrm{L}_{0}$ is thermal expansion in $\%$, T is temperature in $\mathrm{K}$, $\mathrm{T}$ is between 293 and $900 \mathrm{~K}, \mathrm{~L}$ is the length at temperature $\mathrm{T}$, and $\mathrm{L}_{0}$ is length at $293 \mathrm{~K}$

Basak et al. [148] also fitted their data with polynomials (Equation 57 through Equation 64):

Equation 57. Thermal expansion of $(\alpha-\mathrm{U})$ in $\mathrm{U}-2 \mathrm{wt} \%-\mathrm{Zr}$ from 323 to $923 \mathrm{~K}$ according to Basak et al. [148]

$$
\left(\mathrm{L}-\mathrm{L}_{0}\right) / \mathrm{L}_{0}=-0.381+12.238 \times 10^{-4} \times \mathrm{T}-2.793 \times 10^{-7} \times \mathrm{T}^{2}+9.904 \times 10^{-10} \times \mathrm{T}^{3}
$$

where $\left(\mathrm{L}-\mathrm{L}_{0}\right) / \mathrm{L}_{0}$ is thermal expansion in $\%$, T is temperature in $\mathrm{K}, \mathrm{T}$ is between 323 and $923 \mathrm{~K}, \mathrm{~L}$ is the length at temperature $\mathrm{T}$, and $\mathrm{L}_{0}$ is length at $323 \mathrm{~K}$

Equation 58. Thermal expansion of $(\gamma-\mathrm{U})$ in $\mathrm{U}-2 \mathrm{wt} \%$-Zr from 998 to $1173 \mathrm{~K}$ according to Basak et al [148]

$$
\left(\mathrm{L}-\mathrm{L}_{0}\right) / \mathrm{L}_{0}=-7.775+2.405 \times 10^{-2} \times \mathrm{T}-2.105 \times 10^{-5} \times \mathrm{T}^{2}+0.669 \times 10^{-8} \times \mathrm{T}^{3}
$$

$\mathrm{K}$

where $\left(\mathrm{L}-\mathrm{L}_{0}\right) / \mathrm{L}_{0}$ is thermal expansion in \%, T is temperature in $\mathrm{K}$, and $\mathrm{T}$ is between 998 and 1173

Equation 59. Thermal expansion of $(\alpha-\mathrm{U})$ in $\mathrm{U}-5 \mathrm{wt} \%-\mathrm{Zr}$ from 323 to $923 \mathrm{~K}$ according to Basak et al. [148]

$$
\left(\mathrm{L}-\mathrm{L}_{0}\right) / \mathrm{L}_{0}=-0.539+2.181 \times 10^{-3} \times \mathrm{T}-2.1 \times 10^{-6} \times \mathrm{T}^{2}+2.087 \times 10^{-9} \times \mathrm{T}^{3}
$$

where $\left(\mathrm{L}-\mathrm{L}_{0}\right) / \mathrm{L}_{0}$ is thermal expansion in \%, T is temperature in $\mathrm{K}, \mathrm{T}$ is between 323 and $923 \mathrm{~K}, \mathrm{~L}$ is the length at temperature $\mathrm{T}$, and $\mathrm{L}_{0}$ is length at $323 \mathrm{~K}$

Equation 60. Thermal expansion of $(\gamma-\mathrm{U})$ in $\mathrm{U}-5 \mathrm{wt} \%-\mathrm{Zr}$ from 998 to $1173 \mathrm{~K}$ according to Basak et al. [148]

$$
\left(\mathrm{L}-\mathrm{L}_{0}\right) / \mathrm{L}_{0}=-55.041+14.778 \times 10^{-2} \times \mathrm{T}-12.804 \times 10^{-5} \times \mathrm{T}^{2}+3.737 \times 10^{-8} \times \mathrm{T}^{3}
$$

$\mathrm{K}$

where $\left(\mathrm{L}-\mathrm{L}_{0}\right) / \mathrm{L}_{0}$ is thermal expansion in \%, T is temperature in $\mathrm{K}$, and $\mathrm{T}$ is between 998 and 1173

Equation 61. Thermal expansion of $(\alpha-\mathrm{U})$ in $\mathrm{U}-7 \mathrm{wt} \%-\mathrm{Zr}$ from 323 to $923 \mathrm{~K}$ according to Basak et al. [148]

$$
\left(\mathrm{L}-\mathrm{L}_{0}\right) / \mathrm{L}_{0}=-0.62+2.732 \times 10^{-3} \times \mathrm{T}-3.386 \times 10^{-6} \times \mathrm{T}^{2}+3.055 \times 10^{-9} \times \mathrm{T}^{3}
$$

where $\left(\mathrm{L}-\mathrm{L}_{0}\right) / \mathrm{L}_{0}$ is thermal expansion in \%, T is temperature in $\mathrm{K}, \mathrm{T}$ is between 323 and $923 \mathrm{~K}, \mathrm{~L}$ is the length at temperature $\mathrm{T}$, and $\mathrm{L}_{0}$ is length at $323 \mathrm{~K}$

Equation 62. Thermal expansion of $(\gamma-\mathrm{U})$ in $\mathrm{U}-7 \mathrm{wt} \% \mathrm{Z} \mathrm{Zr}$ from 998 to $1173 \mathrm{~K}$ according to Basak et al. [148]

$$
\left(\mathrm{L}-\mathrm{L}_{0}\right) / \mathrm{L}_{0}=-42.52+11.369 \times 10^{-2} \times \mathrm{T}-9.709 \times 10^{-5} \times \mathrm{T}^{2}+2.804 \times 10^{-8} \times \mathrm{T}^{3}
$$


$\mathrm{K}$

where $\left(\mathrm{L}-\mathrm{L}_{0}\right) / \mathrm{L}_{0}$ is thermal expansion in \%, T is temperature in $\mathrm{K}$, and $\mathrm{T}$ is between 998 and 1173

Equation 63. Thermal expansion of $(\alpha-\mathrm{U})$ in $\mathrm{U}-10 \mathrm{wt} \%$-Zr from 323 to $923 \mathrm{~K}$ according to Basak et al. [148]

$\left(\mathrm{L}-\mathrm{L}_{0}\right) / \mathrm{L}_{0}=-0.73+3.489 \times 10^{-3} \times \mathrm{T}-5.154 \times 10^{-6} \times \mathrm{T}^{2}+4.39 \times 10^{-9} \times \mathrm{T}^{3}$

where $\left(\mathrm{L}-\mathrm{L}_{0}\right) / \mathrm{L}_{0}$ is thermal expansion in \%, T is temperature in $\mathrm{K}, \mathrm{T}$ is between 323 and $923 \mathrm{~K}, \mathrm{~L}$ is the length at temperature $\mathrm{T}$, and $\mathrm{L}_{0}$ is length at $323 \mathrm{~K}$

Equation 64. Thermal expansion of $(\gamma-\mathrm{U})$ in $\mathrm{U}-10 \mathrm{wt} \%-\mathrm{Zr}$ from 998 to $1173 \mathrm{~K}$ according to Basak et al. [148]

$\left(\mathrm{L}-\mathrm{L}_{0}\right) / \mathrm{L}_{0}=-25.252+6.669 \times 10^{-2} \times \mathrm{T}-5.441 \times 10^{-5} \times \mathrm{T}^{2}+1.518 \times 10^{-8} \times \mathrm{T}^{3}$

$\mathrm{K}$

where $\left(\mathrm{L}-\mathrm{L}_{0}\right) / \mathrm{L}_{0}$ is thermal expansion in \%, T is temperature in $\mathrm{K}$, and $\mathrm{T}$ is between 998 and 1173

\subsubsection{Thermal Expansion Coefficients}

Thermal expansion coefficients corresponding to Equation 55and Equation 56 (which approximate the thermal conductivity of alloys with 10 and $20 \mathrm{wt} \% \mathrm{Zr}$ ) can be found in reference [6]. Basak et al. published thermal expansion coefficients for an alloy with $50 \mathrm{wt} \% \mathrm{Zr}$ [54], and Rough published single values expressing coefficients of thermal expansion across relatively wide temperature ranges for U-59 $\mathrm{wt} \% \mathrm{Zr}$ and $\mathrm{U}-78 \mathrm{wt} \% \mathrm{Zr}$ [45]. In view of the inconsistencies in the thermal expansion data and the relative lack of interest in high-Zr alloys for fuels, it seems reasonable to postpone summaries of thermal expansion coefficients until further measurements are available.

\subsubsection{Pu-Zr alloys}

\subsubsection{Introduction}

Thermal expansion of $(\delta-\mathrm{Pu}, \mathrm{Zr})$ solid solutions varies with composition: thermal expansion is negative for alloys with less than $\sim 7.5 \mathrm{at} \% \mathrm{Zr}$ and positive for alloys with $\sim 12 \mathrm{at} \% \mathrm{Zr}$. Alloys with intermediate compositions ( $\sim 8-10$ at $\% \mathrm{Zr}$ ) show relatively little thermal expansion.

The available data on $\varepsilon-(\mathrm{Pu}, \mathrm{Zr})$ solid solutions suggest that their thermal expansion is positive, like that of $\varepsilon-\mathrm{Pu}$ and $\beta-\mathrm{Zr}$.

Solubility of $\mathrm{Zr}$ in $\alpha-, \beta-, \gamma$-, and $\delta^{\prime}$-Pu phases is limited, as is solubility of $\mathrm{Pu}$ in $\alpha$-Zr. In the absence of published experimental data, it seems reasonable to assume that thermal expansion of these phases is similar to that of pure $\mathrm{Pu}$ or $\mathrm{Zr}$.

There are no published experimental data on thermal expansion of $\theta-(\mathrm{Pu}-\mathrm{Zr})$.

\subsubsection{Thermal Expansion}

Reference [166] is the primary source for experimental data on thermal expansion of $\delta$-( $\mathrm{Pu}, \mathrm{Zr}$ ) alloys with $\mathrm{Zr}$ concentrations from $\sim 5-12$ at $\%$ ( 2-5 wt\%). It includes measurements of thermal expansion calculated from high-temperature X-ray diffraction data and data from dilatometry. Results obtained using the two sources of data appear consistent. Reference [167] appears to be an earlier publication of results of some of the experiments in reference [166].

Gschneidner et al. [166] developed polynomial equations that expressed the lengths of their samples (for dilatometer data) or lattice parameters (for X-ray data) as functions of temperature (Table 10).

Figure 41 shows thermal expansion calculated from these equations, calculated using a reference temperature of $400^{\circ} \mathrm{C}$ for convenience. The figure shows a consistent pattern in which thermal expansion 
of $\delta$-(Pu-Zr) solid solutions increases with increasing concentration of Zr. Alloys with less than $10 \mathrm{at} \% \mathrm{Zr}$ show negative thermal expansion. Alloys with $\sim 8$ at $\% \mathrm{Zr}$ show relatively little expansion, and may change between negative and positive expansion depending on temperature. Alloys with 10 or 12 at $\% \mathrm{Zr}$ show positive expansion that increases with the concentration of $\mathrm{Zr}$.

Thermal expansion data from high-temperature $\mathrm{X}$-ray diffraction of nine $\mathrm{Pu}-\mathrm{Zr}$ alloys are plotted in [94 Table 6], but are not tabulated in the reference. These results appear qualitatively consistent with results from reference [166], but suggest that positive thermal expansion occurs only in alloys with at least $\sim 15$ at $\% \mathrm{Zr}$.

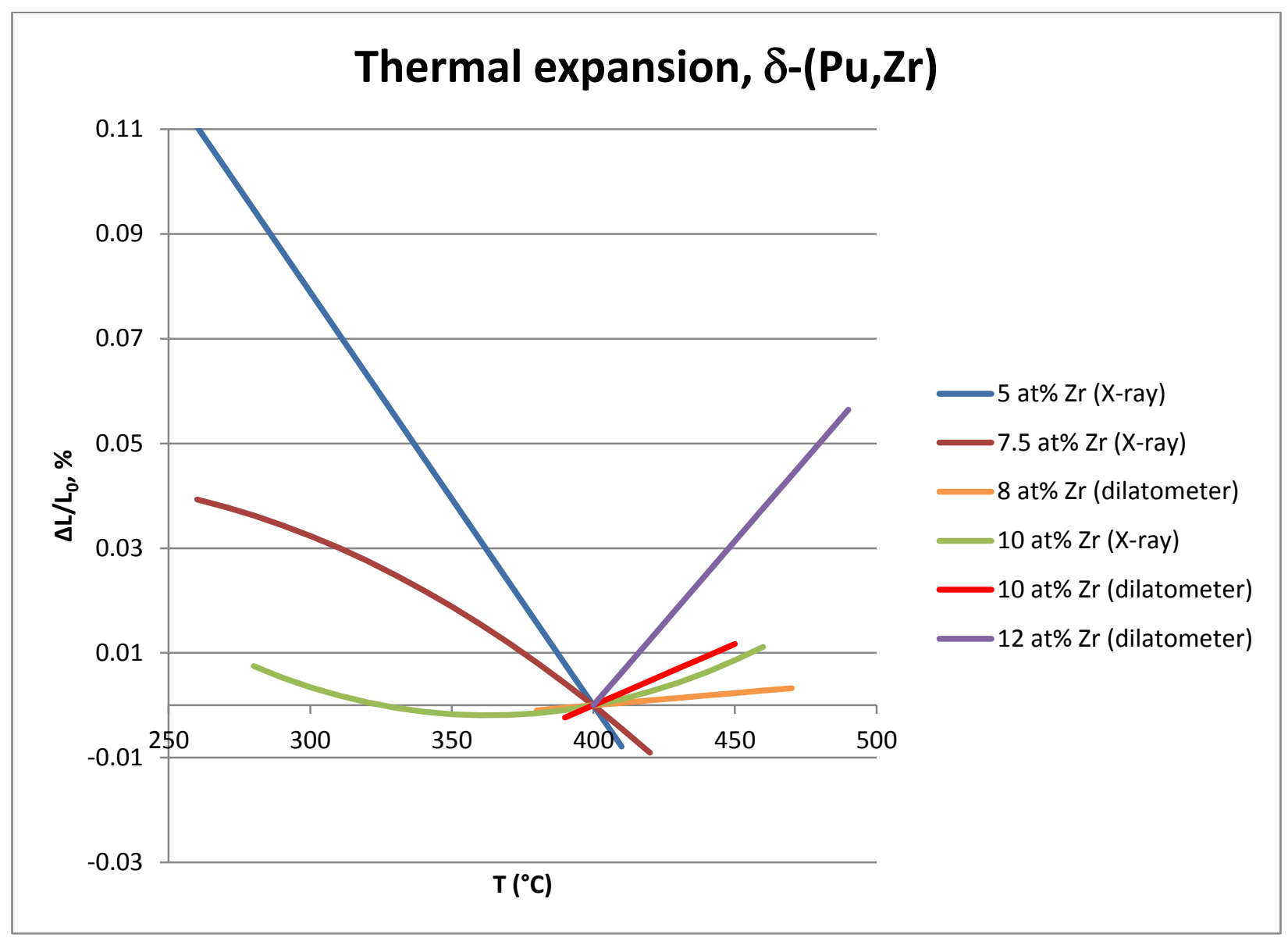

Figure 41. Thermal expansion of Pu-Zr alloys, calculated from data in Table 10 [166] using a reference temperature of $400^{\circ} \mathrm{C}$ 
Table 10. Coefficients for equations expressing lengths of U-Pu alloys, $L=a+b \times T+c \times T 2$, where $L$ is a length (for dilatometer data) or lattice parameter (for X-ray data) and $\mathrm{T}$ is a temperature in ${ }^{\circ} \mathrm{C}$ [166]. The authors emphasize that these coefficients should only be used within the stated temperature ranges.

\begin{tabular}{cllccc}
\hline Composition (at\% Zr) & Measurement Type & $\mathrm{a}$ & $\mathrm{b}$ & $\mathrm{c}$ & $\mathrm{T}$ Range $\left({ }^{\circ} \mathrm{C}\right)$ \\
\hline 5 & X-ray & 4.6495 & $-3.656 \times 10^{-5}$ & -- & $259-410$ \\
7.5 & X-ray & 4.6379 & $1.986 \times 10^{-5}$ & $-4.98 \times 10^{-8}$ & $260-425$ \\
8.0 & Dilatometer & 0.98598 & $0.460 \times 10^{-6}$ & -- & $380-440$ \\
10.0 & X-ray & 4.6459 & $-4.634 \times 10^{-5}$ & $6.39 \times 10^{-8}$ & $275-462$ \\
10.0 & Dilatometer & 0.97372 & $2.284 \times 10^{-6}$ & -- & $391-440$ \\
12.0 & Dilatometer & 1.00776 & $2.284 \times 10^{-6}$ & -- & $401-499$ \\
\hline
\end{tabular}

The only available data on solid solutions between $\varepsilon-\mathrm{Pu}$ and $\beta-\mathrm{Zr}$ indicate that the thermal expansion of this phase is positive, like that of both $\varepsilon-\mathrm{Pu}$ and $\beta-\mathrm{Zr}$ [94].

\subsubsection{Thermal Expansion Coefficients}

Table 11 has thermal expansion coefficients for $\delta$ - $(\mathrm{Pu}, \mathrm{Zr})$ corresponding to the data in Figure 41 and Table 10. A thermal expansion coefficient for $\delta$-Pu is included for comparison. The thermal expansion coefficients are negative for compositions with less than $\sim 8 \mathrm{at} \% \mathrm{Zr}$, small for samples with $\sim 8-10 \mathrm{at} \% \mathrm{Zr}$, and positive for samples with $12 \mathrm{at} \% \mathrm{Zr}$

Table 11. Coefficients of thermal expansion for $\delta-(\mathrm{Pu}, \mathrm{Zr})$. Data for $\mathrm{Pu}$ are from reference [22]; other data are from reference [166]. Coefficients should not be used outside the listed temperature ranges.

\begin{tabular}{|c|c|c|c|}
\hline $\begin{array}{l}\text { Composition } \\
\text { (at } \% \mathrm{Zr} \text { ) }\end{array}$ & $\bar{\alpha} \times 10^{6}{ }^{\circ} \mathrm{C}^{-1}$ & $\begin{array}{l}\text { Temperature } \\
\text { Range } \\
\text { For } \bar{\alpha}\left({ }^{\circ} \mathrm{C}\right)\end{array}$ & $\begin{array}{l}\text { Measurement } \\
\text { Type }\end{array}$ \\
\hline $\mathrm{Pu}$ & -8.6 & $320-440$ & \\
\hline 5.0 & -7.88 & $300-401$ & $\begin{array}{r}\text { X-ray } \\
\text { diffraction }\end{array}$ \\
\hline 7.5 & -3.50 & $300-425$ & $\begin{array}{r}\text { X-ray } \\
\text { diffraction }\end{array}$ \\
\hline 8.0 & 0.47 & $380-440$ & Dilatometer \\
\hline 10.0 & 0.21 & $300-440$ & $\begin{array}{r}\text { X-ray } \\
\text { diffraction }\end{array}$ \\
\hline 10.0 & 2.34 & $391-440$ & Dilatometer \\
\hline 12.0 & 6.28 & $401-440$ & Dilatometer \\
\hline
\end{tabular}

Thermal expansion coefficients for $\varepsilon-\mathrm{Pu} / \beta-\mathrm{Zr}$ solid solutions were reported by Marples [94]. The data show considerable scatter, but suggest that the thermal expansion coefficient decreases from $27 \times 10^{-6}$ per ${ }^{\circ} \mathrm{C}$ for pure $\varepsilon$-Pu to $\sim 20.5 \times 10^{-6} \mathrm{per}^{\circ} \mathrm{C}$ for alloys with 20 at $\% \mathrm{Zr}$. This value for the thermal expansion coefficient of $\varepsilon-\mathrm{Pu}$ is significantly lower than the commonly accepted value of $36.5 \times 10^{-6}$ per ${ }^{\circ} \mathrm{C}$ [22], suggesting that coefficients for $\mathrm{Pu}-\mathrm{Zr}$ alloys may be too low.

\subsubsection{U-Pu alloys}

\subsubsection{Introduction}

Published data on thermal expansion of U-Pu alloys are limited to a single report of thermal expansion of an alloy with $15 \mathrm{wt} \%(\sim 15$ at $\%) \mathrm{Pu}$, early reports of average coefficients of thermal 
expansion for alloys with 10 and $20 \mathrm{at} \% \mathrm{Pu}$, and measurements of changes in lattice parameters in $\zeta-(\mathrm{U}, \mathrm{Pu})$ in an alloy with $60 \mathrm{at} \% \mathrm{Pu}$. No data on the thermal expansion of $\eta-(\mathrm{U}, \mathrm{Pu})$ or any alloy with more than 60 at $\% \mathrm{Pu}$ is available.

Samples of U-Pu alloys may exhibit marked changes as a result of thermal cycling. For example, one sample of an alloy with $10 \mathrm{wt} \% \mathrm{Pu}$ that was cycled between 450 and $700^{\circ} \mathrm{C}$ experienced a $25 \%$ increase in length and 30\% decrease in density, even though the sample was held at temperature for long enough to assure completion of phase transformations between cycles [135].

\subsubsection{Thermal Expansion}

Kaity et al. [118] measured changes in length of a sample of a U-15wt\% Pu alloy with a high-temperature dilatometer. They divided their thermal expansion data into three temperature ranges, separated by two phase transformations: $(\alpha-\mathrm{U})$ to $(\beta-\mathrm{U})$ beginning at $842 \mathrm{~K}$, and $(\beta-\mathrm{U})$ to $(\gamma-\mathrm{U})$ from 992 to $1009 \mathrm{~K}$. The $(\alpha-U)$ to $(\beta-U)$ transformation was associated with a length increase $\left(\Delta \mathrm{L} / \mathrm{L}_{0}\right)$ of $0.275 \%$, and the $(\beta-U)$ to $(\gamma-U)$ transformation was associated with a length increase of $0.14 \%$. Kaity et al. fitted their data using three polynomials (Equation 65, Equation 66, and Equation 67), which are shown in Figure 42.

The corresponding mean coefficient of thermal expansion for the U-15Pu alloy between 300 and $823 \mathrm{~K}$ is $18.58 \times 10^{-6} \mathrm{~K}^{-1}$ [118]. This value is smaller than those reported for U-10 Pu by Kelman et al. $[114,135]\left(19.4 \times 10^{-6}\right.$ per ${ }^{\circ} \mathrm{C}$ from $25^{\circ} \mathrm{C}$ to the first phase transformation, and $25.6 \times 10^{-6 \circ}$ per ${ }^{\circ} \mathrm{C}$ from the end of the transformation to $\left.720^{\circ} \mathrm{C}\right)$ and for U-20 Pu by Boucher et al. $[129,130]\left(21 \times 10^{-6}\right.$ per ${ }^{\circ} \mathrm{C}$ from $20-500^{\circ} \mathrm{C}$ ). However, all of the determinations of the thermal expansion coefficient agree closely enough that it seems reasonable to consider the average coefficient of thermal expansion determined by Kaity et al. [118] to be a reasonable estimate for U-Pu alloys with up to $\sim 20 \% \mathrm{Pu}$. 


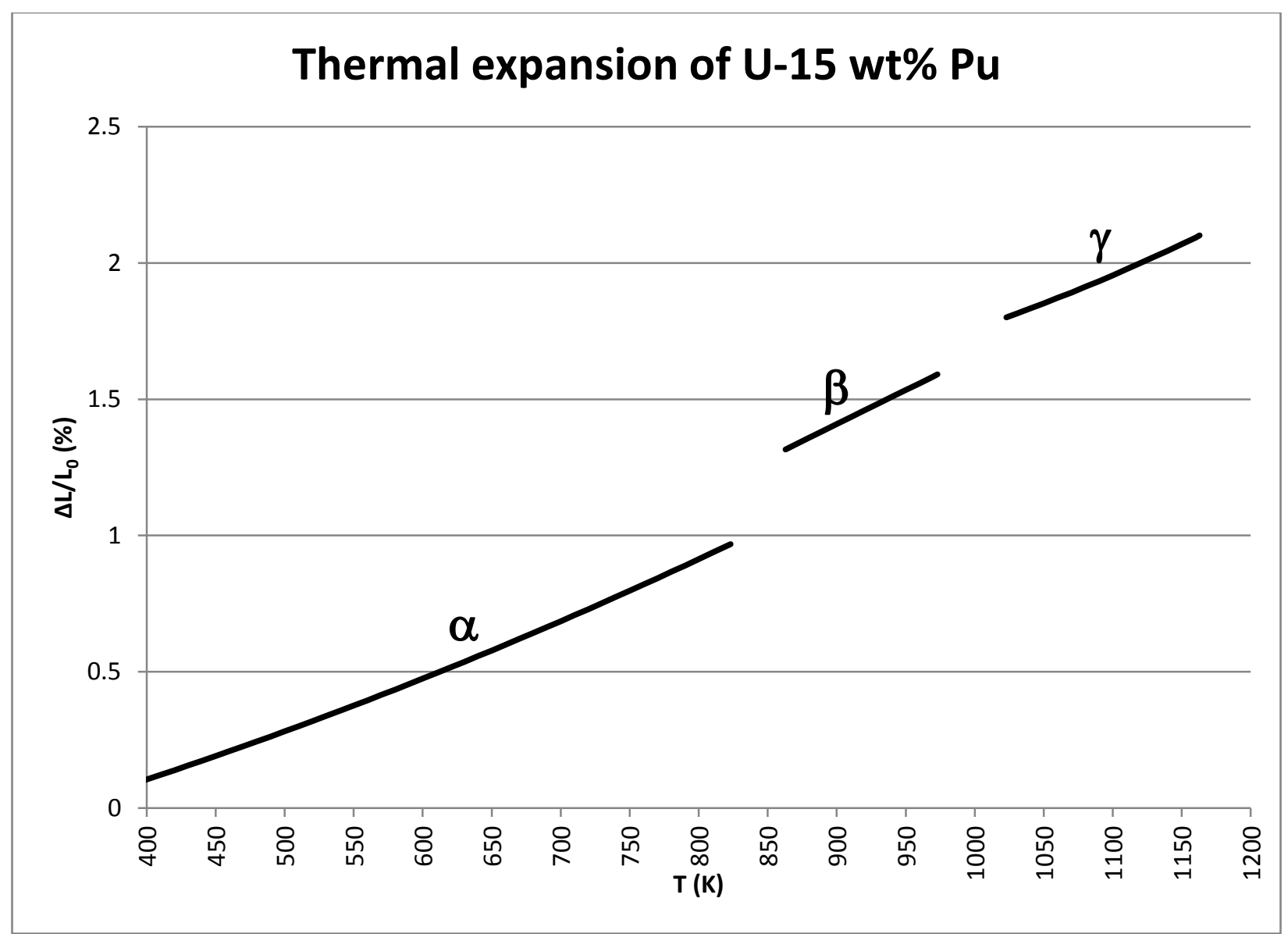

Figure 42. Thermal expansion of U-15 wt $\%$ (15 at\%) Pu, calculated using Equation 65, Equation 66, and Equation 67 
Equation 65. Thermal expansion of $(\alpha-\mathrm{U})$ in $\mathrm{U}-15 \mathrm{wt} \%$-Pu from 393 to $823 \mathrm{~K}$ according to Kaity et al. [118]

$$
\left(\mathrm{L}-\mathrm{L}_{0}\right) / \mathrm{L}_{0}=-0.431+1.000 \times 10^{-3} \times \mathrm{T}+8.509 \times 10^{-7} \times \mathrm{T}^{2}
$$

where $\left(\mathrm{L}-\mathrm{L}_{0}\right) / \mathrm{L}_{0}$ is thermal expansion in \%, T is temperature in $\mathrm{K}, \mathrm{T}$ is between 393 and $893 \mathrm{~K}, \mathrm{~L}$ is the length at temperature $\mathrm{T}$, and $\mathrm{L}_{0}$ is length at $300 \mathrm{~K}$ al. [118]

Equation 66. Thermal expansion of ( $\beta-\mathrm{U})$ in $\mathrm{U}-15 \mathrm{wt} \%$-Pu from 863 to $973 \mathrm{~K}$ according to Kaity et

$$
\left(\mathrm{L}-\mathrm{L}_{0}\right) / \mathrm{L}_{0}=-0.976+2.790 \times 10^{-3} \times \mathrm{T}-1.562 \times 10^{-7} \times \mathrm{T}^{2}
$$

where $\left(\mathrm{L}-\mathrm{L}_{0}\right) / \mathrm{L}_{0}$ is thermal expansion in \%, T is temperature in $\mathrm{K}, \mathrm{T}$ is between 863 and $973 \mathrm{~K}, \mathrm{~L}$ is the length at temperature $\mathrm{T}$, and $\mathrm{L}_{0}$ is length at $300 \mathrm{~K}$

Equation 67. Thermal expansion of $(\gamma-\mathrm{U})$ in U-15 wt\%-Pu from 1023 to $1163 \mathrm{~K}$ according to Kaity et al. [118]

$$
\left(\mathrm{L}-\mathrm{L}_{0}\right) / \mathrm{L}_{0}=2.249-2.710 \times 10^{-3} \times \mathrm{T}+22.204 \times 10^{-7} \times \mathrm{T}^{2}
$$

where $\left(\mathrm{L}-\mathrm{L}_{0}\right) / \mathrm{L}_{0}$ is thermal expansion in \%, T is temperature in $\mathrm{K}, \mathrm{T}$ is between 393 and $893 \mathrm{~K}, \mathrm{~L}$ is the length at temperature $\mathrm{T}$, and $\mathrm{L}_{0}$ is length at $300 \mathrm{~K}$

\subsubsection{Thermal expansion of $\zeta-(U, P u)$}

Lattice parameters of $\zeta$-(U,Pu) in a sample with composition $\mathrm{Pu}_{0.60} \mathrm{U}_{0.40}$ were measured at temperatures between $\sim 302$ and $650 \mathrm{~K}$ [116 Figure 8] using high-resolution neutron diffraction. The lattice parameter $a$ increased with temperature, and the rhombohedral angle $\alpha$ decreased, changing the shape of the unit cell and increasing its volume slightly (Table 12).

Table 12. Lattice parameters and unit-cell volume for $\zeta_{-}(\mathrm{U}, \mathrm{Pu})$ as a function of temperature, based on data read from [116 Figure 8]

\begin{tabular}{rrrr}
\hline $\mathrm{T}(\mathrm{K})$ & $a(\AA)$ & $\begin{array}{c}\alpha \\
\text { (degrees) }\end{array}$ & \multicolumn{1}{l}{$\begin{array}{l}\text { Volume } \\
\left(\AA^{3}\right)\end{array}$} \\
\hline 302 & 10.684 & 89.74 & 1220 \\
430 & 10.704 & 89.71 & 1226 \\
580 & 10.756 & 89.53 & 1244 \\
630 & 10.772 & 89.45 & 1250 \\
675 & 10.783 & 89.33 & 1254 \\
\hline
\end{tabular}

Based on this table, the mean volumetric coefficient of expansion $\Delta \mathrm{V} /\left(\mathrm{V}_{0} \times \Delta \mathrm{T}\right)$ is $\sim 7.5 \times 10^{-5} / \mathrm{K}$ for temperatures between 302 and $675 \mathrm{~K}$.

\subsubsection{U-Pu-Zr alloys}

\subsubsection{Introduction}

Published measurements of thermal expansion coefficients for $\mathrm{U}-\mathrm{Pu}-\mathrm{Zr}$ alloys were originally reported by researchers at CEA [129] and Argonne National Laboratory (ANL) [168]. Other publications (e.g., $[5,114,130,135,169])$ repeat these data. All of the published data are from alloys with 11-20 wt\% $\mathrm{Pu}$ and 6-15 wt\% Zr. Within this composition range, there is generally good agreement about thermal expansion coefficients and thermal expansion associated with phase transformations. No data about thermal expansion of alloys with other compositions are available.

U-Pu-Zr alloys have been reported to experience "catastrophic" events (including density losses of almost $0.7 \mathrm{~g} / \mathrm{cm}^{3}$ and catching fire) during thermal cycling experiments at temperatures as low as 
$\sim 650-750^{\circ} \mathrm{C}[125,129]$. Thermal cycling phenomena are strongly dependent on the starting microstructure (particularly centerline porosity and preferred orientation) [125].

\subsubsection{Thermal Expansion Coefficients}

The published measurements generally fall within two temperature ranges separated by phase transformations: room temperature to $\sim 600^{\circ} \mathrm{C}$, and above $\sim 660^{\circ} \mathrm{C}$ (Table 13, Table 14). Reported coefficients of thermal expansion below the phase transformations range from $16.3 \times 10^{-6} /{ }^{\circ} \mathrm{C}$ to $18.3 \times 10^{-6} /{ }^{\circ} \mathrm{C}$, and reported coefficients of thermal expansion above the phase transformations range from $18.1 \times 10^{-6} /{ }^{\circ} \mathrm{C}$ to $20.1 \times 10^{-6} /{ }^{\circ} \mathrm{C}$. In view of the relatively small variation in the reported values and the lack of an obvious correlation between thermal expansion coefficients and composition, it seems reasonable to estimate the thermal expansion coefficients of alloys with $\sim 10-20 \mathrm{wt} \% \mathrm{Pu}$ and $5-15 \mathrm{wt} \% \mathrm{Zr}$ by using the average values of the reported data $\left(17.4 \times 10^{-6} /{ }^{\circ} \mathrm{C}\right.$ below the phase transformations and $19.4 \times 10^{-6} /{ }^{\circ} \mathrm{C}$ above).

Table 13. Thermal expansion coefficients for U-Pu-Zr alloys between room temperature and $600^{\circ} \mathrm{C}$.

\begin{tabular}{|c|c|c|c|c|}
\hline $\begin{array}{l}\text { Composition } \\
(\mathrm{wt} \%)\end{array}$ & $\begin{array}{l}\text { Composition } \\
\text { (at } \%)\end{array}$ & $\begin{array}{l}\text { Coefficient of } \\
\text { Thermal } \\
\text { Expansion } \\
\times 10^{6}\left(\text { per }^{\circ} \mathrm{C}\right)\end{array}$ & $\begin{array}{l}\text { Temperature } \\
\text { Range } \\
\left({ }^{\circ} \mathrm{C}\right)\end{array}$ & References \\
\hline $\mathrm{U}-11.1 \mathrm{Pu}-6.3 \mathrm{Zr}$ & $\mathrm{U}-10 \mathrm{Pu}-15 \mathrm{Zr}$ & 18.3 & $25-595$ & $\begin{array}{l}{[5,114,135,} \\
168]\end{array}$ \\
\hline $\mathrm{U}-15 \mathrm{Pu}-10 \mathrm{Zr}$ & $\mathrm{U}-13 \mathrm{Pu}-22.5 \mathrm{Zr}$ & 17.6 & $25-595$ & $\begin{array}{l}{[5,114,135,} \\
168]\end{array}$ \\
\hline $\mathrm{U}-15 \mathrm{Pu}-10 \mathrm{Zr}$ & $\mathrm{U}-13 \mathrm{Pu}-22.5 \mathrm{Zr}$ & 16.3 & $20-600$ & $\begin{array}{l}{[5,114,129,} \\
130]\end{array}$ \\
\hline $\mathrm{U}-20 \mathrm{Pu}-10 \mathrm{Zr}$ & $\mathrm{U}-17 \mathrm{Pu}-23 \mathrm{Zr}$ & 17.3 & $20-586$ & $\begin{array}{l}{[5,114,129,130,} \\
169]\end{array}$ \\
\hline $\mathrm{U}-18.5 \mathrm{Pu}-14.1 \mathrm{Zr}$ & $\mathrm{U}-15 \mathrm{Pu}-30 \mathrm{Zr}$ & 17.5 & $25-595$ & $\begin{array}{l}{[5,114,135,} \\
168]\end{array}$ \\
\hline $\mathrm{U}-17.1 \mathrm{Pu}-3.4 \mathrm{Zr}^{1}$ & $\mathrm{U}-15 \mathrm{Zr}-15 \mathrm{Pu}$ & 21.2 & $25-570$ & {$[168]$} \\
\hline Average & & 17.4 & $20-600$ & \\
\hline
\end{tabular}

${ }^{1}$ Weight and atomic percentages are inconsistent. Assuming atomic percentages are correct, this alloy contains $\sim 6.3 \mathrm{wt} \%$ $\mathrm{Zr}$. This alloy is not included in the average value because the range of measured temperatures does not include a gap for phase transformations.

Table 14. Thermal expansion coefficients for $\mathrm{U}-\mathrm{Pu}-\mathrm{Zr}$ alloys between room temperature and $600^{\circ} \mathrm{C}$.

\begin{tabular}{ccccc}
\hline $\begin{array}{c}\text { Composition } \\
(\mathrm{wt} \%)\end{array}$ & $\begin{array}{c}\text { Composition } \\
(\mathrm{at} \%)\end{array}$ & $\left.\begin{array}{c}\text { Coefficient } \\
\text { of Thermal } \\
\text { Expansion } \\
\times 10^{6}(\text { per }\end{array}{ }^{\circ} \mathrm{C}\right)$ & T Range \\
$\left({ }^{\circ} \mathrm{C}\right)$ & References \\
\hline $\mathrm{U}-11.1 \mathrm{Pu}-6.3 \mathrm{Zr}$ & $\mathrm{U}-10 \mathrm{Pu}-15 \mathrm{Zr}$ & 18.1 & $680-950$ & {$[114,135,168]$}
\end{tabular}




\begin{tabular}{|c|c|c|c|c|}
\hline $\mathrm{U}-15 \mathrm{Pu}-10 \mathrm{Zr}$ & $\mathrm{U}-12.9 \mathrm{Pu}-22.5 \mathrm{Zr}$ & 20.1 & $665-950$ & $\begin{array}{l}{[5,114,135,} \\
168]\end{array}$ \\
\hline $\mathrm{U}-18.5 \mathrm{Pu}-14.1 \mathrm{Zr}$ & $\mathrm{U}-15 \mathrm{Pu}-30 \mathrm{Zr}$ & 20.0 & $660-950$ & $\begin{array}{l}{[5,114,135,} \\
168]\end{array}$ \\
\hline U-Pu17.1-Zr3.4 & $\mathrm{U}-15 \mathrm{Zr}-15 \mathrm{Pu}$ & 16.4 & $570-860$ & [168] \\
\hline \multicolumn{2}{|c|}{ Average } & 19.4 & $660-950$ & \\
\hline
\end{tabular}

${ }^{1}$ Weight and atomic percentages are inconsistent. Assuming atomic percentages are correct, this alloy contains $\sim 6.3 \mathrm{wt} \% \mathrm{Zr}$. This alloy is not included in the average value because the range of measured temperatures does not include a gap for phase transformations.

\subsubsection{Thermal Expansion as a Result of Phase Transformations}

Table 15 shows reported changes in length associated with phase transformations in U-Pu-Zr alloys. The total thermal expansion associated with phase transformations between $\sim 585$ and $680^{\circ} \mathrm{C}$ is generally reported as $\sim 0.5 \%$ in data originally published by ANL [168] and $\sim 0.3 \%$ in data originally published by CEA [129]. However, reference [129] recognizes two phase transformations within this temperature range and only reports expansion due to the larger of the two, while reference [168] reported only one transformation. Thus, it seems reasonable to assume that the total thermal expansion $\left(\Delta \mathrm{L} / \mathrm{L}_{0}\right)$ related to all of the phase transformations between $\sim 585$ and $680^{\circ} \mathrm{C}$ is $\sim 0.5 \%$ for alloys with $\sim 10-20 \mathrm{wt} \% \mathrm{Pu}$ and $5-15$ wt $\% \mathrm{Zr}$.

Table 15. Length changes (in \%) from phase transformations in U-Pu-Zr alloys.

$\begin{array}{lccc}\begin{array}{c}\text { Composition } \\ (\mathrm{wt} \%)\end{array} & \begin{array}{c}\text { Length Change } \\ \left(\Delta \mathrm{L} / \mathrm{L}_{0}, \%\right)\end{array} & \begin{array}{c}\text { Temperature Range } \\ \left({ }^{\circ} \mathrm{C}\right)\end{array} & \text { References } \\ \mathrm{U}-11.1 \mathrm{Pu}-6.3 \mathrm{Zr} & 0.51 & 595-680 & {[114,135,168]} \\ \mathrm{U}-15 \mathrm{Pu}-10 \mathrm{Zr} & 0.52 & 595-665 & {[114,135,168]} \\ \mathrm{U}-15 \mathrm{Pu}-10 \mathrm{Zr} & 0.3^{1} & 645^{1} & {[129]} \\ \mathrm{U}-20 \mathrm{Pu}-10 \mathrm{Zr} & 0.3^{1} & 650^{1} & {[129]} \\ \mathrm{U}-18.5 \mathrm{Pu}-14.1 \mathrm{Zr} & 0.50 & 595-660 & {[114,135,168]} \\ \mathrm{U}-\mathrm{Pu} 17.1-\mathrm{Zr} 3.4^{2} & 0.93 & 570-780 & {[168]} \\ { }^{1} \mathrm{Refers} \mathrm{to} \mathrm{only} \mathrm{one} \mathrm{of} \mathrm{two} \mathrm{transformations.} & & \\ { }^{2} \mathrm{Weight} \text { and atomic percentages are inconsistent. Assuming atomic percentages are correct, this alloy contains } \sim 6.3 \mathrm{wt} \% \\ \text { Its length change is not included in discussion, as data do not report thermal expansion from phase transformations }\end{array}$




\subsection{THERMAL CONDUCTIVITY AND THERMAL DIFFUSIVITY}

\subsubsection{U}

\subsubsection{Introduction}

At least 100 measurements of the thermal conductivity of $U$ have been made, with most of them published before 1970. Recommended values in a 2014 review by Kim et al. [170] are in excellent agreement with a 2012 measurement not included in the review [84]. There is also excellent agreement that the thermal conductivity increases by $\sim 0.02 \mathrm{~W} / \mathrm{m} \cdot \mathrm{K}$ between $\sim 290$ and $1173 \mathrm{~K}$, a temperature range that includes the $\alpha-\beta$ phase transformation. However, a 2008 compilation of data by the IAEA [140] recommends thermal conductivity values that are 10-20\% lower than those recommended by Kim et al. The good agreement between the new measurements and the recommended values of Kim et al. suggests that the review may be a better representation of the actual thermal conductivity than the values in the IAEA tabulation. However, more research is needed to resolve this issue.

\subsubsection{Thermal Conductivity}

Reviews of the thermal conductivity of $U$ include those by Touloukian et al. [8], Kim et al. [170], and the IAEA [171]. The review of Kim et al. includes the data used by Touloukian et al. as well as data from Takahashi et al. [172], but does not include the measurements reported by Kaity et al. [84]. The IAEA report provides three estimates of thermal conductivity based on different weightings of the same data, with one of the three being used in a recent IAEA compilation of data [140].

Figure 43 compares thermal conductivity determinations from the reviews by Kim et al. and the IAEA and a recent original measurement not included in either of the reviews [84, 140, 170]. Plotted values from all three sources have similar slopes, which indicate that that the thermal conductivity increases by $\sim 0.02 \mathrm{~W} / \mathrm{m} \mathrm{K}$ within the range of each of the curves; however, the thermal conductivity from the IAEA tabulation is $\sim 10-20 \%$ lower than either of the other curves. The good agreement between the new measurements of Kaity et al. [84] and the recommended thermal conductivity in the review by Kim et al. [170] suggests that the Kim et al. review may be a better representation of the actual thermal conductivity than the values in the IAEA tabulation. However, more research is needed to resolve this issue. 


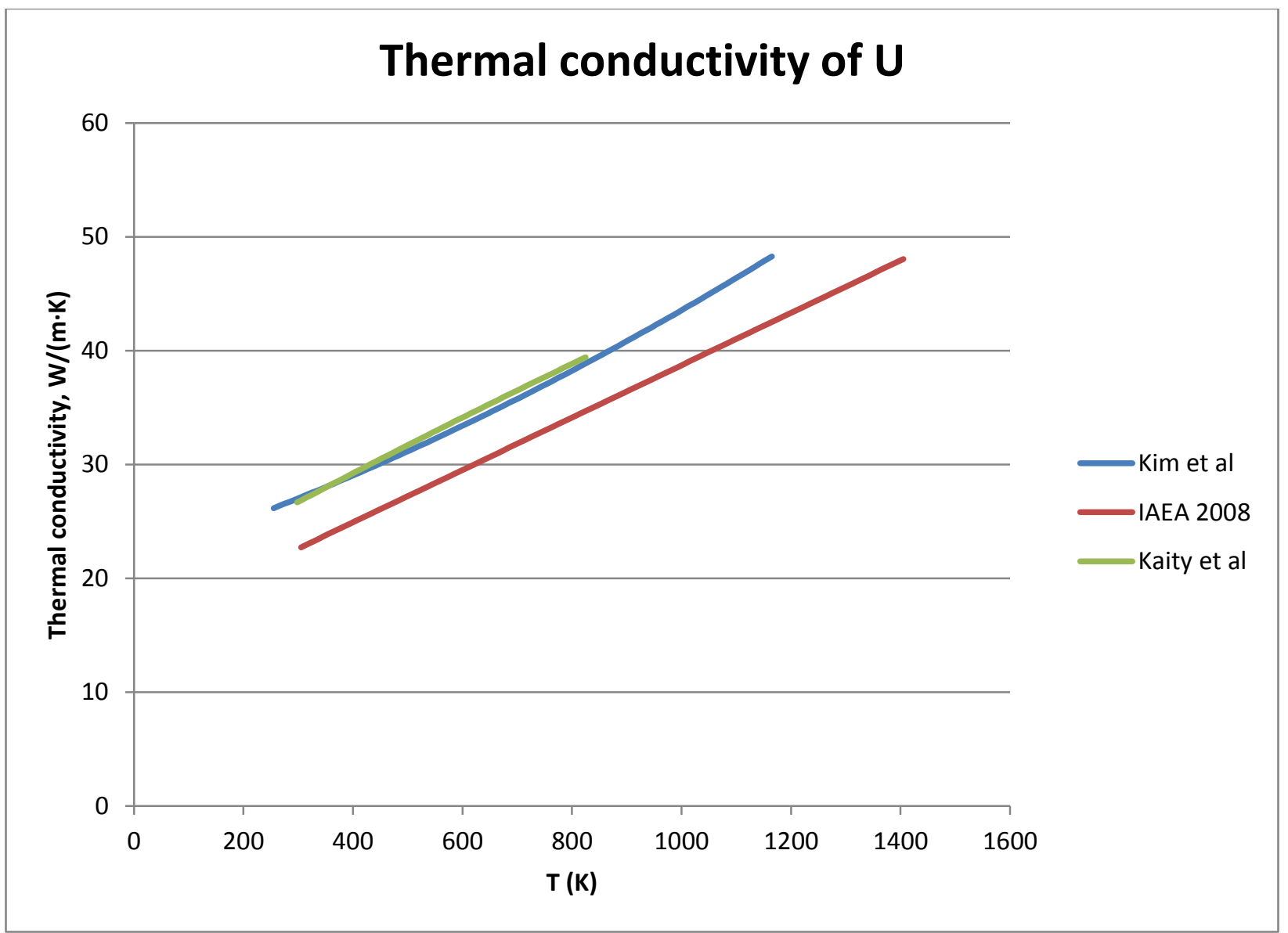

Figure 43. Thermal conductivity of U (Equation 68, Equation 69, and Equation 70).

The equations used to generate the data in the plot are:

Equation 68. Thermal conductivity of $U$ from 255 to $1173 \mathrm{~K}$ according to Kim et al. [170] $\mathrm{k}=21.73+1.591 \times 10^{-2} \times \mathrm{T}+5.907 \times 10^{-6} \times \mathrm{T}^{2}$ K where $\mathrm{k}$ is thermal conductivity in $\mathrm{W} / \mathrm{m} \cdot \mathrm{K}, \mathrm{T}$ is temperature in $\mathrm{K}$, and $\mathrm{T}$ is between 255 and 1173

Equation 69. Thermal conductivity of $U$ from 298 to $823 \mathrm{~K}$ according to Kaity et al. [84] $\mathrm{k}=18.890+2.678 \times 10^{-2} \times \mathrm{T}-2.302 \times 10^{-6} \times \mathrm{T}^{2}$ $\mathrm{K}$ where $\mathrm{k}$ is thermal conductivity in $\mathrm{W} / \mathrm{m} \cdot \mathrm{K}, \mathrm{T}$ is temperature in $\mathrm{K}$, and $\mathrm{T}$ is between 298 and 823

Equation 70. Thermal conductivity of $U$ from 293 to $1405 \mathrm{~K}$ according to the IAEA [140] $\mathrm{k}=22+0.023 \times(\mathrm{T}-273)$ K where $\mathrm{k}$ is thermal conductivity in $\mathrm{W} / \mathrm{m} \cdot \mathrm{K}, \mathrm{T}$ is temperature in $\mathrm{K}$, and $\mathrm{T}$ is between 293 and 1405 


\subsection{2 $\mathrm{Pu}$}

\subsubsection{Introduction}

There are few studies of the thermal conductivity or diffusivity of $\mathrm{Pu}$, and almost all were published before 1980. However, in 2008, Alexander and Wood [173] reported thermal conductivities of all of the solid $\mathrm{Pu}$ phases based on new measurements of thermal diffusivities of two Pu samples. They determined that the thermal conductivity of each phase except $\delta^{\prime}-\mathrm{Pu}$ (which is difficult to study because of its narrow temperature range of stability) increased approximately linearly with temperature, and that the thermal conductivity of $\delta^{\prime}$-Pu decreased with temperature. They also noted that all of their data could be fitted to within an error of $\sim 5 \%$ by a single quadratic equation.

Kim et al. [170] recently reviewed the thermal conductivity of $\mathrm{Pu}$, and agreed with values determined by Alexander and Wood [173] to within $\sim 10 \%$ for all phases except $\delta^{\prime}-\mathrm{Pu}$. The two studies apparently have no data in common. Both of these assessments have thermal conductivity values that are significantly higher than those in a recent IAEA data summary [140] for all solid Pu phases except $\alpha-\mathrm{Pu}$. However, the good agreement between the thermal conductivities determined by Alexander and Wood and by Kim et al. suggests that these studies are good approximations of the actual behavior of $\mathrm{Pu}$, with preference given to the results of Alexander and Wood because they are based on direct measurements of well-characterized starting materials. Either of these studies is probably a more accurate representation of the actual behavior of $\mathrm{Pu}$ than the values in the IAEA tabulation. Unless phase-specific information is required, the single quadratic equation developed by Alexander and Wood is a convenient approximation.

\subsubsection{Lorenz number}

Values of the room-temperature Lorenz number for Pu determined before 1974 vary widely, with a thorough review by Ho et al. [15] concluding that a value of $3.15 \mathrm{~W} \Omega / \mathrm{K}^{2}$ for polycrystalline $\alpha-\mathrm{Pu}$ based on the electrical resistivity and thermal conductivity measurements of Andrew [174] appeared the most plausible. This value appeared in a recent review by Konings [3 Figure 22] and is the best currently available estimate of the Lorenz number for $\mathrm{Pu}$.

\subsubsection{Thermal Conductivity}

Recent attempts to determine the thermal conductivity of Pu have taken different approaches: Alexander and Wood [173] calculated thermal conductivity based on their new measurements of the thermal diffusivity of zone-refined $\mathrm{Pu}$ and heat-capacity, density, and thermal-expansion data from previous publications. In contrast, Kim et al. [170] relied on older publications with thermal-conductivity values for $\alpha-\mathrm{Pu}, \beta-\mathrm{Pu}$, and $\gamma-\mathrm{Pu}$ and estimated the thermal conductivity of other phases based on their electrical resistivity and Lorenz number. Despite the difference in approaches and lack of common data, the two studies produced similar results (Figure 44). 


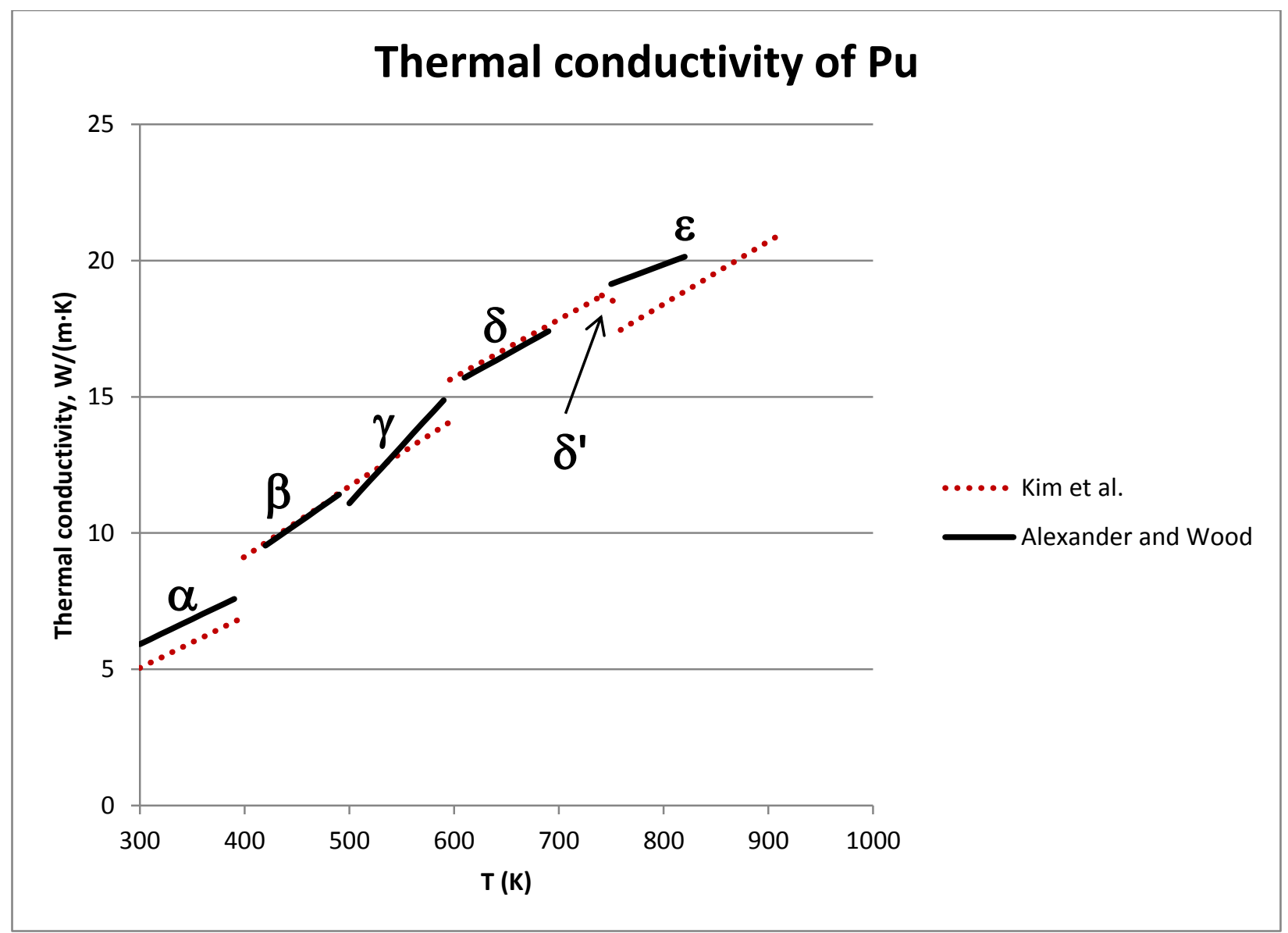

Figure 44. Thermal conductivity of $\mathrm{Pu}$. Data from Alexander and Wood were calculated from Equation 71 through Equation 75.

Alexander and Wood fitted their data for all phases except $\delta^{\prime}$-Pu to linear equations, each of which matched all of their measured data points to within 5\%. These equations are:

Equation 71. Thermal conductivity of $\alpha-\mathrm{Pu}$ from 294 to $394 \mathrm{~K}$ according to Alexander and Wood [173]

$\mathrm{k}=0.01844 \times \mathrm{T}+0.390$

where $\mathrm{k}$ is thermal conductivity in $\mathrm{W} / \mathrm{m} \cdot \mathrm{K}$, $\mathrm{T}$ is temperature in $\mathrm{K}$, and $\mathrm{T}$ is between 294 and $394 \mathrm{~K}$

Equation 72. Thermal conductivity of $\beta$-Pu from 415 to $490 \mathrm{~K}$ according to Alexander and Wood [173]

$\mathrm{k}=0.02679 \times \mathrm{T}-1.716$ K

where $\mathrm{k}$ is thermal conductivity in $\mathrm{W} / \mathrm{m} \cdot \mathrm{K}, \mathrm{T}$ is temperature in $\mathrm{K}$, and $\mathrm{T}$ is between 415 and 490 
Equation 73. Thermal conductivity of $\gamma$-Pu from 491 to $595 \mathrm{~K}$ according to Alexander and Wood [173]

$$
\mathrm{k}=0.04201 \times \mathrm{T}-9.909
$$

where $\mathrm{k}$ is thermal conductivity in $\mathrm{W} / \mathrm{m} \cdot \mathrm{K}$, $\mathrm{T}$ is temperature in $\mathrm{K}$, and $\mathrm{T}$ is between 491 and 595

$\mathrm{K}$ [173]

Equation 74. Thermal conductivity of $\delta$-Pu from 602 to $696 \mathrm{~K}$ according to Alexander and Wood

$$
\mathrm{k}=0.02131 \times \mathrm{T}+2.697
$$

where $\mathrm{k}$ is thermal conductivity in $\mathrm{W} / \mathrm{m} \cdot \mathrm{K}$, $\mathrm{T}$ is temperature in $\mathrm{K}$, and $\mathrm{T}$ is between 602 and 696

$\mathrm{K}$ [173]

Equation 75. Thermal conductivity of $\varepsilon$-Pu from 750 to $822 \mathrm{~K}$ according to Alexander and Wood

$$
\mathrm{k}=0.01428 \times \mathrm{T}+8.423
$$

where $\mathrm{k}$ is thermal conductivity in $\mathrm{W} / \mathrm{m} \cdot \mathrm{K}, \mathrm{T}$ is temperature in $\mathrm{K}$, and $\mathrm{T}$ is between 750 and 822

\section{$\mathrm{K}$}

Alexander and Wood noted that their data for all phases except $\delta^{\prime}$ from temperatures between 400 and $820 \mathrm{~K}$ could be matched to within $\sim 5.4 \%$ by a quadratic equation (Equation 76 ), which provides a convenient approximation across a wide temperature range. This equation is:

Equation 76. Approximate thermal conductivity of $\mathrm{Pu}$ from 400 to $820 \mathrm{~K}$ according to Alexander and Wood [173]

$$
\mathrm{k}=-8.162+4.841 \times 10^{-2} \times \mathrm{T}-0.1614 \times 10^{-4} \times \mathrm{T}^{2}
$$

$\mathrm{K}$

where $\mathrm{k}$ is thermal conductivity in $\mathrm{W} / \mathrm{m} \cdot \mathrm{K}$, $\mathrm{T}$ is temperature in $\mathrm{K}$, and $\mathrm{T}$ is between 400 and 820

\subsubsection{Zr}

\subsubsection{Introduction}

Several hundred measurements of the thermal conductivity and diffusivity of $\mathrm{Zr}$ were reviewed in 1995 by Fink and Leibowitz [175], and a polynomial that fit the most of data to within $~ 10 \%$ across a temperature range from $298-2000 \mathrm{~K}$ was developed. This polynomial shows a decrease in conductivity from 298 to an inflection point at $\sim 530 \mathrm{~K}$, and an increase from $\sim 530 \mathrm{~K}$ to $2000 \mathrm{~K}$, with no changes due to the $\alpha-\beta$ phase transformation. It was adopted by later reviews including those of Kim et al. [170] and the IAEA [140].

\subsubsection{Thermal Conductivity}

Reviews of the thermal conductivity and diffusivity of Zr include those by Touloukian et al. [7, 8], Fink and Leibowitz [175], Kim et al. [170], and the IAEA [140]. The Fink and Leibowitz review included an assessment of all published data available at that time, including that used by Touloukian et al., and led to development of a widely accepted polynomial expressing the thermal conductivity of $\mathrm{Zr}$ at temperatures between 298 and $2000 \mathrm{~K}$ (Figure 45, Equation 77). More recent estimates of thermal conductivity based on diffusivity measurements by Milošević \& Maglić [141] give somewhat higher values, particularly at higher temperatures. However, because of the large numbers of measurements included in the Fink and Leibowitz review, the data of Milošević \& Maglić should probably be considered as outliers unless future measurements indicate otherwise. 


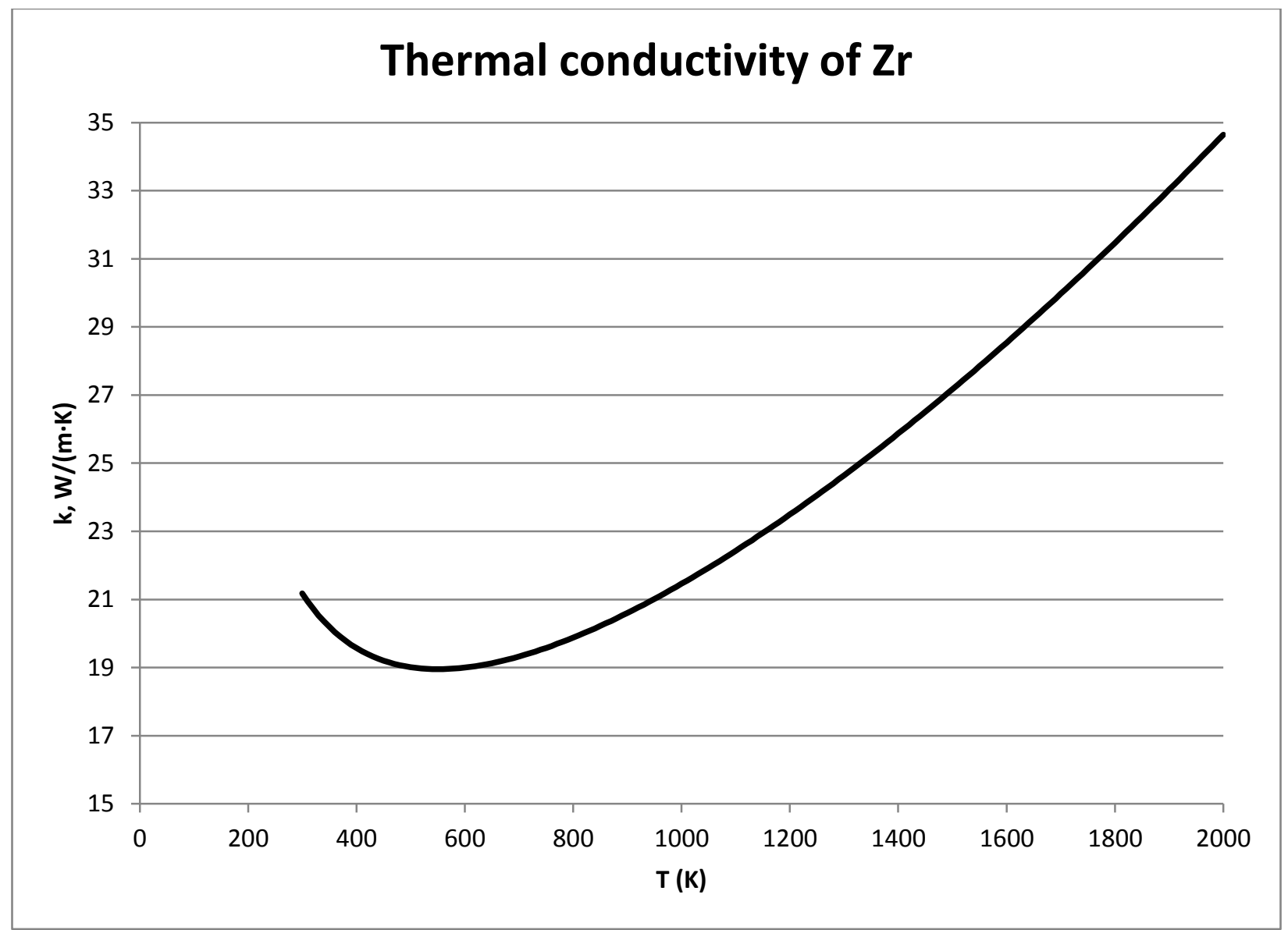

Figure 45. Thermal conductivity of $\operatorname{Zr}$ [175], plotted using Equation 77

Equation 77. Approximate thermal conductivity of Pu according to Fink and Leibowitz [175] $\mathrm{k}=8.857+7.0820 \times 10^{-3} \times \mathrm{T}+2.5329 \times 10^{-6} \times \mathrm{T}^{2}+2.9918 \times 10^{3} \times \mathrm{T}^{-1}$ $\mathrm{K}$

where $\mathrm{k}$ is thermal conductivity in $\mathrm{W} / \mathrm{m} \cdot \mathrm{K}, \mathrm{T}$ is temperature in $\mathrm{K}$, and $\mathrm{T}$ is between 298 and 2000

\subsubsection{U-Zr Alloys}

\subsubsection{Introduction}

Experimental determinations of the thermal conductivity of $\mathrm{U}-\mathrm{Zr}$ alloys with $\mathrm{Zr}$ concentrations between 1 and $79 \mathrm{wt} \%$ (2.5-91 at\%) $\mathrm{Zr}$ have been reported at temperatures up to $1200 \mathrm{~K}$. Thermal conductivities for U-Zr alloys increase with temperature. Conductivities for alloys with different compositions decrease with increasing concentration of $\mathrm{Zr}$ to a minimum value at $\sim 72.4$ at $\%$ (possibly reflecting the very low conductivity of $\left.\delta-\mathrm{UZr}_{2}\right)$ [172] and may increase again in high- $\mathrm{Zr}$ compositions.

Three research groups have developed equations to predict the thermal conductivity of U-Zr alloys as functions of composition and temperature. One of these equations is not considered because it was developed before much of the data were available. The other two produce similar results for compositions of interest for nuclear fuels ( 10-15 wt\% Zr). 


\subsubsection{Thermal Conductivity}

Experimentally determined thermal conductivity values for $\mathrm{U}-\mathrm{Zr}$ alloys with $\sim 1-2,5,6,9,11,17,20$, $29,40,52$, and $79 \mathrm{wt} \% \mathrm{Zr}$ have been reported $[8,84,86,172,176]$. Thermal conductivity was measured directly by ANL [176] and Kaity et al. [84], while thermal conductivity measurements reported by Takahashi et al. [172] and Matsui et al. [86] were calculated from density, thermal diffusivity, and heat capacity. Other researchers have attempted to use the Wiedemann-Franz law to estimate thermal conductivity from the Lorenz number and electrical resistivity; however, it appears that the actual Lorenz number of the sample material may not be known well enough for this approach to be successful [45, 46, 86].

Figure 46 summarizes published thermal conductivity data for U-Zr alloys. It shows that thermal conductivity decreases with increasing concentration of $\mathrm{Zr}$ for samples with less than $\sim 40-50 \mathrm{at} \% \mathrm{Zr}$ and is essentially the same for samples with $\sim 50-90$ at $\%$ Zr. Takahashi et al. suggested that the thermal conductivity of $\mathrm{U}-\mathrm{Zr}$ alloys had a minimum at $\sim 72.4 \mathrm{at} \%$, which was due to the low thermal conductivity of $\delta$-( $\left.\mathrm{UZr}_{2}\right)$; however, thermal conductivity measurements of well-characterized samples known to consist of this phase have not been reported.

For each alloy, thermal conductivity increases with temperature within the measurement range. The thermal conductivity of most compositions is smaller than that of $\mathrm{Zr}$ at relatively low temperatures (below $\sim 300 \mathrm{~K}$ for alloys with 4 at $\% \mathrm{Zr}$, and below $\sim 675 \mathrm{~K}$ for alloys with $\sim 40 \mathrm{at} \% \mathrm{Zr}$ ).

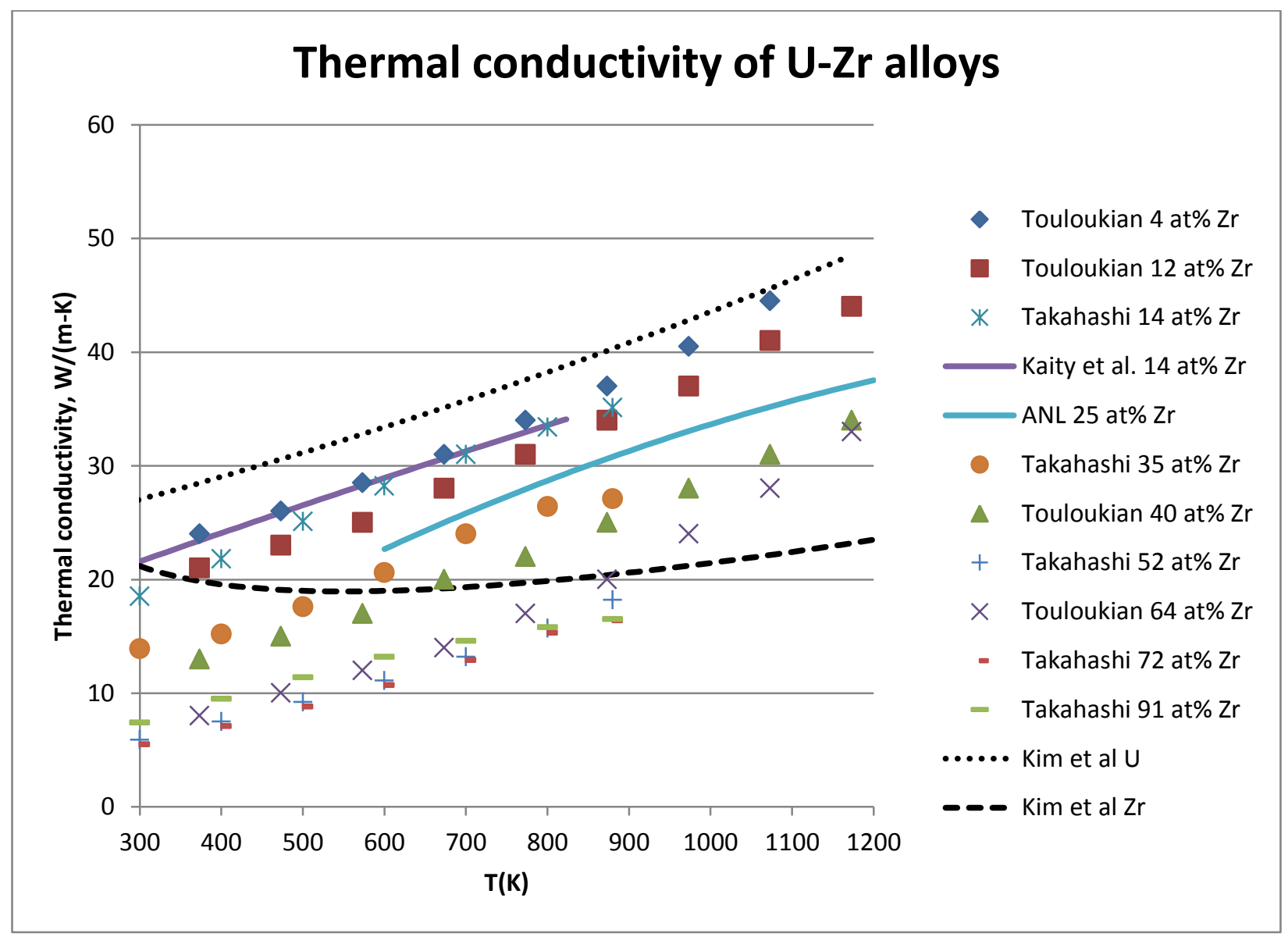

Figure 46. Thermal conductivity of $U-Z r$ alloys, with conductivity of $U$ and $\mathrm{Zr}$ for comparison [8, 84, 170, 172, 176] 
Billone et al. [177], Ogata [72], and Kim et al. [170] developed equations to represent the conductivity of arbitrary U-Zr alloys as a function of temperature and composition. (The Ogata equation is reprinted in [5] with a change in sign of one of the terms. Comparison to the data suggests that the equation in reference [72] is correct.) The Billone et al. equation is not considered further because it was developed too early to consider the extensive measurements made by Takahashi et al. [172].

The equations proposed by Kim et al. and Ogata produce similar results for alloys with concentrations of interest for nuclear fuels ( $10 \mathrm{wt} \% \mathrm{Zr}$ ) (Figure 47), and both are plausible approximations to the actual thermal conductivity of alloys with this composition. The Ogata equation (Equation 78) [72] is far simpler, and, therefore, is preferred based on the currently available data for compositions with relatively low concentrations of Zr. However, the non-linear shape and built-in adjustment factor of the Kim et al. equation may make it worth considering if adjustments to accommodate new data are required.

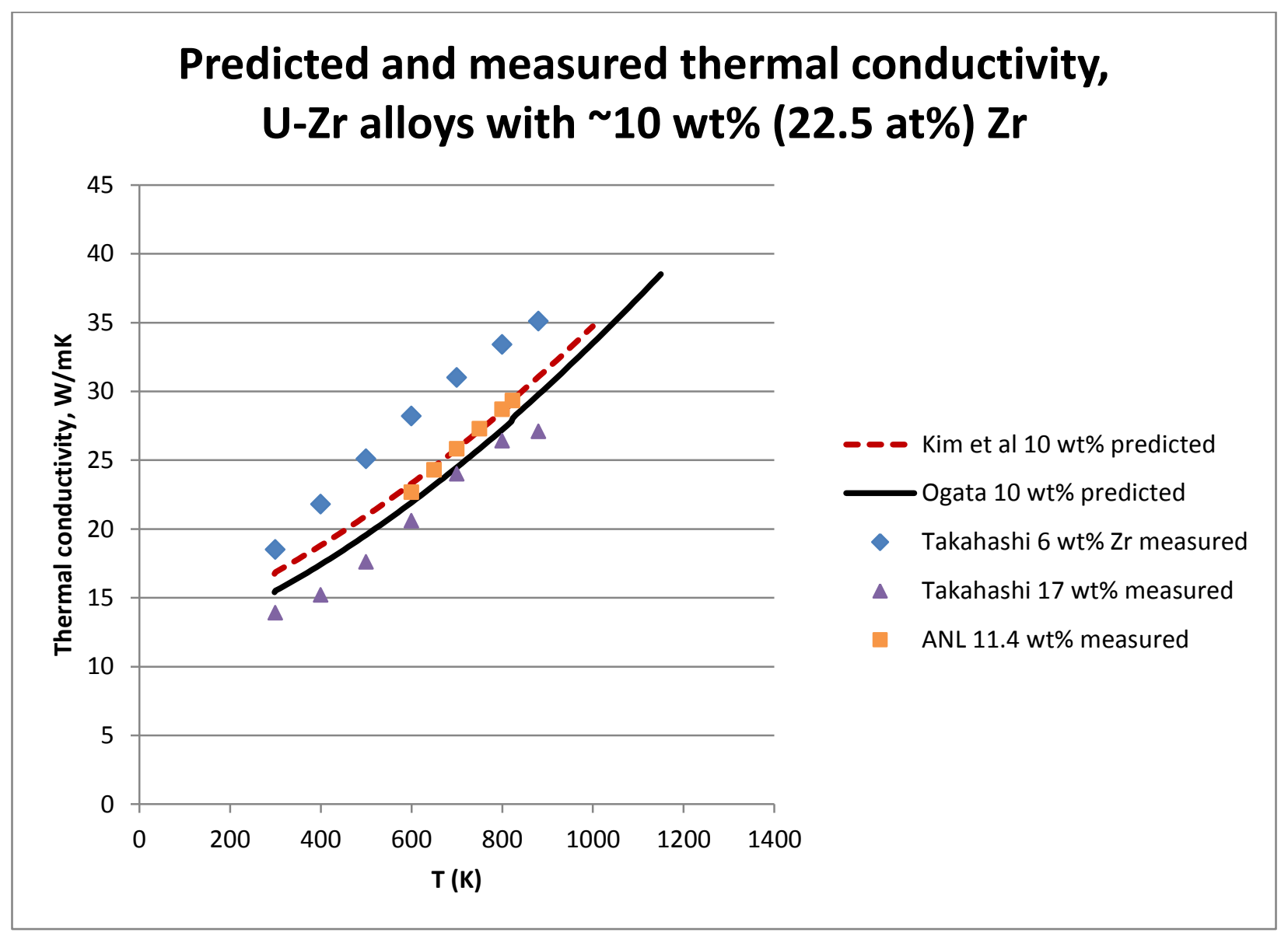

Figure 47. Measured and predicted thermal conductivity for U-Zr alloys with $6-17 \mathrm{wt} \% \mathrm{Zr}$. Ogata's predicted value is from Equation 78

Equation 78. Estimated thermal conductivity of U-Zr alloys according to Ogata [72]

$\mathrm{k}=16.309+0.02713 \times \mathrm{T}-46.27 \times \mathrm{C}_{\mathrm{Zr}}+22.985 \times \mathrm{C}_{\mathrm{Zr}}^{2}$

where $\mathrm{k}$ is thermal conductivity in $\mathrm{W} / \mathrm{m} \cdot \mathrm{K}, \mathrm{C}_{\mathrm{Zr}}$ is atomic fraction of $\mathrm{Zr}, \mathrm{C}_{\mathrm{Zr}}$ is $<0.72, \mathrm{~T}$ is temperature in $\mathrm{K}$, and $\mathrm{T}$ is $<1173 \mathrm{~K}$ 


\subsubsection{Pu-Zr Alloys}

\subsubsection{Introduction}

There are apparently no published measurements of the thermal conductivity or diffusivity of any $\mathrm{Pu}-\mathrm{Zr}$ alloy. Preliminary INL measurements of alloys with 10 and $30 \mathrm{wt} \% \mathrm{Zr}$ indicate that the thermal diffusivity of both alloys increases with temperature (although perhaps not smoothly), and that the diffusivity of the alloy with $30 \% \mathrm{Zr}$ is lower than that of the alloy with $10 \% \mathrm{Zr}$.

Further measurements are clearly needed.

\subsubsection{Thermal Diffusivity}

INL researchers have made three preliminary laser-flash diffusivity measurements of $\mathrm{Pu}-\mathrm{Zr}$ alloys: two measurements of an alloy with $10 \mathrm{wt} \%$ (23 at\%) $\mathrm{Zr}$ and one of an alloy with $30 \mathrm{wt} \%(53 \mathrm{at} \%) \mathrm{Zr}$. The data suggest that thermal diffusivity increases with temperature for both compositions, and that the diffusivity of the alloy with $30 \mathrm{wt} \%$ is smaller than that of the alloy with $10 \mathrm{wt} \% \mathrm{Zr}$ by up to $\sim 0.005 \mathrm{~cm}^{2} / \mathrm{s}$ (Figure 48).

Consideration of the $\mathrm{Pu}-\mathrm{Zr}$ phase diagram (Section 3.1.5) suggests that the "hump" in the $\mathrm{Pu}-30 \mathrm{Zr}$ data at about $200^{\circ} \mathrm{C}$ may be due to formation of the $\delta$-(Pu-Zr) phase. The upward curve in data for this alloy at $\sim 650^{\circ} \mathrm{C}$ does not correspond to an obvious phase transformation but is approximately the melting temperature of pure $\mathrm{Pu}$.

Further investigation of the thermal conductivity and diffusivity of $\mathrm{Pu}-\mathrm{Zr}$ alloys is clearly needed. 


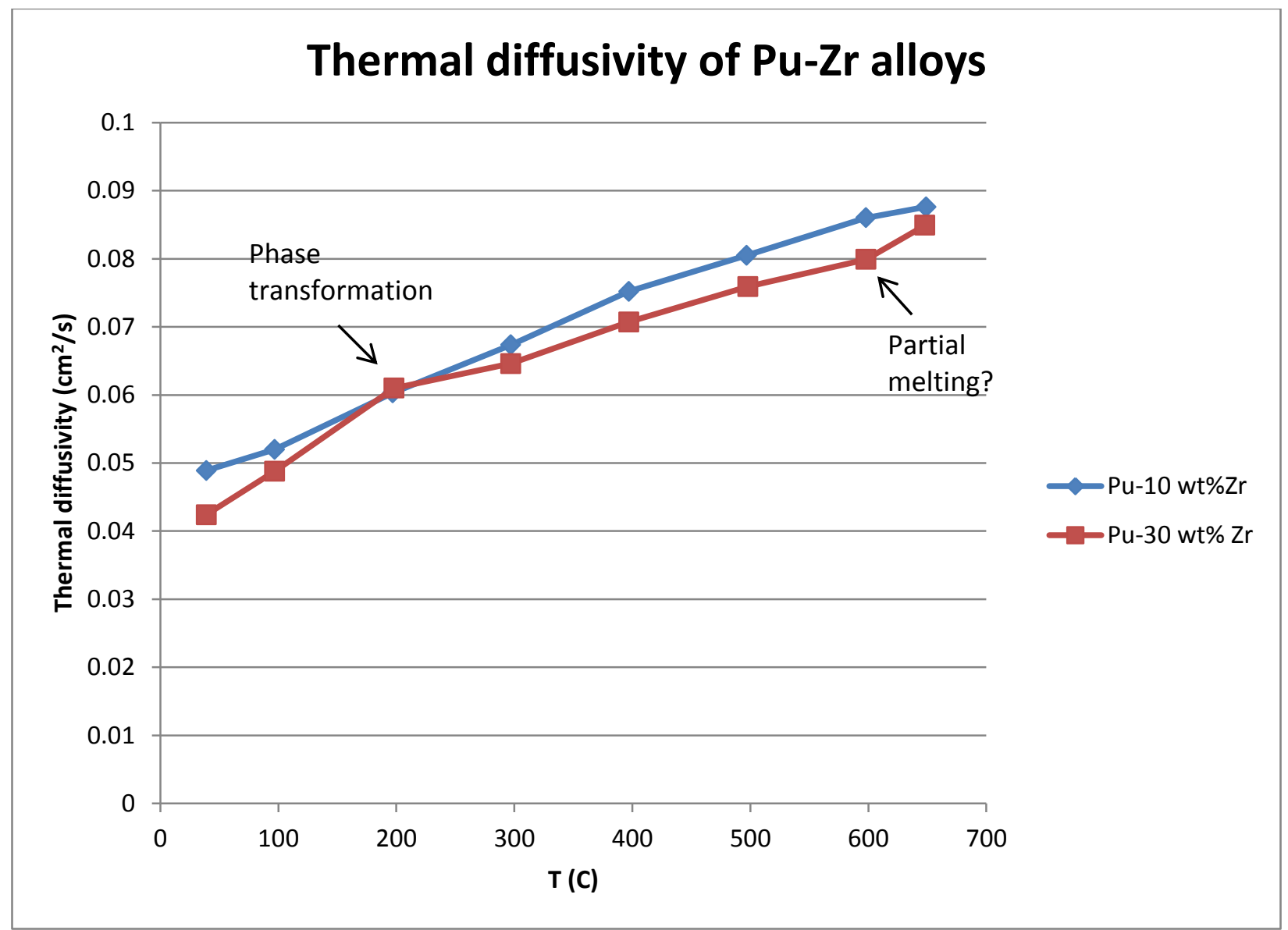

Figure 48. Thermal diffusivity of Pu-10 wt $\% \mathrm{Zr}$ and $\mathrm{Pu}-30 \mathrm{wt} \% \mathrm{Zr}$ alloys (INL preliminary data). Data for $\mathrm{Pu}-10 \mathrm{wt} \%$ alloy are the average of two measurements.

\subsubsection{U-Pu Alloys}

\subsubsection{Introduction}

The only published data for thermal conductivity of any U-Pu alloy are for a composition with 10 $\mathrm{wt} \%(10 \mathrm{at} \%) \mathrm{Pu}$. Thermal conductivity of this alloy increases with temperature, and is $\sim 15 \%$ below the thermal conductivity of $U$ as reported in the same publication. More measurements on this and other alloys are clearly needed.

\subsubsection{Thermal Conductivity}

Kelman et al. ([135] and [168 Figure 7]) published the only available thermal conductivity data for any U-Pu alloy. Kittel et al. [114 Table 17] repeated these data except for the thermal conductivity at $200^{\circ} \mathrm{C}$, which they appear to have erroneously carried over from an adjacent column of the same table.

According to Kelman et al., the thermal conductivity of an alloy with $10 \mathrm{wt} \%$ (10 at $\%) \mathrm{Pu}$ is $\sim 15 \%$ below that of the thermal conductivity of $U$. Since the thermal conductivity of $U$ reported by Kelman et al. [135] is in good agreement with recent publications [84, 170], it seems likely that the thermal conductivity values for $\mathrm{U}-10 \mathrm{Pu}$ in Table 16 represent the actual behavior of the alloy. 
Table 16. Thermal conductivity of $\mathrm{U}-10 \mathrm{Pu}$ [135].

Thermal Conductivity

$\mathrm{T}\left({ }^{\circ} \mathrm{C}\right) \quad(\mathrm{W} / \mathrm{m} \cdot \mathrm{K})$

200

23.43

400

28.86

600

36.39

800

41.83

\subsubsection{U-Pu-Zr Alloys}

\subsubsection{Introduction}

Researchers at ANL, Los Alamos Scientific Laboratory, and CEA published measurements of the thermal conductivity of U-Pu-Zr alloys with $\sim 15-20 \mathrm{wt} \% \mathrm{Pu}$ and $\sim 3.4-14 \mathrm{wt} \% \mathrm{Zr}[125,129,168,178]$. Later publications (e.g., $[5,72,114,130])$ repeat the data.

Thermal conductivity measurements differ by $\sim 25-30 \%$ within the range of compositions represented in the data. The data indicate that thermal conductivity increases with temperature for a given composition, and suggest that increasing the concentration of Pu may lower the thermal conductivity.

Several researchers have published equations for calculating thermal conductivity of U-Pu-Zr alloys with arbitrary compositions. None of these equations seems a good choice for calculating the thermal conductivity of U-Pu-Zr alloys with $15-20 \mathrm{wt} \% \mathrm{Pu}$ and $10-15 \mathrm{wt} \% \mathrm{Zr}$. It is recommended that new curves be fitted after thermal conductivity values for a particular application have been determined.

\subsubsection{Thermal Conductivity}

Figure 49 shows the published measurements of thermal conductivity of U-Pu-Zr alloys [125, 129, $168,178]$. Conductivity increases with temperature for each of the materials studied. Although there are exceptions, conductivity tends to be lower in materials with higher concentrations of $\mathrm{Pu}$. 


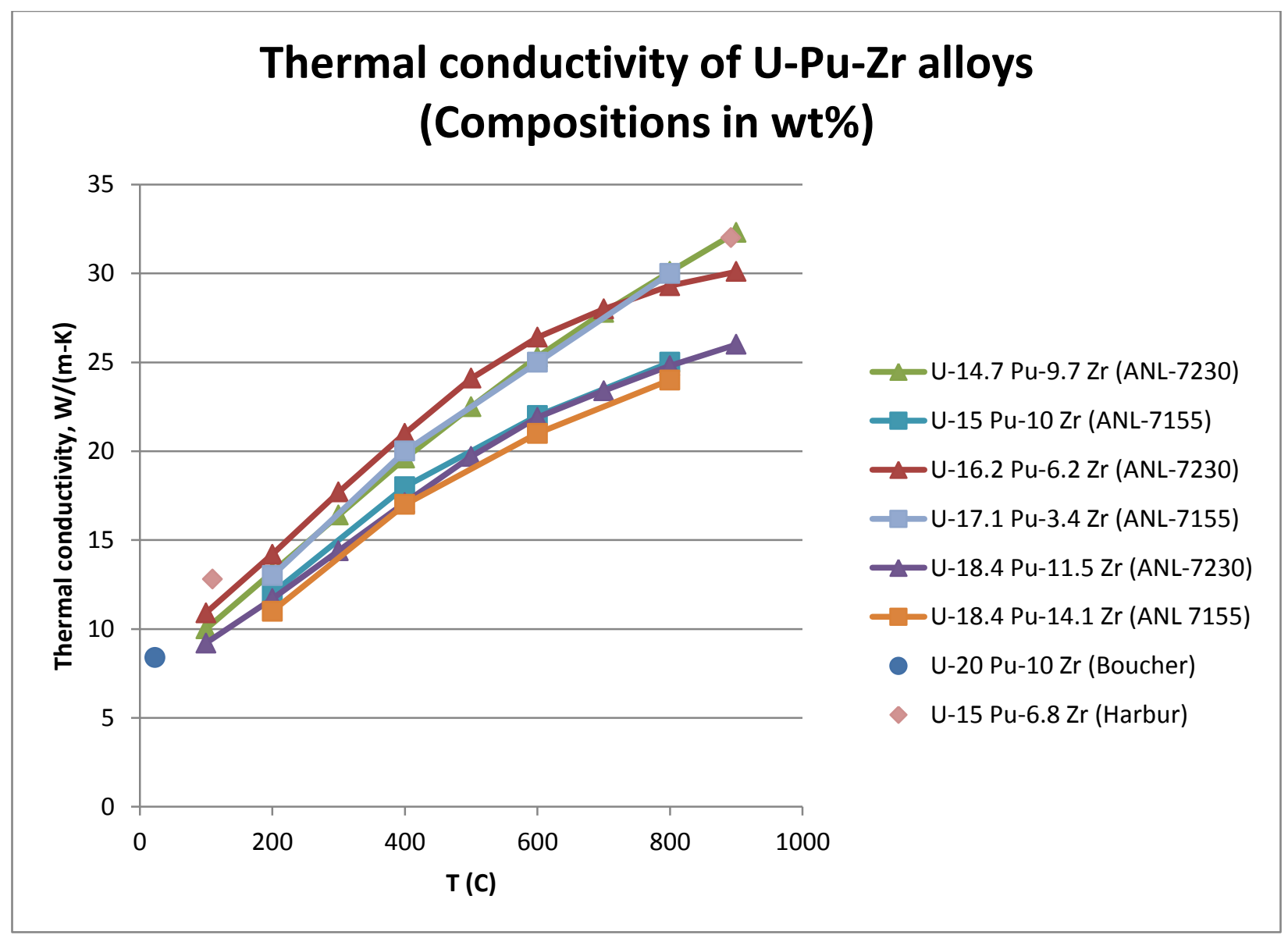

Figure 49. Thermal conductivity of U-Pu-Zr alloys. [125, 129, 168, 178]

Billone et al. [177], Kim et al. [170], and Ogata [5, 72] have developed equations to predict the thermal conductivity of U-Pu-Zr alloys. The Billone et al. model was developed to allow the LIFE-METAL fuel performance code to be used for U-Pu-Zr alloys, and represents the thermal conductivity of an alloy as a quadratic equation in T. The Kim et al. model incorporates "fitting factors" to allow a widely used model for thermal conductivity of a two-phase mixture to be extended to solid solutions, and calculates thermal conductivity based on temperature, composition, and the thermal conductivities of the elements involved. The Ogata model is purely empirical, and represents the thermal conductivities of compositions with less than $72 \mathrm{at} \% \mathrm{Zr}$ and 16 at $\% \mathrm{Pu}$ as linear functions of temperature.

Figure 50 compares the Billone et al. and Ogata models to measured thermal conductivity for alloys with compositions close to $\mathrm{U}-15 \mathrm{Zr}-10 \mathrm{Pu}$ (green) and $\mathrm{U}-18 \mathrm{Pu}-20 \mathrm{Zr}$ (turquoise). The Kim et al. model is not included because the practical difficulties involved in calculating it do not seem justified without a better knowledge of the required thermal conductivity values. The Billone et al. model is a reasonable representation of the available data for $\mathrm{U}-15 \mathrm{Zr}-10 \mathrm{Pu}$, but neither model is a good approximation for the U-18.4-14.1Zr data. Given the widespread availability of curve-fitting software, the best approach is probably to fit a curve to the desired thermal conductivity values rather than using a previously published model. 


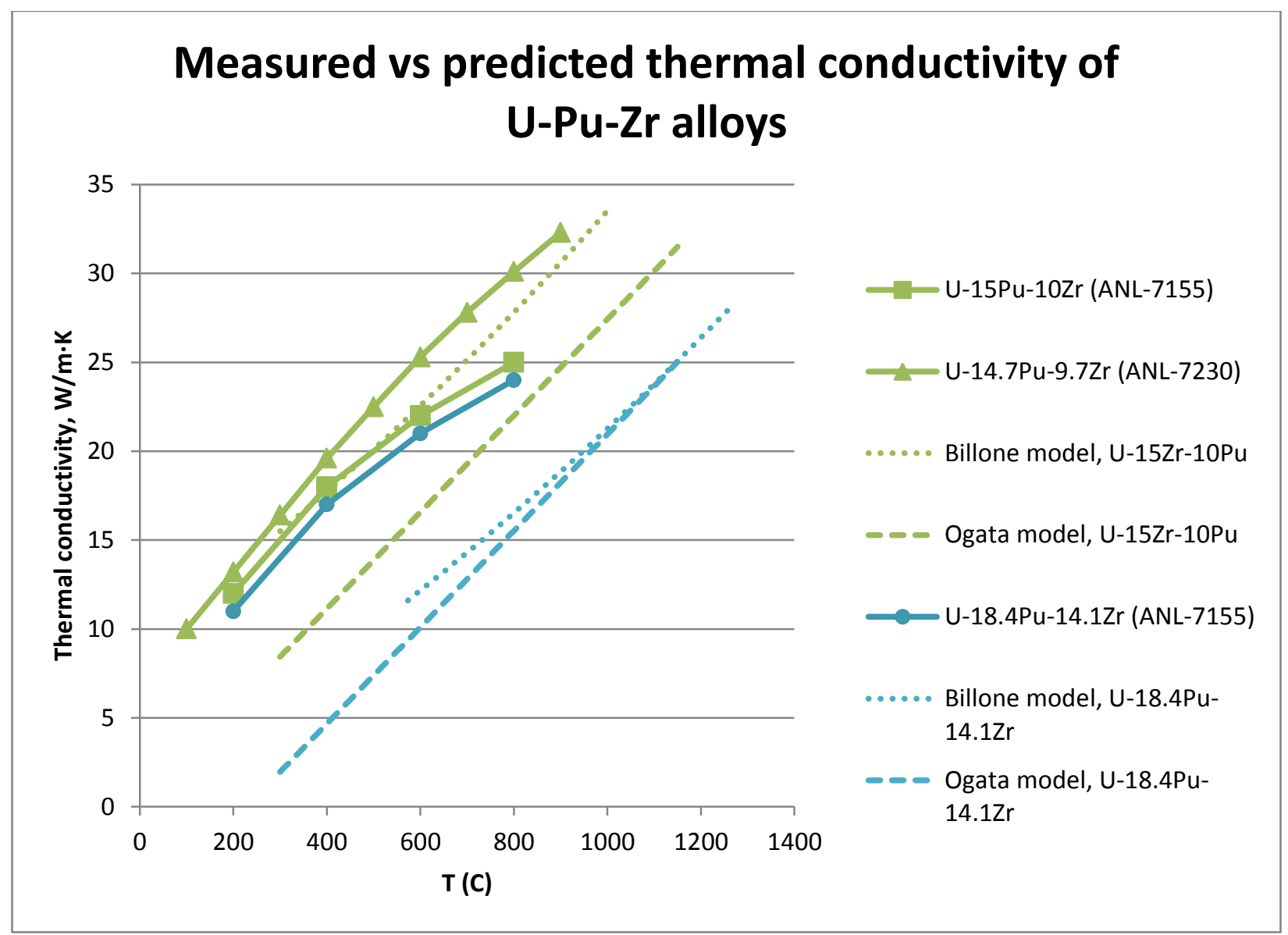

Figure 50. Comparison of measured and predicted thermal conductivity of U-Pu-Zr alloys

There are no measurements of thermal conductivities of individual U-Pu-Zr phases. However, R.J. Dunworth suggested that the thermal conductivity of $\alpha-(\mathrm{U}, \mathrm{Pu})$ and $\delta-(\mathrm{U}, \mathrm{Pu}) \mathrm{Zr}_{2}$ is about twice that of $\zeta_{-}(\mathrm{U}, \mathrm{Pu})$ based on a comparison between thermal conductivity measurements and volume fractions of phases determined from an isothermal section of the U-Pu-Zr phase diagram at $500^{\circ} \mathrm{C}$ [168 page 19]. Since he believed that increasing the concentration of $\mathrm{Pu}$ should increase the proportion of $\zeta-(\mathrm{U}, \mathrm{Pu})$ and decrease that of $\alpha-(\mathrm{U}, \mathrm{Pu})$, Dunworth inferred that alloys with higher proportions of $\mathrm{Pu}$ would have lower thermal conductivities. This suggestion is qualitatively consistent with the data in Figure 49. 


\section{Minor actinides, rare-earth elements, and their alloys 4.1 PHASES, PHASE DIAGRAMS, PHASE TRANSFORMATIONS, PHASE-TRANSFORMATION ENTHALPIES}

\subsubsection{Np}

\subsubsection{Introduction}

There is general agreement about the existence and properties of three $\mathrm{Np}$ phases that are stable at atmospheric pressure. It has been suggested that there may be a fourth $\mathrm{Np}$ phase that has a very narrow temperature range of stability and forms only in high-purity samples; however, further work is needed to determine whether this phase exists. Experimental measurements of high-purity $\mathrm{Np}$ at pressures up to 52 GPa did not show additional high-pressure phases [179]

In addition to being a nuclear material, $\mathrm{Np}$ is of interest because of the behavior of its $5 f$ electrons, leading to research including collection of data at very high pressures and measurements using a variety of spectroscopic techniques. These aspects of actinide science are summarized in two comprehensive reviews $[180,181]$, and will not be considered further in this handbook. Modeling papers too recent to be considered in these reviews include those of Lukoyanov et al. [182] and Bajaj et al. [183].

\subsubsection{Phases}

The currently accepted lattice parameters and crystal structures of $\alpha-\mathrm{Np}$ and $\beta$-Np were first published in 1952 by Zachariasen [184, 185], and have been corroborated or repeated by later researchers (e.g., [3, $30,186,187])$. Neutron-diffraction work by Lawson et al. [188] expanded on these results by measuring Debye-Waller factors and calculating effective Gruneisen constants for $\alpha-\mathrm{Np}$.

High-quality data on the structure of $\gamma-\mathrm{Np}$ is difficult to obtain because of oxidation of the sample and a high degree of overlap between $\mathrm{x}$-ray patterns for $\gamma$-Np and $\mathrm{NpO}[184,186]$. The generally accepted lattice parameter was suggested by Lemire et al. [30] based on a review of the available data.

The generally accepted crystalline Np phases that are stable at atmospheric pressure are [30]:

- $\alpha$-Np, orthorhombic (space group Pnma), $a=6.663 \AA, b=4.723 \AA, c=4.887 \AA$ at $293 \mathrm{~K}$. (Zachariasen [185] used the non-standard setting Pmcn, which can be converted to Pnma by appropriate permutation of the axes.) As-cast $\alpha$-Np commonly shows extensive twinning [189, 190], which may be due to stresses caused by the highly anisotropic thermal expansion of individual crystals [191].

- $\quad \beta$-Np, tetragonal (space group $P 42{ }_{1} 2$ ), $a=4.897 \AA, c=3.388 \AA$ at $586 \mathrm{~K}$

- $\gamma$-Np, bcc (space group $\operatorname{Im} \overline{3} m$ ), $a=3.518 \AA$ at $873 \mathrm{~K}$

Anomalies in thermal analysis data suggest the possible existence of a fourth $\mathrm{Np}$ phase with a very narrow temperature range of stability near the $\beta-\gamma$ phase transformation $[30,186,192]$. Further work on high-purity samples is needed to determine whether this phase exists. There is no published information about its possible crystal structure and lattice parameters.

Some references (e.g., $[110,193]$ ) discuss the properties of a hypothetical fcc Np phase. As there is no experimental evidence indicating that this phase exists, its properties will not be included in this handbook.

\subsubsection{Phase transformations}

Measurements of phase-transformation and melting temperatures of $\mathrm{Np}$ are in good agreement. Phase-transformation mechanisms are less well known, but were investigated by Selle and Rechtien [194]. 
The recommended atmospheric-pressure phase-transformation temperatures from a recent assessment of the experimental data are [2]:

- $\quad \alpha-\beta, 553 \pm 5 \mathrm{~K}\left(280 \pm 5^{\circ} \mathrm{C}\right)$ based on 10 published measurements, which range from 544 to $559 \mathrm{~K}$. This temperature rises slightly $\left(\sim 1.1 \mathrm{kbar} /{ }^{\circ} \mathrm{C}\right)$ for pressures up to a few kbars [195].

- $\quad \beta-\gamma, 850 \pm 3 \mathrm{~K}\left(577 \pm 3{ }^{\circ} \mathrm{C}\right)$ based on 10 published measurements, which range from 830 to $856 \mathrm{~K}$.

- $\gamma$-liquid, $913 \pm 3 \mathrm{~K}\left(640 \pm 3^{\circ} \mathrm{C}\right)$ based on 8 published measurements, which range from 870 to $913 \mathrm{~K}$. The corresponding recommended phase-transformation enthalpies $\left(\Delta \mathrm{H}_{t}\right)$ are [2]:

- $\alpha-\beta, 4.7 \pm 0.5 \mathrm{~kJ} / \mathrm{mol}$ (based on 4 publications with original measurements, which range from 4.73 to $8.37 \mathrm{~kJ} / \mathrm{mol})$

- $\quad \beta-\gamma, 3.0 \pm 0.5 \mathrm{~kJ} / \mathrm{mol}$ (based on 3 publications with original measurements, which range from 2.99 to $5.27 \mathrm{~kJ} / \mathrm{mol}$ )

- $\quad \gamma$-liquid, $3.2 \pm 0.5 \mathrm{~kJ} / \mathrm{mol}$ (based on 6 publications with original measurements, which range from 3.19 to $5.19 \mathrm{~kJ} / \mathrm{mol})$.

\subsubsection{Am}

\subsubsection{Introduction}

It is generally believed that there are three solid Am phases that are stable at atmospheric pressure and temperatures above $300 \mathrm{~K}$. The crystal structures and lattice parameters of two of these phases ( $\alpha$-Am and $\beta$-Am) have been published, although there is some disagreement about phase-transformation temperatures. Thermal analysis data shows a third phase $(\gamma-\mathrm{Am})$, about which little is known.

Recent research on Am has focused on understanding its high-pressure behavior, its superconductivity, and the behavior of its $5 f$ electrons. Much of this research was reviewed by Johansson and $\mathrm{Li}[180]$ and by Moore and van der Laan [181]. More recent research papers include references [182, 196-200].

\subsubsection{Phases}

It is commonly accepted that there are three solid Am phases that are stable at atmospheric pressure. Structure determinations of two of these phases ( $\alpha$ - and $\beta$-Am) by McWhan et al. [201] are commonly accepted in more recent reviews (e.g., [3,202]). There are no published experimental determinations of the structure or lattice parameters of the third phase $(\gamma-\mathrm{Am})$, although it is commonly believed to be bcc.

The crystallographic characteristics of the generally recognized solid Am phases are:

- $\quad \alpha$-Am, dhcp (space group $P 6_{3} / m m c$ ), $a=3.4681 \AA, c=11.241 \AA$ at $20^{\circ} \mathrm{C}$ [201]

- $\quad \beta$-Am, fcc (space group $F m \overline{3} m), a=4.894 \AA$ [201]

- $\quad \gamma$-Am, assumed to be bcc (space group $\operatorname{Im} \overline{3} m$ ) by analogy to the early lanthanides [4]. This phase is known from dilatometry and differential thermal analysis data (e.g [203-206]). A recent paper indicating that $\gamma$-Am has space group $F m 3 m$ and lattice parameter $a=4.894 \AA$ [196 Table 2] is probably mislabeled data from $\beta$-Am.

The existence of other Am phases has been suggested as a result of thermophysical analyses [204, 207], but without information on crystal structures. In particular, a phase with a dhcp structure and lattice parameters significantly larger than those of $\alpha$-Am has been identified by several researchers using X-ray diffraction data [208-210]. Further work is needed to confirm the existence of these phases and investigate their properties. 
Although a transformation to an orthorhombic phase at a pressure of $\sim 152$ kbars has been documented in an Am sample that contained $1000 \mathrm{ppm} \mathrm{Yb} \mathrm{[211],} \mathrm{more} \mathrm{recent} \mathrm{reviews} \mathrm{agree} \mathrm{that} \mathrm{the} \mathrm{lowest-pressure}$ phase transformation in pure Am produces a face-centered cubic structure at a pressure of 5-6 GPa (e.g., $[3,202,212])$. As this pressure is far greater than a nuclear fuel is likely to experience, these phases are not considered in this Handbook.

\subsubsection{Phase transformations}

Published measurements of phase-transformation temperatures for Am vary widely. Measurement of the $\alpha-\beta$ transformation has been particularly difficult, possibly because of its small enthalpy, and some authors have not observed any transformations in the relevant temperature range.

Recommended phase-transformation temperatures from a recent re-assessment of the experimental data are [2]:

- $\quad \alpha-\beta, 1042 \pm 10 \mathrm{~K}\left(769 \pm 10{ }^{\circ} \mathrm{C}\right)$, based on 4 publications with original measurements, which range from 873 to $1066 \mathrm{~K}$

- $\quad \beta-\gamma, 1350 \pm 5 \mathrm{~K}\left(1077 \pm 10^{\circ} \mathrm{C}\right)$ (based on 6 publications with original measurements, which range from 1277 to $1352 \mathrm{~K})$

- $\gamma$-liquid, $1449 \pm 5 \mathrm{~K}\left(1176 \pm 10^{\circ} \mathrm{C}\right)$ (based on 8 publications with original measurements, which range from 1267 to $1466 \mathrm{~K})$.

The corresponding phase-transformation enthalpies $\left(\Delta \mathrm{H}_{\mathrm{t}}\right)$ are [2]:

- $\alpha-\beta, 0.34 \pm 0.5 \mathrm{~kJ} / \mathrm{mol}$ (based on 2 publications with original measurements, which range from 0.34 to $0.35 \mathrm{~kJ} / \mathrm{mol}$ )

- $\quad \beta-\gamma, 3.8 \pm 0.4 \mathrm{~kJ} / \mathrm{mol}$ (based on 3 publications with original measurements, which range from 2.3 to 5.9 $\mathrm{kJ} / \mathrm{mol}$ )

- $\quad \gamma$-liquid, $8.0 \pm 2.0 \mathrm{~kJ} / \mathrm{mol}$ (based on 3 publications with original measurements, which range from 4.9 to $14.4 \mathrm{~kJ} / \mathrm{mol}$ ).

\subsubsection{La}

\subsubsection{Introduction}

It is generally accepted that lanthanum has three solid phases that are stable at atmospheric pressure. Their crystal structures and lattice parameters have been known since the early 1960s. Most relatively recent research involves modeling and attempts to understand low-temperature superconductivity (e.g., [213-219])

\subsubsection{Phases}

Lanthanum phases that are stable at atmospheric pressure are:

- $\alpha$-La, dhcp (space group P6 6 /mmc, $a=3.7740 \AA, c=12.171 \AA$ at $297 \mathrm{~K}$ ) [17, 220]

- $\beta$-La, fcc (space group $F m \overline{3} m, a=5.303 \AA$ at $598 \mathrm{~K}$ ) [17, 220, 221]

- $\gamma$-La, bcc (space group $\operatorname{Im} \overline{3} m, a=4.26 \AA$ at $1160 \mathrm{~K}$ ) [17, 220, 221]

\subsubsection{Phase transformations}

Recommended phase-transformation temperatures and enthalpies are:

- $\quad \alpha-\beta, 566 \pm 10 \mathrm{~K}$ (based on 5 publications with original measurements, which range from 533 to $583 \mathrm{~K})[2]$. Gschneidner and Calderwood [10] note a wide variation between phasetransformation temperatures measured during heating $(583 \mathrm{~K})$ and measured during heating and cooling $(533 \mathrm{~K})$. The phase transformation enthalpy is $\sim 0.40 \mathrm{~kJ} / \mathrm{mol}[2,17]$. 
- $\beta-\gamma, 1140 \pm 5 \mathrm{~K}$ (based on 10 publications with original measurements, which range from 1108 to $1141 \mathrm{~K})$. The corresponding transformation enthalpy is $\sim 3.15 \mathrm{~kJ} / \mathrm{mol}[2,17]$.

- $\quad \gamma$-liquid, $1192 \pm 1 \mathrm{~K}$ (based on 8 publications with original measurements, which range from 1173 to $1194 \mathrm{~K})$. The corresponding transformation enthalpy is estimated at $6.20 \pm 0.30 \mathrm{~kJ} / \mathrm{mol}[2,17]$.

The temperature of the $\alpha-\beta$ transformation decreases with increasing pressure, reaching a temperature of $\sim 100{ }^{\circ} \mathrm{C}$ at a pressure of $\sim 15-20 \mathrm{kbars}[195,222]$. The temperature of the $\beta-\gamma$ transformation and the solidus both rise with increasing pressure, and $\gamma$-La disappears at a pressure of $\sim 20 \mathrm{kbars}$ [222].

\subsubsection{Ce}

\subsubsection{Introduction}

Cerium has four solid phases that are stable at atmospheric pressure. Two of these phases $(\alpha-$ and $\beta$ $\mathrm{Ce})$ are only stable below room temperature, although transformation kinetics are slow enough that $\beta$-Ce may persist for centuries in samples held at room temperature [223]. Structures of the higher-temperature phases ( $\gamma$-Ce and $\delta$-Ce) have been known since at least the early 1960s (e.g., [221]).

Two of the Ce phases ( $\alpha$-Ce and $\gamma$-Ce) have face-centered cubic crystal structures. Lattice parameters of the two phases are significantly different, and the molar volume of $\alpha$-Ce is $\sim 17 \%$ smaller than that of $\gamma$ $\mathrm{Ce}$ at atmospheric pressure [224]. Although atmospheric-pressure transformations between $\alpha$-Ce and $\gamma$-Ce have been reported at temperatures below $200 \mathrm{~K}$ (e.g., [225-227]), they apparently do not represent equilibrium reactions. Pressure-temperature diagrams (e.g., [227, 228]) suggest that equilibrium reactions at atmospheric pressure involve transformations from $\alpha$ to $\beta$ and $\beta$ to $\gamma$. Equilibrium transformations between $\alpha$ - and $\gamma$-Ce occur at pressures between 0.22 and $1.96 \mathrm{GPa}$ (2.2 and $19.6 \mathrm{kbars})$ (e.g., [227, 228]), which are too high to be relevant for fuels research.

Cerium is a subject of active research, with numerous recent publications addressing the nature of the transformation between $\alpha$-Ce and $\gamma$-Ce (e.g., references [229-235] and reviews by Hecker, Moore and van der Laan, and Johansson and $\mathrm{Li}[180,181,236])$. Other relatively recent research involves understanding other phase transformations, high-pressure investigations, spectroscopy, and modeling (e.g., [214, 219, 237-243].

\subsubsection{Phases}

The cerium phases that are stable at atmospheric pressure are [17]:

- $\alpha$-Ce, fcc (space group $F m \overline{3} m, a=4.85 \AA$ at $77 \mathrm{~K}$ )

- $\beta$-Ce, dhcp (space group P6 6 /mmc, $a=3.6810 \AA, c=11.857 \AA$ at $297 \mathrm{~K}$ )

- $\gamma$-Ce, fcc (space group $F m \overline{3} m, a=5.1610 \AA$ at $297 \mathrm{~K}$ )

- $\delta$-Ce, bcc (space group $\operatorname{Im} \overline{3} m, a=4.12 \AA$ at $1030 \mathrm{~K}$ )

\subsubsection{Phase transformations}

Phase-transformation temperatures and enthalpies are:

- $\quad \alpha-\beta, 125 \mathrm{~K}\left(-148{ }^{\circ} \mathrm{C}\right)[2,17]$. This temperature was measured during heating; the $\beta-\alpha$ transformation temperature measured during cooling is $45 \mathrm{~K}\left(-228^{\circ} \mathrm{C}\right)$ [17].

- $\quad \beta-\gamma, 283 \mathrm{~K}\left(10{ }^{\circ} \mathrm{C}\right)[2,17]$. This temperature represents the equilibrium temperature between $\beta$-Ce and $\gamma$-Ce, as estimated from phase-transformation kinetics [228]; temperatures measured during heating and cooling are $412 \mathrm{~K}\left(139^{\circ} \mathrm{C}\right)$ and $257 \mathrm{~K}\left(-16^{\circ} \mathrm{C}\right)$, respectively [17]. The corresponding transformation enthalpy is $0.05 \mathrm{~kJ} / \mathrm{mol}$ [17]. (The enthalpy of $\sim 3.0 \mathrm{~kJ} / \mathrm{mol}$ listed by Konings and Beneš [ 2 p. 043102-7] for the $\beta-\gamma$ transformation seems too large, and may refer to the $\gamma-\delta$ transformation.) 
- $\gamma-\delta, 998 \pm 5 \mathrm{~K}\left(724 \pm 5^{\circ} \mathrm{C}\right)$ (based on 11 publications with original measurements, which range from 950 to $1007 \mathrm{~K}$ ) [2]. The corresponding transformation enthalpy is $\sim 3.10 \mathrm{~kJ} / \mathrm{mol}$ [2 Table 40 , 17]

- $\delta$-liquid, $1070 \pm 3 \mathrm{~K}\left(797 \pm 3{ }^{\circ} \mathrm{C}\right)$ (based on 13 publications with original measurements, which range from 1053 to $1080 \mathrm{~K}$ ) [2]. The corresponding transformation enthalpy is $\sim 5.5 \mathrm{~kJ} / \mathrm{mol}[2$ Table 40, 17]

\subsection{5 $\operatorname{Pr}$}

\subsubsection{Introduction}

Pr has two solid phases that are stable at atmospheric pressure. The crystal structures and lattice parameters of both have been known since the early 1960s (e.g., [221]).

Several other Pr phases have been formed in high-pressure experiments. One of these phases is sometimes confusingly called "alpha-U" or "alpha-uranium" in papers on high-pressure Pr phases because it has the same structure as $\alpha-U$. Despite the name, this is a Pr phase and does not contain uranium.

The existence of a face-centered cubic Pr phase has also been known since the 1960s; however, it was believed to form only at pressures above $\sim 40$ kbars (e.g., [222, 244]). More recently, high-temperature synchrotron diffraction experiments demonstrated formation of a fcc phase at atmospheric pressure [245]. This phase does not appear in recent reviews (e.g., [2, 17]). Little information about it is available, and further research is needed to investigate its thermodynamic stability, relationship to the high-pressure fcc phase, and other properties. It is included in this handbook because the conditions under which it was observed suggest that it may occur in fuels, and because it may be important in understanding possible fcc phases in Pu-Pr and Pu-Nd alloys (Handbook sections 4.1.22 and 4.1.23).

Other relatively recent research involves investigations at high pressures (e.g., [246] and attempts to understand the electronic structure of Pr using spectroscopy and modeling (e.g.,[28, 213, 243]).

\subsubsection{Phases}

The generally accepted praseodymium phases that are stable at atmospheric pressure are:

- $\quad \alpha$-Pr, dhcp (space group P6 $6_{3} / \mathrm{mmc}, a=3.6721 \AA, c=11.8326 \AA$ at $297 \mathrm{~K}$ ) [17, 220]

- $\quad \beta$-Pr, bcc (space group $\operatorname{Im} \overline{3} m, a=4.13 \AA$ at $1094 \mathrm{~K}$ ) [17, 220, 221]

The lattice parameter of the atmospheric-pressure fcc Pr phase is $5.134 \AA$ at 575 K [245].

\subsubsection{Phase transformations}

Recommended phase-transformation temperatures and enthalpies from a recent re-assessment of the experimental data are [2]:

- $\quad \alpha-\beta, 1068 \pm 3 \mathrm{~K}\left(795 \pm 3{ }^{\circ} \mathrm{C}\right)$ (based on 6 publications with original measurements, which range from 1050 to $1073 \mathrm{~K}$ ). The corresponding transformation enthalpy is estimated at $3.06 \pm 0.20 \mathrm{~kJ} / \mathrm{mol}$.

- $\quad \beta$-liquid, $1208 \pm 3 \mathrm{~K}\left(935 \pm 3{ }^{\circ} \mathrm{C}\right.$ ) (based on 5 publications with original measurements, which range from 1190 to $1208 \mathrm{~K})$. The corresponding transformation enthalpy is estimated at $5.58 \pm 0.30 \mathrm{~kJ} / \mathrm{mol}$.

The face-centered cubic phase forms from $\alpha$-Pr during heating by a martensitic transformation occurring across the temperature range from 575 to $1035 \mathrm{~K}$ [245]. Formation of the fcc phase is slow, but occurs more rapidly in samples with thermal gradients. 


\subsubsection{Nd}

\subsubsection{Introduction}

Neodymium has only two solid phases that are stable at atmospheric pressure. There has been general agreement about their crystal structures and lattice parameters since at least the early 1960s (e.g., [221]). Most relatively recent research involves attempts to understand the electronic structure of $\mathrm{Nd}$ using spectroscopy and modeling (e.g.,[213, 243, 247]).

\subsubsection{Phases}

The neodymium phases that are stable at atmospheric pressure are:

- $\quad \alpha-\mathrm{Nd}$, dhcp (space group P6 6 /mmc, $a=3.6582 \AA, c=11.7966 \AA$ at $297 \mathrm{~K}$ ) [17, 220]

- $\beta-N d$, bcc (space group $\operatorname{Im} \overline{3} m, a=4.13 \AA$ at $1156 \mathrm{~K}$ ) [17, 220, 221]

\subsubsection{Phase transformations}

Recommended phase-transformation temperatures and enthalpies from a recent re-assessment of the experimental data are [2]:

- $\alpha-\beta, 1133 \pm 5 \mathrm{~K}\left(860 \pm 5{ }^{\circ} \mathrm{C}\right)$ (based on 11 publications with original measurements, which range from 1036 to $1168 \mathrm{~K})$. The corresponding transformation enthalpy is estimated at $2.48 \pm 0.30 \mathrm{~kJ} / \mathrm{mol}$.

- $\beta$-liquid, $1298 \pm 5 \mathrm{~K}\left(1025 \pm 5^{\circ} \mathrm{C}\right)$ (based on 5 publications with original measurements, which range from 1093 to $1298 \mathrm{~K}$ ). The corresponding transformation enthalpy is estimated at $7.30 \pm 0.40 \mathrm{~kJ} / \mathrm{mol}$.

Although the $\alpha-\beta$ transformation temperature and solidus temperature both increase with increasing pressure, $\beta-\mathrm{Nd}$ apparently persists to a pressure of at least $50 \mathrm{kbars}$. The available information indicates that $\alpha$-Nd transforms to a fcc phase at $\sim 20-30$ kbars [222].

\subsubsection{U-Np}

\subsubsection{Introduction}

In 1959, Mardon and Pearce proposed an experimentally determined U-Np phase diagram. Despite possible uncertainties in sample compositions, the Mardon and Pearce phase diagram was adopted by Sheldon and Peterson [248]. It remains the only available experimentally determined phase diagram for this system. Key features of the phase diagram include a complete solid solution between $\mathrm{U}$ and $\mathrm{Np}$ in a bcc phase at the solidus, significant mutual solubility of $U$ and $N p$ in other phases, and the existence of the intermediate phase $\delta$-(U,Np).

Two models of the solidus and liquidus as regular solutions [110, 249] produced good agreement with the experimental data. A later model of the entire phase diagram based on a thermodynamically consistent database for the U-Np-Pu-Am-Fe-Zr system [250] produced generally good agreement with the experimentally determined phase diagram. This model was adopted by Okamoto [251]. The largest differences between the phase diagrams involve the maximum solubility of $\mathrm{U}$ in $\alpha-\mathrm{Np}$ and the extent to which solubilities of $\mathrm{U}$ in $\beta-\mathrm{Np}$ and $\mathrm{Np}$ in $\alpha-\mathrm{U}$ depend on temperature.

Recent thermodynamic and ab initio modeling studies include those of Xie et al. [252] and Xiong et al. $[70,253]$

\subsubsection{Phases and phase transformations}

Stable phases in the U-Np system are:

- $\quad(\alpha-U)$ : Allotropic modification of $\alpha$-U that can dissolve up to $\sim 45$ at $\% \mathrm{~Np}$ [248, 251]. Addition of $\mathrm{Np}$ causes a slight decrease in all three lattice parameters [254]. 
- $\quad(\beta-U)$ : Allotropic modification of $\beta-U$ that can dissolve up to $\sim 26$ at $\% \mathrm{~Np}[248,251]$. This phase transforms to $(\alpha-\mathrm{U})$ and $\delta$-(U,Np) by a eutectoid reaction at $\sim 645{ }^{\circ} \mathrm{C}[248]$.

- $\quad(\alpha-\mathrm{Np})$ : Allotropic modification of $\alpha-\mathrm{Np}$. According to Mardon and Pearce, the maximum solubility of $U$ in this phase is $\sim 17 \mathrm{wt} \%$ at room temperature, with a maximum of $\sim 20 \mathrm{wt} \%$ at $\sim 185^{\circ} \mathrm{C}$; according to Okamoto [251], the maximum solubility of $\mathrm{U}$ is $\sim 4.7 \mathrm{at} \%$. Incorporation of $\mathrm{U}$ in $\alpha$-Np causes increases in all three lattice parameters [254].

- $(\beta-\mathrm{Np})$ : Allotropic modification of $\beta-\mathrm{Np}$ that can dissolve up to $\sim 26$ at $\% \mathrm{U}$ at $668{ }^{\circ} \mathrm{C}[248,251]$. This phase transforms to $(\alpha-\mathrm{Np})$ and $\delta$-(U,Np) at $185^{\circ} \mathrm{C}$ by a eutectoid reaction, and to $(\gamma-\mathrm{Np})$ and $\delta$-(U,Np) at $612{ }^{\circ} \mathrm{C}$ by a peritectoid reaction [248]

- $\quad \gamma$-(U,Np): Solid solution between $\gamma-\mathrm{U}$ and $\gamma$-Np. This phase is believed to be bcc (space group $\operatorname{Im} \overline{3} m$ ) based on the structures of $\gamma$-U and $\gamma-\mathrm{Np}$; however, Mardon and Pearce were unable to confirm the structure by X-ray diffraction because of similarities in d-spacings with the Np oxides in their samples [254]. Some of Mardon and Pearce's data suggested a small miscibility gap in $\gamma-$ $(\mathrm{U}, \mathrm{Np})$ in compositions with high concentrations of $\mathrm{U}$; however, they did not show this gap in their published phase diagram because they were unable to confirm its existence with further analysis and considered it unlikely based on similarities in sizes between $U$ and $\mathrm{Np}$ [254].

- $\quad \delta-(\mathrm{U}, \mathrm{Np})$ : Intermediate phase with 23-70 at $\% \mathrm{U}[248,251]$. The structure of this phase is unknown, although it was originally believed to be either cubic or tetragonal with a c/a axis ratio close to unity and a crystal structure like that of $\zeta_{-}(\mathrm{U}, \mathrm{Pu})[254]$. It was later established from neutron diffraction that $\zeta_{-}(\mathrm{U}, \mathrm{Pu})$ is actually rhombohedral with a lattice angle close to 90 degrees (Section 3.1.6), and it seems plausible that $\delta$-(U, Np) also has a near-cubic rhombohedral unit cell. Based on a cubic structure, the room-temperature lattice parameter of $\delta$-(U, Np) increases from $10.55 \AA$ at $25 \mathrm{wt} \% \mathrm{U}$ to $10.63 \AA$ at $50 \mathrm{wt} \% \mathrm{U}[254]$.

Critical points in the U-Np system are [248]:

- $\quad \beta-\mathrm{Np} \leftrightarrow \alpha-\mathrm{Np}+\delta$-(U,Np) at $185^{\circ} \mathrm{C}$

- $\quad \beta-\mathrm{Np} \leftrightarrow \gamma-\mathrm{Np}+\delta-(\mathrm{U}, \mathrm{Np})$ at $612^{\circ} \mathrm{C}$

- $\quad \beta-U \leftrightarrow \alpha-U+\delta-(\mathrm{U}, \mathrm{Np})$ at $645 \pm 5^{\circ} \mathrm{C}$

- $\delta$-(U,Np) $\leftrightarrow \beta-U+\gamma-\mathrm{Np}$ at $668 \pm 3{ }^{\circ} \mathrm{C}$

Mardon and Pearce reported that the enthalpy of melting was smaller than that of the solid-state transformations. However, no published quantitative enthalpy measurements for any transformation in any U-Np alloy are available.

\subsubsection{Phase diagrams}

The 1959 phase diagram of Mardon and Pearce was based on measurements from two original 1-g samples (one sample of $\mathrm{Np}$ feedstock and one sample of an alloy with $50 \% \mathrm{U}$ ), which were re-melted with additional $U$ to provide data for other compositions. Major impurities in the Np feedstock were 0.34 $\mathrm{wt} \% \mathrm{Ca}$ and $0.22 \mathrm{wt} \% \mathrm{U}$. Masses lost during melting of some compositions were several tens of milligrams (almost half of the mass of the added $U$ ), suggesting the possibility of serious errors if proportions of $\mathrm{U}$ and $\mathrm{Np}$ lost were significantly different from those in the sample.

The phase diagram was based on experimental data from thermal analysis, dilatometry, X-ray diffraction, and pycnometry ([254], with some preliminary results reported by Lee [255]). It was updated in 1985 by Sheldon and Peterson to reflect more recent phase-transformation temperatures for $\mathrm{U}$ and $\mathrm{Np}$ [248] (Figure 51), and remains the only available experimentally determined phase diagram for the U-Np system. 


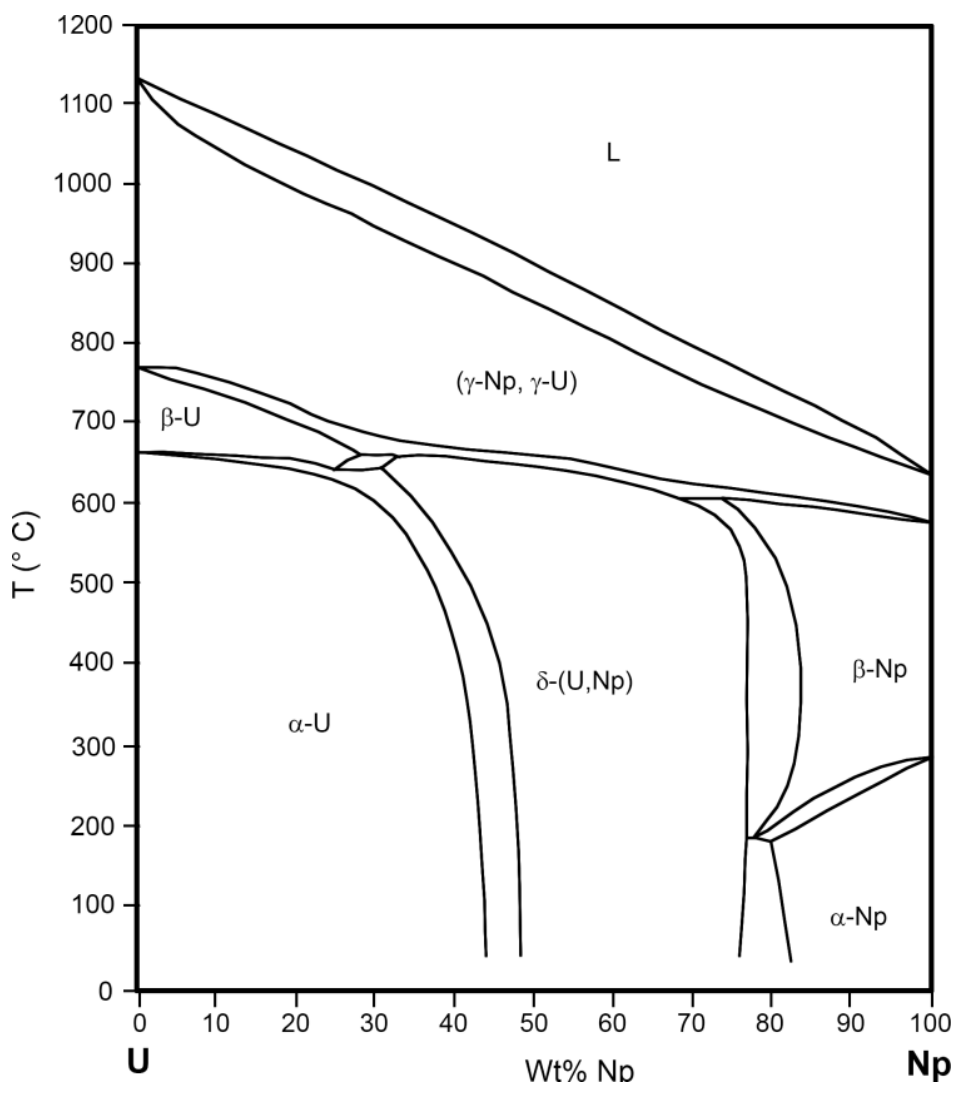

Figure 51. U-Np phase diagram proposed by Mardon and Pearce (re-drawn from [248])

\subsubsection{U-Am}

\subsubsection{Introduction}

No experimentally determined U-Am phase diagrams are available. Very limited experimental data has apparently been published in two conference proceedings papers [256, 257], although it was not possible to obtain a copy of reference [257]. The published versions of both of these conference papers apparently involve alloys with 10\% Am, although Ogawa [110] reports results from reference [256] involving a composition with $\sim 50 \% \mathrm{Am}$.

All of the available data indicates a high degree of immiscibility, and Kurata [62] says that the maximum mutual solubility of Am and $\mathrm{U}$ is less than $1 \mathrm{at} \%$. Phase diagrams for the U-Am system were calculated by Ogawa [110], Kurata [250], and Perron et al. [112].

An experimental investigation of this system is needed. In the absence of this investigation, it is probably reasonable to consider the phase diagram of Perron et al. as the best available representation of the U-Am system.

\subsubsection{Phases and phase transformations}

No experimental information about phases and phase transformations in U-Am alloys is available. Because of the very limited miscibility indicated by both the available data and the phase diagrams, it seems reasonable to assume that properties of solid-solution phases are similar to those of pure elements.

\subsubsection{Phase diagrams}

U-Am phase diagrams were calculated by Ogawa [110], Kurata [250], and Perron et al. [112]. Although all of the calculated phase diagrams show a high degree of immiscibility in solids and liquids, 
the extent of solid solution in the Ogawa phase diagram is not consistent with the data of Kurata (which was not available until later), and the Ogawa phase diagram does not address phase transformations occurring below $800 \mathrm{~K}$. The Kurata phase diagram appears only in a review, with little discussion. It is generally similar to the phase diagram of Perron et al., which is discussed in far more detail. In the absence of experimental data, it is probably reasonable to consider the phase diagram of Perron et al.

(Figure 52) as the best available approximation to the actual U-Am phase diagram.

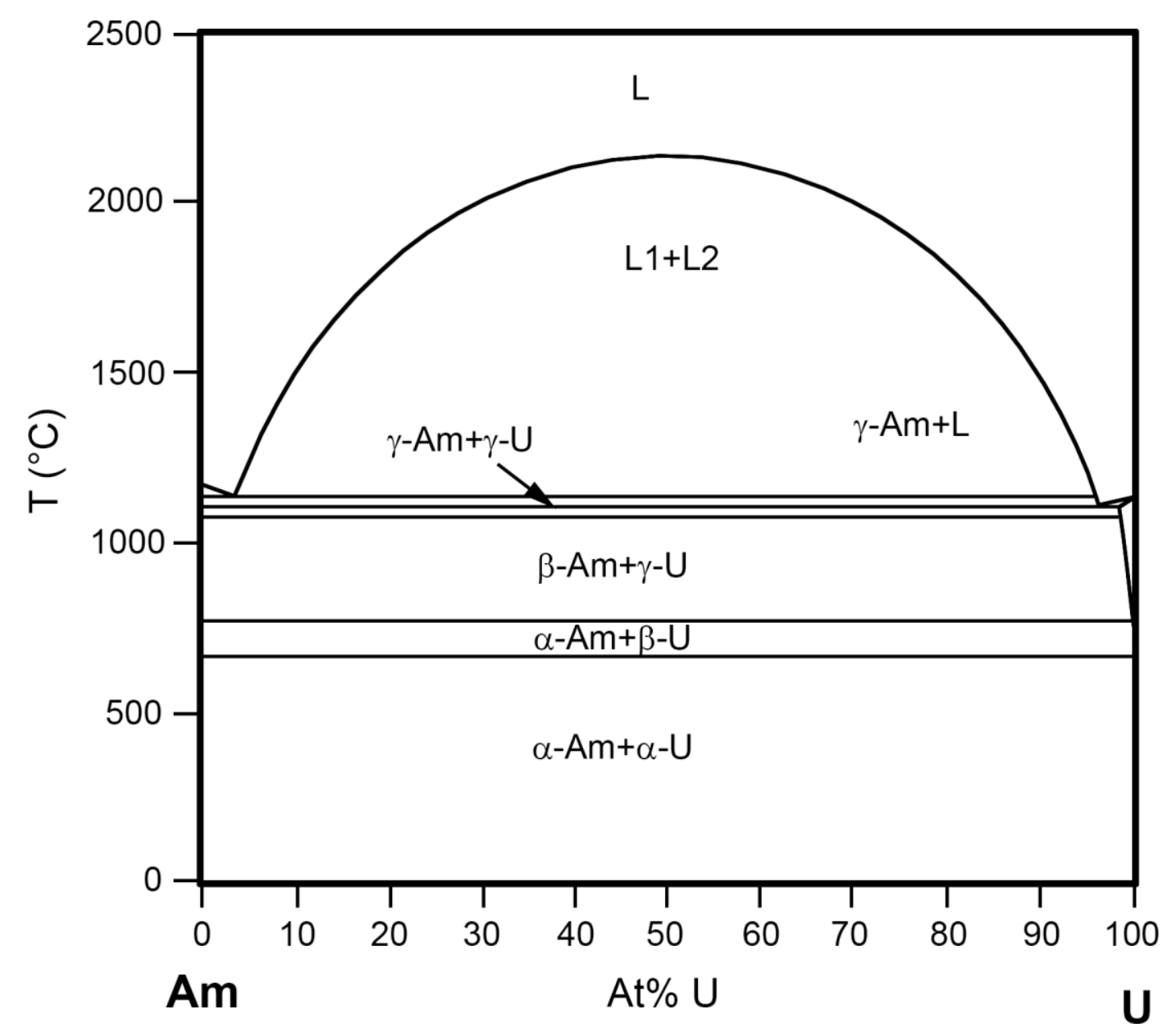

Figure 52. U-Am phase diagram proposed by Perron et al. (re-drawn from [112])

\subsubsection{U-La}

\subsubsection{Introduction}

Published experimental measurements for the U-La phase diagram are limited to temperatures between 1000 and $1500{ }^{\circ} \mathrm{C}$. These measurements suggest a phase diagram with a wide miscibility gap and no intermediate phases. Experimental measurements of the limits of solubility [47, 258, 259] are generally consistent with each other.

Bayanov calculated a variety of thermodynamic properties for liquids in the U-La system [260].

Further work is needed to understand this phase diagram, particularly at temperatures outside the temperature range of the available data and with starting materials that are known to be of high purity. 


\subsubsection{Phases and phase transformations}

No experimental data on crystal structures, lattice parameters, or phase-transformation temperatures or enthalpies in U-La alloys are available. Given the low mutual solubility of $\mathrm{U}$ and La, it seems reasonable to assume that properties of high- $\mathrm{U}$ and high-La phases are similar to those of $\mathrm{U}$ and $\mathrm{La}$.

According to Haefling and Daane, the maximum solubility of $U$ in liquid La rises from $\sim 0.422 \mathrm{wt} \%$ at $1050{ }^{\circ} \mathrm{C}$ to $\sim 1.022 \mathrm{wt} \%$ at $1250{ }^{\circ} \mathrm{C}$. These data are generally consistent with solubilities reported by Rough and Bauer $\left(0.3 \mathrm{wt} \%\right.$ at $1000{ }^{\circ} \mathrm{C}$ and $1.0 \mathrm{wt} \%$ at $\left.1250^{\circ} \mathrm{C}\right)$. The data of Shoji et al. show a maximum solubility of $6.66 \mathrm{wt} \%$ at $1500{ }^{\circ} \mathrm{C}$.

Haefling and Daane suggested that binary phase diagrams involving $U$ and rare-earth elements whose melting temperatures are below that of $U$ (including $L a$ ) have high- $U$ monotectic transformations similar to that in U-Ce phase diagrams. There is no experimental evidence to determine whether this transformation actually occurs in the U-La system.

\subsubsection{Phase diagrams}

None of the papers with experimental data include phase diagrams; however, Okamoto [261] drew a partial phase diagram from 1000 to $1300{ }^{\circ} \mathrm{C}$ based on the data of Haefling and Daane [258]. This phase diagram shows a slight depression of the melting temperature of $\gamma$-U solid solutions corresponding to the eutectic transformation suggested by Haefling and Daane. Figure 53 (new for this Handbook) follows the topology of the Okamoto phase diagram, but extends the temperature range to $1500{ }^{\circ} \mathrm{C}$ to accommodate the data of Shoji et al. [259].

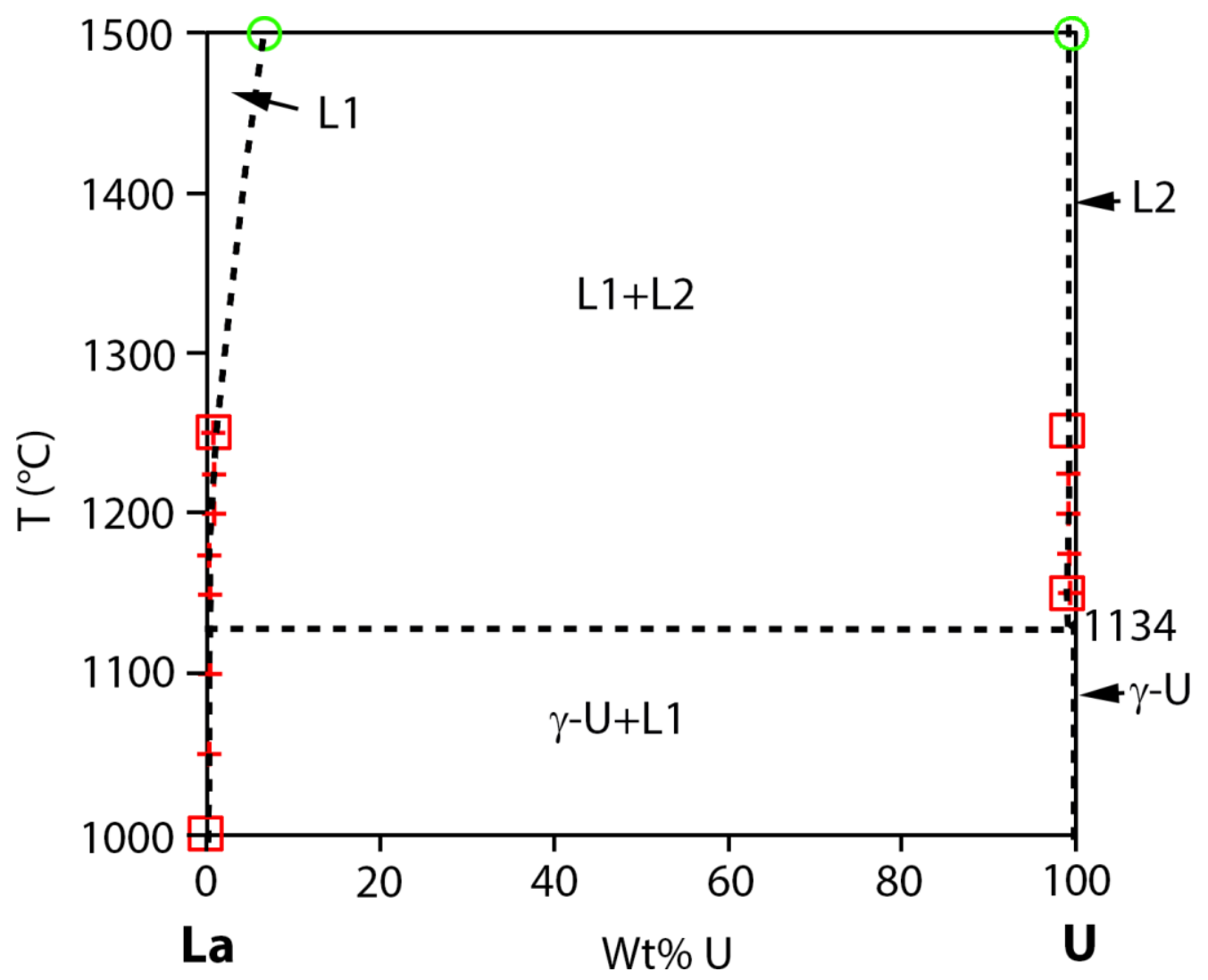

Figure 53. Tentative U-La phase diagram drawn for this Handbook based on the work of Okamoto [261], with experimental data from Haefling and Daane [258] (red "+" symbols), Rough and Bauer [47] (red squares), and Shoji et al. [259] (green circles) 


\subsubsection{U-Ce}

\subsubsection{Introduction}

Experimental data on the U-Ce system is limited to temperatures between 1000 and $1500{ }^{\circ} \mathrm{C}$. Although the mutual solubility of $U$ and $\mathrm{Ce}$ is greater than that of $\mathrm{U}$ and $\mathrm{Nd}$, Pr, or $\mathrm{La}[9,258]$, the data suggest a phase diagram with a wide miscibility gap and no intermediate phases.

Bayanov calculated a variety of thermodynamic properties for liquids in the U-Ce system [260].

Further work is needed to understand this phase diagram, particularly for high-purity materials and at temperatures outside the range of the experimental data.

\subsubsection{Phases and phase transformations}

No experimental data on crystal structures, lattice parameters, or phase-transformation enthalpies in $\mathrm{U}-\mathrm{Ce}$ alloys are available. Given the low mutual solubilities of $\mathrm{U}$ and $\mathrm{Ce}$, it seems reasonable to assume that properties of the high-U and high-Ce solid solution phases are similar to those of $U$ and Ce.

Figure 54 summarizes the experimental measurements showing the maximum mutual solubilities of $\mathrm{U}$ and $\mathrm{Ce}$.

Several researchers have found evidence for a eutectic reaction in U-Ce alloys with high concentrations of $\mathrm{U}$ at $\sim 1000{ }^{\circ} \mathrm{C}[47,258]$. Detailed investigations established the eutectic temperature as $1106{ }^{\circ} \mathrm{C}$ and showed that the maximum solubility of $\mathrm{Ce}$ in $\mathrm{U}$ at this temperature is $\sim 0.18 \mathrm{at} \%$ [258].

Haefling and Daane [258] reported that incorporation of $0.7 \mathrm{wt} \%$ Ce lowers the temperatures of the $\alpha$ $\beta$ and $\beta-\gamma$ transformations in $\mathrm{U}$ to 636 and $752{ }^{\circ} \mathrm{C}$ respectively [258].

\subsubsection{Phase diagrams}

In 1959, Haefling and Daane published experimental data on U-Ce alloys at temperatures between 1000 and $1250{ }^{\circ} \mathrm{C}$. Several reviews of the U-Ce system were published between 1958 and 1961 [9, 47, 262], based on a combination of published and unpublished data. Limits of solubility for similar compositions and temperatures in all of these publications are consistent; however, it is not clear to what extent they should be regarded as independent determinations. Only one of these reviews included a phase diagram (Figure 54).

Shoji et al. [259] determined the mutual solubility of high-purity $U$ and Ce at four temperatures between $\sim 1100$ and $1350{ }^{\circ} \mathrm{C}$ based on vapor-pressure measurements and published a more limited phase diagram based on their data and the data of Haefling and Daane [258]. The phase diagram of Shoji et al. shows the limits of the liquid miscibility gap at temperatures up to $\sim 1525{ }^{\circ} \mathrm{C}$. 


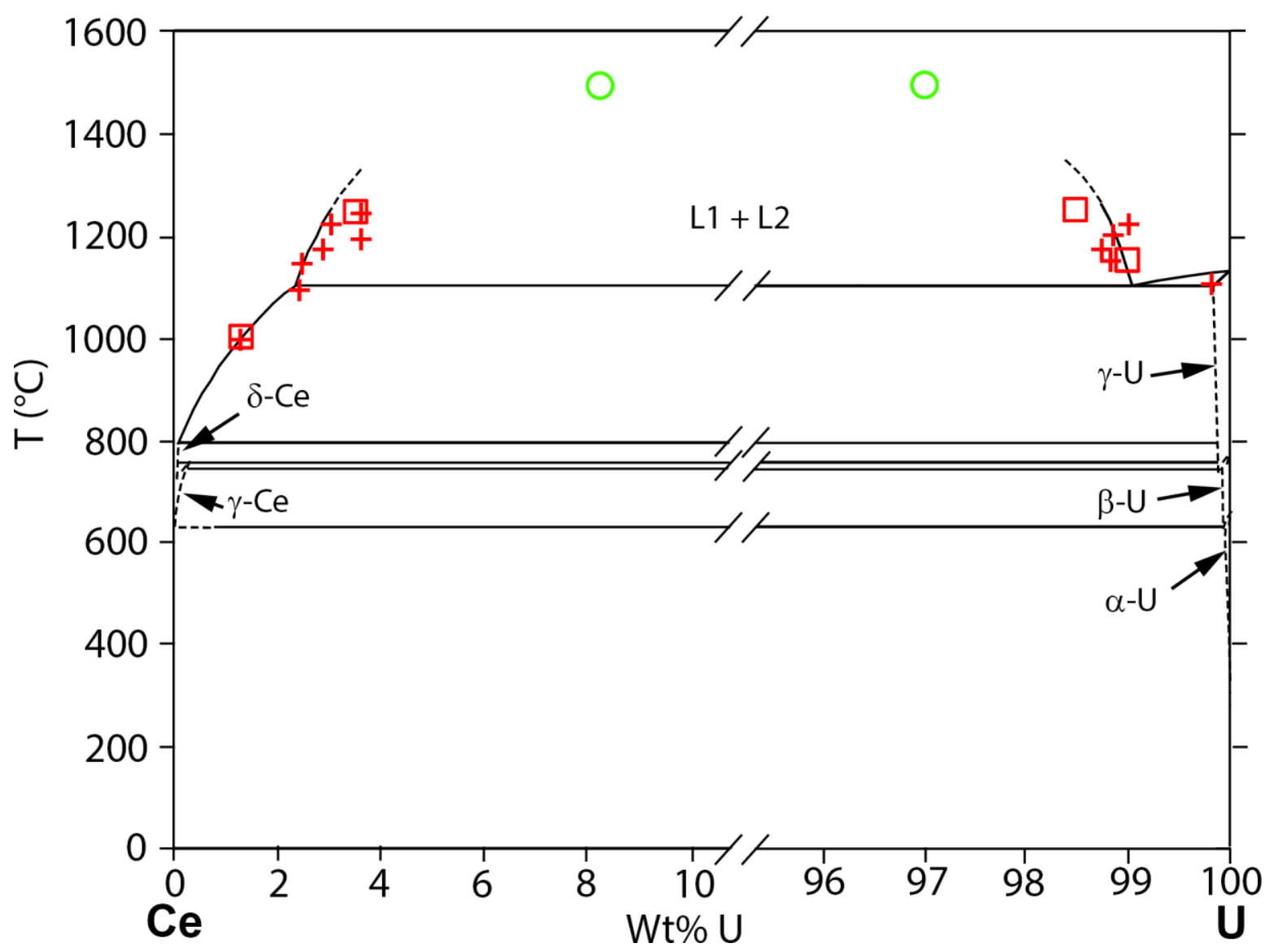

Figure 54. U-Ce phase diagram after Gschneidner [9 Figure 120]. Colored symbols indicate phase boundaries from Haefling and Daane [258] (red "+" symbols), Rough and Bauer [47] (red squares), and Shoji et al. [259] (green circles).

\subsubsection{U-Pr}

\subsubsection{Introduction}

Experimental data on U-Pr alloys is limited to temperatures between 1000 and $1250{ }^{\circ} \mathrm{C}$. Most of the data was originally reported by Haefling and Daane in 1959 [258], although a survey by Rough and Bauer [47] included other unpublished data. All of the available data suggest that $U$ and Pr liquids and solids are almost completely immiscible and that there are no intermediate U-Pr phases.

Bayanov calculated a variety of thermodynamic properties for liquids in the U-Pr system [260].

Although experimental measurements of the limits of solubility are generally consistent with each other, further investigation is required to understand this system because of the limited temperature range and unknown sample purity in the existing data. It seems unlikely that this research will significantly change the conclusion that $U$ and Pr solids and liquids have very low miscibility.

\subsubsection{Phases and phase transformations}

No experimental data on crystal structures, lattice parameters, or phase-transformation temperatures or enthalpies in U-Pr alloys are available. Given the low mutual solubility of $U$ and $\mathrm{Pr}$, it seems reasonable to assume that properties of high- $U$ and high-Pr phases are similar to those of $U$ and $\operatorname{Pr}$. 
According to Haefling and Daane, the maximum solubility of $U$ in liquid Pr rises from $1.063 \mathrm{wt} \%$ at $1000{ }^{\circ} \mathrm{C}$ to $2.028 \mathrm{wt} \%$ at $1250{ }^{\circ} \mathrm{C}$. The maximum solubility of Pr in liquid $\mathrm{U}$ rises from $0.22 \mathrm{wt} \%$ at 1150 ${ }^{\circ} \mathrm{C}$ to $0.39 \mathrm{wt} \%$ at $1250{ }^{\circ} \mathrm{C}$. Solubilities in solid phases are unknown, but probably very low.

Haefling and Daane suggested that binary phase diagrams involving $U$ and rare-earth elements whose melting temperatures are below that of $U$ (including Pr) have high- $U$ monotectic transformations similar to that in U-Ce. There is no experimental evidence to determine whether this transformation actually occurs in the U-Pr system.

\subsubsection{Phase diagrams}

Phase diagrams of the U-Pr system were published by Okamoto [263] and Peatfield et al. [264]. Both of these phase diagrams show phase transformations outside the temperature range of the available data. The Peatfield phase diagram appears to be based on previously published information of $U$ and $\mathrm{Pr}$, possibly combined with extrapolation from samples with at least 30 at $\% \mathrm{C}$. Figure $\mathbf{5 5}$ shows the experimental data with tentative phase boundaries drawn for this Handbook based on those in the U-Ce system.

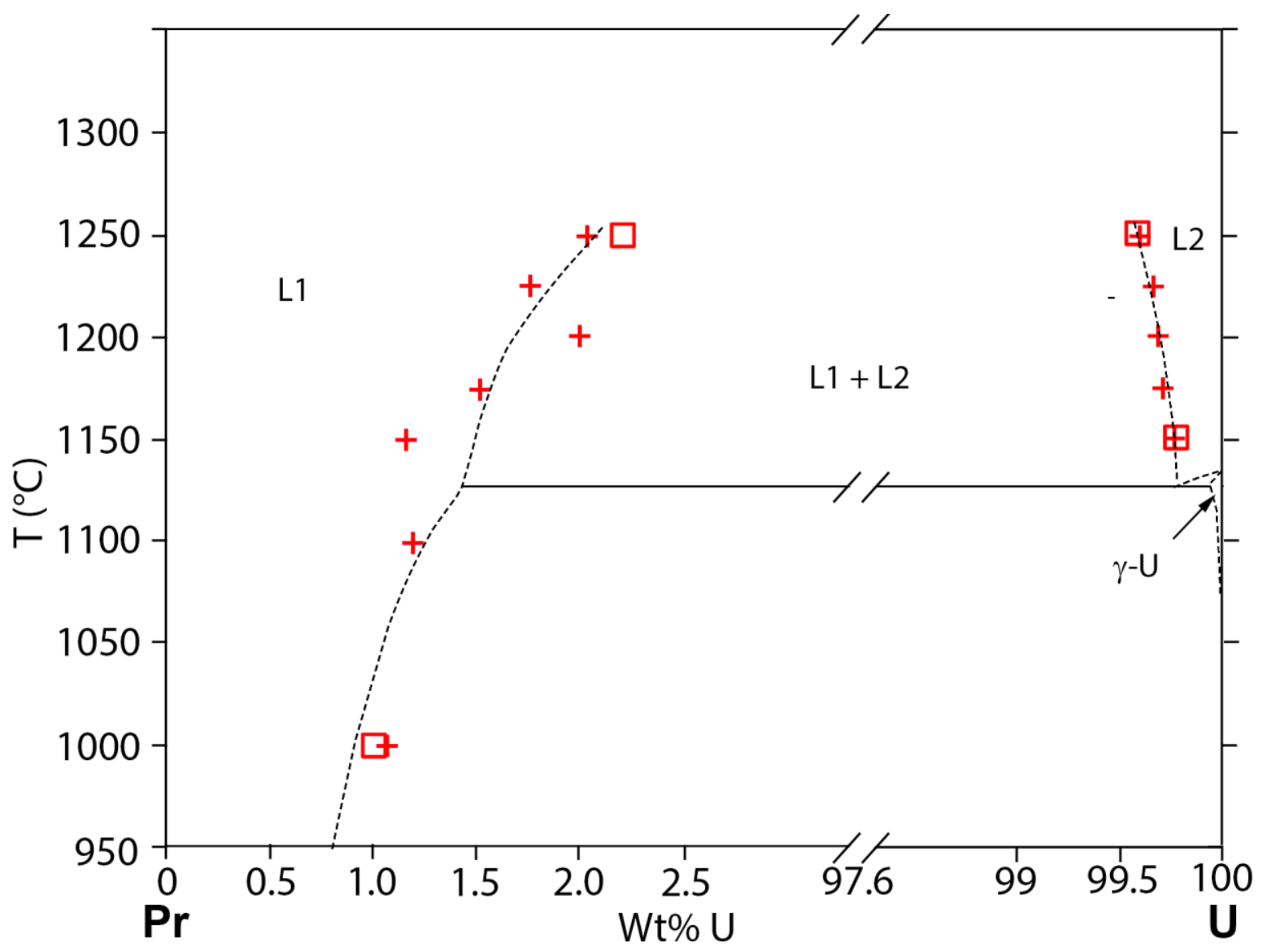

Figure 55. Tentative partial U-Pr phase diagram drawn for this handbook, with experimental data from Haefling and Daane ([258], red “+” symbols) and Rough and Bauer ([47], red squares). Phase boundaries were based on those in the U-Ce system. 


\subsubsection{U-Nd}

\subsubsection{Introduction}

Experimental data on U-Nd alloys is limited to temperatures between 1000 and $1250{ }^{\circ} \mathrm{C}$. Most of the data was originally reported by Haefling and Daane in 1959 [258], although a summary by Rough and Bauer [47] includes earlier unpublished data. The experimental data are consistent and show that $U$ and $\mathrm{Nd}$ liquids and solids are almost completely immiscible.

Despite the consistency of the existing measurements, further investigation is required to understand this system because of the limited temperature range and unknown sample purity in the existing data. It seems unlikely that this research will significantly change the conclusion that $\mathrm{U}$ and $\mathrm{Nd}$ have very low miscibility.

\subsubsection{Phases and phase transformations}

No experimental data on crystal structures, lattice parameters, or phase-transformation temperatures or enthalpies in U-Nd alloys are available. Given the low mutual solubility of $\mathrm{U}$ and $\mathrm{Nd}$, it seems reasonable to assume that properties of high- $\mathrm{U}$ and high-Nd phases are similar to those of $\mathrm{U}$ and $\mathrm{Nd}$.

Haefling and Daane identified a monotectic reaction similar to that in the U-Ce system, but did not report details.

\subsubsection{Phase diagrams}

Parnell et al. [265] published a tentative U-Nd phase diagram as part of an experimental study of UNd-Pd ternary alloys (Figure 56, which shows only the temperature range for which there is experimental data). Although the miscibility gap in this phase diagram is narrower than indicated by the experimental data, this remains the best representation of the U-Nd phase diagram because of the scale at which it is displayed. Okamoto published a similar diagram for temperatures between 500 and $1300{ }^{\circ} \mathrm{C}$ [266], but at a scale that makes it impossible to recognize details.

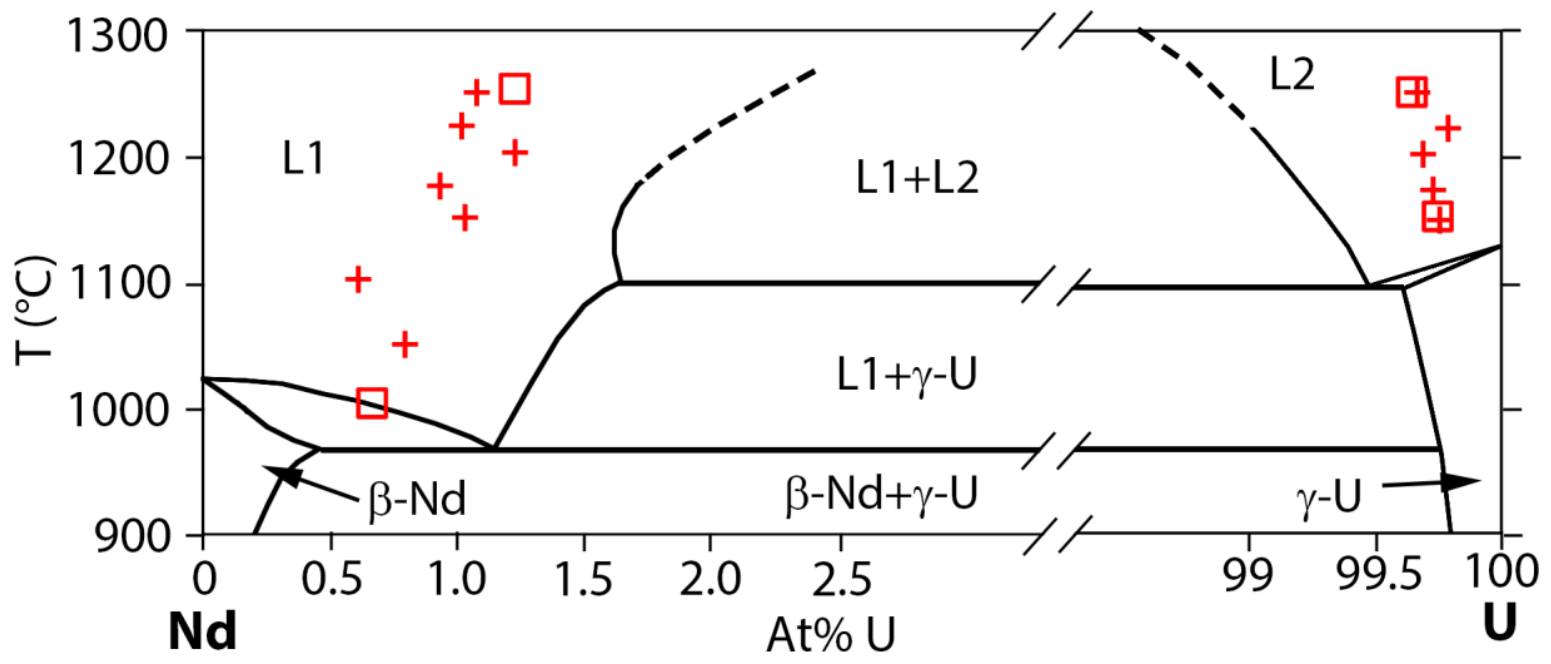

Figure 56. Tentative partial U-Nd phase diagram based onthat of Parnell et al. [265], displaying only the temperature range for which there is experimental data. Red "+" symbols indicate data from Haefling and Daane [258]. Red squares indicate data from Rough and Bauer [47] 


\subsubsection{Np-Pu}

\subsubsection{Introduction}

The Np-Pu system shows far more solubility than is common in binary actinide phase diagrams. Key features include complete miscibility of $\mathrm{Np}$ and $\mathrm{Pu}$ liquids, a complete solid solution between the bcc phases $\gamma-\mathrm{Np}$ and $\varepsilon-\mathrm{Pu}$, very high solubility of $\mathrm{Np}$ in $\alpha-\mathrm{Pu}$ and $\beta$-Pu and low solubility in $\gamma-\mathrm{Pu}, \delta$-Pu, and $\delta$ '-Pu, significant solubility of $\mathrm{Pu}$ in $\alpha-\mathrm{Np}$ and $\beta-\mathrm{Np}$, and the existence of the intermediate phase $\eta-$ $(\mathrm{Np}, \mathrm{Pu})$. Liquidus and solidus temperatures are lower for alloys than for $\mathrm{Np}$ or $\mathrm{Pu}$.

Although preliminary data on $\mathrm{Np}-\mathrm{Pu}$ phases were presented at international conferences in 1958 and 1960 [267-270], the first (and apparently only) thorough experimental investigation of the Np-Pu phase diagram was published by Mardon and colleagues in 1961 [271]. Because of a shortage of Np, samples used to determine the phase diagram were made by progressively re-melting alloys that initially had 10 , 54 , or $97 \mathrm{wt} \% \mathrm{~Np}$, adding enough $\mathrm{Pu}$ to increase the composition of the alloy by $2-3 \mathrm{wt} \% \mathrm{Pu}$ each time. The original $\mathrm{Np}$ feedstock included $\sim 0.34 \mathrm{wt} \% \mathrm{Ca}$ and $0.22 \mathrm{wt} \% \mathrm{U}$ as impurities.

Sheldon and Peterson [272] adopted the phase diagram of Mardon and colleagues with small modifications to accommodate improved knowledge of phase-transformation temperatures in pure $\mathrm{Np}$ and $\mathrm{Pu}$.

Models of the liquidus and solidus by Ogawa [110] are in good agreement with the experimental data of Mardon et al. Kurata [250] modeled the entire system as part of a consistent database of thermodynamic properties of the U-Np-Pu-Zr-Am-Fe system, obtaining general agreement with the experimental data of Mardon et al. in compositions with at least $40 \mathrm{wt} \% \mathrm{Pu}$ despite a lack of thermodynamic data. This phase diagram was presented by Okamoto [273]. Other recent modeling research involves density functional theory calculations by Landa et al. [111].

Further work is needed to confirm phase boundaries in high-Pu compositions, determine the crystal structure of the intermediate phase, and provide information about phase-transformation enthalpies.

Experimental work is also needed to understand relationships between $(\alpha-\mathrm{Np})$ and $(\alpha-\mathrm{Pu})$ solid solutions, and between $(\beta-\mathrm{Np})$ and $(\beta-\mathrm{Pu})$ solid solutions. However, these relationships involve compositions with more than 60 at $\% \mathrm{~Np}$, which are of limited practical interest for FCRD fuels.

\subsubsection{Phases and phase transformations}

Generally recognized phases in the $\mathrm{Np}$-Pu system are:

- $\quad(\alpha-\mathrm{Pu})$ : Allotropic modification of $\alpha-\mathrm{Pu}$. According to Mardon et al. [271], the solubility of Np in $\alpha-\mathrm{Pu}$ is $\sim 75-80 \mathrm{wt} \%$ at room temperature, rising to $96 \mathrm{wt} \%$ at $275^{\circ} \mathrm{C}$. The calculated phase diagram of Kurata shows a much smaller dependence on temperature, with maximum concentrations of $\mathrm{Np}$ between $\sim 90$ and $95 \%$ at temperatures between $\sim 120$ and $270{ }^{\circ} \mathrm{C}$ [273].

Mardon et al. reported that the $a, b$, and $c$ lattice parameters of $(\alpha-\mathrm{Pu})$ decrease with increasing $\mathrm{Np}$, while the lattice angle $\beta$ remains unchanged [271]. The decrease in each lattice parameter is $\sim 0.7 \%$ over the entire compositional range of the phase [271, 274]. These observations are generally consistent with lattice parameters $a=6.12 \pm 0.02 \AA, b=4.80 \pm 0.01 \AA$, $c=10.95 \pm 0.04 \AA, \beta=101.74 \pm 0.23^{\circ}$ determined from single-crystal X-ray diffraction of a sample with $\sim 43.4$ at $\% \mathrm{Pu}[274]$.

- $\quad(\beta-\mathrm{Pu})$ : Allotropic modification of $\beta-\mathrm{Pu}$. According to the phase diagram of Mardon et al., the maximum solubility of $\mathrm{Np}$ in $\beta-\mathrm{Pu}$ is $\sim 60 \mathrm{wt} \%$ at $\sim 300{ }^{\circ} \mathrm{C}$, increasing to $86 \mathrm{wt} \%$ at $540{ }^{\circ} \mathrm{C}$. However, Mardon et al. described the high-Np boundary of the ( $\beta-\mathrm{Pu})$ solid solution field in this temperature range as "extremely uncertain" because of inconsistent data from alloys with similar compositions. The calculated phase diagram of Kurata shows that the maximum concentration of $\mathrm{Np}$ in $\beta-\mathrm{Pu}$ is $\sim 20$ at $\%$, with little dependence on temperature. 
Mardon et al. reported that the $a, b$, and $c$ lattice parameters of $(\beta-\mathrm{Pu})$ decrease with increasing $\mathrm{Np}$.

- $\quad(\gamma-\mathrm{Pu}),(\delta-\mathrm{Pu})$, and $\left(\delta^{\prime}-\mathrm{Pu}\right)$ : Allotropic modifications of $(\gamma-\mathrm{Pu}),(\delta-\mathrm{Pu})$, and $\left(\delta^{\prime}-\mathrm{Pu}\right)$. Mardon et al. determined that the maximum solubility of $\mathrm{Np}$ in each of these phases is less than $\sim 2 \%$, generally consistent with tentative phase boundaries in the diagram of Cope et al. Data read from the calculated phase diagram of Kurata $[250,273]$ suggests a maximum solubility of $\sim 2 \%$ in $\gamma-\mathrm{Pu}$, $6 \%$ in $\delta-\mathrm{Pu}$, and $7 \%$ in $\delta^{\prime}-\mathrm{Pu}$.

- $\quad(\varepsilon-\mathrm{Pu}, \gamma-\mathrm{Np})$ : A continuous bcc solid solution between $\gamma-\mathrm{Np}$ and $\varepsilon-\mathrm{Pu}$. The lattice parameter decreases non-linearly with increasing concentration of $\mathrm{Np}$, and is slightly smaller than would be expected from Vegard's law [271].

- $\quad \eta-(\mathrm{Pu}, \mathrm{Np})$ : An intermediate phase with $\sim 3-50 \mathrm{wt} \% \mathrm{~Np}$, stable between $\sim 288$ and $508{ }^{\circ} \mathrm{C}$. Mardon et al. determined that this phase is not isostructural with either $\eta-(\mathrm{U}, \mathrm{Pu})$ or $\zeta-(\mathrm{U}, \mathrm{Pu})$, but thought it might be orthorhombic. On this basis, they suggested lattice parameters $a=10.86 \AA, b=10.67$ $\AA$, and $c=10.43 \AA$ for an alloy with $19 \mathrm{wt} \% \mathrm{~Np}$ at $375^{\circ} \mathrm{C}$. They reported that each lattice parameter increased with increasing $\mathrm{Pu}$, and that ratios between the sizes of the lattice parameters remained constant.

In his model, Kurata treated $\eta-(\mathrm{Pu}, \mathrm{Np})$ as equivalent to $\eta-(\mathrm{U}-\mathrm{Pu})$ because of similarities between boundaries between these phases and the corresponding body-centered cubic phases in binary phase diagrams. Kurata said this treatment was supported by experimental data in a paper on the U-Np-Pu ternary that is listed in the bibliography of reference [250] as "to be published." Attempts to find a citation for this publication were unsuccessful.

- $\quad \alpha-\mathrm{Np}$ : Allotropic modification of $\alpha$-Np. Mardon et al. reported that the solubility of $\mathrm{Pu}$ in $\alpha-\mathrm{Np}$ increases as the temperature is lowered. Although they had difficulties in determining the maximum solubility of $\mathrm{Pu}$ in $\alpha-\mathrm{Np}$ because the boundary steepened rapidly at lower temperatures decreased, they believed the maximum solubility to be "somewhat less than $20 \%$ plutonium" at room temperature. In contrast, Kurata's calculated phase diagram shows the maximum solubility of $\mathrm{Pu}$ in $\alpha-\mathrm{Np}$ as $\sim 5$ at $\%$, with little dependence on temperature.

- $\quad \beta$-Np: Allotropic modification of $\beta$-Np. Mardon et al. had difficulties in determining the maximum solubility of $\mathrm{Pu}$ in $\beta$-Np because of because of inconsistent results from alloys with similar compositions, but believed the solubility was $\sim 10 \%$ at $540{ }^{\circ} \mathrm{C}$ and somewhat lower at 300 ${ }^{\circ} \mathrm{C}$. The calculated phase diagram of Kurata suggests that the concentration of $\mathrm{Pu}$ in $\beta$-Np is slightly more than 20 at $\%$, with very limited dependence on temperature.

The existence of a second intermediate phase, $\zeta-(\mathrm{Pu}, \mathrm{Np})$, was suggested in an early phase diagram based primarily on variations in the coefficient of thermal expansion [269]; however, attempts to confirm the existence of this phase by X-ray diffraction were not successful [271] and it does not appear in other phase diagrams.

In addition to phase transformations in pure $\mathrm{Np}$ and $\mathrm{Pu}$, Sheldon and Peterson [272] listed eight invariant points in the $\mathrm{Np}-\mathrm{Pu}$ phase diagram. Subscripts indicate compositions (in at $\% \mathrm{Pu}$ ).

- $\quad(\gamma-\mathrm{Np}, \varepsilon-\mathrm{Pu})_{22}+(\beta-\mathrm{Np})_{10} \leftrightarrow(\beta-\mathrm{Pu})_{15}:$ a peritectoid reaction at $540{ }^{\circ} \mathrm{C}$

- $\quad(\gamma-\mathrm{Np}, \varepsilon-\mathrm{Pu})_{66}+(\beta-\mathrm{Pu})_{47} \leftrightarrow \eta-(\mathrm{Pu}, \mathrm{Np})_{15}:$ a peritectoid reaction at $508{ }^{\circ} \mathrm{C}$

- $\quad(\varepsilon-\mathrm{Pu})_{95.5} \leftrightarrow \eta-(\mathrm{Pu}, \mathrm{Np})_{94.5}+\left(\delta^{\prime}-\mathrm{Pu}\right)_{97.8}$ : a eutectoid reaction at $440{ }^{\circ} \mathrm{C}$

- $\quad\left(\delta^{\prime}-\mathrm{Pu}\right)_{97.6} \leftrightarrow \eta-(\mathrm{Pu}, \mathrm{Np})_{95.0}+(\delta-\mathrm{Pu})_{98.3}:$ a eutectoid reaction at $428^{\circ} \mathrm{C}$

- $\eta-(\mathrm{Pu}, \mathrm{Np})_{97.1}+(\delta-\mathrm{Pu})_{99.4} \leftrightarrow(\gamma-\mathrm{Pu})_{99.0}$ : a peritectoid reaction at $325^{\circ} \mathrm{C}$

- $\quad(\beta-\mathrm{Np})_{5.0}+(\beta-\mathrm{Pu})_{38.5} \leftrightarrow(\alpha-\mathrm{Pu})_{25}$ : a peritectoid reaction at $300^{\circ} \mathrm{C}$

- $\eta-(\mathrm{Pu}, \mathrm{Np})_{96.5} \leftrightarrow(\beta-\mathrm{Pu})_{95.5}+(\gamma-\mathrm{Pu})_{98.3}$ : a eutectoid reaction at $288^{\circ} \mathrm{C}$

- $(\beta-\mathrm{Np})_{1.6} \leftrightarrow(\alpha-\mathrm{Np})_{1.0}+(\alpha-\mathrm{Pu})_{4.0}$ : a eutectoid reaction at $275^{\circ} \mathrm{C}$ 


\subsubsection{Phase diagrams}

Preliminary experimental phase diagrams for the Np-Pu system were published by Poole et al. [268] and Cope et al. [269]. The phase diagram of Poole et al. was based in part on unpublished data from Mardon and Pearce, and therefore should probably be considered as a preliminary version of the Mardon et al. phase diagram [271] rather than an independent study. The phase diagram of Cope et al. includes only high-Pu compositions. Its determinations of solubility of $\mathrm{Np}$ in $\alpha, \gamma, \delta$, and $\delta$ '-Pu are similar to those in the phase diagram of Mardon and Pearce; however, it differs from other phase diagrams in that it shows far lower solubility of $\mathrm{Np}$ in $\beta$-Pu and includes the $\zeta-(\mathrm{Pu}, \mathrm{Np})$ intermediate phase. Because of difficulties in obtaining Np feedstock, the phase diagrams of Cope et al. and Mardon et al. both used samples obtained by progressively adding Pu to previously measured samples, and may therefore be subject to errors caused by increasing accumulation of impurities.

Sheldon and Peterson [272] made small changes to the phase diagram of Mardon et al. to accommodate more recent measurements of phase-transformations temperatures in $\mathrm{Np}$ and $\mathrm{Pu}$. Although some of the phase-transformation temperatures used by Sheldon and Peterson differ by a few degrees from those recommended in other sections of this handbook, the difference is unlikely to cause significant errors. Thus, the Sheldon and Peterson phase diagram (Figure 57) is probably the best available representation of the actual behavior of the $\mathrm{Np}-\mathrm{Zr}$ system.

Ogawa [110] modeled the liquidus and solidus using a regular-solution model with interaction parameters determined using Brewer valence bond theory and obtained good agreement with the experimental data. Kurata [250] modeled the $\mathrm{Np}-\mathrm{Pu}$ system using values from a consistent database of thermodynamic properties for the U-Np-Pu-Zr-Am-Fe system. In the absence of needed thermodynamic measurements for the $\mathrm{Np}-\mathrm{Pu}$ system, he drew "reasonable" phase boundaries. The resulting phase diagram generally agrees with the Mardon et al. and Sheldon and Peterson phase diagrams in compositions with at up to $60 \mathrm{wt} \% \mathrm{~Np}$. The Kurata phase diagram was documented by Okamoto [273]. 


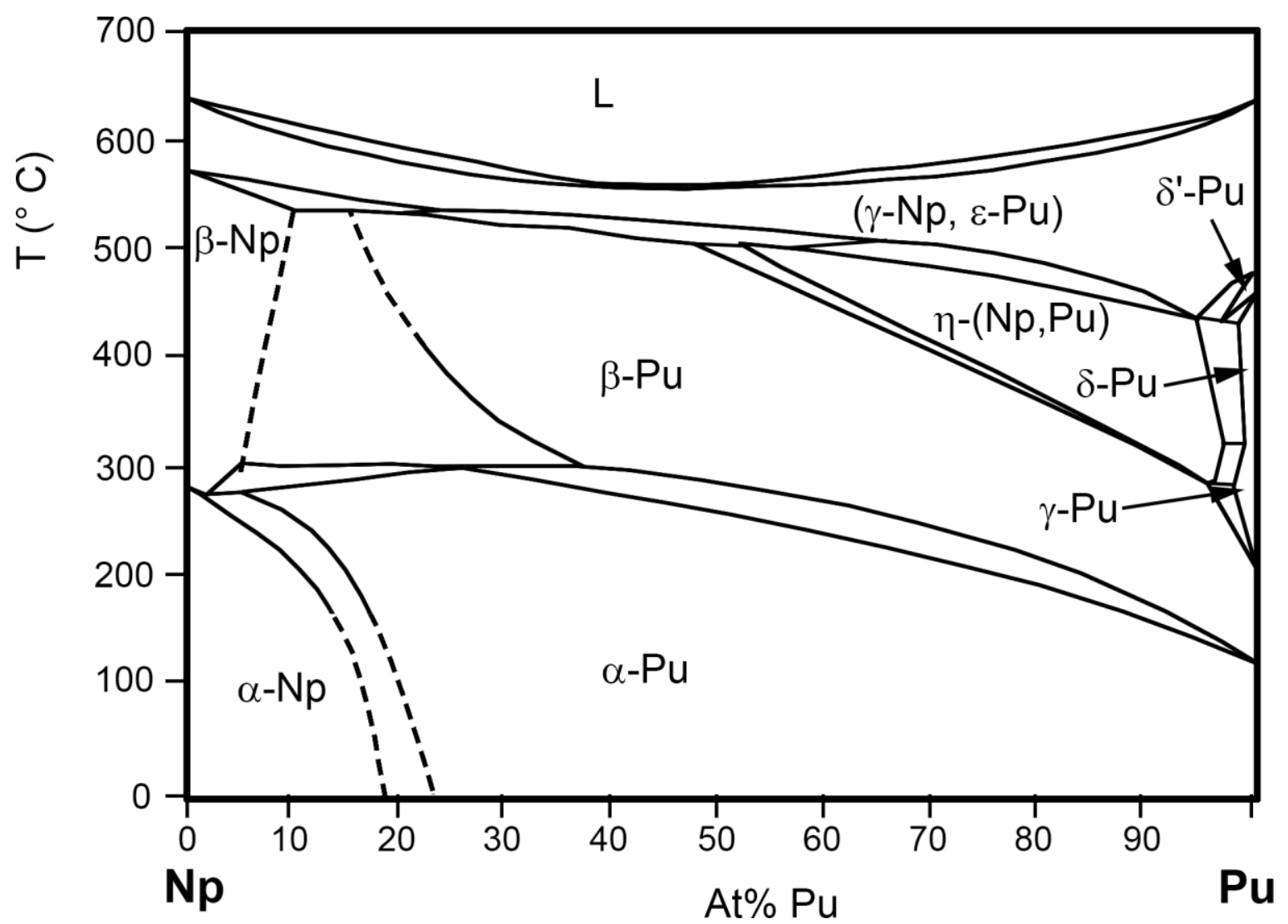

Figure 57. Np-Pu phase diagram of Sheldon and Peterson (re-drawn from [272])

\subsubsection{Np-Am}

\subsubsection{Introduction}

Experimental data for the Np-Am system are available in a single publication by Gibson and Haire that reports phase-transformation temperatures for alloys with 2.3, 5.6, and 46 at $\%$ Am [206]. This publication suggests that the alloys contained separate Am-rich and Np-rich phases, and that solubility of $\mathrm{Np}$ in the Am-rich phases is greater than solubility of Am in the Np-rich phases. Because of limited miscibility in the Np-Am system, Gibson and Haire also suggested that the Np-Am phase diagram might resemble phase the Pu-Pr (Section 4.1.22), $\mathrm{Pu}-\mathrm{Nd}$ (Section 4.1.23), or Pu-Sm phase diagrams more closely than the $\mathrm{Pu}-\mathrm{Am}$ phase diagram (Section 4.1.19).

Np-Am phase diagrams were calculated by Ogawa $[110,275]$ and by Kurata $[250,276]$. Although both models are consistent with the experimental phase-transformation temperatures of Gibson and Haire, they differ significantly in the extent of solubility of $\mathrm{Np}$ in Am, the liquidus temperature, and the possible existence of a small liquid miscibility gap. All of these differences occur in regions of the phase diagram for which there is no experimental data.

Further experimental measurements (including a thorough investigation of the entire system) are clearly needed. In the absence of these measurements, the phase diagram of Ogawa [110,275] (Figure 58) is probably the most accurate representation of the available data (particularly the difference in the extent of solid solution in the high-Np and high-Am phases, assuming the relative miscibilities suggested by Gibson and Haire are correct). 


\subsubsection{Phases and phase transformations}

Experimental determinations of the structures of phases in Np-Am alloys are not available. However, Gibson and Haire reported that their measurements showed coexisting high-Np and high-Am phases that "retain the essential features of the phase relations in pure elements" [206 p. 163].

Transition temperatures in the high-Np phase were $\sim 10-30{ }^{\circ} \mathrm{C}$ below those in the Np feedstock. The $\beta-\gamma$ and melting transformations in the high-Am phase occurred at similar temperatures, which were $\sim 60$ ${ }^{\circ} \mathrm{C}$ below the $\beta-\gamma$ transformation and $\sim 150{ }^{\circ} \mathrm{C}$ below the liquidus in the Am feedstock. Enthalpies of transformations in the high-Np phase were slightly smaller than those in the Np feedstock, and those for the high-Am phase were slightly higher than those in the Am feedstock. Gibson and Haire interpreted these differences as indicating a "greater dissolution of Np in Am than vice versa" [206 p. 163].

Researchers are encouraged to refer to the original paper for details of phase-transformation temperatures and enthalpies, which are presented for a single DTA analysis of an alloy with 46 at\% Am (Fig. 2). Care is needed in interpreting this data because, although phase-transformation temperatures measured from Am and Np feedstocks are similar to those in Sections 4.1.1 and 4.1.2, some phasetransformation enthalpies are significantly higher than the recommended values.

\subsubsection{Phase diagrams}

Np-Am phase diagrams were calculated by Ogawa [110, 275] and by Kurata [250, 276]. The calculations used different approaches: the Ogawa phase diagram was calculated using a regular-solution model with interaction parameters derived from Brewer valence bond theory, and the Kurata phase diagram was based on CALPHAD calculations using an internally consistent database of thermodynamic properties for the U-Np-Pu-Am-Fe-Zr system. Both phase diagrams show complete miscibility of the liquid, although the Ogawa phase diagram has a small liquid miscibility gap that does not appear in the Kurata phase diagram. Both phase diagrams agree that the mutual solubility of $\mathrm{Np}$ and Am is limited, and that the solubility of Am in Np is very small.

Despite these similarities, the phase diagrams show significant differences. The primary difference is the extent of solubility of $\mathrm{Np}$ in Am ( 20 at $\%$ according to the phase diagram of Ogawa and a few at $\%$ according to the phase diagram of Kurata). A second difference concerns the liquidus temperature, which is higher by up to $\sim 100$ degrees in the Ogawa phase diagram. The difference between the solubility of $\mathrm{Np}$ in Am and the solubility of Am in Np in the Ogawa phase diagram is consistent with Gibson and Haire's interpretation of their data, and the relatively similar solubilities in the Kurata phase diagram are not. However, all of the differences between the two phase diagrams occur in compositions for which no experimental measurements are available, and further work is clearly needed. 


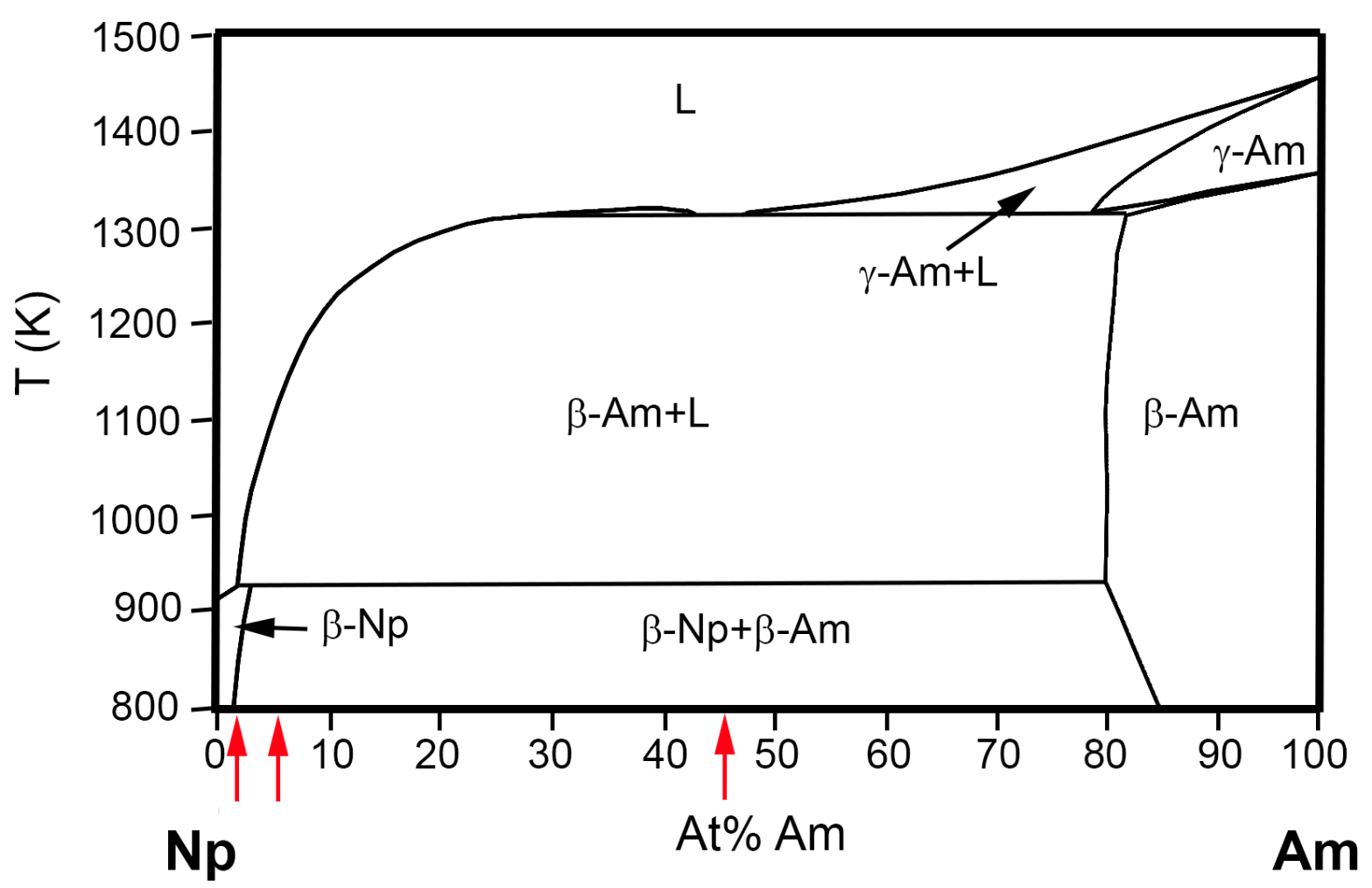

Figure 58. Np-Am phase diagram calculated by Ogawa [110,275]. Red arrows show compositions corresponding to experimental data.

\subsubsection{Np-La}

\subsubsection{Introduction}

There are apparently no published studies of the Np-La phase diagram, and the only available data is from a DTA study of an alloy with 48 at $\% \mathrm{La}$. This data indicated very limited miscibility and suggested that the Np-La phase diagram might be similar to the Pu-La diagram (Section 4.1.20) [206].

Further work on this system is clearly needed.

\subsubsection{Phases and phase transformations}

In view of the apparently limited miscibility of the Np-La system at temperatures up to at least 1200 ${ }^{\circ} \mathrm{C}$, it seems reasonable to assume that phases in this system are similar to those in pure La and Np.

The single DSC study available indicated that the temperatures of all phase transitions in La and Np solid solution phases were lower than those in pure elements. The maximum difference in temperature was less than $15^{\circ} \mathrm{C}[206]$.

\subsubsection{Phase diagrams}

No phase diagrams of the Np-La system are available.

\subsubsection{Np-Ce and $\mathrm{Np}-\mathrm{Pr}$}

\subsubsection{Introduction}

There are apparently no published studies of the Np-Ce and Np-Pr phase diagrams. They do not appear in Massalski's compilation of binary alloy phase diagrams [277] or the ASM Alloy Phase Diagram Database [278]. 
From a purely scientific perspective, further work on both of these systems is clearly needed. However, studies of more complex alloys that include Np, Ce, and $\operatorname{Pr}$ (e.g., [126, 279-283]) show no evidence of phases containing $\mathrm{Np}$ with $\mathrm{Ce}$ or $\mathrm{Pr}$, and these phase diagrams appear to be of limited relevance for FCRD fuels.

\subsubsection{Phases and phase transformations}

No information on phases in Np-Ce and Np-Pr alloys is available. The lack of evidence for phases with $\mathrm{Np}$ and $\mathrm{Ce}$ or Pr in complex alloys suggests that this system has very low miscibility, and that phases in $\mathrm{Np}-\mathrm{Ce}$ and $\mathrm{Np}$-Pr binary alloys are similar to $\mathrm{Np}, \mathrm{Ce}$, and $\mathrm{Pr}$.

\subsubsection{Phase diagrams}

No phase diagrams of the Np-Ce and Np-Pr systems are available.

\subsubsection{Np-Nd}

\subsubsection{Introduction}

There are apparently no published studies of the Np-Nd phase diagram, and the only available data is from a DTA study of an alloy with 40 at $\% \mathrm{~Np}$ [206]. This data indicated very limited miscibility and suggested that the Np-Nd phase diagram might be similar to the Pu-Nd diagram (Section 4.1.23).

Further work on this system is clearly needed. Gibson and Haire noted that these alloys were unusually difficult to measure because of creeping and volatilization of molten Np-Nd alloys [206].

\subsubsection{Phases and phase transformations}

No information on $\mathrm{Np}-\mathrm{Nd}$ phases is available. The lack of evidence for phases with both $\mathrm{Np}$ and $\mathrm{Nd}$ in complex alloys suggests that this system has very low miscibility, and that phases in Np-Nd alloys are similar to $\mathrm{Np}$ and $\mathrm{Nd}$.

\subsubsection{Phase diagrams}

No phase diagrams of the $\mathrm{Np}-\mathrm{Nd}$ system are available.

\subsubsection{Np-Zr}

\subsubsection{Introduction}

Two groups of researchers have attempted to determine the $\mathrm{Np}-\mathrm{Zr}$ phase diagram experimentally, leading to contradictory phase diagrams, both of which are considered "tentative" or "preliminary" by the authors of the papers describing them [284, 285]. The primary differences between the phase diagrams involve the extent of miscibility between the bcc phases $\gamma-\mathrm{Np}$ and $\beta-\mathrm{Zr}$ and the number of intermediate phases in the system.

The available phase-transition temperatures are generally consistent with either of the proposed phase diagrams. Attempts to use models to determine which phase diagram is correct have consistently led to the conclusion that further experimental data is required [62, 68, 253, 286, 287].

Further experimental investigations of this phase diagram are clearly needed. It is particularly important to understand the miscibility between $\gamma-\mathrm{Np}$ and $\beta-\mathrm{Zr}$ because of its implications for predicting possible high-Np phases in fuels containing minor actinides. In the absence of this research, the phase diagram of Rodríguez et al. [285] seems less plausible than that of Gibson et al. [284, 288-290], for reasons that are discussed below. It should be noted, however, that this suggestion implies significant differences from the U-Zr and Pu-Zr systems, both of which have complete miscibility between bcc actinides and $\mathrm{Zr}$ (Sections 3.1.4 and 3.1.5). Ogawa et al. proposed one possible explanation for these differences in terms of the behavior of $5 f$ electrons [68]. 


\subsubsection{Phases and phase transformations}

No systematic survey of phases in the Np-Zr system is available, although some observations have been published. In the absence of experimental data, it may be necessary to assume that Np-Zr phases are similar to those in $\mathrm{Np}$ and $\mathrm{Zr}$. Based on this assumption, phases in the $\mathrm{Np}-\mathrm{Zr}$ system are:

- $\quad(\alpha-\mathrm{Np})$ : Allotropic solid solution of $\alpha-\mathrm{Np}$ with negligible solubility of $\operatorname{Zr}$ [291]

- $\quad(\beta-\mathrm{Np})$ : Allotropic solid solution of $\beta-\mathrm{Np}$. No other information is available.

- $\quad(\gamma-\mathrm{Np})$ Allotropic solid solution of $\gamma$-Np. The phase diagram of Rodríguez et al. shows a continuous solid solution with $\beta-\mathrm{Zr}$; that of Gibson and colleagues does not. Gibson and Haire suggested that incorporation of $\mathrm{Zr}$ might stabilize $\gamma$-Np at the expense of $\beta$-Np and possibly of $\alpha$ $\mathrm{Np}$ [288].

- $\quad(\alpha-Z r)$ : Allotropic solid solution of $\alpha-Z r$ with a maximum solubility of $\mathrm{Np}$ of $\sim 10 \%$, decreasing to zero as the temperature increases to $600{ }^{\circ} \mathrm{C}$ [291]. Incorporation of $\mathrm{Np}$ into $\alpha-\mathrm{Zr}$ increased the $c$ lattice parameter by $4.0 \mathrm{pm}$ and did not change the $a$ parameter [291].

- $\quad(\beta-Z r)$ Allotropic solid solution of $\beta-Z r$. The phase diagram of Rodríguez et al. shows a continuous solid solution with $\beta-\mathrm{Np}$; that of Gibson and colleagues does not.

- $\delta-\mathrm{NpZr}_{2}$ : Hexagonal solid-solution phase (space group P6/mmm, $a=5.024 \AA, c=3.075 \AA$ ) [291], with a structure similar to those of $\delta-\mathrm{UZr}_{2}$ and $\kappa-\mathrm{PuZr}_{2}$. High-temperature powder diffraction data indicates that $\delta-\mathrm{NpZr}_{2}$ decomposes at $\sim 550 \mathrm{C}$ [292]. The range of compositions in this phase is unknown.

- $\quad \theta$-(Np,Zr) Intermediate phase analogous to $\theta-(\mathrm{Pu}, \mathrm{Zr})$. Similarities between powder patterns of this phase and those of $\mathrm{Pu}_{4} \mathrm{Zr}$ suggest that $\theta-(\mathrm{Np}, \mathrm{Zr})$ is a tetragonal phase with composition $\mathrm{Np}_{4} \mathrm{Zr}$; however, a composition of $\mathrm{Np}_{6} \mathrm{Zr}$ has also been suggested [291]. This phase appears in the phase diagram of Gibson et al. [284] and in some modeled phase diagrams [62, 253, 286, 287], but not in the phase diagram of Rodríguez et al. [285]. No published analyses of the composition of this are available.

Although both Gibson and colleagues and Rodríguez et al. published phase-transformation temperatures, it is not clear which transitions are associated with each temperature. It seems likely that some transformation temperatures represent more than one transformation. Many of the measurements were described as "preliminary."

Table 17 summarizes the available experimental data on phase transition temperatures. Values for DSC data include ranges of onset temperatures observed during heating of similar samples. Ranges of values for dilatometry data are those given by Rodríguez et al. [285].

Table 17. Phase-transformation temperatures in $\mathrm{Np}-\mathrm{Zr}$ alloys

$\begin{array}{lccc}\begin{array}{l}\text { Composition } \\ (\text { at } \% \mathrm{~Np})\end{array} & \mathrm{T}\left({ }^{\circ} \mathrm{C}\right) & \begin{array}{c}\text { Experiment } \\ \text { type }\end{array} & \text { References } \\ & & \end{array}$

\begin{tabular}{llll}
\hline 9 & $545-577,780,1630$ & Dilatometer & {$[285]$} \\
25 & $540,630 ?$ & DSC & {$[288,289]$} \\
28 & $530-543,1325$ & Dilatometer & {$[285]$} \\
50 & $511-540,638-640$ & DSC & {$[288,289]$} \\
52 & $540-550,640$ & DSC & {$[288,289]$}
\end{tabular}




$\begin{array}{llll}60 & 533-542,615-642,894 & \text { Dilatometer } & {[285]} \\ 73 & 270,550,640 & \text { DSC } & {[288,289]} \\ 78 & 280,550-553,640 & \text { DSC } & {[288,289]}\end{array}$

Table 18 includes the only available experimental data on enthalpies of phase transitions.

Table 18. Phase-transformation enthalpies in Np-Zr alloys [288]

\begin{tabular}{rll}
$\begin{array}{c}\mathrm{Wt} \\
\% \mathrm{~Np}\end{array}$ & $\mathrm{~T}\left({ }^{\circ} \mathrm{C}\right)$ & $\Delta \mathrm{H}(\mathrm{J} / \mathrm{g})$ \\
\hline 90 & 553 & 13.514 \\
\hline 74 & 540 & 4.444 \\
& 640 & 37.7787 \\
\hline 72 & 511 & 6.156 \\
& 638 & 24.406 \\
\hline 46 & 540 & 8.333 \\
\hline
\end{tabular}

\subsubsection{Phase diagrams}

The phase diagram of Gibson et al. [284, 288-290] (Figure 59) was developed using DSC data. Much of the data was collected using an "in-situ alloying" technique in which starting materials were melted during the first heating, and data on properties of alloys was collected during later heating cycles [288]. Later work including both in-situ alloying and arc-melted samples found that results of these techniques were comparable [289].

The DSC data showed that Np-Zr alloys with up to 20 at $\% \mathrm{Zr}$ have the same melting temperature as pure $\mathrm{Np}$. Because the melting temperature of $\beta-\mathrm{Zr}$ is much higher than that of $\gamma-\mathrm{Np}$, and because other actinide-Zr phase diagrams with complete miscibility between bcc actinides and $\mathrm{Zr}$ show sharp increases in melting temperature with increasing concentrations of $\mathrm{Zr}$, Gibson et al. interpreted their data as indicating a miscibility gap between $\beta-\mathrm{Zr}$ and $\gamma-\mathrm{Np}$.

High-temperature $\mathrm{X}$-ray diffraction data showing that the maximum concentration of $\mathrm{Zr}$ in $\gamma$-Np is only $\sim 4 \%$ at $600{ }^{\circ} \mathrm{C}$ [292] and room-temperature X-ray diffraction of arc-melted samples with 10-90 at $\%$ $\mathrm{Zr}$ that did not have either $\beta-\mathrm{Zr}$ or $\gamma$-Np [291] support the model of Gibson et al. 


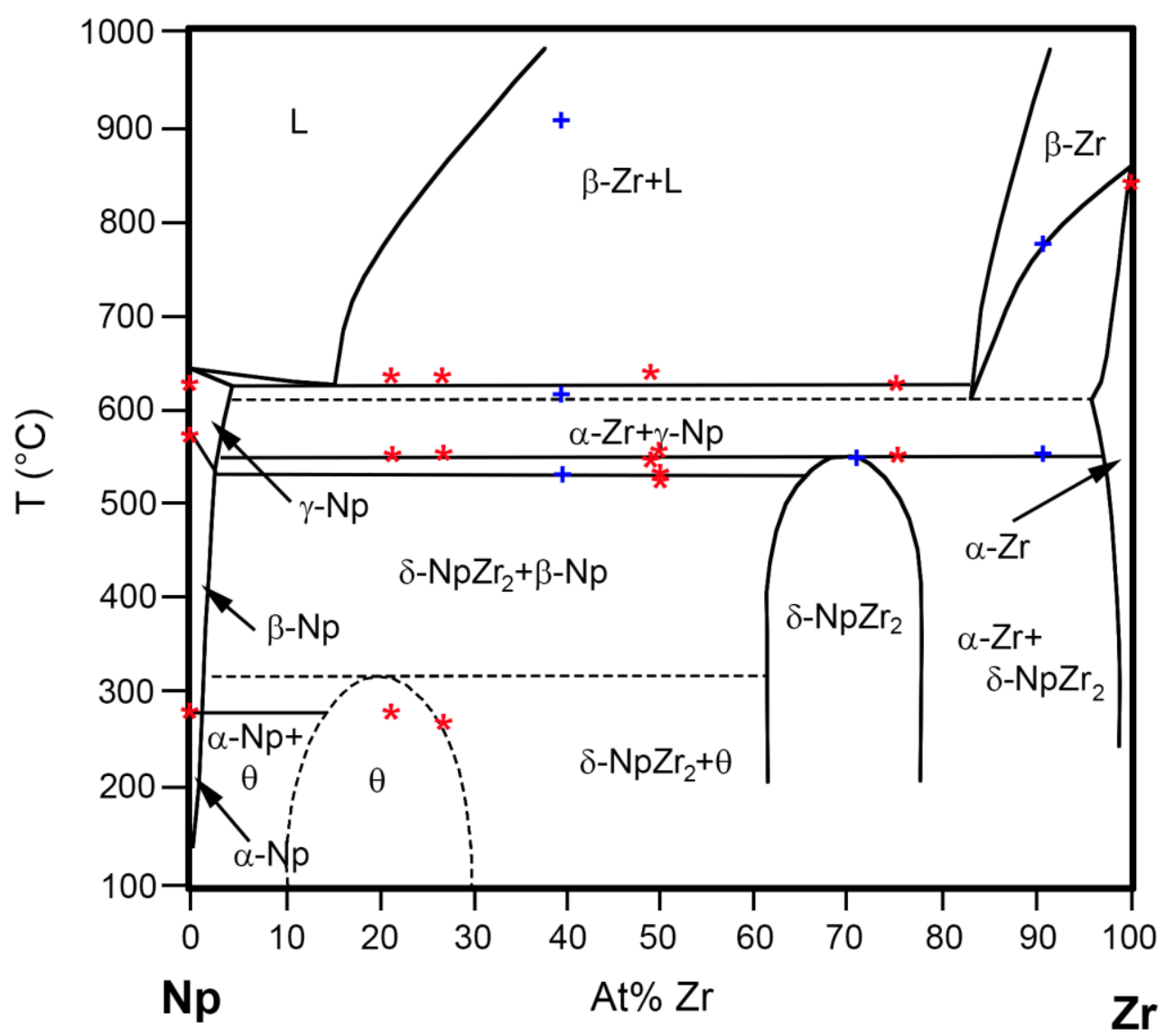

Figure 59. Tentative Np-Zr phase diagram proposed by Gibson and Haire [289]. Colored symbols show data from Table 17. Red symbols are data from Gibson and Haire [288, 289]; blue symbols are data from Rodríguez et al. [285].

In contrast, the phase diagram of Rodríguez et al. [285] (Figure 60) assumes that the Np-Zr phase diagram is similar to those for $\mathrm{U}-\mathrm{Zr}$ and $\mathrm{Pu}-\mathrm{Zr}$, and therefore has a continuous solid solution between $\gamma$ $\mathrm{Np}$ and $\beta-\mathrm{Zr}$. This phase diagram is supported by microscopic observations and microprobe data showing that $\mathrm{Np}-\mathrm{Zr}$ alloys with $50 \mathrm{wt} \% \mathrm{Zr}$ that had been annealed for a week have only one phase, while those with 20 or $80 \% \mathrm{Zr}$ have two phases. Although this phase diagram is consistent with the available phasetransformation data, reasons to regard it with caution include:

- It is inconsistent with the high-temperature X-ray diffraction results of Y. Okamoto et al. [292]

- H. Okamoto [293] suggested that what appears to be the melting curve for the ( $\gamma-\mathrm{Np}, \beta-\mathrm{Zr}$ ) solid solution has not been correctly identified.

- Given the sluggish kinetics of phase separations in other actinide-Zr alloys, it is not clear that it would be possible to recognize early stages of phase separation using optical microscopy or microprobe techniques without longer annealing times. 


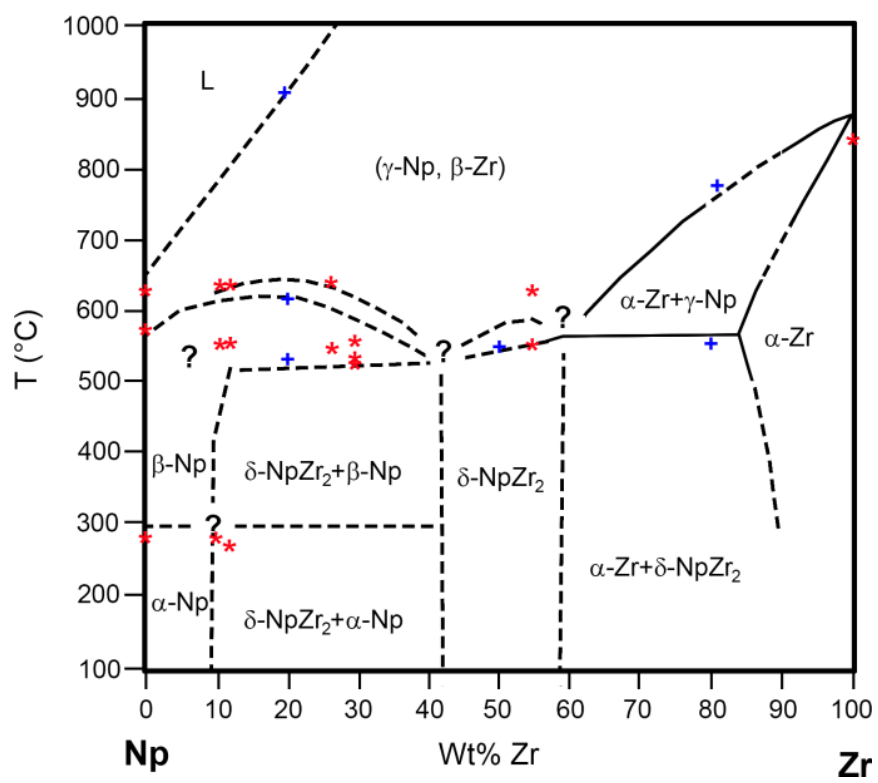

Figure 60. Tentative Np-Zr phase diagram proposed by Rodríguez et al. [285], showing only temperatures from 100 to $1000{ }^{\circ} \mathrm{C}$. Colored symbols are as in Figure 59.

\subsubsection{Pu-Am}

\subsubsection{Introduction}

Two experimental determinations of the $\mathrm{Pu}$-Am phase diagram have been published. The first was based on X-ray diffraction and micrographic techniques. It was documented by Ellinger et al. in a report and journal paper [294, 295]. The second experimental determination, by Shushakov et al. [296], was documented in a short paper in Russian in 1990 but was apparently not considered in the Englishlanguage literature until 2011. Several modeling studies (e.g., [110, 111, 250, 297, 298]) attempted to resolve disagreements between the experimental determinations, but without achieving consensus.

Generally accepted features of the system include the existence of a continuous solid solution between the fcc phases $\delta$-Pu and $\beta$-Am, stabilization of the $\delta$-Pu structure down to room temperature in some compositions, limited solubility of $\mathrm{Am}$ in $\alpha, \beta, \gamma$, and $\delta$ ' $\mathrm{Pu}$, and the absence of intermediate phases. One important area of disagreement is the possible existence of a solid solution between the bec phases $\gamma$ $\mathrm{Am}$ and $\varepsilon$-Pu. Relationships between $\alpha$-Am and $(\beta-\mathrm{Am}, \delta$-Pu) solid solutions and the stability of the $\delta$-Pu structure at temperatures below $\sim 125^{\circ} \mathrm{C}$ are also areas of disagreement, but may be relatively unimportant for fuels because of the sluggish phase-transformation kinetics of this system.

The focus of much of the relatively recent research on Pu-Am alloys involves understanding the electronic structure of the alloys (e.g., [299-303]).

Further experimental work to understand the phase diagram is clearly required. Experimental designs should consider the likelihood of a high degree of sensitivity to impurities and difficulties in determining equilibrium phases because of sluggish phase-transformation kinetics.

\subsubsection{Phases and phase transformations}

Phases in the Pu-Am phase diagram include:

- $\quad(\alpha-\mathrm{Pu}),(\beta-\mathrm{Pu}),(\gamma-\mathrm{Pu}),\left(\delta^{\prime}-\mathrm{Pu}\right)$ : Crystal structures and lattice parameters of these solid-solution phases have not been reported, although they are probably similar to those of the corresponding 
phases in pure $\mathrm{Pu}$. It is generally accepted that solubility of Am in these phases is very limited, and the experimental data of Ellinger et al. [295] suggest that it is at most $\sim 1.5$ at $\% \mathrm{Am}$.

- $\quad(\alpha-A m)$ : The crystal structure and lattice parameters of this solid-solution phase have not been reported, although they are probably similar to those of $\alpha$-Am. The solubility of $\mathrm{Pu}$ in this phase has not been investigated in detail, although Ellinger et al. thought it was $\sim 5$ at $\%$ and Shushakov et al. thought it was 20 at $\%[295,296]$.

- $\quad(\beta-\mathrm{Am}, \delta$-Pu): A solid solution between the fcc phases $\beta$-Am and $\delta$-Pu. The experimental data of Ellinger et al. and Shushakov et al. $[295,296]$ show that alloys with $\sim 6-80$ at\% Am retain this phase down to room temperature, although the calculated phase diagrams of Kurata and GotcuFreis show significantly lower maximum room-temperature concentrations of Am in this phase $[250,297]$. The model of Turchi et al. indicates that this phase decomposes to $\alpha$-Am and $\alpha$-Pu below $\sim 100{ }^{\circ} \mathrm{C}$ [298]. The lattice parameter of this phase increases smoothly with increasing concentrations of Am, with a positive deviation from Vegard's law (Figure 61).

- $\quad(\gamma-\mathrm{Am})$ and $(\varepsilon-\mathrm{Pu})$ : Structures of these solid-solution phases have not been experimentally determined, although it seems likely that both are bcc. The experimental data of Ellinger et al. showed a maximum concentration of $\sim 8$ at $\% \mathrm{Am}$ in $\varepsilon-\mathrm{Pu}$ [295], while the experimental data of Shushakov et al. [296] showed a continuous solid solution between $\gamma$-Am and $\varepsilon-\mathrm{Pu}$. Turchi et al modeled the differences in energy required to produce a solid solution or a miscibility gap between $\gamma$-Am and $\varepsilon-\mathrm{Pu}$, and determined that the difference between the experimental phase diagrams was small enough to be easily influenced by impurities in the sample [298].

Temperatures of phase transformations are poorly known, and phase-transformation enthalpies have not been reported.

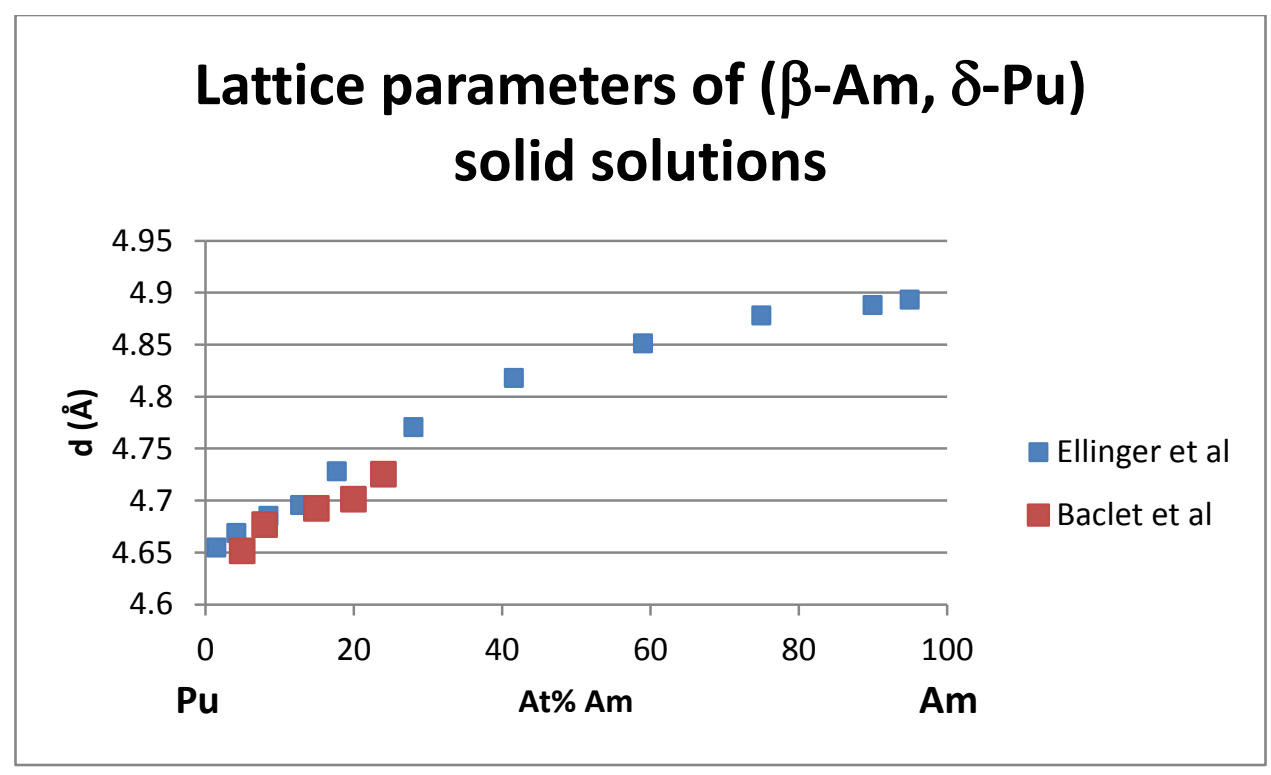

Figure 61. Lattice parameters of ( $\beta$-Am, $\delta$-Pu) solid solutions [295, 299] 


\subsubsection{Phase diagrams}

Ellinger et al. published the first Pu-Am phase diagram in 1965 based on micrographic and X-ray diffraction data [294, 295] (Figure 62). Key features of this phase diagram included the existence of a continuous fcc solid solution between $\delta$-Pu and $\beta$-Am, stabilization of the $\delta$-Pu structure down to room temperature for compositions with $\sim 6-80$ at $\% \mathrm{Am}$, the possible existence of a two-phase field between $\delta$ $\mathrm{Pu}$ and $\alpha$-Am solid solutions, and limited solubility of Am in $\alpha, \beta, \gamma, \delta$, and $\varepsilon-\mathrm{Pu}$.

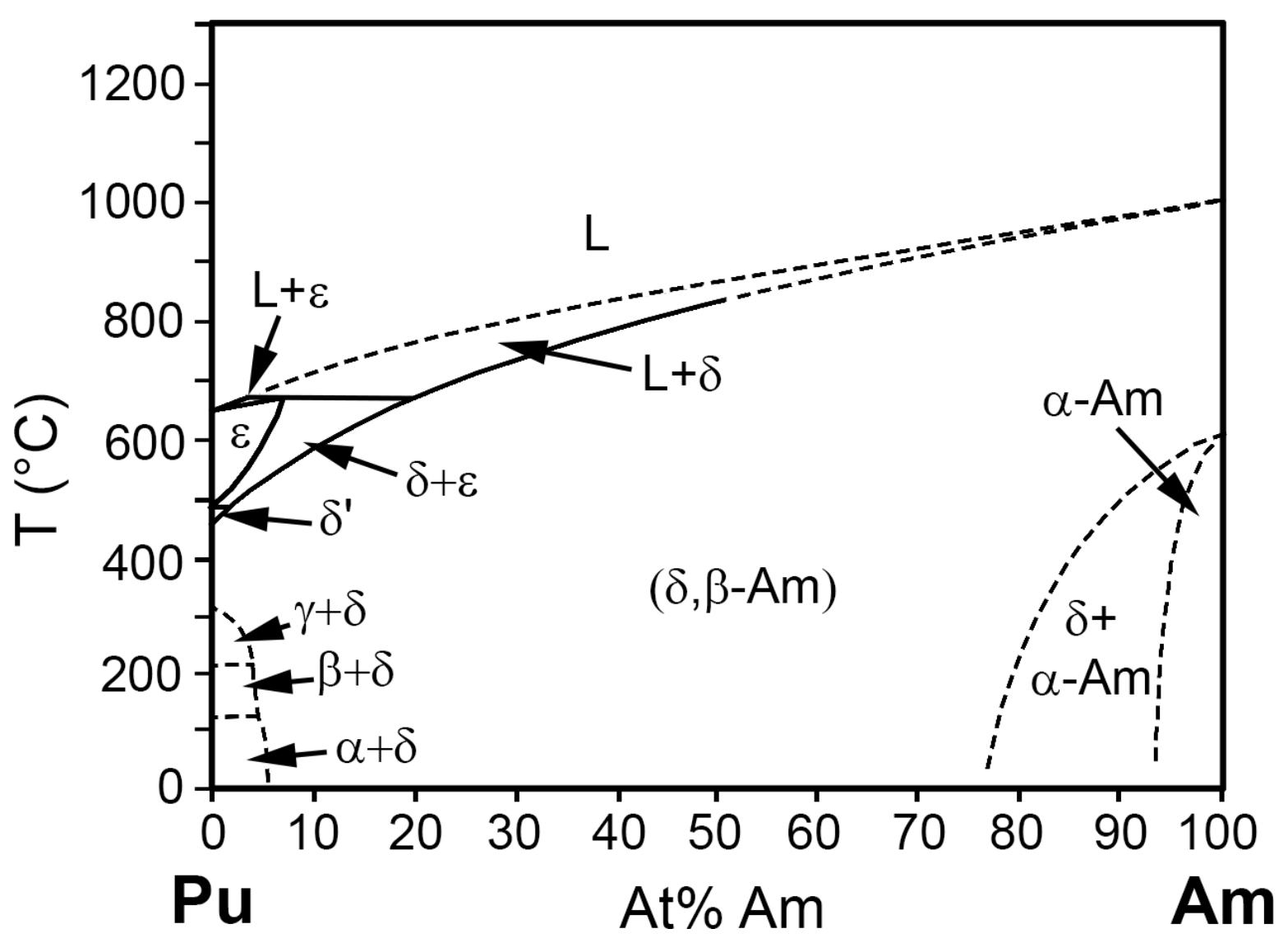

Figure 62. Experimentally determined Pu-Am phase diagram according to Ellinger et al. [294, 295]. $\alpha, \beta$, $\gamma, \delta, \delta$ ' and $\varepsilon$ indicate Pu solid solution phases. Although this phase diagram is based on the most thoroughly documented experimental study of the Pu-Am system to date, it is no longer generally accepted.

Although the Ellinger et al. study [304] is the most thoroughly documented investigation of the PuAm system, the corresponding phase diagram has a number of serious problems. It does not include $\gamma-$ Am, which was unknown at the time. Its temperatures for the $\alpha-\beta$ and melting transformations in Am were the only ones available at the time, but are below the currently accepted values in Section 4.1.2 by 170-180 degrees. The Am feedstock used by Ellinger et al. initially contained up to $0.52 \mathrm{wt} \%$ impurities (primarily La); however, since some samples were obtained by progressively re-casting earlier samples with additional $\mathrm{Pu}$ and "appreciable" weight losses occurred during casting, concentrations of impurities in some samples may have been significantly higher.

Shushakov et al. published a second experimentally determined Pu-Am phase diagram using data from high-temperature X-ray diffraction, DTA, microstructural analysis, and densitometry (Figure 63). This phase diagram was documented in a short paper in a Russian-language journal in 1990 [296]. There 
are no generally available English translations of this paper, and it was apparently not considered in English-language papers until 2011. No information about the purity of the samples is provided.

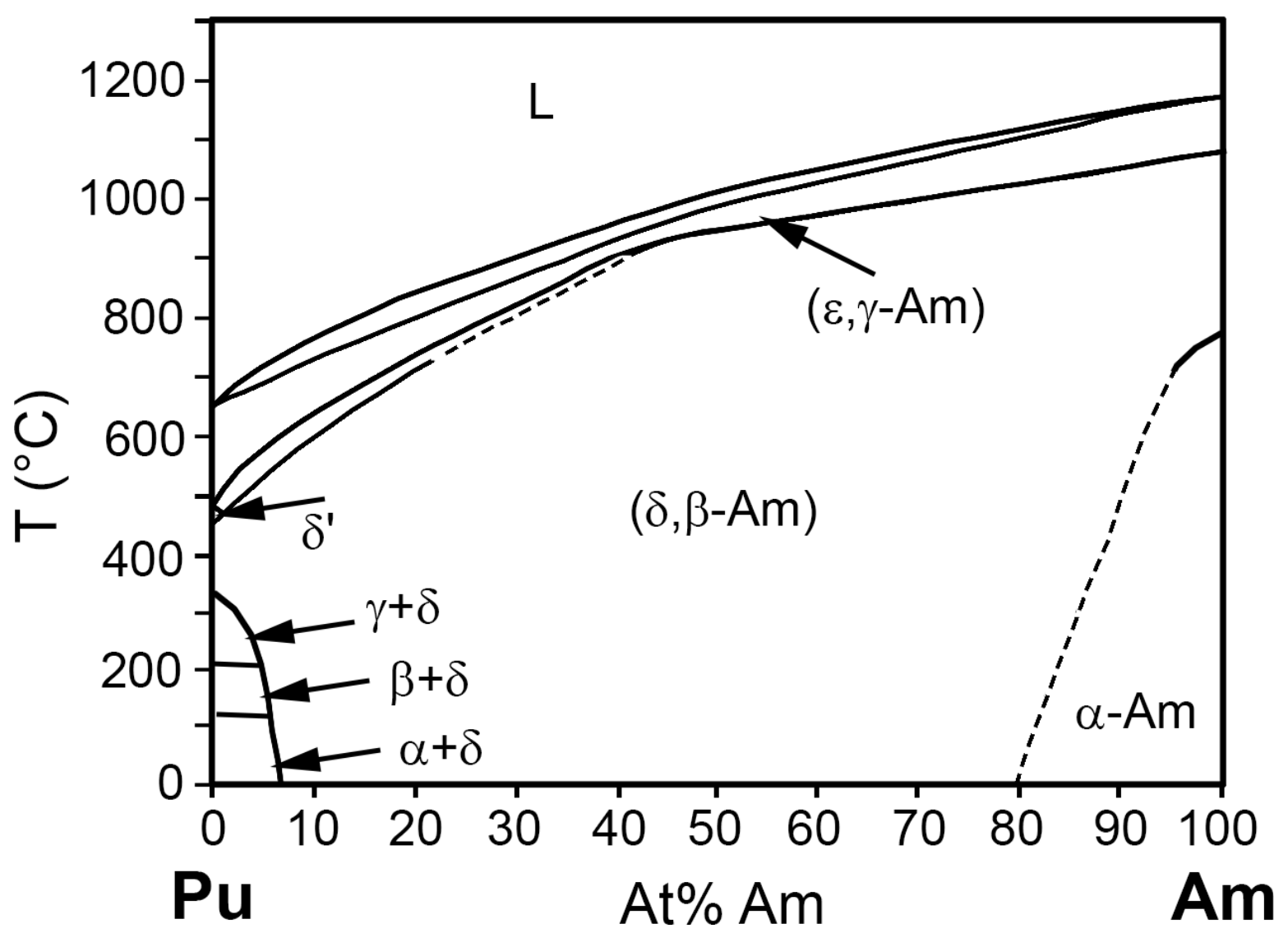

Figure 63. Experimentally determined Pu-Am phase diagram according to Shushakov et al. [296]. $\alpha, \beta, \gamma$, $\delta, \delta$ ' and $\varepsilon$ indicate $\mathrm{Pu}$ phases.

The Shushakov phase diagram remedies two of the problems in the Ellinger phase diagram by incorporating $\gamma$-Am and using higher Am phase-transformation temperatures. Other important differences from the Ellinger phase diagram include the existence of a continuous solid solution between $\gamma$-Am and $\varepsilon$ $\mathrm{Pu}$ and the absence of a two-phase field between $\alpha-\mathrm{Am}$ and $\delta$-Pu.

In 1999, Okamoto [305] suggested a new phase diagram, which combined phase boundaries for the fcc, bcc, and liquid phases calculated by Ogawa [110] with other phase transformations based on the phase diagram of Ellinger et al. after adjusting Ellinger's phase-transformation temperatures for Am to the values recommended in Section 4.1.2. This phase diagram (Figure 64) is the most recent one with experimentally determined phase boundaries. 


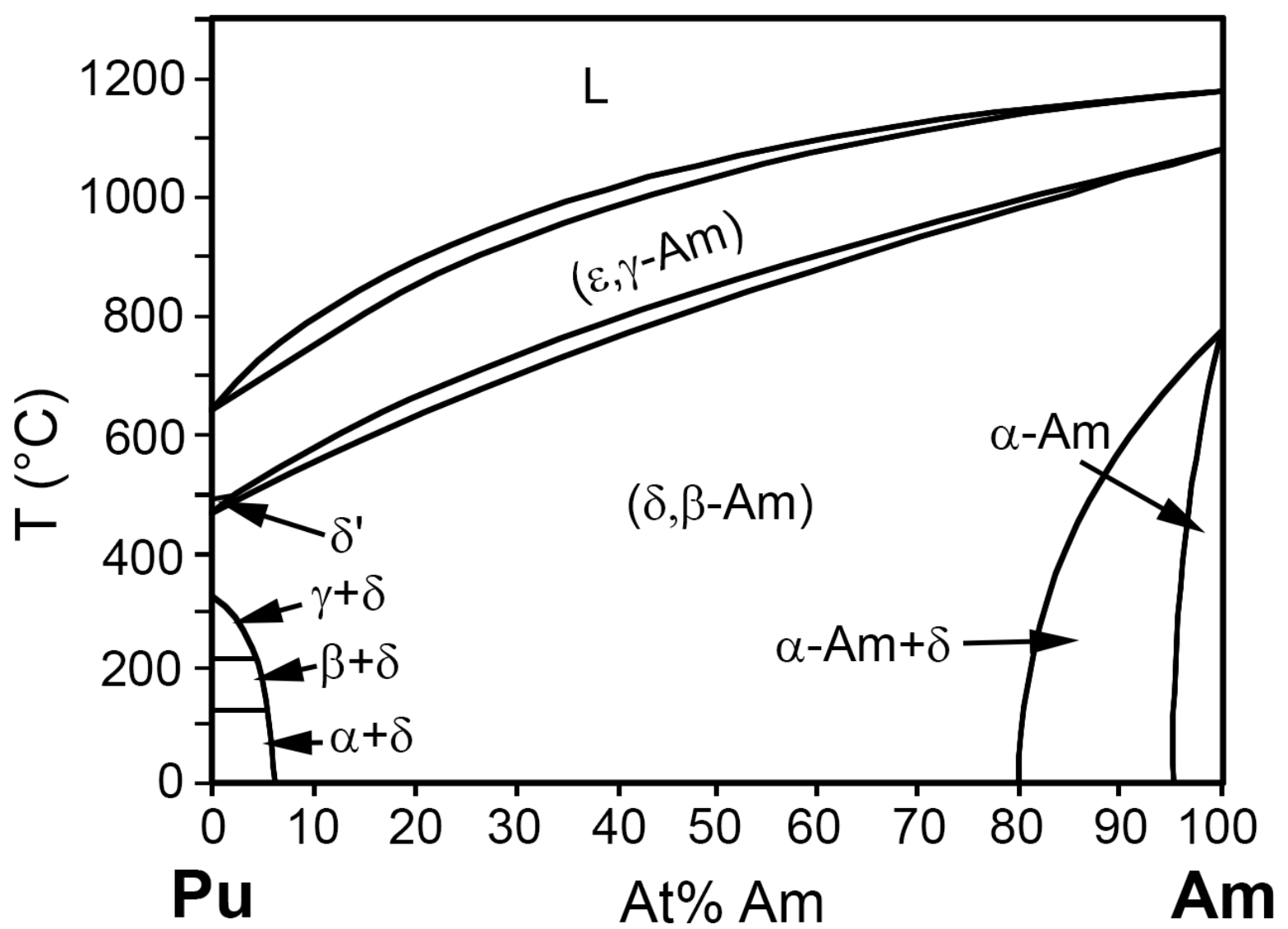

Figure 64. Pu-Am phase diagram of Okamoto [305], which combines the experimental data of Ellinger et al. [295] with modeling by Ogawa [110]. $\alpha, \beta, \gamma, \delta, \delta$ ' and $\varepsilon$ indicate Pu phases.

More recently, Kurata [250], Gotcu-Freis et al. [297], and Turchi et al. [298] published phase diagrams calculated using the CALPHAD method. The Gotcu-Freis et al. and Turchi et al. phase diagrams considered data from both Ellinger et al. and Shushakov et al., while the Kurata phase diagram considered only data from Ellinger et al. The Kurata and Gotcu-Freis phase diagrams resemble the Ellinger phase diagram in that they show two bcc solid solution phases with significantly different concentrations of Am (Figure 65). In contrast, the phase diagram of Turchi et al. resembles that of Shushakov in that it shows a continuous bec solid solution (Figure 66). 


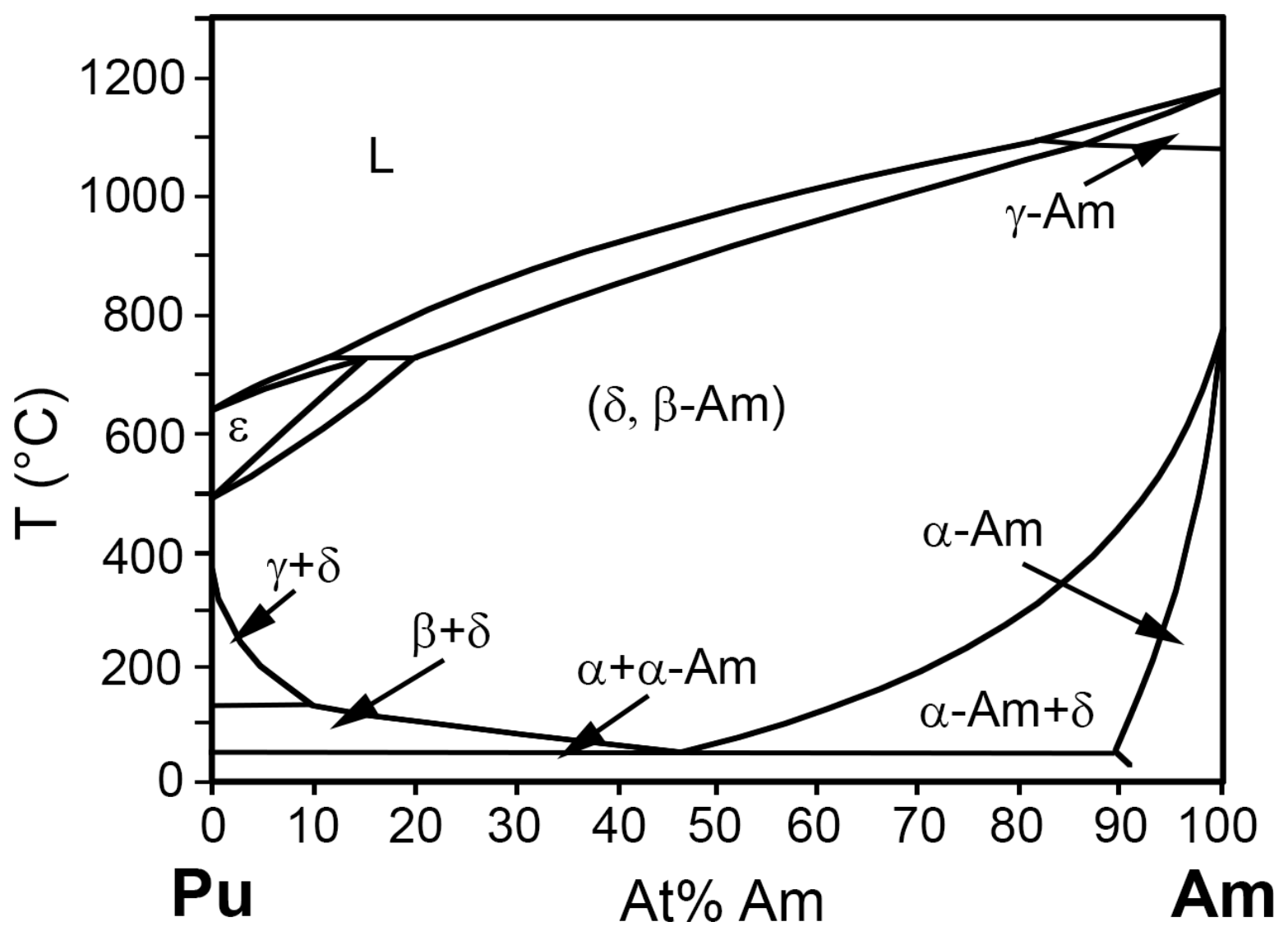

Figure 65. Calculated Pu-Am phase diagram of Gotcu-Freis et al. [297], which shows immiscibility of $\varepsilon$ $\mathrm{Pu}$ and $\gamma$-Am solid solutions. $\alpha, \beta, \gamma, \delta, \delta$ ' and $\varepsilon$ indicate $\mathrm{Pu}$ solid solution phases. 


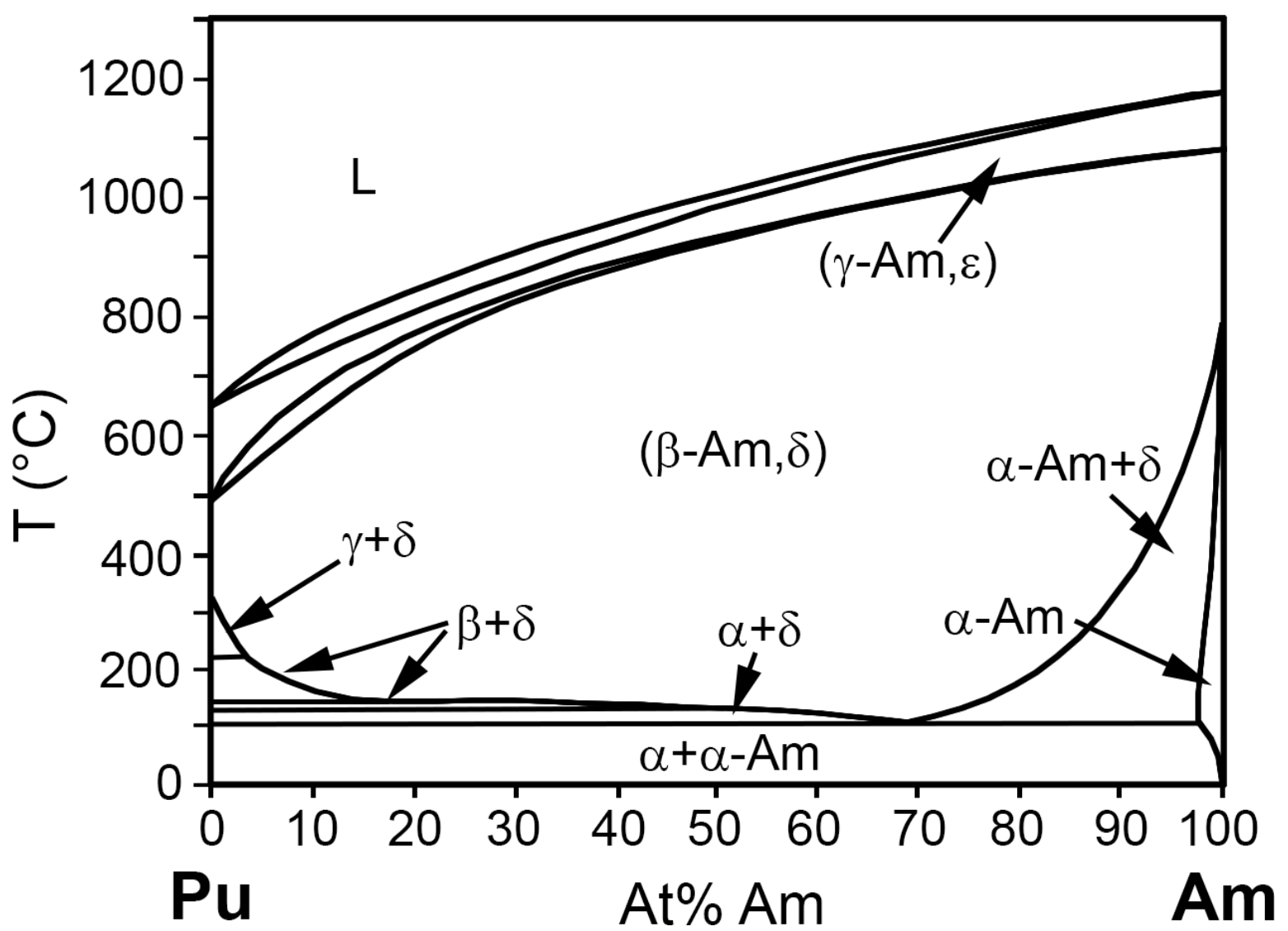

Figure 66. Calculated Pu-Am phase diagram of Turchi et al. [298], which shows a continuous solid solution between $\varepsilon$-Pu and $\gamma$-Am. This phase diagram has two " $\beta+\delta$ " fields because of a small miscibility gap in the $(\delta, \beta-A m)$ solid solution. $\alpha, \beta, \gamma, \delta, \delta$ ' and $\varepsilon$ indicate Pu solid solution phases.

Turchi et al. investigated differences in thermodynamic parameters needed to produce phase diagrams with one or two bcc phases. They concluded that whether a sample was best represented by a phase diagram with or without a continuous $(\varepsilon-\mathrm{Pu}, \gamma-\mathrm{Am})$ solid solution might depend on the impurities in the sample. In this context, it is particularly unfortunate that the purity of the samples studies by Shushakov et al. was not reported.

\subsubsection{Pu-La}

\subsubsection{Introduction}

A preliminary experimental investigation of the Pu-La phase diagram was carried out by Poole et al. [268], followed by a more thorough investigation by Ellinger et al. [306]. The two investigations agreed about key features of the phase diagram including a liquid miscibility gap, very low solubility of La in all $\mathrm{Pu}$ allotropes, maximum solubility of $\sim 20 \mathrm{at} \% \mathrm{Pu}$ in $\beta$-La and $\gamma$-La, and no intermediate phases at temperatures above $\sim 250{ }^{\circ} \mathrm{C}$. The Ellinger et al. phase diagram is generally accepted. Liu et al. [307] modeled the phase diagram using CALPHAD, obtaining good agreement with the experimental data.

Despite the generally good agreement of the experimental and modeling studies, further work is needed to determine the limits of the liquid miscibility gap. It may also be worthwhile to analyze the entire phase diagram again because of the low purity of the La feedstock in the original experimental work (e.g., the feedstock used by Ellinger et al. was only $\sim 99 \mathrm{wt} \% \mathrm{La}$ and included $\sim 2000 \mathrm{ppm} \mathrm{Fe}$ ); however, it seems unlikely that this investigation would cause changes significant enough to affect the use of the phase diagram for fuels work. 


\subsubsection{Phases and phase transformations}

Phases in the Pu-La system are [306]:

- $\quad(\alpha-\mathrm{Pu}),(\beta-\mathrm{Pu}),(\gamma-\mathrm{Pu}),(\delta-\mathrm{Pu}),\left(\delta^{\prime}-\mathrm{Pu}\right),(\varepsilon-\mathrm{Pu})$ : Allotropes of Pu with very small solubility for La. La does not stabilize either $\delta$ - or $\varepsilon$-Pu.

- $(\beta$-La): Allotrope of $\beta$-La with up to 19 at $\% \mathrm{Pu}$. The lattice parameters reported by Ellinger et al. increase linearly from $5.240 \AA$ for a sample with 80 at $\%$ La to $5.306 \AA$ for pure $\beta$-La (consistent with the lattice parameter for $\beta$-La in Section 4.1.3).

- $\quad(\gamma$-La): Allotrope of $\gamma$-La with up to 19 at $\% \mathrm{Pu}$.

- L1 (High-Pu liquid) and L2 (high-La liquid): Immiscible liquids. The limits of solubility and maximum temperature of the miscibility gap have not been experimentally determined.

A sample of ( $\beta$-La) with 2.5 at $\%$ Pu that was annealed for 7 months at $250{ }^{\circ} \mathrm{C}$ showed no evidence of transformation to ( $\alpha$-La) [306]. However, the $\beta$ - $\alpha$ transformation is very sluggish in pure La (Section 4.1.3). Thus, although there is no experimental data about properties of $\alpha$-La solid solutions that include $\mathrm{Pu}$, it is nonetheless possible that these solid solutions exist.

Ellinger et al. report that the incorporation of small amounts of $\mathrm{La}$ in $\varepsilon$-Pu lowers the melting temperature by $\sim 8{ }^{\circ} \mathrm{C}$. Melting temperatures of other $\mathrm{Pu}$ solid-solution phases are similar to those in pure $\mathrm{Pu}$, possibly because of the low solubility of $\mathrm{La}$ in $\mathrm{Pu}$.

Invariant points in the phase diagram of Ellinger et al. include [306]:

- $\quad \mathrm{L} 2 \rightarrow \mathrm{L} 1+(\gamma-\mathrm{La})$, a monotectic transformation at $846{ }^{\circ} \mathrm{C}$ and 77 at $\% \mathrm{La}$

- $\gamma$-La $\rightarrow \mathrm{L} 1+\left(\beta\right.$-La), an inverse peritectic (retrograde melting) transformation at $833{ }^{\circ} \mathrm{C}$ and 82 at $\% \mathrm{La}$

- $\quad \mathrm{L} 2 \rightarrow(\varepsilon-\mathrm{Pu})+(\beta-\mathrm{La})$, a eutectic transformation at $632^{\circ} \mathrm{C}$. Ellinger et al. did not specify the composition at the eutectic, but their phase diagram suggests $1-2$ at $\% \mathrm{Pu}$.

The phase diagram also shows a reaction, $(\beta-\mathrm{La}) \rightarrow(\alpha-\mathrm{La})+(\alpha-\mathrm{Pu})$. Although this reaction seems plausible, it has not been experimentally observed and occurs below the minimum temperature of the experimental data.

\subsubsection{Phase diagrams}

Figure 67 shows the Pu-La phase diagram proposed by Ellinger et al. [306]. This phase diagram appears in Massalski's compilation of phase diagrams [277] and in the ASM Alloy Phase Diagram Database [278]. 


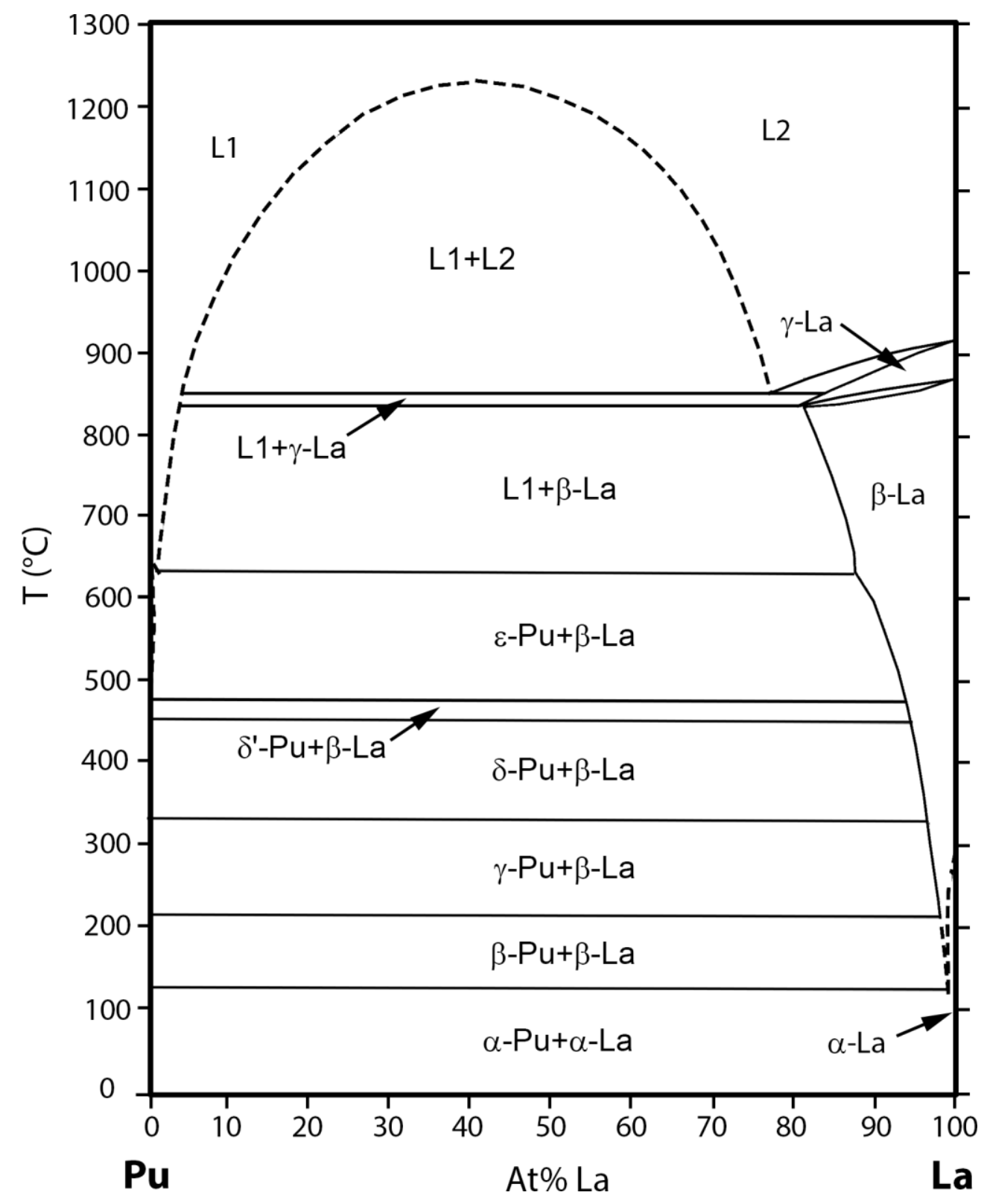

Figure 67. Pu-La phase diagram of Ellinger et al. (re-drawn from [306])

\subsubsection{Pu-Ce}

\subsubsection{Introduction}

$\mathrm{Pu}-\mathrm{Ce}$ phase diagrams based on original investigations were published by Ellinger et al. [308] and by Selle and Etter [309], but have now been largely replaced by composite phase diagrams that combine selected features of the experimental phase diagrams with phase boundaries from other (unspecified) sources. Key features of the all of the Pu-Ce phase diagrams include:

- Stabilization of $\delta$-Pu solid solutions down to room temperature.

- Extremely limited solubility of $\mathrm{Ce}$ in $\alpha-\mathrm{Pu}, \beta-\mathrm{Pu}$, and $\gamma-\mathrm{Pu}$.

- Significant solubility of $\mathrm{Ce}$ in $\varepsilon-\mathrm{Pu}$, and of Pu in $\gamma$-Ce and $\delta$-Ce.

- Absence of intermediate phases. 
Further experimental work on the Pu-Ce system is required. Careful consideration of sample purity, phase-transformation kinetics, possible existence of metastable phases, and fine-scale microstructures is crucial.

\subsubsection{Phases and phase transformations}

Stable phases in the $\mathrm{Pu}-\mathrm{Ce}$ system above room temperature are:

- $\quad(\alpha-P u)$ : Allotropic solid solution of $\alpha-P u$ with monoclinic structure and extremely limited solubility of $\mathrm{Ce}[308,309]$. Lattice parameters have not been reported but are probably similar to those of $\alpha-\mathrm{Pu}$.

- $\quad(\beta-\mathrm{Pu})$ : Allotropic solid solution of $\beta$-Pu with monoclinic structure and extremely limited solubility of $\mathrm{Ce}[308,309]$. Lattice parameters have not been reported but are probably similar to those of $\beta-\mathrm{Pu}$.

- $\quad(\gamma-\mathrm{Pu})$ : Allotropic solid solution of $\gamma$-Pu with an orthorhombic structure. Both of the experimental phase diagrams indicate that solubility of $\mathrm{Ce}$ in this phase is limited [308, 309]; however, Elliott et al. [310] report that $\gamma$-Ce alloys with 15 at $\% \mathrm{Pu}$ are metastable at room temperature. Lattice parameters of $(\gamma-\mathrm{Pu})$ solid solutions have not been reported.

- $\quad(\delta-\mathrm{Pu})$ : Allotropic solid solution of $\delta$-Pu with face-centered cubic structure and up to $23-25$ at $\%$ $\mathrm{Ce}$ at $613{ }^{\circ} \mathrm{C}$ and $\sim 3-18$ at $\% \mathrm{Ce}$ at room temperature [308, 309]. Ellinger et al. notes that $\delta$-Pu may be present in quenched samples with concentrations of Ce that are slightly lower than the minimum concentration required for room-temperature stability. The lattice parameter increases linearly from $4.6485 \AA$ in alloys with 4.68 at\% Ce to $4.6804 \AA$ in alloys with 20.03 at $\%$ Ce [308].

- $\quad\left(\delta^{\prime}-\mathrm{Pu}\right)$ : Allotropic solid solution of $\delta$ '-Pu with body-centered tetragonal structure and less than $0.5 \mathrm{at} \% \mathrm{Ce}$ [308]. This phase does not appear in the phase diagram of Selle and Etter [309]. Lattice parameters have not been reported but are probably similar to those of $\delta$ '-Pu.

- $\quad(\varepsilon-\mathrm{Pu})$ : Allotropic solid solution of $\varepsilon-\mathrm{Pu}$ with body-centered cubic structure and up to 16 at $\% \mathrm{Ce}$ [308, 309]

- $\quad(\gamma-\mathrm{Ce})$ : Allotropic solid solution of $\gamma$-Ce with face-centered cubic structure and up to $-35-37$ at $\%$ $\mathrm{Pu}[308,309]$. Ellinger et al. refer to this phase as " $\beta$-Ce." The lattice parameter decreases linearly from $5.1534 \pm 0.0005 \AA$ in alloys with 2 at\% Pu to $5.009 \pm 0.006 \AA$ in alloys with 30 at\% $\mathrm{Pu}[308]$.

- $\quad(\delta$-Ce): Allotropic solid solution of $\delta$-Ce with body-centered cubic structure and up to $\sim 19.5$ at $\%$ $\mathrm{Pu}$ [309]. Ellinger et al. refer to this phase as " $\gamma$-Ce" and say that it can have up to $\sim 10$ at $\% \mathrm{Pu}$.

In addition to these phases, Gschneidner et al. [224], Elliott et al. [310], and Giessen et al. [311] observed what they believed to be a metastable fcc phase in rapidly cooled Ce alloys with relatively low concentrations of Pu. Gschneidner et al. reported that this phase did not decompose during thermal or pressure cycling, while Elliott et al. thought that it might be an intermediate phase in the decomposition of metastable $\gamma-\mathrm{Pu}$ alloys to form $\delta$-Pu as a result of thermal cycling or abrasion. Elliott et al. indicated that the lattice parameter of this phase was similar to that of $\delta$-Pu. In the absence of research showing the conditions under which this phase forms and decomposes and its relationship to the other fcc phases in the $\mathrm{Pu}-\mathrm{Ce}$ system $(\alpha-\mathrm{Ce}, \gamma-\mathrm{Ce}$, and $\delta$-Pu), the significance of this phase for nuclear fuels is unclear.

Incorporation of $\mathrm{Pu}$ into $(\alpha-\mathrm{Ce})$ inhibits the formation of $(\beta-\mathrm{Ce})$ and raises the temperature of the direct transformation from $\alpha$-Ce to $\gamma$-Ce [224]. However, $(\alpha-\mathrm{Ce})$ and $(\beta-\mathrm{Ce})$ are both low-temperature phases and therefore have limited relevance for nuclear fuels. 


\subsubsection{Phase diagrams}

Two research groups have published $\mathrm{Pu}-\mathrm{Ce}$ phase diagrams based on their own experimental studies. The first was published in 1960 by Ellinger et al. [308], and was based on a combination of thermal analysis, dilatometry, metallography, and room- and high-temperature X-ray diffraction data (Figure 68). This phase diagram indicates that $\delta$-Ce transforms to $\gamma$-Ce by an "inverse peritectic" (retrograde melting) reaction.

Selle and Etter published the second phase diagram in 1964 [309], using data from thermal analysis, $\mathrm{X}$-ray diffraction, and microprobe analysis (Figure 69). Despite many areas of general agreement, the two phase diagrams differ significantly in the nature of the reaction between $\gamma$-Ce and $\delta$-Ce, which Selle and Etter resolved by re-interpreting Ellinger's observations as consequences of non-equilibrium states. A later review by Ellinger et al. follows Selle and Etter's interpretation of this transformation [312].

According to both of these phase diagrams, invariant reactions in the $\mathrm{Pu}-\mathrm{Ce}$ system are:

- $\quad \mathrm{L} \leftrightarrow(\varepsilon-\mathrm{Pu})+(\gamma-\mathrm{Ce})$, a eutectic reaction. Ellinger et al. [308] reported that this reaction involves a liquid with 17.5 at\% Ce, $(\varepsilon-\mathrm{Pu})$ with 16 at\% Ce, and $(\gamma-\mathrm{Ce})$ with 77 at\% Ce. Selle and Etter [309] indicate that it involves a liquid with 16.5 at $\% \mathrm{Ce},(\varepsilon-\mathrm{Pu})$ with 16 at $\% \mathrm{Ce}$, and $(\gamma-\mathrm{Ce})$ with 65.5 at $\% \mathrm{Ce}$. Both phase diagrams agree that this reaction occurs at at $625{ }^{\circ} \mathrm{C}$.

- $\quad(\varepsilon-\mathrm{Pu})+(\gamma-\mathrm{Ce}) \leftrightarrow(\delta-\mathrm{Pu})$, a peritectoid reaction. Ellinger et al. [308] reported that this reaction occurs at $592{ }^{\circ} \mathrm{C}$ and involves ( $(\varepsilon-\mathrm{Pu})$ with 12 at $\% \mathrm{Ce}, \gamma$-Ce with 63 at $\% \mathrm{Ce}$, and $\delta$-Pu with 25 at $\%$ Ce. Selle and Etter [309] indicate that it occurs at $613{ }^{\circ} \mathrm{C}$ and involves $(\varepsilon-\mathrm{Pu})$ with $13.5 \mathrm{at} \% \mathrm{Ce}$, $\gamma$-Ce with 66.5 at $\% \mathrm{Ce}$, and $\delta$-Pu with 23 at $\% \mathrm{Ce}$.

Both of the experimentally based phase diagrams have been largely replaced by phase diagrams combining selected aspects of both of the experimental phase diagrams with a liquidus that does not follow either. The maximum difference between liquidus temperatures in all of the phase diagrams is $\sim 75$ ${ }^{\circ} \mathrm{C}$, and occurs in compositions with $\sim 20$ at $\% \mathrm{Ce}$.

The Rand et al. [313] composite phase diagram incorporated many of the solid-state reactions and invariant points from the phase diagram of Selle and Etter. It forms the basis for later phase diagrams published by Massalski et al. [314] and Okamoto [315] (Figure 70). A second composite phase diagram suggested by Ellinger et al. [312] is based on the original phase diagram of Ellinger et al. This phase diagram was reproduced by Giessen et al. [311]. The primary differences between these composite phase diagrams are the temperatures and compositions of invariant points (see above). It seems plausible that these differences are consequences of variations in sample purity or other experiment-specific conditions. 


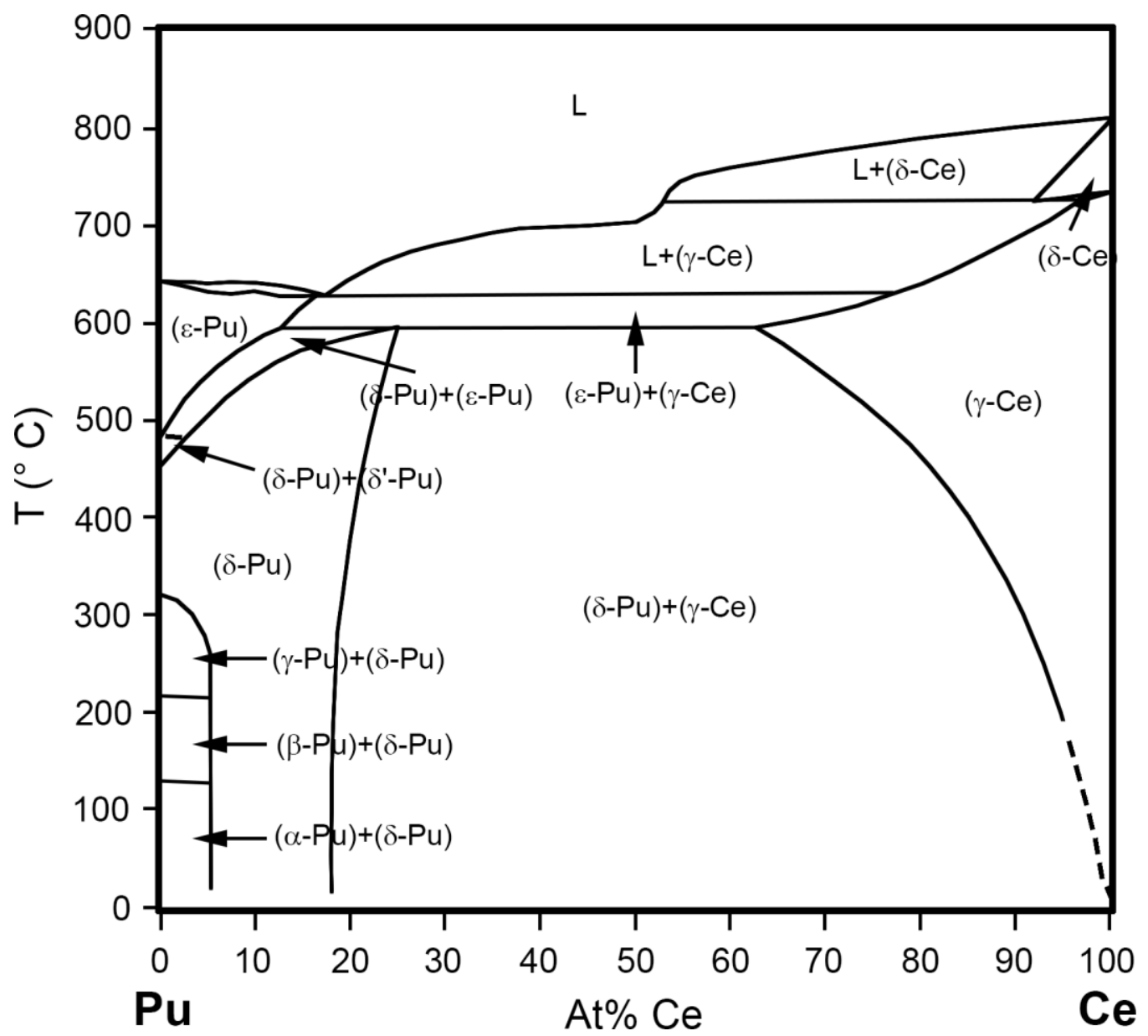

Figure 68. Pu-Ce phase diagram of Ellinger et al. (re-drawn from [308]) 


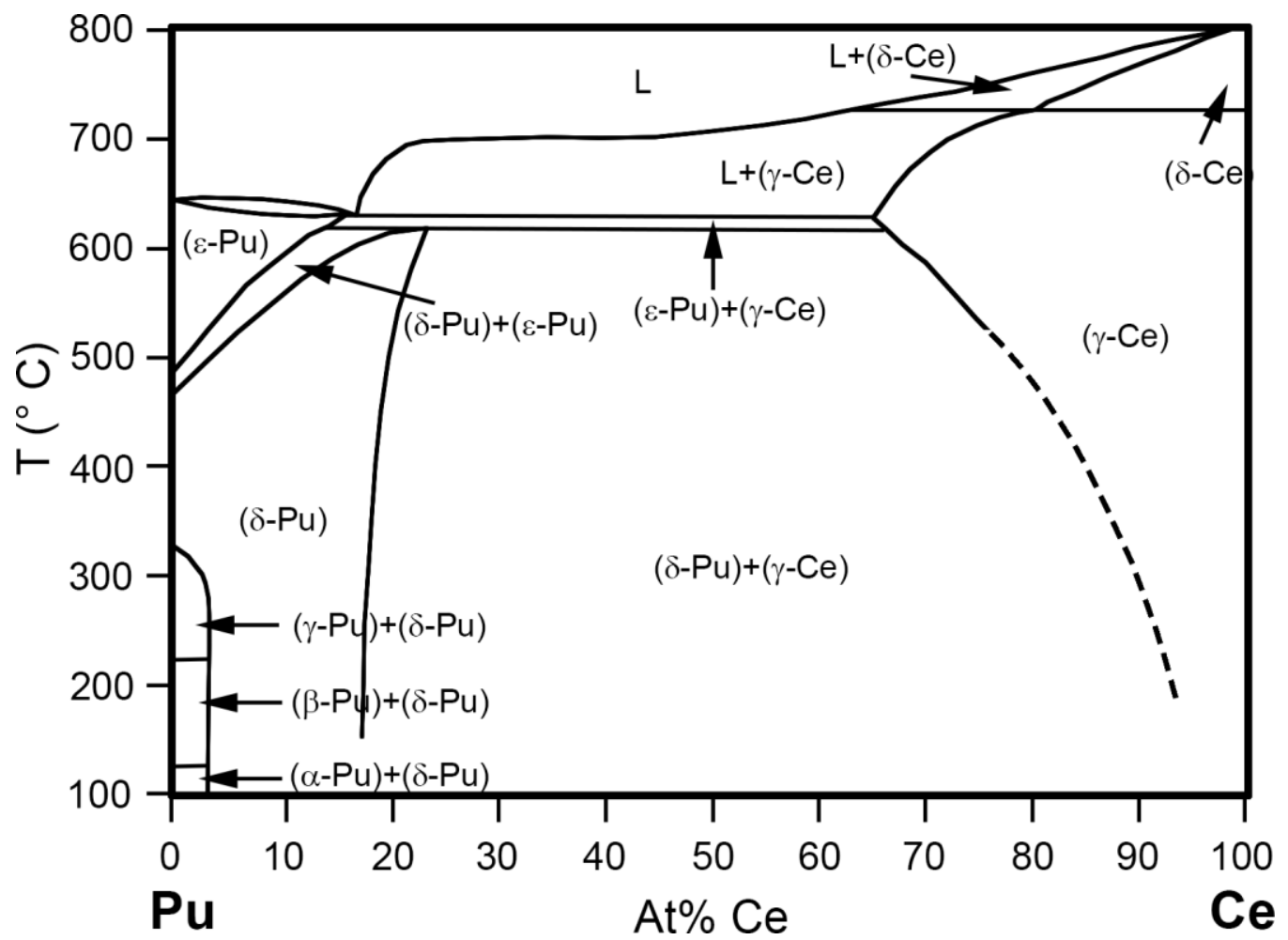

Figure 69. Pu-Ce phase diagram of Selle et al. (re-drawn from [309]) 


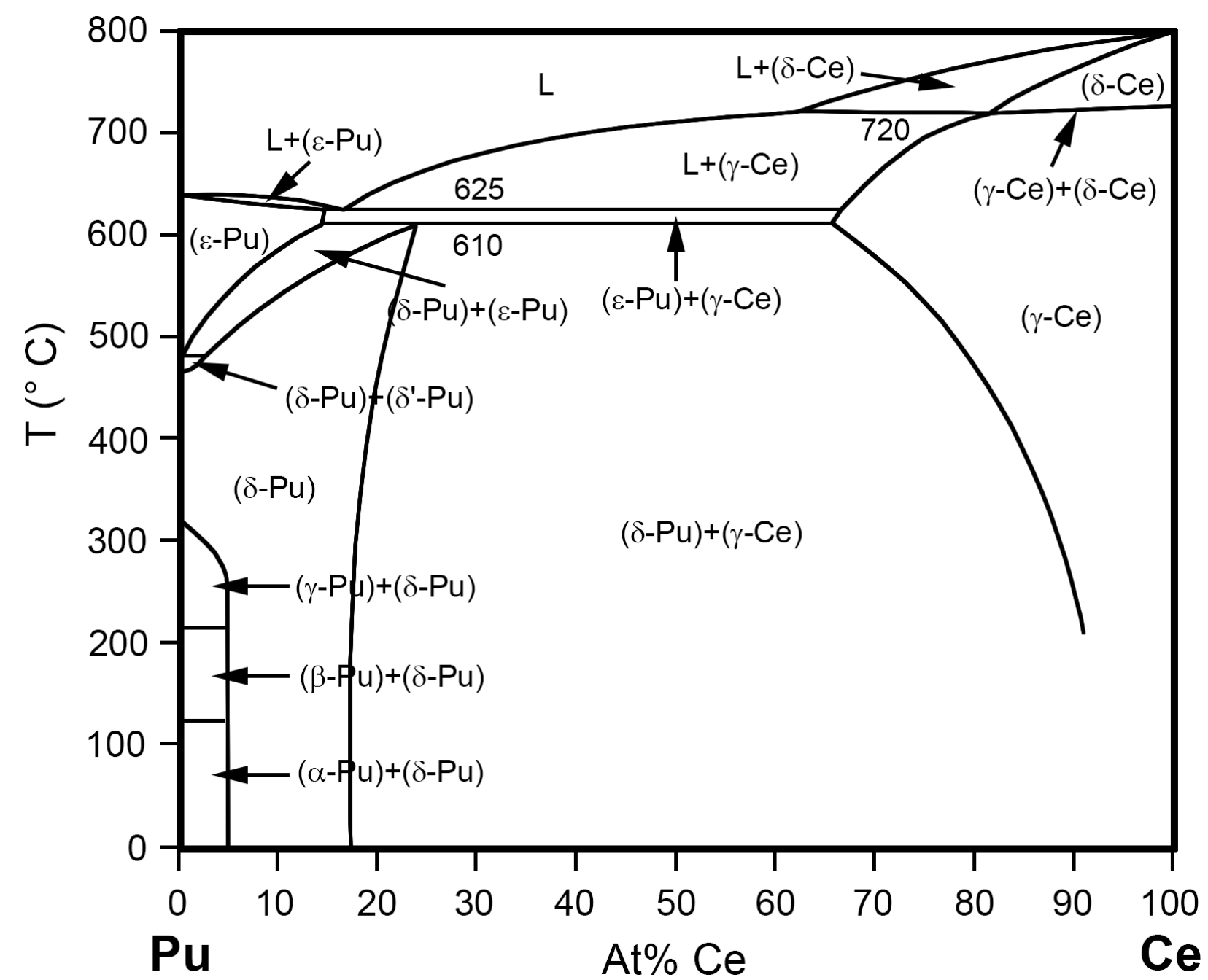

Figure 70. Composite Pu-Ce phase diagram (re-drawn from Okamoto [315])

\subsubsection{Pu-Pr}

\subsubsection{Introduction}

Two research groups published experimentally determined $\mathrm{Pu}-\mathrm{Pr}$ phase diagrams in the 1960s. Kutaitsev et al. [316, 317] published a preliminary Pu-Pr phase diagram for temperatures up to $800{ }^{\circ} \mathrm{C}$. Ellinger et al. published a second phase diagram and brief discussion in 1968, followed by a more extensive publication in 1969 [312, 318]. More recent references (including this handbook) follow the phase diagram of Ellinger et al. [318], which is more thoroughly investigated and documented than the phase diagram of Kutaitsev et al.

Key features of the Ellinger phase diagram include complete miscibility of the liquid phase, limited solubility of $\mathrm{Pr}$ in any $\mathrm{Pu}$ phase, $\mathrm{Pu}$ concentrations up to $29-30$ at $\%$ in $\alpha-\operatorname{Pr}$ and $\beta-\operatorname{Pr}$, coexistence of $\alpha-\operatorname{Pr}$ and $\beta$-Pr in a limited temperature range, and an absence of intermediate phases. The Ellinger et al. $\mathrm{Pu}-\mathrm{Pr}$ phase diagram shows an inverse peritectic (retrograde melting) reaction similar to that in their $\mathrm{Pu}-\mathrm{Ce}$ phase diagram, which was re-interpreted after careful consideration of non-equilibrium microstructures (Section 4.1.21).

Further investigation of Pu-Pr alloys is required. Careful consideration of sample purity, phasetransformation kinetics, and fine-scale microstructures is crucial. In addition to providing information 
about the Pu-Pr system, this investigation may increase our understanding of the enigmatic face-centered cubic structures that have been reported in pure $\mathrm{Pr}$ and in $\mathrm{Pu}-\mathrm{Ce}, \mathrm{Pu}-\mathrm{Pr}$, and perhaps $\mathrm{Pu}-\mathrm{Nd}$ alloys.

\subsubsection{Phases and phase transformations}

Stable phases in the Pu-Pr system are [318]:

- $\quad(\alpha-\mathrm{Pu})$ : Allotropic solid solution of $\alpha-\mathrm{Pu}$ with monoclinic structure and no significant solubility of Pr. Lattice parameters have not been reported but are probably similar to those of $\alpha-\mathrm{Pu}$.

- $\quad(\beta-\mathrm{Pu})$ : Allotropic solid solution of $\beta$-Pu with monoclinic structure and no significant solubility of Pr. Lattice parameters have not been reported but are probably similar to those of $\beta-\mathrm{Pu}$.

- $\quad(\gamma-\mathrm{Pu})$ : Allotropic solid solution of $\gamma-\mathrm{Pu}$ with orthorhombic structure and no significant solubility of Pr. Lattice parameters have not been reported but are probably similar to those of $\gamma-\mathrm{Pu}$.

- $\quad(\delta-\mathrm{Pu}):$ Allotropic solid solution of $\delta$-Pu with face-centered cubic structure that can contain up to 2 at $\% \operatorname{Pr}$. $(\delta-\mathrm{Pu})$ solid solutions could be retained to room temperature in quenched alloys that contained 15 at $\%$ Pr, but not in samples made from filings with 5 at $\%$ Pr. Ellinger et al. believed this was because the $(\delta-\mathrm{Pu})$ alloys were stabilized by finely dispersed particles of $(\alpha-\mathrm{Pr})$. Lattice parameters have not been reported but are probably similar to those of $\delta$-Pu.

- $\quad\left(\delta^{\prime}-\mathrm{Pu}\right)$ : Allotropic solid solution of $\delta$ '-Pu with body-centered tetragonal structure and no significant solubility of Pr. Lattice parameters have not been reported but are probably similar to those of $\delta$ '-Pu.

- $\quad(\varepsilon-\mathrm{Pu})$ : Allotropic solid solution of $\varepsilon-\mathrm{Pu}$ with body-centered cubic structure that can contain up to 2 at $\%$ Pr.

- $\quad(\alpha-\operatorname{Pr})$ : Allotropic solid solution of $\alpha-\operatorname{Pr}$ with a hexagonal structure that can contain up to $\sim 27-29$ at $\% \mathrm{Pu}$. Ellinger et al. noted that the $a$ and $c$ lattice parameters of this phase both increase linearly with the concentration of praseodymium.

- $\quad(\beta-P r)$ : Allotropic solid solution of $\beta$-Pr with body-centered cubic structure and up to $\sim 30$ at $\% \mathrm{Pu}$.

Ellinger et al. [318] observed that a face-centered cubic material (which they called " $\alpha$ '-Pr") coexisted with $\alpha$-Pr in alloys with 5 at $\% \mathrm{Pu}$, and noted that the fraction of $\alpha$ '-Pr generally increased with increasing temperature and concentration of plutonium. They thought that the transformation from $\alpha-\operatorname{Pr}$ to $\alpha$-Pr might be a second-order reaction involving a change in stacking order and did not believe that $\alpha-\operatorname{Pr}$ and $\alpha$ '-Pr were "separate phases in the usual sense." They were unable to distinguish $\alpha$-Pr and $\alpha$ '-Pr in micrographic analyses. In a slightly earlier review with different authors, Ellinger et al. suggested that $\alpha$ 'Pr might be an impurity-stabilized phase [312].

According to Ellinger et al., addition of Pr decreases the melting temperature of Pu by $\sim 15$ degrees, forming a eutectic with 2-3 at\% Pr. There is a second invariant point (an inverse peritectic reaction in which $\beta$-Pr decomposes to $\alpha$-Pr and liquid upon cooling) at $794{ }^{\circ} \mathrm{C}$ and $30 \mathrm{at} \% \mathrm{Pu}$. The transformation from $\alpha$ - $\operatorname{Pr}$ to $\beta$-Pr is congruent, and occurs over a narrow temperature range between $792{ }^{\circ} \mathrm{C}$ for pure $\operatorname{Pr}$ and $801{ }^{\circ} \mathrm{C}$ for materials with 10 at $\% \mathrm{Pu}$.

\subsubsection{Phase diagrams}

Kutaitsev et al. [316, 317] published a preliminary Pu-Pr phase diagram for temperatures up to 800 ${ }^{\circ} \mathrm{C}$ (Figure 71). Little information about experimental methods is provided, and the results are presented in one figure and one paragraph. The Kutaitsev phase diagram shows that incorporation of $\sim 15-20 \mathrm{at} \% \mathrm{Pu}$ causes a decrease of several hundred degrees in the melting temperature of $(\alpha-\operatorname{Pr})$, leading to a broad range of temperatures over which $(\alpha-\operatorname{Pr})$ and $(\beta-P r)$ coexist. A statement that, "In alloys containing more than $5 \%$ plutonium, the face-centered cubic lattice of the $\beta$-phase of praseodymium can be retained down to room temperature by quenching" [317 p. 1280] suggests that Kutaitsev et al. may have observed a fcc 
phase; however, its identity and relationship to other Pu-Pr phases are unclear because the structure of $\beta$ Pr is bec rather than fcc.

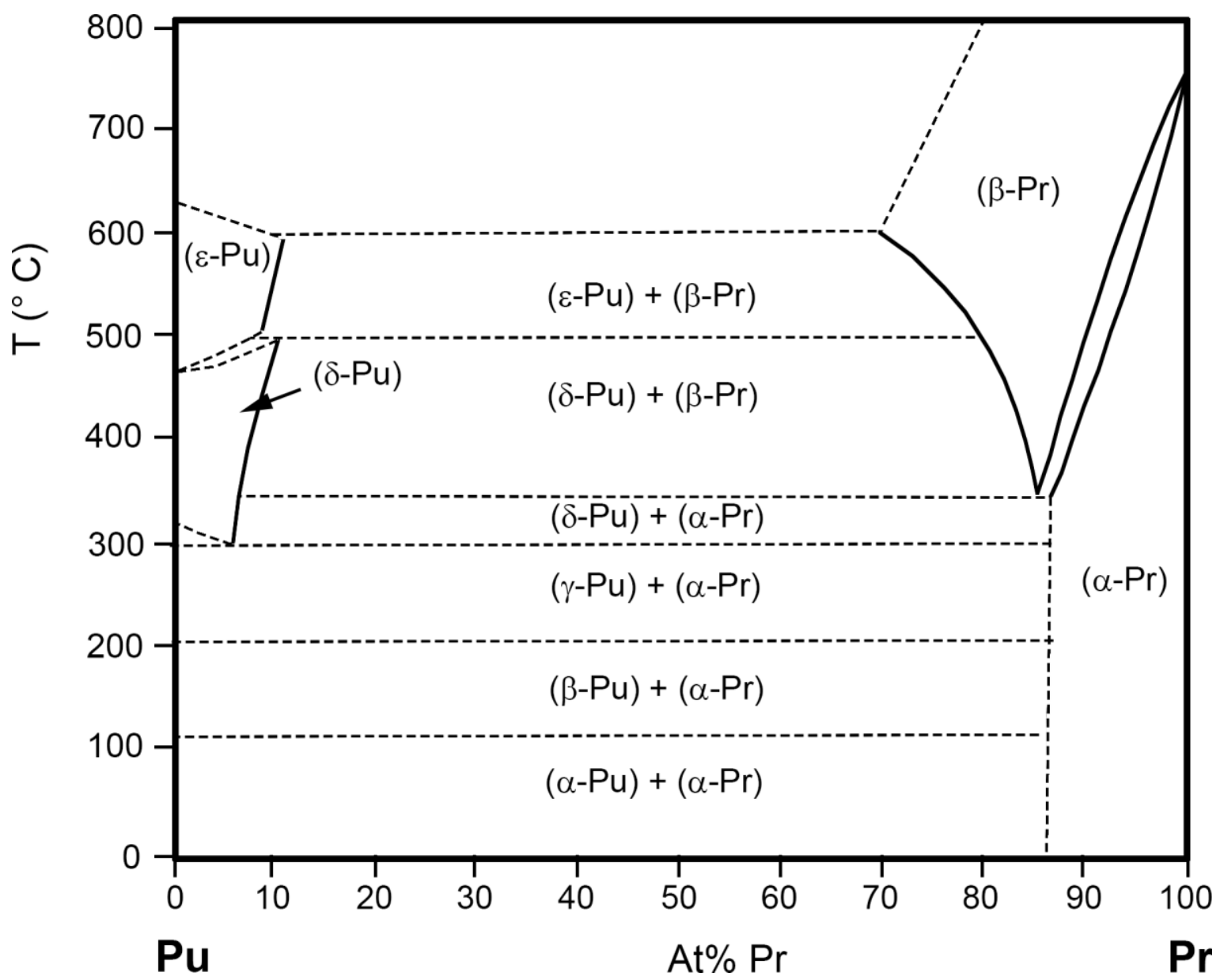

Figure 71. Pu-Pr phase diagram of Kutaitsev et al. (re-drawn from [317])

Ellinger and colleagues developed a second Pu-Pr phase diagram using data from thermal analysis, Xray diffraction, and metallography $[312,318]$ (Figure 72 ). Although this is the most commonly accepted $\mathrm{Pu}-\mathrm{Pr}$ phase diagram, several features suggest areas for future research:

- The liquidus. Ellinger et al. suggested that the liquidus for compositions with $10-40$ at $\%$ Pr may be less flat than is shown in the figure because of experimental difficulties caused by the segregation of rare-earth phases near the top of the sample during slow heating.

- The nature, occurrence, stability, and formation mechanism of the fcc material $\alpha$ '-Pr and its relationship to other Pu-Pr phases

- The transformation between ( $\beta$-Pr) and $(\alpha-\operatorname{Pr})$ during cooling. Ellinger et al. indicated that this transformation involves an inverse peritectic (retrograde melting) reaction in which $\beta$-Pr decomposes into $\alpha$-Pr and a Pu-rich liquid. A similar transformation was originally suggested in the $\mathrm{Pu}$-Ce phase diagram, but was later re-interpreted as a consequence of disequilibrium in the sample (Section 4.1.21). 


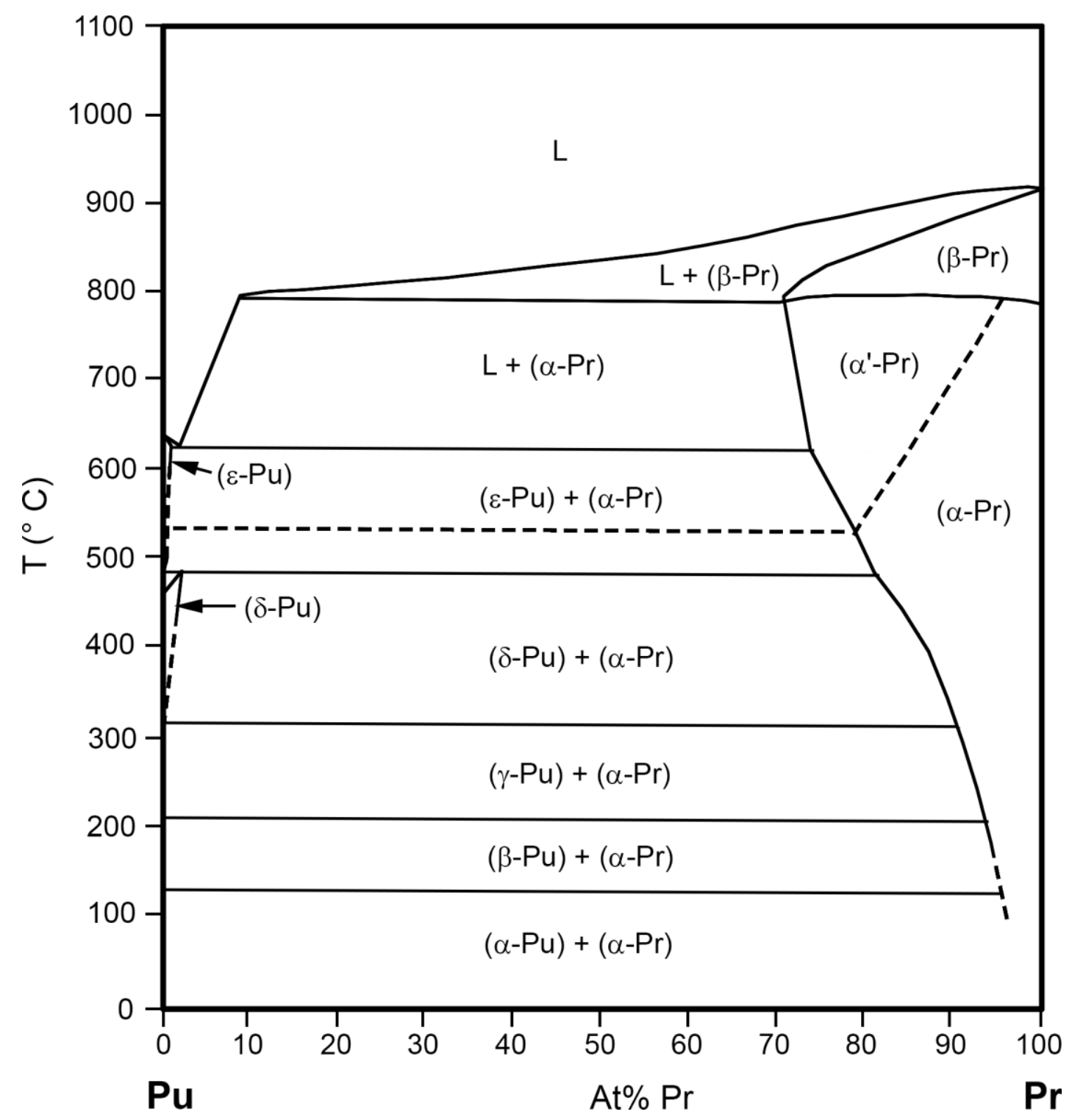

Figure 72. Pu-Pr phase diagram of Ellinger et al. (re-drawn from [318])

\subsubsection{Pu-Nd}

\subsubsection{Introduction}

Two research groups published experimentally determined Pu-Nd phase diagrams in the 1960s. Both of these phase diagrams closely resemble the Pu-Pr phase diagrams proposed by the same research groups. Kutaitsev et al. [316, 317] published a preliminary Pu-Nd phase diagram for temperatures up to $800{ }^{\circ} \mathrm{C}$. Ellinger et al. published a second phase diagram and brief discussion in 1968, followed by a more extensive publication in 1969 [312, 318]. The phase diagrams show numerous areas of disagreement. More recent references (including this handbook) follow the phase diagram of Ellinger et al. [318], which is more thoroughly researched and documented than the phase diagram of Kutaitsev et al.

Key features of the Ellinger et al. phase diagram include complete miscibility of the liquid phase, limited solubility of $\mathrm{Nd}$ in any $\mathrm{Pu}$ phase, $\mathrm{Pu}$ concentrations up to $29-30$ at $\%$ in $\alpha$ - and $\beta-\mathrm{Nd}$, coexistence of $\alpha-\mathrm{Nd}$ and $\beta$-Nd over a limited temperature range, and an absence of intermediate phases. The Ellinger et al. $\mathrm{Pu}-\mathrm{Nd}$ phase diagram shows an inverse peritectic (retrograde melting) reaction similar to that in 
their Pu-Ce phase diagram, in which the reaction was re-interpreted after careful consideration of nonequilibrium microstructures (Section 4.1.21).

Further investigation of Pu-Nd alloys is required. Careful consideration of sample purity, phasetransformation kinetics, and fine-scale microstructures is crucial.

\subsubsection{Phases and phase transformations}

Stable phases in the Pu-Nd system and their characteristics are [318]:

- $\quad(\alpha-\mathrm{Pu})$ : Solid solution of $\alpha-\mathrm{Pu}$ with no significant solubility of $\mathrm{Nd}$. Lattice parameters have not been reported but are probably similar to those of $\alpha-\mathrm{Pu}$.

- $\quad(\beta-\mathrm{Pu})$ : Solution of $\beta$-Pu with no significant solubility of Nd. Lattice parameters have not been reported but are probably similar to those of $\beta$-Pu.

- $\quad(\gamma-\mathrm{Pu})$ : Solid solution of $\gamma$-Pu with no significant solubility of Nd. Lattice parameters have not been reported but are probably similar to those of $\gamma$-Pu.

- $\quad(\delta-\mathrm{Pu})$ : Solid solution of $\delta$-Pu that can contain up to 2 at $\% \mathrm{Nd}$. The $(\delta-\mathrm{Pu})$ solid solution could be retained to room temperature in quenched alloys that contained 15 at $\% \mathrm{Nd}$, but not in samples made from filings with 5 at $\%$ Nd. Ellinger et al. believed this was because the $(\delta$-Pu $)$ alloys were stabilized by finely dispersed particles of $(\alpha-\mathrm{Nd})$. Lattice parameters have not been reported but are probably similar to those of $\delta$-Pu.

- $\quad\left(\delta^{\prime}-\mathrm{Pu}\right)$ : Solid solution of $\delta^{\prime}-\mathrm{Pu}$ with no significant solubility of $\mathrm{Nd}$. Lattice parameters have not been reported but are probably similar to those of $\delta$ '-Pu.

- $\quad(\varepsilon-\mathrm{Pu})$ : Solid solution of $\varepsilon-\mathrm{Pu}$ that can contain up to 2 at $\% \mathrm{Nd}$.

- $\quad(\alpha-\mathrm{Nd})$ : Solid solution of $\alpha-\mathrm{Nd}$ that can contain up to $\sim 27-29$ at $\% \mathrm{Pu}$. The $a$ lattice parameter of this phase increases linearly from $3.597 \AA$ for an alloy with 75 at $\%$ Nd to $3.6646 \AA$ for an alloy with $95 \% \mathrm{Nd}$. The $c$ lattice parameter increases linearly from $11.614 \AA$ for an alloy with 75 at $\%$ Nd to $11.760 \AA$ for an alloy with $95 \% \mathrm{Nd}$.

- $\quad(\beta-\mathrm{Nd})$ : Solid solution of $\beta-\mathrm{Nd}$ with up to $\sim 30 \mathrm{at} \% \mathrm{Pu}$.

Ellinger et al. specifically stated that they did not observe a high-Nd fcc phase. Kutaitsev et al. [316 p. 422] referred to a "f.c.c. solid solution of $\beta-\mathrm{Nb}$ " (probably a typographical error that should have read $\beta$ $\mathrm{Nd}$ ) in alloys with more than $5 \mathrm{at} \% \mathrm{Pu}$ in their 1965 paper; however, this phase is not mentioned in a later paper that generally repeats the same data [317].

According to Ellinger et al., the melting temperature of $\mathrm{Pu}$ decreases by $\sim 15$ degrees to a eutectic with $2-3$ at $\% \mathrm{Nd}$. A second invariant point (an inverse peritectic reaction in which $\beta-\mathrm{Nd}$ decomposes to $\alpha-\mathrm{Nd}$ and liquid upon cooling) occurs at $820^{\circ} \mathrm{C}$ and 33 at $\% \mathrm{Pu}$.

\subsubsection{Phase diagrams}

Kutaitsev et al. [316, 317] published a preliminary Pu-Nd phase diagram for temperatures up to 800 ${ }^{\circ} \mathrm{C}$. Little information about experimental methods is provided, and the results are presented in one figure and one paragraph. Their phase diagram (Figure 73 ) shows that incorporation of $\sim 15-20$ at $\% \mathrm{Pu}$ causes a decrease of several hundred degrees in the melting temperature of $(\alpha-\mathrm{Nd})$, leading to a broad range of temperatures over which $(\alpha-\mathrm{Nd})$ and $(\beta-\mathrm{Nd})$ coexist. 


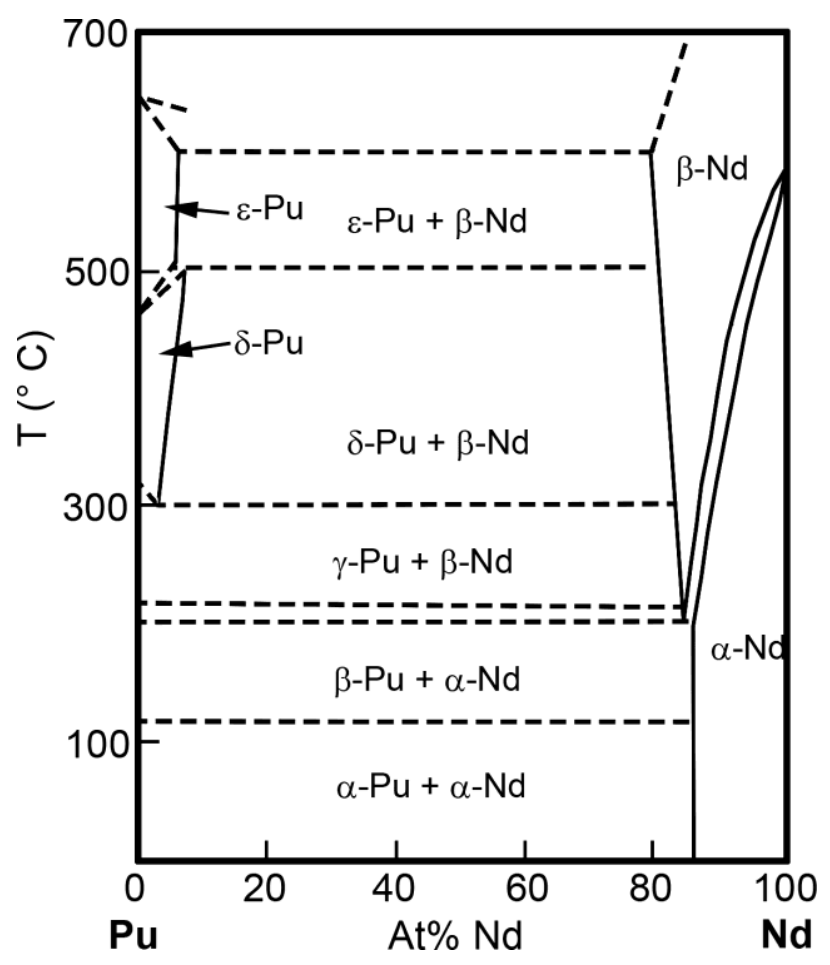

Figure 73. Pu-Nd phase diagram of Kutaitsev et al. [317]

Ellinger and colleagues developed a second $\mathrm{Pu}-\mathrm{Nd}$ phase diagram using data from thermal analysis, $\mathrm{X}$-ray diffraction, and metallography $[312,318]$ (Figure 74). Although this is the most commonly accepted $\mathrm{Pu}-\mathrm{Nd}$ phase diagram, several features suggest areas for future research:

- The liquidus. Ellinger et al. suggested that the liquidus for compositions with $10-40$ at $\% \mathrm{Nd}$ may be less flat than is shown in their phase diagram because of experimental difficulties caused by the segregation of rare-earth phases near the top of the sample during slow heating.

- The transformation from $(\beta-\mathrm{Nd})$ to $(\alpha-\mathrm{Nd})$ during cooling. Ellinger et al. indicated that this transformation involves an inverse peritectic (retrograde melting) reaction in which $(\beta-\mathrm{Nd})$ decomposes into $(\alpha-\mathrm{Nd})$ and a Pu-rich liquid. Ellinger and colleagues suggested a similar transformation in the $\mathrm{Pu}$-Ce phase diagram, which was later re-interpreted as a consequence of disequilibrium in the sample (see Section 4.1.21). 


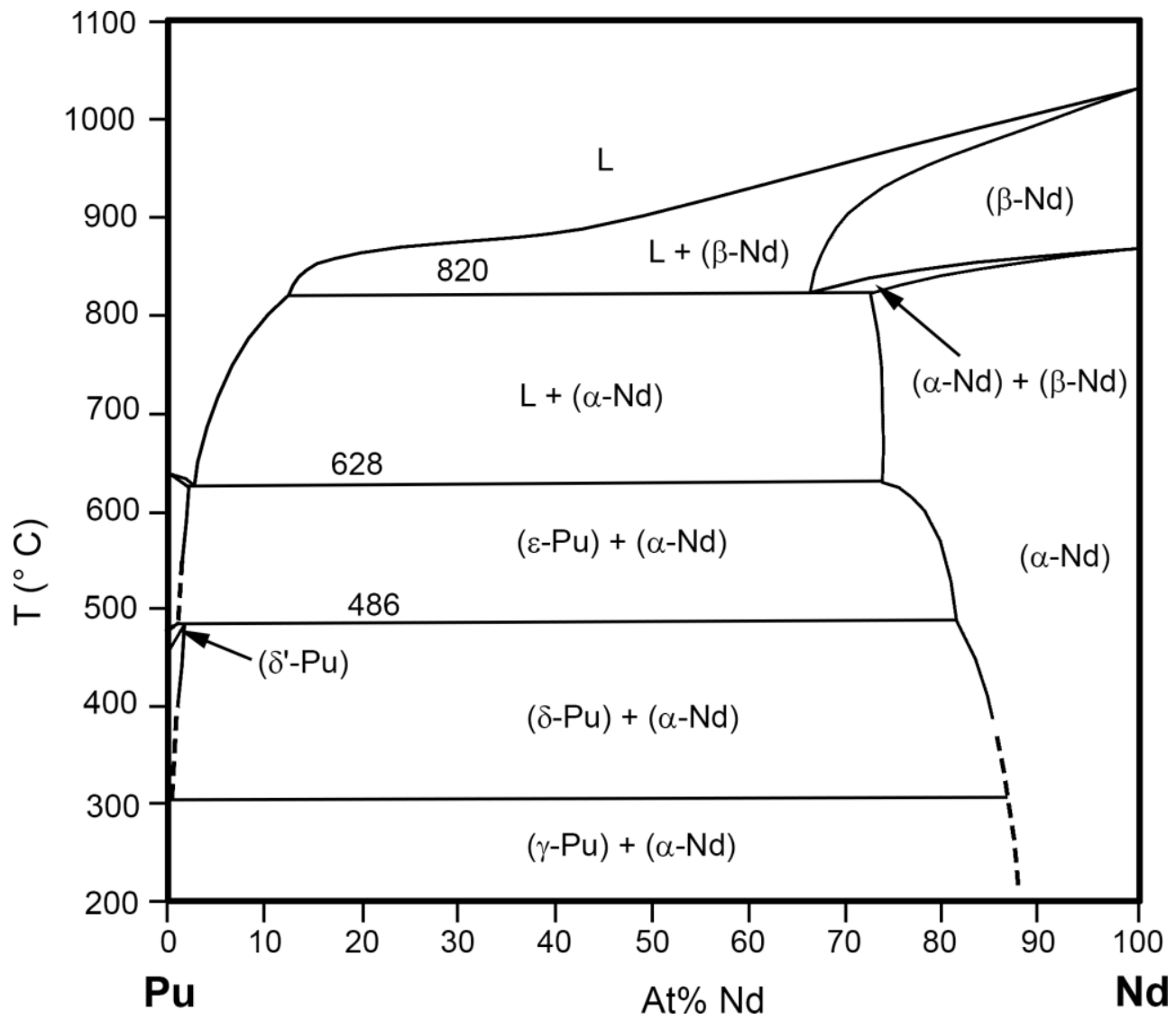

Figure 74. Pu-Nd phase diagram after Ellinger et al. [312, 318]

\subsubsection{Am-La}

\subsubsection{Introduction}

There are apparently no systematic investigations or published phase diagrams of the Am-La binary system, and experimental data at room temperature and above are limited to a single study involving alloys with at most $\sim 3$ at\% Am [319].

Further work on this system is clearly needed.

\subsubsection{Phases and phase transformations}

Samples of La and three Am-La alloys were produced by arc-melting. Significant weight losses during casting were assumed to result from volatilization of Am, leading to differences between starting and as-cast compositions (Table 19).

$\mathrm{X}$-ray diffraction showed that all four materials had face-centered cubic structures. The lattice parameter of the La sample in Table 19 is comparable to the value recommended for $\beta$-La in Section 4.1.3 $(5.303 \AA$ at $598 \mathrm{~K})$. Lattice parameters of the Am-La alloys decreased linearly as a function of Am content. 
Table 19. Lattice parameters of arc-melted La and Am-La alloys [319]

\begin{tabular}{ccc} 
Am $^{\text {Starting }}$ & Am $^{\text {As-cast }}$ & $\begin{array}{c}\text { Lattice } \\
\text { parameter }\end{array}$ \\
\hline 0 & $(\mathrm{at} \%)$ & $(\AA)$ \\
1.25 & 0 & 5.3058 \\
2.20 & 1.39 & 5.3017 \\
3.70 & 2.73 & 5.2998 \\
\hline
\end{tabular}

These data suggest that the maximum solubility of Am in $\beta$-La is at least 3 at $\%$, although possibly not in equilibrium phases.

\subsubsection{Phase diagrams}

No phase diagrams are available.

\subsubsection{Am-Ce}

There are no systematic investigations or published phase diagrams of the Am-Ce binary system. Small amounts of information have been published in a report and patent award addressing possible uses of Am-Ce alloys as radiation sources or materials for radiation detectors [320, 321]. However, these references include very little characterization data. The purity of starting materials was not considered important because it is not crucial for the intended uses of the alloys.

Further research on all aspects of the Am-Ce system is required.

\subsubsection{Am-Zr}

\subsubsection{Introduction}

No experimental data about phases or phase transformations in any Am-Zr alloy is available.

Kurata [250] calculated a phase diagram, which was repeated by Okamoto [322]. This phase diagram shows essentially complete immiscibility between Am and $\mathrm{Zr}$ solids and liquids at temperatures up to $1500 \mathrm{~K}$, with mutual solubilities increasing to $\sim 25$ at $\%$ at $2500 \mathrm{~K}$.

Experimental investigation of this phase diagram is clearly required.

\subsubsection{Phases and phase transformations}

No information about phases in Am-Zr alloys is available. If the low miscibility indicated by the calculated phase diagram is correct, phases in this system are probably similar to Am and Zr.

\subsubsection{Phase diagrams}

The only available phase diagram was calculated by Kurata using an internally consistent database of thermodynamic properties for the U-Np-Pu-Am-Fe-Zr alloy system [250] (Figure 75). 


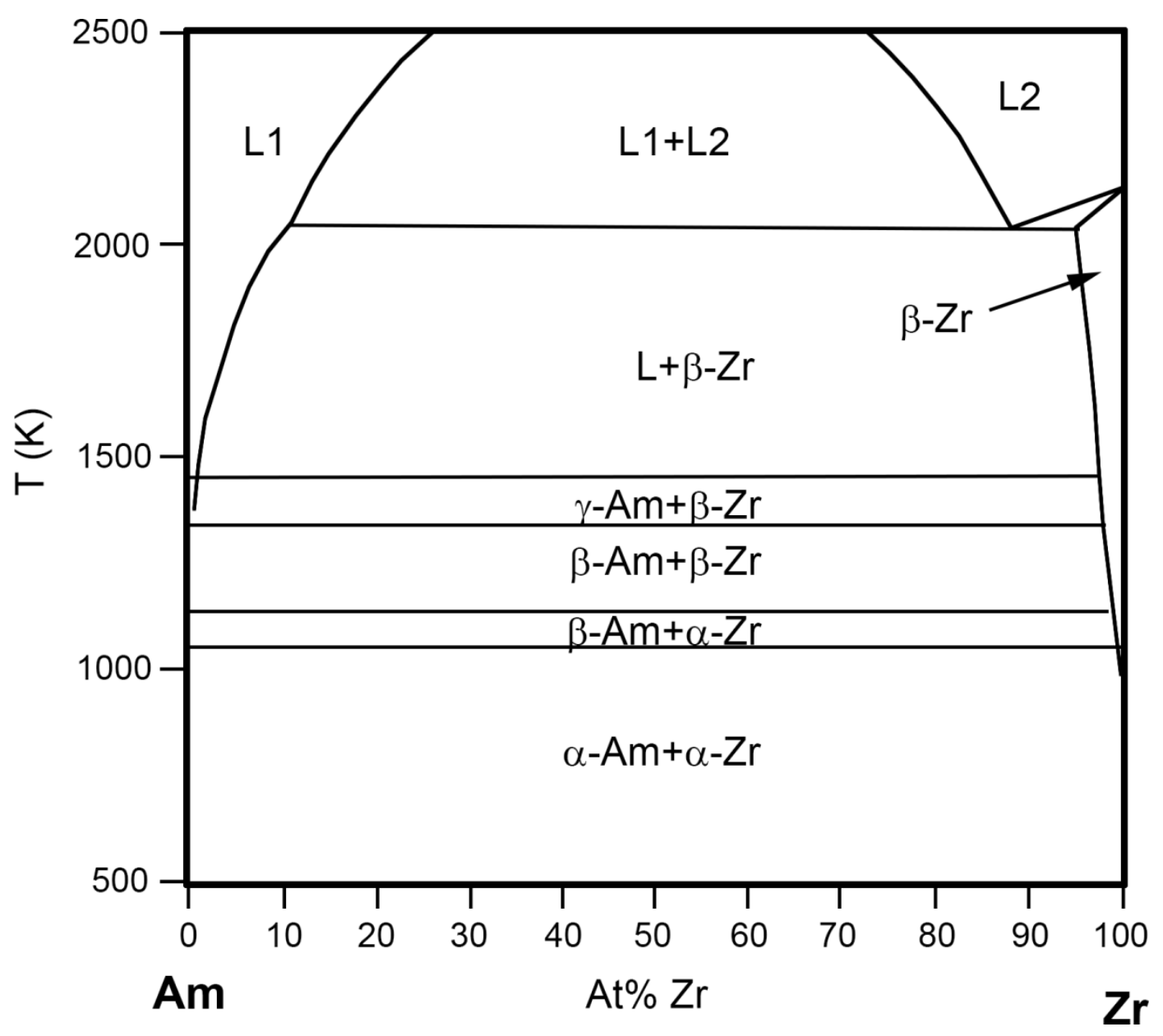

Figure 75. Calculated Am-Zr phase diagram (after [250])

\subsubsection{La-Ce}

\subsubsection{Introduction}

The currently accepted La-Ce phase diagram for temperatures above $0{ }^{\circ} \mathrm{C}$ is based on the work of Vogel and Klose [323]. More recent revisions have eliminated two-phase regions associated with highertemperature phase transformations because these were believed to result from impurities in the samples, clarified the structure of the bcc phase, and changed temperatures of phase transformations as a result of new knowledge of transformation temperatures in La and Ce (e.g., [10, 324]).

Key features of the La-Ce phase diagram include three continuous solid solutions (a dhcp solid solution between $\alpha$-La and $\beta$-Ce, an fcc solid solution between $\beta$-La and $\gamma-\mathrm{Ce}$, and a bcc solid solution between $\gamma$-La and $\delta$-Ce). Boundaries between fcc and bcc solid solutions and between bcc solid solutions and liquid are straight lines, and two-phase fields are narrow. As a consequence of sluggish phasetransition kinetics, temperatures associated with the transformation between the dhep and fcc solid solutions measured during heating and during cooling differ by $50{ }^{\circ} \mathrm{C}$ for pure La and more than $150{ }^{\circ} \mathrm{C}$ for pure $\mathrm{Ce}$, and there are no reliable published experimental measurements of transformation temperatures for intermediate compositions.

Relatively recent experimental publications include data on the lattice parameter of a $\gamma$-Ce solid solution with $5 \mathrm{wt} \% \mathrm{La}$ [325] and a new measurement of phase-transformation temperatures in an alloy 
with 50 at $\% \mathrm{La}$ [326]. Other recent research involves first-principles calculations related to high-pressure properties of alloys of $\alpha-\mathrm{Ce}$ and $\beta$-La $[327,328]$.

Despite the low purity of the samples used in the original determinations of the phase diagrams and the small discrepancies between the currently accepted phase diagram and the more recent experimental data of Bulanova et al [326] (Figure 77), further investigation with high-purity samples seems unlikely to result in significant changes to higher-temperature phase boundaries. Further research addressing transformations between $\alpha-\mathrm{Ce}$, the $(\alpha-\mathrm{La}, \beta-\mathrm{Ce})$ solid solution, and the ( $\beta$-La, $\gamma-\mathrm{Ce})$ solid solution is needed for a complete understanding of the La-Ce phase diagram, but may be of limited relevance for fuels because of the low temperatures and sluggish phase-transformation kinetics involved.

Researchers are encouraged to consult the excellent review of the properties of La-Ce alloys by Gschneidner and Calderwood [10 pp. 9-12].

\subsubsection{Phases and phase transformations}

Atmospheric-pressure phases in the La-Ce system are:

- $\quad(\alpha-\mathrm{Ce})$ : Body-centered cubic solid solution of $\alpha$-Ce (a low-temperature phase of limited relevance for nuclear fuels). The maximum concentration of $\mathrm{La}$ and influence of La concentration on lattice parameters in this phase have not been experimentally determined, although lattice parameters for several alloys were calculated by Zhang et al. [328].

- $\quad(\beta$-Ce, $\alpha$-La): Double hexagonally close packed solid solution between $\beta$-Ce and $\alpha$-La. Lattice parameters of intermediate compositions have not been published. However, because solid solutions of pure rare-earth elements with similar atomic numbers behave as ideal alloys at high temperatures [10], lattice parameters of dhcp La-Ce alloys can be approximated by linear interpolation between lattice parameters of $\beta$-Ce and $\alpha$-La.

- $\quad(\gamma$-Ce, $\beta$-La): Face-centered cubic solid solution between $\gamma$-Ce and $\beta$-La. Gschneidner and Calderwood [10] summarized previously reported lattice parameters from references [329-332]. All of the reported lattice parameters were in good agreement, and followed a trend slightly higher than would be expected from linear interpolation between lattice parameters of pure Ce and $\mathrm{La}$ (positive deviation from Vegard's Law). It should be noted, however, that the alloys in this summary had different annealing temperatures and cooling histories.

More recent lattice parameters reported by Scott et al. [325] for Ce and an alloy with $5 \mathrm{wt} \%$ (5 at \%) La are inconsistent with earlier data (Figure 76), and the 6\% change in lattice parameters caused by the introduction of 5\% La reported by Scott et al. seems anomalously large. Wheeler and Khan reported variations of $\sim 2$ at $\%$ La within individual grains of an alloy with $5 \mathrm{wt} \% \mathrm{La}$ and a face-centered cubic structure [333]. Although this chemical variation probably implies some variation in lattice parameters, it does not seem a likely cause of differences between the lattice parameters reported by Scott et al. and those summarized by Gschneidner and Calderwood [10].

- $\quad(\delta$-Ce, $\gamma$-La) Body-centered cubic solid solution between $\delta$-Ce and $\gamma$-La. Lattice parameters of intermediate compositions are not available.

Temperatures of the $\alpha$-Ce $\leftrightarrow \gamma$-Ce (non-equilibrium) and $\beta$-Ce $\leftrightarrow \gamma$-Ce (equilibrium) transformations were investigated for alloys with up to $4 \mathrm{at} \% \mathrm{La}$ at atmospheric pressure [334]. Addition of La increased the temperature of the $\gamma-\beta$ (cooling) transformation. Addition of $\sim 0.5$ at $\%$ La increased the $\alpha-\gamma$ phasetransformation temperature but decreased the $\gamma-\alpha$ transformation temperature. Addition of larger quantities of La caused a decrease in both the $\alpha-\gamma$ and $\gamma-\alpha$ transformation temperatures.

Because the boundaries between ( $\beta$-La, $\gamma-\mathrm{Ce}),(\gamma-\mathrm{La}, \delta$-Ce), and liquid phases are linear, the corresponding phase-transformation temperatures can in principle be obtained by interpolation between the transformation temperatures of $\mathrm{La}$ and $\mathrm{Ce}$ (Sections 4.1.3 and 4.1.4). For an alloy with 50 at\% La, this interpolation leads to values of $795{ }^{\circ} \mathrm{C}$ for the $(\beta$-La, $\gamma$-Ce $) \leftrightarrow(\gamma$ - La, $\delta$-Ce $)$ transformation and $858{ }^{\circ} \mathrm{C}$ for 
melting. Relatively recent experimental measurements by Bulanova et al. [326] of $755{ }^{\circ} \mathrm{C}$ for the ( $\beta$-La, $\gamma$ $\mathrm{Ce}) \leftrightarrow(\gamma$-La, $\delta$-Ce $)$ transformation and $845^{\circ} \mathrm{C}$ for melting are somewhat below the interpolated temperatures.

Phase-transformation enthalpies for La-Ce alloys have not been reported. However, enthalpies for La and $\mathrm{Ce}$ are sufficiently similar that it seems reasonable to estimate the transformation enthalpies for specific alloys by interpolation from the enthalpies for La and Ce (Sections 4.1.3 and 4.1.4). For an alloy with 50 at $\% \mathrm{La}$, this interpolation gives the following values:

- $\quad(\beta$-Ce, $\alpha$-La) $\leftrightarrow(\gamma-\mathrm{Ce}, \beta$-La): $\sim 0.23 \mathrm{~kJ} / \mathrm{mol}$

- $(\gamma$-Ce, $\beta$-La $) \leftrightarrow(\delta$-Ce, $\gamma$-La): $\sim 3.1 \mathrm{~kJ} / \mathrm{mol}$

- Fusion: $\sim 5.9 \mathrm{~kJ} / \mathrm{mol}$

\subsubsection{Phase diagrams}

An early La-Ce phase diagram by Vogel and Klose [323] showed three solid phases, each forming a continuous solid solution between $\mathrm{La}$ and $\mathrm{Ce}$. Each phase transition involved a two-phase field spanning a temperature range up to $\sim 20{ }^{\circ} \mathrm{C}$. The La used for the investigation had $\sim 3 \%$ impurities (primarily Fe) and the Ce was $99.5 \%$ pure.

Somewhat later, Savitskiy and Terekhov developed a second phase diagram for temperatures between $\sim 750$ and $850{ }^{\circ} \mathrm{C}$ using $\mathrm{La}$ and $\mathrm{Ce}$ that contained $1-1.5 \%$ impurities (primarily other rare-earth elements) [335]. They apparently only recognized two crystal structures (hcp and fcc), and reported a temperature difference of up to $60^{\circ} \mathrm{C}$ between the liquidus and solidus.

Gschneidner and colleagues modified the phase diagram of Vogel and Klose by depicting phase transitions as straight lines and largely eliminating two-phase fields (e.g., [10, 324]). Both of these changes are consistent with their observation that binary alloys between rare-earth elements with similar atomic numbers behave as ideal solutions at high temperatures. Gschneidner and colleagues also extended the phase diagram to temperatures below $300^{\circ} \mathrm{C}$. The phase diagram of Gschneidner and Calderwood [10] (Figure 77) is currently accepted, although it does not include more recent information about the temperature of the phase transformation between $\beta$-Ce and $\gamma$-Ce.

A publication by Bulanova et al. [326] shows a variant of the Gschneidner phase diagram in which the transformation between the hexagonal $(\alpha-\mathrm{La}, \beta-\mathrm{Ce})$ and face-centered cubic $(\beta-\mathrm{La}, \gamma-\mathrm{Ce})$ phases is shown by a single line connecting the transformation temperature measured during heating of La with the average of the transformation temperatures measured during heating and cooling of $\mathrm{Ce}$. Bulanova et al. do not explain why they used this phase transformation temperature; however, it involves temperatures well below all of their experimental measurements. 


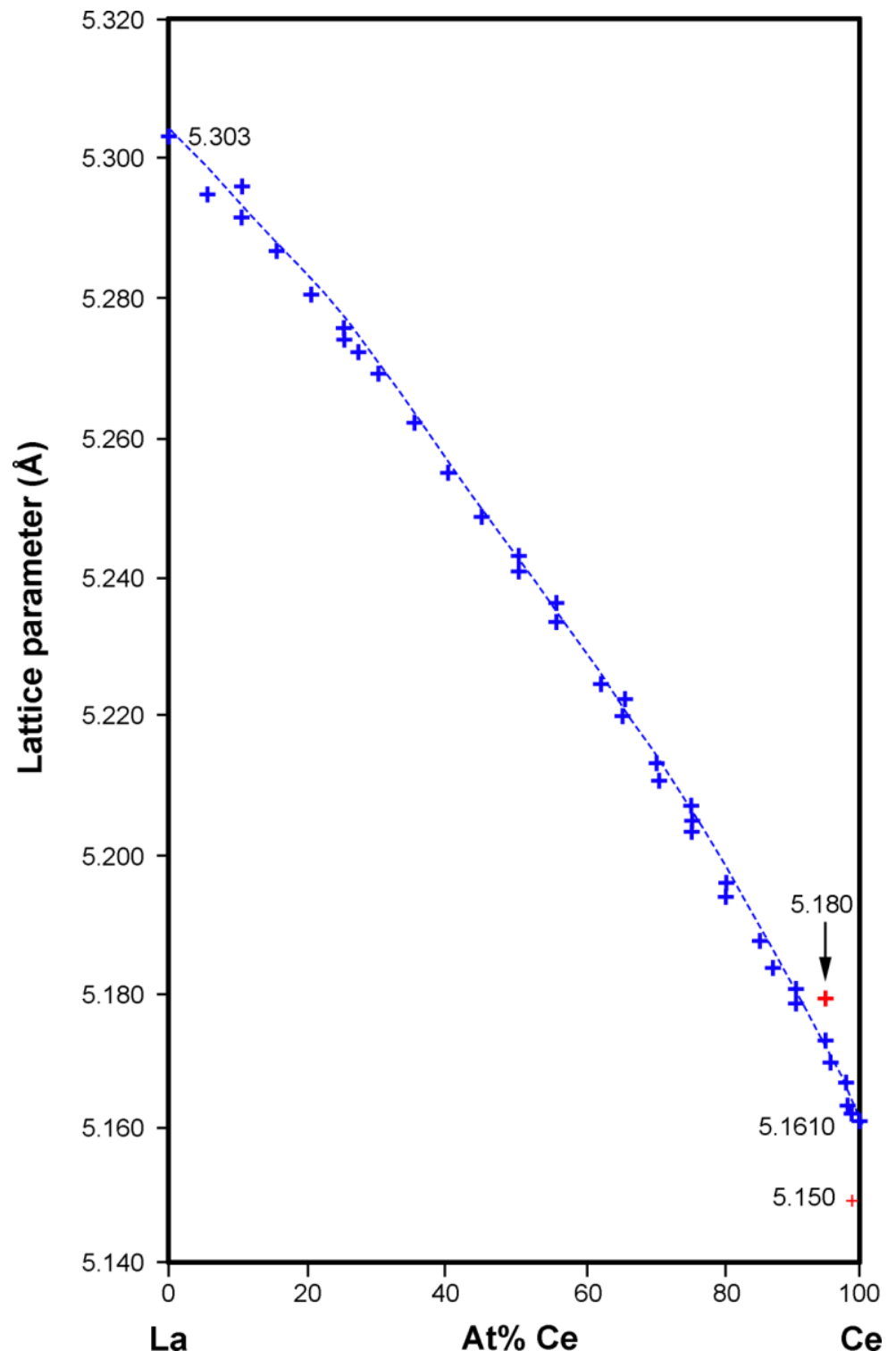

Figure 76: Lattice spacings for ( $\beta$-La, $\gamma$-Ce) solid solutions. Blue symbols indicate values summarized by Gschneidner and Calderwood [10], red symbols indicate values from Scott et al. [325]. 


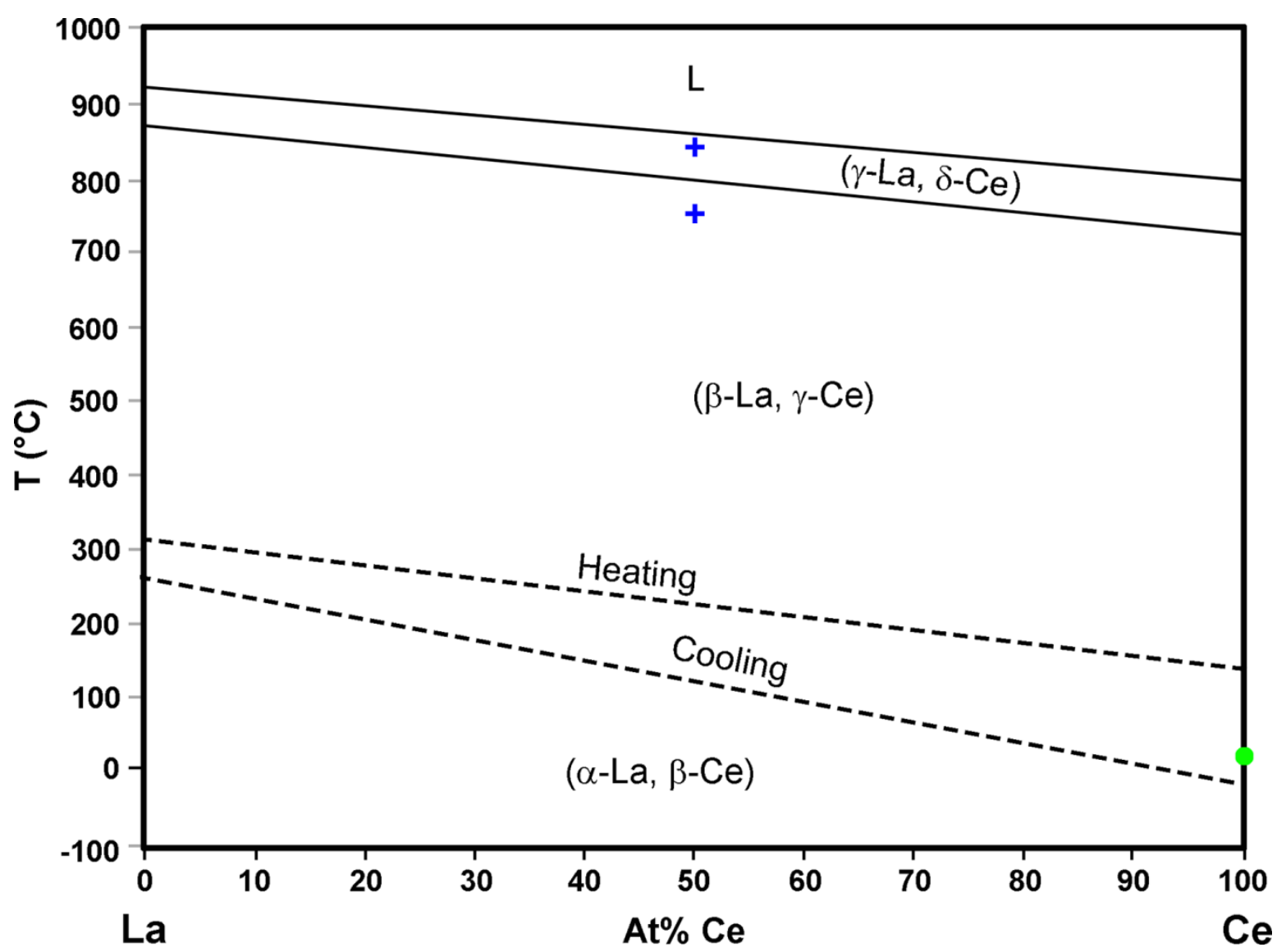

Figure 77: La-Ce phase diagram after Gschneidner and Calderwood [10] with data from Bulanova et al. [326] (blue crosses) and equilibrium temperature from Gschneidner and Pecharsky [228] (green circle)

\subsubsection{La-Pr}

\subsubsection{Introduction}

The La-Pr phase diagram has apparently not been investigated experimentally, although a systematic survey of intra-rare-earth binary phase diagrams suggests that it is similar to that of Ce-Pr [324]. Based on this suggestion, key features of the La-Pr phase diagram include one end member (La) with three polymorphs, one end member ( $\mathrm{Pr}$ ) with two polymorphs, a continuous high-temperature solid solution between two bcc phases ( $\gamma$-La and $\beta$-Pr), a continuous low-temperature solid solution between two dhcp phases ( $\alpha$-La and $\alpha$-Pr), and a eutectoid decomposition of the bec phase into an fcc solid solution ( $\beta$-La) and the dhcp solid solution.

Published phase diagrams (e.g. [336, 337]) are qualitatively consistent with the features described above, but have no experimentally determined values except those for pure La and Pr.

\subsubsection{Phases and phase transformations}

Atmospheric-pressure phases in the La-Pr system are:

- $\quad(\alpha-\mathrm{La}, \alpha-\operatorname{Pr})$ : Double hexagonally close packed solid solution between $\alpha$-La and $\alpha$-Pr. Exerimentally determined lattice parameters of intermediate compositions are not available.

- $\quad(\beta$-La): Face-centered cubic solid solution of $\beta$-La. The composition range of this phase has not been investigated, and the only published lattice parameter is for pure La (Section 4.1.3). 
- $\quad(\gamma$-La, $\beta$-Pr) Body-centered cubic solid solution between $\gamma$-La and $\beta$-Pr. Lattice parameters of intermediate compositions are not available.

Phase-transformation temperatures and enthalpies for this system are known only for pure La and $\mathrm{Pr}$ (Sections 4.1.3 and 4.1.5).

\subsubsection{Phase diagrams}

Published La-Pr phase diagrams (e.g. [336, 337]) are based on the suggestion by Gschneidner et al [324] that the La-Pr phase diagram is similar to the Ce-Pr phase diagram. The phase diagram shown here (Figure 78) follows reference [337], except that dashed lines are used to indicate areas of uncertainty and phase-transformation temperatures have been adjusted to match the recommendations in Sections 4.1.3 and 4.1.5.

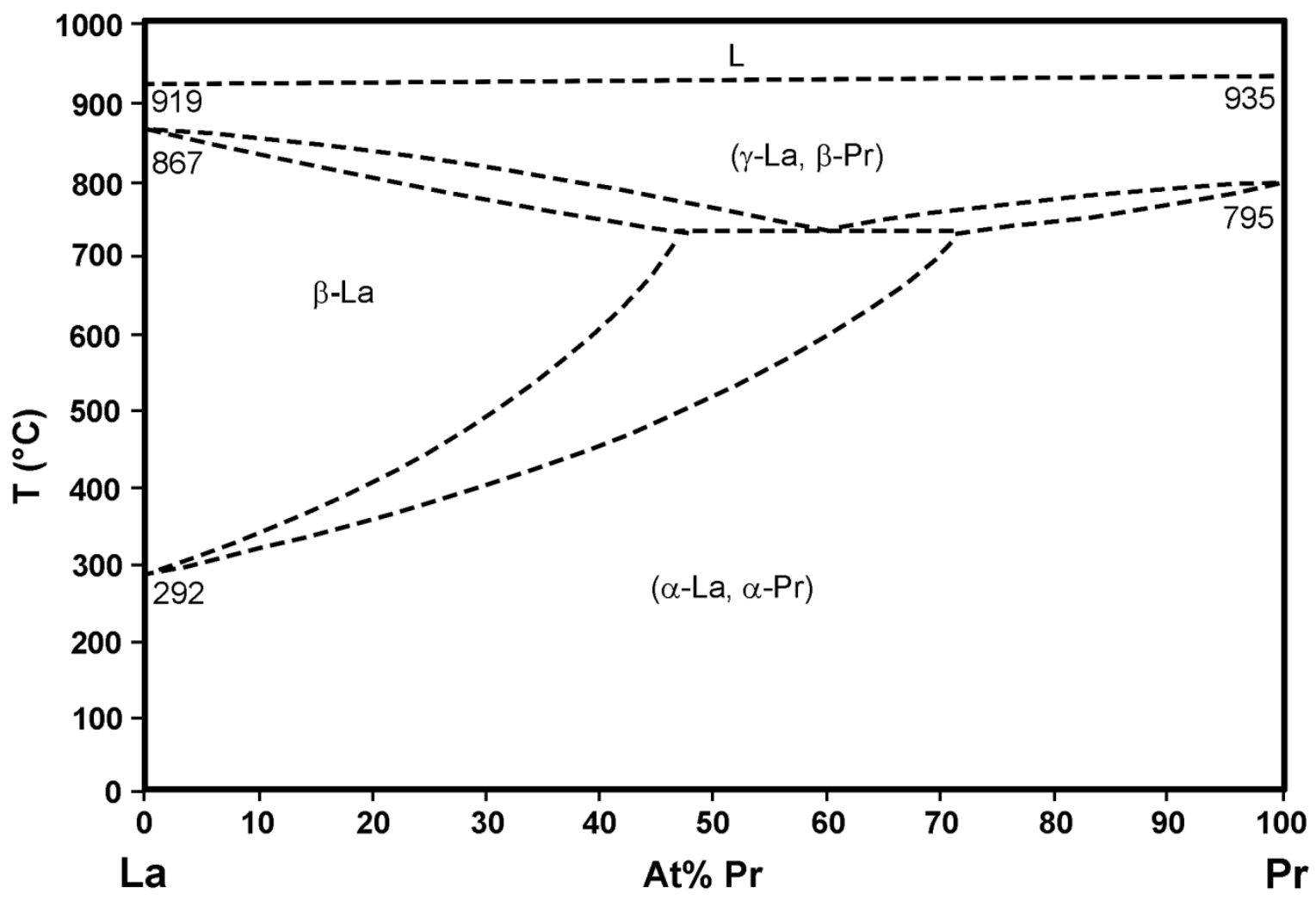

Figure 78. Hypothetical La-Pr phase diagram (reference [337] with phase-transformation temperatures adjusted to match the recommendations in Sections 4.1.3 and 4.1.5)

\subsubsection{La-Nd}

\subsubsection{Introduction}

Published experimental data on La-Nd phases are limited to phase-transformation temperatures, crystal- structure determinations, and lattice parameters from four alloys in a 1954 quarterly progress report for the Atomic Energy Commission [338] and phase identifications in seven compositions investigated as part of a study of the La-Nd-Fe ternary system [339]. The currently accepted phase diagram was proposed in 1961 based on a re-interpretation of the 1954 data, which was required because of new knowledge indicating the existence of a third La phase. This re-interpretation involved adding a 
two-phase field for which there were no experimental measurements [9]. Minor modifications were made more recently to reflect new measurements of $\mathrm{La}$ and $\mathrm{Nd}[10]$.

The La-Nd phase diagram suggested by Gschneidner (Figure 79) resembles his proposed La-Pr phase diagram (Section 4.1.28). Key features of this phase diagram include one end member (La) with three polymorphs, one end member $(\mathrm{Nd})$ with two polymorphs, a continuous high-temperature solid solution between two bcc phases ( $\gamma$-La and $\beta$-Nd), a continuous low-temperature solid solution between two dhcp phases $(\alpha$-La and $\alpha-\mathrm{Nd})$, and a eutectoid decomposition of the bec phase into an fcc solid solution ( $\beta$-La) and the dhcp solid solution.

The 1999 measurements of Wu et al. confirm the existence of the two-phase field, but suggest that it may involve higher concentrations of $\mathrm{Nd}$ than are shown in the Gschneidner phase diagram. Other relatively recent research involves measurement of partial vapor pressures and calculation of thermodynamic quantities [340] and measurements at very low temperatures [341].

In the absence of further data, the Gschneidner phase diagram (Figure 79) is probably the best available representation of the La-Nd phase diagram, despite data suggesting that the miscibility gap occurs at higher concentrations of $\mathrm{Nd}$ than indicated by the phase diagram. Further research is needed to define the phase diagram (particularly the boundaries of the miscibility gap) and understand the importance of impurities. Measurements of phase-transformation enthalpies are also needed.

Researchers are encouraged to consult the excellent review of the properties of $\mathrm{La}-\mathrm{Nd}$ alloys by Gschneidner and Calderwood [10 pp. 13-14].

\subsubsection{Phases and phase transformations}

Atmospheric-pressure phases in the La-Nd system are:

- $\quad(\alpha-\mathrm{Nd}, \alpha$-La): Double hexagonally close packed solid solution between $\alpha$-Nd and $\alpha$-La. The range of compositions in this phase is unknown. Published lattice parameters for three alloys show considerable scatter and a negative deviation from Vegard's Law [10, 338].

- $\quad(\beta$-La): Face-centered cubic solid solution of $\beta$-La. The range of compositions in this phase is unknown, and lattice parameters are not available.

- $\quad(\beta-\mathrm{Nd}, \gamma$-La): Body-centered-cubic solid solution between $\beta$-Nd and $\gamma$-La. Phase-transformation temperatures at the upper and lower boundaries of this phase were reported by Daane and Spedding, and are consistent with the Gschneidner phase diagram.

Phase-transformation enthalpies for La-Nd alloys are not available.

\subsubsection{Phase diagrams}

The La-Nd phase diagram published in 1954 by Daane and Spedding [338] includes only two La polymorphs and shows continuous solid solutions between hep and fcc phases of La and Nd. Later research (e.g., [221]) established the existence of a third La phase, and the 1954 Daane and Spedding phase diagram is no longer accepted.

In 1961, Gschneidner re-interpreted the data of Daane and Spedding to include three La phases and suggested that the La-Nd phase diagram is similar to the Ce-Pr system [9]. Small changes have been made since then to reflect improved knowledge of phase-transformation temperatures [10] (Figure 79). Despite numerous areas of uncertainty, this phase diagram is commonly accepted.

Although the Gschneidner and Calderwood phase diagram seemed plausible, there was no direct experimental evidence for the eutectoid reaction and two-phase field at the time it was proposed. More recently, $\mathrm{Wu}$ et al. identified phases in seven La-Ce alloys as part of a study of an isothermal section of the La-Nd-Fe ternary system at $770 \mathrm{~K}$ [339]. The new data confirms the presence of the two-phase field, but suggests that it may occur at significantly higher concentrations of $\mathrm{Nd}$ than indicated by the Gschneidner and Calderwood phase diagram. 


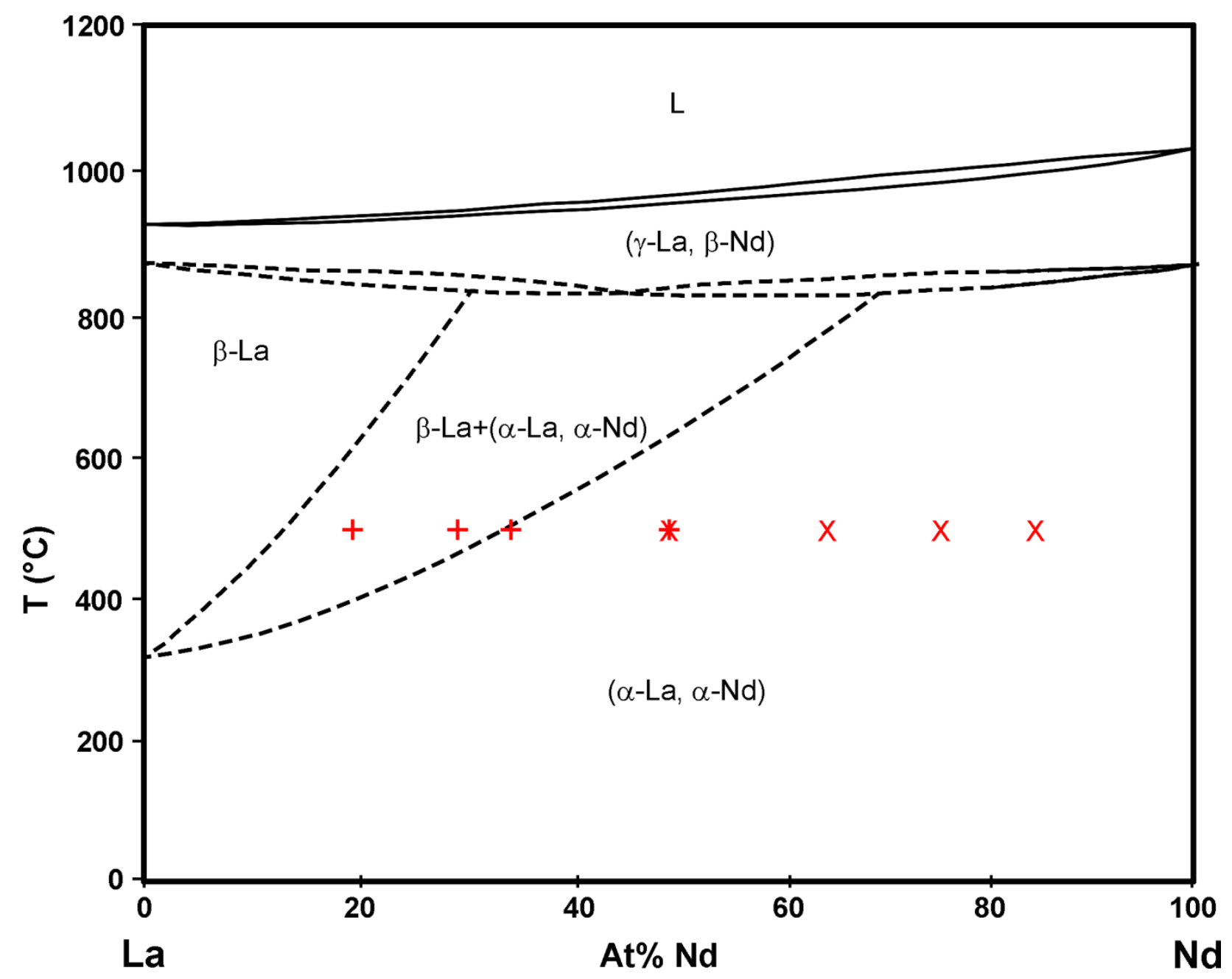

Figure 79. La-Nd phase diagram after Gschneidner and Calderwood [10]. Red symbols represent data from $\mathrm{Wu}$ et al. [339]: plus symbols are ( $\beta$-La), $\mathrm{x}$ symbols are $(\alpha-\mathrm{Nd})$, and superimposed symbols indicate that both phases were identified.

\subsubsection{La-Zr}

\subsubsection{Introduction}

There are no published phase diagrams for the La-Zr binary system and experimental data is limited. All of the data indicates that $\mathrm{La}$ and $\mathrm{Zr}$ are immiscible, and that there are no intermediate $\mathrm{La}-\mathrm{Zr}$ phases.

\subsubsection{Phases and phase transformations}

Experimental data on binary $\mathrm{La}-\mathrm{Zr}$ alloys is limited to a single publication reporting that an arcmelted specimen showed no detectable solid solution between La and $\mathrm{Zr}$ [338]. Recent studies of the La$\mathrm{Zr}-\mathrm{Si}$ and Al-Zr-La ternary systems confirmed that neither has intermediate $\mathrm{La}-\mathrm{Zr}$ phases at $500{ }^{\circ} \mathrm{C}(773$ K) $[342,343]$.

In the absence of experimental data, it seems reasonable to assume that phases in La-Zr alloys are similar to those in $\mathrm{La}$ and $\mathrm{Zr}$. 


\subsubsection{Phase diagrams}

No phase diagrams are available.

\subsubsection{Ce-Pr}

\subsubsection{Introduction}

In 1982, Gschneidner and Calderwood [344] developed a phase diagram based on the 1980 data of Altunbas and Harris [345]. Key features of this phase diagram include one end member (Ce) with three polymorphs above room temperature, one end member (Pr) with two polymorphs, a bec solid solution between $\delta$-Ce and $\beta-\operatorname{Pr}$, a dhcp solid solution between $\beta$-Ce and $\alpha-\operatorname{Pr}$, and a eutectoid decomposition of the bcc solid solution into an fcc solid solution $(\gamma-\mathrm{Ce})$ and the dhcp solid solution. Although it was published as "preliminary," the Gschneidner and Calderwood phase diagram has been extensively reprinted (e.g., [10, 324, 346, 347], and remains the only binary Ce-Pr phase diagram in the ASM Alloy Phase Diagram Database.

Despite the uncertain purity of some of the samples used by Altunbas and Harris, it seems unlikely that further investigation would change the boundaries of higher-temperature phase transitions significantly. Further research addressing transformations involving $\alpha$-Ce and the boundaries of the $(\alpha-\operatorname{Pr}$, $\beta$-Ce) solid solution is needed for a complete understanding of the phase diagram, but may be of limited relevance for fuels because of the low temperatures and sluggish kinetics involved. In the absence of this research, the Gschneidner and Calderwood phase diagram (Figure 80) is the best available approximation of the Ce-Pr phase diagram.

Researchers are encouraged to consult the excellent review of the properties of Ce-Pr alloys by Gschneidner and Calderwood [10 pp. 30-32].

\subsubsection{Phases and phase transformations}

Atmospheric-pressure phases in the Ce-Pr system are:

- ( $\alpha$-Ce): Low-temperature fcc solid solution of $\alpha$-Ce. The maximum concentration of Pr and influence of Pr concentration on lattice parameters in this phase have apparently not been published.

- $\quad(\beta-C e, \alpha-P r)$ : Double hexagonally close packed solid solution between $\beta$-Ce and $\alpha$-Pr. Lattice parameters of intermediate compositions have apparently not been published.

- $\quad(\gamma-\mathrm{Ce})$ : Higher-temperature face-centered cubic solid solution of $(\gamma-\mathrm{Ce})$. The lattice parameter for an alloy with 5 at $\% \operatorname{Pr}$ is $0.001 \AA$ larger than that for pure Ce, and lattice parameters with lower concentrations of Pr follow Vegard's law [10, 332, 344]. Lattice parameters for alloys with higher concentrations of $\operatorname{Pr}$ are not available.

- $\quad(\delta$-Ce, $\beta$-Pr): Body-centered cubic solid solutions between $\delta$-Ce and $\beta$-Pr. Lattice parameters of intermediate compositions are not available.

Altunbas and Harris noted "hysteresis" (i.e., differences in onset temperatures measured during heating and cooling) in their DTA and resistivity data. They attributed this phenomenon to elastic deformation associated with changes in crystal structures.

Addition of $\sim 1$ at $\%$ Pr increases the temperature of the $(\alpha-\mathrm{Ce}) \leftrightarrow(\gamma-\mathrm{Ce})$ transformation relative to that in pure Ce. However, addition of larger concentrations of $\operatorname{Pr}$ (to a few at $\%$ ) decrease this transformation temperature [334]. There is no available information about the temperature of the $(\alpha-\mathrm{Ce}) \leftrightarrow(\gamma-\mathrm{Ce})$ transition in alloys with higher concentrations of Pr or the influence of $\operatorname{Pr}$ on the $(\alpha-\mathrm{Ce}) \leftrightarrow(\beta-\mathrm{Ce})$ transformation temperature. Nonetheless, it seems likely that $(\alpha-\mathrm{Ce})$ solid solutions occur only at temperatures too low to be relevant for fuels.

Addition of a few percent Pr increased the temperature of the $(\beta-\mathrm{Ce}) \leftrightarrow(\gamma-\mathrm{Ce})$ transformation by about 15 degrees [334]. Altunbas and Harris [345] published a figure showing that phase-transformation 
temperatures increase for alloys with higher concentrations of Pr; however, it not possible to reliably quantify the increase because of the scatter in the data.

Altunbas and Harris [345] also published a graphical presentation of temperatures for the liquidus and $(\gamma-\mathrm{Ce}) \leftrightarrow(\delta$-Ce, $\beta$-Pr $)$ transformation. Liquidus temperatures appear to rise linearly with increasing concentration of $\operatorname{Pr}$. The temperature of the $(\gamma-\mathrm{Ce}) \leftrightarrow(\delta$-Ce, $\beta$-Pr) transformation also generally increases with concentration of Pr, but levels off or decreases slightly at high concentrations.

Phase-transformation enthalpies for Ce-Pr alloys are not available.

\subsubsection{Phase diagrams}

In 1980, Altunbas and Harris [345] used DTA and electrical resistivity to study phase-transformation temperatures in Ce-Pr alloys. They also used X-ray diffraction to determine phases in powdered samples that had been annealed at $600{ }^{\circ} \mathrm{C}$ and rapidly cooled to room temperature, and reported that samples with 66-74 at\% Pr had two phases. They presented their transformation-temperature data graphically as a function of Pr concentration, but did not integrate this data with their X-ray diffraction data or suggest a phase diagram.

In 1982, Gschneidner and Calderwood published a "preliminary" Ce-Pr phase diagram based on the data of Altunbas and Harris [344] (Figure 80). The temperature of the $\beta$-Ce $\leftrightarrow \gamma$-Ce transformation in the phase diagram $\left(61^{\circ} \mathrm{C}\right)$ is the average of the transformations measured during heating and cooling, and is significantly higher than the most recent estimate of the equilibrium transformation temperature $\left(10^{\circ} \mathrm{C}\right.$, Section 4.1.4). Other phase-transformation temperatures for $\mathrm{Ce}$ and $\mathrm{Pr}$ are from Section 4.1.4 and Section 4.1.5, and are within a few degrees of the values used by Gschneidner and Calderwood. 


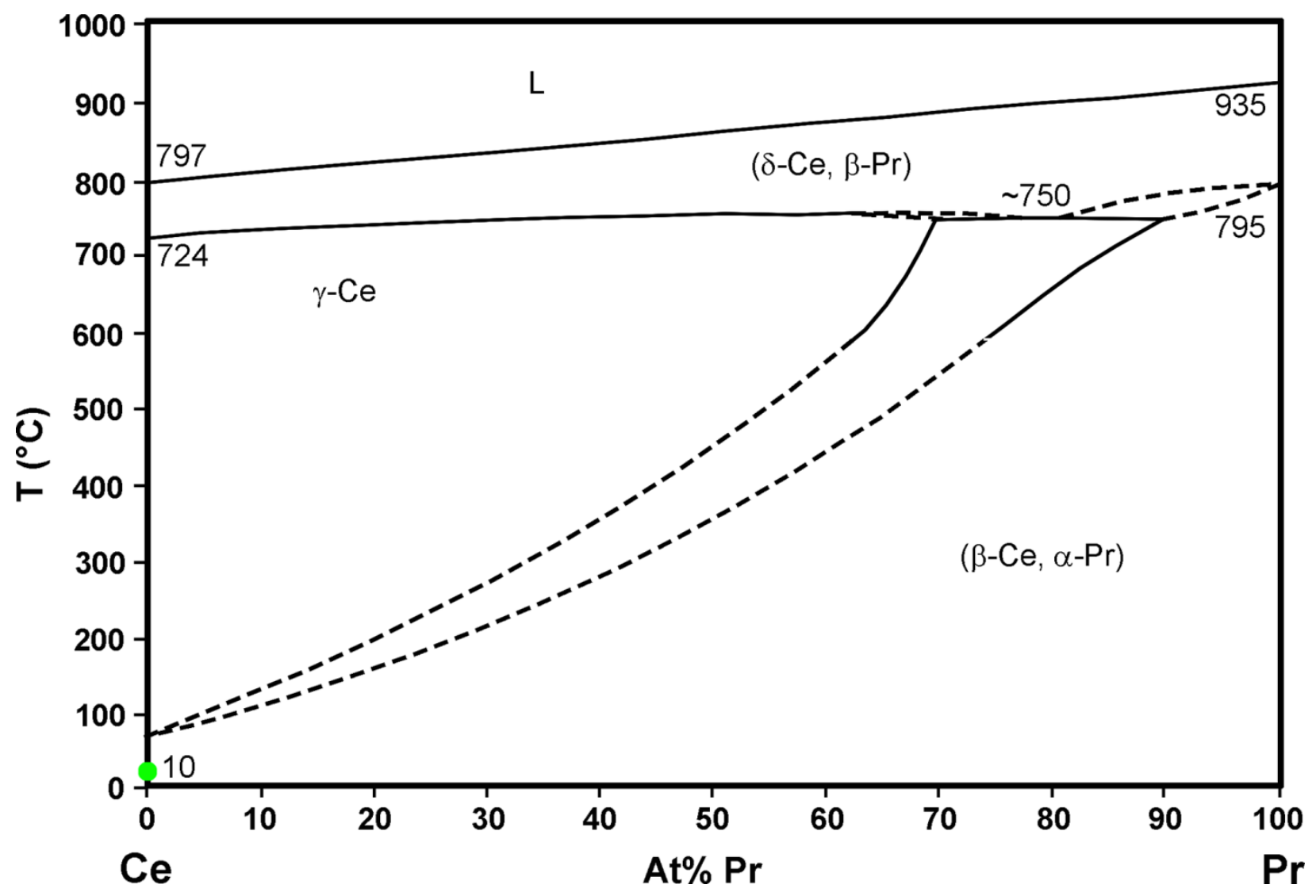

Figure 80. Ce-Pr phase diagram after Gschneidner and Calderwood [10], with phase-transformation temperatures for Ce and Pr from Sections 4.1.4 and 4.1.5 of this handbook

\subsubsection{Ce-Nd}

\subsubsection{Introduction}

The Ce-Nd phase diagram has apparently not been investigated systematically, although isolated measurements are available in several studies [348-350]. A systematic survey of intra-rare-earth binary phase diagrams suggests that the Ce-Nd and Ce-Pr phase diagrams are similar [324]. If this suggestion is true, key features of the Ce-Nd phase diagram include one end member $(\mathrm{Ce})$ with three polymorphs above room temperature, one end member $(\mathrm{Nd})$ with two polymorphs, a continuous bcc solid solutions between $\delta$-Ce and $\beta-\mathrm{Nd}$, a continuous dhcp solid solution between $\beta-\mathrm{Ce}$ and $\beta-\mathrm{Nd}$, and a eutectoid decomposition of the $(\delta-\mathrm{Ce}, \beta-\mathrm{Nd})$ solid solution into the $(\beta-\mathrm{Ce}, \alpha-\mathrm{Nd})$ solid solution and an fcc phase $(\gamma-\mathrm{Ce})$.

The only available Ce-Nd phase diagram (Figure 81) was suggested by Moffatt [351] based on X-ray diffraction data from Speight et al. [348]. This phase diagram appears in the ASM Alloy Phase Diagram Database [352]. Although the experimental data supports the existence of phases with fcc and hcp structures in alloys with different compositions, boundaries of the two-phase field shown by three experimental studies are inconsistent.

Further research on the entire system is clearly needed. Researchers are encouraged to consult the excellent review of the properties of Ce-Nd alloys by Gschneidner and Calderwood [10 pp. 33-34].

\subsubsection{Phases and phase transformations}

Atmospheric-pressure phases in the Ce-Nd system are: 
- $\quad(\beta-\mathrm{Ce}, \alpha-\mathrm{Nd})$ : Double hexagonally close packed solid solution between $\beta$-Ce and $\alpha$-Nd. The $a-$ lattice parameters of intermediate compositions vary approximately linearly between $\sim 11.795 \AA$ $(\mathrm{Nd})$ and $\sim 11.836 \AA$ (alloy with 60 at $\% \mathrm{Ce}$ ), and the $c$-lattice parameters vary approximately linearly between $3.656 \AA(\mathrm{Nd})$ and $3.673 \AA$ (alloy with 60 at $\% \mathrm{Ce}$ ) [10, 348, 353]. Lattice parameters in the original data of Speight et al. are expressed in units of $\mathrm{kX}$, which can be converted to Å by multiplying by 1.00202 [354].

- $\quad(\gamma-\mathrm{Ce})$ : Face-centered cubic solid solution of $\gamma$-Ce. Speight et al. determined that lattice parameters for this phase in alloys with $70-100$ at $\%$ Ce are essentially independent of composition, with $a \approx 5.161 \AA[10,348,353]$. This data is consistent with a measured lattice parameter of $5.1600 \AA$ in an alloy with 2 at $\% \mathrm{Nd}$ by Gschneidner et al. [332].

- $\quad(\delta$-Ce, $\beta$-Nd) Body-centered cubic solid solution between $\delta$-Ce and $\beta$-Nd. Lattice parameters of solid solutions have apparently not been published.

Phase-transformation temperatures of $\mathrm{Ce}$ and $\mathrm{Nd}$ can be found in Section 4.1.4 and Section 4.1.6. Phase-transformation temperatures of alloys have not been reported; however, because Ce and $\mathrm{Nd}$ are trivalent rare-earth metals with similar atomic numbers, Ce-Nd alloys behave as ideal alloys at high temperatures [10 p. 7]. As a consequence, the temperatures of the liquidus and solidus are the same to within a few degrees, and the combined liquidus and solidus can be represented by a straight line between the melting temperatures of $\mathrm{Ce}$ and $\mathrm{Nd}[10]$. Other phase-transformation temperatures have apparently not been reported.

Transformation enthalpies for $\mathrm{Ce}$ and $\mathrm{Nd}$ can be found in Sections 4.1.4 and 4.1.6. Transformation enthalpies for alloys are not available.

\subsubsection{Phase diagrams}

Three researchers have published experimental data on phases in Ce-Nd alloys, but none of them have suggested phase diagrams. The only available phase diagram was suggested by Moffatt [351] based on X-ray diffraction data from alloys that had been rapidly cooled from $600{ }^{\circ} \mathrm{C}$ [348] (Figure 81).

Two sets of experimental data have been published since the Moffatt phase diagram. One of them measured coexisting compositions in diffusion couples using energy-dispersive X-ray analysis in a scanning electron microscope and interpreted them as boundaries of a two-phase region [349]. A second study determined that an alloy with $10 \mathrm{wt} \% \mathrm{Nd}$ that had been heat treated at $610{ }^{\circ} \mathrm{C}$ for 2 hours was primarily fcc material with some dhcp material and that an alloy with $50 \mathrm{wt} \% \mathrm{Ce}$ was dhcp [350]. Although these data suggest that the boundaries of the miscibility gap may be incorrect, further research is needed to determine the correct boundaries. 


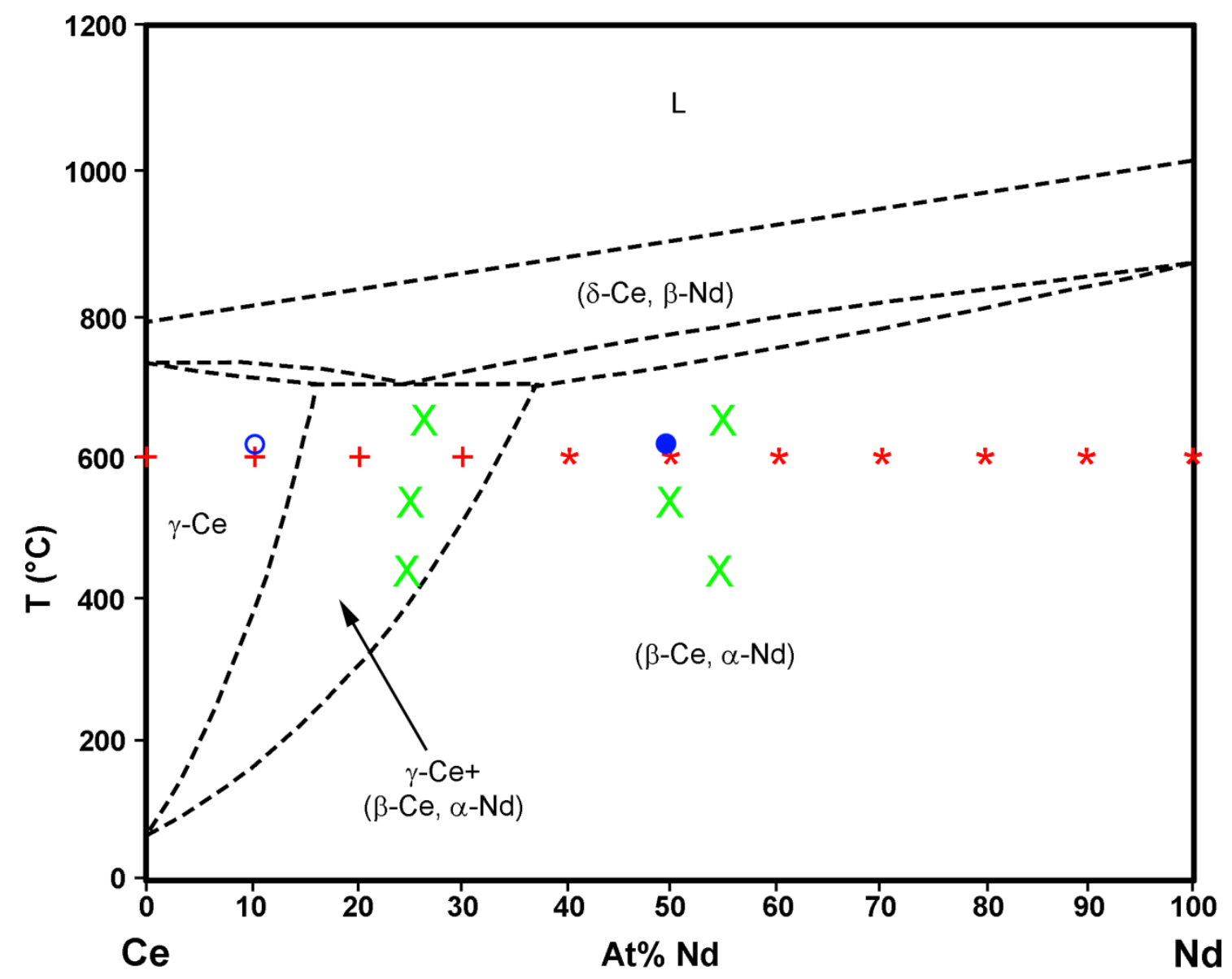

Figure 81. Tentative Ce-Nd phase diagram after Okamoto [337] with experimental data from Speight et al. [348] (red; + indicates an alloy with reported fcc lattice parameters, * indicates an alloy with reported dhcp lattice parameters), Keiser [349] (green; x symbols indicate boundaries of the two-phase region), and Hachimi et al. [350] (blue; open circle indicates an alloy with predominantly fcc structure, filled circle indicates an alloy with dhcp structure).

\subsubsection{Ce-Zr}

\subsubsection{Introduction}

The first systematic investigation of the Ce-Zr phase diagram was published in 2014 [355], using a combination of new experimental data and thermodynamic modeling. Key features of this phase diagram include limited miscibility between solid phases, a miscible liquid phase, liquidus temperatures that increase with $\mathrm{Zr}$ content, and an absence of intermediate phases. The low miscibility of the solid phases, absence of intermediate phases, and phase transformation temperatures in this phase diagram are consistent with older experimental data (e.g., [338, 356]).

The Ce-Zr phase diagram is unusually well known (particularly in comparison to other phase diagrams in this handbook), based on experimental data from temperatures between $\sim 600$ and $1600 \mathrm{~K}$. Further research is needed to measure phase-transition enthalpies, which have apparently not been reported previously.

\subsubsection{Phases and phase transformations}

Stable phases in the $\mathrm{Ce}-\mathrm{Zr}$ system at atmospheric pressure and above room temperature are: 
- $\quad(\alpha-Z r)$ : Allotropic solid solution of $\alpha-Z r$. The maximum solubility of Ce is $\sim 3-6$ at $\%$ [355, 356]. The $a$ and $c$ lattice parameters both increase with increasing concentration of $\mathrm{Zr}$; however, quantifying the rate of increase is complicated by differences in annealing temperatures in the available data [356 Table 1 and Figures 1 and 2].

- $\quad(\beta-Z r)$ : Allotropic solid solution of $\beta-Z r$. The maximum solubility of Ce is $\sim 8$ at $\%$ [355]

- $\quad(\gamma-\mathrm{Ce})$ : Allotropic solid solution of $\gamma$-Ce. The maximum solubility of $\mathrm{Zr}$ is $<2$ at $\%$ [355]. The lattice parameter is similar to that of pure $\gamma$-Ce [356].

- ( $\delta$-Ce): Allotropic solid solution of $\delta$-Ce. The maximum solubility of $\mathrm{Zr}$ is $<1$ at $\%$ [355]

The liquid phase is completely miscible [355].

Phase-transformation temperatures were measured by a number of early researchers, with conflicting results. The values quoted here are from new DSC measurements by Mattern et al. [355]. They are generally consistent with the X-ray diffraction data from annealed samples reported by Harris and Raynor [356].

Except for the liquidus, phase-transformation temperatures show little variation with composition. They are [355]:

- $\quad(\alpha-\mathrm{Zr})$ to $(\beta-\mathrm{Zr}): \sim 1110 \mathrm{~K}$

- $\quad(\gamma-\mathrm{Ce})$ to $(\delta$-Ce): $\sim 990 \mathrm{~K}$

- Melting of $(\delta-\mathrm{Ce}): \sim 1060 \mathrm{~K}$

No information on phase-transformation enthalpies is available.

\subsubsection{Phase diagrams}

Until recently, there were no systematic investigations of the Ce-Zr phase diagram. Moffatt [357] suggested a phase diagram based on the X-ray diffraction data of Harris and Raynor [356] and the assumption that the $\mathrm{Ce}-\mathrm{Zr}$ and $\mathrm{Ce}-\mathrm{Ti}$ systems are similar. This phase diagram is shown here (Figure 82) because it has been widely reproduced (e.g., [358-360]), although it is almost certainly less accurate than the recent phase diagram of Mattern et al. [355]. 


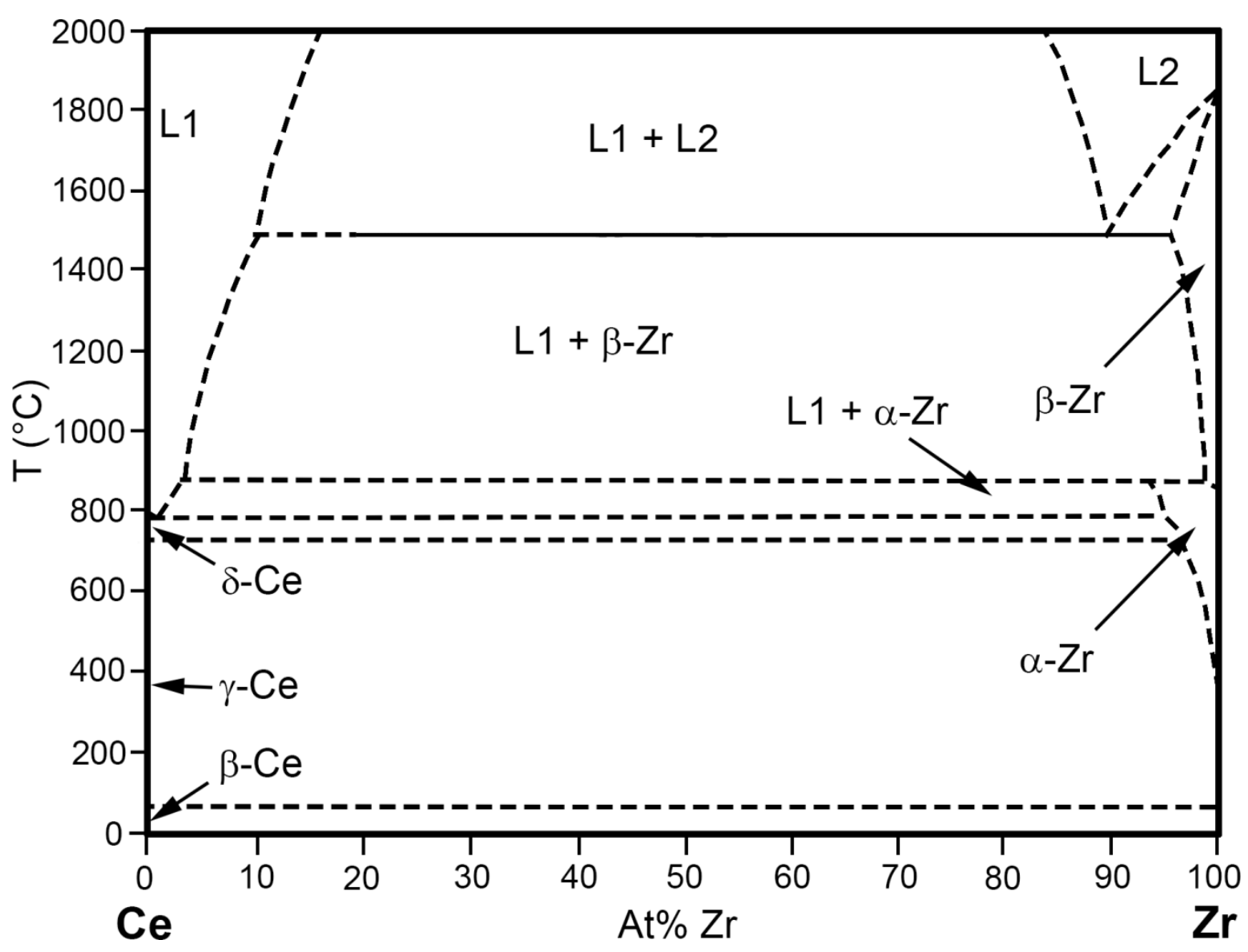

Figure 82. Commonly reproduced Ce-Zr phase diagram suggested by Moffatt [357], based on the assumption that the $\mathrm{Ce}-\mathrm{Zr}$ and $\mathrm{Ce}-\mathrm{Ti}$ phase diagrams are similar (redrawn from [360])

Mattern et al. [355] suggested a new Ce-Zr phase diagram in 2014, based on a combination of their experimental data and thermodynamic modeling (Figure 83). The new data included extensive measurements of the liquidus at temperatures up to $1600 \mathrm{~K}$ using in-situ high-temperature synchrotron diffraction to observe structural changes in small droplets of liquid. Other new measurements included DSC and high-temperature X-ray data to confirm temperatures of solid-state phase changes and SEM observations of microstructures and phase compositions. A thermodynamic model produced good agreement with the experimental observations, and was used to supplement the experimental data. 


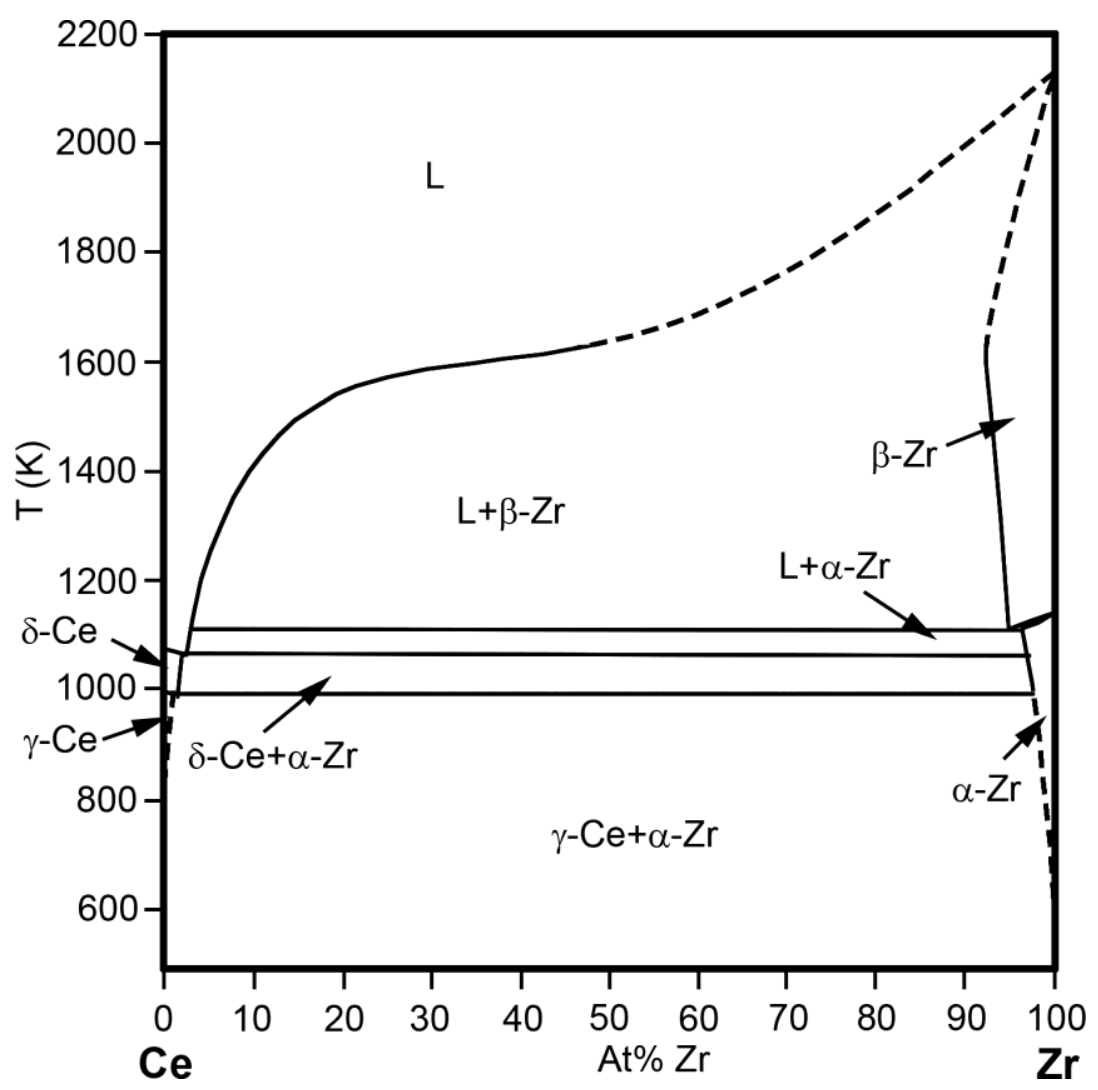

Figure 83. Recent Ce-Zr phase diagram based on new experimental data and thermodynamic modeling (after Mattern et al. [355]). Solid lines indicate areas with new data.

\subsubsection{Pr-Nd}

\subsubsection{Introduction}

The currently accepted Pr-Nd phase diagram (Figure 84) is based on a 1982 re-interpretation of early experimental data [361-363]. Key features of this phase diagram include a completely miscible liquid and solid solutions between the dhcp phases $\alpha$-Pr and $\alpha-\mathrm{Nd}$ and between the bcc phases $\beta$-Pr and $\beta$-Nd. The original experimental data showed two-phase fields associated with phase transformations, which do not appear in the 1982 phase diagram because they were attributed to impurities.

Although the 1982 phase diagram was published as "provisional," it has been repeated in Massalski's compilation of binary alloy phase diagrams [364] and the ASM Alloy Phase Diagram database [365].

Despite the low purity of some of the samples used in the original determinations of the phase diagrams, it seems unlikely that further investigation would change the boundaries of higher-temperature phase transitions by more than a few degrees. Actual transformation temperatures for specific alloys of interest to fuels programs (including possible two-phase fields) should be experimentally addressed if high precision is required.

Researchers are encouraged to consult the excellent review of the properties of Pr-Nd alloys by Gschneidner and Calderwood [10 pp 56-59].

\subsubsection{Phases and phase transformations}

Atmospheric-pressure phases in the Pr-Nd system are: 
- ( $\alpha-\operatorname{Pr}, \alpha-\mathrm{Nd})$ : Double hexagonally close packed solid solution between $\alpha-\operatorname{Pr}$ and $\alpha-\mathrm{Nd}$. Roomtemperature lattice parameters decrease linearly from $\mathrm{Pr}$ to $\mathrm{Nd}$ as a function of the atomic proportion of $\mathrm{Nd}$ [362].

- $\quad(\beta-\operatorname{Pr}, \beta-N d)$ : Body-centered cubic solid solution between $\beta$-Pr and $\beta$-Nd. Lattice parameters vary linearly as a function of the atomic proportions of $\mathrm{Pr}$ and $\mathrm{Nd}$ [362].

Phase-transformation temperatures have not been reported for Pr-Nd alloys. However, given the ideal behavior of these alloys at high temperatures, it seems reasonable to approximate phase-transition temperatures by linear interpolation between transformation temperatures of $\mathrm{Pr}$ and $\mathrm{Nd}$.

\subsubsection{Phase diagrams}

The first Pr-Nd phase diagram was published in 1963 by Markova et al. [361]using Pr and Nd with purities of 97 and $98 \%$, respectively. This phase diagram established the existence of a miscible liquid and two solid solutions involving dhep and fcc structures. It shows two-phase regions with temperature differences of up to $\sim 100{ }^{\circ} \mathrm{C}$ between the liquidus and solidus and between the dhep and fcc solid solutions.

A few years later, Lundin and Pool measured enthalpies of solution for Pr-Nd alloys [366]. Lundin and colleagues also measured room-temperature lattice parameters and densities for solid and liquid $\mathrm{Nd}$, $\mathrm{Pr}$, and a number of alloys and determined thermodynamic activities of Pr and seven alloys at temperatures of 1475,1500 , and $1525^{\circ} \mathrm{C}$ [362]. Although neither of the publications by Lundin and colleagues includes a phase diagram, these publications demonstrated that Pr-Nd alloys behave as ideal solutions.

In 1982, Gschneidner and Calderwood used the results of Markova et al. and Lundin et al. to develop a new phase diagram (Figure 84). The Gschneidner and Calderwood phase diagram considers Pr-Nd alloys to behave as ideal solutions, and therefore represents phase transformations by straight lines rather than showing two-phase fields. This representation is consistent with the general principle that alloys of trivalent rare-earth elements with atomic numbers that differ by less than $\sim \pm 4$ behave as ideal solutions at high temperatures [10], with experimental data from Lundin and colleagues [362,366], and with a phase diagram calculated by Shiflet et al. [367]. However, it is not consistent with the phase diagram of Markova et al., which shows two-phase fields involving temperature differences of up to $\sim 100{ }^{\circ} \mathrm{C}$. It seems likely that the range of temperatures included in a possible two-phase fields are highly dependent on the impurity content of the individual samples used to construct the phase diagram $[363,367]$. 


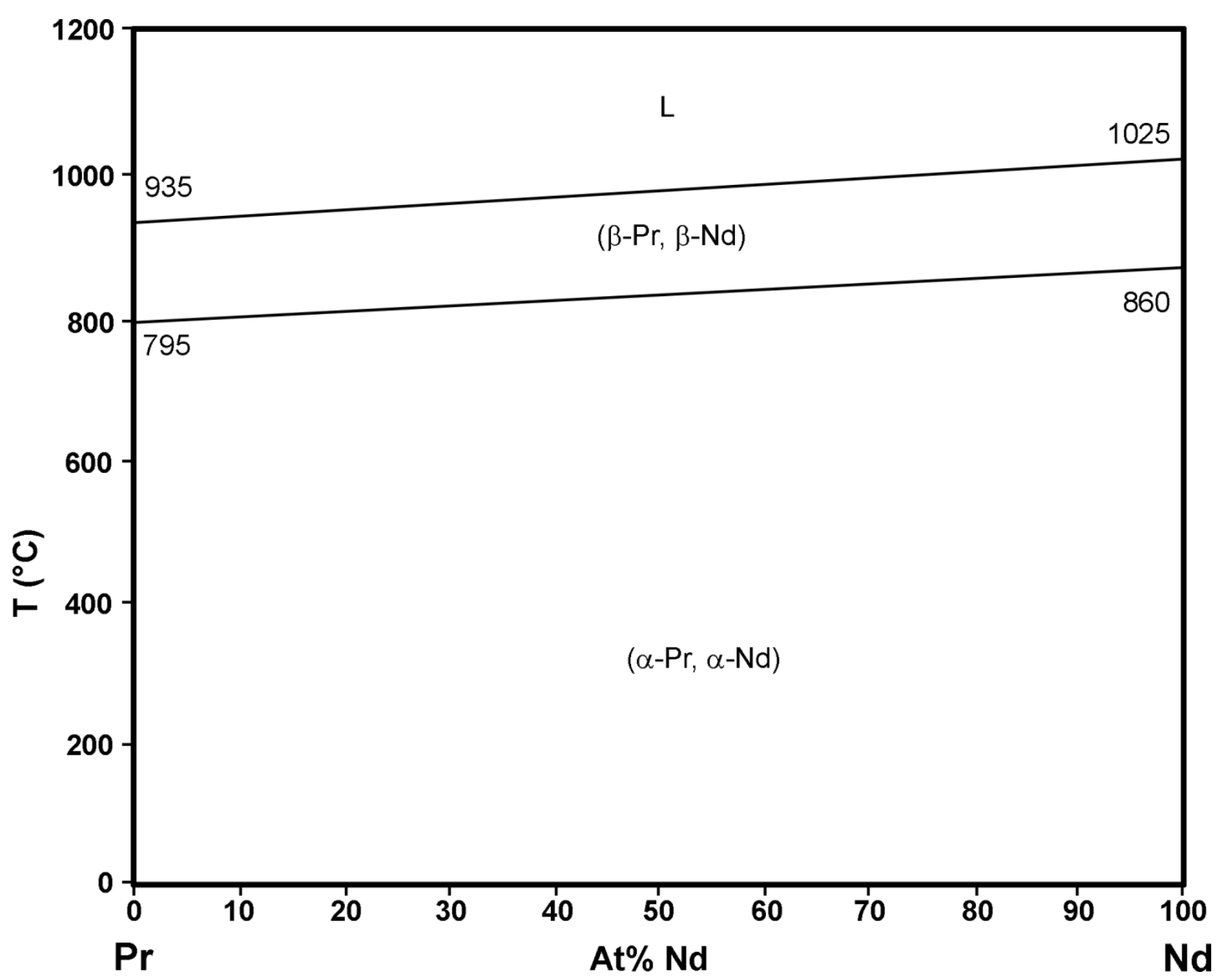

Figure 84: Pr-Nd phase diagram after [363], with phase-transformation temperatures adjusted slightly for consistency with recommendations in Sections 4.1.5 and 4.1.6 of this handbook.

\subsubsection{Pr-Zr}

There are no published phase diagrams for the Pr-Zr binary system. An investigation of the Pr-Zr-Al ternary system at $500{ }^{\circ} \mathrm{C}(773 \mathrm{~K})$ concluded that there is little solid solution and no intermediate phases in the Pr-Zr binary system [368, 369].

\subsubsection{Nd-Zr}

\subsubsection{Introduction}

Although research on ternary alloys indicated that miscibility of $\mathrm{Nd}$ and $\mathrm{Zr}$ was limited (e.g., [370]), there were apparently no published binary Nd-Zr phase diagrams until 2014. Recent interest in improving the properties of $\mathrm{Mg}$ alloys by addition of $\mathrm{Nd}$ and $\mathrm{Zr}$ led to publication of three binary $\mathrm{Nd}-\mathrm{Zr}$ phase diagrams in 2014 and 2015 [371-373]. Each of these phase diagrams was based on a combination of new experimental research and thermodynamic modeling.

All three phase diagrams agree about the existence of a reaction involving $\mathrm{Nd}, \mathrm{Zr}$, and a high- $\mathrm{Nd}$ liquid, and all three agree that there is a phase transformation at $\sim 830-845^{\circ} \mathrm{C}$. Two of the phase diagrams agree that there is a second transformation at $\sim 995-1000^{\circ} \mathrm{C}$. Despite these areas of agreement, the phase diagrams disagree about the identities of the phases involved in each reaction, the liquidus temperature, 
and the possible existence of immiscible liquids. Careful consideration of the data involved shows that the phase diagram of Mattern et al. [372] is the only one to include high-temperature X-ray diffraction data or measurements at temperatures above $\sim 1000{ }^{\circ} \mathrm{C}$, and that none of the phase diagrams used diffraction data to identify the phases involved in lower-temperature reactions.

Further detailed research involving samples with only a few at $\%$ of $\mathrm{Nd}$ or $\mathrm{Zr}$ is needed to understand phase-transformation reactions. Unless this information is of specific interest for fuels, it seems reasonable to consider the phase diagram of Mattern et al. [372] to be an adequate representation of the $\mathrm{Nd}-\mathrm{Zr}$ system. Researchers interested in details of solid-state phase-transformation reactions should also consider the phase diagram of Cheng et al. [371].

\subsubsection{Phases and phase transformations}

Phases in the Nd-Zr phase diagram are:

- $\quad(\alpha-\mathrm{Nd}$ ): Allotropic solid solution of $\alpha-\mathrm{Nd}$ that can contain up to $\sim 2$ at $\% \mathrm{Zr}$ [372] (Table 20 reaction 3). Because of the low concentration of $\mathrm{Zr}$, it seems likely that lattice parameters of $(\alpha-$ $\mathrm{Nd})$ solid solutions are similar to those of $\alpha-\mathrm{Nd}$.

- $\quad(\beta-\mathrm{Nd}$ ): Allotropic solid solution of $\beta-\mathrm{Nd}$ that can contain up to $\sim 3-4$ at $\% \mathrm{Zr}$ (references [371, 372 ] and Table 20 reaction 1). Mattern et al. assume that the lattice parameters of solid solutions of $\beta-\mathrm{Nd}$ and $\beta-\mathrm{Zr}$ follow Vegard's Law (i.e., they vary linearly between the lattice parameters of $\mathrm{Nd}$ and $\mathrm{Zr}$ as a function of composition), which means that lattice parameters of $(\beta-\mathrm{Nd})$ solid solutions are slightly smaller than those of pure $\beta$-Nd. However, because the maximum concentration of $\mathrm{Zr}$ is small, differences in lattice parameters of $\beta-\mathrm{Nd}$ and $(\beta-\mathrm{Nd})$ solid solutions are probably unimportant for fuels research.

- $\quad\left(\alpha-\mathrm{Zr}\right.$ ): solid solution of $\alpha-\mathrm{Zr}$ (hcp structure, space group $P 6_{3} / m m c$ ) that can contain $\sim 3-4$ at $\% \mathrm{Nd}$ (reference [372] and Table 20 reaction 1). Because of the low concentration of $\mathrm{Nd}$, it seems likely that lattice parameters of $(\alpha-Z r)$ solid solutions are similar to those of pure $\alpha-Z r$.

- $\quad(\beta-\mathrm{Zr}$ ): solid solution of $\beta-\mathrm{Zr}$ (bcc structure, space group $\operatorname{Im} \overline{3} m$ ) that can contain up to $\sim 5$ at $\% \mathrm{Nd}$ at $1700 \mathrm{~K}$ [372]. The phase diagram of Cheng et al. [371] shows a calculated maximum concentration of $\sim 10$ at $\% \mathrm{Zr}$ but has no experimental data at this temperature. Mattern et al. assume that the lattice parameters of solid solutions of $\beta-\mathrm{Nd}$ and $\beta-\mathrm{Zr}$ follow Vegard's Law, which means that lattice parameters of $(\beta-\mathrm{Zr})$ solid solutions are slightly larger than those of pure $\beta-Z r[372]$.

Table 20 shows the experimentally measured phase-transformation temperatures from all three phase diagrams, with associated reactions indicated by the references. Difficulties in identifying the phase transitions associated with each temperature may be due to the very similar temperatures of the $\alpha-\beta$ transformations in $\mathrm{Nd}$ and $\mathrm{Zr}$ (Section 4.1.6 and Section 3.1.3, respectively). Heavy lines separate data from what appear to be different reactions. Because of the limited miscibility of $\mathrm{Nd}$ and $\mathrm{Zr}$, the temperature of each reaction is essentially independent of composition. 
Table 20: Phase transformations in the Nd-Zr system [371 Table III, 372 Table 3, 373 Figure 4]. Subscripts in the data from Mattern et al. indicate the calculated composition (at $\% \mathrm{Zr}$ ) in each phase.

$\mathrm{T}(\mathrm{K}) \quad \mathrm{T}\left({ }^{\circ} \mathrm{C}\right) \quad$ Mattern et al. [372]

Cheng et al.

Peng et al.

$1274 \pm 10 \quad 1001 \pm 10 \quad \mathrm{~L}_{4.0} \leftrightarrow \beta-\mathrm{Nd}_{2.0}+\beta-\mathrm{Zr}_{97.0}$

990-997

$\mathrm{L}+\beta-\mathrm{Zr} \leftrightarrow \alpha-\mathrm{Nd}$

$962-964$

(Not identified) $^{1}$

$983^{2}$

$\mathrm{L}+\alpha-\mathrm{Nd} \leftrightarrow \alpha-\mathrm{Nd}$

$1167 \pm 10 \quad 894 \pm 10 \quad \beta-\mathrm{Nd}_{2.2}+\beta-\mathrm{Zr}_{97.8} \leftrightarrow \alpha-\mathrm{Zr}_{96.6}$

$1118 \pm 10 \quad 845 \pm 10 \quad \beta-\mathrm{Nd}_{1.9} \leftrightarrow \alpha-\mathrm{Zr}_{97.1}+\alpha-\mathrm{Nd}_{1.5}$

$833-842$

$\beta-\mathrm{Zr} \leftrightarrow \alpha-\mathrm{Zr}+\alpha-\mathrm{Nd}$

$831-834$

(Not identified)

${ }^{1}$ Assumed to correspond to the highest-temperature reaction reported by other authors despite the difference in temperature because it produces the second of two large peaks in DSC heating curves

${ }^{2}$ Only observed in alloy with $5 \mathrm{at} \% \mathrm{Zr}$

\subsubsection{Phase diagrams}

The phase diagram of Mattern et al. [355, available on-line on March 13, 2014] was apparently the first binary Nd-Zr phase diagram to be published. Temperatures between $\sim 1160$ and $1270 \mathrm{~K}$ were investigated using DSC and SEM data (including EDX analyses) from four alloys with 40 to 95 at $\% \mathrm{Zr}$. Coexisting compositions at temperatures between $\sim 1200$ and $1800 \mathrm{~K}$ were determined using in situ hightemperature synchrotron X-ray diffraction and pyrometry applied to gas-levitated droplets of an alloy with $40 \mathrm{at} \% \mathrm{Nd}$. This data made it possible to determine temperatures of solid-state transformations, as well as compositions of liquids and ( $\square-\mathrm{Zr}$ ) solid solutions at a large number of temperatures. Thermodynamic modeling was used at temperatures above $1800 \mathrm{~K}$ and to determine the limits of solid solution in $\alpha-\mathrm{Zr}, \alpha-\mathrm{Nd}$, and $\beta-\mathrm{Nd}$.

The phase diagram of Cheng et al. [371, available on-line on April 1,2014] used a combination of DSC, SEM, room-temperature XRD, and microprobe data to determine phase-transformation temperatures and compositions in nine annealed and quenched alloys with 5 to $97 \mathrm{at} \% \mathrm{Zr}$. All of the data represents temperatures between 500 and $1000{ }^{\circ} \mathrm{C}$. Thermodynamic modeling was used to determine the liquidus and details of phase transformations, and to determine the limits of solid solution at temperatures outside the range of the experimental data. The Cheng et al. phase diagram does not have a $(\beta-\mathrm{Nd}+\alpha-\mathrm{Zr})$ field, and details of phase transformations in high-Nd and high-Zr solids differ from those in the phase diagram of Mattern et al. Although the shape of the liquidus generally resembles the liquidus in the Mattern phase diagram, liquidus temperatures for most compositions in the Cheng phase diagram are lower.

The phase diagram of Peng et al. [373, available in print in 2015] was based on EDS and DSC of three alloys with 5 to 30 at $\% \mathrm{Zr}$. At temperatures below the liquidus (at $\sim 1600{ }^{\circ} \mathrm{C}$ for most compositions), this phase diagram generally resembles that of Cheng et al. However, the Peng et al. phase diagram shows a broad liquid-phase miscibility gap. The maximum temperature of this miscibility gap is not indicated, 
but is above the melting temperature of $\mathrm{Zr}$.

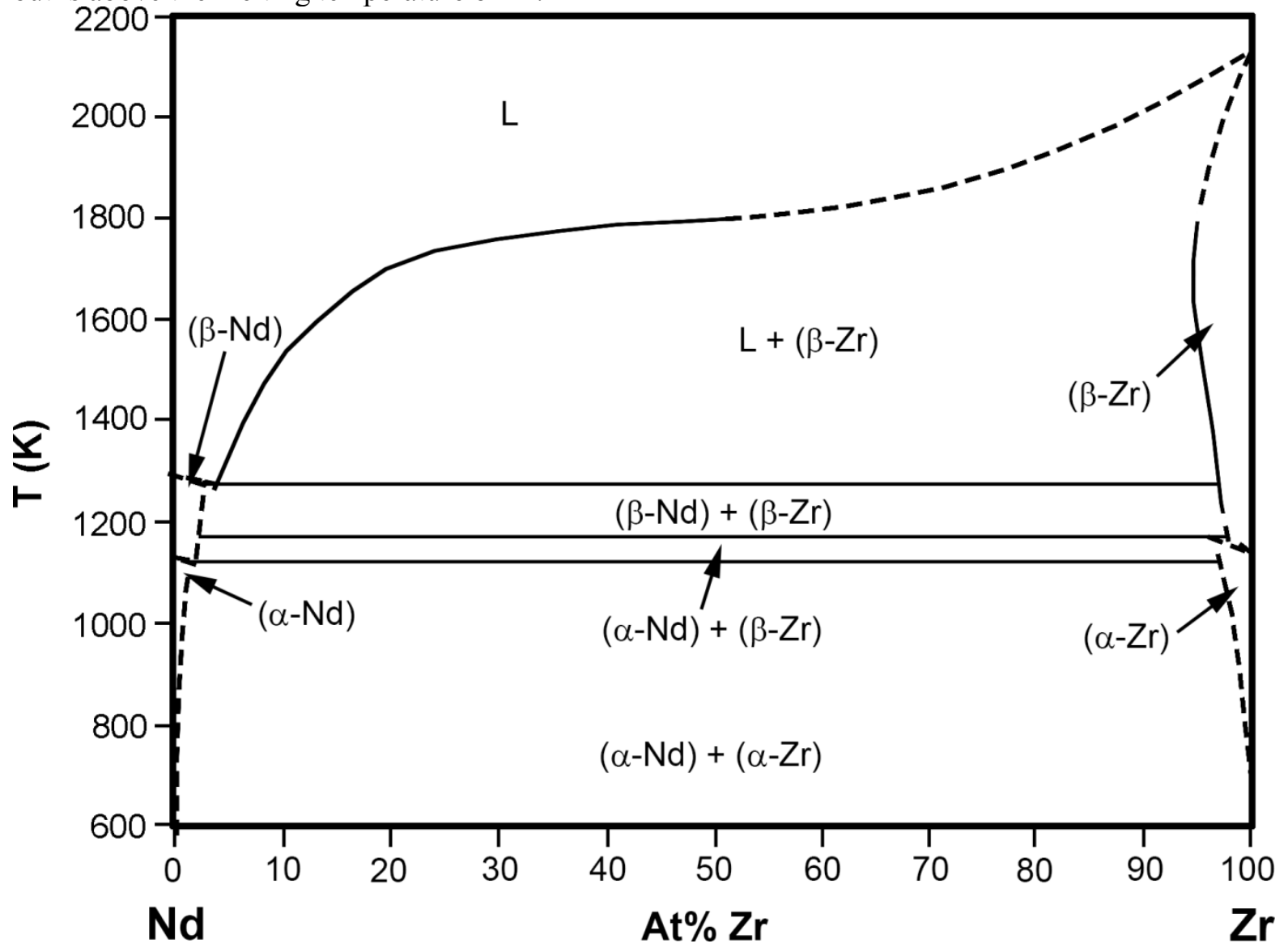

Figure 85

Figure 85 shows the phase diagram of Mattern et al. [372]. As it is the only one of the three phase diagrams with experimental data at temperatures above $1000{ }^{\circ} \mathrm{C}$, it is probably be the best representation of the liquidus and maximum concentration of $\mathrm{Nd}$ in $\beta-\mathrm{Zr}$. None of the phase diagrams used diffraction data to identify the $\mathrm{Nd}$ and $\mathrm{Zr}$ solid-solution phases in lower-temperature reactions, and researchers interested in these transformations should also consult the publication by Cheng et al. [371]. 


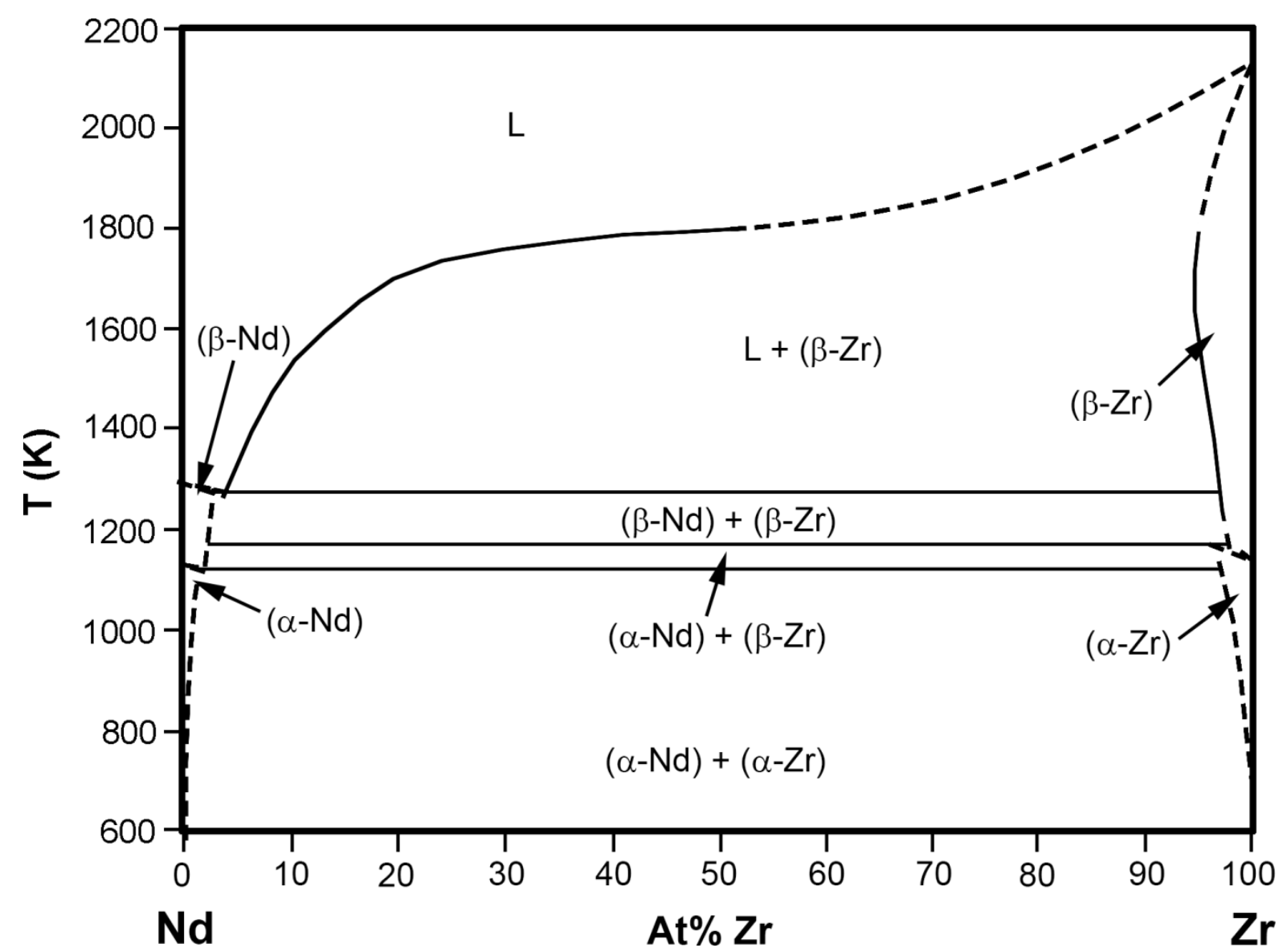

Figure 85: Nd-Zr phase diagram after Mattern et al. [372]. Solid lines indicate areas with new data.

\subsubsection{U-Np-Pu}

\subsubsection{Introduction}

U-Np-Pu alloys have been proposed as nuclear fuels for long-life reactor cores and for production of ${ }^{238} \mathrm{Pu}$ as part of a Np-burning fuel cycle (e.g., [374, 375]). Despite this interest, no experimental characterization data from these alloys is available.

The only available information about the U-Np-Pu phase diagram is a calculated isothermal section at $923 \mathrm{~K}$. Experimental work on all aspects of this system is clearly needed.

\subsubsection{Phases and phase transformations}

No information is available.

\subsubsection{Phase diagrams}

Kurata [62 Figure 29] published a calculated isothermal section at $923 \mathrm{~K}$, based in part on unpublished data showing compositions of phases in an alloy whose bulk composition included $\sim 10$ at $\%$ $\mathrm{Np}, 25 \% \mathrm{Pu}$, and 65\% U (Figure 86). The phase identifications in Figure 86 were not included in the original Kurata paper, but were added to Figure 86 based on comparison to Kurata's calculated binary phase diagrams. The identification of $\beta-\mathrm{U}$ is particularly tentative, as the temperature of Figure 86 is close to the phase-transformation temperature between $\alpha-U$ and $\beta-U$.

Experimental work on this system is clearly needed. 


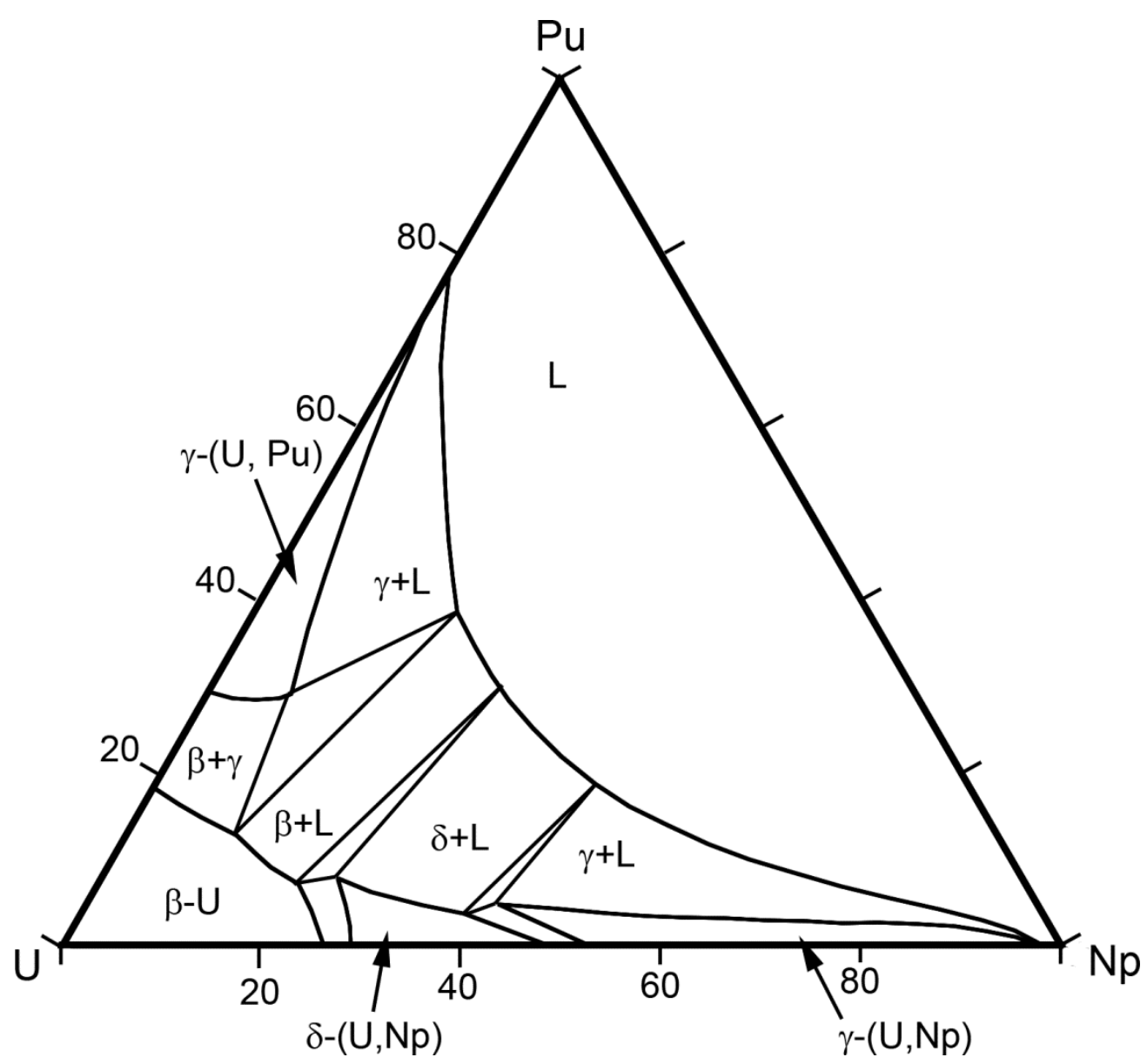

Figure 86. Calculated U-Np-Pu phase diagram [62], with phase identifications suggested by comparison to binary phase diagrams. $\beta$ refers to $\beta-\mathrm{U}$ solid solutions, $\delta$ refers to $\delta$-(U,Np) solid solutions, and $\gamma$ refers to $\gamma$-(U,Np) or $\gamma$-(U,Pu) depending on composition.

\subsubsection{U-Np-Zr}

\subsubsection{Introduction}

Rodríguez et al. published "tentative" isothermal sections of the U-Np-Zr phase diagram at temperatures of 520,595, and $700{ }^{\circ} \mathrm{C}$ [285]. All but two of the eleven alloys considered had $67-88 \mathrm{wt} \%$ $\mathrm{U}$. No diffraction data was used, and some of the microprobe analyses of fine-grained phases were described as "relatively inaccurate."

The system has apparently not been modeled, and calculated phase diagrams or isothermal sections have not been published.

Experimental work on this system is clearly needed.

\subsubsection{Phases and phase transformations}

In the absence of diffraction data, Rodríguez et al. tentatively identified the phases in their samples using a combination of metallography, microprobe analyses, and information about phases in binary systems. They presented both observed compositions and tentative isothermal phase diagrams on which measurements from individual alloys were identified, but did not otherwise address the properties of individual phases. 
Rodríguez et al. identified solid-state phase transformations at temperatures of 567-598 and 614-655 ${ }^{\circ} \mathrm{C}$ in all of their alloys. Melting temperatures were between 955 and 1170 degrees. Neither phasetransition nor melting temperatures showed a clear systematic correlation to alloy compositions.

Researchers are encouraged to refer to the original paper [285] for data on compositions of alloys and phases, phase-transformation temperatures, and tentative phase identifications.

\subsubsection{Phase diagrams}

Rodríguez et al. presented tentative partial isothermal sections at temperatures of 520, 595, and 700 ${ }^{\circ} \mathrm{C}$ (Figure 87, Figure 88, and Figure 89). Phase designations correspond to those in the U-Np, U-Zr, and $\mathrm{Np}$-Zr binary phase diagrams.

The designation " $\gamma$ " refers to a body-centered cubic solid solution between $\gamma-\mathrm{U}, \gamma-\mathrm{Np}$, and $\beta-\mathrm{Zr}$. Although Rodríguez et al. believed that $\gamma-\mathrm{Np}$ and $\beta-\mathrm{Zr}$ form a continuous solid solution, more recent data suggests that they are not miscible (Section 4.1.18). Thus, the boundaries of the " $\gamma$ " field in Figure 89 need revision.

The isothermal sections at 520 and $595^{\circ} \mathrm{C}$ (Figure 88 and Figure 89) show a single phase identified as " $\delta$," which appears to be a solid solution between $\delta-\mathrm{UZr}_{2}, \delta-\mathrm{NpZr}_{2}$, and $\delta-(\mathrm{U}, \mathrm{Np})$. Consideration of crystal structures makes it seem unlikely that " $\delta$ " is really a single phase. $\delta-\mathrm{UZr}_{2}$ and $\delta-\mathrm{NpZr}_{2}$ have similar crystal structures and lattice parameters (Sections 3.1.4 and 4.1.17) and a solid solution between them is plausible. However, the structure of $\delta$-(U,Np) is not like that of $\delta-\mathrm{UZr}_{2}$ and $\delta-\mathrm{NpZr}_{2}$ but instead probably resembles the structure of $\zeta$-(U,Pu) (Section 3.1.6). A solid solution between $\delta$-(U,Np) and $\delta$ $\mathrm{UZr}_{2}$ or $\delta-\mathrm{NpZr}_{2}$ seems implausible, and it is likely that the " $\delta$ " field includes at least two distinct phases. 


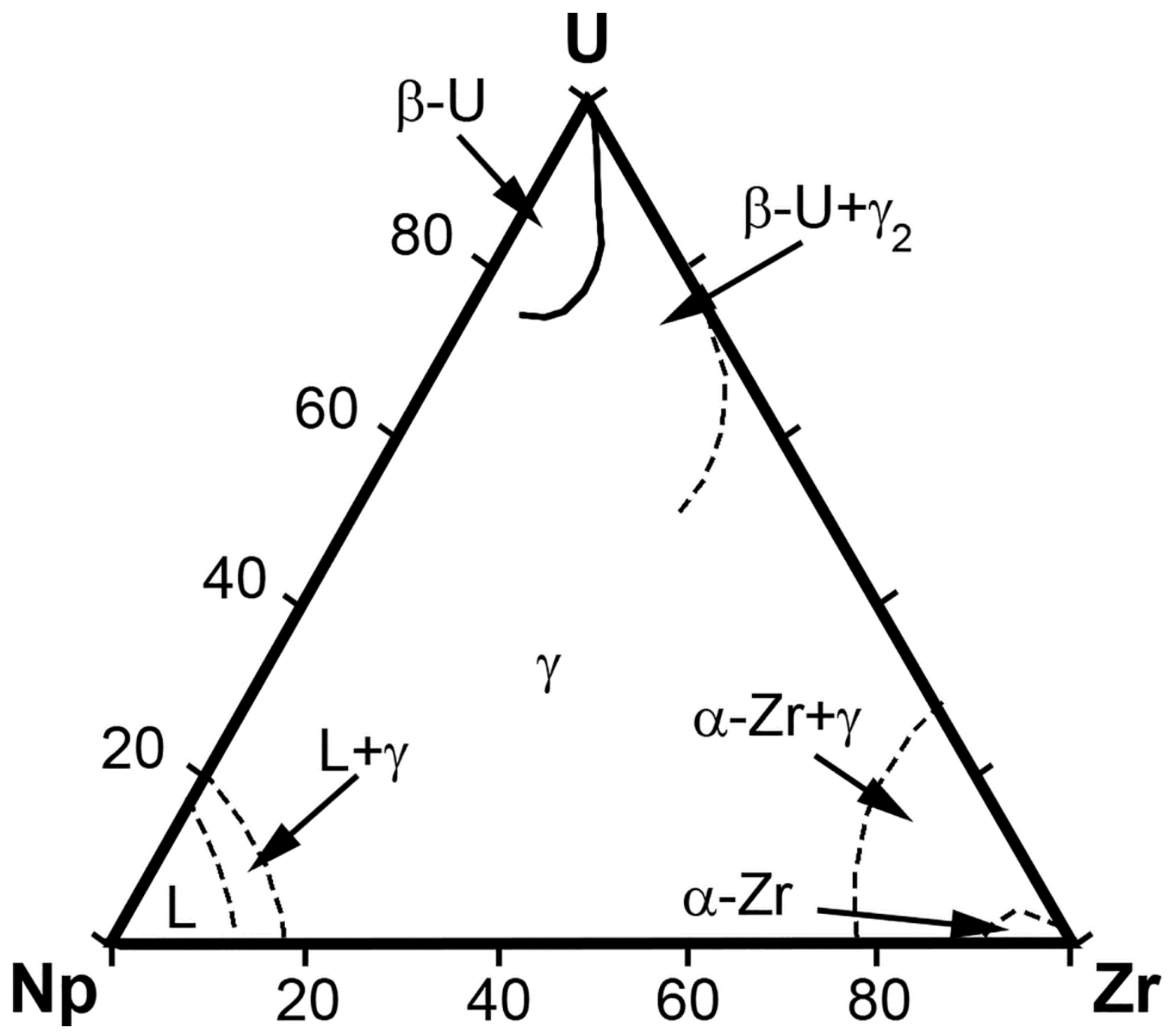

Figure 87: Tentative partial isothermal section of the U-Np-Zr system at $700{ }^{\circ} \mathrm{C}$ suggested by Rodríguez et al. [285] 


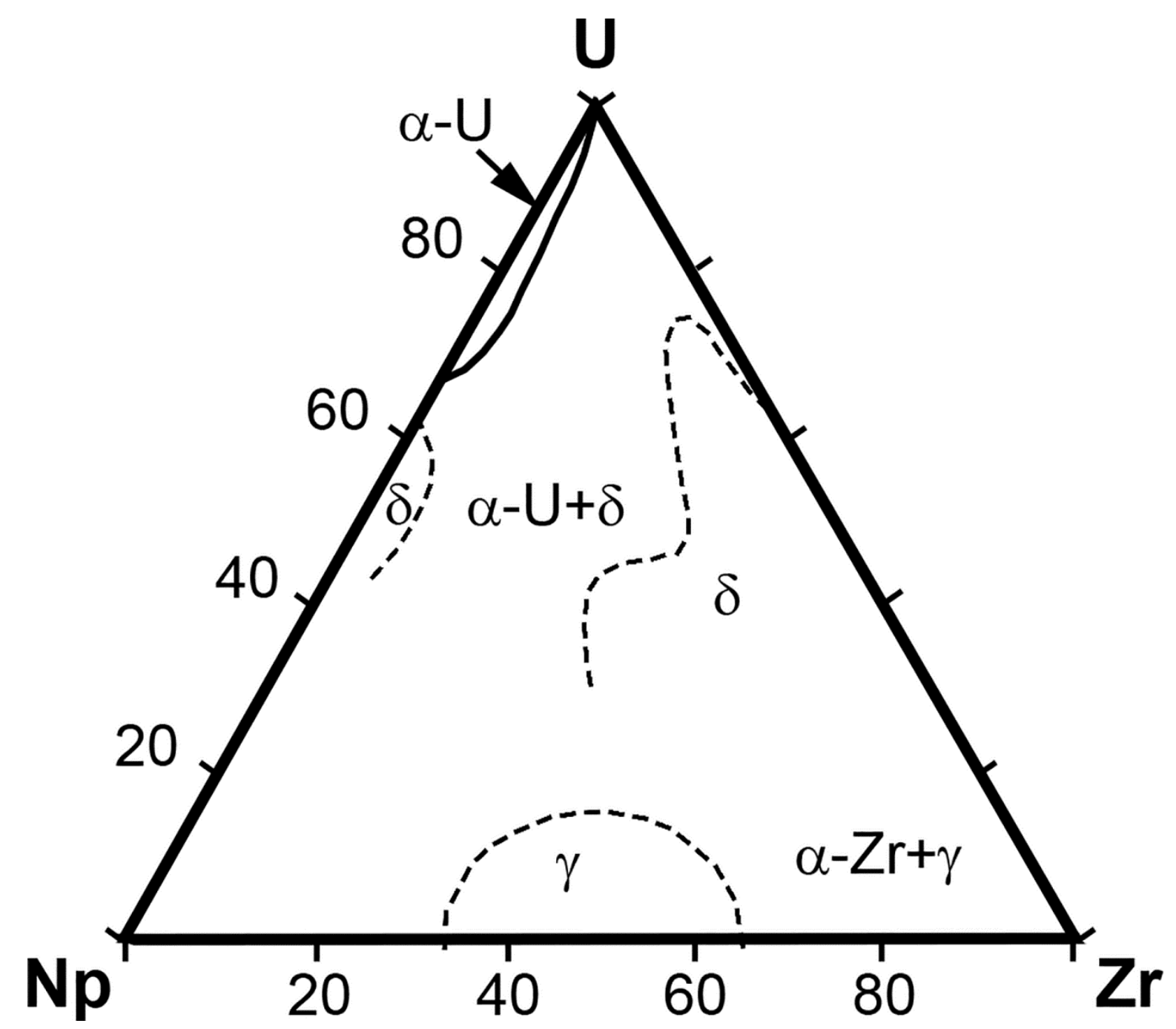

Figure 88: Tentative partial isothermal section of the U-Np-Zr system at $595{ }^{\circ} \mathrm{C}$ suggested by Rodríguez et al. [285] 


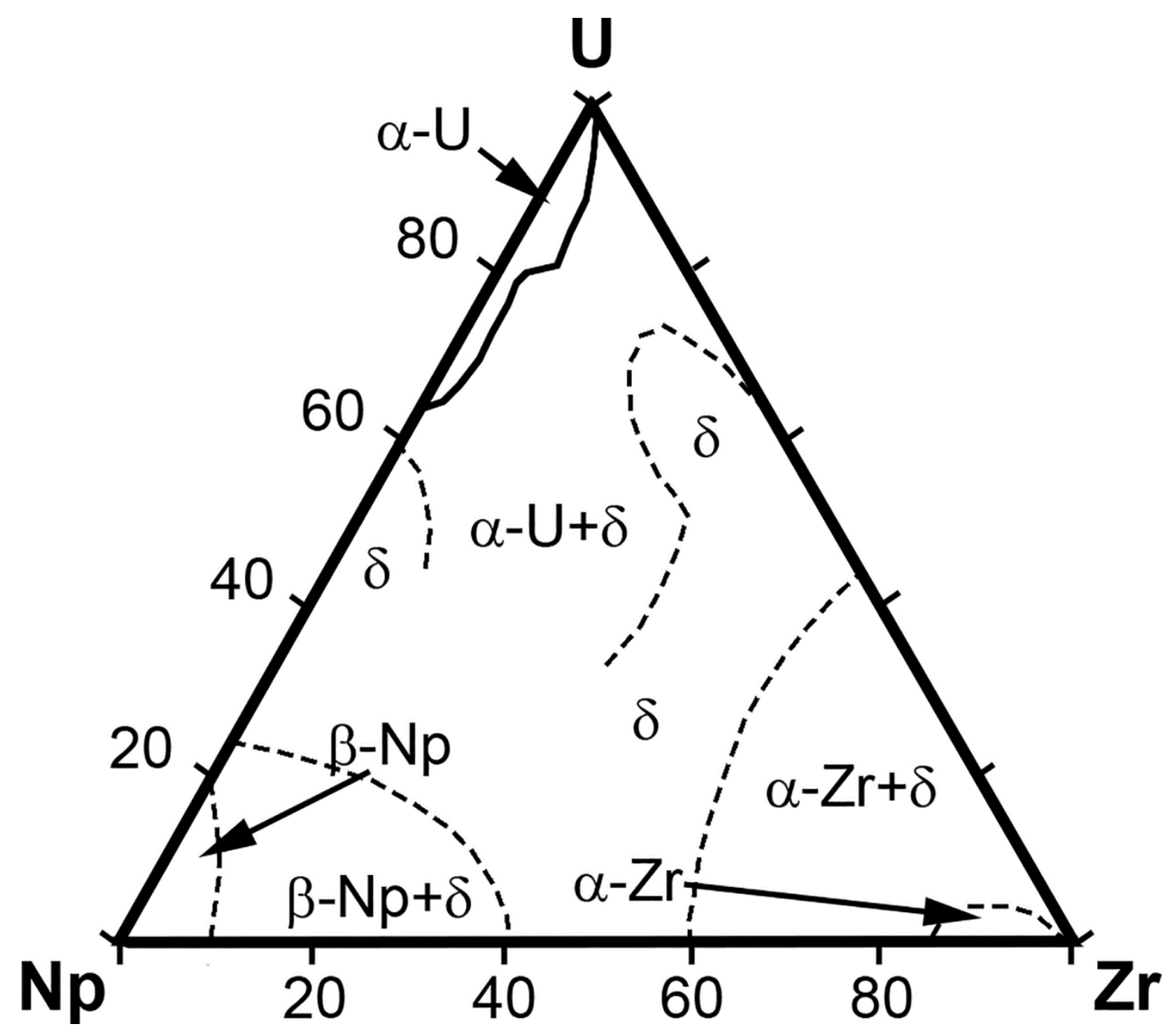

Figure 89: Tentative partial isothermal section of the U-Np-Zr system at $520{ }^{\circ} \mathrm{C}$ suggested by Rodríguez et al. [285]

\subsubsection{U-Pu-Am}

\subsubsection{Introduction}

Although some information on the U-Pu, U-Am, and Pu-Am binary systems is presented in Sections 3.1.6, 4.1.8, and 4.1.19, there is apparently no published experimental data on ternary phases in the U-PuAm system. The system was modeled by Ogawa [110], Kurata [250], and Perron et al. [112]. All three models agree that incorporation of $\mathrm{Pu}$ increases the mutual solubility of high-U and high-Am liquids. However, there are significant differences between the isothermal sections produced by the models at lower temperatures. Some of these differences probably reflect underlying differences in the phase diagrams for the U-Am and Pu-Am binary systems, neither of which is well known. In the almost total absence of experimental data, the isothermal sections of Perron et al. may be the best available representation of the U-Pu-Am system. Further experimental work is needed.

\subsubsection{Phases and phase transformations}

No information is available. 


\subsubsection{Phase diagrams}

No experimentally determined phase diagrams of the U-Pu-Am system are available. The system was modeled by Ogawa [110], Kurata [250], and Perron et al. [112].

The Ogawa model used "a regular solution model with interaction parameters derived from the Brewer valence bond theory" [110] to calculate a liquidus projection and an isotherm at $1200 \mathrm{~K}$. Only liquid, fcc, and bcc phases were considered.

Kurata developed a CALPHAD model for the U-Pu-Am system using a consistent database of thermodynamic properties for the U-Np-Pu-Am-Fe-Zr system [57, 250]. Kurata's model included lowtemperature phases not considered in Ogawa's model. Kurata published an isothermal section at $897 \mathrm{~K}$ $\left(624^{\circ} \mathrm{C}\right)$ calculated using this model [250 Figure 8]. Perron et al. calculated additional isothermal sections at $1500,1200,900,600$, and $300 \mathrm{~K}$ using the thermodynamic data published by Kurata [112 Figure 7].

Perron et al. developed a model using CALPHAD for thermodynamic calculations, supplemented by $a b$ initio electronic-structure calculations to determine needed parameters in the absence of experimental data. They used this model to calculate isothermal sections at $1500,1200,900,600$, and $300 \mathrm{~K}$. In view of uncertainties about the existence of a continuous solid solution between $\gamma$-Am and $\varepsilon$-Pu (Section 4.1.19), Perron et al. included two variations: a preferred model with a solid solution and an alternate model with a miscibility gap. Comparison of the isothermal sections from these model variations shows little difference except in high-Pu compositions, and only the model preferred by Perron et al. is considered here.

Figure 90 shows isothermal sections at $1200 \mathrm{~K}$ calculated from the three models. Comparison with binary phase diagrams indicates that the fcc phase is a solid solution that includes $\beta$-Am and that the bcc phase(s) are ternary modifications of the $(\gamma-\mathrm{U}, \varepsilon-\mathrm{Pu})$ solid solution from the U-Pu binary system and (in the Ogawa and Perron sections) the $(\gamma-\mathrm{Am}, \varepsilon-\mathrm{Pu})$ solid solution from the Pu-Am binary system. The Ogawa model shows far more miscibility in ternary compositions than the Kurata and Perron models, and also suggests that addition of $\mathrm{Pu}$ increases miscibility in the bec phase. The isothermal sections from the Kurata and Perron models are similar to one another.
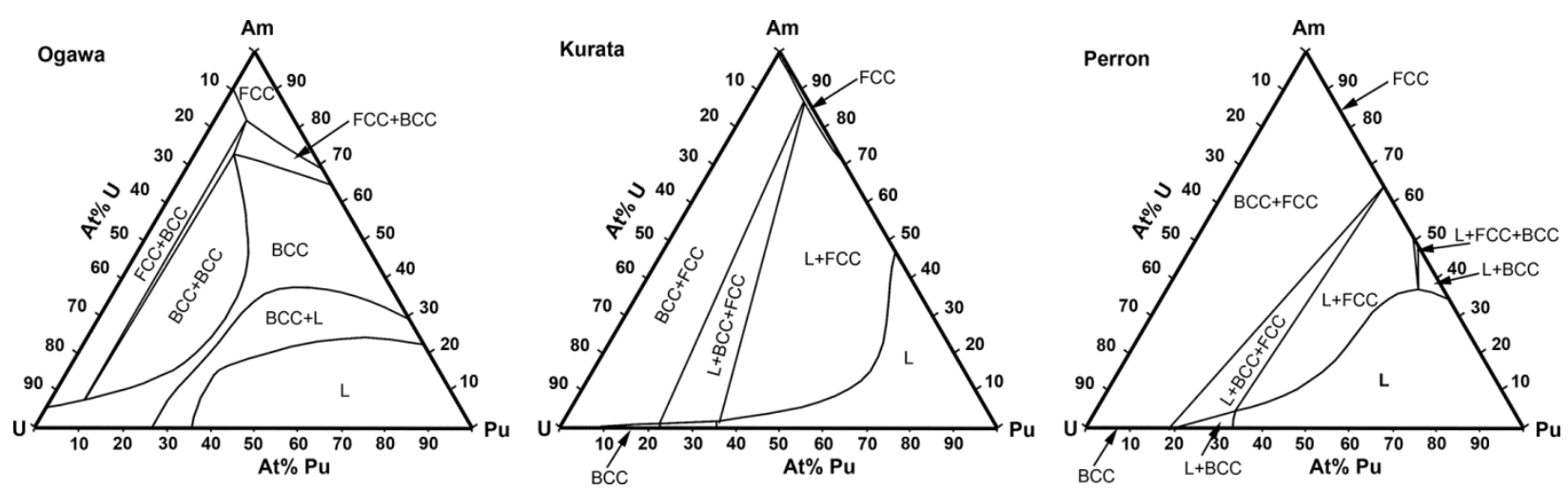

Figure 90. Calculated isothermal sections at $1200 \mathrm{~K}$ based on the models of Ogawa [110], Kurata [250] (as calculated by Perron et al. [112 Figure 7]), and the preferred model of Perron et al. [112 Figure 8].

Figure 91 shows isothermal sections at $900 \mathrm{~K}$ calculated from the Kurata and Perron models. (The Ogawa model considers only liquid, fcc, and bcc phases, and therefore is only appropriate for higher temperatures.) Comparison with binary phase diagrams indicates that the fcc phase is the ( $\beta-\mathrm{Am}, \delta-\mathrm{Pu})$ solid solution with a low concentration of $\mathrm{Pu}$ and the bec phase is the $(\gamma-\mathrm{U}, \varepsilon-\mathrm{Pu})$ solid solution with a low concentration of $\mathrm{Pu} . \eta$ is the $\eta-(\mathrm{U}, \mathrm{Pu})$ solid solution, which appears to have a negligible 
concentration of Am. The isothermal sections are generally similar to one another except for high-Pu compositions, where the phase diagram calculated by Perron et al. from Kurata's model does not match the phase diagram published by Kurata [250 Figure 8] and neither of the isothermal sections published by Perron et al. is entirely consistent with the most commonly accepted U-Pu phase diagram [106].
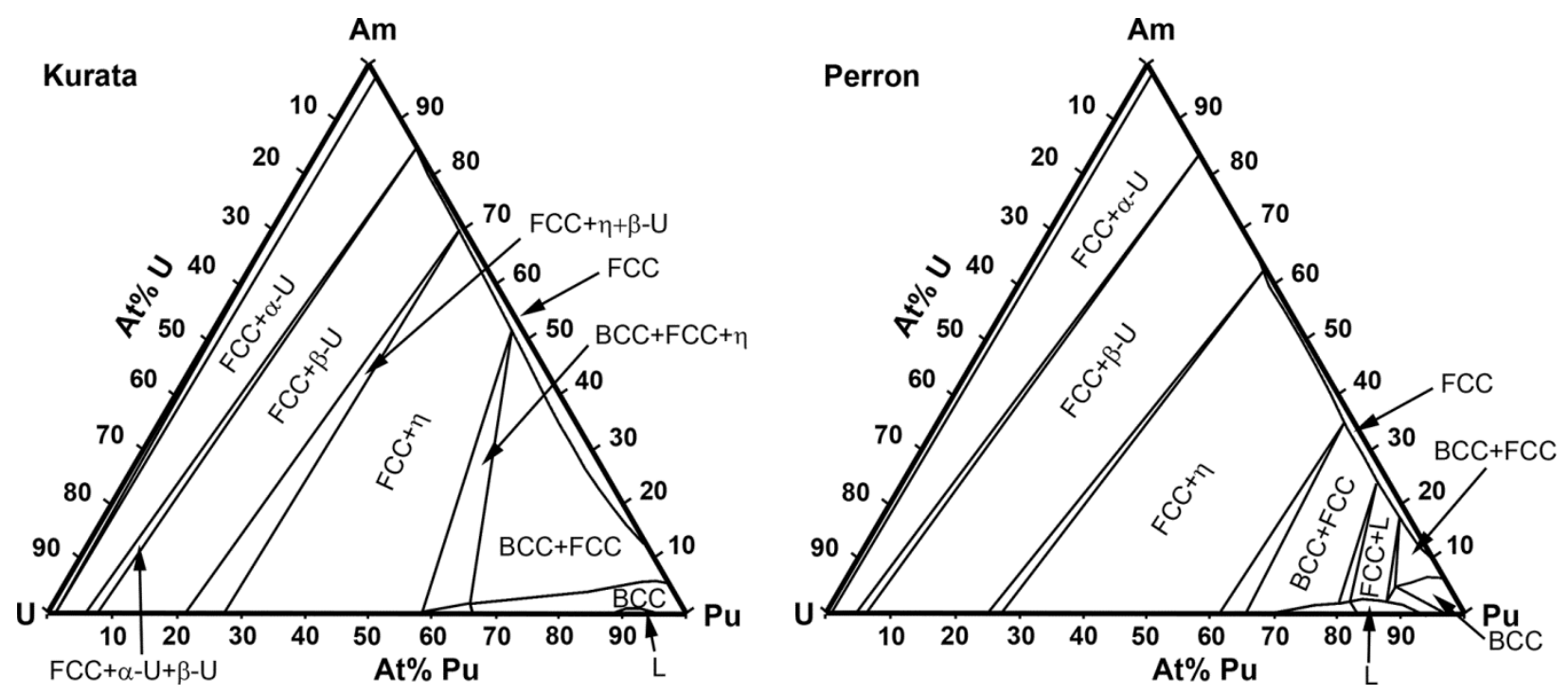

Figure 91. Calculated isothermal sections at $900 \mathrm{~K}$ based on the model of Kurata [250] (as calculated by Perron et al. [112 Figure 7]) and the preferred model of Perron et al. [112 Figure 8].

Figure 92 shows isothermal sections at $600 \mathrm{~K}$ calculated from the Kurata and Perron models. Comparison with binary phase diagrams indicates that the fcc phase is the $(\beta-\mathrm{Am}, \delta-\mathrm{Pu})$ solid solution with a low concentration of $\mathrm{Pu}$, the dhcp phase is $\alpha$-Am with low concentrations of $\mathrm{U}$ and of $\mathrm{Pu}, \eta$ is the $\eta-(\mathrm{U}, \mathrm{Pu})$ solid solution with a negligible concentration of $\mathrm{Am}$, and $\zeta$ is the $\zeta-(\mathrm{U}, \mathrm{Pu})$ solid solution with a negligible concentration of Am. Although the isothermal sections from the Kurata and Perron models both indicate very limited miscibility in this system, definitions of two- and three-phase fields differ significantly. 

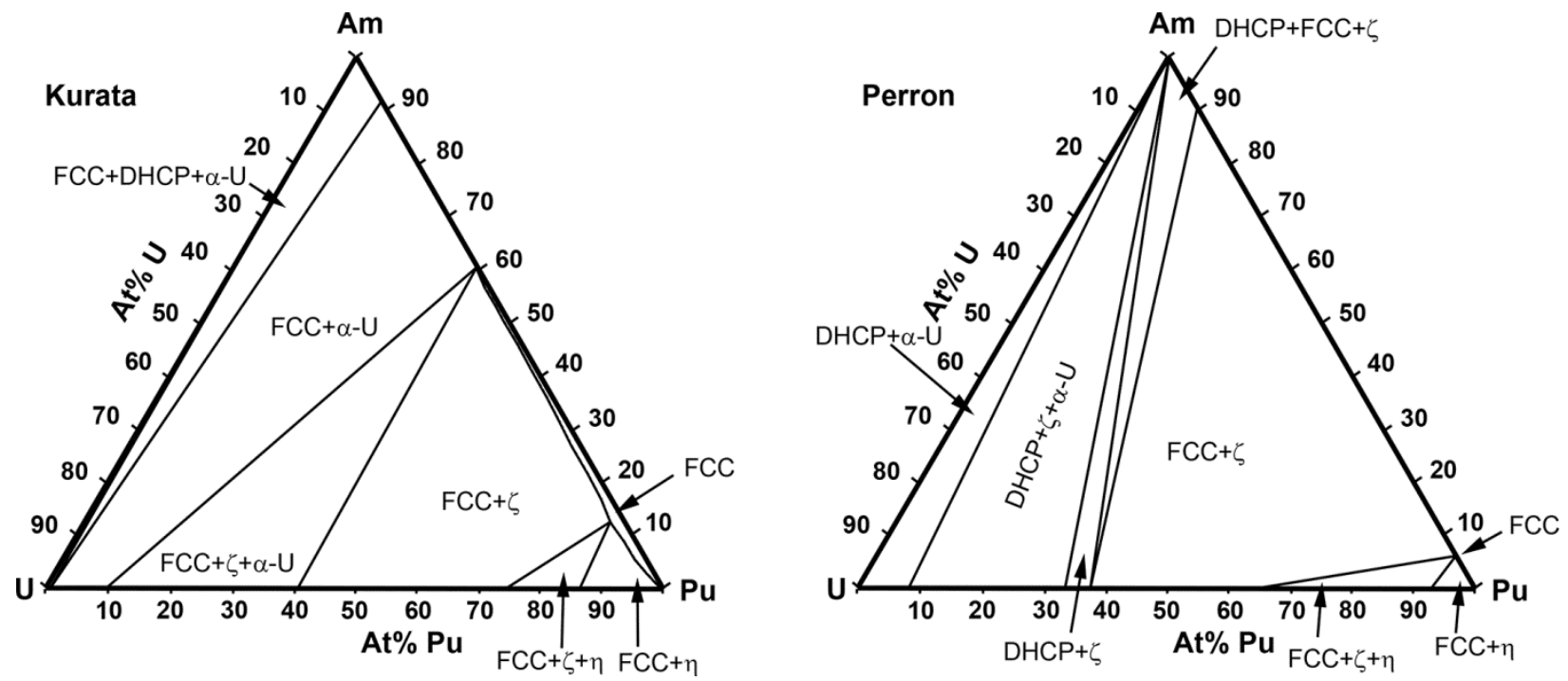

Figure 92. Calculated isothermal sections at $600 \mathrm{~K}$ based on the model of Kurata [250] (as calculated by Perron et al. [112 Figure 7]) and the preferred model of Perron et al. [112 Figure 8].

Figure 93 shows isothermal sections at $300 \mathrm{~K}$ calculated from the Kurata and Perron models. Comparison with binary phase diagrams indicates that the fcc phase is the $(\beta-\mathrm{Am}, \delta-\mathrm{Pu})$ solid solution with a low concentration of $\mathrm{Pu}$, the dhep phase is $\alpha$-Am with low concentrations of $\mathrm{U}$ and of $\mathrm{Pu}$, and $\zeta$ is the $\zeta-(\mathrm{U}, \mathrm{Pu})$ solid solution with a negligible concentration of Am. Although the isothermal sections both indicate very low miscibility in this system, definitions of two- and three-phase fields differ significantly.
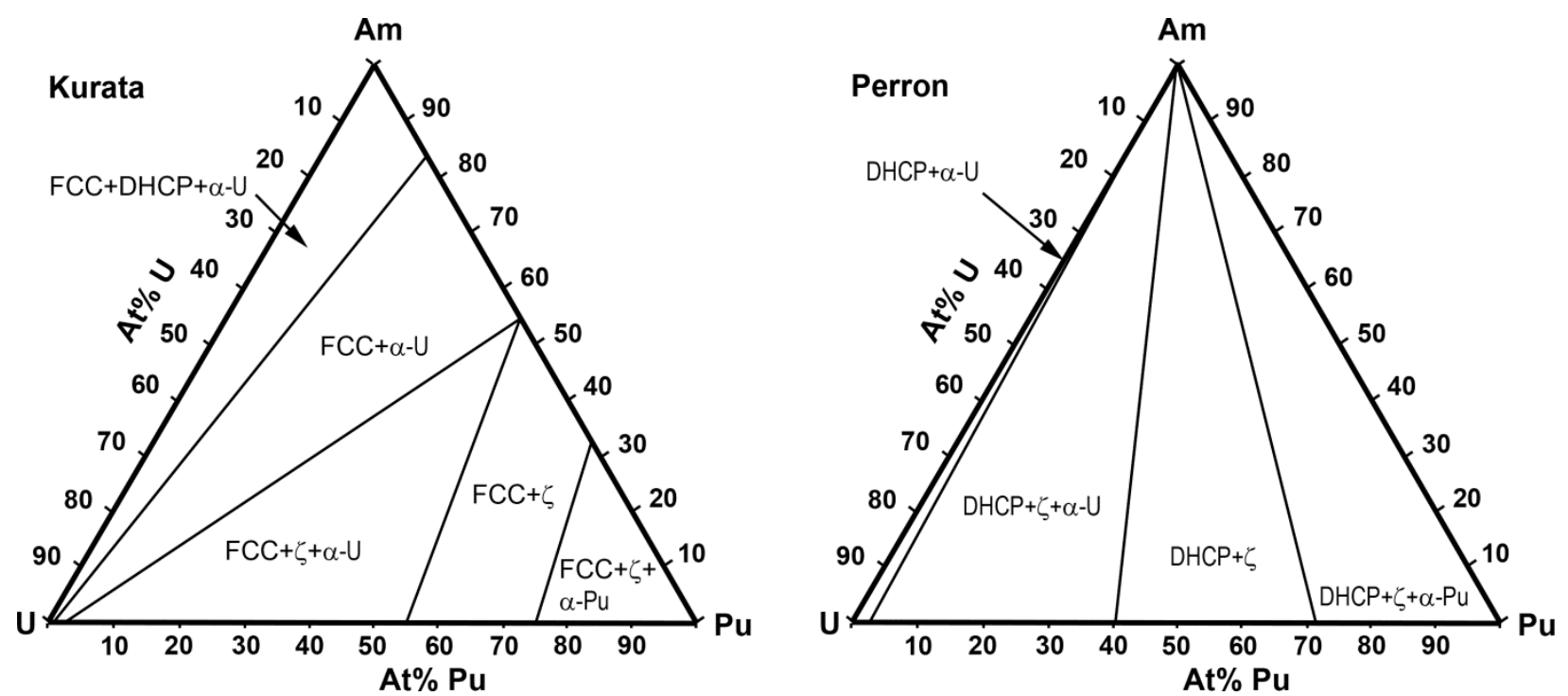

Figure 93. Calculated isothermal sections at $300 \mathrm{~K}$ based on the model of Kurata [250] (as calculated by Perron et al. [112 Figure 7]) and the preferred model of Perron et al. [112 Figure 8]. 


\subsubsection{U-Ce-Zr}

\subsubsection{Introduction}

The available data on U-Ce-Zr phases is from alloys with $10 \mathrm{wt} \% \mathrm{Zr}$ and up to $6 \mathrm{wt} \% \mathrm{Ce}$ [376] and from a diffusion couple involving U-23 at $\% \mathrm{Zr}$ against U-23 at $\% \mathrm{Zr}-1.3$ at $\% \mathrm{Ce}$ [377]. All of these samples indicate that $\mathrm{Ce}$ forms discrete precipitates in a U-Zr matrix, and that miscibility between the precipitates and matrix is extremely limited.

As these results are consistent with data showing that rare-earth elements occur as discrete precipitates in more complex alloys of actinides with rare-earth elements and zirconium (e.g., [126, 279283], further research on this phase diagram is unlikely to produce results of interest for nuclear fuels.

\subsubsection{Phases and phase transformations}

Because of the limited miscibility of Ce with U-Zr alloys, it seems reasonable to assume that phases in these alloys will be similar to those in Ce and in $\mathrm{U}-\mathrm{Zr}$ alloys (Sections 4.1.4 and 3.1.4, respectively).

\subsubsection{Phase diagrams}

No phase diagrams are available.

\subsubsection{Np-Pu-Am}

\subsubsection{Introduction}

Although some information on the $\mathrm{Np}-\mathrm{Pu}, \mathrm{Np}-\mathrm{Am}$, and $\mathrm{Pu}-\mathrm{Am}$ binary systems is available in Sections 4.1.13, 4.1.14, and 4.1.19, no experimental data on ternary Np-Pu-Am alloys is available. Calculated isothermal sections at 792, 1000, and $1300 \mathrm{~K}$ have been published based on models developed by Ogawa [110] and Kurata [62, 250].

All three of the isothermal sections suggest limited solid-phase miscibility except in alloys with low concentrations of $\mathrm{Np}$. However, further work is clearly needed before any of the published $\mathrm{Np}-\mathrm{Pu}-\mathrm{Am}$ isothermal sections can be considered as more than preliminary.

\subsubsection{Phases and phase transformations}

No information is available.

\subsubsection{Phase diagrams}

Calculated isothermal sections at 792, 1000, and $1300 \mathrm{~K}$ have been published based on models developed by Ogawa [110] and Kurata [62, 250] (Figure 94 and Figure 95).

The Ogawa model used "a regular solution model with interaction parameters derived from the Brewer valence bond theory" [110] to calculate isotherms at 1000 and $1300 \mathrm{~K}$ (Figure 94). Comparison with binary phase diagrams indicates that the fcc phase is the $(\beta-\mathrm{Am}, \delta-\mathrm{Pu})$ solid solution. The bcc phase is the $(\varepsilon-\mathrm{Pu}, \gamma-\mathrm{Am})$ solid solution, whose existence as a continuous solid solution has not been conclusively established from experimental evidence (Section 4.1.19).

Kurata developed a CALPHAD model for the U-Pu-Am system using thermodynamic properties from a consistent database for the U-Np-Pu-Am-Fe-Zr system [57, 250] and calculated an isothermal section at $792 \mathrm{~K}$ for the U-Pu-Am ternary (Figure 95). This model included low-temperature phases not considered in Ogawa's model, as well as experimental data that were not described in detail or published elsewhere. Comparison with binary phase diagrams indicates that the fcc phase is the $(\beta-\mathrm{Am}, \delta$-Pu) solid solution, the bcc phase is $(\varepsilon-\mathrm{Pu})$, and the dhcp phase is $(\alpha-\mathrm{Am})$. Although Kurata's binary Pu-Am phase diagram does not show a continuous solid solution between $\varepsilon$-Pu and $\gamma$-Am, the existence of a bcc phase with the composition shown in this isothermal section is consistent with all of the experimental data and models. 
Ogawa $1300 \mathrm{~K}$

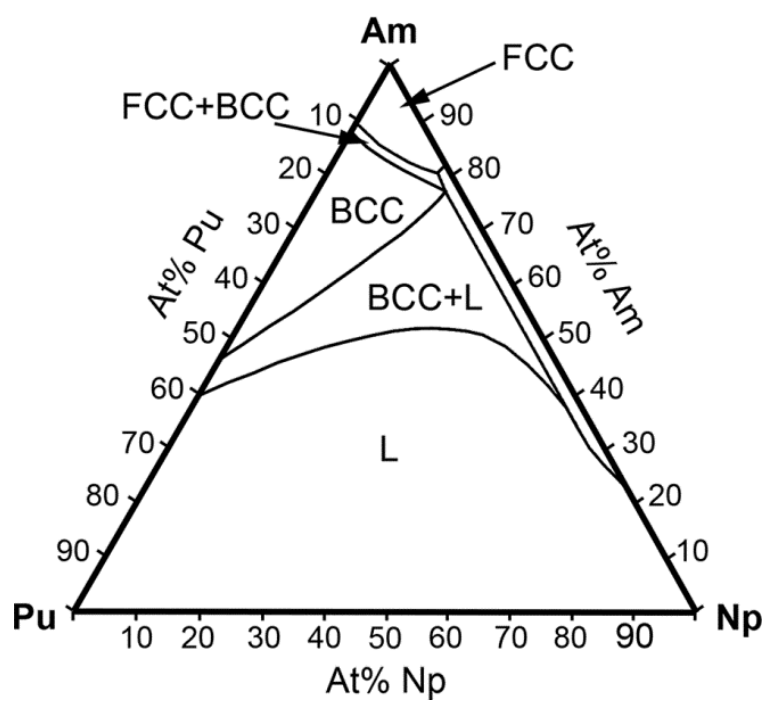

Ogawa $1000 \mathrm{~K}$

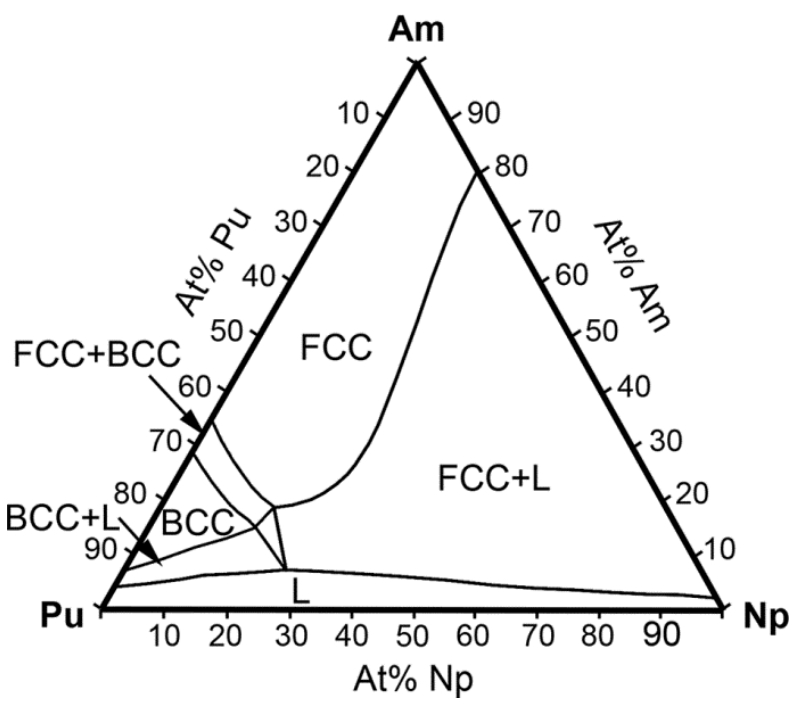

Figure 94. Isothermal sections calculated by Ogawa [110]

Kurata $792 \mathrm{~K}$

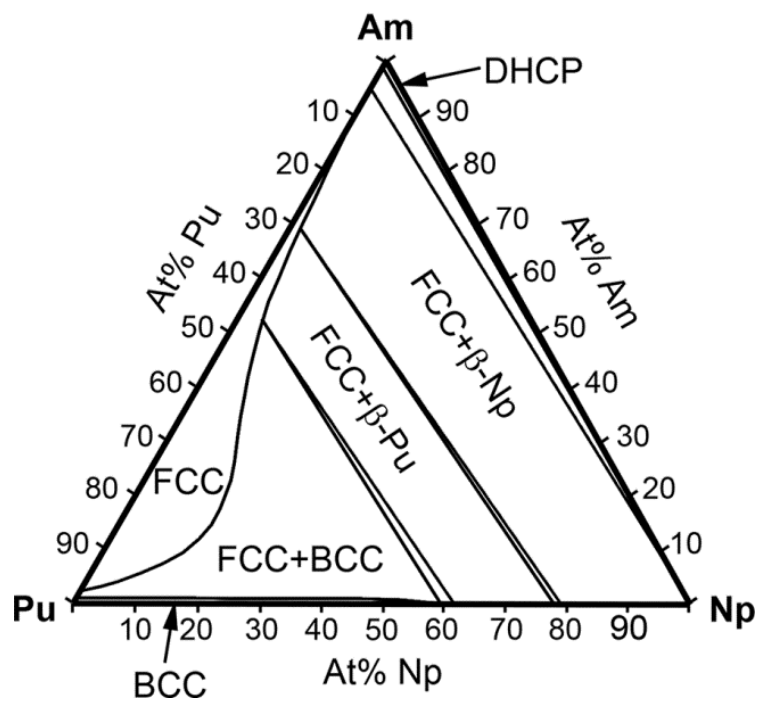

Figure 95. Isothermal section calculated by Kurata $[62,250]$

\subsubsection{Np-Pu-Zr}

\subsubsection{Introduction}

All of the available data on phases in $\mathrm{Np}-\mathrm{Pu}-\mathrm{Zr}$ alloys is from a small number of samples of an alloy with nominal composition with $50 \mathrm{wt} \% \mathrm{Pu}, 10 \mathrm{wt} \% \mathrm{~Np}$ and $40 \mathrm{wt} \% \mathrm{Zr}(\sim 30$ at $\% \mathrm{Pu}, 6$ at $\% \mathrm{~Np}$, and 64 at $\% \mathrm{Zr}$ ) that was studied at Idaho National Laboratory [378-381].

No phase diagrams of this system are available, and further work on this system is clearly required. 


\subsubsection{Phases and phase transformations}

X-ray diffraction data showed two phases in the Pu-10Np-40Zr alloys. These phases, with tentative identifications, are:

- $\delta$-(Np,Pu,Zr): Face-centered cubic phase similar to $\delta$-Pu with lattice parameter $a=4.57 \AA$ [378]. The lattice parameter of $45.5 \mathrm{pm}$ in reference [379] is smaller than the atomic radii of $\mathrm{Np}, \mathrm{Pu}$, and $\mathrm{Zr}$ [382], and is not plausible.

- $\delta$-(Np,Pu) $\mathrm{Zr}_{2}$ : Hexagonal phase with lattice parameters $a=5.07 \AA$ and $c=3.01 \AA$ and a structure similar to that of $\delta-\mathrm{UZr}_{2}, \delta-\mathrm{NpZr}_{2}$, and $\kappa-\mathrm{PuZr}_{2}$ [378]. Lattice parameters of 50.6 and $31.2 \mathrm{pm}$ in reference [379] are smaller than the atomic radii of $\mathrm{Np}, \mathrm{Pu}$, and $\mathrm{Zr}$ [382], and are not plausible.

These suggested compositions of these phases are based on SEM data showing that $\mathrm{Np}, \mathrm{Pu}$, and $\mathrm{Zr}$ are present throughout the material. However, SEM images such as [379 Figure 2] suggest that the sample may be too fine-grained for accurate analysis of individual phases.

\subsubsection{Phase diagrams}

No phase diagrams are available.

\subsubsection{Pu-Am-Zr}

\subsubsection{Introduction}

All of the published data on phases in $\mathrm{Pu}-\mathrm{Am}-\mathrm{Zr}$ alloys is from an alloy with $48.5 \mathrm{wt} \% \mathrm{Pu}, 11.9 \mathrm{wt} \%$ Am, and $40.9 \mathrm{wt} \% \mathrm{Zr}$ that was investigated at Idaho National Laboratory [383-385].

No phase diagrams of this system are available, and further work is clearly required.

\subsubsection{Phases and phase transformations}

$\mathrm{X}$-ray diffraction data suggest that the alloy consists primarily of a single fcc phase with lattice parameter $a=4.57 \AA$ [385]. (The lattice parameter of $45.7 \mathrm{pm}$ in some references [383, 386] is smaller than the atomic radii of $\mathrm{Np}, \mathrm{Pu}$, and $\mathrm{Zr}$ [382], and is not plausible.) This phase has been tentatively identified as a solid solution between $\delta$-(Pu, Zr) and $(\beta-A m)$.

DSC/DTA and TMA data showed a reversible phase transformation at $\sim 700{ }^{\circ} \mathrm{C}$, which was tentatively interpreted as a transition between the fcc solid solution and a bcc solid solution. There was no evidence for melting at temperatures up to $1000^{\circ} \mathrm{C}[381,383]$.

Although both of these interpretations seem plausible, further work is required to understand the relationships between the ternary solid solutions suggested by the $\mathrm{Pu}-\mathrm{Am}-\mathrm{Zr}$ data and the reported limited miscibility of Am with $\mathrm{Zr}$ and perhaps $\mathrm{Pu}$ (Section 4.1.26 and 4.1.19)

\subsubsection{Phase diagrams}

No phase diagrams are available.

\subsection{HEAT CAPACITY AND RELATED PROPERTIES (ENTROPY, ENTHALPY, SPECIFIC HEAT CAPACITY)}

\subsubsection{Np}

\subsubsection{Introduction}

Experimental data on the heat capacity of $\alpha$-Np at temperatures above $300 \mathrm{~K}$ are available in two publications, which are in good agreement at the single temperature they have in common. As experimental measurements of the heat capacity of $\beta-\mathrm{Np}, \gamma-\mathrm{Np}$, and liquid $\mathrm{Np}$ are not available, these properties are commonly approximated by analogy to those of $\mathrm{U}$ and $\mathrm{Pu}$ phases. 
Further experimental measurements are clearly needed.

\subsubsection{Heat Capacities of Solid and Liquid Phases}

Two publications $[387,388]$ report experimental measurements of the heat capacity of $\alpha$-Np. One of these publications (by Eldred and Curtis) is a half-page letter that reports the average heat capacity between 20 and $99{ }^{\circ} \mathrm{C}(293$ and $372 \mathrm{~K})$ as $0.0319 \mathrm{cal} / \mathrm{g} \cdot{ }^{\circ} \mathrm{C}(\sim 31.65 \mathrm{~J} / \mathrm{mol} \cdot \mathrm{K})$ [387]. The other publication (by Evans and Mardon) reports heat capacities at five temperatures between 60 and $207{ }^{\circ} \mathrm{C}(333$ and 480 $\mathrm{K})$ [388]. The publications are in good agreement about the heat capacity of $\mathrm{Np}$ at the single temperature they have in common $\left(\sim 62^{\circ} \mathrm{C}\right)$.

Konings and Beneš [2] expanded the work of Evans and Mardon [388] to other temperatures by fitting a quadratic equation to their data (Figure 96, Equation 79). The heat capacity at $298 \mathrm{~K}(29.63$ $\mathrm{J} / \mathrm{mol}-\mathrm{K})$ is the same as earlier estimates by Oetting et al. $[4,19]$, which were based on the same experimental data.

Equation 79. Heat capacity of $\alpha-\mathrm{Np}[2]$

$$
\mathrm{C}_{\mathrm{p}}=30.132-36.2372 \times 10^{-3} \mathrm{xT}+115.89 \times 10^{-6} \times \mathrm{T}^{2}
$$

where $\mathrm{C}_{\mathrm{p}}$ is constant-pressure heat capacity in $\mathrm{J} / \mathrm{mol} \cdot \mathrm{K}$ and $\mathrm{T}$ is temperature in $\mathrm{K}$

In the absence of experimental data, heat-capacity values for $\beta$-Np and $\gamma$-Np have been estimated based on analogies to $\mathrm{U}$ and $\mathrm{Pu}$ phases with similar crystallographic characteristics (e.g., [2, 4]. For example, the heat capacity of $\beta-\mathrm{Np}$ is estimated from the heat capacities of $\delta$ '-Pu and $\beta-\mathrm{U}$ because all three phases are tetragonal, and the heat capacity of $\gamma-\mathrm{Np}$ is estimated from the heat capacities of $\varepsilon-\mathrm{Pu}$ and $\gamma-U$ because all three phases have body-centered cubic structures.

Using this approach, Konings and Beneš estimated the heat capacity of $\beta$-Np as $40 \mathrm{~J} / \mathrm{mol}-\mathrm{K}$, the heat capacity of $\gamma-\mathrm{Np}$ as $36 \mathrm{~J} / \mathrm{mol}-\mathrm{K}$, and the heat capacity of liquid $\mathrm{Np}$ as $46 \mathrm{~J} / \mathrm{mol}-\mathrm{K}$ [2].

Although estimating the heat capacity of $\mathrm{Np}$ based on properties of structurally similar phases of other elements is perhaps the best experimentally based approach given the available data, it has at least two significant disadvantages:

- It involves comparisons between materials with different space groups at different temperatures (Figure 97).

- It depends on the heat capacities of $\beta-\mathrm{U}, \gamma-\mathrm{U}, \delta^{\prime}-\mathrm{Pu}, \varepsilon-\mathrm{Pu}$, liquid $\mathrm{U}$, and liquid $\mathrm{Pu}$. Some of these heat capacities are also poorly known.

Heat capacities of $\alpha$-Np and $\beta-\mathrm{Np}$ were recently modeled by Filanovich and Povzner [389]. Although this paper apparently used only data from temperatures below $300 \mathrm{~K}$, its results for $\alpha$-Np appear comparable to the polynomial suggested by Konings and Beneš (Equation 79). The modeled heat capacity of $\beta-\mathrm{Np}$ increases with temperature, with an average value that is similar to the constant value suggested by Konings and Beneš. 


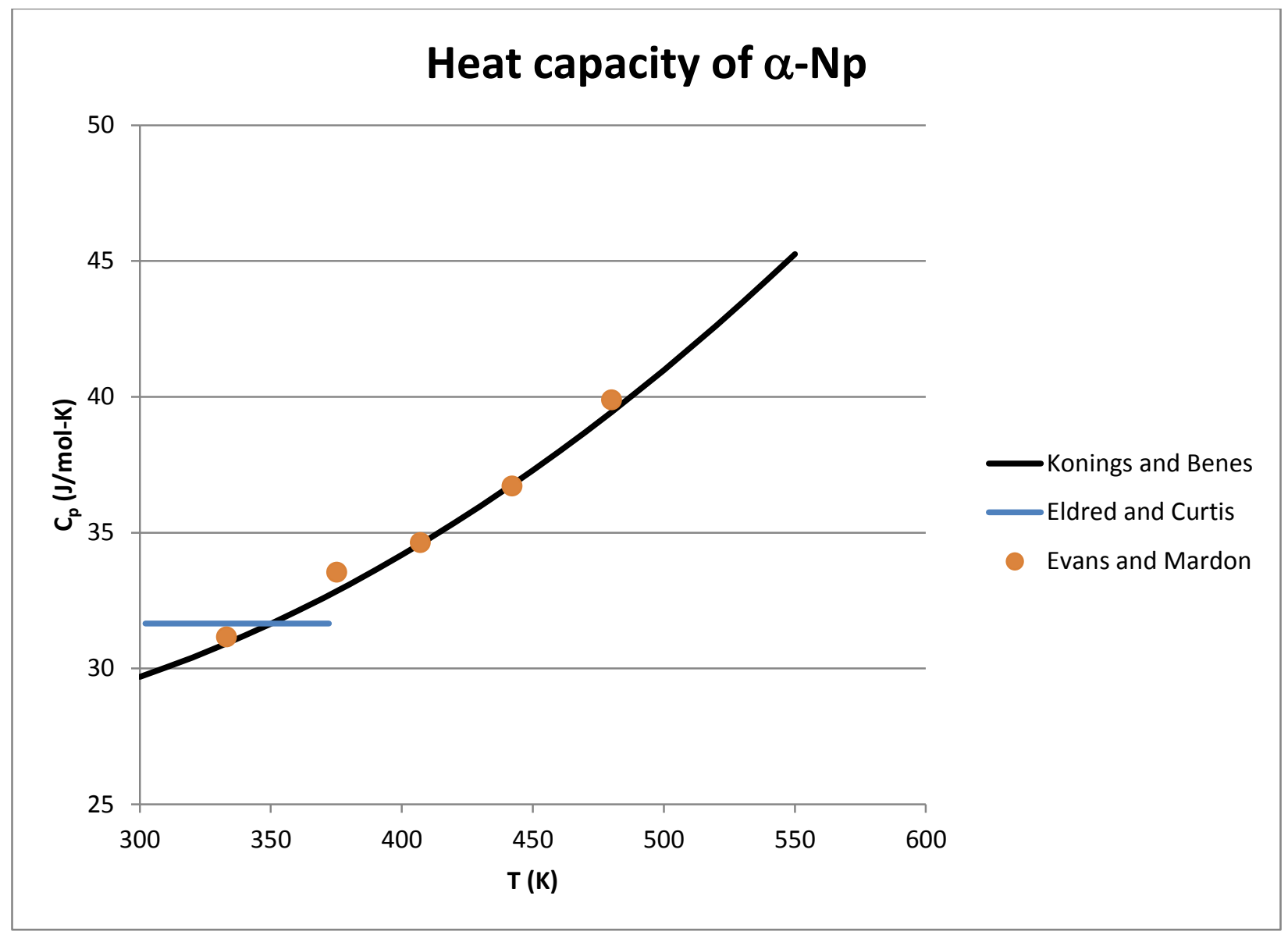

Figure 96. Heat capacity of $\alpha-\mathrm{Np}[2,387,388]$ 


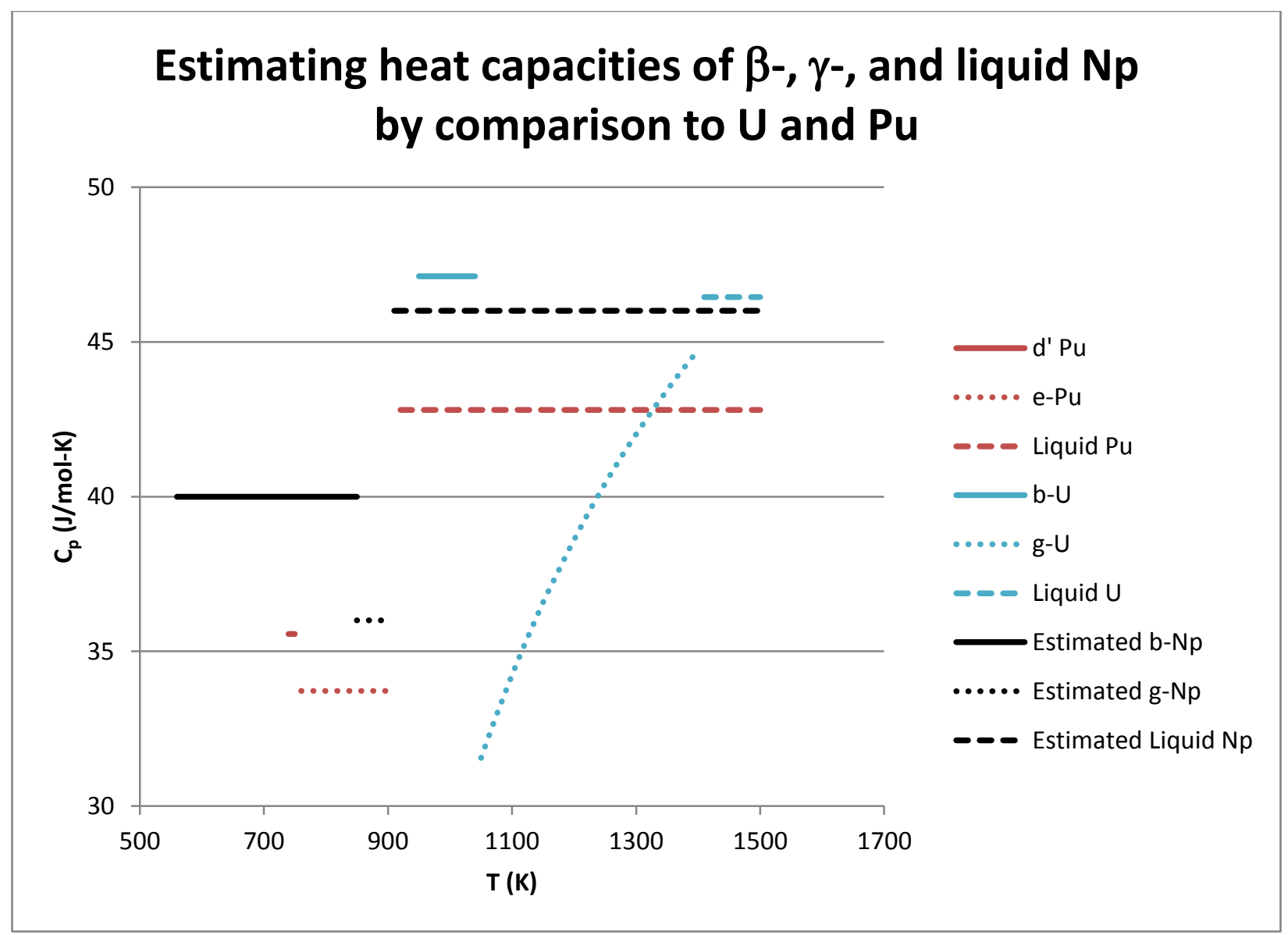

Figure 97. Estimated heat capacities of $\beta-, \gamma$-, and liquid $\mathrm{Np}$, with the heat capacities of $U$ and $\mathrm{Pu}$ phases on which the estimates are based. Heat-capacity values for $\mathrm{Np}$ are from Konings \& Beneš [2]. Solid lines indicate tetragonal phases (space groups $P 42{ }_{1} 2$ for $\beta-\mathrm{Np}, P 42 \mathrm{mnm}$ for $\beta-\mathrm{U}$, and $I 4 / \mathrm{mmm}$ for $\delta$ '-Pu), dotted lines indicate bcc phases (space group $\operatorname{Im} \overline{\mathbf{3}} \boldsymbol{m}$ ), and dashed lines indicate liquids.

\subsubsection{Am}

\subsubsection{Introduction}

Although the heat capacity of three Am samples has been experimentally determined at $298 \mathrm{~K}$ [390], experimental heat-capacity measurements at higher temperatures are not available. Several estimates of higher-temperature heat capacities have been published [4, 19, 391, 392], but all rely on interpretation of the low-temperature data and reasoning by analogy to rare-earth elements.

Povzner et al. [393] calculated the electron contribution to the heat capacity of Am, obtaining good agreement with the low-temperature experimental data of Hall et al. [394].

Further experimental data at temperatures of interest for nuclear fuels is clearly required.

\subsubsection{Heat Capacities of Solid and Liquid Phases}

Hall and colleagues [390, 394] measured the specific heats of two samples of ${ }^{241} \mathrm{Am}$ and one sample of ${ }^{243} \mathrm{Am}$ from 15 to $300 \mathrm{~K}$. They originally reported the constant-pressure heat capacity of Am at $298 \mathrm{~K}$ as $28 \mathrm{~J} / \mathrm{mol}-\mathrm{K}$, but later decreased this value to $25.5 \mathrm{~J} / \mathrm{mol}-\mathrm{K}$ based on a more careful analysis of the original measurements [394]. Values accepted by later researchers (e.g., references [4, 19, 202, 391, 392]) differ slightly, but all are between $\sim 25.0$ and $25.8 \mathrm{~J} / \mathrm{mol}-\mathrm{K}$ for $\alpha$-Am at $298 \mathrm{~K}$. 
There are no published experimental measurements of the heat capacity of Am at temperatures above $300 \mathrm{~K}$. Three approaches have been used to estimate it:

- Analogies to heat capacities of phases of lanthanides (primarily La) with crystal structures similar to Am phases. This approach was adopted by Oetting et al., [4] in a review for the IAEA and accepted in a more recent review by Runde and Schulz [202].

- Ward et al. [19, 395] developed a correlation relating entropy to metallic radius, atomic weight, magnetic properties, and atomic structure. They used this correlation with known properties of $\mathrm{Pr}$ to estimate the entropy of Am at $298 \mathrm{~K}$ as $55.27 \mathrm{~J} / \mathrm{mol}-\mathrm{K}$, in good agreement with a value of 55.4 $\mathrm{J} / \mathrm{mol}-\mathrm{K}$ determined by Hall et al. [394]. Ward et al. did not explain how they estimated heat capacities at other temperatures, although continuing the analogy to Pr seems likely. Silva [391] generally accepted the values of Ward et al., but with small differences at temperatures below $\sim 600 \mathrm{~K}$ to match the low-temperature data better.

- Konings [392] divided the heat capacity of a metal into harmonic, anharmonic, dilatation, electronic, and magnetic contributions. He estimated the heat capacities of $\alpha$-Am and $\beta$-Am by estimating the value of each contribution, combining low-temperature heat-capacity, thermal expansion, compressibility, and energy-level data when available and supplementing by analogy to La when necessary. In the absence of experimental data, Konings estimated heat capacities for $\gamma$-Am and Am liquid based on analyses of trends in the lanthanide elements from La to Gd. This estimate is repeated in later reviews by Konings and colleagues [2, 3]

Figure 98 shows estimated heat capacities obtained using these approaches. There is relatively little difference between the results of Oetting et al. and of Ward et al. However, the estimates of Konings are significantly different, particularly for $\gamma$-Am and Am liquid. Further measurements are clearly required. 


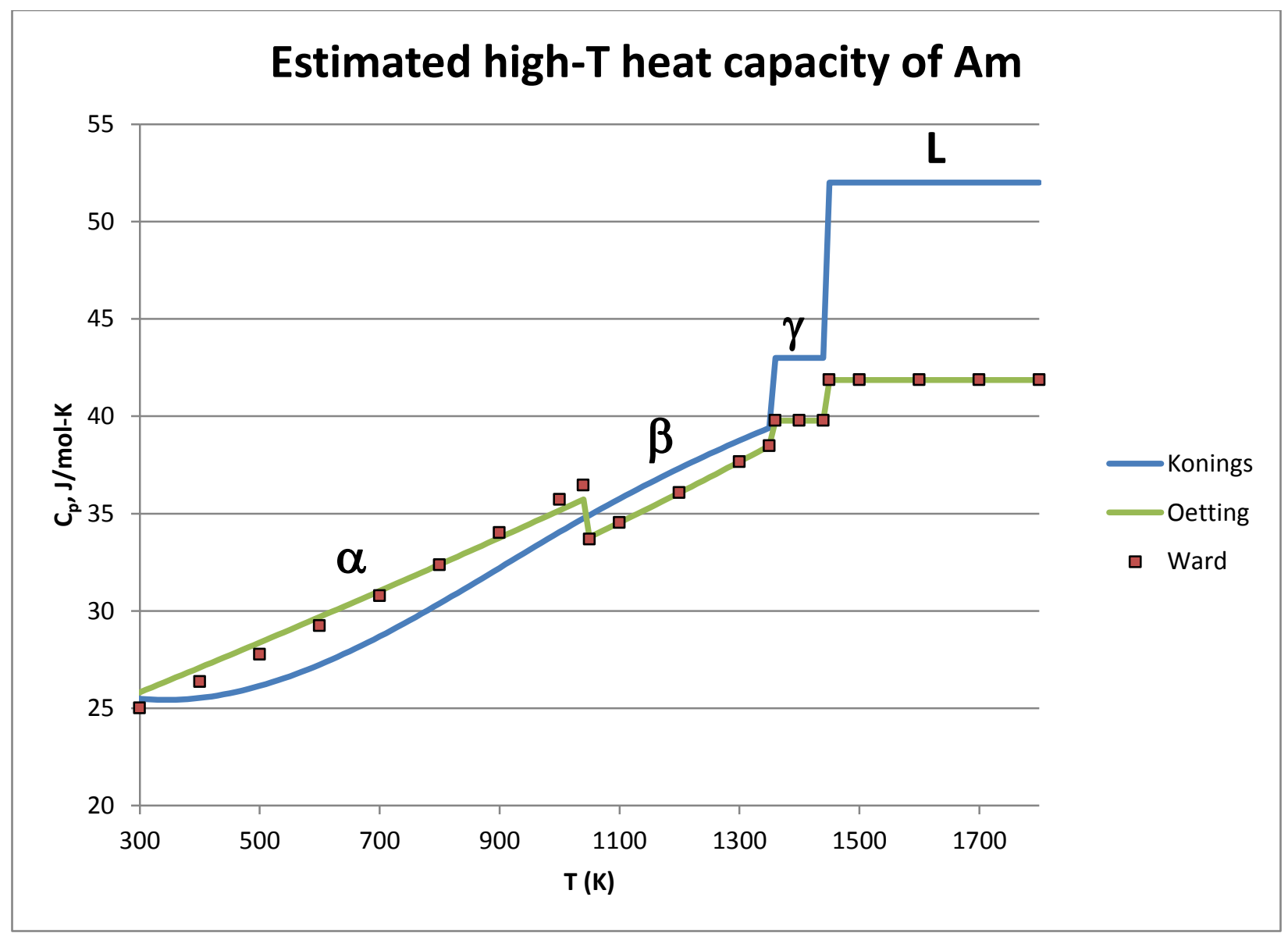

Figure 98. Estimated heat capacity of Am, showing values from Oetting et al. [4], Konings [392], and Ward et al. [19 Table A.6]

\subsubsection{La}

\subsubsection{Introduction}

Three research groups have published measurements of the incremental enthalpy of La at temperatures above $300 \mathrm{~K}$ [396-398], although one of them (reference [397]) indicated that their data was not suitable for determinations of heat capacity. Other research groups have published more direct measurements of heat capacity from a variety of instruments [399-402]. The reported heat capacities vary widely for some phases, and heat capacities determined from incremental enthalpy measurements are consistently below those from other sources.

Konings and Beneš [2] recently assessed the experimental data and developed equations representing heat-capacity values for La. Although further work is desirable to increase confidence that these heatcapacity values are accurate (particularly for $\gamma$-La), the values recommended by Konings and Beneš are the best available approximation.

\subsubsection{Heat Capacities of Solid and Liquid Phases}

Konings and Beneš [2] re-assessed the experimental data and developed equations representing the heat-capacity data for La (Equation 80 through Equation 83). These equations are based primarily on incremental enthalpy data [396, 398], with adjustments to match lower-temperature measurements for $\alpha$ La. As a result of these adjustments, the heat capacity for $\alpha$-La calculated from these equations is somewhat higher than that calculated from the data of Berg et al. [396], but is consistent with the room- 
temperature heat capacity of $\mathrm{La}$ in a recent tabulation $(27.1 \mathrm{~J} / \mathrm{mol}-\mathrm{K})$ [17]. The heat capacities of $\beta$-La and $\gamma$-La in Equation 81 and Equation 82 are very similar to those published by Berg et al. [396], and the heat capacity of the liquid is identical to that published by Stretz and Bautista [398].

Equation 80. Heat capacity of $\alpha-\mathrm{La}[2]$

$\mathrm{C}_{\mathrm{p}}=25.8730+3.5907 \times 10^{-3} \times \mathrm{T}-0.26059 \times 10^{5} \times \mathrm{TT}^{-2}$

where $\mathrm{C}_{\mathrm{p}}$ is constant-pressure heat capacity in $\mathrm{J} / \mathrm{mol} \cdot \mathrm{K}$ and $\mathrm{T}$ is temperature in $\mathrm{K}$

Equation 81. Heat capacity of $\beta$-La (after [2], but with the last coefficient multiplied by $\mathrm{T}$ rather than $\mathrm{T}^{2}$ for consistency with data from Berg et al. [396])

$\mathrm{C}_{\mathrm{p}}=19.9335+12.9990 \times 10^{-3} \mathrm{xT}$

where $\mathrm{C}_{\mathrm{p}}$ is constant-pressure heat capacity in $\mathrm{J} / \mathrm{mol} \cdot \mathrm{K}$ and $\mathrm{T}$ is temperature in $\mathrm{K}$

Equation 82. Heat capacity of $\gamma$-La [2]

$\mathrm{C}_{\mathrm{p}}=39.54$

where $\mathrm{C}_{\mathrm{p}}$ is constant-pressure heat capacity in $\mathrm{J} / \mathrm{mol} \cdot \mathrm{K}$

Equation 83. Heat capacity of La liquid $\left(\mathrm{C}_{\mathrm{p}}\right.$ in $\left.\mathrm{J} / \mathrm{mol}-\mathrm{K}\right)$ [2]

$\mathrm{C}_{\mathrm{p}}=32.66$

where $\mathrm{C}_{\mathrm{p}}$ is constant-pressure heat capacity in $\mathrm{J} / \mathrm{mol} \cdot \mathrm{K}$

Figure 99 shows the experimentally determined heat capacities and the values recommended by Konings and Beneš [2]. 


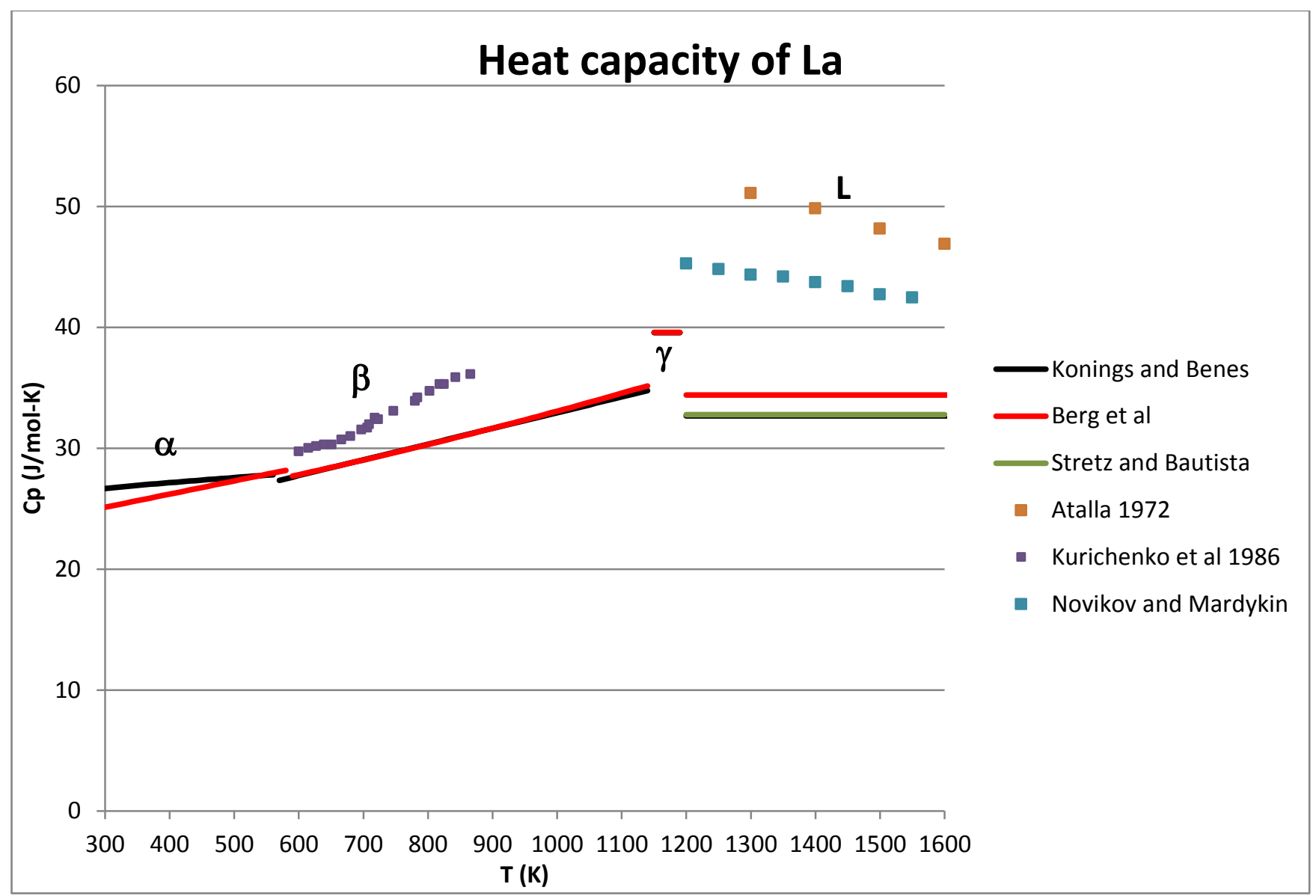

Figure 99. Heat capacity of La (references [396, 398, 399, 401, 402] and Equation 80, Equation 81, Equation 82, and Equation 83))

\subsubsection{Ce}

\subsubsection{Introduction}

A number of research groups have published values for the heat capacity of Ce above room temperature [399, 402-404]. There is generally good agreement about the heat capacity of $\gamma$-Ce and $\delta$-Ce, but not about the heat capacity of the liquid.

Konings and Beneš [2] recently assessed the experimental data and developed equations representing heat-capacity values for Ce (Equation 84, Equation 85, Equation 86, and Equation 87). Their recommendations match the available data for $\gamma$-Ce and $\delta$-Ce, and seem a reasonable approximation for the heat capacity of liquid Ce.

\subsubsection{Heat Capacities of Solid and Liquid Phases}

Spedding et al. [403] published measurements of the incremental enthalpy of Ce from room temperature to $1100{ }^{\circ} \mathrm{C}$, and Kuntz and Bautista [404] published incremental enthalpy measurements for liquid Ce between $\sim 1400$ and $2500 \mathrm{~K}$. Both of these research groups used their enthalpy measurements to calculate heat capacities, which they fitted with equations. Kurichenko et al. [402] published measurements of heat capacity from 600 to $792 \mathrm{~K}$, and Atalla [399] published heat capacity measurements of liquid Ce. 
Kuntz and Bautista [404] represented their heat capacity data for liquid Ce with two equations: a linear function of temperature from $\sim 1400$ and $1700 \mathrm{~K}$, and a constant from 1700 to $2500 \mathrm{~K}$ (Equation 88, Equation 89). They suggested that differences in heat capacities in these two temperature ranges might indicate a change in the clustering of atoms in the liquid as temperature increased. Konings and Beneš suggested an alternative, in which they used a single polynomial to fit the data of Kuntz and Bautista for all temperatures between the melting point and $2500 \mathrm{~K}$ (Equation 86), then assumed that the heat capacity was constant above that temperature (Equation 87). Further research is needed to determine which of these possibilities best represents the actual behavior of liquid $\mathrm{Ce}$.

All of these heat capacity measurements are shown in Figure 100. The heat capacity measurements of Kurichenko et al. and Spedding et al. are similar, and the measurements of Atalla are similar to those of Kuntz and Bautista for the temperature ranges in which they overlap. Despite the large differences in heat capacity values for liquid $\mathrm{Ce}$ in the measurements of Kuntz et al. and Spedding et al., the measured incremental enthalpies published by these researchers are similar.

Equation 84. Heat capacity of $\gamma$-Ce between 373 and $998 \mathrm{~K}$ [2]

$$
\mathrm{C}_{\mathrm{p}}=20.8689+16.8508 \times 10^{-3} \mathrm{xT}+0.98410 \times 10^{5} \mathrm{xT}^{-2}
$$

where $\mathrm{C}_{\mathrm{p}}$ is constant-pressure heat capacity in $\mathrm{J} / \mathrm{mol} \cdot \mathrm{K}$, $\mathrm{T}$ is temperature in $\mathrm{K}$, and $\mathrm{T}$ is between 373 and $998 \mathrm{~K}$

Equation 85. Heat capacity of $\delta$-Ce between 998 and $1070 \mathrm{~K}$ [2]

$\mathrm{C}_{\mathrm{p}}=37.85$

where $\mathrm{C}_{\mathrm{p}}$ is constant-pressure heat capacity in $\mathrm{J} / \mathrm{mol} \cdot \mathrm{K}$

Equation 86. Heat capacity of Ce liquid between 1070 and $2500 \mathrm{~K}$ [2]

$\mathrm{C}_{\mathrm{p}}=18.7747+3.3867 \times 10^{-3} \mathrm{xT}+2.7240 \times 10^{7} \times \mathrm{T}^{-2}$

where $\mathrm{C}_{\mathrm{p}}$ is constant-pressure heat capacity in $\mathrm{J} / \mathrm{mol} \cdot \mathrm{K}, \mathrm{T}$ is temperature in $\mathrm{K}$, and $\mathrm{T}$ is between 1700 and $2500 \mathrm{~K}$

Equation 87. Heat capacity of Ce liquid above $2500 \mathrm{~K}$ [2]

$\mathrm{C}_{\mathrm{p}}=31.6$

where $\mathrm{C}_{\mathrm{p}}$ is constant-pressure heat capacity in $\mathrm{J} / \mathrm{mol} \cdot \mathrm{K}$

Equation 88. Heat capacity of Ce liquid between 1400 and $1700 \mathrm{~K}$ [404]

$\mathrm{C}_{\mathrm{p}}=-0.0251 \mathrm{xT}+75.305$

where $C_{p}$ is constant-pressure heat capacity in $\mathrm{J} / \mathrm{mol} \cdot \mathrm{K}, \mathrm{T}$ is temperature in $\mathrm{K}$, and $\mathrm{T}$ is between 1400 and $1700 \mathrm{~K}$

Equation 89. Heat capacity of Ce liquid between 1700 and $2500 \mathrm{~K}$ [404]

$\mathrm{C}_{\mathrm{p}}=18.7747+3.3867 \times 10^{-3} \mathrm{xT}+2.7240 \times 10^{7} \mathrm{xT}^{-2}$

where $\mathrm{C}_{\mathrm{p}}$ is constant-pressure heat capacity in $\mathrm{J} / \mathrm{mol} \cdot \mathrm{K}$, $\mathrm{T}$ is temperature in $\mathrm{K}$, and $\mathrm{T}$ is between 1700 and $2500 \mathrm{~K}$ 


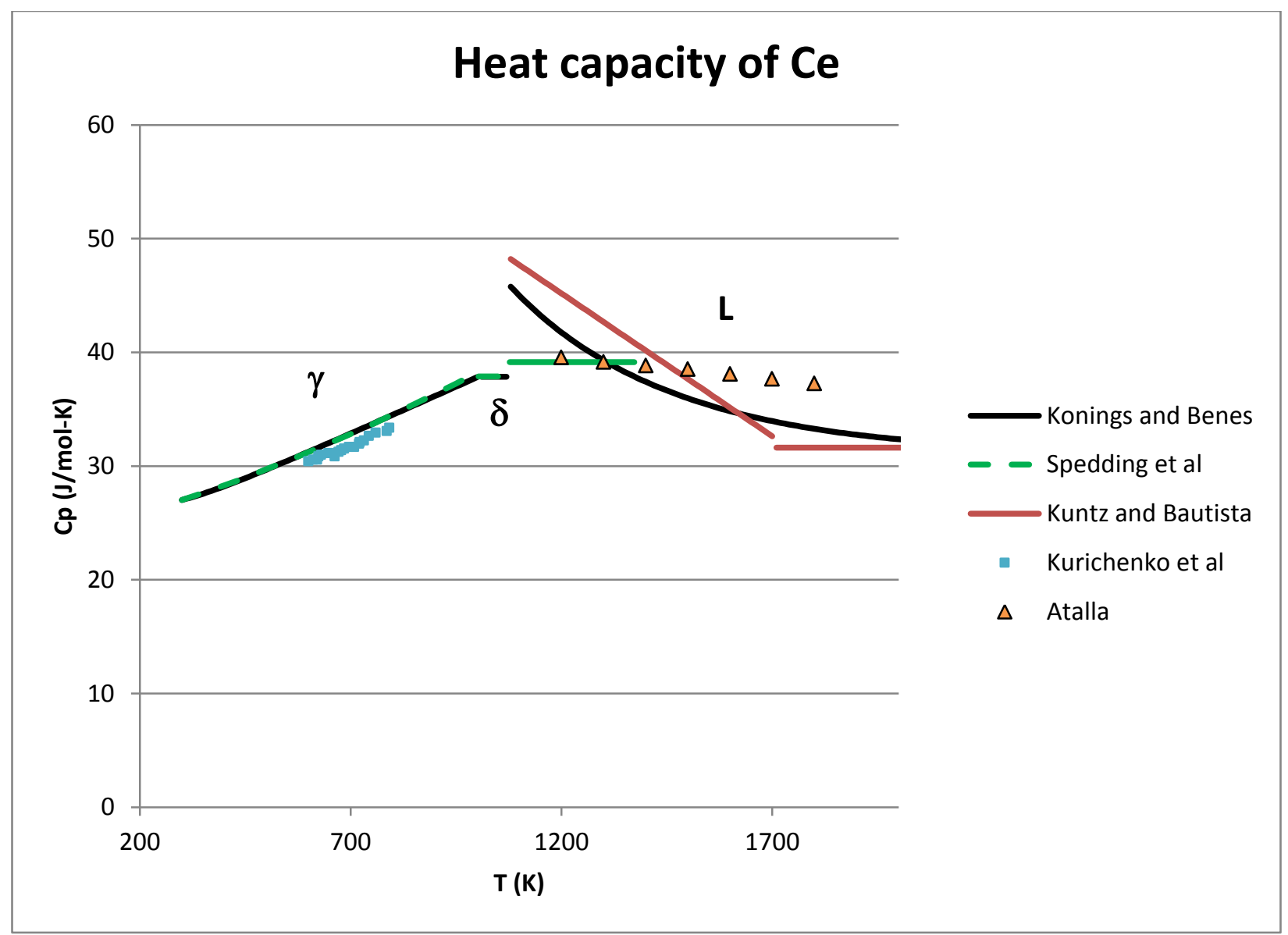

Figure 100. Heat capacity of Ce (references $[400,403]$ and Equation 84 through Equation 87). Data of Spedding et al. for $\gamma$-Ce is dashed to make it possible to see values from Konings and Beneš.

\subsection{5 $\mathrm{Pr}$}

\subsubsection{Introduction}

A number of research groups have published values for the heat capacity of Pr above room temperature [396, 401, 402, 405, 406]. There is generally good agreement about the heat capacity of $\alpha-\operatorname{Pr}$ and (because there is only one measurement) about the heat capacity of $\beta-\operatorname{Pr}$, but not about the heat capacity of the liquid.

Konings and Beneš [2] recently assessed the experimental data and developed equations representing heat-capacity values for Pr. Based on the available data, their recommendations match the available data for $\alpha$-Pr and $\beta$-Pr. The recommendations of Konings and Beneš are also the best available approximation for the heat capacity of liquid $\mathrm{Ce}$, although more work is required to understand the heat capacity of this phase.

\subsubsection{Heat Capacities of Solid and Liquid Phases}

Berg et al. [396] used drop calorimetry to measure the incremental enthalpy of Pr from 25 to $1100{ }^{\circ} \mathrm{C}$ and developed equations to represent the corresponding heat capacities. Novikov and Mardykin [401], Kurichenko et al. [402], and [405] determined heat capacity over temperature ranges of 1200 to 1550,746 to 904 , and 1210 to $2000 \mathrm{~K}$, respectively. Berezovskii et al. [406] measured the heat capacity of a highpurity sample at temperatures between 5.6 and $314 \mathrm{~K}$. Other lower-temperature measurements were summarized by Konings and Beneš [2]. 
Konings and Beneš [2] thoroughly re-assessed the experimental data except for that of Banchila and Filippov. They followed the equations of Berg et al. for $\beta$-Pr and liquid, but thought that the heat capacities of Berg et al. were probably too low near the lower end of their measurement range based on a comparison with the measurements of Berezovskii et al. [406]. Konings and Beneš therefore suggested an alternative equation for the heat capacity of $\alpha$-Pr based on the enthalpy data of Berg et al., but using the room-temperature heat capacity of $28.15 \mathrm{~J} / \mathrm{mol}-\mathrm{K}$ determined by Berezovskii et al. This value is higher than the value of $27.00 \mathrm{~J} / \mathrm{mol}-\mathrm{K}$ determined by Berg et al., which is consistent with the value of 27.2 $\mathrm{J} / \mathrm{mol}-\mathrm{K}$ in a recent tabulation by Gschneidner [17].

Figure 101 shows the measured and estimated heat capacity of Pr. Heat capacities of $\alpha$-Pr calculated using the equation of Konings and Beneš (Equation 90) differ from those of Berg et al. by at most $4 \%$. The heat capacity of $\beta$-Pr (Equation 91) follows Berg et al. All of the available data suggest that the heat capacity of liquid Pr is only slightly dependent on temperature, although there is disagreement about whether it is constant (Equation 91, which follows Berg et al.) or decreases slightly with increasing temperature [401, 405].

Equation 90. Heat capacity of $\alpha-\operatorname{Pr}[2]$

$\mathrm{C}_{\mathrm{p}}=32.5962-18.8071 \times 10^{-3} \mathrm{xT}+27.6631 \times 10^{-6} \mathrm{xT}^{2}-0.11537 \times 10^{6} \mathrm{xT}^{-2}$

where $\mathrm{C}_{\mathrm{p}}$ is constant-pressure heat capacity in $\mathrm{J} / \mathrm{mol} \cdot \mathrm{K}$, $\mathrm{T}$ is temperature in $\mathrm{K}$

Equation 91. Heat capacity of $\beta-\operatorname{Pr}[2]$

$\mathrm{C}_{\mathrm{p}}=38.45$

where $\mathrm{C}_{\mathrm{p}}$ is constant-pressure heat capacity in $\mathrm{J} / \mathrm{mol} \cdot \mathrm{K}$

Equation 92. Heat capacity of Pr liquid [2]

$\mathrm{C}_{\mathrm{p}}=43.01$

where $C_{p}$ is constant-pressure heat capacity in $\mathrm{J} / \mathrm{mol} \cdot \mathrm{K}$ 


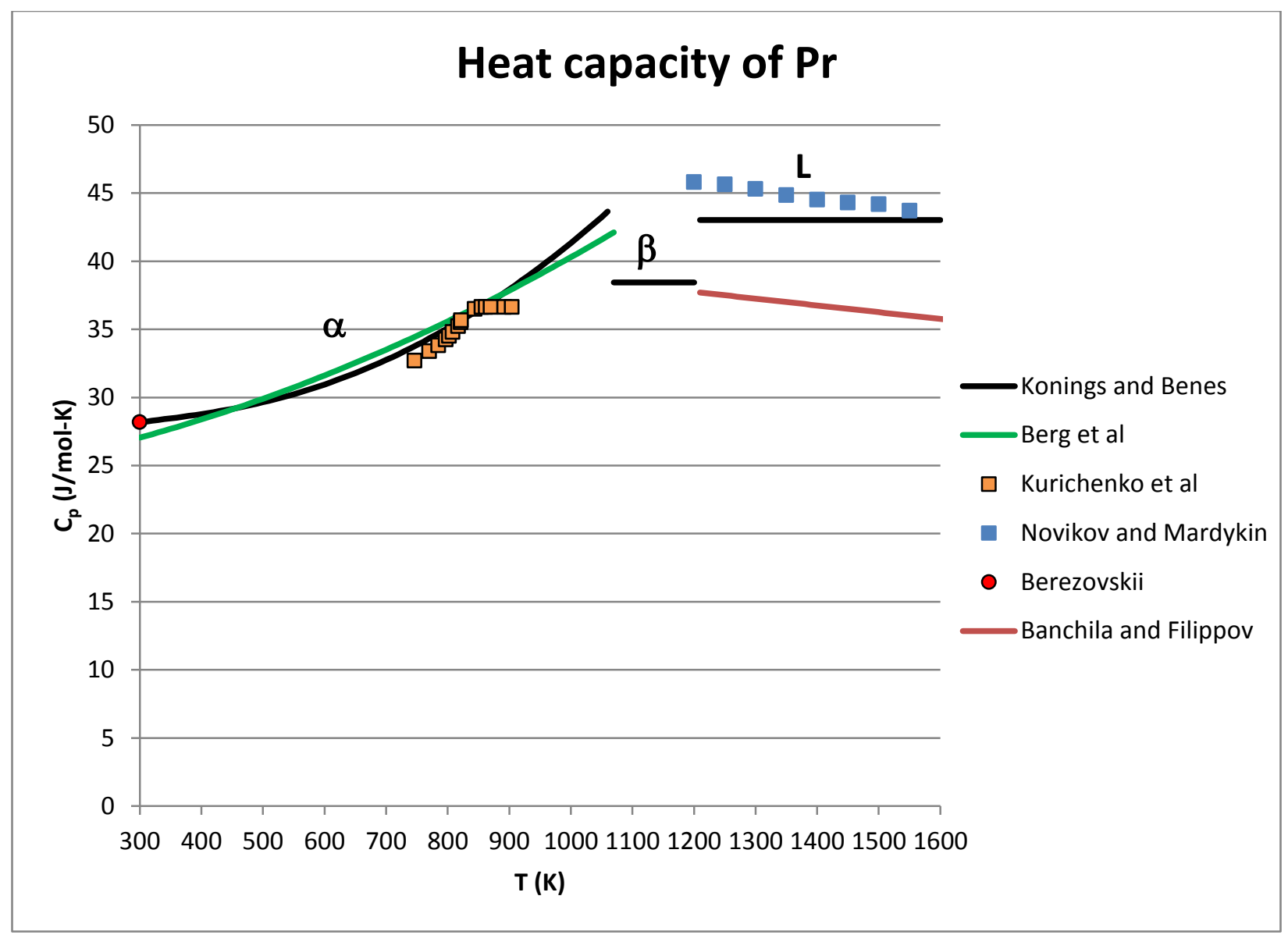

Figure 101. Heat capacity of $\operatorname{Pr}$ (references [396, 401, 402, 405, 406] and Equation 90 through Equation 92)

\subsubsection{Nd}

\subsubsection{Introduction}

Experimental measurements of incremental enthalpy or heat capacity of $\mathrm{Nd}$ at temperatures above $300 \mathrm{~K}$ have been published by Jaeger et al. [407], Kurichenko et al. [400], Spedding and colleagues [403], and Atalla [399]. There is generally good agreement about the heat capacity of $\alpha$-Nd below $\sim 1000 \mathrm{~K}$. Agreement about the heat capacity of $\alpha-\mathrm{Nd}$ at higher temperatures, the heat capacity of $\beta-\mathrm{Nd}$, and the heat capacity of the liquid is less good.

Konings and Beneš [2] recently assessed the experimental data and developed equations representing heat-capacity values for Nd (Equation 93, Equation 94, Equation 95). Although they are not a perfect fit for the data, these equations are probably the most useful approximation of the heat capacity of $\mathrm{Nd}$. Further research is required, particularly at higher temperatures.

\subsubsection{Heat Capacities of Solid and Liquid Phases}

Figure 102 shows the heat-capacity values suggested by Konings and Beneš [2] and the experimentally determined heat capacities. The very old (1938) data from Jaeger et al. [407] is not shown because the incremental enthalpy data seems anomalously high, possibly because of the relatively low purity of the sample. The value suggested by Konings and Benes for $\beta-\mathrm{Nd}(44.576 \mathrm{~kJ} / \mathrm{mol})$ is close to that of Spedding et al. ( $44.59 \mathrm{~kJ} / \mathrm{mol})$. However, the polynomial suggested by Konings \& Beneš for $\alpha-\mathrm{Nd}$ (Equation 79) is only close to the experimental data of Spedding et al. and Kurichenko et al. for 
temperatures between $\sim 300$ and $800 \mathrm{~K}$, then increases until it is $\sim 4 \mathrm{~J} / \mathrm{mol}-\mathrm{K}$ higher than the experimental data at the $\alpha-\beta$ phase transformation. The value suggested by Konings and Benes for liquid $\mathrm{Nd}$ ( 44.00 $\mathrm{J} / \mathrm{mol}-\mathrm{K})$ is $\sim 10 \%$ lower than the data of Spedding et al. $(48.8 \mathrm{~kJ} / \mathrm{mol})$. It is not clear why these differences occur.

Equation 93. Heat capacity of $\alpha-\mathrm{Nd}[2]$

$\mathrm{C}_{\mathrm{p}}=31.9343-20.8734 \times 10^{-3} \mathrm{xT}+33.3054 \times 10^{-6} \mathrm{xT}^{2}-0.03386 \times 10^{6} \mathrm{xT}^{-2}$

where $\mathrm{C}_{\mathrm{p}}$ is constant-pressure heat capacity in $\mathrm{J} / \mathrm{mol} \cdot \mathrm{K}$ and $\mathrm{T}$ is temperature in $\mathrm{K}$

Equation 94. Heat capacity of $\beta-\mathrm{Nd}$ (in $\mathrm{J} / \mathrm{mol}-\mathrm{K}$ ) [2]

$\mathrm{C}_{\mathrm{p}}=44.576$

where $\mathrm{C}_{\mathrm{p}}$ is constant-pressure heat capacity in $\mathrm{J} / \mathrm{mol} \cdot \mathrm{K}$

Equation 95. Heat capacity of $\mathrm{Nd}$ liquid (in $\mathrm{J} / \mathrm{mol}-\mathrm{K}$ ) [2]

$\mathrm{C}_{\mathrm{p}}=44.00$

where $\mathrm{C}_{\mathrm{p}}$ is constant-pressure heat capacity in $\mathrm{J} / \mathrm{mol} \cdot \mathrm{K}$

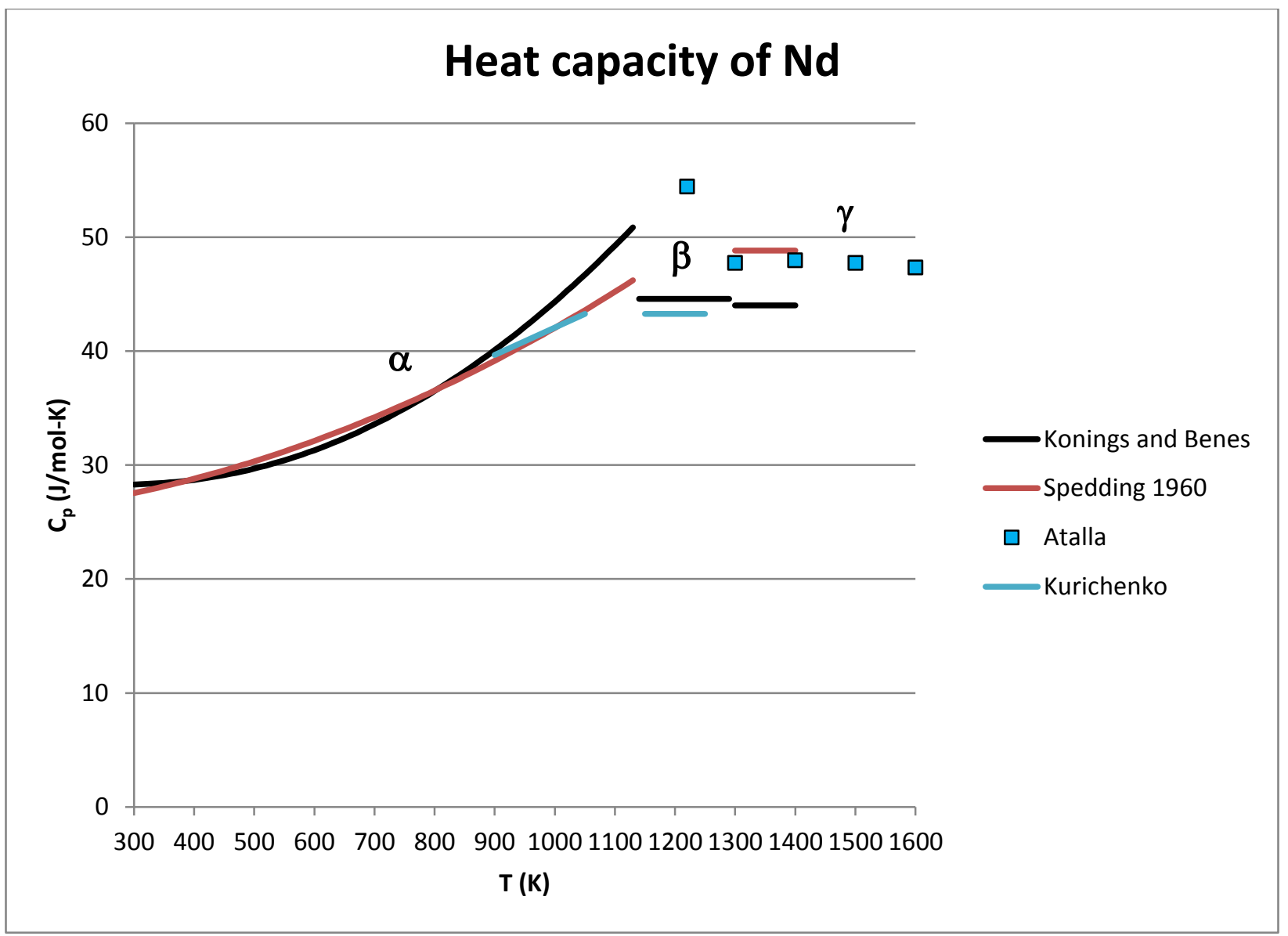

Figure 102. Heat capacity of Nd (references [399, 403] and Equation 92 through Equation 95) 


\subsubsection{U-La, U-Ce, U-Pr, U-Nd}

There are no published measurements of the heat capacity, specific heat, or incremental enthalpy of solid phases in any binary alloy of $\mathrm{U}$ with $\mathrm{La}, \mathrm{Ce}, \mathrm{Pr}$, or Nd. Bayanov calculated interatomic interaction constants as functions of temperature for coexisting high-U and high-rare-earth liquids at temperatures between 1423 and $1523 \mathrm{~K}\left(\sim 1150\right.$ and $\left.1250{ }^{\circ} \mathrm{C}\right)$, and also calculated activity coefficients and excess enthalpy, entropy, and Gibbs free energy for these liquids at $1500 \mathrm{~K}\left(\sim 1226^{\circ} \mathrm{C}\right)$ [260]. Data on coexisting compositions of $\mathrm{U}, \mathrm{La}, \mathrm{Ce}, \mathrm{Pr}$, and $\mathrm{Nd}$ in the Bayanov paper is not original, but is from an earlier review by Gschneidner.

\subsubsection{Pu-Am}

\subsubsection{Introduction}

The only available heat capacities of $\mathrm{Pu}$-Am alloys are from Am-stabilized $\delta$-Pu alloys (i.e., $\mathrm{Pu}-\mathrm{Am}$ alloys with the $\delta$-Pu structure at temperatures below the stability limit for pure $\delta$-Pu), measured at temperatures between 4.5 and $300 \mathrm{~K}[408,409]$. These measurements show that the heat capacities of Am-stabilized $\delta$-Pu alloys with 8,15 , and $20 \%$ Am are all $\sim 30 \mathrm{~J} / \mathrm{mol} \cdot \mathrm{K}$ at $300 \mathrm{~K}$.

Further experimental measurements involving other temperatures, crystal structures, and compositions are clearly needed.

\subsubsection{Heat Capacities of Solid and Liquid Phases}

In the absence of measured heat capacities, it seems reasonable to assume that the heat capacities of $(\alpha-\mathrm{Pu}),(\beta-\mathrm{Pu}),(\gamma-\mathrm{Pu})$, and $\left(\delta^{\prime}-\mathrm{Pu}\right)$ solid solutions are similar to the heat capacities of the corresponding phases in pure $\mathrm{Pu}$ because the maximum concentration of Am in each of these phases is low. Similarly, it seems reasonable to assume that the heat capacity of $(\alpha-\mathrm{Am})$ is similar to that of $\alpha-\mathrm{Am}$. If $(\varepsilon-\mathrm{Pu})$ and $(\gamma-$ $\mathrm{Am})$ are separate phases, it seems reasonable to assume that their heat capacities are similar to those of $\varepsilon$ $\mathrm{Pu}$ and $\gamma$-Am.

In the absence of experimental data, it may be necessary to approximate the heat capacities of the solid solution phases $(\delta$-Pu, $\beta$-Am) and perhaps $(\varepsilon-\mathrm{Pu}, \gamma-\mathrm{Am})$ by cautious use of the Kopp-Neumann Law (Section 2.5.1).

\subsubsection{La-Ce}

\subsubsection{Introduction}

Constant-pressure heat capacities of La-Ce alloys have been measured at temperatures below $300 \mathrm{~K}$ [410], and constant-volume heat capacities have been calculated at high pressures [328]. However, data on the heat capacities of La-Ce alloys at temperatures and pressures of interest for nuclear fuels are not available, and experimental investigation is required.

\subsubsection{Heat Capacities of Solid and Liquid Phases}

In the absence of experimental data, it may be necessary to approximate the heat capacities of La-Ce alloys using the Kopp-Neumann Law (Section 2.5.1). Figure 103 shows an example of the use of this law to approximate the heat capacity of a La-Ce alloy with 50 at\% La. Because alloys of pure La and $\mathrm{Ce}$ behave as ideal alloys at high temperatures, the temperatures of phase transitions in the alloy were determined by interpolation between the transition temperatures of $\mathrm{La}$ and $\mathrm{Ce}$. To reduce errors introduced by phase transitions, heat capacities are shown only for temperature ranges in which the binary phase diagram in Section 4.1.27 indicates that $\mathrm{La}, \mathrm{Ce}$, and the alloy should all have the same crystal structure. As a result, there are no estimated heat capacities for the dhcp and bcc phases. 


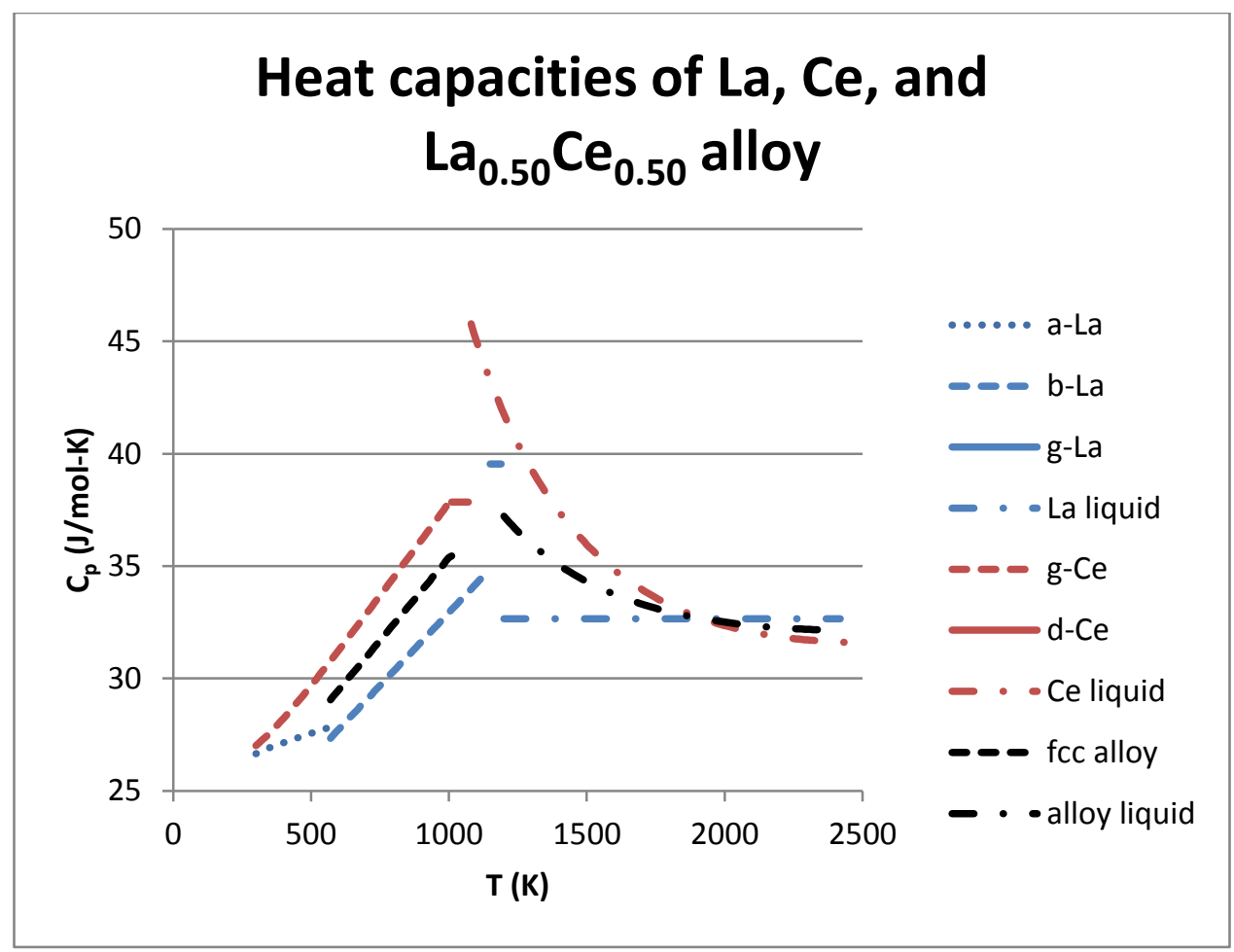

Figure 103. Heat capacity of a La-Ce alloy with 50 at $\%$ La, estimated using the Kopp-Neumann Law and elemental heat capacities from the equations in Sections 4.2.3 and 4.2.4 of this handbook. Heat capacities of $\mathrm{La}$ and $\mathrm{Ce}$ are included for comparison. Colors indicate compositions, and line types (dots, etc.) indicate phases. The fcc alloy is a solid solution between $\beta$-La and $\gamma$-Ce.

\subsubsection{La-Pr}

There are apparently no reported heat capacities of any La-Pr alloy. For some compositions and temperature ranges, it may be appropriate to cautiously use approximate heat capacities obtained using the Kopp-Neumann Law (Section 2.5.1), while bearing in mind that the poor understanding of the La-Pr phase diagram (Section 4.1.28) makes it difficult to avoid temperatures close to phase transitions, and that errors in the available data on heat capacities of La and $\operatorname{Pr}$ (Sections 4.2.3 and 4.2.5)will propagate into heat capacities of La-Pr alloys estimated using the Kopp-Neumann Law.

\subsubsection{La-Nd}

Heat capacities of La-Nd alloys have been measured at temperatures below $300 \mathrm{~K}$ [341, 410]. However, no heat capacities of La-Nd alloys at temperatures of interest for nuclear fuels are available.

For some compositions and temperature ranges, it may be appropriate to use approximate heat capacities obtained using the Kopp-Neumann Law (Section 2.5.1). However, the currently poor understanding of the La-Nd phase diagram (Section 4.1.29) makes it difficult to reliably avoid temperatures close to phase transitions. Errors in the available data on the heat capacities of La and $\mathrm{Nd}$ (Sections 4.2.3 and 4.2.6) will propagate into heat capacities of La-Nd alloys estimated using the KoppNeumann Law.

\subsubsection{Ce-Pr, Ce-Nd}

No reported heat capacities of any Ce-Pr or Ce-Nd alloy were found. For some compositions and temperature ranges, it may be appropriate to use approximate heat capacities obtained using the KoppNeumann Law (Section 2.5.1), while bearing in mind that the poor understanding of the binary phase 
diagrams (Sections 4.1.31 and 4.1.32) makes it difficult to reliably avoid temperatures close to phase transitions, and that uncertainties in the heat capacities of $\mathrm{Ce}$, Pr, and $\mathrm{Nd}$ may lead to uncertainties in heat capacities of alloys estimated using the Kopp-Neumann Law.

\subsubsection{Pr-Nd}

\subsubsection{Introduction}

Lundin et al. measured activities of Pr and $\mathrm{Nd}$ and determined that the heat of mixing is linearly related to the composition in a variety of Pr-Nd alloys [362, 366]. However, experimentally determined heat capacities of Pr-Nd alloys are not available.

Given the similarities between the currently available measurements of the heat capacities of Pr and $\mathrm{Nd}$, the Kopp-Neumann Law (Section 2.5.1) appears to provide a plausible estimate for the heat capacities of Pr-Nd alloys. Because uncertainties in the heat capacities of elements propagate into the estimated heat capacities of alloys, the most useful information for improving the accuracy of information about heat capacities of Pr-Nd alloys may involve measurements of the heat capacities of Pr and Nd.

\subsubsection{Heat Capacities of Solid and Liquid Phases}

Currently available measurements indicate that the heat capacities of $\mathrm{Pr}$ and $\mathrm{Nd}$ are similar, and the Kopp-Neumann Law appears to provide a plausible estimate for the heat capacities of Pr-Nd alloys. Figure 104 shows an example of the application of this law to a Pr-Nd alloy with 50 at\% Pr. Because alloys of pure Pr and $\mathrm{Nd}$ behave as ideal alloys at high temperatures, the temperatures of phase transitions in the alloy were determined by interpolation between the transition temperatures of $\mathrm{Pr}$ and $\mathrm{Nd}$. To reduce errors introduced by phase transitions, heat capacities are shown only for temperature ranges in which the binary phase diagram in Section 4.1.33 indicates that $\mathrm{Pr}$ and $\mathrm{Nd}$ have the same crystal structure.

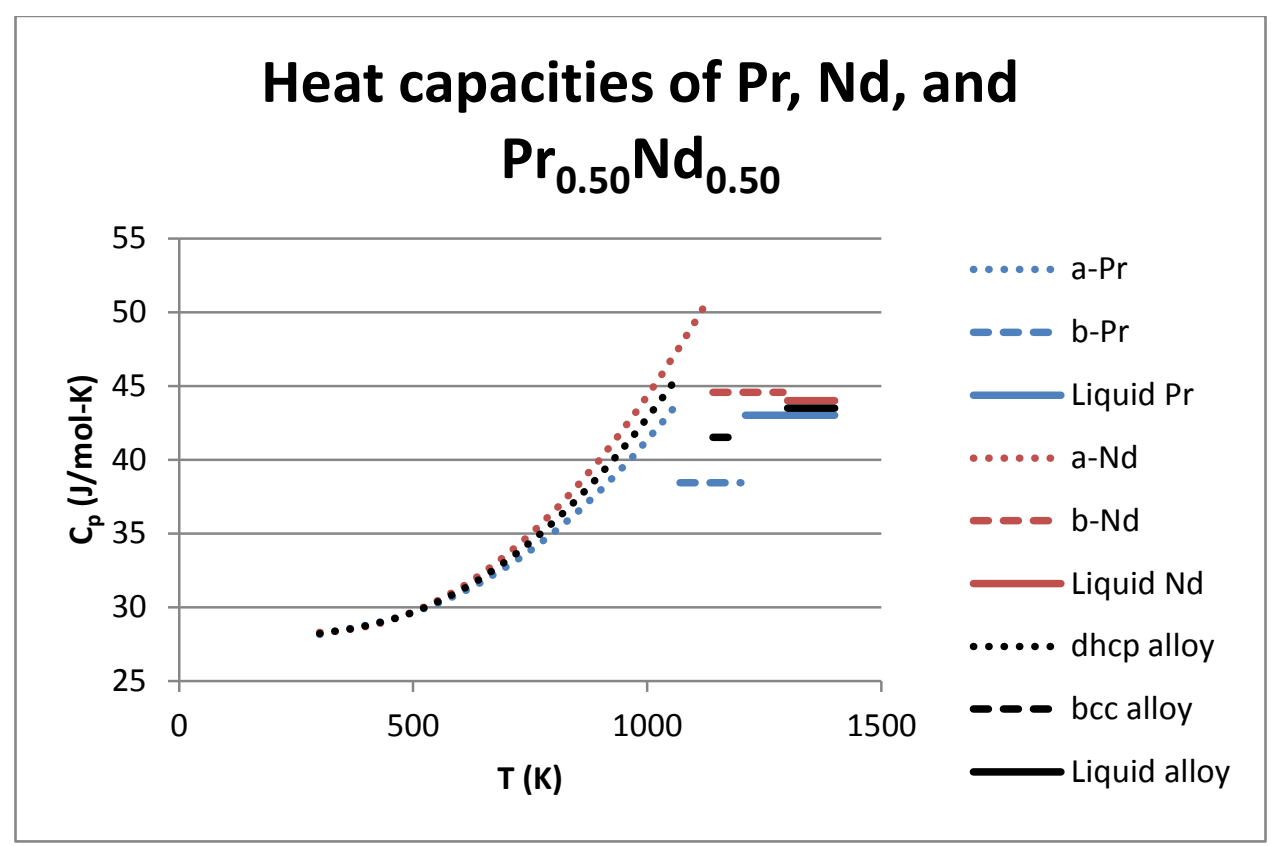

Figure 104. Heat capacity of a Pr-Nd alloy with 50 at\% Pr, estimated using the Kopp-Neumann Law with heat capacities of $\mathrm{Pr}$ and $\mathrm{Nd}$ from the equations in Sections 4.2.5 and 4.2.6 of this handbook. Heat capacities of pure $\mathrm{Pr}$ and $\mathrm{Nd}$ are included for comparison. Colors indicate compositions, and line types (dots, etc.) indicate phases. The dhep alloy is a solid solution of $\alpha-\operatorname{Pr}$ and $\alpha-\mathrm{Nd}$, and the bec alloy is a solid solution of $\beta-P r$ and $\beta-\mathrm{Nd}$. 


\subsubsection{U-Ce-Zr}

Measured heat capacities of U-4Ce-10Zr and U-6Ce-10Zr alloys were reported by Kim et al. [411]. Although Kim et al. reported that the heat capacities of the alloys with Ce were slightly higher than those of U-10Zr alloys at temperatures between $\sim 400$ and $650 \mathrm{C}$ (the onset temperature of a phase transformation), the difference is smaller than the difference between reported heat capacities of $\mathrm{U}-10 \mathrm{Zr}$ alloys (Section 3.2.4).

In view of the immiscibility of Ce and $\mathrm{U}-\mathrm{Zr}$ alloys and the relative heat capacities of these materials (Section 4.1.33 and Section 3.2.4), it seems unlikely that increasing the concentration of Ce would significantly increase the heat capacity of U-Zr-Ce alloys. Further experimental investigation of this system may be of limited relevance for nuclear fuels.

\subsection{THERMAL EXPANSION, THERMAL EXPANSION COEFFICIENTS, AND DENSITY-TEMPERATURE RELATIONSHIPS}

\subsubsection{Np}

\subsubsection{Introduction}

The thermal expansion of single crystals of $\alpha-\mathrm{Np}$ and $\beta-\mathrm{Np}$ is anisotropic, as reported in the single paper with experimental measurements. The thermal expansion of single crystals of $\gamma$-Np has not been reported.

The linear thermal expansion coefficient for polycrystalline $\alpha$-Np has been experimentally measured by two research groups and modeled by a third group, with good agreement. Experimental measurements of the linear thermal expansion coefficient for polycrystalline $\beta$-Np were reported by the same research groups, with much less good agreement. It has been suggested that the lack of agreement is a consequence of the strongly anisotropic thermal expansion of $\beta-\mathrm{Np}$, which would cause differences in thermal expansion coefficients for polycrystalline samples with different preferred orientations. The linear thermal expansion coefficient for polycrystalline $\gamma$-Np has been reported in a single publication, but may be too low because of sample deformation during measurement.

Reported densities of $\mathrm{Np}$ phases at different temperatures are commonly quoted from a single X-ray diffraction study. Densities determined from thermal expansion are in good agreement with the X-ray data for $\beta$-Np. The density of $\gamma-\mathrm{Np}$ is less well known, and densities determined using different techniques differ by several percent.

Further work with high-purity samples is needed.

\subsubsection{Thermal expansion of single crystals}

The thermal expansion of single crystals of $\alpha-\mathrm{Np}$ is anisotropic. Thermal expansion coefficients (in space group Pnma are $34 \times 10^{-6} / \mathrm{K}$ parallel to the $a$ axis, $24 \times 10^{-6} / \mathrm{K}$ parallel to $b$, and $25 \times 10^{-6} / \mathrm{K}$ parallel to $c$, for temperatures between $\sim 300$ and $550 \mathrm{~K}$ [184].

The thermal expansion of single crystals of $\beta-\mathrm{Np}$ is also anisotropic. Thermal expansion coefficients are $64 \times 10^{-6} / \mathrm{K}$ parallel to the $a$ and $b$ axes, and approximately 0 parallel to $c$, for temperatures between $\sim 555$ and $700 \mathrm{~K}[184]$.

The thermal expansion of single crystals of $\gamma-\mathrm{Np}$ has not been reported.

\subsubsection{Coefficients of thermal expansion for polycrystalline $\mathrm{Np}$}

Original measurements of coefficients of thermal expansion for polycrystalline $\alpha$-Np and $\beta$-Np were reported by Cort [191] and by Lee et al. [186] (Table 21). A recently developed model [389] produces values in good agreement with the data of Cort. 
Table 21. Coefficients of thermal expansion for $\mathrm{Np}$

Phase $\mathrm{T}(\mathrm{K}) \quad$ Coefficient of thermal Reference

\begin{tabular}{llll}
\multicolumn{3}{c}{ expansion $\left(\mathrm{K}^{-1}\right)$} \\
\hline$\alpha-\mathrm{Np}$ & $313-513$ & $27.5 \times 10^{-6}$ & {$[186]$} \\
$\alpha-\mathrm{Np}$ & $300-525$ & $27.0 \times 10^{-6}$ & {$[191]$} \\
$\beta-\mathrm{Np}$ & $573-813$ & $41 \times 10^{-6}$ & {$[186]$} \\
$\beta-\mathrm{Np}$ & $550-870$ & $60.5 \times 10^{-6}$ & {$[191]$} \\
$\gamma-\mathrm{Np}$ & $\sim 850-973 ?$ & $33 \times 10^{-6}$ & {$[255]$} \\
\hline
\end{tabular}

The measured coefficients of thermal expansion for $\alpha-\mathrm{Np}$ in the two studies are similar. However, the measured coefficients of thermal expansion for $\beta$-Np are not. Cort suggests that the difference may be due to the thermal anisotropy of $\mathrm{Np}$ and preferred orientation in his samples. However, consideration of his measurements of phase-transformation temperatures and instantaneous coefficients of thermal expansion (Figure 105) suggests that his highest-temperature measurement (which he identified as $\gamma$-Np) may actually represent $\gamma$-Np. If so, the thermal expansion coefficients for $\beta$-Np from the two references may be more similar than they appear from Table 21.

Attempts to measure thermal expansion at higher temperatures are difficult because of sample creep or "sagging" [186, 191], and only one measurement identified as the thermal expansion coefficient for $\gamma$ $\mathrm{Np}$ has been reported. This value may be too low as a result of experimental difficulties [255]. 


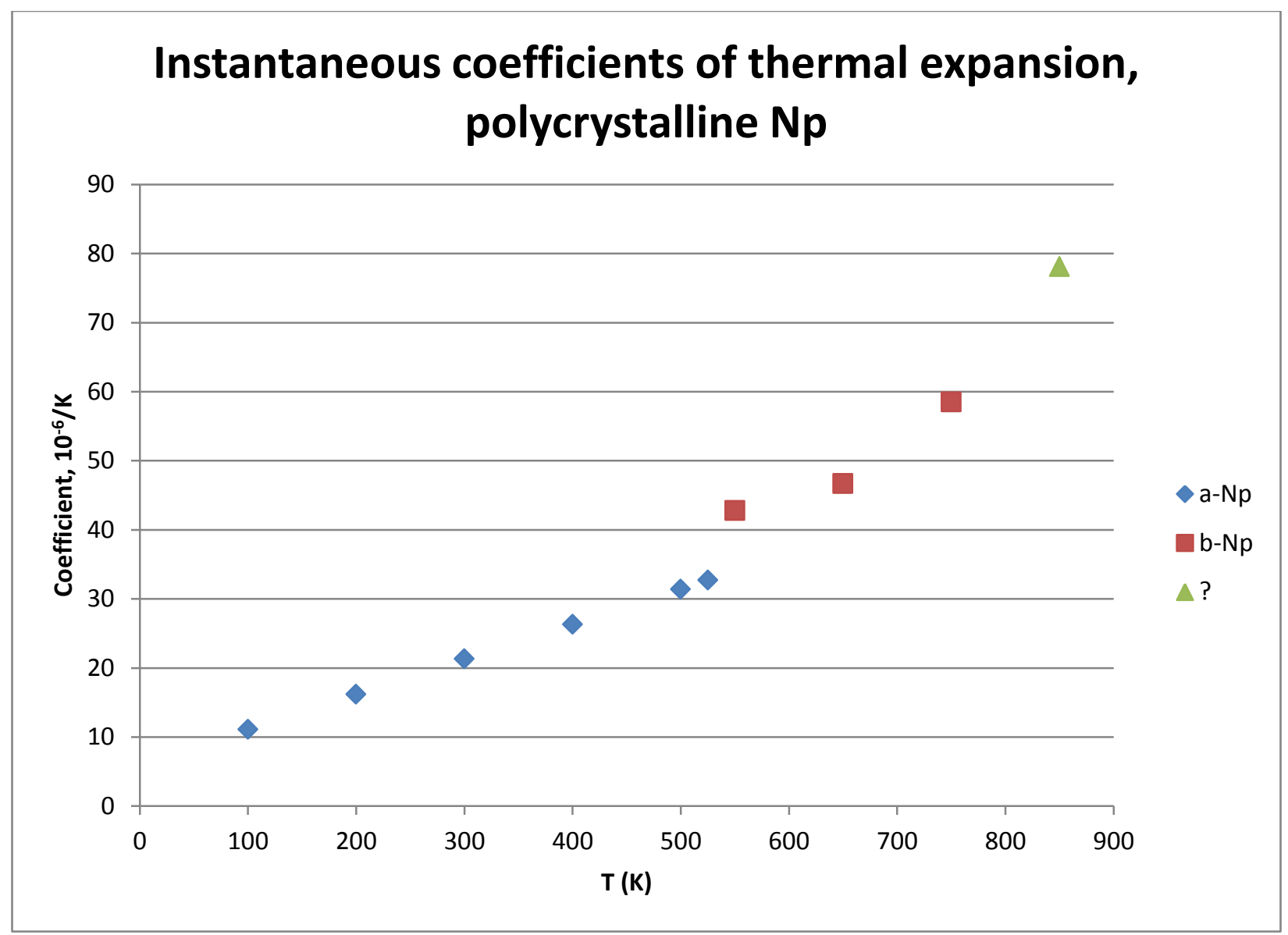

Figure 105. Instantaneous coefficients of thermal expansion for polycrystalline $\alpha$ - and $\beta$-Np at selected temperatures [191 Table 4]

\subsubsection{Density and volume}

Densities calculated from X-ray diffraction of $\alpha$-Np are $\sim 20.45$ to $20.48 \mathrm{~g} / \mathrm{cm}^{3}$ at $20{ }^{\circ} \mathrm{C}[184,186]$. Measured values are lower $\left(19.5\right.$ to $\left.20.3 \mathrm{~g} / \mathrm{cm}^{3}\right)$, possibly because the samples contain inclusions of lower-density materials [186, 387, 412].

Densities calculated from X-ray diffraction data from $\beta-\mathrm{Np}$ at $\sim 290^{\circ} \mathrm{C}$ are 19.4 to $19.5 \mathrm{~g} / \mathrm{cm}^{3}[184$, 186]. These densities are generally consistent with a density of $19.3 \mathrm{~g} / \mathrm{cm}^{3}$ at $302{ }^{\circ} \mathrm{C}(575 \mathrm{~K})$ determined from thermal expansion data [191].

The density of $\gamma$-Np is not well known. X-ray diffraction data suggests a density of $\sim 18 \mathrm{~g} / \mathrm{cm}^{3}$ at 592 ${ }^{\circ} \mathrm{C}$, assuming a bcc structure that could not be reliably determined from the X-ray data $[184,186]$.

Thermal expansion data indicates a density of $18.30 \mathrm{~g} / \mathrm{cm}^{3}$ at $567{ }^{\circ} \mathrm{C}(840 \mathrm{~K})$ [191]. Foltyn calculated the density of $\gamma$-Np at $583{ }^{\circ} \mathrm{C}$ as $18.40 \mathrm{~g} / \mathrm{cm}^{3}$ [192] using the Clausius-Clapeyron relation (Equation 6) with data on the enthalpy of the $\beta-\gamma$ transition from new DTA measurements, high-pressure data from reference [413], and the density of $\beta$-Np from the X-ray diffraction data of Zachariasen [184].

In combination, these data suggest that the density of $\gamma$-Np at temperatures of $\sim 580-600{ }^{\circ} \mathrm{C}$ is slightly more than $18 \mathrm{~g} / \mathrm{cm}^{3}$. Further work is required to determine this density with greater precision and at other temperatures.

The density of liquid $\mathrm{Np}$ has not been reported, although the volume increases by $\sim 1.5 \%$ during melting $[414,415]$. 
Figure 106 shows relationships between density and temperature for $\alpha, \beta$, and $\gamma$-Np based on X-ray diffraction data [184], and the corresponding molar volumes calculated for ${ }^{237} \mathrm{~Np}$. The molar volume increases by $\sim 2.8 \%$ at the $\alpha-\beta$ transition, and by $\sim 4.5 \%$ at the $\beta-\gamma$ transition. These values differ from those presented by Wittenberg and colleagues (3.3 and 3.6\% increases in volume at the $\alpha-\beta$ and $\beta-\gamma$ transformations, respectively) [414, 415] and by Selle and Rechtien (increases of 2.85 and 3.25\%) [194]. The reasons for these differences are not clear.

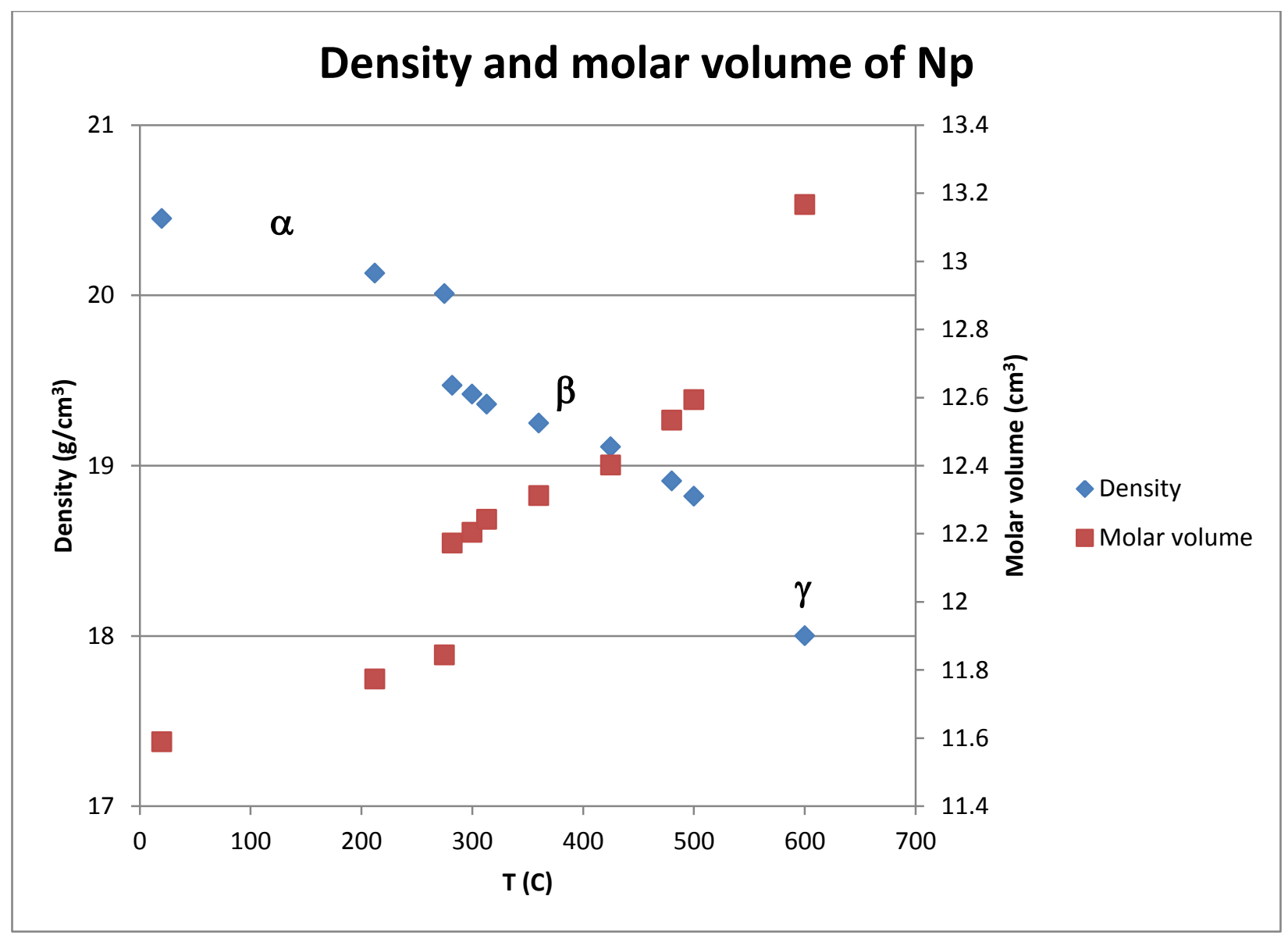

Figure 106. Density and molar volume of Np from Zachariasen's X-ray data [184]

\subsubsection{Am}

\subsubsection{Introduction}

There are apparently only two papers with original reports of experimental measurements of the thermal expansion of Am. One of these papers is the primary source for data on the crystal structures of $\alpha$ - and $\beta$-Am; the other has a single figure showing dilatometry results in a letter reporting the use of thermal expansion measurements to investigate phase-transformation temperatures. Data from these sources is inconsistent.

The room-temperature density of $\alpha$-Am has been measured by several researchers, and is approximately $13.6 \mathrm{~g} / \mathrm{cm}^{\square}$. Lower densities $\left(\sim 11.7 \mathrm{~g} / \mathrm{cm}^{3}\right)$ are sometimes reported, but correspond to a different phase with the same space group as $\alpha$-Am and larger lattice parameters (Section 4.1.2).

The densities of $\alpha$-Am and $\beta$-Am are similar. 


\subsubsection{Thermal expansion}

McWhan and colleagues determined the lattice parameters of $\alpha$-Am at temperatures from -120 to $+605{ }^{\circ} \mathrm{C}$ using high-temperature X-ray diffraction [201]. They fitted their data to two polynomials (Equation 96 and Equation 97) using a least-squares technique.

Equation 96. Lattice parameter of $\alpha$-Am parallel to the $a$ crystallographic direction [201]

$$
a=3.4672+2.60 \times 10^{-5} \times \mathrm{T}+0.54 \times 10^{-8} \times \mathrm{T}^{2}
$$

where $a$ is a lattice parameter, $\mathrm{T}$ is temperature in ${ }^{\circ} \mathrm{C}$, and $\mathrm{T}$ is between -120 and $+605{ }^{\circ} \mathrm{C}$

Equation 97. Lattice parameter of $\alpha$-Am parallel to the $c$ crystallographic direction [201]

$$
c=11.237+6.95 \times 10^{-5} \mathrm{xT}+6.8 \times 10^{-8} \mathrm{xT}^{2}
$$

where $c$ is a lattice parameter, $\mathrm{T}$ is temperature in ${ }^{\circ} \mathrm{C}$, and $\mathrm{T}$ is between -120 and $+605^{\circ} \mathrm{C}$

Figure 107 shows the thermal expansion $\left(\Delta \mathrm{L} / \mathrm{L}_{0}\right.$, in $\left.\%\right)$ parallel to the $a$ and $c$ lattice parameters, calculated using Equation 96 and Equation 97 with $\mathrm{L}_{0}$ representing a lattice parameter at $20^{\circ} \mathrm{C}$. The corresponding thermal expansion coefficients are $\sim 7.6 \times 10^{-6} /{ }^{\circ} \mathrm{C}$ parallel to $a$ and $5.6 \times 10^{-6} /{ }^{\circ} \mathrm{C}$ parallel to $c$ over the interval between 20 and $30^{\circ} \mathrm{C}$. Although differences between the curves for expansion parallel to $a$ and $c$ suggest that the thermal expansion is anisotropic, it seems likely that the anisotropy is smaller than the errors in the thermal expansion data, and it can therefore be neglected.

In a recent review [3], Konings and colleagues present a different equation representing the thermalexpansion data of McWhan et al. (Equation 98). This equation does not seem to be an accurate representation of the data of McWhan et al.

Equation 98. Thermal expansion of Am [3]

$$
\left(\mathrm{L}-\mathrm{L}_{0}\right) / \mathrm{L}_{0}=-2.315 \times 10^{-3}+6.965 \times 10^{-6} \times \mathrm{T}+3.176 \times 10^{-9} \times \mathrm{T}^{2} \times 100
$$

where $\left(\mathrm{L}-\mathrm{L}_{0}\right) / \mathrm{L}_{0}$ is thermal expansion in $\%$, $\mathrm{T}$ is temperature in $\mathrm{K}, \mathrm{L}$ is the length at temperature $\mathrm{T}$, and $\mathrm{L}_{0}$ is the length at $298 \mathrm{~K}$

The thermal expansion measurements of Rose et al. [204 Figure 1] are presented as a single figure in a letter. The focus of the letter is determination of phase-transition temperatures, and the implications of the data for the thermal expansion of individual phases are not discussed. The data of Rose et al. is qualitatively inconsistent with the data of McWhan et al. in two important respects:

- Rose et al. show that the thermal expansion of $\alpha$-Am is negative between $\sim 66^{\circ} \mathrm{C}$ (the minimum temperature for their measurements) and $\sim 300{ }^{\circ} \mathrm{C}$, while McWhan et al. observed expansion between 20 and $+605^{\circ} \mathrm{C}$.

- Rose et al. show a large expansion at the $\alpha-\beta$ transition, which is inconsistent with the similar densities of $\alpha$ - and $\beta$-Am determined from the X-ray data of McWhan et al.

Stephens et al. applied the Clausius-Clapeyron relation (Equation 6) to their compressibility data and previously published values of the latent heat of phase transitions to estimate that the volume increases associated with the $\beta-\gamma$ and melting transformations in Am are approximately 1.1 and $2.3 \%$, respectively [203]. The enthalpy values they used (1.40 and $3.44 \mathrm{kcal} / \mathrm{mol}$ for the $\beta-\gamma$ and melting transformations, respectively) are at the high end of the range reported by Konings and Beneš [2], suggesting that the actual volume increases associated with the phase transformations may be smaller than estimated.

Melting results in a volume loss $(\Delta \mathrm{V} / \mathrm{V})$ of $2.3 \%[414,415]$.

Further experimental data are clearly needed to understand the thermal expansion of Am. In the absence of this data, the results presented by McWhan et al. [201] are the best available approximation to the actual thermal expansion of Am. 


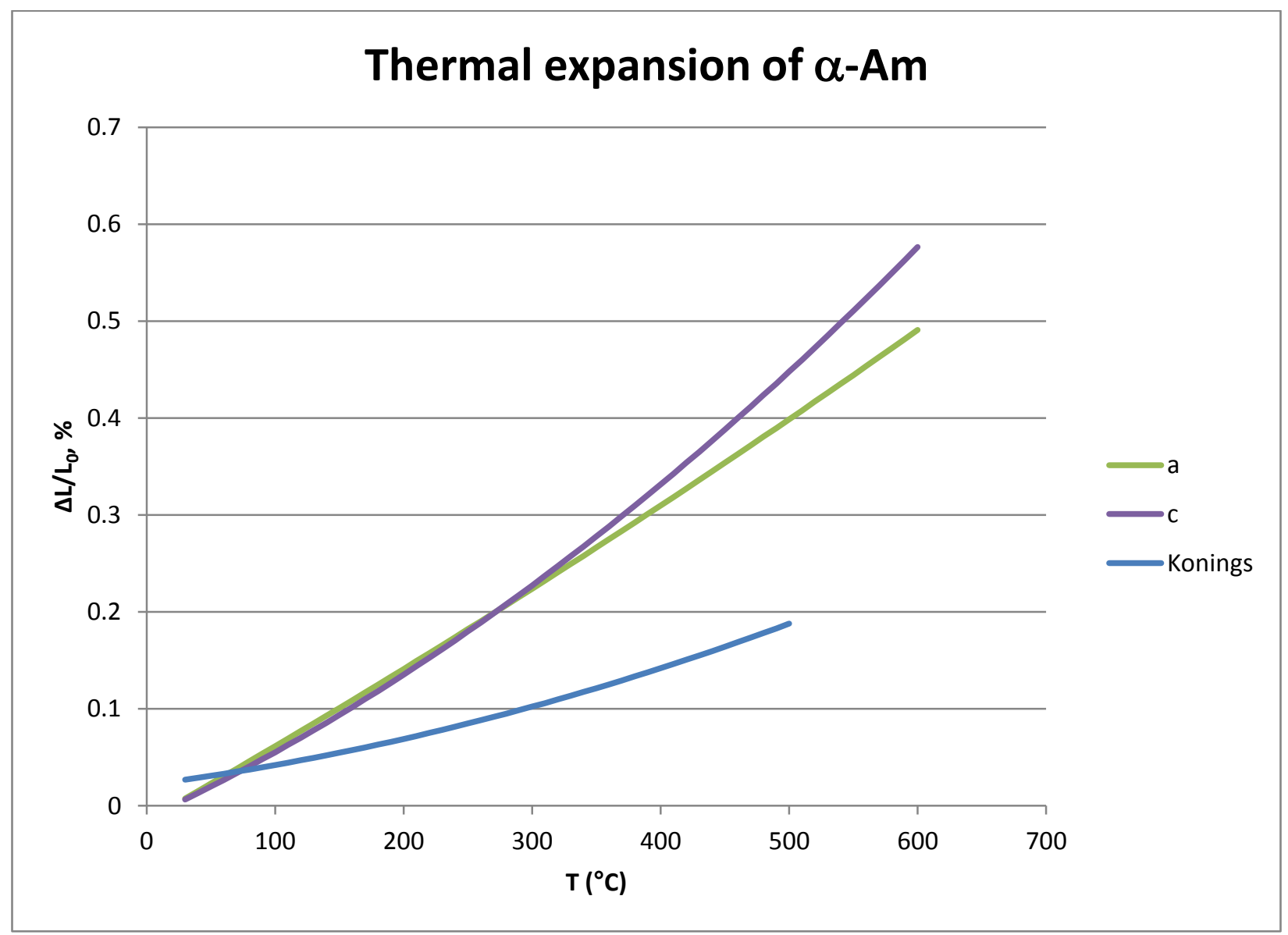

Figure 107. Thermal expansion of $\alpha$-Am. The $a$ and $c$ lattice parameters are from McWhan et al. (Equation 96 and Equation 97); "Konings" value is from Equation 98.

\subsubsection{Coefficients of thermal expansion}

McWhan and colleagues determined that the coefficients of thermal expansion for $\alpha$-Am at $20{ }^{\circ} \mathrm{C}$ are (7.5 \pm 0.2$) \times 10^{-6} /{ }^{\circ} \mathrm{C}$ in the $a$ direction and $(6.2 \pm 0.4) \times 10^{-6} /{ }^{\circ} \mathrm{C}$ in the $c$ direction [201]. These values were repeated in a recent review [202], where they were printed without specifying the temperature at which they were determined or noting that the coefficient of thermal expansion may be temperature-dependent.

McWhan et al. determined that the mean coefficient of thermal expansion for $\beta$-Am between 22 and $360{ }^{\circ} \mathrm{C}$ is $9 \pm 3 \times 10^{-6} /{ }^{\circ} \mathrm{C}$ [201].

\subsubsection{Room-temperature density}

Several researchers have reported that the density of $\alpha-A m$ is $\sim 13.6 \mathrm{~g} / \mathrm{cm}^{3}$ at room temperature [201, $208,416]$. This value is slightly higher than that measured by Rose et al. $\left(13.38 \mathrm{~g} / \mathrm{cm}^{3}\right)$ from a sample that had up to $0.4 \mathrm{wt} \%$ of measured impurities [204].

Other researchers $[209,210]$ report the room-temperature density of Am as $\sim 11.7 \mathrm{~g} / \mathrm{cm}^{3}$. This density probably does not represent $\alpha$-Am, but instead corresponds to a different phase with the same space group and larger lattice parameters (Section 4.1.2). 
Although McWhan and colleagues [201] did not quantify the density of $\beta$-Am, calculations based on their crystal structure and lattice parameters indicate that the densities of $\alpha$-Am and $\beta$-Am are essentially identical.

\subsubsection{La}

\subsubsection{Introduction}

Most of the available experimental data about thermal expansion of $\mathrm{La}$ is from a single reference with high-temperature X-ray diffraction data for single crystals of hcp and fcc phases [221]. Limited data about the thermal expansion of polycrystalline samples is presented graphically in several other references [417419].

More recent research has focused on understanding thermal atomic displacements using high-T neutron-diffraction data [420, 421] and on new approaches to calculating the equation of state [422].

\subsubsection{Thermal expansion}

Spedding et al. [221] used high-temperature X-ray diffraction to measure the lattice parameters of $\alpha$ and $\beta$-La, and developed polynomials that can be used to calculate lattice parameters as functions of temperature (Equation 99 through Equation 101). Figure 108 shows the corresponding thermal expansion of individual lattice parameters of $\alpha$ - and $\beta$-La, calculated based on a reference temperatures of $300 \mathrm{~K}$ $\left(\sim 27^{\circ} \mathrm{C}\right)$.

Equation 99. $a$ lattice parameter of $\alpha$-La between 20 and $293^{\circ} \mathrm{C}$ [221 Table IV]

$$
a=3.77+1.7 \times 10^{-5} \times \mathrm{T}
$$

where $a$ is a lattice parameter, $\mathrm{T}$ is temperature in ${ }^{\circ} \mathrm{C}$, and $\mathrm{T}$ is between 20 and $293{ }^{\circ} \mathrm{C}$

Equation 100. $c$ lattice parameter of $\alpha$-La between 20 and $293{ }^{\circ} \mathrm{C}$ [221 Table IV]

$$
c=12.13+33 \times 10^{-5} \times \mathrm{T}
$$

where $c$ is a lattice parameter, $\mathrm{T}$ is temperature in ${ }^{\circ} \mathrm{C}$, and $\mathrm{T}$ is between 20 and $293{ }^{\circ} \mathrm{C}$

Equation 101. Lattice parameter of $\beta$-La between 20 and $598^{\circ} \mathrm{C}$ [221 Table IV]

$$
a=5.303+3.4 \times 10^{-5} \times \mathrm{TT}+1.0 \times 10^{-8} \mathrm{xT}^{2}
$$

where $a$ is a lattice parameter, $\mathrm{T}$ is temperature in ${ }^{\circ} \mathrm{C}$, and $\mathrm{T}$ is between 20 and $598{ }^{\circ} \mathrm{C}$

Barson et al. [417], Spedding et al. [418], and Frizen et al. [419] measured the thermal expansion of polycrystalline La using dilatometry. Although results of these studies were presented graphically, it is clear that all three measurements fall between the single-direction expansions of the $a$ and $c$ lattice parameters calculated from the high-temperature X-ray data of Spedding et al. [221]. Because the thermal expansion of $\alpha$-La is anisotropic, the thermal expansion of actual samples may vary between the singledirection expansions as a result of differences in preferred orientation between the samples. Thus, the polycrystalline expansion data of Barson et al., Spedding et al., and Frizen et al. (references [417-419]) is consistent with the single-direction data of reference [221].

The measurements of Barson et al. for polycrystalline $\beta$-La [417 Figure 2] are significantly higher than the values calculated from the single-direction data of Spedding et al. [221], and the measurements of Frizen et al. [419 Figure 1] are significantly lower. It is not clear why these differences occur, although Barson et al. noted difficulties in obtaining accurate measurements because of sample creep or softening at high temperatures. In the absence of further experimental measurements, it seems reasonable to consider the single-crystal data of Spedding et al. to be the best available measurements of the thermal expansion of $\beta$-La. 
Data from Eliseev et al. [423] are inconsistent with those of other researchers, and should probably be disregarded because they were collected from a sample whose DTA curves show several large peaks from unidentified phases.

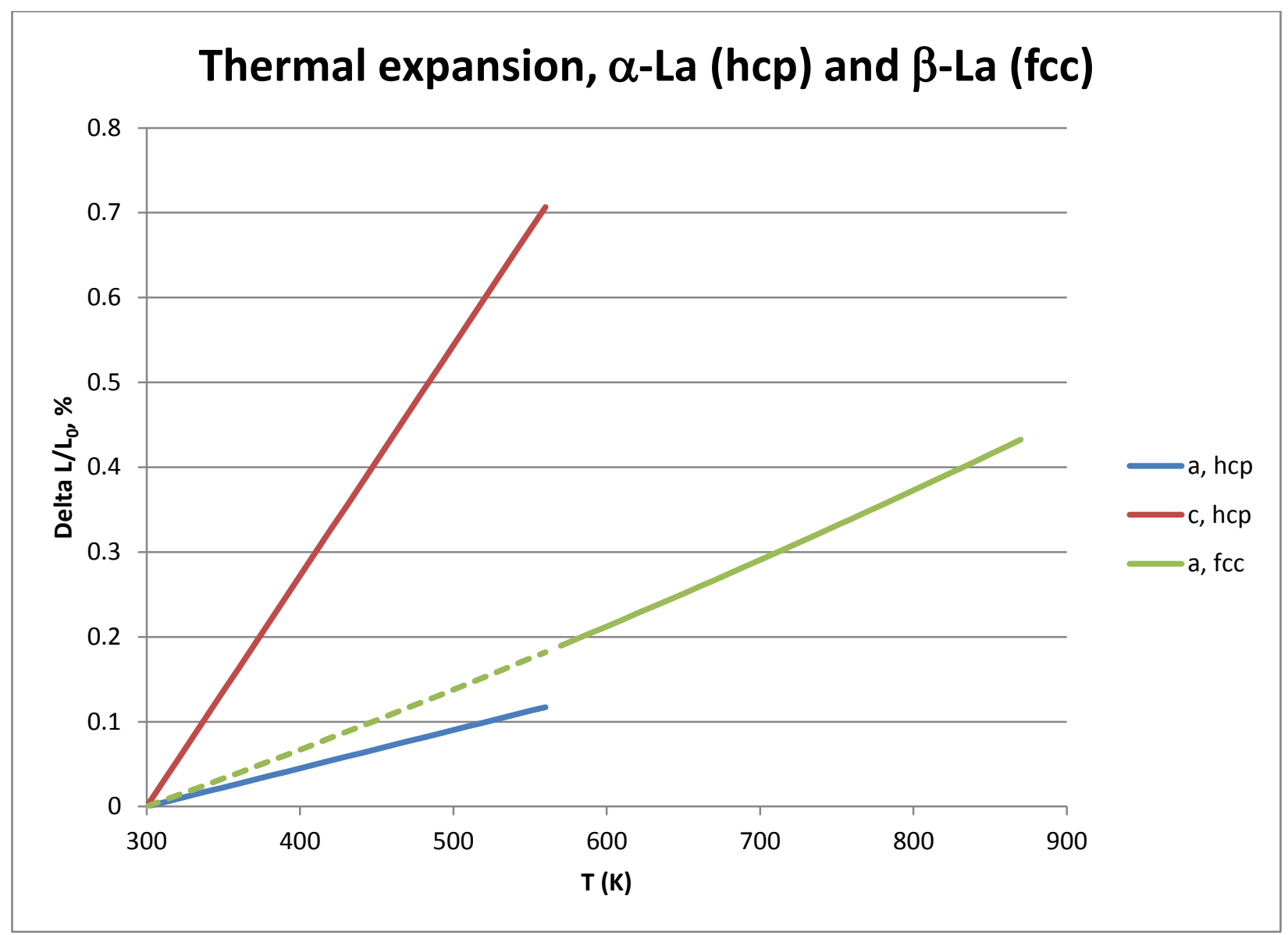

Figure 108: Thermal expansion of single crystals of $\alpha$ - and $\beta$-La, based on values calculated from Equation 99 through Equation 101 using a reference temperature of $300 \mathrm{~K}$. Dotted line for $\beta$-La indicates that it is likely to be present (particularly during coolig) but is not thermodynamically stable.

\subsubsection{Coefficients of thermal expansion}

Published coefficients of thermal expansion are summarized in Table 22. Values from reference [220] are derived from the single-crystal data originally published in reference [221] and repeated in the CRC Handbook of Chemistry and Physics [17]. These values are therefore consistent with each other and with the figures and equations in this section of the handbook. Values from reference [9] are derived from the polycrystalline material measured by Barson et al. [417]. Similarities between the coefficients of thermal expansion for the polycrystalline data and the single-direction coefficient parallel to the $a$ axis suggest that the sample used by Barson et al. may have had a high degree of preferred orientation.

Spedding et al. noted that their measurements were generally within $\sim 5 \%$ of previous measurements from polycrystalline samples (e.g., reference [417]) for "mid-range" temperatures of approximately 400 ${ }^{\circ} \mathrm{C}$. However, they also noted that average deviations between their measurements and previous ones were $\sim 20 \%$ at the ends of the measurement range. Thus, the agreement between the values in Table 22 
suggests that they were all derived from the same measurements, and should not be interpreted as independent. Further measurements are needed.

Table 22. Coefficients of thermal expansion for La. Coefficients with ranges of temperatures are averages across the temperature ranges.

\begin{tabular}{llcl} 
Description & $\mathrm{T}\left({ }^{\circ} \mathrm{C}\right)$ & $\begin{array}{c}\text { Coefficient } \\
\left(\times 10^{6} /{ }^{\circ} \mathrm{C}\right)\end{array}$ & Reference \\
\hline $\begin{array}{l}\alpha \text {-La, parallel } \\
\text { to } a \text { axis }\end{array}$ & 25 & 4.5 & {$[17,220]$} \\
$\begin{array}{l}\alpha \text {-La, parallel } \\
\text { to } c \text { axis }\end{array}$ & 25 & 27.2 & {$[17,220]$} \\
$\begin{array}{l}\alpha \text {-La, } \\
\text { polycrystal }\end{array}$ & 25 & 12.1 & {$[17,220]$} \\
$\begin{array}{l}\alpha \text {-La, not } \\
\text { specified }\end{array}$ & 25 & 4.9 & {$[9]$} \\
$\begin{array}{l}\alpha \text {-La, not } \\
\text { specified }\end{array}$ & -173 to +310 & 5.2 & {$[9]$} \\
$\beta$-La & 400 & 7.9 & {$[221]$} \\
$\beta$-La & +325 to +775 & 9.6 & {$[9]$} \\
\hline
\end{tabular}

\subsubsection{Molar volumes and densities}

Molar volumes for $\alpha$ - and $\beta$-La can be calculated using Equation 102 and Equation 103. Densities can be calculated either from equations in reference [221] or by dividing the molar mass of La (138.91 $\mathrm{g})$ by the molar volumes (Equation 3).

Figure 109 shows molar volumes and densities for La as functions of temperature. Data for $\beta$-La is extrapolated to the $\beta-\gamma$ phase transformation temperature, following Spedding et al. [221 Figure 1]. Data for $\gamma$-La is the average of three widely scattered measurements.

Gschneidner reported the molar volumes of $\alpha$-La, $\beta$-La, and $\gamma$-La as $22.54,22.54$, and $23.3 \mathrm{~cm}^{3} / \mathrm{mol}$, respectively [9]. Although he did not specify the temperatures at which these volumes were measured, they appear generally consistent with values in Figure 109. However, a more recent tabulation (also by Gschneidner) provides slightly different values: $22.602 \mathrm{~cm}^{3} / \mathrm{mol}$ for $\alpha$-La at $297 \mathrm{~K}, 22.45 \mathrm{~cm}^{3} / \mathrm{mol}$ for $\beta$ La at $325^{\circ} \mathrm{C}$, and $23.3 \mathrm{~cm}^{3} / \mathrm{mol}$ for $\gamma$-La at $887^{\circ} \mathrm{C}$ [17].

The high-temperature X-ray diffraction data of Spedding et al. [221] indicate a volume decrease of $\sim 0.5 \%$ during the $\alpha-\beta$ transformation and a gain of $\sim 1.3 \%$ during the $\beta-\gamma$ transformation. These values are consistent with the decrease in volume of $\sim 0.3 \%$ during the $\alpha-\beta$ transformation in polycrystalline $\mathrm{La}$ measured by Barson et al. using dilatometry [417]. The volume increase during melting is $0.6 \%$ [415].

Equation 102. Molar volume of $\alpha$-La between 20 and $293{ }^{\circ} \mathrm{C}$ [221 Table IV]

$$
\mathrm{V}=22.5+70 \times 10^{-5} \mathrm{xT}
$$
${ }^{\circ} \mathrm{C}$

where $\mathrm{V}$ is the volume of one mole in $\mathrm{cm}^{3}$, $\mathrm{T}$ is temperature in ${ }^{\circ} \mathrm{C}$, and $\mathrm{T}$ is between 20 and 293 
Equation 103. Molar volume of $\beta$-La between 20 and $598^{\circ} \mathrm{C}$ [221 Table IV]

$$
\mathrm{V}=22.46+44 \times 10^{-5} \times \mathrm{T}+13 \times 10^{-8} \times \mathrm{T}^{2}
$$

where $\mathrm{V}$ is the volume of one mole in $\mathrm{cm}^{3}$, $\mathrm{T}$ is temperature in ${ }^{\circ} \mathrm{C}$, and $\mathrm{T}$ is between 20 and 598 ${ }^{\circ} \mathrm{C}$

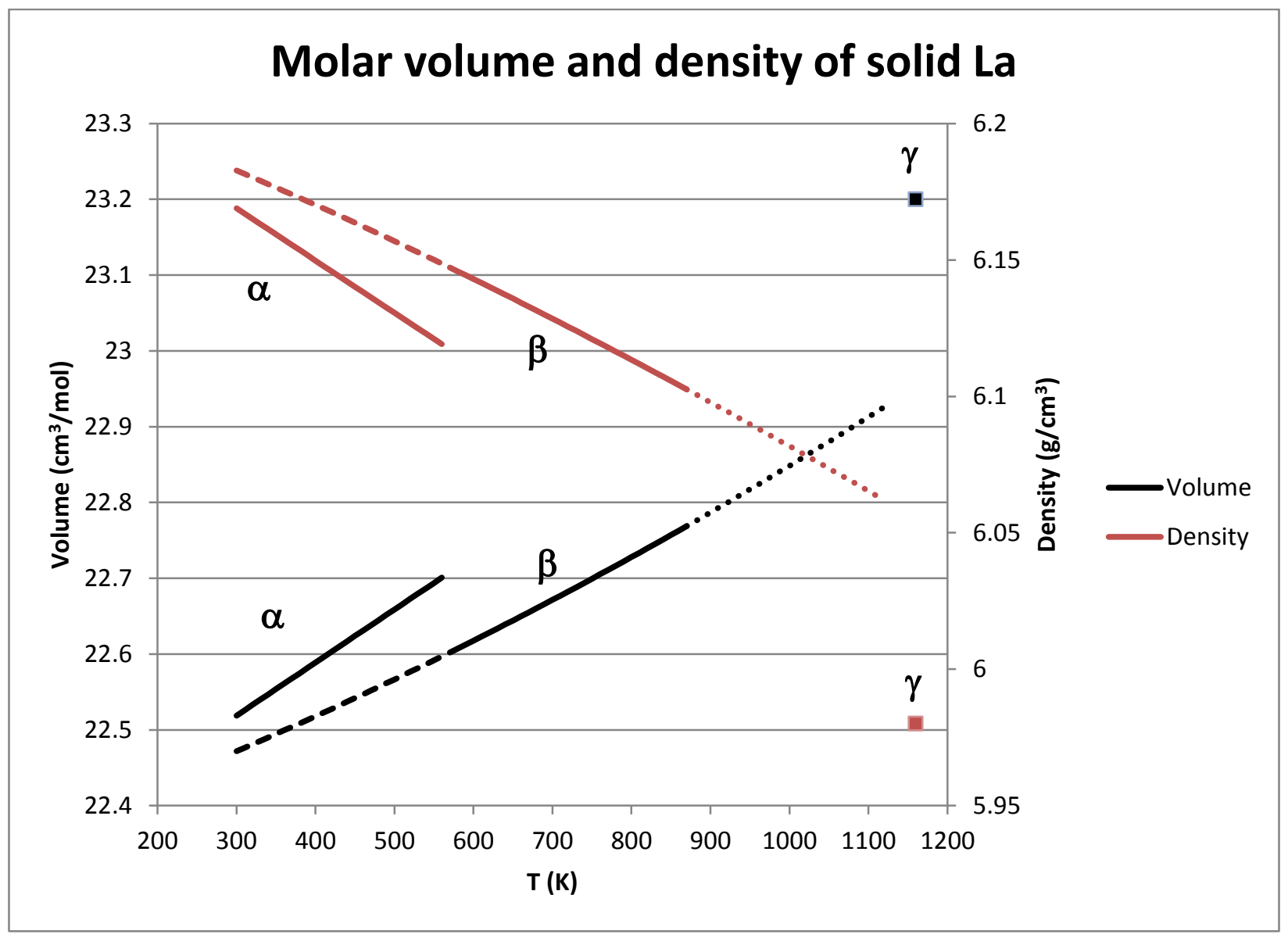

Figure 109: Densities and molar volumes of La phases ([221], Equation 102, Equation 103). Dashed lines show properties of $\beta$-La at temperatures where it is thermodynamically unstable but likely to occur; dotted lines show extrapolation beyond the upper temperatures of the equations following [221 Figure 1].

Measured densities of La liquids near the melting temperature vary between 5.91 and $5.98 \mathrm{~g} / \mathrm{cm}^{3}$, as summarized by Kononenko et al. [424]. The value of $5.96 \mathrm{~g} / \mathrm{cm}^{3}$ in the CRC Handbook of Chemistry and Physics [17 Table 12] is a defensible approximation to the actual value.

There is less agreement about changes in the density of liquid La as a function of temperature. Wittenberg et al. reported that the density of liquid La decreased by $2.37 \times 10^{-4} \mathrm{~g} / \mathrm{cm}^{3} \cdot \mathrm{K}$ based on four measurements between 951 and $1004^{\circ} \mathrm{C}(1224$ and1277 K) [425, 426], and Kononenko et al. reported that it decreased by $0.61 \times 10^{-4} \mathrm{~g} / \mathrm{cm}^{3}-\mathrm{K}$ over the temperature range from 1193 to $1873 \mathrm{~K}$ [424].

\subsubsection{Ce}

\subsubsection{Introduction}

Experimental measurements of the thermal expansion of solid Ce phases are limited to hightemperature X-ray diffraction of single crystals of $\gamma$-Ce and a single figure with dilatometer data from a 
sample of polycrystalline Ce at temperatures between $\sim 0$ and $750{ }^{\circ} \mathrm{C}$. The thermal expansion shown by the dilatometry data is greater than the thermal expansion from the X-ray diffraction data.

The single available measurement of the density of $\delta$-Ce indicates that it is $6.67 \mathrm{~g} / \mathrm{cm}^{3}$ at $757{ }^{\circ} \mathrm{C}$.

\subsubsection{Thermal expansion}

Spedding et al. [221] used high-temperature X-ray diffraction of $\gamma$-Ce to develop a polynomial that can be used to calculate the lattice parameter as a function of temperature (Equation 104, Figure 110).

Equation 104. $a$ lattice parameter of $\gamma$-Ce between 20 and $619^{\circ} \mathrm{C}$ [221 Table IV]

$$
a=5.1604+3.28 \times 10^{-5} \times \mathrm{T}-0.59 \times 10^{-8} \mathrm{xT}^{2}+1.37 \times 10^{-11} \mathrm{xT}^{3}
$$

where $a$ is a lattice parameter in $\AA$, T is temperature in ${ }^{\circ} \mathrm{C}$, and $\mathrm{T}$ is between 20 and $619{ }^{\circ} \mathrm{C}$

Barson et al. measured the thermal expansion of polycrystalline $\gamma$-Ce using dilatometry. The single figure in which they presented their results suggests a thermal expansion higher than that determined from the X-ray diffraction data [417 Figure 2]. It seems likely that the single-crystal data of Spedding et al. may represent the polycrystalline thermal expansion of $\gamma$ La more accurately than the dilatometer data of Barson et al.; however, further measurements are required.

The volume of Ce decreases by $\sim 1 \%$ during melting [415].

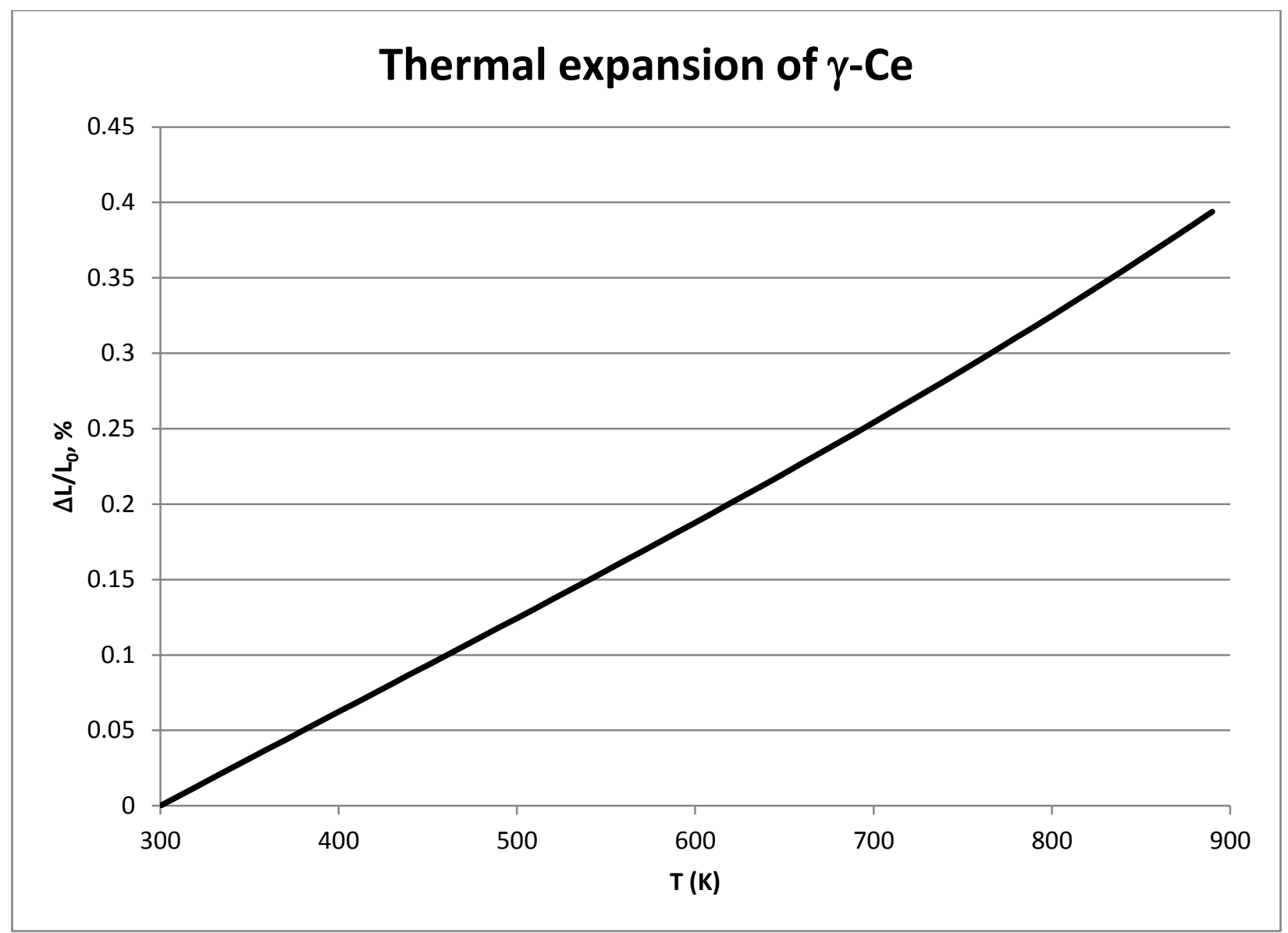

Figure 110: Thermal expansion of $\gamma$-Ce, based on values calculated from Equation 104 using a reference temperature of $300 \mathrm{~K}$. 


\subsubsection{Coefficients of thermal expansion}

Published coefficients of thermal expansion for $\gamma$-Ce are summarized in Table 23. Values from reference [220] are derived from the high-temperature X-ray diffraction data in reference [221] and repeated in reference [17]. These values are therefore consistent with each other and with the figures and equations in this section of the handbook. Values from reference [9] are derived from the work of Barson et al. [417], which involved dilatometer measurements.

As noted by Spedding et al [221], thermal expansion values based on their X-ray diffraction data are consistent with the dilatometry measurements of Barson et al. [417 Figure 3]) for "mid-range" temperatures of approximately $400{ }^{\circ} \mathrm{C}$. However, the thermal conductivity of Barson et al. is significantly higher than that of Spedding et al. at $25^{\circ} \mathrm{C}$, and the thermal conductivity of Barson et al. at $600{ }^{\circ} \mathrm{C}$ is significantly higher than would be expected from the almost linear thermal expansion measurements of Spedding et al. (Figure 110). Barson et al. reported that their sample exhibited plastic flow and permanent deformation at the high-temperature end of their measurement range, which may explain why their results differ from those of Spedding et al. Thus, it seems likely that the X-ray diffraction data of Spedding et al. $[17,220,221]$ is a better representation of the actual thermal expansion of Ce than the dilatometry data of Barson et al. [417]. However, further measurements are needed.

Table 23. Coefficients of thermal expansion for $\gamma$-Ce (single crystals and polycrystals)

\begin{tabular}{lcc}
$\mathrm{T}\left({ }^{\circ} \mathrm{C}\right)$ & $\begin{array}{c}\text { Coefficient } \\
\left(\times 10^{6} /{ }^{\circ} \mathrm{C}\right)\end{array}$ & References \\
\hline 25 & 6.3 & $\begin{array}{c}{[17,220]} \\
\text { following [221] }\end{array}$ \\
25 & 8.5 & {$[9]$} \\
400 & 6.7 & {$[221]$} \\
400 & $\sim 6.5$ & {$[417$ Figure 2] } \\
600 & $\sim 8.5$ & {$[417$ Figure 2] } \\
25 to 725 & 7.1 & {$[9]$} \\
\hline
\end{tabular}

\subsubsection{Molar volumes and densities}

Spedding et al. represented the density of $\gamma$-Ce as a function of temperature by a polynomial (Equation 105, Figure 111). This equation indicates a density of $\sim 6.767 \mathrm{~g} / \mathrm{cm}^{3}$ at $300 \mathrm{~K}$, which is consistent with the room-temperature density of $6.770 \mathrm{~g} / \mathrm{cm}^{3}$ in the CRC Handbook of Chemistry and Physics [17 Table 2]. The density of $6.67 \mathrm{~g} / \mathrm{cm}^{3}$ for $\delta$-Ce at $757{ }^{\circ} \mathrm{C}$ reported by Spedding et al. is also consistent with the value in the CRC Handbook [17 Table 3]. Given the scarcity of published data, it seems likely that densities from both references are based on the same experimental measurements.

The transformation from $\gamma$ - to $\delta$-Ce causes a volume increase of $\sim 0.1 \%$ [221].

Equation 105. Density of $\gamma$-Ce between 20 and $619^{\circ} \mathrm{C}$ [221 Table IV]

$$
\rho=6.771-12.6 \times 10^{-5} \times \mathrm{T}+1.5 \times 10^{-8} \times \mathrm{T}^{2}-4.5 \times 10^{-11} \mathrm{xT}^{3}
$$

where $\rho$ is the density in $\mathrm{g} / \mathrm{cm}^{3}, \mathrm{~T}$ is temperature in ${ }^{\circ} \mathrm{C}$, and $\mathrm{T}$ is between 20 and $619{ }^{\circ} \mathrm{C}$ 
Measurements of the density of liquid Ce close to the melting point range from $6.41 \mathrm{~g} / \mathrm{cm}^{3}$ [427] to $6.94 \mathrm{~g} / \mathrm{cm}^{3}$ [426]. In the absence of definitive measurements, the value of $6.68 \mathrm{~g} / \mathrm{cm}^{3}$ in the CRC Handbook of Chemistry and Physics [17 Table 12] may be the best available estimate.

Measurements of the temperature dependence of the density of liquid Ce include $2.27 \times 10^{-4} \mathrm{~g} / \mathrm{cm}^{3} \cdot \mathrm{K}$ [428], $2.37 \times 10^{-4} \mathrm{~g} / \mathrm{cm}^{3} \cdot \mathrm{K}$ [425], $7 \times 10^{-4} \mathrm{~g} / \mathrm{cm}^{3} \cdot \mathrm{K}$ [424], and $8.31 \times 10^{-4} \mathrm{~g} / \mathrm{cm}^{3} \cdot \mathrm{K}$ [427], with the larger measurements being the most recent. In the absence of definitive measurements, it seems likely that the density of liquid Ce decreases by $\sim 8 \times 10^{-4} \mathrm{~g} / \mathrm{cm}^{3} \cdot \mathrm{K}$.

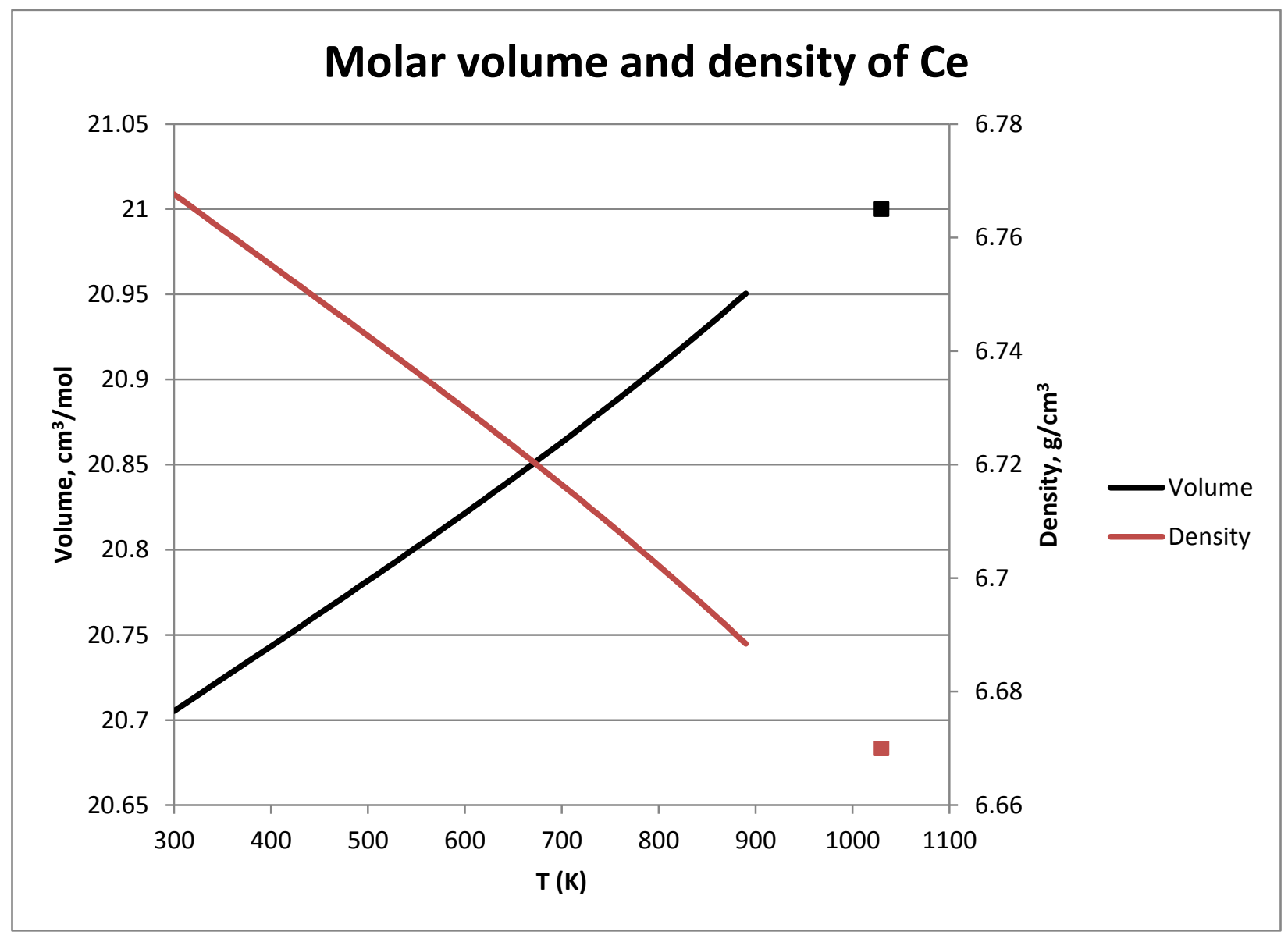

Figure 111: Densities and molar volumes of $\gamma$-Ce (lines calculated from Equation 105) and $\rho$-Ce (symbols showing values from reference [221]

\subsection{5 $\mathrm{Pr}$}

\subsubsection{Introduction}

Experimental measurements of the thermal expansion of $\alpha$-Pr phases include high-temperature X-ray diffraction of single crystals [221], two papers with figures showing dilatometer data from polycrystalline samples $[417,419]$, and recent synchrotron diffraction measurements of changes in the $c$ lattice parameter [245]. Data on the thermal expansion of $\beta$-Pr includes two publications with average values of the coefficient of thermal expansion. Data on thermal expansion of the room-temperature fcc phase is found in a single figure that shows measurements from synchrotron diffraction [245 Figure 5]. 


\subsubsection{Thermal expansion}

Spedding et al. [221] used high-temperature X-ray diffraction to measure the lattice parameters of $\alpha$ $\mathrm{Pr}$, and developed polynomials that can be used to calculate the lattice parameters as functions of temperature (Equation 106 and Equation 107).

Figure 108 shows the corresponding thermal expansion values, calculated based on a reference temperature of $300 \mathrm{~K}$.

Equation 106. $a$ lattice parameter of $\alpha$-Pr between 20 and $449^{\circ} \mathrm{C}$ [221 Table IV]

$$
a=3.6702+1.66 \times 10^{-5} \times \mathrm{T}
$$

where $a$ is a lattice parameter in $\AA$, T is temperature in ${ }^{\circ} \mathrm{C}$, and $\mathrm{T}$ is between 20 and $449{ }^{\circ} \mathrm{C}$

Equation 107. $c$ lattice parameter of $\alpha$-Pr between 20 and $449^{\circ} \mathrm{C}$ [221 Table IV]

$$
c=11.828+13.3 \times 10^{-5} \times \mathrm{T}
$$

where $c$ is a lattice parameter in $\AA$, T is temperature in ${ }^{\circ} \mathrm{C}$, and $\mathrm{T}$ is between 20 and $449{ }^{\circ} \mathrm{C}$

The thermal expansion of the $c$ lattice parameter in Figure 112 is consistent with the "equilibrium" results of Kuznetsov et al. [245 Figure 5b], which were obtained using angle-dispersive synchrotron diffraction. The "non-equilibrium" results of Kuznetsov et al. [245 Figure 5a] show a similar total difference in $c$ at $\sim 300$ and $700 \mathrm{~K}$, but with a stronger dependence on temperature. (In the context of the Kuznetsov et al. paper, "equilibrium" and "non-equilibrium" refer to the absence or presence of a significant a thermal gradient in the sample during data collection rather than to the thermodynamic stability of the phases present.)

Barson et al. measured the thermal expansion of polycrystalline Pr using dilatometry. Their results are shown graphically [417 Figure 2], and fall between the single-crystal values for the $a$ and $c$ directions from the high-temperature X-ray diffraction data of Spedding et al. [221] (Figure 112).

In view of the close agreement between the thermal expansion values for the $c$ lattice parameter in the data of Spedding et al. and the "equilibrium" data of Kuznetsov et al., it seems likely that both values are fairly accurate representations of the thermal expansion of $\alpha-\operatorname{Pr}$ in the absence of a thermal gradient. Differences between the "equilibrium" and "non-equilibrium" values of Kuznetsov et al. may be relevant for nuclear fuels, where thermal gradients are likely.

\subsubsection{Coefficients of thermal expansion}

Published coefficients of thermal expansion for Pr are summarized in Table 24. The table shows values from a review paper by Beaudry and Gschneidner [220], which are derived from the data of Spedding et al. [221] and repeated by Gschneidner in the CRC Handbook of Chemistry and Physics [17]. These values (and the figures and equations in this section of the Handbook) are derived from the same experimental data and are therefore consistent with each other. Values from the 1961 review by Gschneidner [9] are derived from the dilatometry results of Barson et al. [417]. The coefficient of thermal expansion parallel to $c$ at $300 \mathrm{~K}$ reported by Kuznetsov et al. is an independent measurement, and is $\sim 13 \%$ higher than the coefficient derived from the data of Spedding et al. [245]

The coefficient for polycrystalline $\alpha$-Pr in Table 24 seems to be a weighted average of the coefficients parallel to the $a$ and $c$ directions rather than an experimental measurement. It is higher than the experimental measurement of Barson et al. [417 Figure 5].

The thermal expansion coefficient of the fcc Pr phase is negative between 550 and $800 \mathrm{~K}$, and close to zero at higher temperatures [245]. 
Table 24. Coefficients of thermal expansion for $\alpha-\operatorname{Pr}$

\begin{tabular}{llll} 
Description & $\mathrm{T}(\mathrm{K})$ & Coefficient $\left(\times 10^{6} / \mathrm{K}\right)$ & Reference \\
\hline Parallel to $a$ axis & 298 & 4.5 & {$[17,220]$} \\
Parallel to $c$ axis & 298 & 11.2 & {$[17,220]$} \\
Parallel to $c$ axis & 300 & 12.73 & {$[245]$} \\
Parallel to $c$ axis & 900 & 20.23 & {$[245]$} \\
Polycrystal & 298 & 6.7 & {$[17,220]$} \\
Polycrystal & $25 \mathrm{C}$ & 4.8 & {$[9]$} \\
Polycrystal & $25-725$ C & 6.5 & {$[9]$} \\
\hline
\end{tabular}

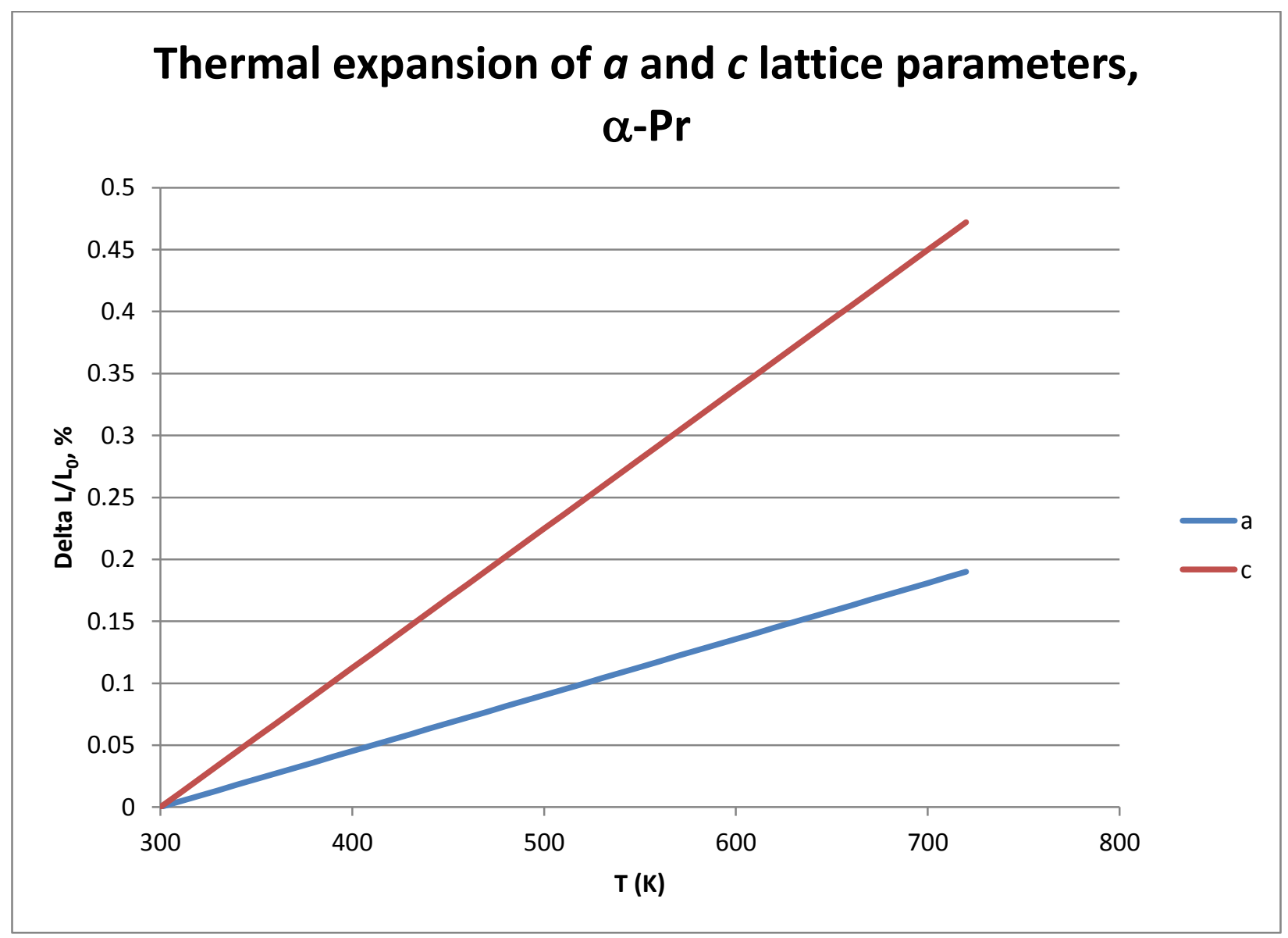

Figure 112: Thermal expansion of a and c lattice parameters of $\alpha$-Pr, calculated from Equation 106 and Equation 107 with a reference temperature of $300 \mathrm{~K}$

\subsubsection{Molar volumes and densities}

Figure 113 shows molar volumes of Pr phases as functions of temperature. Approximations for the molar volume of $\alpha$-Pr are based on the high-temperature X-ray diffraction data of Spedding et al. [221] 
(Equation 108). Approximations for the molar volume of the fcc phase are also shown twice: once for measurements from samples without thermal gradients, and once for measurements from samples with sharp thermal gradients.

Equation 108. Molar volume of $\alpha$-Pr between 20 and $293{ }^{\circ} \mathrm{C}$ [221 Table IV]

$$
\mathrm{V}=20.778+42.4 \times 10^{-5} \times \mathrm{T}
$$

where $\mathrm{V}$ is the molar volume in $\mathrm{cm}^{3}$, $\mathrm{T}$ is temperature in ${ }^{\circ} \mathrm{C}$, and $\mathrm{T}$ is between 20 and $293{ }^{\circ} \mathrm{C}$

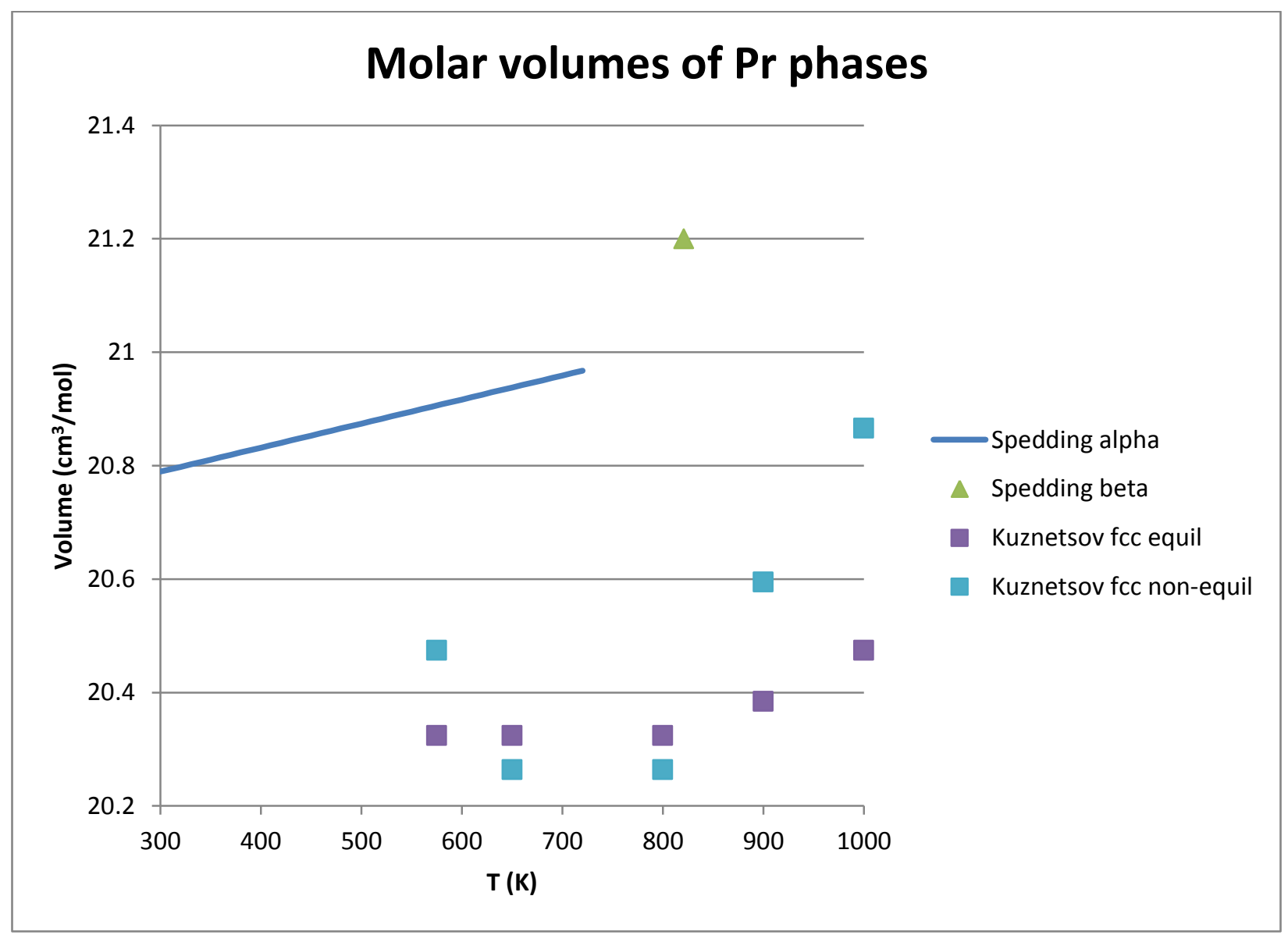

Figure 113: Molar volumes of Pr phases (Equation 108 and references [221 Table 2] and [245 Figure 4])

The transformation from $\beta$-Pr to liquid causes a volume increase of $\sim 0.02 \%$ [415].

Measurements of the density of liquid Pr close to the melting point range from $6.27 \mathrm{~g} / \mathrm{cm}^{3}$ to 6.66 $\mathrm{g} / \mathrm{cm}^{3}$ (as summarized in reference [424]). In the absence of definitive measurements, the value of 6.59 $\mathrm{g} / \mathrm{cm}^{3}$ in the CRC Handbook of Chemistry and Physics [17 Table 12] may be the best available estimate.

Measurements of the temperature dependence of the density of liquid Pr include $2.48 \times 10^{-4} \mathrm{~g} / \mathrm{cm}^{3}-\mathrm{K}$ [425] and $0.93 \times 10^{-4} \mathrm{~g} / \mathrm{cm}^{3}-\mathrm{K}$ [424]. Further research is needed to determine the correct value. 


\subsubsection{Nd}

\subsubsection{Introduction}

Most of the available experimental data about thermal expansion of $\mathrm{Nd}$ is from a single reference with high-temperature X-ray diffraction data for single crystals of $\alpha$-Nd [221]. Limited data about the thermal expansion of polycrystalline samples is presented graphically in two other references $[417,419]$.

\subsubsection{Thermal expansion}

Spedding et al. [221] used high-temperature X-ray diffraction to measure the lattice parameters of $\alpha$ $\mathrm{Nd}$, and developed a polynomial that can be used to calculate the lattice parameters as functions of temperature (Equation 109 and Equation 110). These equations correspond to lattice parameters $a=3.659$ $\AA$ and $c=11.806 \AA$ at $300 \mathrm{~K}$. Figure 114 shows the corresponding thermal expansions of the individual lattice parameters, calculated based on a reference temperature of $300 \mathrm{~K}$.

Equation 109. $a$ lattice parameter of $\alpha-\mathrm{Nd} 20$ and $969^{\circ} \mathrm{C}$ [221 Table IV]

$$
a=3.6582+3.18 \times 10^{-5} \mathrm{xT}-3.96 \times 10^{-8} \mathrm{xT}^{2}+4.92 \times 10^{-11} \mathrm{xT}^{3}
$$

where $a$ is a lattice parameter in $\AA$, T is temperature in ${ }^{\circ} \mathrm{C}$, and $\mathrm{T}$ is between 20 and $969{ }^{\circ} \mathrm{C}$

Equation 110. $c$ lattice parameter of $\alpha-\mathrm{Nd}$ between 20 and $969^{\circ} \mathrm{C}$ [221 Table IV]

$$
c=11.802+16.6 \times 10^{-5} \times \mathrm{T}-14.1 \times 10^{-8} \mathrm{xT}^{2}+17.8 \times 10^{-11} \mathrm{xT}^{3}
$$

where $c$ is a lattice parameter in $\AA$, T is temperature in ${ }^{\circ} \mathrm{C}$, and $\mathrm{T}$ is between 20 and $969{ }^{\circ} \mathrm{C}$

Barson et al. [417] and Frizen et al. [419] measured the thermal expansion of polycrystalline Nd using dilatometry. The measurements of Barson et al. fall between the single-direction expansions of the $a$ and $c$ lattice parameters in Figure 114. The measurements of Frizen et al. are similar to the single-direction expansion of the $a$ parameter from the X-ray diffraction data of Spedding et al.

Because the thermal expansion of $\alpha-\mathrm{Nd}$ is anisotropic, the thermal expansion of actual samples may vary as a result of differences in preferred orientation between the samples. It therefore seems reasonable to approximate the thermal expansion of polycrystalline $\mathrm{Nd}$ by a weighted average of the expansions in the $a$ and $c$ directions (i.e., expansion in the a direction is weighted twice as heavily as expansion in the c direction because of crystal symmetry).

The volume change associated with the transformation from $\alpha-\mathrm{Nd}$ to $\beta-\mathrm{Nd}$ is small $[221,417]$.

No information about the thermal expansion of $\beta-\mathrm{Nd}$ is available.

\subsubsection{Coefficients of thermal expansion}

Published coefficients of thermal expansion for $\mathrm{Nd}$ are summarized in Table 25. Values from Beaudry and Gschneidner [220] are derived from the data of Spedding et al. [221] and repeated by Gschneidner in a 2015 review [17]. These values are therefore consistent with each other and with the figures and equations in this section of the handbook. The coefficient for polycrystalline $\alpha-\mathrm{Nd}$ appears to be a weighted average of the coefficients parallel to the $a$ and $c$ directions rather than an experimental measurement. Values from a 1961 review by Gschneidner et al. [9] are derived from the work of Barson et al. [417], which involved polycrystalline material.

Spedding et al. noted that their measurements were generally within $\sim 5 \%$ of previous measurements (e.g., [417]) for "mid-range" temperatures of approximately $400^{\circ} \mathrm{C}$. However, they also noted that average deviations between their measurements and previous ones were $\sim 20 \%$ at the ends of the measurement range. Thus, the agreement between the values in Table 25 may indicate that they were all derived from the same measurements and should not be considered as independent verification. Further measurements are needed. 
Table 25. Coefficients of thermal expansion for $\alpha-\mathrm{Nd}$

\begin{tabular}{|c|c|c|c|}
\hline Description & $\mathrm{T}\left({ }^{\circ} \mathrm{C}\right)$ & $\begin{array}{l}\text { Coefficient } \\
\left(\times 10^{6} /{ }^{\circ} \mathrm{C}\right)\end{array}$ & Reference \\
\hline $\begin{array}{l}\alpha-\mathrm{Nd} \text {, parallel } \\
\text { to } a \text { axis }\end{array}$ & 25 & 7.6 & {$[17,220]$} \\
\hline $\begin{array}{l}\alpha-\mathrm{Nd} \text {, parallel } \\
\text { to } a \text { axis }\end{array}$ & 400 & 4.5 & [221] \\
\hline $\begin{array}{l}\alpha-\mathrm{Nd} \text {, parallel } \\
\text { to } c \text { axis }\end{array}$ & 25 & 13.5 & {$[17,220]$} \\
\hline $\begin{array}{l}\alpha-\mathrm{Nd} \text {, parallel } \\
\text { to } c \text { axis }\end{array}$ & 400 & 11.7 & [221] \\
\hline $\begin{array}{c}\alpha-\mathrm{Nd}, \\
\text { polycrystal }\end{array}$ & 25 & 9.6 & {$[17,220]$} \\
\hline $\begin{array}{c}\alpha-\mathrm{Nd}, \\
\text { polycrystal }\end{array}$ & 25 & 6.7 & [9] \\
\hline $\begin{array}{c}\alpha-\mathrm{Nd}, \\
\text { polycrystal }\end{array}$ & 400 & 6.8 & [221] \\
\hline $\begin{array}{c}\alpha-\mathrm{Nd}, \\
\text { polycrystal }\end{array}$ & -173 to 850 & 8.6 & [9] \\
\hline
\end{tabular}




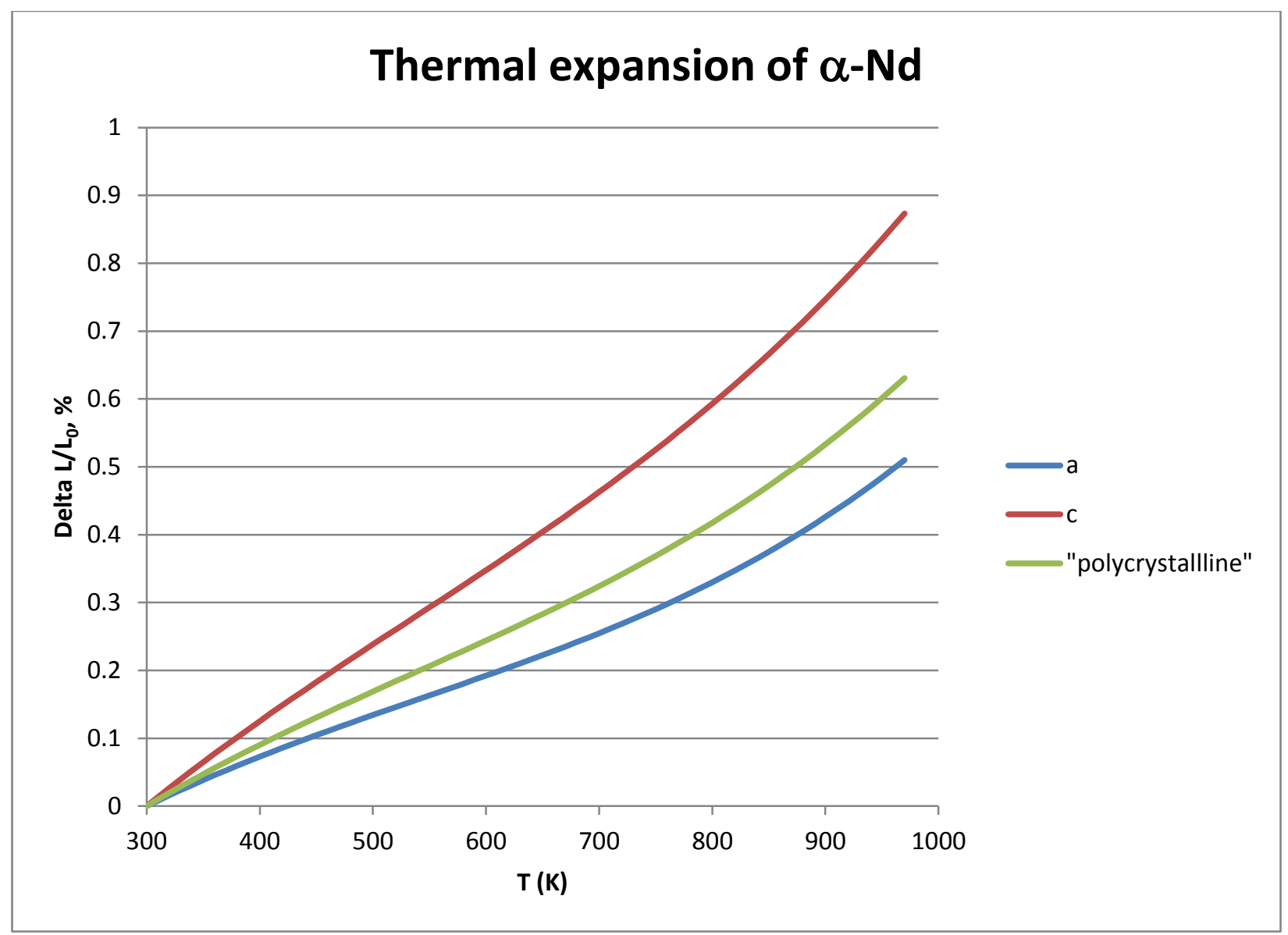

Figure 114: Thermal expansion of $\alpha-\mathrm{Nd}$. "a" and "c" are single-direction expansions in the $a$ and $c$ directions, based on values calculated from Equation 109 and Equation 110 using a reference temperature of $300 \mathrm{~K}$. The "polycrystalline" value is a weighted average of the single-direction values.

\subsubsection{Molar volumes and densities}

The molar volume of $\alpha-\mathrm{Nd}$ can be calculated as a function of temperature from an equation published by Spedding et al [221] (Equation 111, Figure 115), giving a room-temperature volume of $\sim 20.6 \mathrm{~cm}^{3} / \mathrm{mol}$. The molar volume of $\beta-\mathrm{Nd}$ is $21.2 \mathrm{~cm}^{3} / \mathrm{mol}$, based on four measurements with an average temperature of $883{ }^{\circ} \mathrm{C}$ [221]. The corresponding density is $6.80 \mathrm{~g} / \mathrm{cm}^{3}$. These molar volumes are consistent with those in a recent tabulation $\left(20.583 \mathrm{~cm}^{3}\right.$ for $\alpha-\mathrm{Nd}$ at $24{ }^{\circ} \mathrm{C}$ and $21.2 \mathrm{~g} / \mathrm{cm}^{3}$ for $\beta-\mathrm{Nd}$ at $\left.883 \mathrm{~K}\right)$ [17], which may be derived from the same experimental data.

The temperature dependence of the density of liquid Nd has been reported twice. Rohr [428] found that the density decreased by $\sim 0.5 \mathrm{mg} / \mathrm{cm}^{3}-\mathrm{K}$ between 1310 and $1505 \mathrm{~K}$, while Kononenko et al. reported a decrease of $\sim 0.76 \mathrm{mg} / \mathrm{cm}^{3}-\mathrm{K}$ from 1289 to $1630 \mathrm{~K}$.

Equation 111. Molar volume of $\alpha-\mathrm{Nd}$ between 20 and $696{ }^{\circ} \mathrm{C}$ [221 Table IV]

$\mathrm{V}=20.60+65 \times 10^{-5} \mathrm{xT}-70 \times 10^{-8} \mathrm{xT}^{2}+88 \times 10^{-11} \mathrm{xT}^{3}$

where $\mathrm{V}$ is molar volume in $\mathrm{cm}^{3}$, $\mathrm{T}$ is temperature in ${ }^{\circ} \mathrm{C}$, and $\mathrm{T}$ is between 20 and $696{ }^{\circ} \mathrm{C}$ 


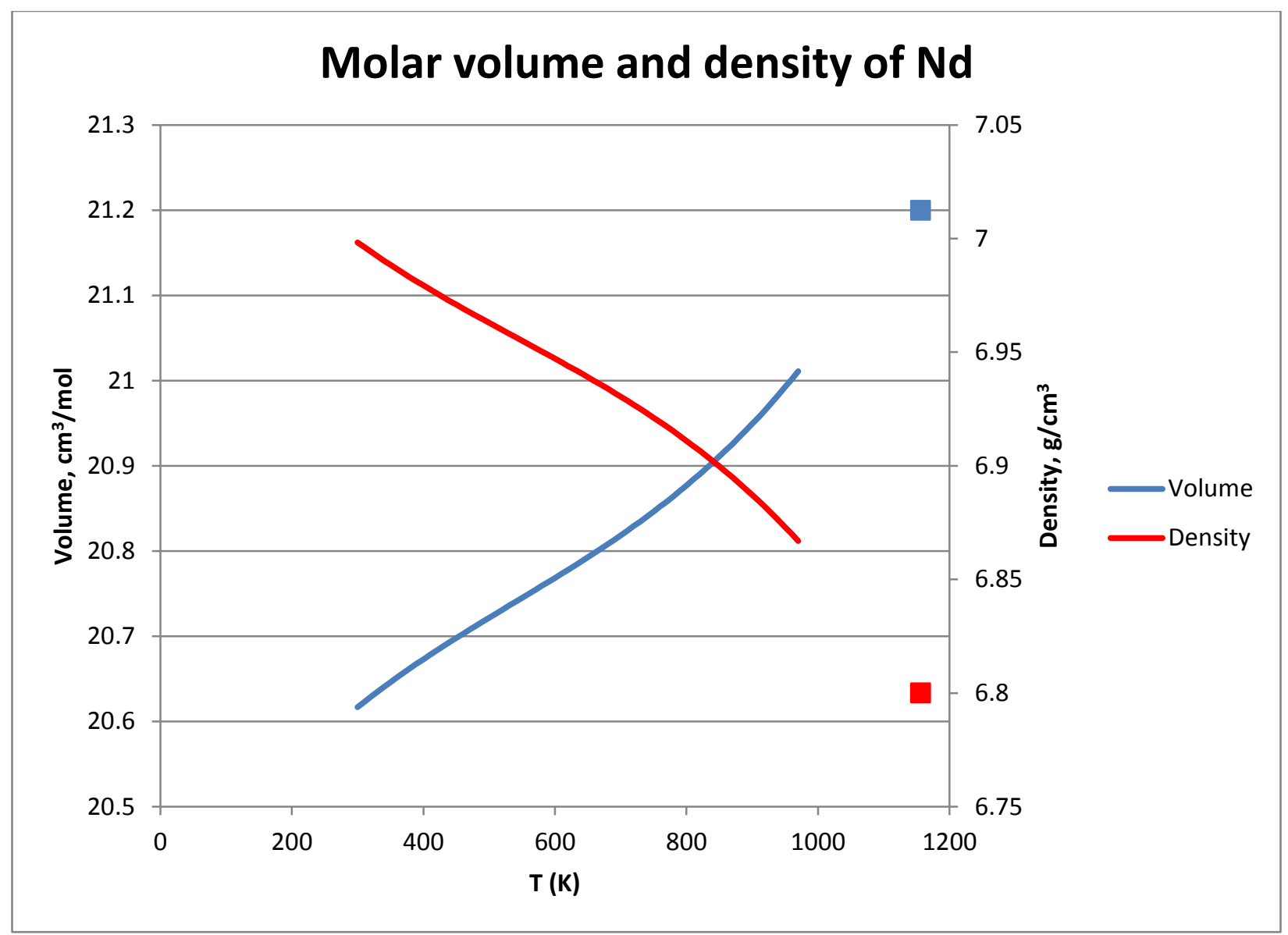

Figure 115: Molar volumes and densities of $\alpha-\mathrm{Nd}$ (curves) and $\beta-\mathrm{Nd}$ (squares) (Equation 111 and reference [221]).

The transformation from $\beta$-Nd to liquid causes a volume increase of $\sim 0.9 \%$ [415].

Measurements of the density of liquid $\mathrm{Nd}$ close to the melting point range from $6.46 \mathrm{~g} / \mathrm{cm}^{3}$ to 6.92 $\mathrm{g} / \mathrm{cm}^{3}$ (as summarized by [424]). In the absence of definitive measurements, the value of $6.72 \mathrm{~g} / \mathrm{cm}^{3}$ in the CRC Handbook of Chemistry and Physics [17 Table 12] may be the best available estimate.

Measurements of the temperature dependence of the density of liquid Pr include $2.48 \times 10^{-4} \mathrm{~g} / \mathrm{cm}^{3} \cdot \mathrm{K}$ [425] and $0.93 \times 10^{-4} \mathrm{~g} / \mathrm{cm}^{3} \cdot \mathrm{K}$ [424]. Further research is needed to determine the correct value.

\subsubsection{U-Np}

\subsubsection{Introduction}

No systematic studies of thermal expansion or density in U-Np alloys are available, although Mardon and Pearce reported some data as part of their investigation of the U-Np phase diagram [254]. In interpreting this data, it is important to remember that measurements are from alloys made by progressively re-melting two original $1-\mathrm{g}$ samples (one sample of pure $\mathrm{Np}$, one sample of an alloy with $50 \% \mathrm{~Np}$ ), adding more $\mathrm{U}$ with each re-melting cycle. Masses lost during melting of some compositions were several tens of milligrams (almost half of the mass of the added $U$ ), suggesting the possibility of significant differences between nominal and actual compositions, and also possibly progressive accumulation of impurities such as oxygen. However, data from an alloy with $\sim 50 \% \mathrm{~Np}$ obtained by progressive addition of $\mathrm{U}$ to the original $\mathrm{Np}$ sample were generally in good agreement with data from the original 50 at $\% \mathrm{~Np}$ sample. 


\subsubsection{Thermal expansion}

Quantitative data on the thermal expansion of $(\alpha-U)$ solid solutions is not available. Qualitatively, however, the thermal expansion of $(\alpha-\mathrm{U})$ with $40 \mathrm{wt} \% \mathrm{~Np}$ resembles that of $\alpha-\mathrm{U}$ in that both phases expand in the $a$ and $c$ directions and contract slightly in the $b$ direction during heating [254]. In the absence of experimental data, it is probably reasonable to use the thermal expansion data from Section 3.3.1 of the handbook to approximate the thermal expansion of $\alpha-U$ solid solutions.

\subsubsection{Coefficients of thermal expansion}

The $a$ lattice parameter of a ( $\beta$-Np) solid solution with $\sim 15 \mathrm{wt} \% \mathrm{U}$ varies linearly from $\sim 4.91 \AA$ at $280{ }^{\circ} \mathrm{C}$ to $5.01 \AA$ at $560{ }^{\circ} \mathrm{C}$, and the $c$ lattice parameter varies from $\sim 3.39 \AA$ at $280{ }^{\circ} \mathrm{C}$ to $\sim 3.383 \AA$ at 465 ${ }^{\circ} \mathrm{C}$ [254 Fig. 4] (Figure 116). As a result, the unit-cell volume increases from $\sim 82 \AA^{3}$ at $280{ }^{\circ} \mathrm{C}$ to $\sim 95 \AA^{3}$ at $465^{\circ} \mathrm{C}$ (Equation 5). It should be noted, however, that the data for the $c$ lattice parameter shows considerable scatter.

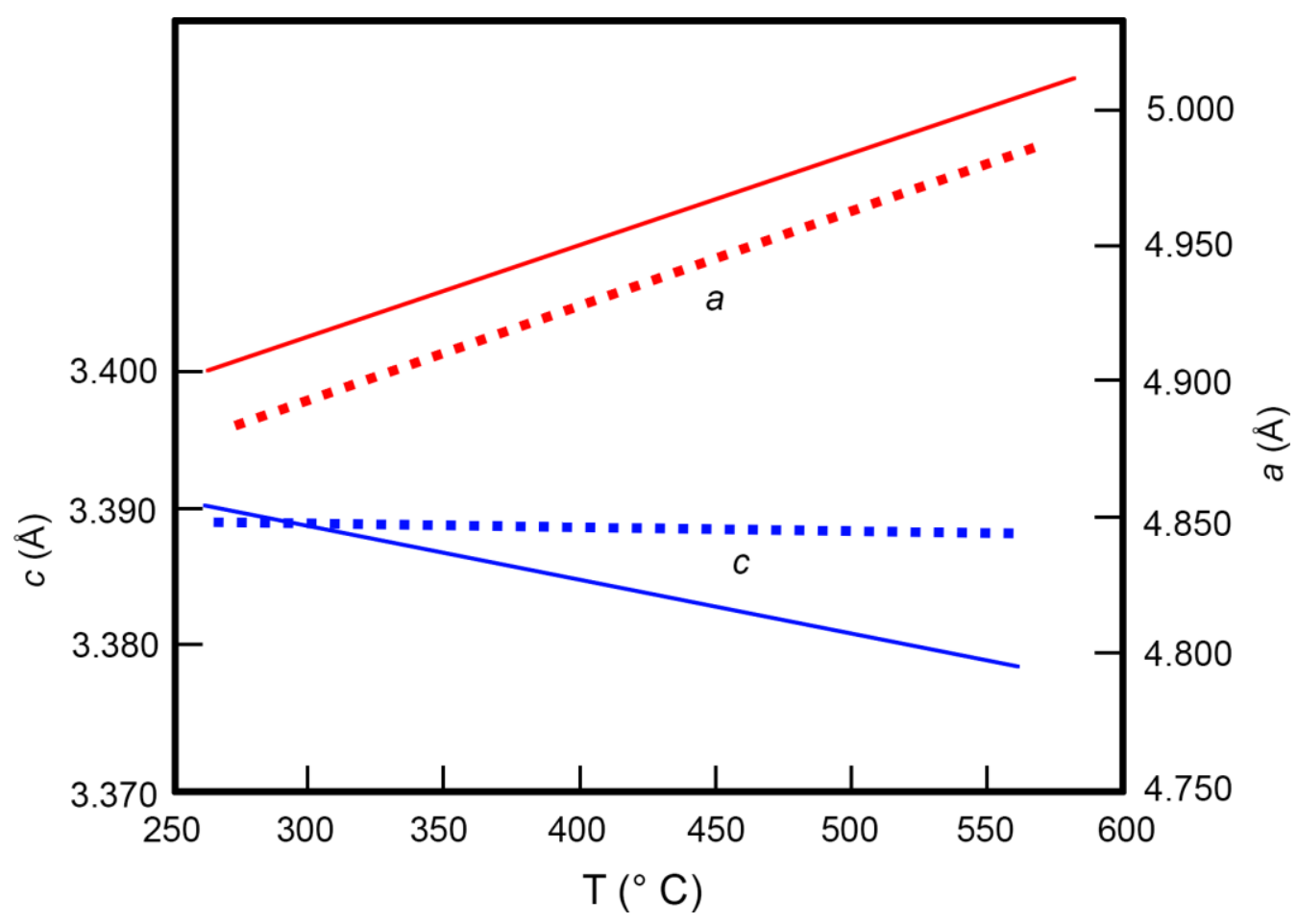

Figure 116. Thermal expansion of individual lattice parameters of $\mathrm{Np}-14.9 \mathrm{wt} \% \mathrm{U}$ (solid lines), with $\beta$ $\mathrm{Np}$ lattice parameters for comparison (dotted lines) (after [254 Fig. 4])

No information is available about coefficients of thermal expansion for other phases.

\subsubsection{Molar volumes and densities}

According to the X-ray data of Mardon and Pearce [254], the room-temperature density of an ( $\alpha-U)$ solid solution with the highest concentration of dissolved $\mathrm{Np}$ is $\sim 19.4 \mathrm{~g} / \mathrm{cm}^{3}$. Although it is not possible to calculate the density of $\delta$-(U,Np) from the X-ray data without knowing its structure, pycnometry data suggests that the room-temperature density of $\delta$-(U,Np) with $25 \% \mathrm{U}$ is $\sim 19.2 \mathrm{~g} / \mathrm{cm}^{3}$ and the roomtemperature density of $\delta$-(U,Np) with $50 \% \mathrm{U}$ is $\sim 18.8 \mathrm{~g} / \mathrm{cm}^{3}$ (Figure 117). Care is needed in interpreting this data, as the pycnometry was intended to assist in identifying phase boundaries rather than to provide quantitative densities. The densities measured by Mardon and Pearce using pycnometry are generally $\sim 0.2-0.3 \mathrm{~g} / \mathrm{cm}^{3}$ lower than the densities calculated from their X-ray diffraction data. 


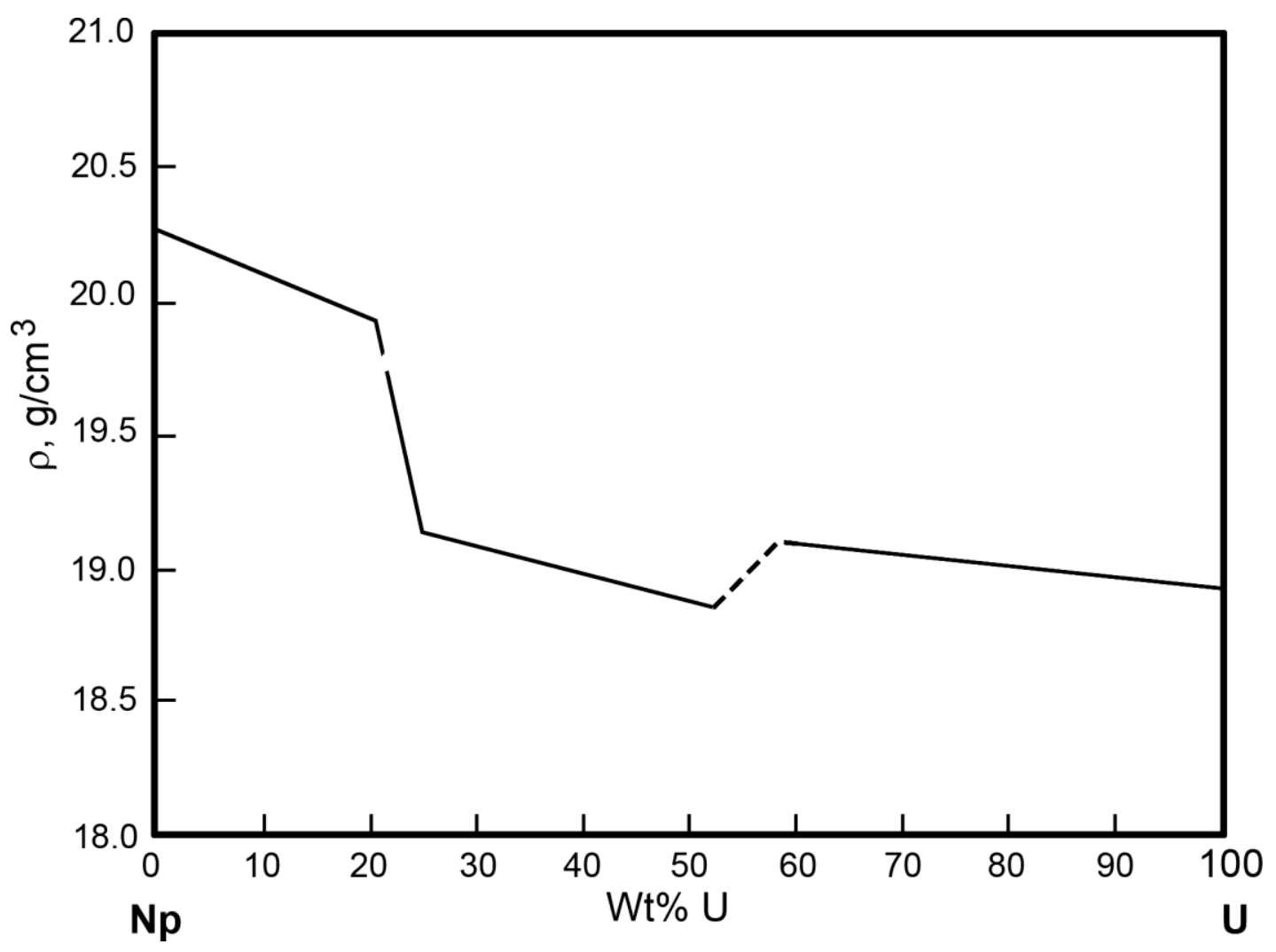

Figure 117. Room-temperature densities of U-Np alloys from pycnometry (re-drawn from [254 Figure 2]). Although Mardon and Pearce did not identify the phases involved, their phase diagram shows that the three room-temperature phases are $(\beta-\mathrm{Np}), \delta$-(U,Np), and $(\alpha-\mathrm{U})$.

\subsubsection{Np-Pu}

\subsubsection{Introduction}

The thermal expansion and density of $\mathrm{Np}$-Pu alloys have apparently not been systematically studied, although Mardon et al. obtained some information as part of their investigation of the Np-Pu phase diagram [271] (Section 4.1.13).

Further work on thermal expansion of $\mathrm{Np}-\mathrm{Pu}$ is needed, including verification of previous measurements with high-purity feedstocks. In the absence of experimental data, it seems reasonable to approximate the thermal expansion of $\mathrm{Np}$-Pu phases by those of the corresponding pure $\mathrm{Np}$ and $\mathrm{Pu}$ phases.

\subsubsection{Coefficients of thermal expansion}

Although Mardon et al. were unable to determine the structure of $\eta-(\mathrm{Np}, \mathrm{Pu})$, they reported its linear thermal expansion coefficients as $\sim 25 \pm 5 \times 10^{-6} /{ }^{\circ} \mathrm{C}$ in each of three mutually orthogonal directions based on high-temperature X-ray diffraction data and a postulated orthorhombic structure [271].

Coefficients of thermal expansion for other $\mathrm{Np}-\mathrm{Pu}$ phases are not available.

\subsubsection{Densities}

Mardon et al. [271] estimated the density of the $\eta-(\mathrm{Np}-\mathrm{Pu})$ structure in an alloy with $19 \mathrm{wt} \% \mathrm{~Np}$ as $17.56 \mathrm{~g} / \mathrm{cm}^{3}$ at $450{ }^{\circ} \mathrm{C}$. This estimate was $\sim 5.5 \%$ above the actual measured value, matching the adjustment required to bring the measured densities of the $\alpha-\mathrm{Pu}$ and $\beta$-Pu solid solution phases in the 
same alloy into agreement with the theoretical densities of these phases. Mardon et al. believed that this adjustment was needed to compensate for voids in the sample.

Mardon et al. reported that the maximum room-temperature density for $\alpha-(\mathrm{Pu}, \mathrm{Np})$ solid solution phases is $\sim 20.1 \mathrm{~g} / \mathrm{cm}^{3}$. This value is significantly larger than the value of $19.816 \mathrm{~g} / \mathrm{cm}^{3}$ listed for pure $\alpha$ $\mathrm{Pu}$ in Section 3.3.2 of the Handbook. Although Mardon et al. reported that the density of $\alpha$-Pu solid solutions increased slightly with higher concentrations of Np because of a decrease of $\sim 1 \%$ in the $a, b$, and $c$ lattice parameters without a corresponding change in the lattice angle $\beta$, it seems likely that most of the difference between Mardon's density and that in Section 3.3.2 is due to use of different values for the density of $\alpha-\mathrm{Pu}$. It may be reasonable to approximate the density of $\alpha-(\mathrm{Pu}, \mathrm{Np})$ solid solutions by using the change in densities reported by Mardon et al., but starting from the value of the density of $\alpha$-Pu in Section 3.3.2.

Densities of other $(\mathrm{Np}-\mathrm{Pu})$ phases are not available.

\subsubsection{Pu-Am}

Shushakov et al. [296] studied the thermal expansion of a number of Am-stabilized $\delta$-Pu- alloys (Figure 118). The thermal expansion of Am-stabilized $\delta$-Pu resembles that of $\delta$-Pu stabilized by Ce and $\mathrm{Zr}$ (Section 4.1.21 and Section 3.3.5) in that alloys with low concentrations of $\delta$-stabilizing elements (Am, $\mathrm{Ce}$, and $\mathrm{Zr}$ ) have negative thermal expansion and alloys with higher concentrations of stabilizing elements have positive thermal expansion.

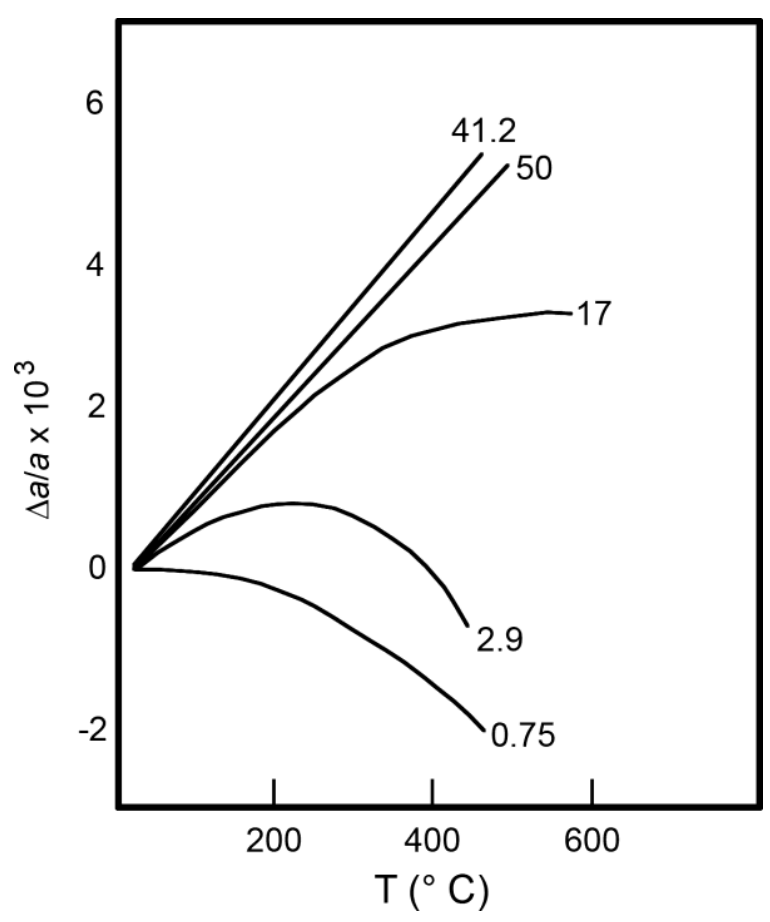

Figure 118. Thermal expansion of Am-stabilized $\delta$-Pu alloys (re-drawn from [296 Figure 2]), based on changes in the a lattice parameter from high-temperature X-ray diffraction. Numbers next to the curves indicate alloy compositions in (\% Am) 


\subsubsection{Pu-Ce}

\subsubsection{Introduction}

Experimental X-ray diffraction and dilatometry measurements of the thermal expansion of Cestabilized $\delta$-Pu were published by Gschneidner and colleagues [166, 167], by Goldberg et al. [429], and by Dormeval et al. [430]. The papers by Elliott et al. and by Gschneidner et al. were based on the same original experiments, and many results are repeated in both papers. Unless indicated otherwise, the results presented here from Gschneidner and colleagues are from reference [166] rather than [167], as it is the more recent of the two papers.

Measurements of the thermal expansion of other $\mathrm{Pu}-\mathrm{Ce}$ phases are not available.

\subsubsection{Thermal expansion of Ce-stabilized $\delta$-Pu}

Gschneidner et al. [166] used least-squares fitting to determine quadratic equations to represent lattice parameters from X-ray diffraction data and sample lengths from dilatometry. They expressed their results in a quadratic equation (Equation 112) and table of coefficients (Table 26). These values should not be applied for temperatures outside the ranges specified in the table.

Equation 112. Lattice parameter (for X-ray diffraction data) or sample length (for dilatometer data) for Pu-Ce alloys, to be used with coefficients from Table 26 [166]

$$
a=\mathrm{A}+\mathrm{Bx} 10^{-5} \mathrm{xT}+\mathrm{Cx} 10^{-8} \mathrm{xT}^{2}
$$

where $a$ is the lattice parameter (in $\AA$ ) from X-ray diffraction data or the specimen length for dilatometer data, $\mathrm{T}$ is the temperature in ${ }^{\circ} \mathrm{C}$, and $\mathrm{A}, \mathrm{B}$, and $\mathrm{C}$ are constants listed in Table 26.

Table 26. Coefficients for calculating thermal expansion of Pu-Ce alloys using Equation 112 [166]

\begin{tabular}{clllll}
$\begin{array}{c}\text { At } \\
\% \mathrm{Ce}\end{array}$ & $\begin{array}{l}\text { T range } \\
\left({ }^{\circ} \mathrm{C}\right)\end{array}$ & $\mathrm{A}$ & $\mathrm{B}$ & $\mathrm{C}$ & $\begin{array}{l}\text { Measurement } \\
\text { type }^{1}\end{array}$ \\
\hline 1.0 & $294-446$ & 4.6571 & -8.881 & 6.48 & XRD \\
1.4 & $295-437$ & 4.6556 & -9.033 & 7.79 & XRD \\
2.0 & $313-392$ & 4.6506 & -3.782 & -- & XRD \\
2.4 & $288-445$ & 4.6474 & -3.907 & -- & XRD \\
3.0 & $289-457$ & 4.6240 & 10.824 & -19.63 & XRD \\
3.4 & $276-448$ & 4.6544 & -3.778 & -- & XRD \\
4.0 & $297-452$ & 4.6734 & -13.258 & 14.53 & XRD \\
5.0 & $356-441$ & 0.98697 & -1.145 & -- & DG Dil \\
8.0 & $19-473$ & 4.6544 & 1.202 & -0.38 & XRD
\end{tabular}

${ }^{1} \mathrm{XRD}$ is X-ray diffraction, DG Dil is dial-gauge dilatometer

Figure 119 shows lattice parameters calculated using Equation 112 and Table 26. The roomtemperature lattice parameter of the alloy with $8 \% \mathrm{Ce}$ and increase in lattice parameters with increasing concentration of $\mathrm{Ce}$ are consistent with the room-temperature data reported by Ellinger et al. [308] (Section 4.1.21). 


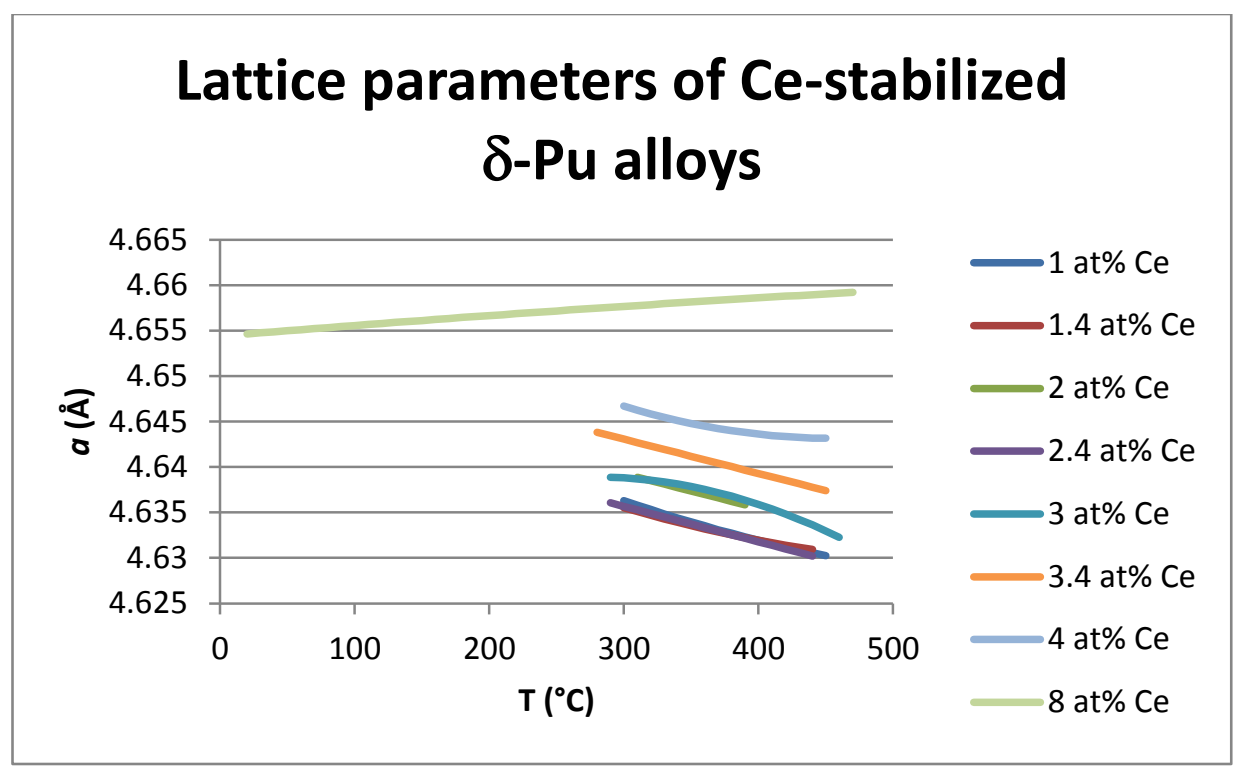

Figure 119. Lattice parameters of $\delta$-Pu alloys from X-ray diffraction data (Equation 112 and Table 26)

Figure 120 shows the linear thermal expansion of Pu-Ce alloys reported by Gschneidner et al. [166], based on lengths calculated using Equation 113. Thermal expansion is negative for the alloys with Ce concentrations of 5 at $\%$ or less and positive for the alloy with $8 \% \mathrm{Ce}$, consistent with the suggestion of Gschneidner et al. that the thermal expansion of $\delta$-Pu alloys with $\sim 6$ at $\% \mathrm{Ce}$ is zero. Although there is some scatter in the data, the thermal expansion for alloys with up to 5 at $\%$ Ce generally becomes less negative as the concentration of Ce increases. 


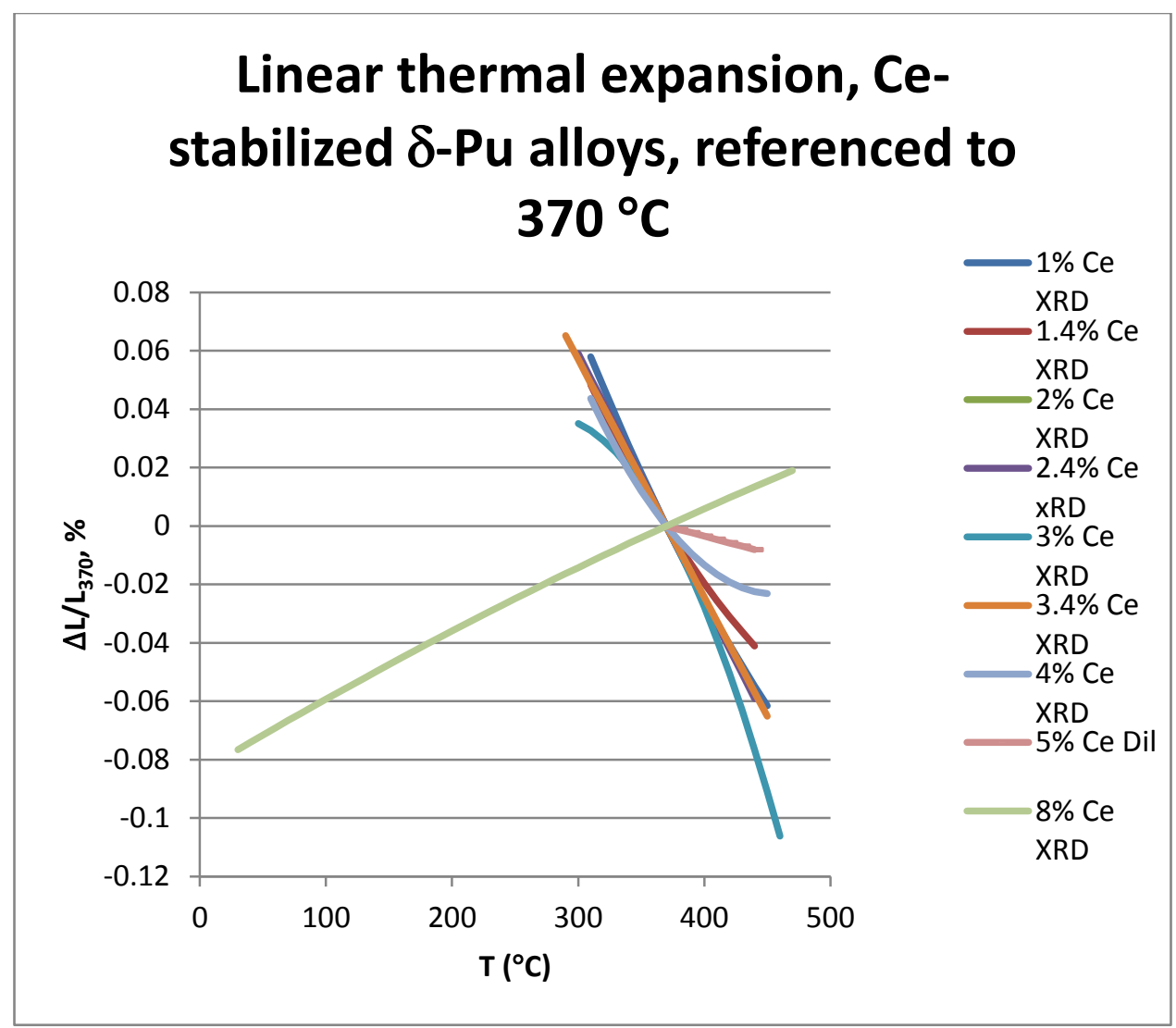

Figure 120. Linear thermal expansion from Equation 112, Equation 113, and Table 26

Equation 113. Linear thermal expansion of Ce-stabilized $\delta$-Pu, referenced to $370{ }^{\circ} \mathrm{C}$

$$
\frac{\Delta L}{L_{370}}=\frac{L-L_{370}}{L_{370}} \times 100
$$

where $\Delta \mathrm{L} / \mathrm{L}_{370}$ is the linear thermal expansion referenced to the lattice parameter (for X-ray diffraction data) or sample length (for dilatometer data) at $370{ }^{\circ} \mathrm{C}$ in percent, $\mathrm{L}$ is the lattice parameter or sample length at an arbitrary temperature, and $\mathrm{L}_{370}$ is the lattice parameter or sample length at 370 ${ }^{\circ} \mathrm{C}$.

\subsubsection{Coefficients of thermal expansion of Ce-stabilized $\delta$-Pu}

Gschneidner et al. calculated the average values of the coefficients of linear thermal expansion using data from X-ray diffraction and two kinds of dilatometer (dial-gauge and strain-gauge). Their results, which should be used only within the temperature ranges specified, are in Table 27.

Table 27. Average coefficients of linear thermal expansion for Ce-stablized $\delta$-Pu alloys [166]

\begin{tabular}{llll}
$\begin{array}{l}\mathrm{At} \% \\
\mathrm{Ce}\end{array}$ & $\begin{array}{l}\text { T range } \\
\left({ }^{\circ} \mathrm{C}\right)\end{array}$ & $\begin{array}{l}\bar{\alpha}\left(\mathrm{x} 10^{6}\right), \\
{ }^{\circ} \mathrm{C}^{-1}\end{array}$ & $\begin{array}{l}\text { Measurement } \\
\text { type }\end{array}$ \\
\hline 1.0 & $300-440$ & -8.81 & $\mathrm{XRD}$ \\
1.4 & $300-437$ & -7.10 & $\mathrm{XRD}$ \\
2.0 & $313-392$ & -8.15 & $\mathrm{XRD}$
\end{tabular}




$\begin{array}{llll}2.4 & 300-440 & -8.43 & \text { XRD } \\ 3.0 & 300-440 & -7.98 & \text { XRD } \\ 3.4 & 300-440 & -8.14 & \text { XRD } \\ 3.4 & 280-438 & -7.8 & \text { SG Dil } \\ 4.0 & 300-440 & -5.39 & \text { XRD } \\ 5.0 & 356-440 & -1.16 & \text { DG Dil } \\ 5.0 & 280-438 & -5.1 & \text { SG Dil } \\ 5.9 & 280-438 & +0.5 & \text { SG Dil } \\ 8.0 & 300-440 & +1.98 & \text { XRD } \\ 8.0 & 280-438 & +1.8 & \text { SG Dil } \\ 10.0 & 280-438 & +3.1 & \text { SG Dil }\end{array}$

${ }^{1} \mathrm{XRD}$ is X-ray diffraction, DG Dil is dial-gauge dilatometer, SG Dil is strain-gauge dilatometer

Goldberg et al. [429] used a vertical dilatometer to measure thermal expansion of annealed $\mathrm{Pu}-\mathrm{Ce}$ alloys with $\sim 3-12$ at $\%$ Ce and determined average coefficients of thermal expansion for temperature ranges of $300-450{ }^{\circ} \mathrm{C}$. They indicated that the thermal expansion of Ce became positive for compositions with more than $\sim 7$ at $\% \mathrm{Ce}$, but did not report their data numerically.

Dormeval et al. [430] used a horizontal dilatometer to obtain coefficients of thermal expansion for $\delta$ $\mathrm{Pu}$ solid solutions with 3.5-8.1 at $\% \mathrm{Ce}$. Their results were not reported numerically, but are generally consistent with values reported by other researchers (Figure 121). 
Figure 121

Coefficients of thermal expansion, Ce-stabilized $\delta$-Pu alloys

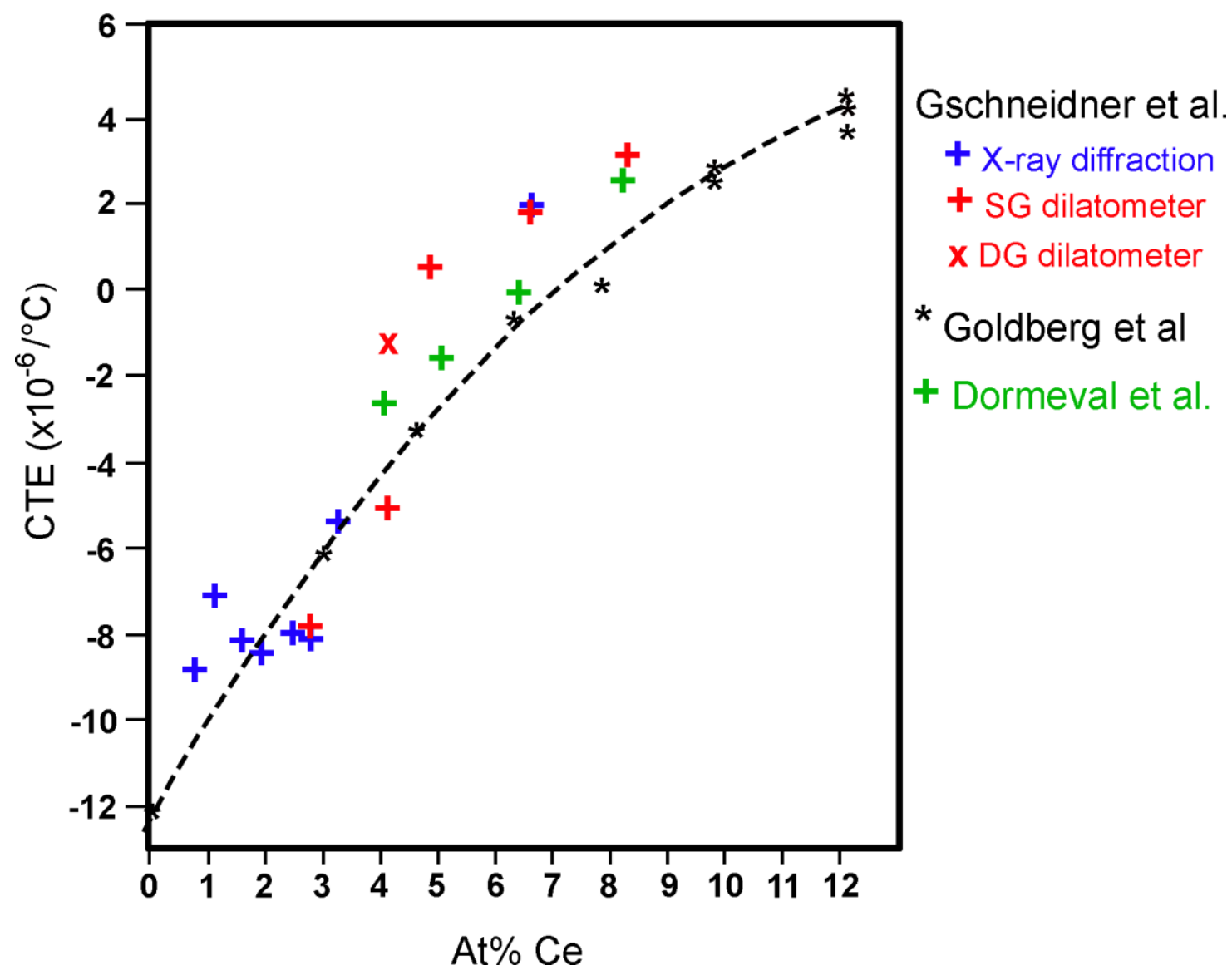

Figure 121 shows the coefficients of thermal expansion from Table 27, the experimental results of Goldberg et al. [429] and Dormeval et al. [430], and a curve that Goldberg et al. believed represented the thermal expansion of Pu-Ce alloys based on their data. Despite considerable scatter and an unusually low coefficient of thermal expansion for pure $\delta$-Pu used by Goldberg et al. $\left(-12.15 \times 10^{-6} /{ }^{\circ} \mathrm{C}\right.$, which is outside the range of values reported in Section 3.3.2), the curve appears to be a reasonably good representation of the data. It is not clear why different researchers obtain different values, although it has been suggested that both sample purity and measurement technique may be important [429] and that samples with low concentrations of $\mathrm{Ce}$ may contain both $\alpha$-Pu and $\delta$-Pu solid solution phases [430]. 


\section{Coefficients of thermal expansion, Ce-stabilized $\delta$-Pu alloys}

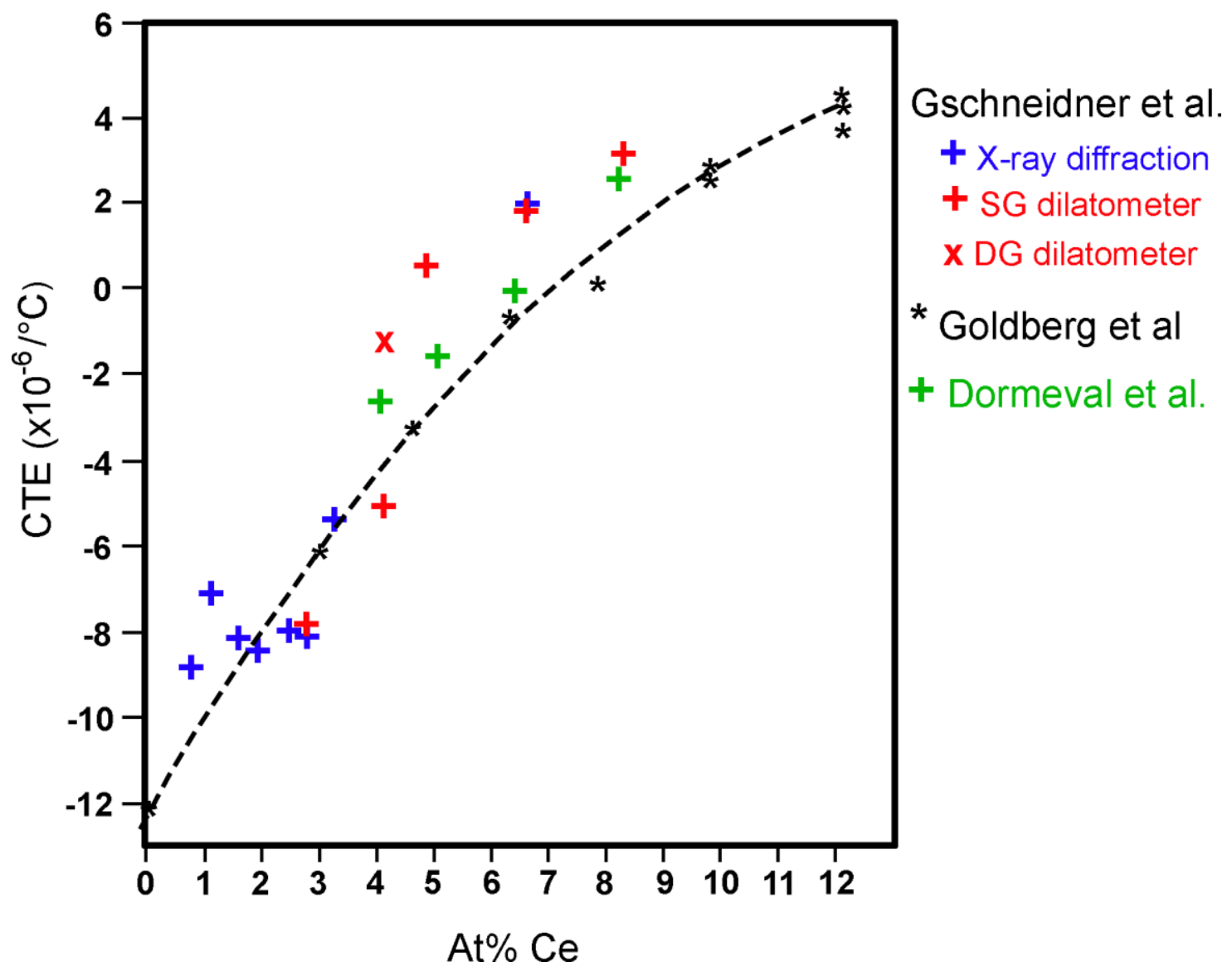

Figure 121. Coefficients of thermal expansion, Ce-stabilized $\delta$-Pu alloys [166, 429]. The dashed line represents the "best fit" estimate of Goldberg et al.

\subsubsection{Coefficients of thermal expansion of $\varepsilon-P u$ solid solutions}

The only available data on the thermal expansion of $\varepsilon$-Pu solid solutions in $\mathrm{Pu}-\mathrm{Ce}$ alloys is from Goldberg et al. [429], who measured alloys with up to $\sim 12$ at $\%$ Ce. Their data shows that the thermal expansion has only a limited dependence on composition for alloys with up to $\sim 7$ at $\% \mathrm{Ce}$, then increases with higher concentrations of $\mathrm{Ce}$ (

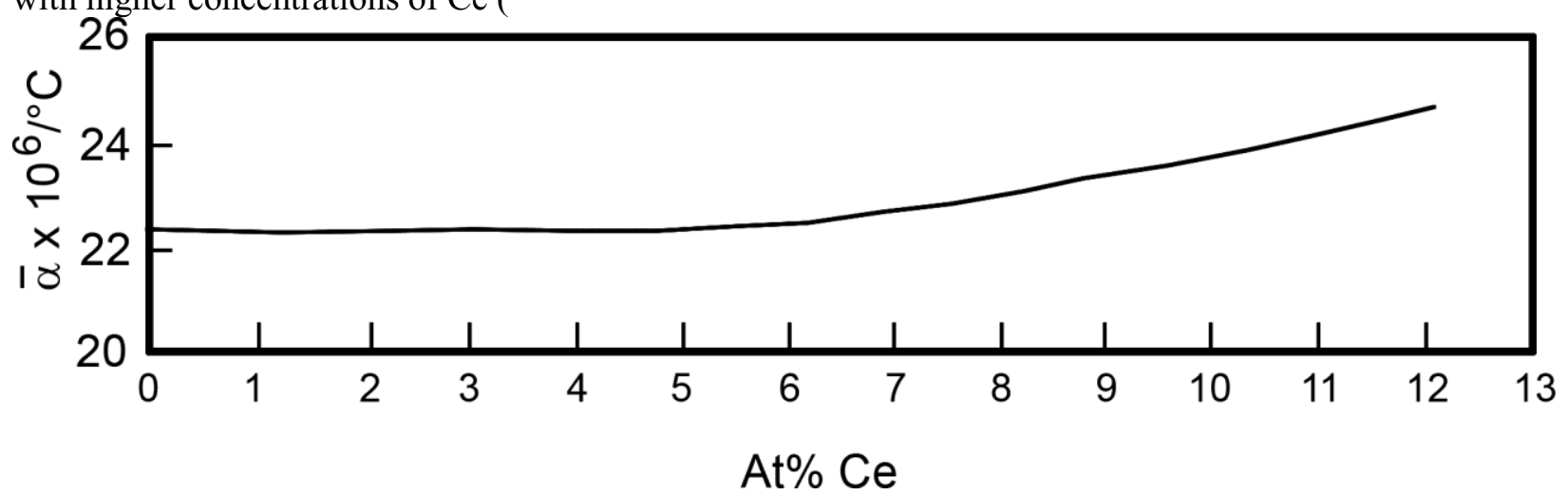


Figure 122).

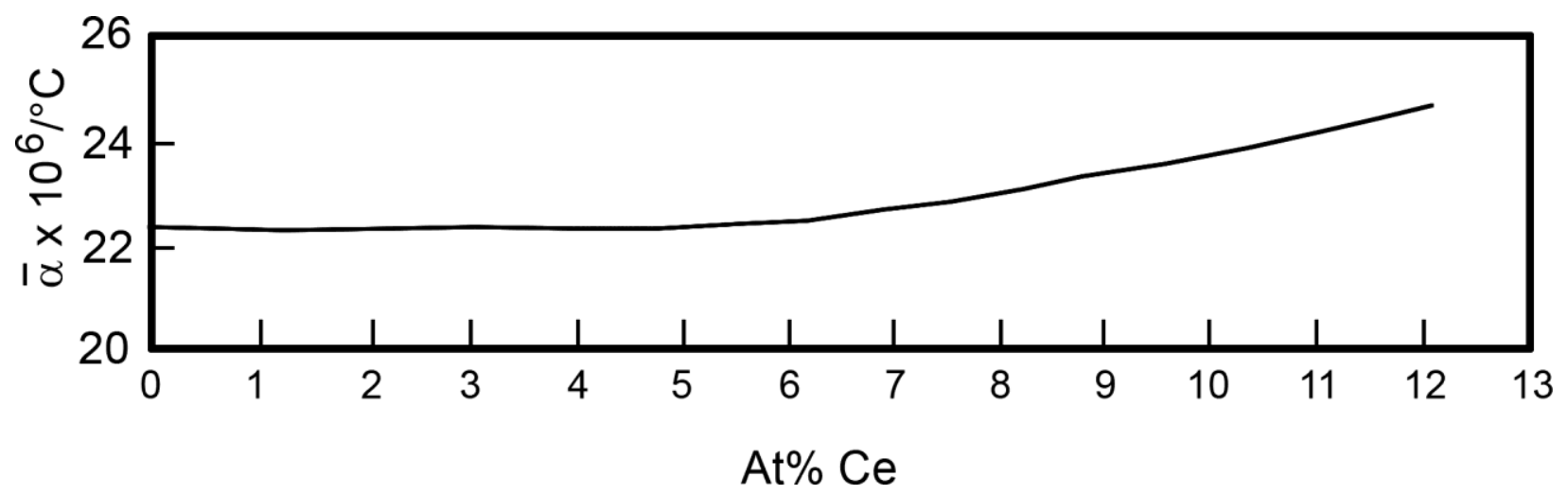

Figure 122: Coefficient of thermal expansion of $\varepsilon$-Pu solid solutions in Pu-Ce alloys as a function of composition (re-drawn from [429 Figure 7])

\subsubsection{Volume changes associated with the transition between $\delta$-Pu and $\varepsilon$-Pu solid solutions}

The only available data on the volume change associated with the transition from $\delta$-Pu to $\varepsilon$-Pu solid solutions in $\mathrm{Pu}-\mathrm{Ce}$ alloys is from Goldberg et al. [429]. They measured the $\delta$ - $\varepsilon$ contraction (loss in volume associated with the transition from $\delta$-Pu to $\varepsilon$-Pu solid solutions) in $\mathrm{Pu}-\mathrm{Ce}$ alloys with up to $\sim 12 \mathrm{at} \% \mathrm{Pu}$. The volume loss was always smaller than that in pure $\mathrm{Pu}$, and reached a minimum value at $\sim \mathrm{at} \% \mathrm{Ce}$ (Figure 123).

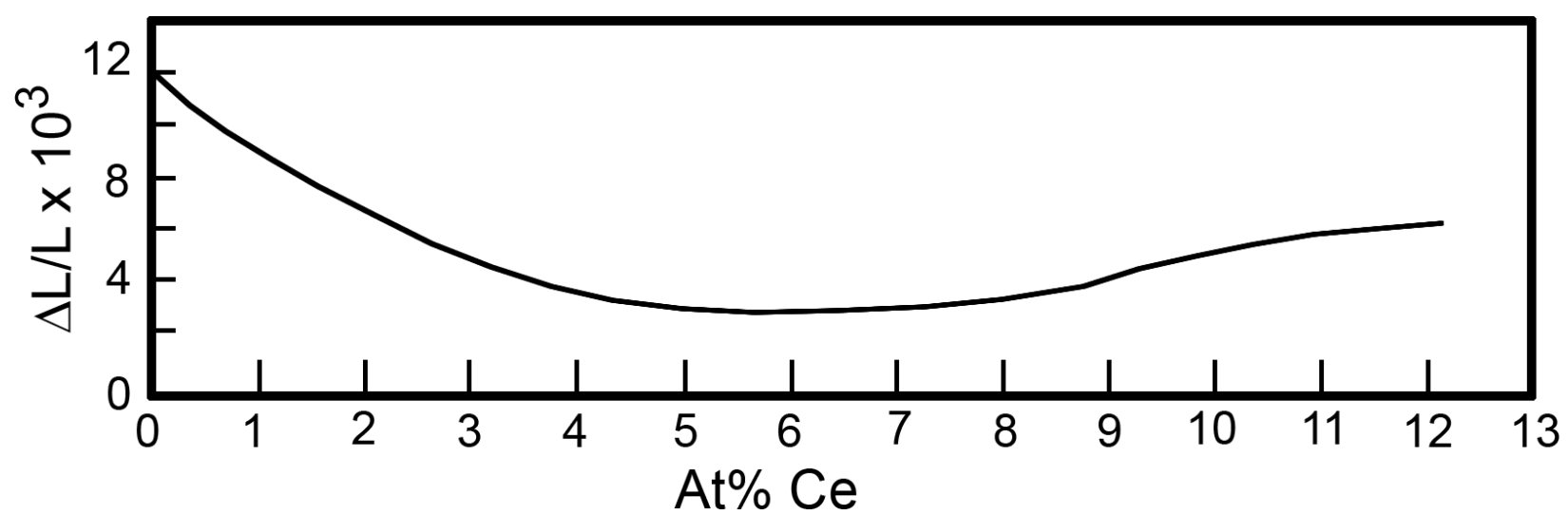

Figure 123: Change in length of Pu-Ce alloys associated with the transition from $\delta$-Pu to $\varepsilon$-Pu structures as a function of composition [429 Figure 6]

\subsubsection{Room temperature densities of Ce-stabilized $\delta$-Pu solid solutions}

Two values for the room-temperature density of Ce-stabilized $\delta$-Pu solid solutions are available. One of these values $\left(\sim 15.3 \mathrm{~g} / \mathrm{cm}^{3}\right)$ is obtained by calculating the density of an alloy with 8 at $\%$ Ce using Equation 5 with the lattice parameter calculated from Equation 112 and Table 26. The other value is the room-temperature density of $14.97 \mathrm{~g} / \mathrm{cm}^{3}$, which Andrew [431] reported without specifying how the value was obtained. 
In combination, these values suggest that the room-temperature density of a Ce-stabilized $\delta$-Pu alloy with $\sim 8-10$ at $\%$ Ce is approximately $15 \mathrm{~g} / \mathrm{cm}^{3}$. New measurements are needed if greater precision is required.

\subsubsection{Am-Ce}

\subsubsection{Introduction}

No information on the thermal expansion of Am-Ce alloys is available. Limited information on roomtemperature densities of selected alloys is available in a patent award addressing possible use of Am-Ce alloys as radiation sources or materials for radiation detectors. The purity of the alloys is unknown (and irrelevant for purposes of the patent).

\subsubsection{Room-temperature densities}

Conner [321] reported the room-temperature densities of Ce and of alloys with 10.5 and $21 \mathrm{wt} \% \mathrm{Am}$ as $6.771,7.183$ and $7.649 \mathrm{~g} / \mathrm{cm}^{3}$ respectively. If it is assumed that the Ce is $\beta$-Ce, the density reported by Conner is in reasonably good agreement with the value of $6.689 \mathrm{~g} / \mathrm{cm}^{3}$ in the CRC Handbook of Chemistry and Physics [17].

\subsubsection{La-Ce}

\subsubsection{Introduction}

Experimental data on the thermal expansion of La-Ce alloys is limited to measurements of the density of liquids with less than $\sim 10$ at $\%$ Ce [432]. This data shows that the density of these alloys increases with increasing concentration of $\mathrm{Ce}$ and decreases linearly with increasing temperature. Reported densities of La-Ce alloys seem anomalously high in comparison to the density of pure La.

Zhang et al. [328] calculated high-pressure thermal expansion coefficients for fcc solid solutions between $(\alpha-\mathrm{Ce})$ and $(\beta-\mathrm{La})$ from first principles. Because of the pressures and phases involved, this research has limited relevance for FCRD fuels.

Further research is needed to measure the thermal expansion of solid La-Ce alloys, confirm the existing measurements of the thermal expansion of liquid La-Ce alloys, and measure the thermal expansion of liquids with higher concentrations of $\mathrm{Ce}$.

\subsubsection{Densities of liquid alloys}

Bezukladnikova et al. measured densities of five La-Ce alloys with $\sim 1.2$ to 9.9 at\% La using optical microscopy to observe changes in the sizes of drops of liquid in a vacuum [432]. They determined that the density of each alloy decreases linearly with increasing temperature, and developed Equation 114 and Table 28 to express this relationship.

Equation 114. Density of La-Ce alloys (after [432])

$$
\rho=\rho_{0}-\mathrm{b} \times 10-3 \times \mathrm{T}
$$

where $\rho$ is the density in $g / \mathrm{cm}^{3}, \rho_{0}$ and $b$ are values from Table 28 and $\mathrm{T}$ is a temperature in $\mathrm{K}$ within the range specified in Table 28. 
Table 28. Coefficients for calculating densities of La-Ce liquids (after [432])

\begin{tabular}{llll}
$\begin{array}{l}\text { Composition, } \\
\text { at\% Ce }\end{array}$ & T range & $\rho_{0}$ & $\mathrm{~b}$ \\
\hline 1.21 & $(\mathrm{~K})$ & 6.86 & 0.66 \\
2.49 & $1250-1627$ & 6.82 & 0.62 \\
5.33 & $1263-1630$ & 7.01 & 0.74 \\
7.72 & $1253-1626$ & 7.07 & 0.77 \\
9.91 & $1268-1607$ & 6.87 & 0.63 \\
\hline
\end{tabular}

Figure 124 shows densities calculated using Equation 114 and Table 28. Densities decrease linearly as a function of increasing temperature. There is a general tendency for the density to increase with increasing concentrations of $\mathrm{Ce}$, consistent with the higher density of $\mathrm{Ce}$ in comparison to La (Sections 4.3.4 and 4.3.3). The density of the alloy with $1.21 \mathrm{at} \% \mathrm{Ce}$ is $\sim 6.03 \mathrm{~g} / \mathrm{cm} 3$ at $980{ }^{\circ} \mathrm{C}$, which is slightly higher than the density of $5.96 \mathrm{~g} / \mathrm{cm}^{3}$ for pure La at a temperature "near the melting point" $\left(918^{\circ} \mathrm{C}\right)[17$ Table 12].

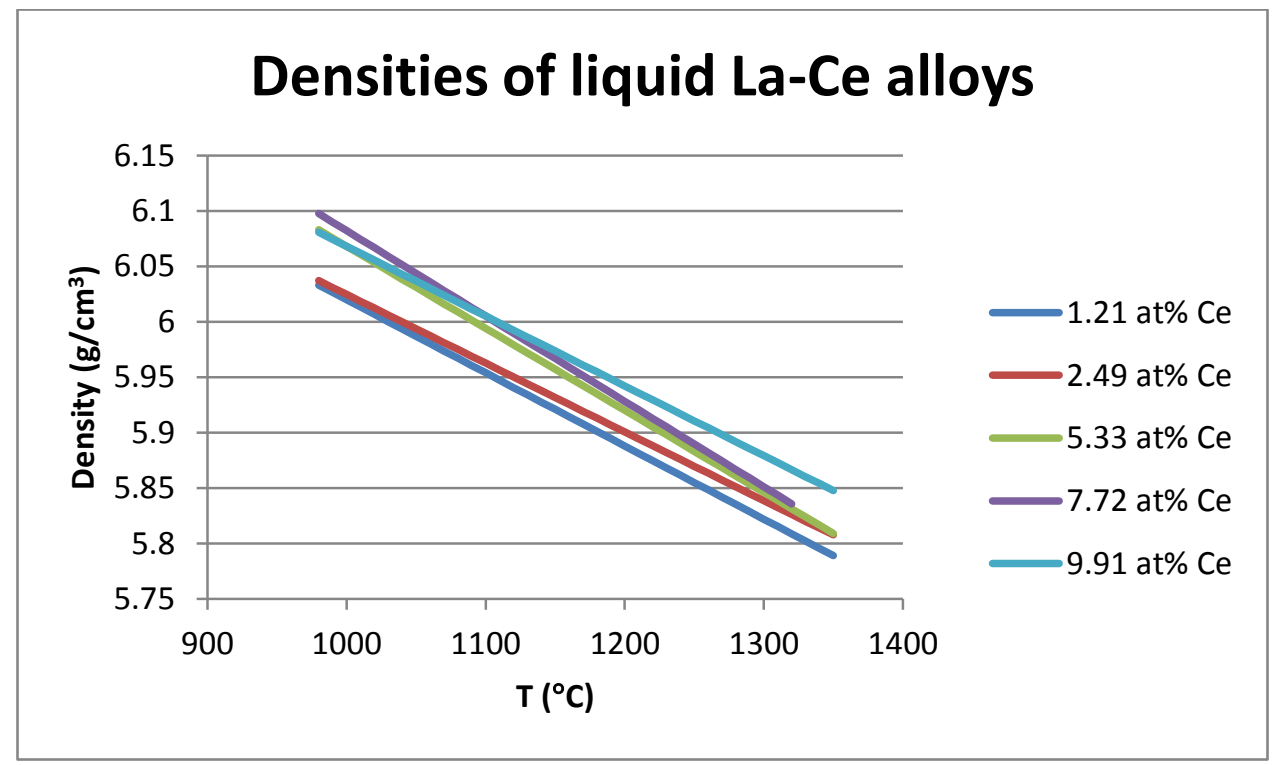

Figure 124. Densities of La-Ce liquids calculated using Equation 114 and Table 28

\subsubsection{La-Pr}

\subsubsection{Introduction}

No information about the thermal expansion of solid La-Pr alloys is available.

Densities of liquid La-Pr alloys increase with increasing concentration of Pr and decrease with increasing temperature $[432,433]$. The increase in density as a function of temperature is linear for each alloy. The increase in density as a function of concentration is not precisely linear, possibly because of impurities in the materials used. 
Further research is needed to obtain data about the thermal expansion of solids. Further research is also appropriate if high-precision data on densities or thermal expansion of liquids are needed, but may not be important for FCRD fuels.

\subsubsection{Densities of liquid alloys}

Bezukladnikova et al. measured densities of liquid La, Pr, and La-Pr alloys using optical microscopy to observe changes in the sizes of drops of liquid in a vacuum $[432,433]$. The La feedstock had $\sim 0.19 \%$ impurities, and the Pr feedstock had up to $\sim 0.25 \%$. Bezukladnikova et al. determined that the density of each alloy decreases linearly with increasing temperature, and developed Equation 115 and Table 29 to express this relationship.

Equation 115. Density of La-Pr alloys (after $[432,433]$ )

$$
\rho=\rho_{0}-\mathrm{b} \times 10^{-3} \times \mathrm{T}
$$

where $\rho$ is the density in $\mathrm{g} / \mathrm{cm}^{3}, \rho_{0}$ and $\mathrm{b}$ are values from Table 29 and $\mathrm{T}$ is a temperature in ${ }^{\circ} \mathrm{C}$ or $\mathrm{K}$ within the range specified in the table.

Table 29. Coefficients for calculating densities of La-Pr liquids

\begin{tabular}{llllll}
$\begin{array}{l}\text { Composition, } \\
\text { at\% Pr }\end{array}$ & $\begin{array}{l}\text { T range } \\
\left({ }^{\circ} \mathrm{C}\right)\end{array}$ & $\begin{array}{l}\text { T range } \\
(\mathrm{K})\end{array}$ & $\rho_{0}$ & $\mathrm{~b}$ & Reference \\
\hline 0 & $947-1354$ & & 6.77 & 0.73 & {$[433]$} \\
1.48 & & $1249-1630$ & 7.18 & 0.87 & {$[432]$} \\
3.01 & $1270-1686$ & 7.09 & 0.80 & {$[432]$} \\
5.19 & $1297-1690$ & 7.06 & 0.77 & {$[432]$} \\
7.52 & & $1291-1703$ & 7.12 & 0.81 & {$[432]$} \\
11.58 & $1313-1720$ & 7.04 & 0.75 & {$[432]$} \\
11.59 & & & 6.84 & 0.75 & {$[433]$} \\
19.08 & $1040-1447$ & & 7.06 & 0.89 & {$[433]$} \\
29.54 & $1110-1413$ & & 6.98 & 0.8 & {$[433]$} \\
39.38 & $1100-1390$ & & 7.09 & 0.87 & {$[433]$} \\
49.59 & $1070-1369$ & & 7.25 & 0.95 & {$[433]$} \\
59.53 & $1040-1380$ & & 7.43 & 1.01 & {$[433]$} \\
69.63 & $1060-1386$ & & 7.48 & 1.00 & {$[433]$} \\
80.11 & $1006-1040$ & & 7.60 & 1.04 & {$[433]$} \\
89.85 & $1080-1410$ & & 7.73 & 1.11 & {$[433]$} \\
100 & $1055-1316$ & & 1.14 & {$[433]$} \\
\hline
\end{tabular}


Figure 125 shows densities of La, Pr, and nine alloys calculated using Equation 115 and Table 29. The lowest-temperature densities of $\mathrm{La}$ and $\mathrm{Pr}$ are each $\sim 0.1 \mathrm{~g} / \mathrm{cm}^{3}$ higher than the values in the CRC Handbook of Chemistry and Physics for densities of liquid rare-earth metals "near the melting point" [17 Table 12].

Bezukladnikova et al. noted that the molar volumes of alloys at $1473 \mathrm{~K}$ were not linear functions of composition, but considered the deviation as "insignificant" [433].

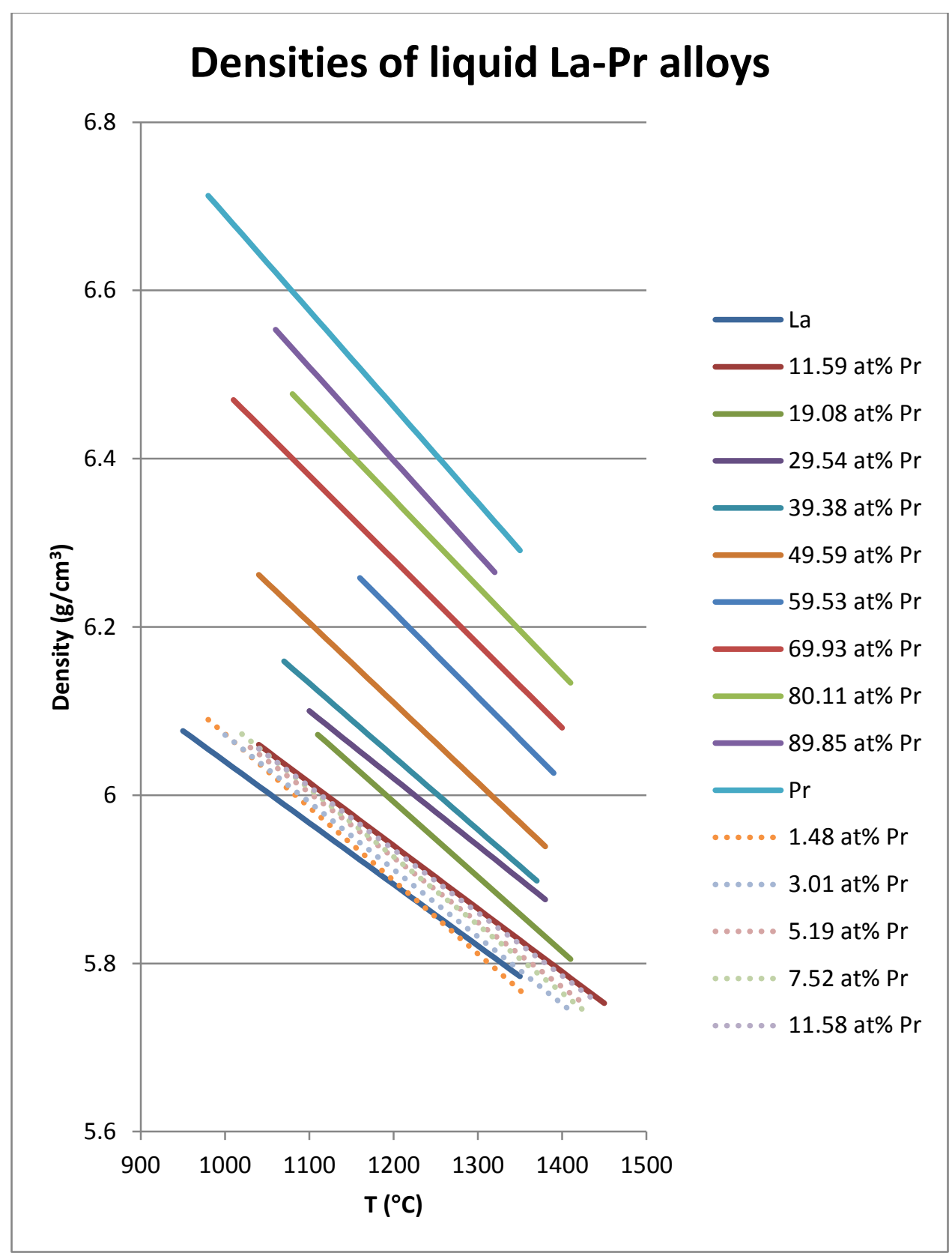

Figure 125. Densities of La-Pr liquids calculated using Equation 115 and Table 29. Solid lines show data from reference [433]; dotted lines show data from reference [432]. 


\subsubsection{La-Nd}

\subsubsection{Introduction}

Experimental data on the thermal expansion of La-Nd alloys is limited to measurements of the density of liquids with less than $\sim 10$ at $\% \mathrm{Nd}$ [432]. This data shows that the density of these alloys increases with increasing concentration of $\mathrm{Nd}$ and decreases linearly with increasing temperature.

No experimental measurements of the thermal expansion of solid La-Nd alloys are available.

Further research is needed to measure the thermal expansion of solid La-Nd alloys, confirm the existing measurements of the thermal expansion of liquid La-Nd alloys, and measure the thermal expansion of liquids with higher concentrations of $\mathrm{Nd}$.

\subsubsection{Densities of liquid alloys}

Bezukladnikova et al. measured densities of five La-Nd alloys with $\sim 1.1$ to 9.9 at\% La using optical microscopy to observe changes in the sizes of drops of liquid in a vacuum [432]. Their results showed that the density of each alloy decreases linearly with increasing temperature. Equation 116 and Table 30 express this relationship.

Equation 116. Density of La-Nd alloys (after [432])

$$
\rho=\rho_{0}-\mathrm{b} \times 10^{-3} \times \mathrm{T}
$$

where $\rho$ is the density in $\mathrm{g} / \mathrm{cm}^{3}, \rho_{0}$ and $\mathrm{b}$ are values from Table $\mathbf{3 0}$ and $\mathrm{T}$ is a temperature in $\mathrm{K}$ within the range specified in the table.

Table 30. Coefficients for calculating densities of La-Nd liquids (after [432])

$\begin{array}{llll}\begin{array}{l}\text { Composition, } \\ \text { at\% Nd }\end{array} & \begin{array}{l}\text { T range } \\ (\mathrm{K})\end{array} & \rho_{0} & \mathrm{~b} \\ 1.14 & 1257-1620 & 7.13 & 0.85 \\ 2.79 & 1270-1613 & 7.12 & 0.83 \\ 5.02 & 1293-1617 & 7.07 & 0.79 \\ 7.23 & 1301-1633 & 7.19 & 0.87 \\ 9.89 & 1313-1617 & 7.22 & 0.88\end{array}$

Figure 126 shows densities calculated using Equation 116 and Table 30. Densities decrease linearly as a function of increasing temperature. There is a general tendency for the density to increase with increasing concentrations of $\mathrm{Nd}$, consistent with the higher density of $\mathrm{Nd}$ in comparison to La (Sections 4.3.6 and 4.3.3). The density of the alloy with $1.14 \mathrm{at} \% \mathrm{Nd}$ is $\sim 6.06 \mathrm{~g} / \mathrm{cm} 3$ at $980{ }^{\circ} \mathrm{C}$, which is slightly higher than the density of $5.96 \mathrm{~g} / \mathrm{cm}^{3}$ for pure $\mathrm{La}$ at a temperature "near the melting point" $\left(918^{\circ} \mathrm{C}\right)[17$ Table 12]. 


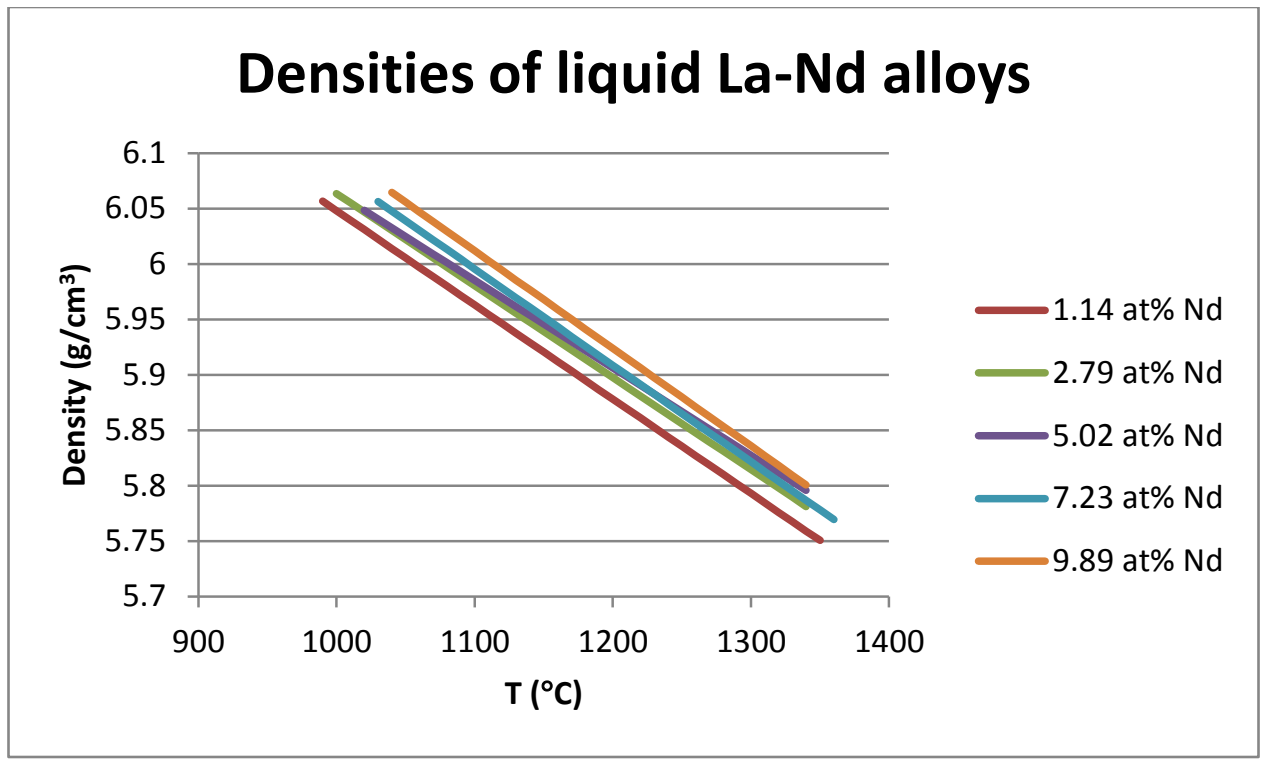

Figure 126. Densities of La-Nd liquids calculated using Equation 116 and Table 30

\subsubsection{Pr-Nd}

\subsubsection{Introduction}

No information on thermal expansion of Pr-Nd alloys is available.

Densities of solids at room temperature and of liquids at $1240{ }^{\circ} \mathrm{C}$ vary linearly between those of $\mathrm{Pr}$ and $\mathrm{Nd}$ as a function of composition [362]. Given the strong evidence that Pr-Nd alloys behave as ideal alloys $[362,366]$, it seems reasonable to approximate the densities of Pr-Nd alloys at other temperatures by linear interpolation between the properties of $\mathrm{Pr}$ and $\mathrm{Nd}$ as long as there are no differences in crystal structures.

It is less clear that it is appropriate to interpolate between the densities of $\mathrm{Pr}$ and $\mathrm{Nd}$ in temperatures and compositions in which Pr and Nd have different crystal structures because of possible density changes due to phase transformations. Further work on these alloys is needed.

\subsubsection{Room temperature densities of solids}

Lundin et al. measured the room-temperature densities of nine Pr-Nd alloys and observed that the densities varied linearly between the room-temperature densities of $\mathrm{Nd}$ and $\mathrm{Pr}$ as a function of composition [362]. The linear variation in densities is consistent with linear variation in lattice parameters observed in the same study and the ideal behavior of Pr-Nd alloys.

\subsubsection{Densities of liquids at $1240{ }^{\circ} \mathrm{C}$}

Lundin et al. also measured densities of three Pr-Nd liquids at $1240{ }^{\circ} \mathrm{C}$ and observed that the densities varied linearly between those of $\mathrm{Pr}$ and $\mathrm{Nd}$ as a function of composition [362].

\subsubsection{U-Ce-Zr}

Information on thermal expansion of $\mathrm{U}-\mathrm{Zr}-\mathrm{Ce}$ alloys is limited to a single conference presentation with data from two alloys with $10 \% \mathrm{Zr}$ and up to $6 \% \mathrm{Ce}$ [411]. No significant differences in thermal expansion of alloys with 0,2 , and $6 \%$ Ce were reported. In the absence of a more extensive study, it seems reasonable to neglect the presence of Ce in estimating the thermal conductivity of U-Zr-Ce alloys with concentrations of $\mathrm{Ce}$ that are relevant for FCRD fuels. 


\subsubsection{Np-Pu-Zr}

Data on thermal expansion of Np-Pu-Zr alloys is limited to measurements from several as-cast alloys with $\sim 8-9 \mathrm{wt} \% \mathrm{~Np}$ and $\sim 50 \mathrm{wt} \% \mathrm{Pu}$. Researchers at Idaho National Laboratory measured the thermal expansion of these alloys from room temperature to $910^{\circ} \mathrm{C}$ using a TMA, with information about phase transitions from DSC measurements of the same materials [378]. X-ray diffraction indicated that the alloys contained phases with structures similar to those of $\delta-\mathrm{Pu}$ and $\delta-\mathrm{UZr}_{2}$.

The TMA curve for these alloys shows linear coefficients of thermal expansion of $\sim 4.7 \times 10^{-6} /{ }^{\circ} \mathrm{C}$ at temperatures below $444{ }^{\circ} \mathrm{C}$ and $\sim 24 \times 10^{-6} /{ }^{\circ} \mathrm{C}$ between $\sim 555$ and $910{ }^{\circ} \mathrm{C}$. Thermal expansion measurements between these temperature ranges show a sharp increase followed by a contraction. Care is needed in interpreting thermal expansion data in the intermediate range $\left(\sim 444-555^{\circ} \mathrm{C}\right)$ because the corresponding DSC data indicates that it includes two phase transitions [378 Figure 1].

Reliably interpreting changes in thermal expansion coefficients in terms of phase transformations requires a thorough understanding of the $\mathrm{Np}-\mathrm{Pu}-\mathrm{Zr}$ ternary phase diagram. Given the current state of knowledge of this system, the interpretations proposed in reference [378] should be regarded as tentative.

\subsubsection{Pu-Am-Zr}

Data on thermal expansion of $\mathrm{Pu}-\mathrm{Am}-\mathrm{Zr}$ alloys is limited to measurements from several alloys with $\sim 12 \mathrm{wt} \%$ Am and $\sim 40 \mathrm{wt} \% \mathrm{Zr}$. Researchers at Idaho National Laboratory measured the thermal expansion of these alloys from room temperature to $1200{ }^{\circ} \mathrm{C}$ using a TMA, with information about phase transitions from DSC/TGA measurements of the same materials. X-ray diffraction suggests that the alloys consist primarily of a single phase with a structure similar to that of $\delta-\mathrm{Pu}$ [383].

The DSC/TGA data shows a single phase transition at $\sim 700^{\circ} \mathrm{C}$, which is indicated by a contraction in the TMA data. The coefficient of thermal expansion below this transition is reported as $\sim 8 \times 10^{-6} / \mathrm{K}$, and the coefficient of thermal expansion above it is reported as $\sim 5 \times 10^{-6} / \mathrm{K}$ [383]. The reported value below the phase transition seems plausible. The value above the transformation requires further investigation, as it may be too low.

\subsection{THERMAL CONDUCTIVITY AND THERMAL DIFFUSIVITY}

\subsubsection{Np}

\subsubsection{Introduction}

The thermal conductivity of $\mathrm{Np}$ at $300 \mathrm{~K}$ has been determined using two measurement techniques, leading to four different thermal conductivity values ranging from $\sim 4.2$ to $7.7 \mathrm{~W} / \mathrm{m} \cdot \mathrm{K}$. The commonly accepted value of $6.3 \mathrm{~W} / \mathrm{m} \cdot \mathrm{K}$ is the best currently available approximation to the actual value, which is probably between $\sim 6$ and $7 \mathrm{~W} / \mathrm{m} \cdot \mathrm{K}$.

Measurements of thermal conductivity at higher temperatures are not available. Although it is possible in principle to approximate it from measurements of electrical resistivity using the WiedemannFranz Law (Section 2.5.2), this approximation requires the Lorenz number, whose value is poorly known. Estimates using two plausible values for the Lorenz number give thermal conductivity values that differ by $\sim 10 \%$.

Further research on the thermal conductivity of $\mathrm{Np}$ at temperatures of interest for FCRD fuels is clearly required.

\subsubsection{Lorenz number}

Wagner [434] calculated the Lorenz number for $\mathrm{Np}$ at room temperature as $3.21 \times 10^{-8} \mathrm{~W} \Omega \mathrm{K}^{-2}$ using his thermal diffusivity data and previously published values for density, heat capacity, and electrical resistivity. Some of these values are no longer accepted, and Wagner's value of the Lorenz number should not be used. 
Calculation of the room-temperature Lorenz number for $\mathrm{Np}$ using the best available data (thermal diffusivity of $0.027 \mathrm{~cm}^{2} / \mathrm{sec}$ [434], electrical resistivity of $116.5 \mu \Omega / \mathrm{cm}$ [435], heat capacity of 29.7 $\mathrm{J} / \mathrm{mol}-\mathrm{K}$ (Section 4.2.1), and density of $20.48 \mathrm{~g} / \mathrm{cm}^{3}$ (Section 4.3 .1 )) gives a value of $\sim 2.62 \times 10^{-8} \mathrm{~W} \cdot \Omega / \mathrm{K}^{2}$.

This value is slightly larger than the theoretical value $\left(2.44 \times 10-8 \mathrm{~W} \cdot \Omega / \mathrm{K}^{2}\right)$, which in turn appears to be slightly larger than the Lorenz number for Np presented graphically (and without explanation of where the value comes from) in a 2012 review [3 Figure 22].

In the absence of compelling data indicating otherwise, it seems reasonable to assume that the roomtemperature Lorenz number for $\mathrm{Np}$ can be approximated by the theoretical value. The temperature dependence of the Lorenz number is unknown.

\subsubsection{Thermal conductivity at $300 \mathrm{~K}$}

Two of the four estimates of thermal conductivity of $\mathrm{Np}$ at $300 \mathrm{~K}$ were derived from electrical resistivity measurements by Lee [435]. The earliest determination was that of Lee, who applied a method developed by Kannuluik [436] to his electrical resistivity data and concluded that the thermal conductivity of $\mathrm{Np}$ is " $0.01 \pm 0.001$ c.g.s. units at $300^{\circ} \mathrm{K}$ " [255 p. 464]. Touloukian et al. [8] re-calculated the thermal conductivity using the same data and method, and obtained a value of $4.18 \mathrm{~W} / \mathrm{m}-\mathrm{K}$. This value appears in a recent review by Konings [3].

Another estimate of the thermal conductivity of $\mathrm{Np}$ based on the data of Lee et al. was published by Ho et al. [15]. They rejected Touloukian's value because it produced a Lorenz number that they believed was implausibly low, and instead estimated the thermal conductivity of $\mathrm{Np}$ at $300 \mathrm{~K}$ as $6.3 \mathrm{~W} / \mathrm{m}-\mathrm{K}$. Although Ho et al. did not explain why they suggested this value, it can be obtained from the Wiedemann-Franz law with Lee's resistivity data and the theoretical Lorenz number. This value for the thermal conductivity of Np appears in the CRC Handbook of Chemistry and Physics [437] and was recommended in a recent review by Kim et al. [170].

The remaining two estimates of thermal conductivity are based on the diffusivity data of Wagner [434]. Wagner estimated the room-temperature thermal conductivity of $\mathrm{Np}$ as $7.70 \mathrm{~W} / \mathrm{m}-\mathrm{K}$ at $300 \mathrm{~K}$ based on a thermal diffusivity of $0.027 \mathrm{~cm}^{2} / \mathrm{sec}$, a heat capacity of $32.9 \mathrm{~J} / \mathrm{mol}-\mathrm{K}$, and a density of 20.4 $\mathrm{g} / \mathrm{cm}^{3}$. This value for heat capacity is significantly higher than the value of $29.63 \mathrm{~J} / \mathrm{mol}-\mathrm{K}$ recommended in Section 4.2.1, and this value for density is slightly lower than the theoretical density of 20.45-20.48 $\mathrm{g} / \mathrm{cm}^{3}$ (Section 4.3.1). Re-calculating the thermal conductivity of $\mathrm{Np}$ based on Wagner's diffusivity data using a heat capacity of $29.7 \mathrm{~J} / \mathrm{mol}-\mathrm{K}$ and density of $20.48 \mathrm{~g} / \mathrm{cm}^{3}$ gives a thermal conductivity of 6.92 $\mathrm{W} / \mathrm{m}-\mathrm{K}$ for $\mathrm{Np}$ at $300 \mathrm{~K}$.

Better experimental data is needed to determine the actual thermal conductivity of $\mathrm{Np}$, although it seems likely that it is between 6 and $7 \mathrm{~W} / \mathrm{m}-\mathrm{K}$. In the absence of this data, the value of $6.3 \mathrm{~W} / \mathrm{m}-\mathrm{K}$ proposed by Ho et al. [15] for the room-temperature thermal conductivity of $\mathrm{Np}$ seems the most defensible estimate.

\subsubsection{Thermal conductivity at higher temperatures}

No measurements of the thermal conductivity of $\mathrm{Np}$ at higher temperatures are available. However, this data can be approximated for temperatures up to $900 \mathrm{~K}$ by using the Wiedemann-Franz Law. Figure 127 shows thermal conductivity values calculated using electrical resistivity measurements reported by Lee et al. [435] and the theoretical value for the Lorenz number. 


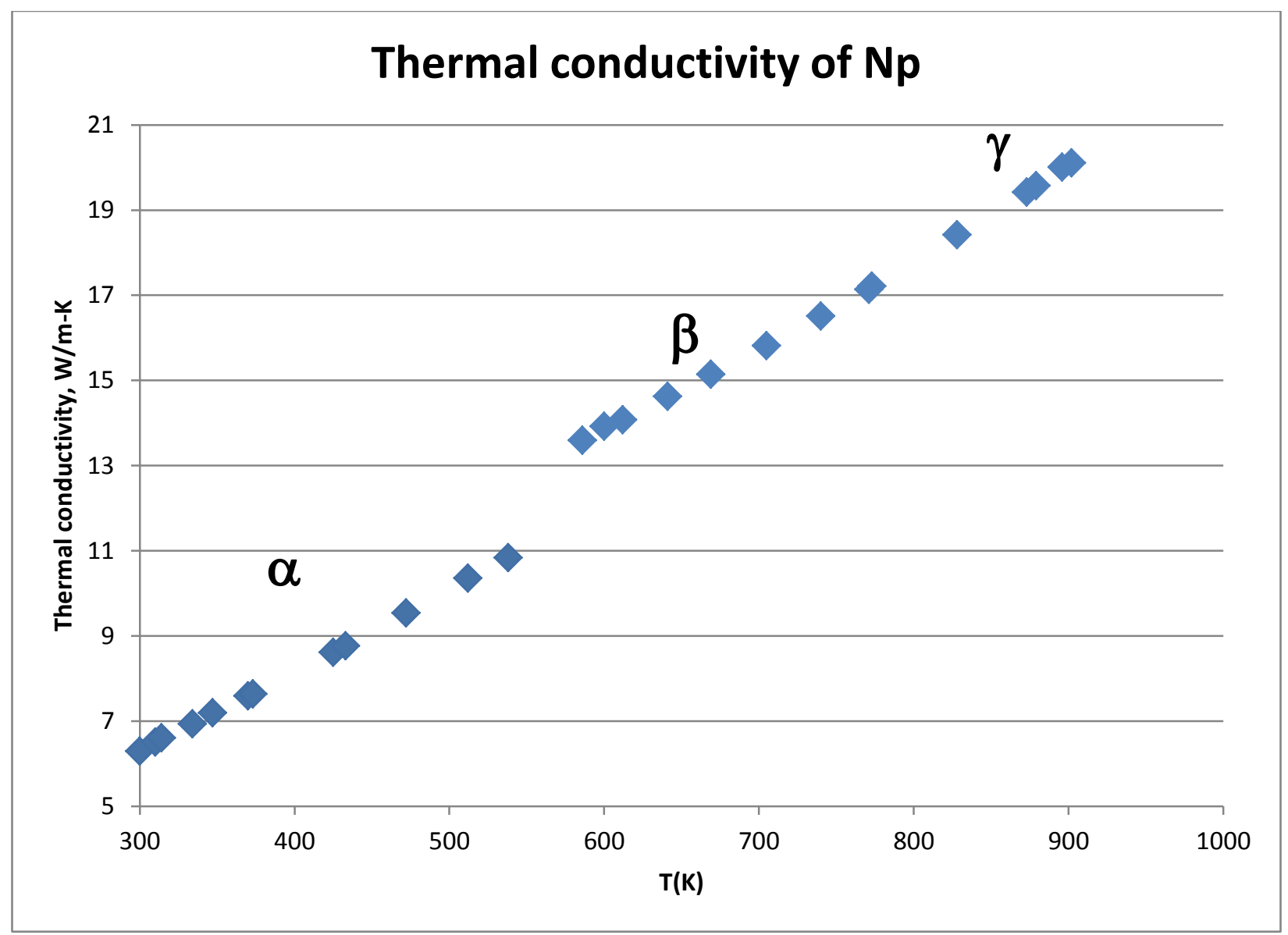

Figure 127. Thermal conductivity of $\mathrm{Np}$ calculated using the theoretical value of the Lorenz number $\left(2.44 \times 10^{-8} \mathrm{~W} \Omega / \mathrm{K}^{2}\right)$ and electrical resistivity data from Lee [435].

\subsubsection{Am}

Experimental measurements of the thermal conductivity or thermal diffusivity of Am are not available.

Two research laboratories agreed that the electrical resistivity of Am at $300 \mathrm{~K}$ and atmospheric pressure is $68.90 \mu \Omega \cdot \mathrm{cm}[390,438]$.

If the Lorenz number for Am is close to the theoretical value, the Wiedemann-Franz Law (Section 2.5.2) indicates that the room-temperature thermal conductivity of Am is $\sim 10.64 \mathrm{~W} / \mathrm{m}-\mathrm{K}$. However, a recent review of properties of the actinide elements suggested (without giving a reason) that the Lorenz number for Am is closer to $3.25 \times 10^{-8} \mathrm{~W} \mathrm{~K}^{-2}$ [3], which corresponds to a thermal conductivity of $\sim 14.15$ $\mathrm{W} / \mathrm{m}-\mathrm{K}$.

Further experimental work on the thermal conductivity and Lorenz number of Am is needed, particularly at temperatures of interest for nuclear fuels.

\subsubsection{La}

\subsubsection{Introduction}

Papers reporting experimental measurements of the thermal diffusivity and conductivity of La at temperatures above $\sim 300 \mathrm{~K}$ were commonly first published in Soviet journals, although English translations of many of these papers have been published. Although two of the original publications 
(references [399, 402]) present results numerically, other publications (references [400, 405, 439, 440]) only present their results graphically. Touloukian et al. [8] published numerical values obtained from the graphical data of Golubkov et al. [440].

Figure 128 shows the published numerical values of the thermal conductivity of La. The apparently good agreement for the thermal conductivity of $\alpha$-La is because the values shown in the figure are derived from the same set of measurements; one set of data incorporates a correction for "impurities" that the other does not. It seems likely that the actual value for the thermal conductivity of $\beta$-La is between the two sets of data shown, and that the thermal conductivity of liquid La is significantly lower than shown in the figure. Further research is clearly needed.

\subsubsection{Lorenz number}

Jolliffe et al. determined the Lorenz number of $\alpha$-La at $291 \mathrm{~K}$ to be $2.9 \times 10^{-8}{\mathrm{~W} \Omega \mathrm{K}^{-2}}_{\text {[441]. This value }}$ is somewhat higher than the value of $2.63 \times 10^{-8} \mathrm{~W} \mathrm{~K}^{-2}$ reported in an earlier review [9], and also higher than the value of $2.75 \times 10^{-8}{\mathrm{~W} \Omega \mathrm{K}^{-2}}$ calculated from room-temperature thermal conductivity and electrical resistivity data in the CRC Handbook of Chemistry and Physics [17 Table 9]. Although further research is needed to determine the actual Lorenz number and its temperature dependence, it seems likely that the Lorenz number of $\mathrm{La}$ is significantly higher than the theoretical value.

Lorenz numbers for liquid $\mathrm{La}$ at temperatures between 1190 and $2000 \mathrm{~K}$ are between 2.12 and $2.65 \times 10^{-8}{\mathrm{~W} \Omega \mathrm{K}^{-2}}^{2}$, with no obvious relationship between temperature and variations in values [17 Tables 4 and 12, 399].

\subsubsection{Thermal conductivity}

Values of the thermal conductivity of La published by Atalla and by Kurichenko et al. [399, 402] were calculated from their measurements of thermal diffusivity and heat capacity (both of which are provided in the references), combined with previously available information on density. The heat-capacity values used by Kurichenko et al. are significantly higher than those recommended in Section 4.2.3 (Figure 99).

The thermal conductivity values for $\alpha$-La recommended by Touloukian, Ho, and colleagues $[8,15]$ are based on the room-temperature measurements and the data of Golubkov et al. [440], but are 5\% higher to compensate for the relatively low purity of Golubkov's sample [15]. In the absence of further experimental measurements, any of the thermal conductivity values in this section is a defensible approximation of the actual thermal conductivity of $\alpha$-La.

The thermal conductivity values for $\beta$-La recommended by Touloukian, Ho, and colleagues $[8,15]$ are based on the Wiedemann-Franz law with the theoretical value of the Lorenz number and a correction for the lattice component of thermal conductivity determined from room-temperature data [15]. Since the heat capacity values used by Kurichenko et al. [402] are $~ 15-20 \%$ higher than the values recommended in Section 4.2.3 of this Handbook, it seems likely that the thermal conductivity values of Kurichenko et al. are correspondingly too high. In the absence of new experimental data, it seems reasonable to assume that the actual thermal conductivity of $\beta$-La lies between the values of Kurichenko et al. and Ho et al.

There are apparently no published measurements or estimates of the thermal conductivity or diffusivity of $\gamma$-La. Krieg et al. reported the electrical resistivity of $\mathrm{La}$ as $126 \mu \Omega$-cm at $884{ }^{\circ} \mathrm{C}(1157 \mathrm{~K})$ and $128 \mu \Omega-\mathrm{cm}$ at $1193 \mathrm{~K}$ (the melting temperature for the sample in their study) [442]. Although the phase in this sample was not characterized, the temperatures suggest that these data may be from $\gamma$-La. These values are similar to the value of $126 \mu \Omega-\mathrm{cm}$ at $890^{\circ} \mathrm{C}(1163 \mathrm{~K})$ reported in an earlier review by Gschneidner [9]. 
The Lorenz number for $\gamma$-La has not been reported; however, based on a Lorenz number of $2.63 \times 10^{-8}$ $\mathrm{W} \Omega \mathrm{K}^{-2}$ (appropriate for $\alpha$-La at $25^{\circ} \mathrm{C}$, and the best available approximation for other La phases and temperatures) [9], the thermal conductivity of $\gamma-\mathrm{La}$ is approximately $41 \mathrm{~W} / \mathrm{m}-\mathrm{K}$.

Atalla calculated the thermal conductivity of La using their measurements of thermal diffusivity and heat capacity (both of which are provided in their paper) [399]. The heat capacity values in this paper are at least 50\% higher than those recommended in Section 4.2.3 of this Handbook. If it is assumed that the thermal diffusivity measurements of Atalla are correct, the actual thermal conductivity of liquid La is significantly below that shown in Figure 128.

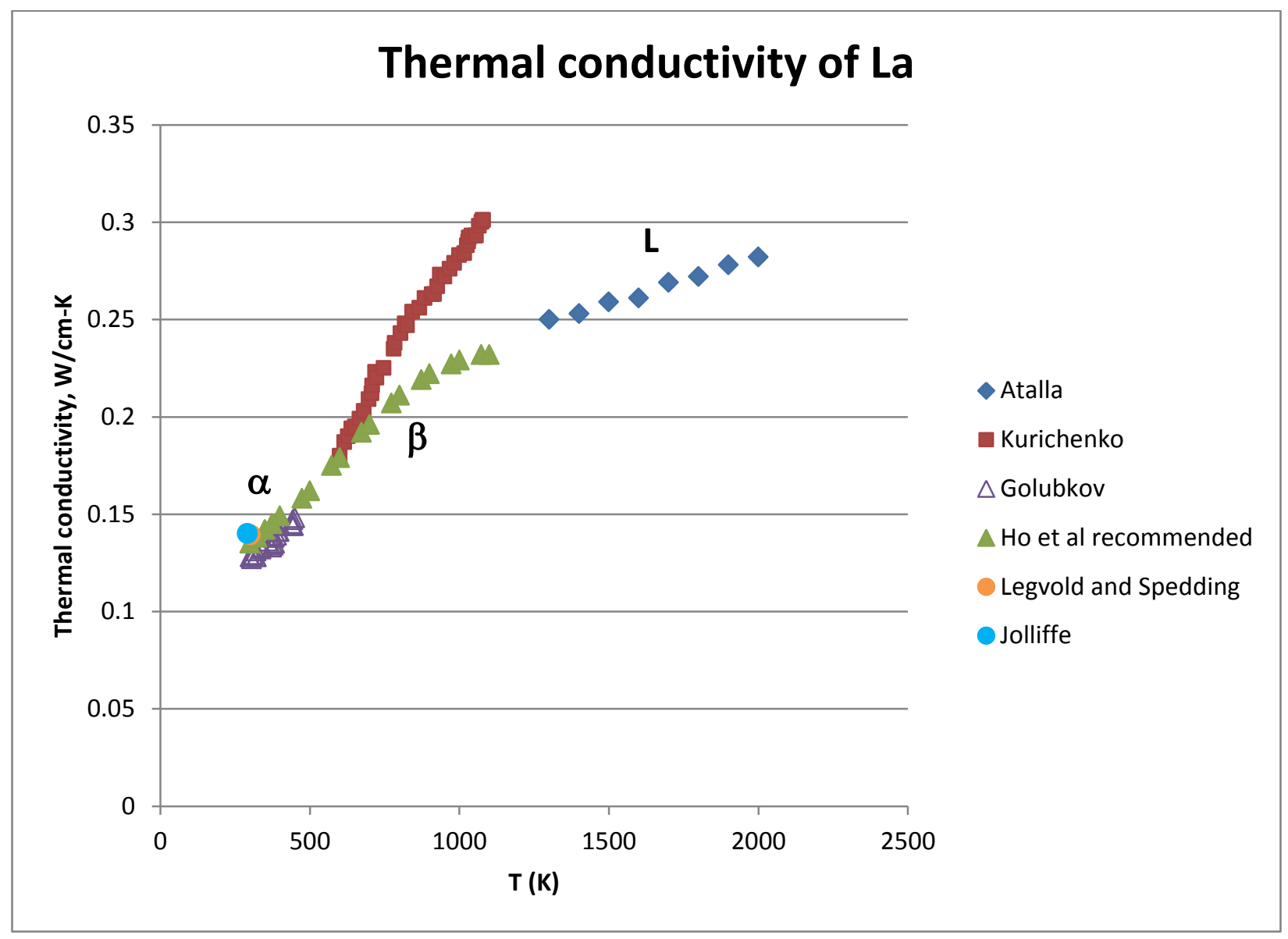

Figure 128. Thermal conductivity of $\mathrm{La}[15,399,402,440,441,443]$

\subsubsection{Ce}

\subsubsection{Introduction}

There are very few experimental measurements of the thermal diffusivity or conductivity of $\mathrm{Ce}$ at temperatures above $\sim 300 \mathrm{~K}$. Many of these measurements are from poorly characterized samples, and phases are rarely identified. The data on thermal conductivity of $\gamma$-Ce and $\delta$-Ce are generally consistent, although values for liquids vary by an order of magnitude for some temperatures. Further research is required, particularly for liquids. 


\subsubsection{Lorenz number}

Jolliffe and colleagues calculated the Lorenz number for Ce at $18{ }^{\circ} \mathrm{C}$ as $\sim 2.8 \times 10^{-8} \mathrm{~W}-\Omega / \mathrm{K}^{2}$ based on their thermal conductivity and electrical resistivity measurements $[441,444]$. This value is consistent with both the value of $2.7 \times 10^{-8} \mathrm{~W} \Omega / \mathrm{K}^{2}$ at $25^{\circ} \mathrm{C}$ in an earlier review by Gschneidner [9] and the value of $2.8 \times 10^{-8} \mathrm{~W} \Omega / \mathrm{K}^{2}$ at $300 \mathrm{~K}$ calculated from data in the CRC Handbook of Chemistry and Physics [17 Table 9], and indicates that the Lorenz number for $\mathrm{Ce}$ is significantly higher than the theoretical value.

Lorenz numbers for liquid Ce are between $2.28 \times 10^{-8}$ and $2.68 \times 10^{-8} \mathrm{~W} \Omega / \mathrm{K}^{2}$ at temperatures between 1200 and $1800 \mathrm{~K}$, and may decrease with increasing temperature [399]. These values are consistent with the value of $\sim 2.55 \times 10^{-8} \mathrm{~W} \Omega / \mathrm{K}^{2}$ for the Lorenz number of Ce liquid calculated from thermal expansion an electrical resistivity values "near the melting point" [17 Table 12].

\subsubsection{Thermal conductivity}

Thermal conductivities published by Atalla and by Kurichenko et al. were calculated from their measurements of thermal diffusivity and heat capacity (both of which are provided in the references), combined with previously available information on density. The heat capacity values used by Kurichenko et al. are consistent with the values recommended in Section 4.2.4 of this Handbook (Figure 100). Values from Zinov'ev et al. [445] were derived from earlier studies not otherwise considered in this Handbook. Values from Novikov and Mardykin [446] were calculated from their electrical resistivity values using the Wiedemann-Franz law with a Lorenz number of $2.2 \times 10^{-8} \mathrm{~W} \Omega / \mathrm{K}^{2}(90 \%$ of the theoretical value, as suggested by Novikov and Mardykin for temperatures between $\sim 1200$ and $1300 \mathrm{~K}$ ).

Figure 129 shows the experimental measurements. Phase identifications in Figure 129 correspond to phase-transformation temperatures in the Ce phases section of this handbook and (particularly for measurements close to room temperature) may not correspond to the phase(s) actually present in the samples.

Figure 129 also shows the provisional thermal conductivity values of Touloukian et al. and Ho et al. $[8,15]$. These values were obtained by drawing a smooth curve through data measured at temperatures below $\sim 22 \mathrm{~K}$ and the room-temperature data of Powell and Jolliffe [444] and of Legvold and Spedding [443]. Although they are consistent with the data of Zinov'ev et al., they are not supported by measurements above room temperature. 


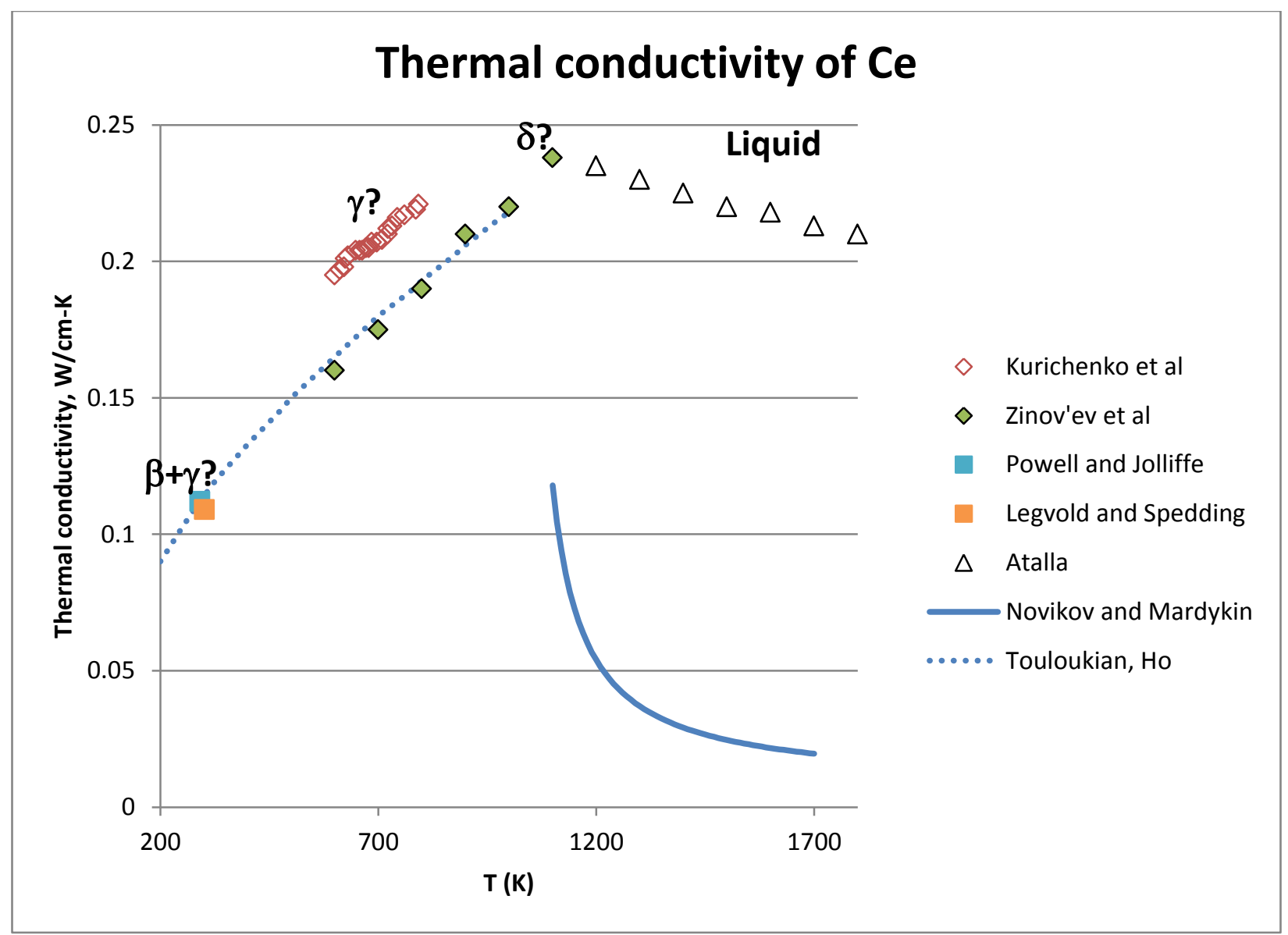

Figure 129. Thermal conductivity of Ce based on references [8, 15, 399, 402, 443-446]

\subsection{5 $\mathrm{Pr}$}

\subsubsection{Introduction}

Publications with numerical data on the thermal conductivity of $\alpha$-Pr at temperatures above $\sim 300 \mathrm{~K}$ are limited to two publications with room-temperature thermal conductivity [441, 443], one paper with calculated conductivities based on experimentally measured thermal diffusivities at temperatures above $\sim 300 \mathrm{~K}$ [402], and one paper with data on the thermal diffusivity of liquid Pr [405]. Other researchers (e.g., $[419,447])$ presented their data graphically.

Although very sparse, the available data on the thermal conductivity of $\alpha$-Pr show good agreement. No data on the thermal conductivity, thermal diffusivity, or electrical resistivity of $\beta$-Pr is available. Further work is clearly needed on other samples and phases.

\subsubsection{Lorenz number}

Jolliffe and colleagues calculated the Lorenz number for Pr at $291 \mathrm{~K}$ as $\sim 2.7 \times 10^{-8} \mathrm{~W}-\Omega / \mathrm{K}^{2}$ based on their thermal conductivity and electrical resistivity measurements [441]. This value is generally consistent with the value of $2.67 \times 10^{-8} \mathrm{~W}-\Omega / \mathrm{K}^{2}$ at $25^{\circ} \mathrm{C}$ in an earlier review by Gschneidner [9], and indicates that the room-temperature value of the Lorenz number for Pr is significantly higher than the theoretical value. 


\subsubsection{Thermal conductivity}

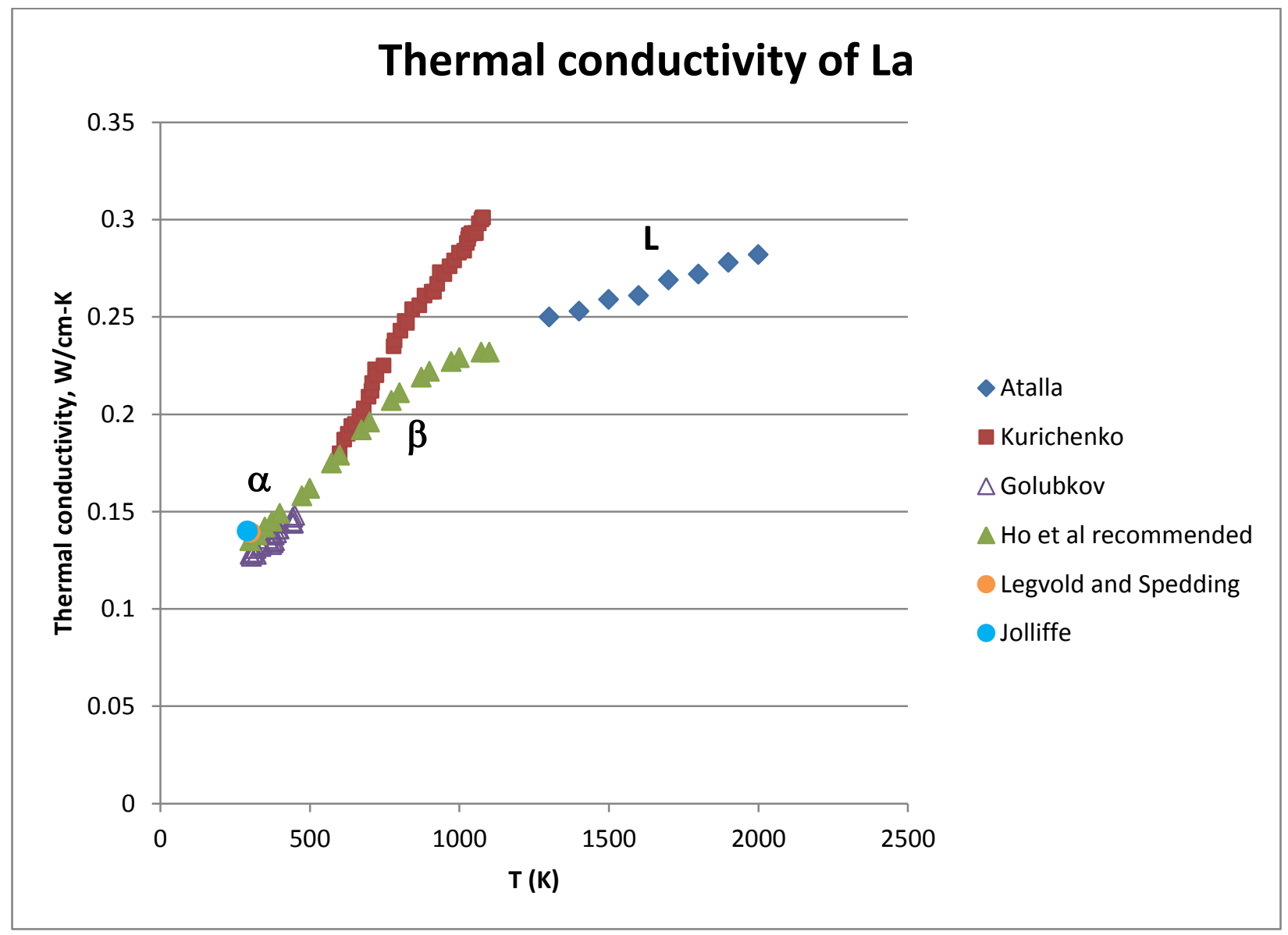

Figure 128 shows the measurements of the thermal conductivity of $\alpha$-Pr at temperatures above $\sim 290$ $\mathrm{K}$. Values published by Kurichenko et al. were calculated from new measurements of thermal diffusivity and heat capacity (both of which are provided in the reference), combined with previously available information on density. The heat capacity values used by Kurichenko et al. are consistent with the values recommended in Section 4.2.5 of this Handbook (Figure 101).

Figure 130 also shows the provisional thermal conductivity values of Touloukian et al. and Ho et al. $[8,15]$. At the time of these reviews, no measurements of thermal conductivity at temperatures above 380 $\mathrm{K}$ were available. Higher-temperature provisional values were calculated from electrical resistivity measurements using the theoretical value of the Lorenz number with a correction factor for the lattice component of the thermal conductivity from room-temperature data [15].

As shown in Figure 130, there is generally good agreement about the thermal conductivity of $\alpha$-Pr at temperatures between $\sim 300$ and $1000 \mathrm{~K}$. The steep rise in the values of Kurichenko et al. between $\sim 1000$ and $1100 \mathrm{~K}$ may be related to the $\alpha-\beta$ phase transformation at $\sim 1068 \mathrm{~K}$.

Banchila and Filippov [405] published an equation representing their measurements of thermal diffusivity of Pr liquid, and Hiemstra et al. [448] published electrical resistivity measurements between the melting temperature and $\sim 1200 \mathrm{C}$. 


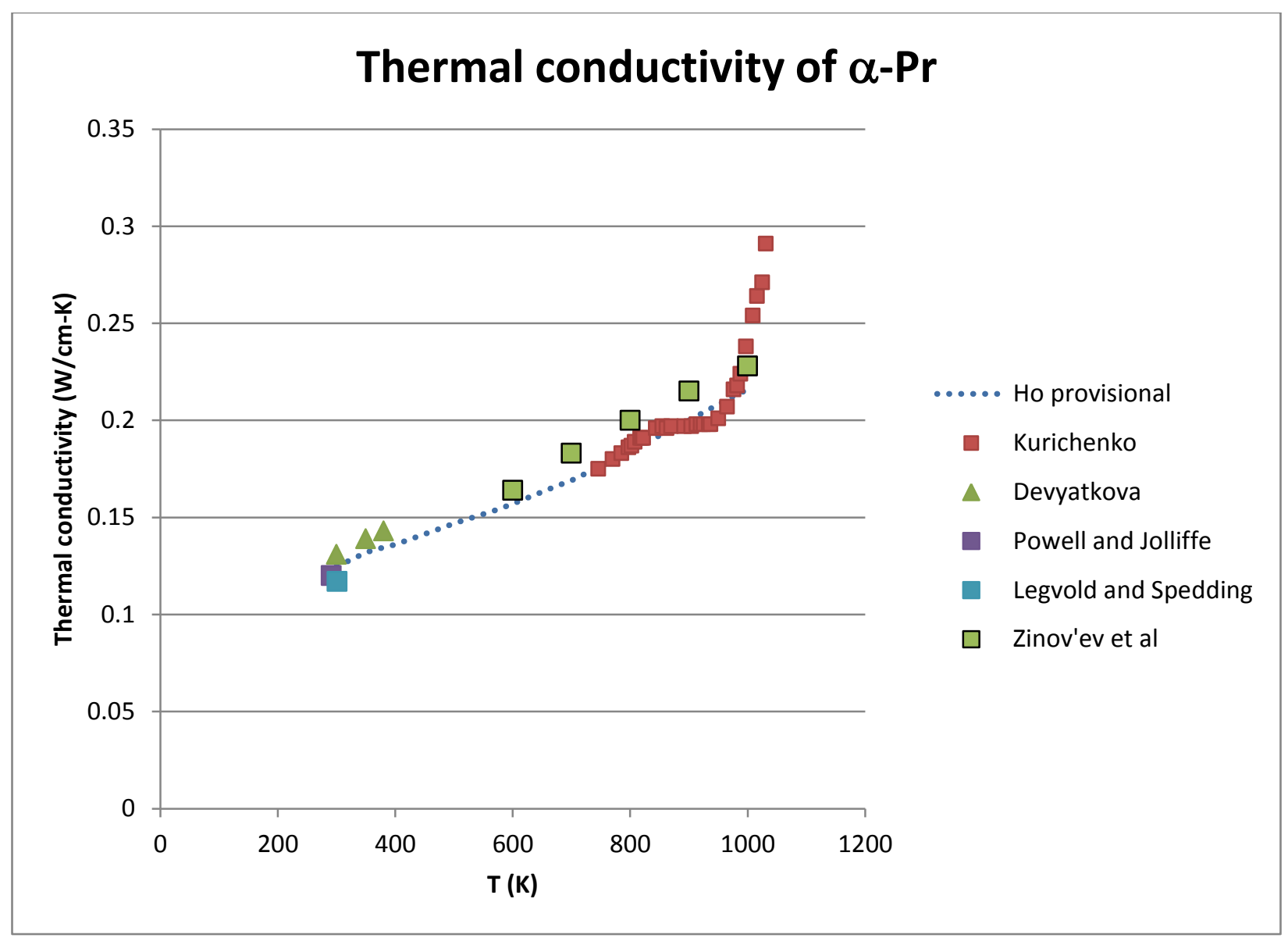

Figure 130. Thermal conductivity of $\alpha$-Pr from references [399, 402, 443-445]

\subsubsection{Nd}

\subsubsection{Introduction}

The thermal conductivity of $\mathrm{Nd}$ at temperatures above $\sim 300 \mathrm{~K}$ has been measured by a number of research groups using a variety of techniques [16, 399, 400, 441, 443-445, 449]. Room-temperature conductivities agree to within $\sim 0.02 \mathrm{~W} / \mathrm{cm}-\mathrm{K}$, and higher-temperature thermal conductivities for solid phases agree to within $\sim 0.05 \mathrm{~W} / \mathrm{cm}-\mathrm{K}$. There is general agreement that thermal conductivities rise with increasing temperature, and that there is little difference between the thermal conductivities of $\alpha-\mathrm{Nd}$ and $\beta-\mathrm{Nd}$.

Further research with high-purity samples is needed if greater precision is required.

\subsubsection{Lorenz number}

Jolliffe and colleagues calculated the Lorenz number for $\mathrm{Nd}$ at $291 \mathrm{~K}$ as $\sim 3.7 \times 10^{-8} \mathrm{~W}-\Omega / \mathrm{K}^{2}$ based on their thermal conductivity and electrical resistivity measurements [441]. This value is generally consistent with the value of $3.54 \times 10-8 \mathrm{~W}-\Omega / \mathrm{K}^{2}$ calculated from information in the CRC Handbook of Chemistry and Physics [17 Table 9], but is significantly larger than the value of $2.80 \times 10^{-8} \mathrm{~W}-\Omega / \mathrm{K}^{2}$ at $25^{\circ} \mathrm{C}$ in an earlier review by Gschneidner [9] and the value of almost $3 \times 10^{-8} \mathrm{~W}-\Omega / \mathrm{K}^{2}$ reported by Binkele [16 Figure 5]. The value of $3.54 \times 10^{-8} \mathrm{~W}-\Omega / \mathrm{K}^{2}$ from data in the CRC Handbook is probably the most reliable value, as it is the most recent. 
Lorenz numbers for $\mathrm{Nd}$ liquids are between 2.2 and $2.40 \mathrm{~W}-\Omega / \mathrm{K}^{2}$ at temperatures between 1220 and $1600 \mathrm{~K}$, with no obvious relationship between temperature and variations in values [399]. These values are consistent with the value of $\sim 2.3 \times 10^{-8} \mathrm{~W} \Omega / \mathrm{K}^{2}$ for the Lorenz number of $\mathrm{Nd}$ liquid calculated from thermal expansion an electrical resistivity values "near the melting point" [17 Table 12].

\subsubsection{Thermal conductivity}

Figure 131 shows the experimental data on the thermal conductivity of $\mathrm{Nd}$ at temperatures above $\sim 300 \mathrm{~K}$. Values published by Kurichenko et al. were calculated from new measurements of thermal diffusivity and heat capacity (both of which are provided in the reference) obtained using an experimental instrument, combined with previously available information on density. The heat capacity values used by Kurichenko et al. are consistent with the values recommended in Section 4.2.6 (Figure 102). Values published by Binkele were measured directly using a modification of the Kohlrausch technique, which involves measuring changes in temperature in response to electrical currents [16, 450].

The data from Atalla was obtained using a device that they developed for simultaneously measuring thermal conductivity, thermal diffusivity, and heat capacity [399]. Although the paper indicates that the data is from liquids, it overlaps the temperature range for $\beta$-Nd (Section 4.1.6).

The provisional values of Ho et al. $[8,15]$ are provided for comparison, as they are more widely available than much of the other data shown in Figure 131. These values were based on room-temperature thermal conductivity and estimated values for electrical resistivity, and did not consider highertemperature thermal conductivity measurements.

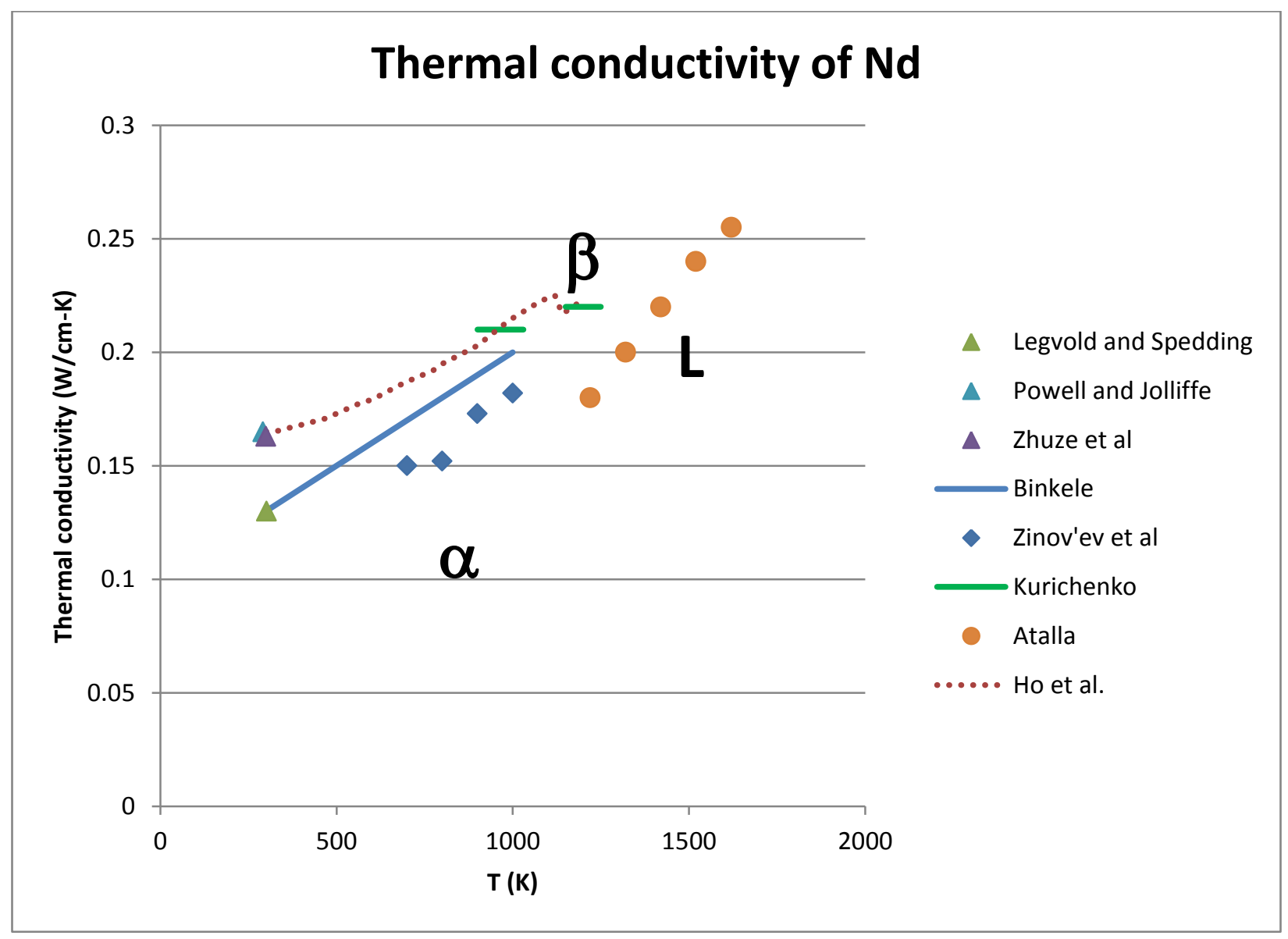


Figure 131. Thermal conductivity of $\mathrm{Nd}[15,16,399,400,441,443-445,449]$

Experimental data on the electrical resistivity of $\mathrm{Nd}$ has been published in a number of papers (e.g., references [445, 448, 451-454], but was not considered in this Handbook because more direct measurements of thermal conductivity are available.

\subsubsection{Np-Pu}

\subsubsection{Introduction}

Experimental measurements of the thermal conductivity of $\mathrm{Np}-\mathrm{Pu}$ alloys are not available, and electrical resistivity values are limited to temperatures below $400 \mathrm{~K}$. All of the measurements are from samples with the $\alpha-\mathrm{Pu}$ structure. The electrical resistivity of alloys with $0.5-25$ at $\% \mathrm{~Np}$ is within a few percent of the resistivity value for $\mathrm{Pu}$ at temperatures of 300-400 K, suggesting that the thermal conductivity of these alloys can be approximated by the thermal conductivity of $\mathrm{Pu}$.

Measurements of thermal conductivity are needed, particularly at temperatures relevant for FCRD fuels.

\subsubsection{Thermal conductivity}

Although no measurements of thermal conductivity for $\mathrm{Np}-\mathrm{Pu}$ alloys are available, two sets of measurements of electrical resistivity have been reported $[455,456]$.

The earlier set of measurements was apparently in progress at the time of they were presented in a conference paper [456]. These measurements show differences in electrical resistivity of $\mathrm{Pu}$ and $\mathrm{Np}-\mathrm{Pu}$ alloys with 9 and 50 at $\% \mathrm{~Np}$ as a function of temperature, reported relative to resistivities of the same materials at $0^{\circ} \mathrm{C}$ rather than as measured values (Figure 132). Resistivities of all three materials decrease smoothly with increasing temperatures in the range from $\sim 100-400 \mathrm{~K}$, but resistivities of materials with higher concentrations of $\mathrm{Np}$ decrease less rapidly. 


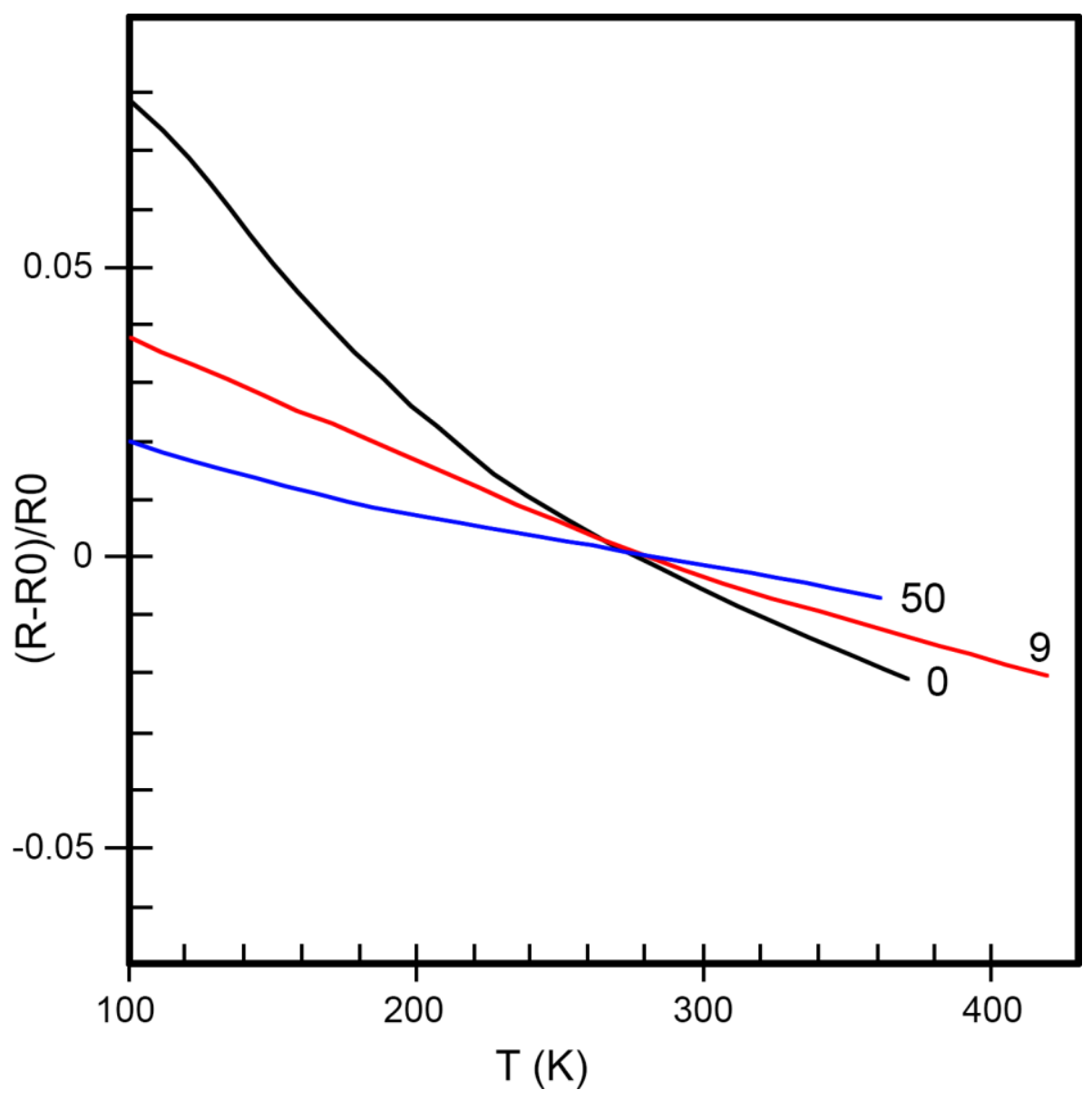

Figure 132. Electrical resistivity of $\mathrm{Pu}$ and $\mathrm{Np}$-Pu alloys (after [456 Figure 2.9], with lower-temperature data not shown). Data for each material is expressed relative to R0, the resistivity of the material at $273 \mathrm{~K}$. Numbers next to curves indicate compositions (in at $\% \mathrm{~Np}$ ).

The second set of data includes measurements of electrical resistivity of $\mathrm{Np}, \mathrm{Pu}$, and nine $\mathrm{Np}-\mathrm{Pu}$ alloys at temperatures up to $300 \mathrm{~K}$ by Olsen and Elliott [455] (Table 31). The reported electrical resistivity of $\mathrm{Pu}$ is comparable to that in other studies (e.g., [174, 457]). The reported electrical resistivity of $\mathrm{Np}$ is significantly below the resistivity of $116.4 \mu \Omega-\mathrm{cm}$ reported for $\mathrm{Np}$ at $310 \mathrm{~K}$ in an extensive study by Lee [435]. All of the room-temperature resistivity values for alloys with up to $25 \mathrm{at} \% \mathrm{~Np}$ reported by Olsen and Elliott are within a few percent of the resistivity of $\mathrm{Pu}$, and there is no clear trend relating $\mathrm{Np}$ concentration to resistivity.

Table 31 and Figure 133 show thermal conductivity values calculated from the resistivity data of Olsen and Elliott using the Wiedemann-Frank Law with the best available estimate of the Lorenz number for $\mathrm{Pu}\left(3.15 \times 10^{-8} \mathrm{~W} \Omega \mathrm{K}^{-2}\right.$, Section 3.4.2). 
Table 31. Electrical resistivity and thermal conductivity of $\mathrm{Np}-\mathrm{Pu}$ alloys with the $(\alpha-\mathrm{Pu})$ structure at 300 $\mathrm{K}$. Resistivity data are from [455]; conductivity values were calculated assuming a Lorenz number of $3.15 \times 10^{-8}{\mathrm{~W} \Omega \mathrm{K}^{-2}}^{-2}$

\begin{tabular}{lll}
$\begin{array}{l}\text { Composition } \\
(\text { At\% Np) }\end{array}$ & $\begin{array}{l}\text { Resistivity } \\
(\mu \Omega-\mathrm{cm})\end{array}$ & $\begin{array}{l}\text { Conductivity } \\
(\mathrm{W} / \mathrm{m}-\mathrm{K})\end{array}$ \\
\hline 0 & 149.7 & 6.31 \\
0.5 & 147.4 & 6.41 \\
1 & 146.3 & 6.46 \\
2 & 147.0 & 6.43 \\
4 & 146.8 & 6.44 \\
6 & 150.0 & 6.30 \\
8 & 149.8 & 6.31 \\
15 & 141.8 & 6.66 \\
25 & 146.0 & 6.47 \\
50 & 187.6 & 5.04 \\
100 & 99.5 & 9.50 \\
\hline
\end{tabular}




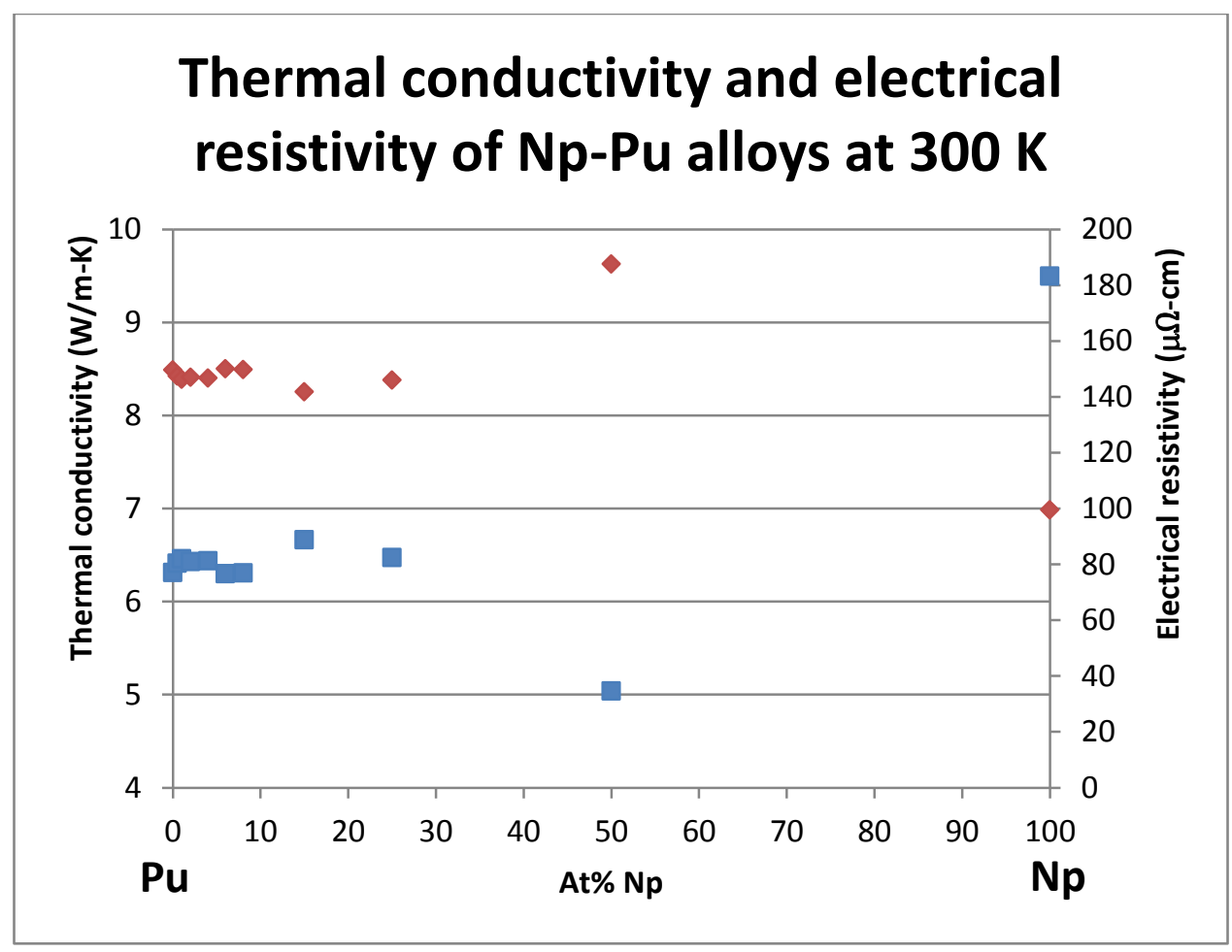

Figure 133. Thermal conductivities (blue squares) and electrical resistivities (red diamonds) from Olsen and Elliott [455]

It seems likely that the differences in electrical resistivity and thermal conductivity as a function of composition are smaller than the uncertainties in the data for compositions with up to $\sim 25 \mathrm{at} \% \mathrm{~Np}$, and it is therefore reasonable to assume that the thermal conductivity of these alloys can be approximated by the thermal conductivity of $\mathrm{Pu}$.

\subsubsection{Pu-Am}

\subsubsection{Introduction}

Experimental measurements of the thermal conductivity of Pu-Am alloys are not available.

Baclet et al. [299] measured the low-temperature electrical resistivities of Am-stabilized $\delta$-Pu solid solutions in four alloys with $8-43$ at\% Am at temperatures up to $300 \mathrm{~K}$. Their measurements indicated that the electrical resistivity of each alloy was essentially independent of temperature above $\sim 150 \mathrm{~K}$. A model developed by Tsiovkin et al. [458] extends the upper end of the temperature range over which the resistivity of each composition is essentially constant to $700 \mathrm{~K}$.

Table 32 shows electrical resistivities at $300 \mathrm{~K}$ read from reference [299 Figure 4] and the corresponding thermal conductivities calculated using the recommended value of the room-temperature Lorenz number for $\mathrm{Pu}\left(3.15 \times 10^{-8} \mathrm{~W} \Omega \mathrm{K}^{-2}\right.$, Section 3.4.2). Given the currently available information, the values in Table 32 represent the best approximation to the thermal conductivities of $\mathrm{Pu}$-Am alloys. According to the Wiedemann-Franz Law, the thermal conductivity of each material is proportional to the temperature in $\mathrm{K}$, so thermal conductivities for each alloy will increase with temperature even when resistivities do not.

Further research is needed to confirm both the thermal conductivities in Table 32 and the temperature dependence of the conductivities. It is important that this research should also include measurements of $\mathrm{Am}$ and $\mathrm{Pu}$ to allow comparison to results from other studies. 


\subsubsection{Thermal conductivity}

Table 32 shows electrical resistivities from Baclet et al. [299 Figure 4] and the corresponding thermal conductivities calculated using the recommended value of the room-temperature Lorenz number for $\mathrm{Pu}$ (3.15 $\times 10^{-8} \mathrm{WK}^{-2}$, Section 3.4.2). The electrical resistivity for Am (which was quoted from a Ph.D. thesis rather than measured by Baclet et al.) is $\sim 20 \mu \Omega$-cm higher than the values in Section 4.4.2 of this Handbook, and the thermal conductivity calculated from this resistivity is correspondingly reduced. No data on the thermal conductivity of Pu-Am alloys from other sources isis available for comparison to the measurements made by Baclet et al.

Table 32. Electrical resistivity and thermal conductivity of Pu-Am alloys at $300 \mathrm{~K}$. Thermal conductivities were calculated using the Wiedemann-Franz Law with the Lorenz number for $\mathrm{Pu}$

\begin{tabular}{lll}
$\begin{array}{l}\text { Compositon } \\
(\mathrm{at} \% \mathrm{Am})\end{array}$ & $\begin{array}{l}\text { Electrical } \\
\text { Resistivity } \\
(\mu \Omega-\mathrm{cm})\end{array}$ & $\begin{array}{l}\text { Thermal } \\
\text { conductivity } \\
(\mathrm{W} / \mathrm{m}-\mathrm{K})\end{array}$ \\
\hline 8 & 335 & 2.9 \\
23 & 205 & 4.6 \\
28 & 260 & 3.6 \\
43 & 290 & 3.3 \\
100 & 90 & 10.5 \\
\hline
\end{tabular}

\subsubsection{Pu-Ce}

\subsubsection{Introduction}

No measurements of the thermal conductivity, thermal diffusivity, or electrical resistivity of $\mathrm{Pu}-\mathrm{Ce}$ alloys above room temperature are available. Andrew reported that the thermal conductivity of a Cestabilized $\delta$-Pu solid solution with 10 at $\%$ Ce increases monotonically between $75 \mathrm{~K}$ and room temperature, with a room-temperature value electrical resistivity of $98.1 \mu \Omega \cdot \mathrm{cm}$ and thermal conductivity of $\sim 10.75 \mathrm{~W} / \mathrm{m}-\mathrm{K}[431]$.

More recently, Dormeval et al measured the low-temperature electrical resistivity of $\mathrm{Pu}-\mathrm{Ce}$ alloys with 4.6, 6.1, and 8.1 at\% $\mathrm{Ce}$, and reported room-temperature electrical resistivities between $\sim 180$ and $220 \mu \Omega \cdot \mathrm{cm}$. They found that the resistivity increased with the concentration of Ce and was essentially independent of temperature between $\sim 150$ and $300 \mathrm{~K}$ [430].

Resistivity values in the two references are inconsistent, and further research is needed to determine accurate thermal conductivity values for Pu-Ce alloys.

\subsubsection{Lorenz number}

Andrew used a modified Kohlrausch apparatus to determine that the the room-temperature electrical resistivity and thermal conductivity of Ce-stabilized $\delta$-Pu alloy with 10 at $\% \mathrm{Ce}$ are $98.1 \mu \Omega$-cm and 10.75

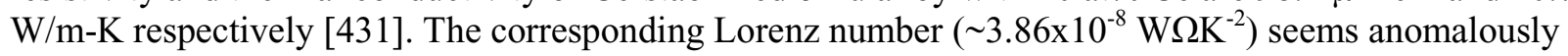
large in comparison to the recommended value of the room-temperature value of the Lorenz number for $7-\mathrm{Pu}\left(3.15 \times 10^{-8} \mathrm{~W} \Omega \mathrm{K}^{-2}\right.$, Section 3.4.2). 


\subsubsection{La-Ce}

No data on thermal conductivity or diffusivity of La-Ce alloys is available, and data on electrical resistivity at room temperature and above is limited to brief mentions in two papers.

Petersen et al. measured the low-temperature electrical resistivity of two La-Ce alloys and determined that the room-temperature electrical resistivity of an alloy with 70 at $\% \mathrm{La}$ is $\sim 67 \mu \Omega$-cm and the roomtemperature electrical resistivity of an alloy with $22 \mathrm{at} \% \mathrm{La}$ is $\sim 74 \mu \Omega-\mathrm{cm}$ [410]. These values are generally consistent with room-temperature electrical resistivities of $\alpha$-La $(61.5 \mu \Omega$-cm) and $\gamma$-Ce $(74.4$ $\mu \Omega-\mathrm{cm})$ in the CRC Handbook of Chemistry and Physics [17 Table 9].

Vedernikov et al. reported in a very short paper that the room-temperature electrical resistivity of LaCe alloys is slightly higher than would be expected if the resistivity were a linear function of composition [459]. They did not provide quantitative resistivity data, information about the purity of their samples, or information about their analytical methods.

Further research on this system is clearly needed.

\subsubsection{La-Pr}

No data on the thermal conductivity or diffusivity of La-Pr alloys is available. Information on electrical resistivity is limited to a very short paper in which Vedernikov et al. reported that the roomtemperature resistivity of these alloys varies linearly with composition [459]. This paper does not include quantitative data, information about sample purity, or information about the methods on which the results are based.

Further research on this system is clearly needed.

\subsubsection{Ce-Pr}

Experimental measurements of the thermal expansion of Ce-Pr alloys are not available. Data on resistivity are limited to temperatures of 298 and $368 \mathrm{~K}$ and compositions with less than 25 at $\%$ Ce [460]. Despite considerable scatter, which the authors attributed to inaccuracies in measuring the specimen dimensions (apparently required to convert measured resistances to resistivities), it was concluded that there was a linear relationship between composition and electrical resistivity at each temperature.

It is not clear how the higher-temperature data in this study was obtained, as the only measurement techniques discussed involved measurements of electrical resistivity at cryogenic temperatures (1.5-300 $\mathrm{K})$.

Further work on this system is clearly required.

\subsubsection{Pr-Nd}

No data on the thermal conductivity or diffusivity of Pr-Nd alloys is available. Information on electrical resistivity is limited to a very short paper in which Vedernikov et al. reported that the roomtemperature resistivity of these alloys varies linearly with composition [459]. This paper does not include quantitative data, or information about the samples or methods on which the results are based.

Further research on this system is clearly needed.

\subsubsection{Pu-Am-Zr}

Data related to the thermal conductivity of $\mathrm{Pu}-\mathrm{Am}-\mathrm{Zr}$ alloys is limited to measurements of thermal diffusivity from several alloys with $\sim 12 \mathrm{wt} \% \mathrm{Am}$ and $\sim 40 \mathrm{wt} \% \mathrm{Zr}$. Researchers at Idaho National Laboratory measured the thermal diffusivity of these alloys from room temperature to $1000{ }^{\circ} \mathrm{C}$ using the laser-flash method and fitted it with two polynomial equations (Equation 117 and Equation 118). Figure 134 shows the thermal diffusivity data. 
Equation 117. Thermal diffusivity of $\mathrm{Pu}-12 \mathrm{Am}-40 \mathrm{Zr}$ from 100 to $700{ }^{\circ} \mathrm{C}$

$\alpha=-4.301 \times 10^{-8} \times T^{2}+9.699 \times 10^{-5} \times \mathrm{T}+4.189 \times 10^{-2}$ ${ }^{\circ} \mathrm{C}$

where $\alpha$ is thermal diffusivity in $\mathrm{cm}^{2} / \mathrm{sec}$, $\mathrm{T}$ is a temperature in ${ }^{\circ} \mathrm{C}$, and $\mathrm{T}$ is between 100 and 700

Equation 118. Thermal diffusivity of $\mathrm{Pu}-12 \mathrm{Am}-40 \mathrm{Zr}$ from 700 to $1000{ }^{\circ} \mathrm{C}$

$\alpha=2.482 \times 10^{-8} \mathrm{xT}^{2}+2.436 \times 10^{-5} \times \mathrm{xT}+5.959 \times 10^{-2}$

where $\alpha$ is thermal diffusivity in $\mathrm{cm}^{2} / \mathrm{sec}$, $\mathrm{T}$ is a temperature in ${ }^{\circ} \mathrm{C}$, and $\mathrm{T}$ is between 700 and $1000{ }^{\circ} \mathrm{C}$

\section{Thermal diffusivity of Pu-12Am-40Zr}

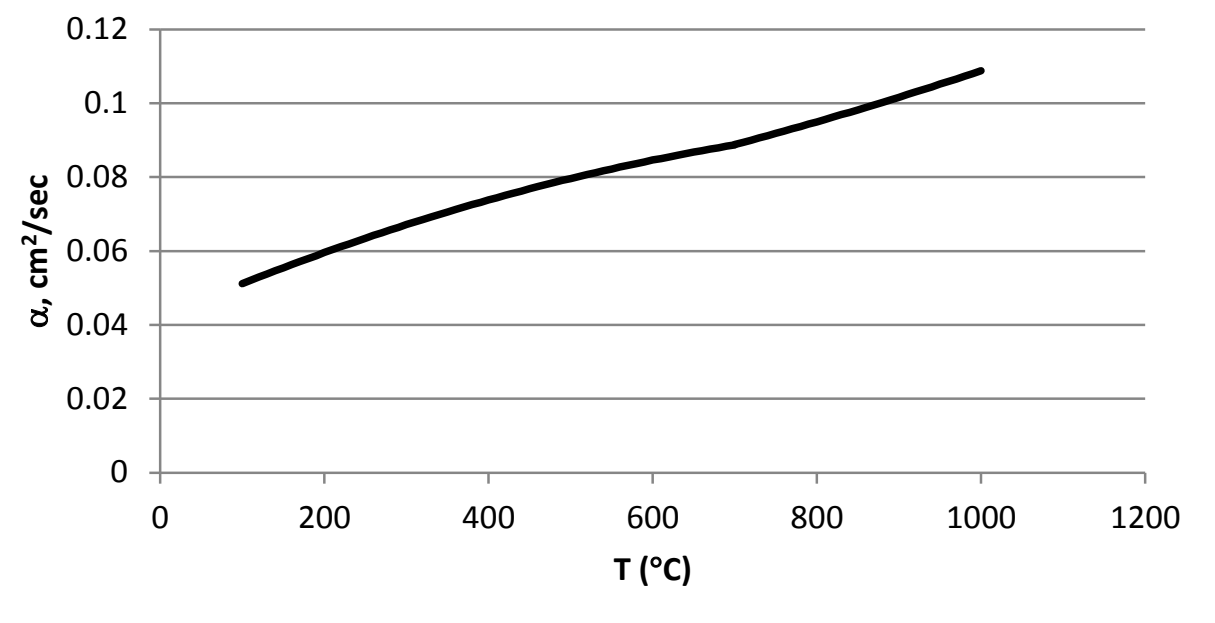

Figure 134. Thermal diffusivity of Pu-12Am-40Zr (Equation 117 and Equation 118)

\section{REFERENCES}

[1] D.E. Janney, C.A. Papesch, FCRD Transmutation Fuels Handbook 2015 (Idaho National Laboratory Report INL/EXT-15-36520), Idaho Falls, ID, 2015.

[2] R.J.M. Konings, O. Beneš, The Thermodynamic Properties of the $f$-Elements and Their Compounds. I. The Lanthanide and Actinide Metals, Journal of Physical and Chemical Reference Data, 39 (2010) 043102.

[3] R.J.M. Konings, O. Beneš, J.-C. Griveau, The actinides elements: properties and characteristics, in: R.J.M. Konings (Ed.) Comprehensive Nuclear Materials, volume 2, Elsevier, 2012, pp. 1-20.

[4] F.L. Oetting, M.H. Rand, R.J. Ackermann, The chemical thermodynamics of actinide elements and compounds, part 1: The actinide elements, International Atomic Energy Agency, Vienna, Austria, 1976.

[5] T. Ogata, Metal Fuel, in: R.J.M. Konings (Ed.) Comprehensive Nuclear Materials, volume 3, Elsevier, 2012, pp. 1-40.

[6] Y.S. Touloukian, R.K. Kirby, R.E. Taylor, P.D. Desai, Thermal Expansion: Metallic elements and alloys (Thermophysical Properties of Matter vol. 12), IFI/Plenum, New York, 1975.

[7] Y.S. Touloukian, P.W. Powell, C.Y. Ho, M.C. Nicolaou, Thermal Diffusivity (Thermophysical Properties of Matter vol. 10), IFI/Plenum, 1973. 
[8] Y.S. Touloukian, R.W. Powell, C.Y. Ho, P.G. Klemens, Thermal Conductivity (Thermophysical Properties of Matter vol. 1), IFI/Plenum, New York, 1970.

[9] K.A. Gschneidner Jr., Rare earth alloys: a critical review of the alloy systems of the rare earth, scandium, and yttrium metals, D. Van Nostrand Company, Inc. (on-line copy at http://hdl.handle.net/2027/mdp.39015078670422), Princeton, New Jersey, 1961.

[10] K.A. Gschneidner Jr., F.W. Calderwood, Intra rare earth binary alloys: phase relationships, lattice parameters and systematics, in: K.A. Gschneidner Jr., L. Eyring (Eds.) Handbook on the Physics and Chemistry of Rare Earths, Elsevier Science Publishers B.V., Amsterdam, 1986, pp. 1-161.

[11] W.M. Haynes, ed., Conversion factors, in: CRC Handbook of Chemistry and Physics, 96th Edition (Internet Version 2016), CRC Press/Taylor and Francis, Boca Raton, FL, 2016.

[12] P. Hirsch, A. Howie, R. Nicholson, D.W. Pashley, M.J. Whelan, Electron Microscopy of Thin Crystals, Robert E. Krieger Publishing Co., Inc., Malabar, FL, 1977.

[13] T. Tsuji, Heat Capacity of Solids, in: S.L. Chaplot, R. Mittal, N. Choudhury (Eds.) Thermodynamic Properties of Solids: Experiment and Modeling, WILEY-VCH Verlag GmbH \& Co. KGaA, Weinheim, Germany, 2010, pp. 159-196.

[14] G.S. Kumar, G. Prasad, R.O. Pohl, Experimental determinations of the Lorenz number, Journal of Materials Science, 28 (1993) 4261-4272.

[15] C.Y. Ho, R.W. Powell, P.E. Liley, Thermal conductivity of the elements: a comprehensive review, Journal of Physical and Chemical Reference Data, 3 (1974) 1-1 to 1-796.

[16] L. Binkele, Transport properties of yttrium and six rare-earth metals in the temperature range 3001000 K, High Temperatures-High Pressures, 21 (1989) 131-137.

[17] K.A. Gschneidner Jr., Physical Properties of the Rare Earth Metals, in: W.M. Haynes (Ed.) CRC Handbook of Chemistry and Physics, 96th Edition (Internet Version 2016), CRC Press/Taylor and Francis, Boca Raton, FL, 2015.

[18] A.C. Lawson, C.E. Olsen, J.W. Richardson Jr., M.H. Mueller, G.H. Lander, Structure of $\beta$-uranium, Acta Crystallographica, B44 (1988).

[19] J.W. Ward, P.D. Kleinschmidt, D.E. Peterson, Thermochemical properties of the actinide elements and selected actinide-noble metal intermetallics, in: A.J. Freeman, C. Keller (Eds.) Handbook on the Physics and Chemistry of the Actinides, Elsevier, 1986, pp. 309-412.

[20] I. Grenthe, J. Fuger, R.J.M. Konings, R.J. Lemire, A.B. Muller, C. Nguyen-Trung, H. Wanner, Chemical Thermodynamics of Uranium, Elsevier North-Holland, Amsterdam, 1992.

[21] S.S. Hecker, M. Stan, Properties of plutonium and its alloys for use as fast reactor fuels, Journal of Nuclear Materials, 383 (2008) 112-118.

[22] D.L. Clark, S.S. Hecker, G.D. Jarvinen, M.P. Neu, Plutonium, in: L.R. Morss, N.M. Edelstein, J. Fuger (Eds.) The Chemistry of the Actinide and Transactinide Elements, Springer, Dordrecht, The Netherlands, 2010, pp. 813-1264.

[23] A. Saxena, T. Lookman, R.C. Albers, Landau free energy for structural phase transitions in Pu, in: J.M. Howe, D.E. Laughlin, J.K. Lee (Eds.) Proceedings of an International Conference on Solid State Phase Transformations in Organic Materials 2005, 2006, pp. 69-74.

[24] G.V. Ionov, F.A. Sapozhnikov, V.V. Dremov, D.L. Preston, M.A. Zocher, The generalized embedded atom model of interatomic interaction and its application to $\alpha$-Pu, Journal of Nuclear Materials, 436 (2013) 10-16.

[25] P. Söderlind, A. Landa, J.E. Klepeis, First-principles electronic and elastic properties of plutonium metal, in: Actinides 2009, Institute of Physics, Temple Back, Bristol, United Kingdom, 2010.

[26] P. Söderlind, First-principles phase stability, bonding, and electronic structure of actinide metals, Journal of Electron Spectroscopy and Related Phenomena, 194 (2014) 2-7. 
[27] A.V. Karavaev, V.V. Dremov, MD study of the finite temperature effects on the phase ordering, stacking fault energy, and edge dislocation core structure in elemental $\mathrm{Pu}$ and $\mathrm{Pu}-\mathrm{Ga}$ alloys, Journal of Nuclear Materials, 457 (2015) 94-99.

[28] N. Lanatà, Y. Yao, C.-Z. Wang, K.-M. Ho, G. Kotliar, Phase diagram and electronic structure of praseodymium and plutonium, Physical Review X, 5 (2015) 011008.

[29] T. Hahn, ed., International Tables for Crystallography, Volume A: Space-Group Symmetry, Springer, Dordrecht, The Netherlands, 2005.

[30] R.J. Lemire, J. Fuger, H. Nitsche, P. Potter, M.H. Rand, J. Rydberg, K. Spahiu, J.C. Sullivan, W.J. Ullman, P. Vitorge, H. Warner, Chemical Thermodynamics of Neptunium and Plutonium, Elsevier North Holland, Amsterdam, The Netherlands, 2001.

[31] S.M. Ennaceur, The effects of thermal conditioning and recovery processes on the $\delta \rightarrow \gamma$ phase transformation mechanisms in plutonium, Thermochimica Acta, 565 (2013) 151-158.

[32] S.M. Ennaceur, Methodology for describing the $\alpha \rightarrow \beta$ phase transformation in plutonium, Thermochimica Acta, 539 (2012) 84-91.

[33] S.M. Ennaceur, Study of the $\gamma \rightarrow \delta$ phase transformation kinetics and reaction mechanism in plutonium, Thermochimica Acta, 566 (2013) 181-185.

[34] S.M. Ennaceur, A differential scanning calorimetry study of the kinetics of the $\beta \rightarrow \gamma$ phase transformation in plutonium, Thermochimica Acta, 547 (2012) 99-105.

[35] M. Boivineau, Thermophysical properties of solid and liquid pure and alloyed Pu: a review, Journal of Nuclear Materials, 392 (2009) 568-577.

[36] W.M. Haynes, ed., Crystal structures and lattice parameters of allotropes of the elements, in: CRC Handbook of Chemistry and Physics, 96th Edition (Internet Version 2016), CRC Press/Taylor and Francis, Boca Raton, FL, 2016.

[37] A. Cezairliyan, F. Righini, Thermodynamic studies of the $\alpha \rightarrow \beta$ phase transformation in zirconium using a subsecond pulse heating technique, Journal of Research of the National Bureau of Standards, 79A (1974) 81-84.

[38] W.M. Haynes, ed., Density of molten elements and representative salts, in: CRC Handbook of Chemistry and Physics, 96th Edition (Internet Version 2016), CRC Press/Taylor and Francis, Boca Raton, FL, 2016.

[39] P.F. Paradis, W.K. Rhim, Thermophysical properties of zirconium at high temperature, Journal of Materials Research, 14 (1999) 3713-3719.

[40] W.M. Haynes, ed., Enthalpy of fusion, in: CRC Handbook of Chemistry and Physics, 96th Edition (Internet Version 2016), CRC Press/Taylor and Francis, Boca Raton, FL, 2016.

[41] R.I. Sheldon, D.E. Peterson, The U-Zr (uranium-zirconium) system, Bulletin of Alloy Phase Diagrams, 10 (1989) 165-171 and 205-206.

[42] R.I. Sheldon, D.E. Peterson, U-Zr (uranium-zirconium), in: T.B. Massalski (Ed.) Binary Alloy Phase Diagrams, II ed., 1990, pp. 3520-3523.

[43] S. Ahn, S. Irukuvarghula, S.M. McDeavitt, Thermophysical investigations of the uranium-zirconium alloy system, Journal of Alloys and Compounds, 611 (2014) 355-362.

[44] S. Ahn, S.M. McDeavitt, Transformation Enthalpies of Uranium-Zirconium Alloy System, Transactions of the American Nuclear Society, 106 (2012) 239-241.

[45] F.A. Rough, An evaluation of data on zirconium-uranium alloys (Battelle Memorial Institute Report BMI-1030), Battelle Memorial Institute, Columbus, OH, 1955.

[46] A.A. Bauer, ed., An evaluation of the properties and behavior of zirconium-uranium alloys (Battelle Memorial Institute Report BMI-1350), Battelle Memorial Institute, Columbus, OH, 1959. 
[47] F.A. Rough, A.A. Bauer, Constitution of uranium and thorium alloys (Battelle Memorial Institute Report BMI-1300), Battelle Memorial Institute, Columbus, OH, 1958.

[48] M. Akabori, A. Itoh, T. Ogawa, F. Kobayashi, Y. Suzuki, Stability and structure of the $\delta$ phase of the U-Zr alloys, Journal of Nuclear Materials, 188 (1992) 249-254.

[49] M. Akabori, T. Ogawa, A. Itoh, Y. Morii, The lattice stability and structure of $\delta-\mathrm{UZr}_{2}$ at elevated temperatures, Journal of Physics: Condensed Matter, 7 (1995) 8249-8257.

[50] S. Balakrishnan, K. Ananthasivan, K.C. Hari Kumar, Measurement of the solidus and liquidus in the U-Zr system by the spot-technique, Journal of Alloys and Compounds, 689 (2016) 751-758.

[51] J.T. McKeown, S. Irukuvarghula, S. Ahn, M.A. Wall, L.L. Hsiung, S. McDeavitt, P.E.A. Turchi, Coexistence of the $\alpha$ and $\delta$ phases in an as-cast uranium-rich U-Zr alloy, Journal of Nuclear Materials, 436 (2013) 100-104.

[52] Y. Zhang, X. Wang, G. Zeng, H. Wang, J. Jia, L. Sheng, P. Zhang, Microstructural investigation of as-cast uranium rich U-Zr alloys, Journal of Nuclear Materials, 471 (2016) 59-64.

[53] S.T. Zegler, The uranium-rich end of the uranium-zirconium system (Argonne National Laboratory report ANL-6055), Argonne National Laboratory, Argonne, IL, 1962.

[54] C.B. Basak, Microstructural evolution of U-rich U-Zr alloys under near-equilibrium condition, Journal of Nuclear Materials, 416 (2011) 280-287.

[55] C.B. Basak, S. Neogy, D. Srivastava, G.K. Dey, S. Banerjee, Disordered bcc gamma-phase to deltaphase transformation in Zr-rich U-Zr alloy, Philosophical Magazine, 91 (2011) 3290-3306.

[56] C.B. Basak, N. Prabhu, M. Krishnan, On the formation mechanism of $\mathrm{UZr}_{2}$ phase, Intermetallics, 18 (2010) 1707-1712.

[57] M. Kurata, Thermodynamic database on U-Pu-Zr-Np-Am-Fe alloy system I - Re-evaluation of U-PuZr alloy, IOP Conference Series: Materials Science and Engineering, 9 (2010) 1-8.

[58] J. Belak, J.1. Fattebert, A. Landa, P. Söderlind, L. Zepeda-Ruiz, P. Turchi, Modeling UZr metallic fuels: coupling thermodynamics with microstructure, Transactions of the American Nuclear Society, 102 (2010) 841-842.

[59] P.Y. Chevalier, E. Fischer, B. Cheynet, Progress in the thermodynamic modelling of the O-U-Zr ternary system, CALPHAD: Computer Coupling Phase Diagrams and Thermochemistry, 28 (2004) 1540 .

[60] M. Kurata, Thermodynamic assessment of the Pu-U, Pu-Zr, and Pu-U-Zr systems, CALPHADComputer Coupling of Phase Diagrams and Thermochemistry, 23 (1999) 305-337.

[61] M. Kurata, T. Ogata, K. Nakamura, T. Ogawa, Thermodynamic assessment of the Fe-U, U-Zr, and Fe-U-Zr systems, Journal of Alloys and Compounds, 271/273 (1998) 636-640.

[62] M. Kurata, Phase diagrams of actinide alloys, in: R.J.M. Konings (Ed.) Comprehensive Nuclear Materials, volume 2, Elsevier, 2012, pp. 139-195.

[63] A. Landa, P. Söderlind, B. Grabowski, P.E.A. Turchi, A.V. Ruban, L. Vitos, Ab Initio Study of Advanced Metallic Nuclear Fuels for Fast Breeder Reactors, Actinides and Nuclear Energy Materials, 1444 (2012) 67-78.

[64] A. Landa, P. Söderlind, P.E.A. Turchi, Density-functional study of the U-Zr system, Journal of Alloys and Compounds, 478 (2009) 103-110.

[65] A. Landa, P. Söderlind, P.E.A. Turchi, Density-functional study of U-Mo and U-Zr alloys, Journal of Nuclear Materials, 414 (2011) 132-137.

[66] L. Leibowitz, E. Veleckis, R.A. Blomquist, A.D. Pelton, Solidus and liquidus temperatures in the uranium-plutonium-zirconium system, Journal of Nuclear Materials, 154 (1988) 145-153.

[67] L. Leibowitz, R.A. Blomquist, A.D. Pelton, Thermodynamics of the uranium-zirconium system, Journal of Nuclear Materials, 167 (1989) 76-81. 
[68] T. Ogawa, J.K. Gibson, R.G. Haire, M.M. Gensini, M. Akabori, Thermodynamic analysis of Zr-U and Zr-Np alloys in view of f-d interaction, Journal of Nuclear Materials, 223 (1995) 67-71.

[69] T. Ogawa, T. Iwai, Thermochemical modelling of U-Zr alloys, Journal of the Less-Common Metals, 170 (1991) 101-108.

[70] W. Xiong, W. Xie, C. Shen, D. Morgan, Thermodynamic modeling of the U-Zr system -- a revisit, Journal of Nuclear Materials, 2013 (2013).

[71] A.P. Moore, B. Beeler, C. Deo, M.I. Baskes, M.A. Okuniewski, Atomistic modeling of high temperature uranium-zirconium alloy structure and thermodynamics, Journal of Nuclear Materials, 467 part 2 (2015) 802-819.

[72] T. Ogata, Irradiation behavior and thermodynamic properties of metallic fuel, Journal of Nuclear Science and Technology, 39 Supplement 3 (2002) 675-681.

[73] A.P. Moore, C. Deo, M.I. Baskes, M.A. Okuniewski, Atomistic mechanisms of morphological evolution and segregation in U-Zr alloys, Acta Materialia, 115 (2016) 178-188.

[74] W. Xie, C.A. Marianetti, D. Morgan, Response to letter Electron correlation and relativity of the $5 f$ electrons in the U-Zr alloy system, Journal of Nuclear Materials, 476 (2016) 110-112.

[75] J.-Y. Zhao, W. Liu, X.-G. Lu, Assessments of molar volume of the binary C14 Laves phase, CALPHAD: Computer Coupling of Phase Diagrams and Thermochemistry, 50 (2015) 82-91.

[76] J.G. Huber, P.H. Ansari, The superconductivity of BCC U-Zr alloys, Physica, 135B (1985) 441-444.

[77] A.K. Rai, R. Subramanian, R.N. Hajra, H. Tripathy, M. Rengachari, S. Saibaba, Calorimetric study of phase stability and phase transformation in $\mathrm{U}-x \mathrm{Zr}(x=2,5,10 \mathrm{wt}$ pct $)$ alloys, Metallurgical and Materials Transactions A, 46 (2015) 4986-5001.

[78] S. Irukuvarghula, S. Ahn, S.M. McDeavitt, Decomposition of the $\gamma$ phase in as-cast and quenched UZr alloys, Journal of Nuclear Materials, 473 (2016) 206-217.

[79] S.M. McDeavitt, A.A. Solomon, Preparation and performance of U-10Zr alloy nuclear fuel using powder metallurgy techniques, in: J.M. Capus (Ed.) Advances in Powder Metallurgy, 1992, pp. 109-123.

[80] J. Lehmann, R.F. Hills, Nomenclature proposee pour les phases des alliages d'uranium (Proposed nomenclature for phases in uranium alloys), Journal of Nuclear Materials, 2 (1960) 261-268 (in French and English).

[81] B.A. Hatt, The orientation relationship between the gamma and alpha structures in uraniumzirconium alloys, Journal of Nuclear Materials, 19 (1966) 131-141.

[82] G. Lagerberg, Phase transformations in a uranium-zirconium alloy containing 2 weight percent zirconium, Journal of Nuclear Materials, 9 (1963) 261-276.

[83] R.F. Hills, B.R. Butcher, B.W. Howlett, D. Stewart, The effect of cooling rate on the decomposition of the $\gamma$-phase in uranium-zirconium alloys, Journal of Nuclear Materials, 16 (1965) 25-38.

[84] S. Kaity, J. Banerjee, M.R. Nair, K. Ravi, S. Dash, T.R.G. Kutty, A. Kumar, R.P. Singh, Microstructural and thermophysical properties of U-6 wt.\%Zr alloy for fast reactor application, Journal of Nuclear Materials, 427 (2012) 1-11.

[85] Y. Takahashi, K. Yamamoto, T. Ohsato, H. Shimada, T. Terai, M. Yamawaki, Heat capacities of uranium-zirconium alloys from 300 to 1100 K, Journal of Nuclear Materials, 167 (1989) 147-151.

[86] T. Matsui, T. Natsume, K. Naito, Heat capacity measurements of $\mathrm{U}_{0.80} \mathrm{Zr}_{0.20}$ and $\mathrm{U}_{0.80} \mathrm{Mo}_{0.20}$ alloys from room temperature to $1300 \mathrm{~K}$, Journal of Nuclear Materials, 167 (1989) 152-159.

[87] P. Chiotti, V.V. Akhachinskij, I. Ansara, M.H. Rand, The Chemical Thermodynamics of Actinide Elements and Compounds, Part 5: The actinide binary alloys, IAEA, Vienna, Austria, 1981.

[88] D. Summers-Smith, Journal of the Institute of Metals, 83 (1954-1955) 277.

[89] M. Kanno, M. Yamawaki, T. Koyama, N. Morioka, Thermodynamic activity measurements of U-Zr alloys by Knudsen effusion mass spectrometry, Journal of Nuclear Materials, 154 (1988) 154-160. 
[90] A. Maeda, Y. Suzuki, T. Ohmichi, Uranium activity of uranium-rich U-Zr alloys by Knudsen effusion mass spectrometry, Journal of Alloys and Compounds, 179 (1992) L21-L24.

[91] H. Okamoto, Pu-Zr (plutonium-zirconium), Journal of Phase Equilibria, 14 (1993) 400-401.

[92] H. Okamoto, Pu-Zr (plutonium-zirconium), Journal of Phase Equilibria, 16 (1995) 287-288.

[93] J.A.C. Marples, The plutonium-zirconium phase diagram, Journal of the Less-Common Metals, 2 (1960) 331-351.

[94] J.A.C. Marples, The lattice parameters of some $\delta$ - and $\varepsilon$-plutonium alloys, Journal of Physics and Chemistry of Solids, 25 (1964) 521-534.

[95] A.F. Berndt, The theta phase in the plutonium-zirconium system, Journal of the Less-Common Metals, 12 (1967) 82-83.

[96] A.A. Bochvar, S.T. Konobeevskii, V.I. Kutaitsev, T.S. Men'shikova, N.T. Chebotarev, Interaction between plutonium and other metals in connection with their arrangement in Mendeleev's periodic table, in: Proceedings of the UN International Conference on Peaceful Uses of Atomic Energy, 1958, pp. 11771191.

[97] D. Calais, M. Dupuy, M. Mouchnino, A.Y. Portnoff, A. Van Craeynest, Diffusion of plutonium in the solid state, in: A.E. Kay, M.B. Waldron (Eds.) Plutonium 1965, Chapman and Hall, 1965, pp. 358391.

[98] Monsanto Research Corporation, Reactor Fuels and Materials Development Plutonium Research: January-June, 1967 (Mound Laboratory Report MLM-1445), Miamisburg, OH, 1967.

[99] Y. Suzuki, A. Maeda, T. Ohmichi, Phase diagram of the Pu-Zr system in the Zr-rich region, Journal of Alloys and Compounds, 182 (1992) L9-L14.

[100] J.C. Lauthier, N. Housseau, A. Van Craeynest, D. Calais, Contribution a l'etude du diagramme de phases plutonium-zirconium, Journal of Nuclear Materials, 23 (1967) 313-319.

[101] F.H. Ellinger, C.C. Land, On the plutonium-zirconium phase diagram, Nuclear Metallurgy, 17 (1971) 686-698.

[102] D.T. Cromer, The crystal structure of $\zeta-\mathrm{Pu}-\mathrm{Zr}$, ideal formula $\mathrm{Pu}_{28} \mathrm{Zr}$, Acta Crystallographica, B35 (1979) 14-19.

[103] J.M. Taylor, Plutonium-zirconium equilibrium diagram from 0 to 10 at $\% \mathrm{Zr}$, Journal of Nuclear Materials, 30 (1969) 346-350.

[104] J.C. Walden, P.L. Wallace, J.W. Magana, X-ray spectometric analysis of plutonium-zirconium alloys, Applied Spectroscopy, 29 (1975) 175-178.

[105] A. Maeda, Y. Suzuki, Y. Okamoto, T. Ohmichi, Vaporization behavior of plutonium-zirconium binary alloy, Journal of Alloys and Compounds, 205 (1994) 35-38.

[106] D.E. Peterson, E.M. Foltyn, The Pu-U (plutonium-uranium) system, Bulletin of Alloy Phase Diagrams, 10 (1989) 160-164.

[107] Y. Okamoto, A. Maeda, Y. Suzuki, T. Ohmichi, Investigation of the Pu-U phase diagram, Journal of Alloys and Compounds, 213/214 (1994) 372-374.

[108] F.H. Ellinger, R.O. Elliott, E.M. Cramer, The plutonium-uranium system, Journal of Nuclear Materials, 1 (1959) 233-243.

[109] L. Leibowitz, R.A. Blomquist, A.D. Pelton, Thermodynamic modeling of the phase equilibria of the plutonium-uranium system, Journal of Nuclear Materials, 184 (1991) 59-64.

[110] T. Ogawa, Alloying behaviour among U, Np, Pu and Am predicted with the Brewer valence bond model, Journal of Alloys and Compounds, 194 (1993) 1-7.

[111] A. Landa, P. Söderlind, P.E.A. Turchi, L. Vitos, O.E. Peil, A.V. Ruban, Density-functional study of bcc Pu-U, Pu-Np, Pu-Am, and Pu-Cm alloys, Journal of Nuclear Materials, 408 (2011) 61-66. 
[112] A. Perron, P.E.A. Turchi, A. Landa, P. Söderlind, B. Ravat, B. Oudot, F. Delaunay, The Pu-U-Am system: An ab initio informed CALPHAD thermodynamic study, Journal of Nuclear Materials, 458 (2015) 425-441.

[113] A. Perron, P.E.A. Turchi, A. Landa, P. Söderlind, B. Ravat, B. Oudot, F. Delaunay, M. Kurata, Thermodynamic re-assessment of the $\mathrm{Pu}-\mathrm{U}$ system and its application to the ternary $\mathrm{Pu}-\mathrm{U}-\mathrm{Ga}$ system, Journal of Nuclear Materials, 454 (2014) 81-95.

[114] J.H. Kittel, J.E. Ayer, W.N. Beck, M.B. Brodsky, D.R. O'Boyle, S.T. Zegler, F.H. Ellinger, W.N. Miner, F.W. Schonfeld, R.D. Nelson, Plutonium and plutonium alloys as nuclear fuel materials, Nuclear Engineering and Design, 15 (1971) 373-440.

[115] A.F. Berndt, Room temperature lattice constants of alloys of plutonium in alpha-uranium, Journal of Nuclear Materials, 9 (1963) 53-58.

[116] A.C. Lawson, J.A. Goldstone, B. Cort, R.J. Martinez, F.A. Vigil, T.G. Zocco, J.W. Richardson Jr., M.H. Mueller, Structure of $\zeta$-phase plutonium-uranium, Acta Crystallographica B: Structural Science, 52 (1996) 32-37.

[117] H. Savage, The heat content and specific heat of some metallic fast-reactor fuels containing plutonium, Journal of Nuclear Materials, 25 (1968) 249-259.

[118] S. Kaity, J. Banerjee, K. Ravi, R. Keswani, T.R.G. Kutty, A. Kumar, G.J. Prasad, Characterization and property evaluation of U-15 wt\% Pu alloy for fast reactor, Journal of Nuclear Materials, 433 (2013) 206-214.

[119] Monsanto Research Corporation, Reactor Fuels and Materials Development Plutonium Research: 1966 Annual Report (Mound Laboratory Report MLM-1402), Miamisburg, OH, 1967.

[120] H. Okamoto, Pu-U (plutonium-uranium), Journal of Phase Equilibria, 17 (1996) 372b.

[121] D.R. O'Boyle, A.E. Dwight, The uranium-plutonium-zirconium ternary alloy system, in: W.N. Miner (Ed.) Plutonium 1970 and Other Actinides, Metallurgical Society of AIME, 1970, pp. 720-732.

[122] A. Landa, P. Söderlind, P.E.A. Turchi, L. Vitos, A. Ruban, Density-functional study of Zr-based actinide alloys: 2. U-Pu-Zr system, Journal of Nuclear Materials, 393 (2009) 141-145.

[123] Z. Wenzhong, C. Unal, U-Pu-Zr fuel properties and thermal performance modeling for sodium fast reactors, Transactions of the American Nuclear Society, 106 (2012) 264-264.

[124] J.D. Galloway, C. Unal, N.N. Carlson, Modeling Constituent Redistribution in U-Pu-Zr Metallic Fuel Using the Advanced Fuel Performance Code BISON, 2013.

[125] D.R. Harbur, J.W. Anderson, W.J. Maraman, Studies on the U-Pu-Zr alloy system for fast breeder reactor applications (Los Alamos National Laboratory Report LA-4512), 1970.

[126] M. Kurata, T. Inoue, C. Sari, Redistribution behavior of various constituents in U-Pu-Zr alloy and $\mathrm{U}-\mathrm{Pu}-\mathrm{Zr}$ alloy containing minor actinides and rare-earths in a temperature-gradient, Journal of Nuclear Materials, 208 (1994) 144-158.

[127] Argonne National Laboratory, Reactor development program progress report, September 1965 (Argonne National Laboratory Report ANL-7105), Argonne, IL, 1965.

[128] M.H. Mueller, J.W. Richardson Jr., R.V. Strain, G.L. Hofman, Phase analysis of metallic plutonium-containing fuel alloys using neutron diffraction, in: C.S. Barrett, J.V. Gilfrich, I.C. Noyan, T.C. Huang, P.K. Predecki (Eds.) Advances in X-ray analysis, Plenum, Steamboat Springs, CO, 1991, pp. 447-457.

[129] R. Boucher, P. Barthelemy, Comparaison des alliages U-Pu-Mo, U-Pu-Nb, U-Pu-Ti, U-Pu-Zr (CEA Report CEA-R-2531), translated into English by B. Blumenthal as "Comparison of the Alloys U-Pu-Mo, U-Pu-Nb, U-Pu-Ti, U-Pu-Zr" (Argonne National Laboratory translation ANL-TRANS-138), 1964.

[130] R. Boucher, P. Barthelemy, C. Milet, A study of plutonium-based alloys carried out at Fontenayaux-Roses, in: A.E. Kay, M.B. Waldron (Eds.) Plutonium 1965: Proceedings of the third international 
conference on plutonium, London, 1965, Chapman and Hall for The Institute of Metals, London, 1965, pp. 485-509.

[131] P.A. Tucker, D.E. Etter, J.M. Gebhart, Phase study of uranium-plutonium-zirconium alloys, Transactions of the American Nuclear Society, 11 (1968) 99.

[132] M.C. Petri, M.A. Dayananda, Isothermal diffusion in uranium-plutonium-zirconium alloys, Journal of Nuclear Materials, 240 (1997) 131-143.

[133] Y.H. Sohn, M.A. Dayananda, G.L. Hofman, R.V. Strain, S.L. Hayes, Analysis of constituent redistribution in the gamma (bcc) U-Pu-Zr alloys under gradients of temperature and concentrations, Journal of Nuclear Materials, 279 (2000) 317-329.

[134] G.L. Hofman, R.G. Pahl, C.E. Lahm, D.L. Porter, Swelling behavior of U-Pu-Zr fuel, Metallurgical Transactions A (Physical Metallurgy and Materials Science), 21A (1990) 517-528.

[135] L.R. Kelman, H.V. Rhude, J.G. Schnizlein, H. Savage, Status of metallic plutonium fast powerbreeder fuels, in: A.E. Kay, M.B. Waldron (Eds.) Plutonium 1965: Proceedings of the third international conference on plutonium, London, 1965, Chapman and Hall for The Institute of Metals, London, 1965, pp. 458-484.

[136] I. Grenthe, J. Drożdżyński, T. Fujino, E.C. Buck, T.E. Albrecht-Schmitt, S.F. Wolf, Uranium, in: L.R. Morss, N.M. Edelstein, J. Fuger (Eds.) The Chemistry of the Actinide and Transactinide Elements, Springer, Dordrecht, The Netherlands, 2010, pp. 253-698.

[137] F.L. Oetting, R.O. Adams, The chemical thermodynamics of nuclear materials VII. The hightemperature heat capacity of unalloyed plutonium metal, Journal of Chemical Thermodynamics, 15 (1983) 537-554.

[138] L.J. Wittenberg, C.R. Hudgens, T.K. Engel, D.L. Roesch, D.B. Sullenger, P.A. Tucker, D.E. Etter, K.D. Phipps, W.G. Rohr, J.E. Selle, G.A. Vaughn, Reactor fuels and materials development, Plutonium research: April-September, 1966 (Mound Laboratory Report MLM-1347), Mound Laboratory, Miamisburg, OH, 1967.

[139] M.W. Chase Jr., NIST-JANAF Thermochemical Tables, Fourth Edition, Part II (Cr-Zr), Journal of Physical and Chemical Reference Data, Monograph No. 9 (1998).

[140] International Atomic Energy Agency (IAEA), Thermophysical Properties of Materials for Nuclear Engineering: A Tutorial and Collection of Data, International Atomic Energy Agency (IAEA), Vienna, Austria, 2008.

[141] N.D. Milošević, K.D. Maglić, Thermophysical properties of solid phase zirconium at high temperatures, International Journal of Thermophysics, 27 (2006) 1140-1159.

[142] G.B. Fedorov, E.A. Smirnov, Heat capacity of uranium-zirconium systems, Soviet Journal of Atomic Energy, 25 (1968) 795-797 (translated from Atomnaya Énergiya vol 725 no. 791 pp. 754-756, July 1968).

[143] S. Dash, K. Ghoshal, T.R.G. Kutty, Thermodynamic investigations of uranium-rich binary and ternary alloys, Journal of Thermal Analysis and Calorimetry, 112 (2013) 179-185.

[144] Mu Yeh Wu, J. Wadsworth, O.D. Sherby, Internal stress superplasticity in anisotropic polycrystalline zinc and uranium, Metallurgical Transactions A (Physical Metallurgy and Materials Science), 18A (1987) 451-462.

[145] C.A. Calhoun, J.A. Wollmershauser, D.W. Brown, R.P. Mulay, E. Garlea, S.R. Agnew, Thermal residual strains in depleted $\alpha-U$, Scripta Materialia, 69 (2013) 566-569.

[146] D.W. Brown, M.A.M. Bourke, B. Clausen, D.R. Korzekwa, R.C. Korzekwa, R.J. McCabe, T.A. Sisneros, D.F. Teter, Temperature and direction dependence of internal strain and texture evolution during deformation of uranium, Materials Science and Engineering A-Structural Materials Properties Microstructure and Processing, 512 (2009) 67-75. 
[147] H.H. Klepfer, P. Chiotti, Characteristics of the solid state transformations in uranium (Ames Laboratory, report ISC-893 to the United States Atomic Energy Commission), Ames Laboratory, Ames, IA, 1957.

[148] C. Basak, G.J. Prasad, H.S. Kamath, N. Prabhu, An evaluation of the properties of as-cast U-rich UZr alloys, Journal of Alloys and Compounds, 480 (2009) 857-962.

[149] J. Thewlis, An X-ray powder study of $\beta$-uranium, Acta Crystallographica, 5 (1952) 790-794.

[150] N.M. Edelstein, J. Fuger, J.J. Katz, L.R. Morss, Summary and comparison of the properties of the actinide and transactinide elements, in: L.R. Morss, N.M. Edelstein, J. Fuger (Eds.) The Chemistry of the Actinide and Transactinide Elements, Springer, Dordrecht, The Netherlands, 2010, pp. 1753-1832.

[151] S.M. Ennaceur, Phase stability of $\alpha^{\prime}-$ phase in a Pu-1at\% Ga alloy following low temperature treatment, Thermochimica Acta, 593 (2014) 22-29.

[152] T. Lee, M.I. Baskes, A.C. Lawson, S.P. Chen, S.M. Valone, Atomistic modeling of the negative thermal expansion in $\delta$-plutonium based on the two-state description, Materials, 5 (2012) 1040-1054.

[153] A. Solontsov, V.P. Antropov, Effects of spin fluctuations and anomalous thermal expansion of delta-Pu, Physical Review B, 81 (2010) 214402.

[154] A.C. Lawson, J.A. Roberts, B. Martinez, Invar model for $\delta$-phase Pu: Thermal expansion, elastic and magnetic properties, Philosophical Magazine, 86 (2006) 2713-2733.

[155] W.A. Harrison, Theory of the thermal properties of delta-plutonium, Physical Review B, 69 (2004) 224109.

[156] A. Migliori, I. Mihut-Stroe, J.B. Betts, Plutonium elastic moduli, electron localization, and temperature, in: D.C. Shuh, B.W. Chung, T. Albrecht-Schmitt (Eds.) Actinides 2008--Basic Science, Applications, and Technology (Materials Research Society Symposium Proceedings vol. 1104), Materials Research Society, Warrendale, PA, 2008, pp. 249-252.

[157] Z.P. Yin, X. Deng, K. Basu, Q. Yin, G. Kotliar, Temperature-dependent electronic structures, atomistic modelling and the negative thermal expansion of $\delta \mathrm{Pu}$, Philosophical Magazine Letters, 94 (2014) 620-628.

[158] F.W. Schonfeld, R.E. Tate, The thermal expansion behavior of unalloyed plutonium (Los Alamos National Laboratory Report LA-13034-MS), Los Alamos, NM, 1996.

[159] O.J. Wick, ed., Plutonium Handbook, Gordon and Branch, New York, 1967.

[160] V. Petukhov, Thermal expansion of zirconium in the solid phase, High Temperatures-High Pressures, 35/36 (2003/2004) 15-23.

[161] S.V. Boyarskii, Internal friction and coefficient of linear expansion of zirconium and cobalt in the phase transition region, Journal of Engineering Physics, 50 (1986) 444-447.

[162] Y.-J. Hao, L. Zhang, X.-R. Chen, L.-C. Cai, Q. Wu, D. Alfe, Ab initio calculations of the thermodynamics and phase diagram of zirconium, Physical Review B, 78 (2008) 134101.

[163] K. Masuda-Jindo, Vu Van Hung, P.E.A. Turchi, Application of statistical moment method to thermodynamic properties and phase transformations of metals and alloys, Diffusion and Defect Data Part B (Solid State Phenomena), 138 (2008) 209-239.

[164] W.M. Haynes, ed., Physical constants of inorganic compounds, in: CRC Handbook of Chemistry and Physics, 96th Edition (Internet Version 2016), CRC Press/Taylor and Francis, Boca Raton, FL, 2016. [165] H.A. Saller, R.F. Dickerson, W.E. Murr, Uranium alloys for high-temperature application (Battelle Memorial Institute Report BMI-1098), Battelle Memorial Institute, Columbus, OH, 1956.

[166] K.A. Gschneidner Jr., R.O. Elliott, J.T. Waber, Influence of alloying on the negative thermal expansion of delta plutonium, Acta Metallurgica, 11 (1963) 947-955. 
[167] R.O. Elliott, K.A. Gschneidner Jr., C.A. Kempter, Thermal expansion of some delta plutonium solid solution alloys, in: E. Grison, W.B.H. Lord, R.D. Fowler (Eds.) Plutonium 1960, Cleaver-Hume Press, London, 1961, pp. 142-155 (Paper no. 134).

[168] Argonne National Laboratory, Metallurgy Division Annual Progress Report for 1965 (Argonne National Laboratory Report ANL-7155), Argonne National Laboratory, Argonne, IL, 1965.

[169] Y.S. Kim, G.L. Hofman, A.M. Yacout, Migration of minor actinides and lanthanides in fast reactor metallic fuel, Journal of Nuclear Materials, 392 (2009) 164-170.

[170] Y.S. Kim, T.W. Cho, D.-S. Sohn, Thermal conductivities of actinides (U, Pu, Np, Cm, Am) and uranium-alloys (U-Zr, U-Pu-Zr, and U-Pu-TRU-Zr), Journal of Nuclear Materials, 445 (2014) 272-280.

[171] International Atomic Energy Agency (IAEA), Thermophysical properties of materials for watercooled reactors (IAEA-TECDOC-949), 1997.

[172] Y. Takahashi, M. Yamawaki, K. Yamamoto, Thermophysical properties of uranium-zirconium alloys, Journal of Nuclear Materials, 154 (1988) 141-144.

[173] C.A. Alexander, V.E. Wood, Thermal conductivity of plutonium above room temperature, Journal of Applied Physics, 103 (2008) 063704.

[174] J.F. Andrew, Thermal conductivity of plutonium metal, Journal of Physics and Chemistry of Solids, 28 (1967) 577-580.

[175] J.K. Fink, L. Leibowitz, Thermal conductivity of zirconium, Journal of Nuclear Materials, 226 (1995) 44.

[176] Argonne National Laboratory, Chemical Technology Division Annual Technical Report for 1986 (Argonne National Laboratory Report ANL-87-19), Argonne National Laboratory, Argonne, IL, 1987.

[177] M.C. Billone, Y.Y. Liu, E.E. Gruber, T.H. Hughes, J.M. Kramer, Status of fuel element modeling codes for metallic fuels, in: Proceedings of the International Conference on Reliable Fuels for Liquid Metal Reactors, Tucson, AZ, 7-11 Sept, American Nuclear Society, La Grange Park, IL, 1986.

[178] Argonne National Laboratory, Reactor Development Progress Report (Argonne National Laboratory Report ANL-7230), Argonne National Laboratory, Argonne, IL, 1966.

[179] S. Dabos, C. Dufour, U. Benedict, M. Pagès, Bulk modulus and $P-V$ relationship up to $52 \mathrm{GPa}$ of neptunium metal at room temperature, Journal of Magnetism and Magnetic Materials, 63-64 (1987) 661663.

[180] B. Johansson, S. Li, Itinerant $f$-electron elements, Philosophical Magazine, 89 (2009) 1793-1799.

[181] K.T. Moore, G. van der Laan, Nature of the $5 f$ states in actinide metals, Reviews of Modern Physics, 81 (2009) 235-298.

[182] A.V. Lukoyanov, A.O. Shorikov, V.B. Bystrushkin, A.A. Dyachenko, L.R. Kabirova, Y.Y. Tsiovkin, A.A. Povzner, V.V. Dremov, M.A. Korotin, V.I. Anisimov, Electronic structure and magnetic state of transuranium metals under pressure, Journal of Physics: Condensed Matter, 22 (2010) 495501.

[183] S. Bajaj, C. Sevik, T. Cagin, A. Garay, P.E.A. Turchi, R. Arróyave, On the limitations of the DFT + U approach to energetics of actinides, Computational Materials Science, 59 (2012) 48-56.

[184] W.H. Zachariasen, Crystal chemical studies of the $5 f$-series of elements. XVIII. Crystal structure studies of neptunium metal at elevated temperatures, Acta Crystallographica, 5 (1952) 664-667.

[185] W.H. Zachariasen, Crystal chemical studies of the $5 f$-series of elements. XVII. The crystal structure of neptunium metal, Acta Crystallographica, 5 (1952) 660-664.

[186] J.A. Lee, P.G. Mardon, J.H. Pearce, R.O.A. Hall, Some physical properties of neptunium metal II: A study of the allotropic transformations in neptunium, Journal of Physics and Chemistry of Solids, 11 (1959) $177-181$. 
[187] Z. Yoshida, S.G. Johnson, T. Kimura, J.R. Krsul, Neptunium, in: L.R. Morss, N.M. Edelstein, J. Fuger (Eds.) The Chemistry of the Actinide and Transactinide Elements, Springer, Dordrecht, The Netherlands, 2010, pp. 699-812.

[188] A.C. Lawson, J.A. Goldstone, B. Cort, R.I. Sheldon, E.M. Foltyn, Atomic thermal vibrations of the light actinide elements, Journal of Alloys and Compounds, 213/214 (1994) 426-428.

[189] M.F. Stevens, An examination of twinning in alpha-neptunium, Journal of Nuclear Materials, 148 (1987) 99-106.

[190] J.J. Rechtien, A.G. Crocker, R.D. Nelson, Twinning in alpha-neptunium, Journal of Nuclear Materials, 40 (1971) 134-140.

[191] B. Cort, Thermal expansion of neptunium, Journal of the Less-Common Metals, 135 (1987) L13L17.

[192] E.M. Foltyn, Allotropic transitions of neptunium and plutonium determined using differential thermal analysis, Journal of Nuclear Materials, 172 (1990) 180-183.

[193] P. Söderlind, B. Johansson, L. Yongming, L. Nordström, Calculated thermal-expansion of the actinide elements, International Journal of Thermophysics, 12 (1991) 611-615.

[194] J.E. Selle, J.J. Rechtien, Internal friction of neptunium, Journal of Nuclear Materials, 31 (1969) 203-210.

[195] D. McWhan, P.W. Montgomery, H.D. Stromberg, G. Jura, Pressure-temperature-resistance properties of lanthanum, bismuth, neptunium, plutonium, and americium to 450 degrees and $30 \mathrm{~kb}$, Journal of Physical Chemistry, 67 (1963) 2308-2311.

[196] J.-C. Griveau, É. Colineau, Superconductivity in transuranium elements and compounds, Comptes Rendus Physique, 15 (2014) 599-615.

[197] A.G. Volkov, A. Povzner, A. Filanovich, The peculiarities of americium electronic structure and magnetic susceptibility, Journal of Superconductivity and Novel Magnetism, 26 (2013) 1765-1769.

[198] P. Söderlind, K.T. Moore, A. Landa, B. Sadigh, J.A. Bradley, Pressure-induced changes in the electronic structure of americium metal, Physical Review B, 84 (2011) 075138.

[199] A.B. Shick, J. Kolorenc, A.I. Lichtenstein, L. Havela, Electronic structure and spectral properties of Am, Cm, and Bk: Charge-density self-consistent LDA plus HIA calculations in the FP-LAPW basis, Physical Review B, 80 (2009) 085106.

[200] Y.Y. Tsiovkin, A.V. Lukoyanov, A.O. Shorikov, L.Y. Tsiovkina, A.A. Dyachenko, V.B. Bystrushkin, M.A. Korotin, V.I. Anisimov, V.V. Dremov, Electrical resistivity of pure transuranium metals under pressure, Journal of Nuclear Materials, 413 (2011) 41-46.

[201] D.B. McWhan, B.B. Cunningham, J.C. Wallman, Crystal structure, thermal expansion, and melting point of americium metal, Journal of Inorganic and Nuclear Chemistry, 24 (1962) 1025-1038.

[202] W.H. Runde, W.W. Schulz, Americium, in: L.R. Morss, N.M. Edelstein, J. Fuger (Eds.) The Chemistry of the Actinide and Transactinide Elements, Springer, Dordrecht, The Netherlands, 2010, pp. $1265-1395$.

[203] D.R. Stephens, H.D. Stromberg, E.M. Lilley, Phase diagram. Compressibility and resistance of americium as a function of pressure, Journal of Physics and Chemistry of Solids, 29 (1968) 815-821.

[204] R.L. Rose, R.E. Kelley, D.R. Lesuer, Dilatometry and differential thermal analysis of americium metal, Journal of Nuclear Materials, 79 (1979) 414-416.

[205] C. Sari, W. Müller, U. Benedict, Phase transition of americium metal, Journal of Nuclear Materials, $45(1972 / 73) 73-74$.

[206] J.K. Gibson, R.G. Haire, Phase relations in neptunium, americium, and the binary alloy systems Np-Am and Np-Ln (Ln = La, Nd, Lu), Journal of Nuclear Materials, 195 (1992) 156-165. 
[207] R.O.A. Hall, M.J. Mortimer, D.L. McElroy, W. Müller, J.C. Spirlet, The specific heat of americium-241 metal from 15 to 300K, in: W. Müller, R. Lindner (Eds.) Transplutonium Elements, North-Holland Publishing Company, Amsterdam, 1976.

[208] D.B. McWhan, J.C. Wallman, B.B. Cunningham, L.B. Asprey, F.H. Ellinger, W.H. Zachariasen, Preparation and crystal structure of americium metal, Journal of Inorganic and Nuclear Chemistry, 15 (1960) 185-187.

[209] P. Graf, B.B. Cunningham, C.H. Dauben, J.C. Wallman, D.H. Templeton, H. Ruben, Crystal structure and magnetic susceptibility of americium metal, Journal of the American Chemical Society, 78 (1956) 2340.

[210] E.F.J. Westrum, L. Eyring, The preparation and some properties of americium metal, Journal of the American Chemical Society, 73 (1951) 3396-3398.

[211] R.B. Roof, R.G. Haire, D. Schiferl, L. Schwalbe, E.A. Kmetko, J.L. Smith, High-pressure phase in americium metal, Science, 207 (1980) 1353-1355.

[212] A. Lindbaum, S. Heathman, T. Le Bihan, R.G. Haire, M. Idiri, G.H. Lander, High-pressure crystal structures of actinide elements to $100 \mathrm{GPa}$, Journal of Physics: Condensed Matter, 15 (2003) S2297S2303.

[213] Z. Felfli, A.Z. Msezane, D. Sokolovski, Resonances in low-energy electron elastic cross sections for lanthanide atoms, Physical Review A - Atomic, Molecular, and Optical Physics, 79 (2009) 012714.

[214] J.K. Baria, A.R. Jani, Lattice dynamics of La, Yb, Ce and Th, Physica B: Condensed Matter, 405 (2010) 2065-2071.

[215] H.M. Tütüncü, G.P. Srivastava, Ab initio investigations of the phonon anomaly and superconductivity in fec La, Journal of Applied Physics, 104 (2008) 063916.

[216] L.W. Nixon, D.A. Papaconstantopoulos, M.J. Mehl, Electronic structure and superconducting properties of lanthanum, Physical Review B, 78 (2008) 214510.

[217] P. Souvatzis, T. Björkman, O. Eriksson, P. Andersson, M.I. Katsnelson, S.P. Rudin, Dynamical stabilization of the body centered cubic phase in lanthanum and thorium by phonon-phonon interaction, Journal of Physics Condensed Matter, 21 (2009) 175402.

[218] P. Loptien, L. Zhou, A.A. Khajetoorians, J. Wiebe, R. Wiesendanger, Superconductivity of lanthanum revisited: enhanced critical temperature in the clean limit, Journal of Physics Condensed Matter, 26 (2014) 425703.

[219] F. Jie, J. Zhao, Gupta potential for rare earth elements of the fcc phase: lanthanum and cerium, Modelling and Simulation in Materials Science and Engineering, 21 (2013) 065003.

[220] B.J. Beaudry, K.A. Gschneidner Jr., Preparation and basic properties of the rare earth metals, in: K.A. Gschneidner Jr., L. Eyring (Eds.) Handbook on the Physics and Chemistry of Rare Earths, North Holland Publishing Company, 1978, pp. 173-232.

[221] F.H. Spedding, J.J. Hanak, A.H. Daane, High temperature allotropy and thermal expansion of the rare-earth metals, Journal of the Less-Common Metals, 3 (1961) 110-124.

[222] J.F. Cannon, Behavior of the elements at high pressures, Journal of Physical and Chemical Reference Data, 3 (1974) 781-824.

[223] K.A. Gschneidner Jr., V.K. Pecharsky, J. Cho, S.W. Martin, $\beta$ to $\gamma$ transformation in cerium -- a twenty year study, Scripta Materialia, 34 (1996) 1717-1722.

[224] K.A. Gschneidner Jr., R.O. Elliott, R.R. McDonald, Effects of alloying additions on the $\alpha \leftrightarrow \gamma$ transformation of cerium--part II. Effects of scandium, thorium, and plutonium additions, Journal of Physics and Chemistry of Solids, 23 (1962) 1191-1199.

[225] C.J. McHargue, H.L.J. Yakel, L.K. Jetter, Allotropic modifications of metallic cerium, Acta Crystallographica, 10 (1957) 832-833. 
[226] A.F. Schuch, J.H. Sturdivant, The structure of cerium at the temperature of liquid air, Journal of Chemical Physics, 18 (1950) 145.

[227] K.A. Gschneidner Jr., R.O. Elliott, R.R. McDonald, Effects of alloying additions on the $\gamma \leftrightarrow \alpha$ transformation of cerium--part I. Pure cerium, Journal of Physics and Chemistry of Solids, 23 (1962) 555 566.

[228] K.A. Gschneidner Jr., V.K. Pecharsky, The standard state of cerium, Journal of Phase Equilibria, 20 (1999) 612-614.

[229] B. Amadon, A. Gerossier, Comparative analysis of models for the alpha-gamma phase transition in cerium: A DFT plus DMFT study using Wannier orbitals, Physical Review B, 91 (2015) 161103.

[230] M.-F. Tian, H.-F. Song, H.-F. Liu, C. Wang, Z. Fang, X. Dai, Thermodynamics of the alpha-gamma transition in cerium studied by an LDA plus Gutzwiller method, Physical Review B, 91 (2015) 125148.

[231] N. Devaux, M. Casula, F. Decremps, S. Sorella, Electronic origin of the volume collapse in cerium, Physical Review B. Condensed Matter and Materials Physics, (2015).

[232] B. Johansson, W. Luo, S. Li, R. Ahuja, Cerium; Crystal Structure and Position in The Periodic Table, Scientific Reports, 4 (2014) 6398.

[233] T. Jarlborg, Role of thermal disorder for magnetism and the alpha-gamma transition in cerium: Results from density-functional theory, Physical Review B, 89 (2014) 184426.

[234] J. Bieder, B. Amadon, Thermodynamics of the alpha-gamma transition in cerium from first principles, Physical Review B, 89 (2014) 195132.

[235] B. Chakrabarti, M.E. Pezzoli, G. Sordi, K. Haule, G. Kotliar, Alpha-gamma transition in cerium: Magnetic form factor and dynamic magnetic susceptibility in dynamical mean-field theory, Physical Review B, 89 (2014) 125113.

[236] S.S. Hecker, The magic of plutonium: $5 f$ electrons and phase instability, Metallurgical and Materials Transactions A, 35A (2004) 2207-2221.

[237] C.-E. Hu, Z.-Y. Zeng, L. Zhang, L.-C. Cai, Lattice stability and thermal equation of state of $\beta$-La from first-principles calculations, Solid State Communications, 151 (2011) 1802-1805.

[238] B. Siberchicot, J. Clérouin, Properties of hot liquid cerium by LDA+U molecular dynamics, Journal of Physics Condensed Matter, 24 (2012) 455603.

[239] S.S. Agafonov, M.S. Blanter, V.P. Glazkov, V.A. Somenkov, M.N. Shushunov, Thermal vibrations and polymorphic $\beta \rightarrow \gamma$ transition in cerium, Physics of Metals and Metallography, 110 (2010) 338-345.

[240] V.V. Hung, D.T. Hai, H.K. Hieu, Thermodynamic properties and structural phase transition of cerium under high pressure, Vacuum, 114 (2015) 119-123.

[241] I. Loa, E.I. Isaev, M.I. McMahon, D.Y. Kim, B. Johansson, A. Bosak, M. Krisch, Lattice dynamics and superconductivity in cerium at high pressure, Physical Review Letters, 108 (2012) 045502.

[242] A. Cadien, Q.Y. Hu, Y. Meng, Y.Q. Cheng, M.W. Chen, J.F. Shu, H.K. Mao, H.W. Sheng, Firstorder liquid-liquid phase transition in cerium, Physical Review Letters, 110 (2013) 125503.

[243] J.A. Bradley, K.T. Moore, G. van der Laan, J.P. Bradley, R.A. Gordon, Core and shallow-core $d$ - to $f$-shell excitations in rare-earth metals, Physical Review B, 84 (2011) 205105.

[244] G.J. Piermarini, C.E. Weir, Allotropy in some rare-earth metals at high pressures, Science, 144 (1964) 69-71.

[245] A.Y. Kuznetsov, V.P. Dmitriev, O.I. Bandilet, H.P. Weber, High-temperature fcc phase of Pr: Negative thermal expansion and intermediate valence state, Physical Review B, 68 (2003) 064109.

[246] S.R. Evans, I. Loa, L.F. Lundegaard, M.I. McMahon, Phase transitions in praseodymium up to 23 GPa: An x-ray powder diffraction study, Physical Review B, 80 (2009) 134105.

[247] Z. Felfli, A.Z. Msezane, D. Sokolovski, Low-energy electron elastic scattering from complex atoms: Nd, Eu, and Tm, Canadian Journal of Physics, 87 (2009) 321-327. 
[248] R.I. Sheldon, D.E. Peterson, The Np-U (Neptunium-Uranium) System, Bulletin of Alloy Phase Diagrams, 6 (1985) 217-219.

[249] K.S. Chan, J.K. Lee, H.I. Aaronson, Kaufman approach calculations of partial phase diagrams amongst Th, U, Np and Pu, Journal of Nuclear Materials, 92 (1980) 237-242.

[250] M. Kurata, Thermodynamic database on U-Pu-Zr-Np-Am-Fe alloy system II - Evaluation of Np, Am, and Fe containing systems, IOP Conference Series: Materials Science and Engineering, 9 (Actinides 2009) (2010).

[251] H. Okamoto, Np-U (Neptunium-Uranium), Journal of Phase Equilibria and Diffusion, 34 (2013) $70-71$.

[252] W. Xie, Y.A. Chang, D. Morgan, Ab initio energetics for modeling phase stability of the Np-U system, Journal of Nuclear Materials, 479 (2016) 260-270.

[253] W. Xiong, W. Xie, D. Morgan, Thermodynamic evaluation of the Np-Zr system using CALPHAD and ab initio methods, Journal of Nuclear Materials, 452 (2014) 569-577.

[254] P.G. Mardon, J.H. Pearce, An investigation of the neptunium-uranium equilibrium diagram, Journal of the Less-Common Metals, 1 (1959) 467-475.

[255] J.A. Lee, A review of the physical metallurgy of neptunium, in: H.M. Finniston, J.P. Howe (Eds.) Progress in Nuclear Energy Series V: Metallurgy and Fuels, Pergamon, Oxford, 1961, pp. 453-467.

[256] T. Inoue, T. Matsumura, A. Sasahara, L. Koch, J.C. Spirlet, Transmutation of transuranium elements by a metallic fuel FBR, in: Information Exchange Meeting on Actinide and Fission Product Separataion and Transmutation, OECD Nuclear Energy Agency, 1990, pp. 397-423.

[257] M. Kurata, in: Materials Models and Simulations for Nuclear Fuels, Tokyo University, Japan, December 13-14 2007, 2007.

[258] J.F. Haefling, A.H. Daane, The immiscibility limits of uranium with the rare-earth metals, Transactions of the Metallurgical Society of AIME, 215 (1959) 336-338.

[259] Y. Shoji, T. Matsui, K. Nakamura, T. Inoue, Vaporization study on lanthanum-uranium and ceriumuranium alloys, Journal of Nuclear Materials, 265 (1999) 134-138.

[260] A.P. Bayanov, Thermodynamic properties of liquid alloys of uranium with certain rare earth metals, Soviet Radiochemistry, 12 (1970) 735-737 (Translated from Radiokhimiya, vol. 712, no. 735, pp. 768771, 1970).

[261] H. Okamoto, La-U (lanthanum-uranium), Journal of Phase Equilibria, 20 (1999) 639.

[262] C.E. Lundin, Rare-earth metal phase diagrams, in: F.H. Spedding, A.H. Daane (Eds.) The Rare Earths, John Wiley \& Sons, Inc., for the American Society for Metals in Cooperation with the Office of Technical Information, United States Atomic Energy Commission, New York, 1961, pp. 224-385.

[263] H. Okamoto, Pr-U phase diagram, in: P. Villars, H. Okamoto, K. Cenzual (Eds.) ASM Alloy Phase Diagrams Center, ASM International, Materials Park, OH, 1990.

[264] M. Peatfield, N.H. Brett, P.E. Potter, Constitutional studies on carbide nuclear fuels for fast breeder reactors II. The uranium-praseodymium-carbon ternary system, Journal of Nuclear Materials, 89 (1980) 27-34.

[265] D.G. Parnell, N.H. Brett, H.R. Haines, P.E. Potter, Phase relationships in the ternary system U-Nd$\mathrm{Pd}$, Journal of the Less-Common Metals, 118 (1986) 141-152.

[266] H. Okamoto, Nd-U phase diagram, in: P. Villars, H. Okamoto, K. Cenzual (Eds.) ASM Alloy Phase Diagrams Center, ASM International, Materials Park, OH, 1990.

[267] H.A.C. McKay, J.S. Nairn, M.B. Waldron, The chemistry and metallurgy of neptunium, in: Proceedings of the Second United Nations International Conference on the Peaceful Uses of Atomic Energy (held in Geneva, 1 September - 13 September 1958), 1958, pp. 299-306. 
[268] D.M. Poole, M.G. Bale, P.G. Mardon, J.A.C. Marples, J.L. Nichols, Phase diagrams of some plutonium binary alloy systems, in: E. Grison, W.B.H. Lord, R.D. Fowler (Eds.) Plutonium 1960 (Proceedings of the second international conference on plutonium metallurgy, Grenoble, France, 19-22 April 1960), Cleaver-Hume Press Limited for Commissariat à l'énergie atomique, London, 1961, pp. 267281.

[269] R.G. Cope, D.G. Hughes, R.G. Loasby, D.C. Miller, The plutonium-ruthenium and plutoniumneptunium binary phase diagrams, in: E. Grison, W.B.H. Lord, R.D. Fowler (Eds.) Plutonium 1960 (Proceedings of the second international conference on plutonium metallurgy, Grenoble, France, 19-22 April 1960), Cleaver-Hume Press Limited for Commissariat à l'énergie atomique, London, 1961, pp. 280 289.

[270] M.B. Waldron, J. Garstone, J.A. Lee, P.G. Mardon, J.A.C. Marples, D.M. Poole, G.K. Williamson, The physical metallurgy of plutonium, in: Proceedings of the Second United Nations International Conference on the Peaceful Uses of Atomic Energy (Geneva, 1 September - 13 September 1958), United Nations, Geneva, 1958, pp. 162-169.

[271] P.G. Mardon, J.H. Pearce, J.A.C. Marples, Constitution studies on the neptunium-plutonium alloy system, Journal of the Less-Common Metals, 3 (1961) 281-292.

[272] R.I. Sheldon, D.E. Peterson, The Np-Pu (Neptunium-Plutonium) System, Bulletin of Alloy Phase Diagrams, 6 (1985) 215-217.

[273] H. Okamoto, Np-Pu (Neptunium-Plutonium), Journal of Phase Equilibria and Diffusion, 34 (2013) 154-155.

[274] A.F. Berndt, Single crystal study of an alpha-plutonium-neptunium alloy, Journal of Nuclear Materials, 11 (1964) 352.

[275] H. Okamoto, Am-Np (Americium-Neptunium), Journal of Phase Equilibria, 20 (1999) 450.

[276] H. Okamoto, Am-Np (Americium-Neptunium), Journal of Phase Equilibria and Diffusion, 33 (2012) 502.

[277] T.B. Massalski, H. Okamoto, P.R. Subramanian, L. Kacprzak, ed., Binary Alloy Phase Diagrams, Second Edition, ASM International, 1990.

[278] P. Villars, H. Okamoto, K. Cenzual, ASM Alloy Phase Diagrams Database, in, ASM International, Materials Park, OH, 2016.

[279] T. Inoue, M. Kurata, L. Koch, J.C. Spirlet, C.T. Walker, C. Sari, Characterization of fuel alloys with minor actinides, Transactions of the American Nuclear Society, 64 (1991) 552-553.

[280] C. Sari, C.T. Walker, M. Kurata, T. Inoue, Interaction of U-Pu-Zr alloys containing minor actinides and rare-earths with stainless-steel, Journal of Nuclear Materials, 208 (1994) 201-210.

[281] D.E. Janney, J.R. Kennedy, As-cast microstructueres in U-Pu-Zr alloy fuel pins with 5-8 wt\% minor actinides and 0-1.5 wt\% rare-earth elements, Materials Characterization, 61 (2010) 1194-1202.

[282] D.E. Janney, J.R. Kennedy, J.W. Madden, T.P. O'Holleran, Am phases in the matrix of a U-Pu-Zr alloy with Np, Am, and rare-earth elements, Journal of Nuclear Materials, 456 (2015) 46-53.

[283] D.E. Janney, J.W. Madden, T.P. O'Holleran, High- and low-Am RE inclusion phases in a U-Np-PuAm-Zr alloy, Journal of Nuclear Materials, 458 (2015) 106-114.

[284] J.K. Gibson, R.G. Haire, M.M. Gensini, T. Ogawa, Alloying behavior in selected neptunium binary systems: the role of $5 \mathrm{f}$ bonding, Journal of Alloys and Compounds, 213/214 (1994) 106-110.

[285] R.J. Rodríguez, C. Sari, A.J.C. Portal, Investigation of the Np-Zr and U-Np-Zr systems, Journal of Alloys and Compounds, 209 (1994) 263-268.

[286] S. Bajaj, A. Garay, A. Landa, P. Söderlind, P. Turchi, R. Arróyave, Thermodynamic study of the Np-Zr system, Journal of Nuclear Materials, 409 (2011) 1-8. 
[287] H. Okamoto, Np-Zr (Neptunium-Zirconium), Journal of Phase Equilibria and Diffusion, 34 (2013) 59-60.

[288] J.K. Gibson, R.G. Haire, High-temperature DTA of transuranium metals with application to the NpZr phase diagram, Thermochimica Acta, 207 (1992) 65-78.

[289] J.K. Gibson, R.G. Haire, Investigation of the neptunium-zirconium phase diagram by differential thermal analysis, Journal of Nuclear Materials, 201 (1993) 225-230.

[290] J.K. Gibson, R.G. Haire, T. Ogawa, Semi-empirical models of actinide alloying, Journal of Nuclear Materials, 273 (1999) 139-145.

[291] M.M. Gensini, R.G. Haire, J.K. Gibson, Investigation of the neptunium-zirconium system by X-ray diffraction, Journal of Alloys and Compounds, 213/214 (1994) 402-405.

[292] Y. Okamoto, R.G. Haire, J.K. Gibson, T. Ogawa, The investigation of selected Np-Zr alloys by Xray diffraction up to $700{ }^{\circ} \mathrm{C}$, Journal of Alloys and Compounds, 232 (1996) 302-306.

[293] H. Okamoto, Np-Zr (Neptunium-Zirconium), Journal of Phase Equilibria, 17 (1996) 166-167.

[294] F.H. Ellinger, K.A. Johnson, V.O. Struebing, The plutonium-americium system (Los Alamos

Scientific Laboratory Report LA-DC-7095), Los Alamos, New Mexico, 1965.

[295] F.H. Ellinger, K.A. Johnson, V.O. Struebing, The plutonium-americium system, Journal of Nuclear Materials, 20 (1966) 83-86.

[296] V.D. Shushakov, N.S. Kosulin, N.T. Chebotarev, Pu-Am phase diagram, Voprosy Atom. Nauki Tekh. Ser. Materialoved. Novye Mater., 3 (1990) 14-15.

[297] P. Gotcu-Freis, J.-Y. Colle, C. Guéneau, N. Dupin, B. Sundman, R.J.M. Konings, A thermodynamic study of the Pu-Am-O system, Journal of Nuclear Materials, 414 (2011) 408-421.

[298] P.E.A. Turchi, A.I. Landa, P.A. Söderlind, Thermodynamic assessment of the Am-Pu system with input from ab initio, Journal of Nuclear Materials, 418 (2011) 165-173.

[299] N. Baclet, M. Dormeval, L. Havela, J.M. Fournier, C. Valot, F. Wastin, T. Gouder, E. Colineau, C.T. Walker, S. Bremier, C. Apostolidis, G.H. Lander, Character of $5 f$ states in the Pu-Am system from magnetic susceptibility, electrical resistivity, and photoelectron spectroscopy measurements, Physical Review B, 75 (2007) 035101.

[300] A. Shick, L. Havela, J. Kolorenč, V. Drchal, T. Gouder, P.M. Oppeneer, Electronic structure and nonmagnetic character of $\delta$-Pu-Am alloys, Physical Review B, 73 (2006) 104415.

[301] J. Kolorenč, A.B. Shick, L. Havela, A.I. Lichtenstein, Electronic structure theory of Pu-Am and PuCe alloys, and thin $\delta$-Pu films, in: Basic Actinide Science and Materials for Nuclear Applications, 2010, pp. 111-115.

[302] B. Ravat, L. Jolly, C. Valot, N. Baclet, Local structure in plutonium alloys stabilized in delta-phase, Plutonium Futures--The Science, 673 (2003) 7-8.

[303] P. Söderlind, A. Landa, W.G. Wolfer, Atomic-volume variations of $\alpha-\mathrm{Pu}$ alloyed with Al, Ga, and Am from first-principles theory, Journal of Computer-Aided Materials Design, 14 (2007) 349-355.

[304] F.H. Ellinger, Crystal structure of $\delta^{\prime}$-plutonium and the thermal expansion characteristics of $\delta, \delta$, and $\varepsilon$ plutonium, Journal of Metals (Transactions AIME), 8 (1956) 1526-1529.

[305] H. Okamoto, Am-Pu (americium-plutonium), Journal of Phase Equilibria, 20 (1999) 451.

[306] F.H. Ellinger, C.C. Land, K.A. Johnson, The plutonium-lanthanum system, Transactions of the Metallurgical Society of AIME, 239 (1967) 895-898.

[307] X.J. Liu, Q. He, D. Wang, Y. Lu, M.H. Chen, J.P. Jia, C.P. Wang, Thermodynamic assessments of the $\mathrm{Pu}-\mathrm{Zn}$ and $\mathrm{La}-\mathrm{Pu}$ systems, Journal of Nuclear Materials, 453 (2014) 169-175. 
[308] F.H. Ellinger, C.C. Land, E.M. Cramer, Plutonium-Cerium Phase Diagram, in: Extractive and Physical Metallurgy of Plutonium and its Alloys (Proceedings of a symposium sponsored by the Metallurgical Society of AIME, San Francisco, February 16-17, 1959), Interscience, 1960, pp. 149-166. [309] J.E. Selle, D.E. Etter, The plutonium-cerium system, Transactions of the Metallurgical Society of AIME, 230 (1964) 1000-1005.

[310] R.O. Elliott, W.N. Miner, R.B. Roof Jr., C.C. Land, Transformation-induced precipitation of $\delta$ plutonium in metastable cerium-plutonium alloys, Journal of the Less-Common Metals, 15 (1968) 106108.

[311] B.C. Giessen, V.O. Struebing, R.O. Elliott, Metastable fcc Pu-Ce solid solutions, Materials Science and Engineering, 18 (1975) 239-243.

[312] F.H. Ellinger, W.N. Miner, D.R. O'Boyle, F.W. Schonfeld, Constitution of Plutonium Alloys (Los Alamos National Laboratory Report LA-3870), Los Alamos National Laboratory, Los Alamos, NM, 1968.

[313] M.H. Rand, D.T. Livey, P. Feschotte, H. Nowotny, K. Seifert, R. Ferro, ed., Plutonium: Physicochemical properties of its compounds and alloys, International Atomic Energy Agency, Vienna, 1966.

[314] T.B. Massalski, Ce-Pu (cerium-plutonium), in: T.B. Massalski, H. Okamoto, P.R. Subramanian, L. Kacprzak (Eds.) Binary Alloy Phase Diagrams, Second Edition, ASM, Materials Park, OH, 1990, pp. $1132,1134$.

[315] H. Okamoto, Ce-Pu phase diagram, in: P. Villars, H. Okamoto, K. Cenzual (Eds.) ASM Alloy Phase Diagrams Center, ASM International, Materials Park, OH, 1990.

[316] V.I. Kutaitsev, N.T. Chebotarev, I.G. Lebedev, M.A. Andrianov, V.N. Konev, T.S. Menshikova, Phase diagrams of plutonium with the metals of groups IIA, IVA, VIIIA and IB, in: A.E. Kay, M.B. Waldron (Eds.) Plutonium 1965, Chapman and Hall for The Institute of Metals, 1965, pp. 420-449.

[317] V.I. Kutaitsev, N.T. Chebotarev, M.A. Andrianov, V.N. Konev, I.G. Lebedev, V.I. Bagrova, A.V. Beznosikova, A.A. Kruglov, P.N. Petrov, E.S. Smotritskaya, Phase diagrams of plutonium with metals of groups IIA, IVA, VIII, and IB, Soviet Atomic Energy, 23 (1967) 1279-1287 (Translated from Atomnaya Énergiya, vol 1223, no. 1276, pp. 1511-1519, 1967).

[318] F.H. Ellinger, C.C. Land, K.A. Johnson, Binary systems of plutonium with praseodymium, neodymium, and samarium, Journal of Nuclear Materials, 29 (1969) 178-183.

[319] H.H. Hill, F.H. Ellinger, The effective size of americium dissolved in lanthanum, Journal of the Less-Common Metals, 23 (1971) 92-94.

[320] W.V. Conner, Investigation of americium-241 metal alloys (Rocky Flats Plant Report RFP-3106), 1981.

[321] W.V. Conner, Ductile transplutonium alloys (United States Patent 4380470), (1983).

[322] H. Okamoto, Am-Zr (Americium-Zirconium), Journal of Phase Equilibria and Diffusion, 33 (2012) 504.

[323] R. Vogel, H. Klose, Über die Zustandsbilder Cer-Lanthan, Lanthan-Antimon und Cer-Indium, Zeitschrift für Metallkunde, 45 (1954) 633-638.

[324] K.A. Gschneidner Jr., Systematics of the intra-rare-earth binary alloy systems, Journal of the LessCommon Metals, 114 (1985) 29-42.

[325] T.B. Scott, C.M. Younes, M. Ling, C.P. Jones, J.A. Nicholson, P.J. Heard, R. Jenkins, Initial microstructural study of a Ce-La alloy using electron backscattered diffraction, Journal of Alloys and Compounds, 509 (2011) 4284-4289.

[326] M.V. Bulanova, P.N. Zheltov, K.A. Meleshevich, Lanthanum-cerium-silicon system, Journal of Alloys and Compounds, 347 (2002) 149-155. 
[327] Z.-Y. Zeng, C.-E. Hu, Z.-G. Li, W. Zhang, L.-C. Cai, High pressure phase transition of Ce-La alloy from first-principles calculations, Journal of Alloys and Compounds, 640 (2015) 201-204.

[328] L.-Q. Zhang, Y. Cheng, Z.-W. Niu, G.-F. Ji, First-principles investigations on structural, elastic, and thermodyamic properties of Ce-La alloys under high pressure, Zeitschrift für Naturforschung Section A, 69 (2014) 52-60.

[329] E. King, I.R. Harris, High pressure resistance measurements of some lanthanum-cerium alloys, Journal of the Less-Common Metals, 27 (1972).

[330] M. Norman, I.R. Harris, G.V. Raynor, Lattice spacings and effective atomic diameters in the ternary systems formed by Th and Ce with Y, La, Gd and Er, and by Th, Pr, and Y, Journal of the LessCommon Metals, 13 (1967) 24-44.

[331] D.S. Evans, G.V. Raynor, Lattice spacing relationships in system thorium-cerium-lanthanum, Journal of Nuclear Materials, 5 (1962) 308-316.

[332] K.A. Gschneidner Jr., R.O. Elliott, R.Y. Prince, The lattice spacings of some cerium-rich, ceriumrare-earth alloys, in: J.F. Nachman, C.E. Lundin (Eds.) Rare Earth Research (Proceedings of the 2nd conference on rare-earth research, 1961), Gordon and Breach, New York, 1962, pp. 71.

[333] D.W. Wheeler, I. Khan, A Raman spectroscopy study of cerium oxide in a cerium-5 wt\% lanthanum alloy, Vibrational Spectroscopy, 70 (2014) 200-206.

[334] K.A. Gschneidner Jr., R.O. Elliott, R.R. McDonald, Effects of alloying additions on the $\alpha \leftrightarrow \gamma$ transformation of cerium--part III. Effects of yttrium and rare earth additions, Journal of Physics and Chemistry of Solids, 23 (1962) 1201-1208.

[335] Y.M. Savitskiy, V.F. Terekhov, Phase diagrams of alloys of lanthanum with cerium, and lanthanum with calcium, Journal of Inorganic Chemistry, USSR, 3 (1958) 298-309 (translated from Zhurnal Neorganicheskoi Khimii vol III no 293 pp 758-762, 1958).

[336] H. Okamoto, La-Pr phase diagram, in: P. Villars, H. Okamoto, K. Cenzual (Eds.) ASM Alloy Phase Diagrams Center, ASM International, Materials Park, OH, 1990.

[337] H. Okamoto, La-Pr (Lanthanum-Praseodymium), in: T.B. Massalski, H. Okamoto, P.R.

Subramanian, L. Kacprzak (Eds.) Binary Alloy Phase Diagrams, Second Edition, ASM, Materials Park, OH, 1990, pp. 2411, 2413.

[338] A.H. Daane, F.H. Spedding, Quarterly Summary Research Report in Physics for July, August, and September, 1954 (USAEC report ISC-530), Ames Laboratory, Ames, IA, 1954.

[339] S. Wu, L. Zhang, L. Zeng, Y. Zhuang, Phase relationship of the La-Nd-Fe system at 770 K, Journal of Alloys and Compounds, 291 (1999) 220-221.

[340] Y. Shoji, T. Matsui, Vaporization study on lanthanum-neodymium alloys by mass-spectometry, Journal of Nuclear Materials, 273 (1999) 310-314.

[341] E.M. Forgan, S.L. Lee, W.G. Marshall, S. Zochowski, Magnetism in the Nd-La system, Journal of Magnetism and Magnetic Materials, 104-7 (1992) 1519-1520.

[342] D. Peng, Y. Zhang, J. She, M. Pang, Y. Du, Phase equilibria in the ternary Al-Zr-La system, Journal of Alloys and Compounds, 507 (2010) 62-66.

[343] C. Li, Y. Zhan, J. She, Q. Huang, M. Pang, W. Yang, Phase diagrams of the Zr-Si-Re (RE = La and Er) ternary systems at $773 \mathrm{~K}\left(500{ }^{\circ} \mathrm{C}\right)$, Metallurgical and Materials Transactions A, 43 (2012) 20-28.

[344] K.A. Gschneidner Jr., F.W. Calderwood, The Ce-Pr (cerium-praseodymium) system, Bulletin of Alloy Phase Diagrams, 3 (1982) 187-188.

[345] M. Altunbas, I.R. Harris, Structural and constitutional studies of some cerium-praseodymium alloys, Journal of Materials Science, 15 (1980) 693-701.

[346] K.A. Gschneidner Jr., Cerium-praseodymium binary phase diagram, in: P. Villars, H. Okamoto, K. Cenzual (Eds.) ASM Alloy Phase Diagrams Center, ASM International, Materials Park, OH, 1990. 
[347] K.A. Gschneidner Jr., F.W. Calderwood, Ce-Pr (cerium-praseodymium), in: T.B. Massalski, H. Okamoto, P.R. Subramanian, L. Kacprzak (Eds.) Binary Alloy Phase Diagrams, Second Edition, ASM, Materials Park, OH, 1990, pp. 1095, 1097.

[348] J.D. Speight, I.R. Harris, G.V. Raynor, Alloys of cerium with neodymium, samarium and terbium, and of praseodymium with terbium, Journal of the Less-Common Metals, 15 (1968) 317-330.

[349] D.D. Keiser Jr., Diffusion in the Ce-Nd system, Scripta Metallurgical et Materialia, 33 (1995) 959965.

[350] O. Hachimi, S. Hayun, A. Venkert, M.P. Dariel, Microstructural study of Ce-Nd alloys, Journal of Alloys and Compounds, 427 (2007) 104-109.

[351] W.G. Moffatt, ed., Handbook of Binary Phase Diagrams, Genium Publishing Corp., Schenectady, NY, 1984.

[352] H. Okamoto, Ce-Nd phase diagram, in: P. Villars, H. Okamoto, K. Cenzual (Eds.) ASM Alloy Phase Diagrams Center, ASM International, Materials Park, OH, 1990.

[353] K.A. Gschneidner Jr., F.W. Calderwood, The Ce-Nd (cerium-neodymium) system, Bulletin of Alloy Phase Diagrams, 3 (1982) 90.

[354] W.L. Bragg, E.A. Wood, The conversion factor for $\mathrm{kX}$ units to Ångstrom units, Journal of the American Chemical Society, 69 (1947) 2919.

[355] N. Mattern, Y. Yokoyama, A. Mizuno, J.H. Han, O. Fabrichnaya, H. Wendrock, T. Harada, S. Kohara, J. Eckert, Experimental and thermodynamic assessment of the Ce-Zr system, CALPHAD: Computer Coupling of Phase Diagrams and Thermochemistry, 46 (2014) 213-219.

[356] I.R. Harris, G.V. Raynor, The electronic state of cerium in zirconium-cerium alloys, Journal of the Less-Common Metals, 6 (1964) 70-80.

[357] W.G. Moffatt, ed., Handbook of Binary Phase Diagrams, Genium Publishing Corporation, Schenectady, NY, 1978.

[358] T.B. Massalski, Ce-Zr (cerium-zirconium), in: T.B. Massalski, H. Okamoto, P.R. Subramanian, L. Kacprzak (Eds.) Binary Alloy Phase Diagrams, Second Edition, ASM, Materials Park, OH, 1990, pp. $1132,1134$.

[359] H. Okamoto, Ce-Zr phase diagram, in: P. Villars, H. Okamoto, K. Cenzual (Eds.) ASM Alloy Phase Diagrams Center, ASM International, Materials Park, OH, 1990.

[360] A. Palenzona, S. Cirafici, The Ce-Zr (cerium-zirconium) system, Journal of Phase Equilibria, 12 (1991) 49-52.

[361] I.A. Markova, V.F. Terekhova, E.M. Savitskii, Equilibrium diagram of the alloys of the neodymium-praseodymium system, Russian Journal of Inorganic Chemistry, 8 (1963) 1041-1042.

[362] C.E. Lundin, A.S. Yamamoto, J.F. Nachman, Studies of solution ideality in the praseodymiumneodymium system, Acta Metallurgica, 13 (1965) 149-154.

[363] K.A. Gschneidner Jr., F.W. Calderwood, The Nd-Pr (neodymium-praseodymium) system, Bulletin of Alloy Phase Diagrams, 3 (1982) 196-198.

[364] K.A. Gschneidner Jr., F.W. Calderwood, Nd-Pr (Neodymium-Praseodymium), in: T.B. Massalski, H. Okamoto, P.R. Subramanian, L. Kacprzak (Eds.) Binary Alloy Phase Diagrams, Second Edition, ASM, Materials Park, OH, 1990, pp. 2794, 2796.

[365] K.A. Gschneidner Jr., Neodymium-praseodymium binary phase diagram, in: P. Villars, H.

Okamoto, K. Cenzual (Eds.) ASM Alloy Phase Diagrams Center, ASM International, Materials Park, $\mathrm{OH}, 1990$.

[366] C.E. Lundin, M.J. Pool, Heats of mixing in praseodymium-neodymium solid solutions, Journal of the Less-Common Metals, 9 (1965) 48-53. 
[367] G.J. Shiflet, J.K. Lee, H.I. Aaronson, Application of the Kaufman approach to the calculation of intra-rare earth phase diagrams, CALPHAD, 3 (1979) 129-137.

[368] V. Raghavan, Al-Pr-Zr (Aluminum-Praseodymium-Zirconium), Journal of Phase Equilibria and Diffusion, 32 (2010) 67.

[369] J. She, Y. Zhan, C. Li, Y. Du, H. Xu, Y. He, Phase equilibria of the Al-Pr-Zr ternary system at 773 K, Journal of Alloys and Compounds, 503 (2010) 57-60.

[370] V. Raghavan, Al-Nd-Zr (Aluminum-Neodymium-Zirconium), Journal of Phase Equilibria and Diffusion, 32 (2011) 468.

[371] K. Cheng, H. Zhou, B. Hu, Y. Du, L. Zhang, S. Liu, H. Xu, L. Liu, Experimental investigation and thermodynamic modeling of the $\mathrm{Nd}-\mathrm{Zr}$ and the $\mathrm{Mg}-\mathrm{Nd}-\mathrm{Zr}$ systems, Metallurgical and Materials Transactions A, 45A (2014) 2708-2718.

[372] N. Mattern, Y. Yokohama, A. Mizuno, J.H. Han, O. Fabrichnaya, T. Harada, S. Kohara, J. Eckert, Experimental and thermodynamic assessment of the Nd-Zr system, CALPHAD: Computer Coupling of Phase Diagrams and Thermochemistry, 46 (2014) 103-107.

[373] K. Peng, Z. Jieyu, L. Qian, Z. Zhang, Phase equilibria in the Mg-Nd-Zr ternary system, Shanghai Metals, 37 (2015) 60-65 (in Chinese with English abstract and captions).

[374] K. Nikitin, M. Saito, M. Kawashima, V. Artisyuk, A. Shmelev, Long-life water cooled small reactor with U-Np-Pu fuel, Journal of Nuclear Science and Technology, 38 (2001) 511-516.

[375] P. Wydler, W. Heer, P. Stiller, H.U. Wenger, A uranium-plutonium-neptunium fuel cycle to produce isotopically denatured plutonium, Nuclear Technology, 49 (1980) 115-120.

[376] S.-J. Oh, K.-H. Kim, C.-B. Lee, C.-T. Lee, S.-J. Jang, Effects of Ce element addition on the characteristics of U-Zr alloys, Transactions of the American Nuclear Society, 98 (2008) 1047-1048.

[377] T. Ogata, M. Akabori, A. Itoh, Diffusion of cerium in uranium-zirconium solid solutions, Materials Transactions, 44 (2003) 47-52.

[378] J.R. Kennedy, Thermal characteristics of a neptunium-bearing Pu-40Zr based alloy, in: Global 2003: Atoms for prosperity: updating Eisenhower's global vision for nuclear energy, American Nuclear Society, 2003, pp. 2297-2298.

[379] J.R. Kennedy, J.R. Stuart, D.D. Keiser, S.M. Frank, M.K. Meyer, Phase relations in neptunium bearing plutonium-zirconium alloys, Transactions of the American Nuclear Society, 87 (2002) 357-359.

[380] D.D. Keiser, Jr., J.R. Kennedy, Characterization of as-cast transmutation alloys containing Pu, Zr, Am, and Np, in: G.D. Jarvinen (Ed.) Plutonium Futures--The Science, 2003, pp. 154-155.

[381] D.D. Keiser, Jr., J.R. Kennedy, B.A. Hilton, S.L. Hayes, The development of metallic nuclear fuels for transmutation applications: materials challenges, JOM, 60 (2008) 29-32.

[382] M. Mantina, R. Valero, C.J. Cramer, D.G. Truhlar, Atomic radii of the elements, in: W.M. Haynes (Ed.) CRC Handbook of Chemistry and Physics, 96th Edition (Internet Version 2016), CRC Press/Taylor and Francis, Boca Raton, FL, 2015.

[383] J.R. Kennedy, Investigation of the thermal characteristics of an americium bearing Pu-40Zr-based alloy, in: Plutonium Futures--The Science. (Third topical conference on plutonium and actinides), Albuquerque, NM (6-10 July 2003), 2003.

[384] J.R. Kennedy, M.J. Lambregts, A.W. Maddison, Thermal conductivity of minor actinide doped Pu$\mathrm{Zr}$ and U-Pu-Zr transmutation fuels, Transactions of the American Nuclear Society, 91 (2004) 457-458.

[385] J.I. Cole, D.D. Keiser Jr., J.R. Kennedy, Microstructural characterization of as-cast metallic transmutation fuels, in: Global 2007, American Nuclear Society, Boise, ID (September 9-13, 2007), 2007.

[386] M.K. Meyer, D.D. Keiser, S.M. Frank, J.R. Kennedy, G. Knighton, Fabrication and characterization of Pu-Zr and Pu-Am-Zr alloys, Transactions of the American Nuclear Society, 87 (2002) 356-357. 
[387] V.W. Eldred, G.C. Curtis, Some properties of neptunium metal, Nature (London), 179 (1957) 910. [388] J.P. Evans, P.G. Mardon, Some physical properties of neptunium metal I: A determination of the specific heat of $\alpha$-neptunium, Journal of Physics and Chemistry of Solids, 10 (1959) 311-313.

[389] A. Filanovich, A. Povzner, The influence of photon anharmonicity on thermal and elastic properties of neptunium, Journal of Nuclear Materials, 437 (2013) 102-106.

[390] W. Müller, R. Schenkel, H.E. Schmidt, J.C. Spirlet, D.W. McElroy, R.O.A. Hall, M.J. Mortimer, The electrical resistivity and specific heat of americium metal, Journal of Low Temperature Physics, 30 (1978) 561.

[391] R.J. Silva, G. Bidoglio, M.H. Rand, P.B. Robouch, H. Wanner, I. Puigdomenech, Chemical Thermodynamics of Americium, Elsevier North-Holland, Amsterdam, 1995.

[392] R.J.M. Konings, The high-temperature heat capacity of americium, Journal of Alloys and Compounds, 348 (2003) 38-42.

[393] A.A. Povzner, A.N. Filanovich, V.A. Os'kina, A.G. Volkov, Electron heat capacity and lattice properties of americium, Technical Physics, 58 (2013) 1844-1847 (translated from Zhurnal

Tekhnicheskoi Fiziki, vol. 1883, no. 1812, pp. 1141-1143, 2013).

[394] R.O.A. Hall, J.A. Lee, M.J. Mortimer, D.L. McElroy, W. Müller, J.-C. Spirlet, Thermodynamic functions of americium metal, Journal of Low Temperature Physics, 41 (1980) 397-404.

[395] J.W. Ward, Systematic properties of actinide metals, Journal of the Less-Common Metals, 121 (1986) 1-13.

[396] J.R. Berg, F.H. Spedding, A.H. Daane, The high temperature heat contents and related thermodynamic properties of lanthanum, praseodymium, europium, ytterbium, and yttrium (US-AEC Technical Report IS-327), 1961.

[397] F.M. Jaeger, J.A. Bottema, E. Rosenbohm, The exact measurement of the specific heats of metals at high temperatures. XXVII. The specific heats and the electrical resistance of lanthanum, Proceedings of the KNAW (Koninklijke Nederlandse Akademie van Wetenschappen), 38 (1936) 921-927.

[398] L.A. Stretz, R.G. Bautista, The high-temperature enthalpy of liquid lanthanum by levitation calorimetry, Journal of Chemical Thermodynamics, 7 (1975) 83-88.

[399] S.R. Atalla, Experimental investigation of thermophysical properties of liquid metals at elevated temperatures, High Temperatures-High Pressures, 4 (1972) 447-451.

[400] A.A. Kurichenko, A.D. Ivliev, V.E. Zinoviev, Thermal and kinetic properties of light rare earth metals near high temperature structural transition points, Solid State Communications, 56 (1985) 10651068.

[401] I.I. Novikov, I.P. Mardykin, Specific heat of yttrium, lanthanum, and praseodymium at high temperatures, High Temperature 13 (1975) 293-297 (translated from Teplofizika Vysokikh Temperatur, vol 213, no. 292, pp. 318-323, 1975).

[402] A.A. Kurichenko, A.D. Ivliev, V.E. Zinoviev, The study of the thermophysical properties of rareearth metals with the use of molecular laser radiation, High Temperature, 24 (1986) 369-375 (translated from Teplofizika Vysokikh Temperatur, vol. 324, no. 363, pp. 493-499, 1986).

[403] F.H. Spedding, J.J. McKeown, A.H. Daane, The high temperature thermodynamic functions of cerium, neodymium and samarium, Journal of Physical Chemistry, 64 (1960) 289-294.

[404] L.K. Kuntz, R.G. Bautista, The heat capacities and heat content of molten cerium by levitation calorimetry, Metallurgical Transactions B, 7 (1976) 107-113.

[405] S.N. Banchila, L.P. Filippov, Experimental study of the set of thermal properties of certain rareearth metals at high temperatures, Journal of Engineering Physics, 27 (1974) 839-841 (Translated from Inzhenerno-Fizicheskii Zhurnal, vol. 827, no. 831, pp. 868-871, 1974). 
[406] G.A. Berezovskii, G.S. Burkhanov, N.B. Kal'chugina, I.E. Paukov, A.B. Tagaev, O.D. Chistyakov, Specific heat of praseodymium in the range from 5.6 to $314 \mathrm{~K}$, Russian Journal of Physical Chemistry, 64 (1990) 1419-1422 (translated from Zhurnal Fizicheskoi Khimii vol 1464 pp 2636-2640, 1990).

[407] F.M. Jaeger, J.A. Bottema, E. Rosenbohm, The exact measurement of the specific heats of metals at high temperatures. XXIX. Specific heats, electrical resistance, thermoelectrical behaviour and thermal expansion of neodynium in connection with its allotropic changes, Proceedings of the KNAW (Koninklijke Nederlandse Akademie van Wetenschappen), 41 (1938) 120-138.

[408] P. Javorský, L. Havela, F. Wastin, E. Colineau, D. Bouëxière, Specific heat of delta-Pu stabilized by Am, Physical Review Letters, 96 (2006) 156404.

[409] L. Havela, P. Javorský, A. Shick, F. Wastin, E. Colineau, Specific heat in the Pu-Am system, in: Materials Research Society Symposium Proceedings vol. 986 (Actinides 2006--Basic Science, Applications, and Technology), 2007, pp. 129-134.

[410] T.S. Petersen, S. Legvold, K.A. Gschneidner, T.-W.E. Tsang, J.O. Moorman, Magnetic ordering in Ce-La and Nd-La alloys, Journal of Applied Physics, 49 (1978) 2115-2117.

[411] S.K. Kim, K.H. Kim, S.J. Oh, C.T. Lee, C.B. Lee, Thermal Properties of U-Zr alloys for SFR fuel by gravity casting, Transactions of the American Nuclear Society, 106 (2012) 1256-1257.

[412] E.F. Westrum, L. Eyring, The melting point and the density of neptunium metal -- a micro melting point apparatus for metals, Journal of the American Chemical Society, 73 (1951) 3399-3400.

[413] D.R. Stephens, Phase diagram and compressibility of neptunium, Journal of Physics and Chemistry of Solids, 27 (1966) 1201-1204.

[414] L.J. Wittenberg, D.A. Vaughn, R. DeWitt, Phase relationships in uranium, neptunium, and plutonium, in: W.N. Miner (Ed.) Plutonium 1970 and Other Actinides, The Metallurgical Society of AIME, 1970, pp. 659-668.

[415] L.J. Wittenberg, R. DeWitt, Volume contraction during melting; emphasis on lanthanide and actinide metals, Journal of Chemical Physics, 56 (1972) 4256.

[416] W.Z. Wade, T. Wolf, Preparation and some properties of americium metal, Journal of Inorganic and Nuclear Chemistry, 29 (1967) 2577-2587.

[417] F. Barson, S. Legvold, F.H. Spedding, Thermal expansion of rare earth metals, Physical Review, 105 (1957) 418-424.

[418] F.H. Spedding, K.A. Gschneidner Jr., A.H. Daane, The lanthanum-carbon system, Transactions of the Metallurgical Society of AIME, 215 (1959) 192-199.

[419] S.A. Frizen, A.D. Ivliyev, L.K. Katanova, N.I. Moreva, Peculiarities of the thermal expansion of polycrystalline lanthanum, praseodymium and neodymium in the temperature range 290-970 K, Physics of Metals and Metallography, 60 (1985) 176-178 (translated from Fizika metallov i metallovedenie, vol. 160, no. 172, pp. 398-400, 1985).

[420] M.S. Blanter, V.P. Glazkov, V.A. Somenkov, Anisotropy of thermal vibrations and polymorphic transformations in lanthanum and uranium, Physica Status Solidi B, 246 (2009) 1044-1049.

[421] V.A. Somenkov, V.P. Glazkov, M.S. Blanter, Thermal vibrations and $\alpha \rightarrow \beta$ polymorphic transformation in lanthanum, Physics of Metals and Metallography, 101 (2006) 159-164.

[422] F. Mozaffari, Improved equation of state for metals from surface tension, Physics and Chemistry of Liquids, 53 (2015) 481-489.

[423] A.A. Eliseev, E.I. Yarembash, E.S. Vigileva, L.I. Antonova, V.A. Zachatskaya, Polymorphism of lanthanum, Russian Journal of Inorganic Chemistry, 9 (1964) 565-567.

[424] V.I. Kononenko, A.L. Sukhman, S.L. Gruverman, V.V. Torokin, Density and surface tension of liquid rare earth metals, scandium, and yttrium, Physica Status Solidi A, 84 (1984) 423. 
[425] L.J. Wittenberg, D. Ofte, W.G. Rohr, The viscosity and density of molten lanthanum, cerium, and praseodymium metals, in: K.S. Vorres (Ed.) Rare Earth Research, Gordon and Breach, New York, 1964, pp. 257-275.

[426] L.J. Wittenberg, D. Ofte, W.G. Rohr, The viscosity and density of molten lanthanum, cerium, and praseodymium metals, in: Third International Rare Earth Conference, Clearwater, FL, 1963.

[427] J. Li, T. Ishikawa, J. Okada, Y. Watanabe, J. Yu, S. Yoda, Z. Yuan, Noncontact thermophysical property measurement of liquid cerium by electrostatic levitation, Journal of Materials Research, 24 (2009) 2449-2452.

[428] W.G. Rohr, The liquid densities of cerium and neodymium metals, Journal of the Less-Common Metals, 10 (1966) 389-391.

[429] A. Goldberg, R.L. Rose, D.K. Matlock, The delta and epsilon thermal expansion coefficients and the delta-to-epsilon contraction for some plutonium-rich alloys, in: W.N. Miner (Ed.) Proceedings of the 4th International Conference on Plutonium and Other Actinides, The Metallurgical Society of AIME, 1970, pp. 1056.

[430] M. Dormeval, N. Baclet, C. Valot, P. Rofidal, J.M. Fournier, Crystalline and electronic structure of $\mathrm{Pu}-\mathrm{Ce}$ and $\mathrm{Pu}-\mathrm{Ce}-\mathrm{Ga}$ alloys stabilized in the $\delta$ phase, Journal of Alloys and Compounds, 350 (2003) 8694.

[431] J.F. Andrew, Thermal conductivity of some delta-plutonium alloys, Journal of Nuclear Materials, 30 (1969) 343-345.

[432] L. Bezukladnikova, V. Kononenko, Influence of small amounts of rare-earth metals on the surface and volume properties of lanthanum, Russian Metallurgy (Metally), (1997) 22-27 (Translated from Izvestiya Rossiiskoi Akademii Nauk. Metally no. 25, pp. 22-27, 1997).

[433] L.L. Bezukladnikova, V.I. Kononenko, M.M. Mit'ko, Density and surface tension of La-Pr melts, Russian Metallurgy (Metally), 5 (1989) 25-29 (Translated from Izvestiya Akademii Nauk SSSR, Metally, No. 25 pp. 31-35).

[434] P. Wagner, Thermal conductivity of neptunium at 300 degrees K, Journal of the Less-Common Metals, 24 (1971) 106.

[435] J.A. Lee, J.P. Evans, R.O.A. Hall, E. King, Some physical properties of neptunium metal III: The electrical resistivity and thermoelectric power of neptunium metal in the range 300-900 degrees K, Journal of Physics and Chemistry of Solids, 11 (1959) 278-283.

[436] W.G. Kannuluik, On the thermal conductivity of some metal wires, Proceedings of the Royal Society of London Series A--Mathematical and Physical Sciences, 131 (1931) 320-335.

[437] W.M. Haynes, ed., Thermal and physical properties of pure metals, in: CRC Handbook of Chemistry and Physics, 96th Edition (Internet Version 2016), CRC Press/Taylor and Francis, Boca Raton, FL, 2016.

[438] R. Schenkel, W. Müller, The electrical resistivity of ${ }^{241}$ Am metal, Journal of Physics and Chemistry of Solids, 38 (1977) 1301-1305.

[439] I.P. Mardykin, V.I. Kashin, P.P. Sbitnev, Thermal properties of solid and liquid lanthanum, Russian Metallurgy (Metally), 6 (1973) 44-47.

[440] A.V. Golubkov, E.D. Devyatkova, V.P. Zhuze, V.M. Sergeeva, I.A. Smirnov, Thermal conductivity of lanthanum and its monochalcogenides, Soviet Physics--Solid State (Translated from Fizika Tverdogo Tela), 8 (1966) 1403-1410.

[441] B.W. Jolliffe, R.P. Tye, R.W. Powell, The thermal and electrical conductivities of scandium, yttrium and manganese and twelve rare-earth metals, at normal temperature, Journal of the Less-Common Metals, 11 (1966) 388-394.

[442] G. Krieg, R.B. Genter, A.V. Grosse, Electrical conductivity of liquid lanthanum, Inorganic and Nuclear Chemistry Letters, 5 (1969) 819-823. 
[443] S. Legvold, F.H. Spedding, Quarterly summary research report in physics for April, May, and June 1954 (USAEC report ISC-508), Ames Laboratory, Ames, Iowa, 1954.

[444] R.W. Powell, B.W. Jolliffe, The thermal conductivities of scandium and some rare earth metals, Physics Letters, 14 (1965) 171-172.

[445] V.E. Zinov'ev, P.V. Gel'd, A.L. Sokolov, High-temperature transport properties of cerium, praseodymium, neodymium, and europium, Soviet Physics--Solid State 18 (1976) 764-766 (Translated from Fizika Tverdogo Tela vol 718 pp. 1329-1332, May 1976).

[446] I.I. Novikov, I.P. Mardykin, Thermal properties of lanthanides at high temperatures, High Temperature, 11 (1974) 472-476 (Translated from Teplofizika Vysokikh Temperatur vol. 411, no 473, pp. 527-532, 1973).

[447] E.D. Devyatkova, V.P. Zhuze, A.V. Golubkov, V.M. Sergeeva, I.A. Smirnov, Thermal conductivity of Sm, Pr, and their monochalcogenides, Soviet Physics--Solid State, 6 (1964) 343-346 (Translated from Fizika Tverdogo Tela, vol. 346 no. 342 pp 430-435, 1964).

[448] C. Hiemstra, P. Keegstra, W.T. Masselink, Electrical resistitivities of solid and liquid Pr, Nd, and Sm, Journal of Physics F--Metal Physics, 14 (1984) 1867-1875.

[449] V.P. Zhuze, A.V. Golubkov, E.V. Goncharova, V.M. Sergeeva, Electrical properties of rare-earth monochalcogenides (cerium subgroup), Soviet Physics--Solid State, 6 (1964) 205-212 (Translated from Fizika Tverdogo Tela, vol. 206, no. 201, pp. 257-267, January 1964).

[450] H.G. Jensen, Kohlrausch heat conductivity apparatus for intermediate or advanced laboratory, American Journal of Physics, 38 (1970) 870-874.

[451] A.T. Burkov, M.V. Vedemikov, Temperature dependences of the thermoelectric power and electrical resistivity of praseodymium and neodymium in solid and liquid states, Soviet Physics--Solid State, 26 (1984) 2211-2212 (Translated from Fizika Tverdogo Tela, vol 2216, no 2211, pp 3673-3676, December 1984).

[452] I.P. Mardykin, Electrical resistivity of lanthanum, neodymium, and erbium at high temperatures, High Temperature, 13 (1975) 191-193 (Translated from Teplofizika Vysokikh Temperatur, vol 113, no 191, pp 211-213, January-February 1975).

[453] J.K. Alstad, R.V. Colvin, S. Legvold, F.H. Spedding, Electrical resistivity of lanthanum, praseodymium, neodymium, and samarium, Physical Review, 121 (1961) 1637-1639.

[454] F.H. Spedding, A.H. Daane, K.W. Herrmann, Electrical resistivities and phase transformations of lanthanum, cerium, praseodymium, and neodymium, Journal of Metals, 9 (1957) 895-897.

[455] C.E. Olsen, R.O. Elliott, Electrical behavior of plutonium-neptunium alloys, Physical Review, 139 (1965) A437.

[456] J.A. Lee, R.O.A. Hall, E. King, G.T. Meaden, Some properties of plutonium and plutonium-rich alloys, in: E. Grison, W.B.H. Lord, R.D. Fowler (Eds.) Plutonium 1960 (The proceedings of the second international conference on plutonium metallurgy, Grenoble, France, 19-22 April 1960), Cleaver-Hume Press Ltd., London, 1961, pp. 39-50.

[457] T.A. Sandenaw, R.B. Gibney, The electrical resistivity and thermal conductivity of plutonium metal, Journal of Physics and Chemistry of Solids, 6 (1958) 81-88.

[458] Y.Y. Tsiovkin, A.A. Povzner, L.Y. Tsiovkina, V.V. Dremov, L.R. Kabirova, A.A. Dyachenko, V.B. Býstrushkin, M.V. Ryabukhina, A.V. Lukoyanov, A.O. Shorikov, Temperature and concentration dependences of the electrical resistivity for alloys of plutonium with americium under normal conditions, Journal of Experimental and Theoretical Physics, 111 (2010) 1019-1027 (translated from Zhurnal Ëksperimental'noï i Teoterischeskoï Fiziki, Vol. 1138, No. 1015, pp. 1153-1162, 2010).

[459] M.V. Vedernikov, I.A. Markova, G.N. Meshkova, Electrical resistivity and thermal EMF of La-Ce, La-Pr, and Pr-Nd alloys, Fiz. Tverd. Tela, 7 (1965). 
[460] M. Altunbas, K.N.R. Taylor, G.A. Wilkinson, Kondo resistivity of Pr-Ce alloys, Philosophical Magazine, 29 (1974) 349-371. 